\title{
Le contrôle
}

de constitutionnalité

des décisions de justice :

une nouvelle étape après la QPC?

sous la direction

de Marthe Fatin-Rouge Stefanini

et Caterina Severino

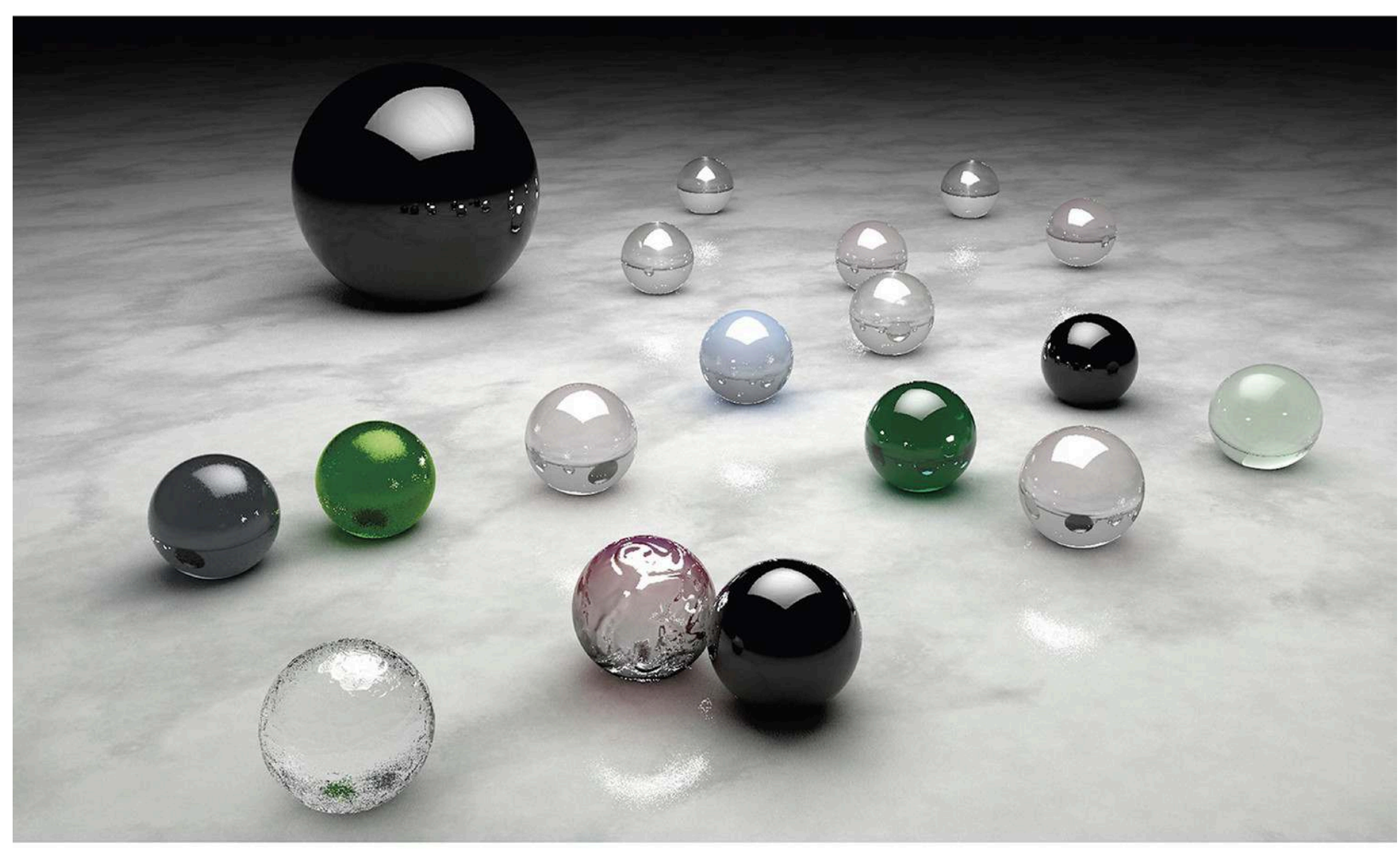


Le contrôle de constitutionnalité des décisions de justice : une nouvelle étape après la QPC ?

Marthe Fatin-Rouge Stefanini et Caterina Severino (dir.)

DOI : 10.4000/books.dice.5330

Éditeur : DICE Éditions

Lieu d'édition : Aix-en-Provznce

Année d'édition : 2017

Date de mise en ligne : 11 février 2022

Collection : Confluence des droits

EAN électronique : 9791097578015

\section{OpenEdition}

\section{Books}

https://books.openedition.org

Édition imprimée

Nombre de pages : 504

Référence électronique

FATIN-ROUGE STEFANINI, Marthe (dir.) ; SEVERINO, Caterina (dir.). Le contrôle de constitutionnalité des décisions de justice : une nouvelle étape après la QPC ? Nouvelle édition [en ligne]. Aix-en-Provence : DICE Éditions, 2017 (généré le 09 janvier 2023). Disponible sur Internet : <http://books.openedition.org/ dice/5330>. ISBN : 9791097578015. DOI : https://doi.org/10.4000/books.dice.5330. 


\section{RÉSUMÉS}

Présentant une version enrichie des actes du colloque international organisé à Aix-en-Provence en juin 2016, cet ouvrage explore la possibilité de franchir une nouvelle étape au sein du système de justice constitutionnelle français, par la mise en place d'un contrôle de constitutionnalité des décisions de justice. Au regard de l'introduction récente de la QPC, un tel questionnement pouvait paraître surprenant, car l'adoption d'une telle procédure a été considérée comme un réel progrès pour l'État de droit français. Toutefois, malgré le succès remarquable de la QPC, il est apparu légitime de se demander si l'objectif affiché par la réforme, à savoir celui d'ouvrir une nouvelle voie de recours aux justiciables pour assurer la protection de leurs droits fondamentaux, avait bien été atteint. Or, l'analyse du fonctionnement concret de la QPC laisse apparaître des difficultés, notamment en ce qui concerne le filtrage opéré par les juridictions administratives et judiciaires, et des angles morts du contrôle de constitutionnalité. L'objectif poursuivi par le colloque était double : d'une part, tirer les leçons du fonctionnement des systèmes étrangers qui pratiquent un contrôle de la constitutionnalité des décisions de justice, en vérifiant si ce contrôle est une véritable plus-value pour la protection des droits et libertés et, d'autre part, vérifier l'état du système de justice constitutionnelle français après cette réforme capitale, tout en s'interrogeant sur ses possibles perfectionnements.

\section{MARTHE FATIN-ROUGE STEFANINI (DIR.)}

Directrice de recherches au CNRS, Directrice-adjointe de l'UMR DICE, Aix Marseille Univ, Université de Toulon, Univ Pau \& Pays Adour, CNRS, DICE, ILF-GERJC, Aix-enProvence, France.

\section{CATERINA SEVERINO (DIR.)}

Maître de conférences HDR, Aix Marseille Univ, Université de Toulon, Univ Pau \& Pays Adour, CNRS, DICE, CDPC Jean-Claude Escarras, Toulon, France. 


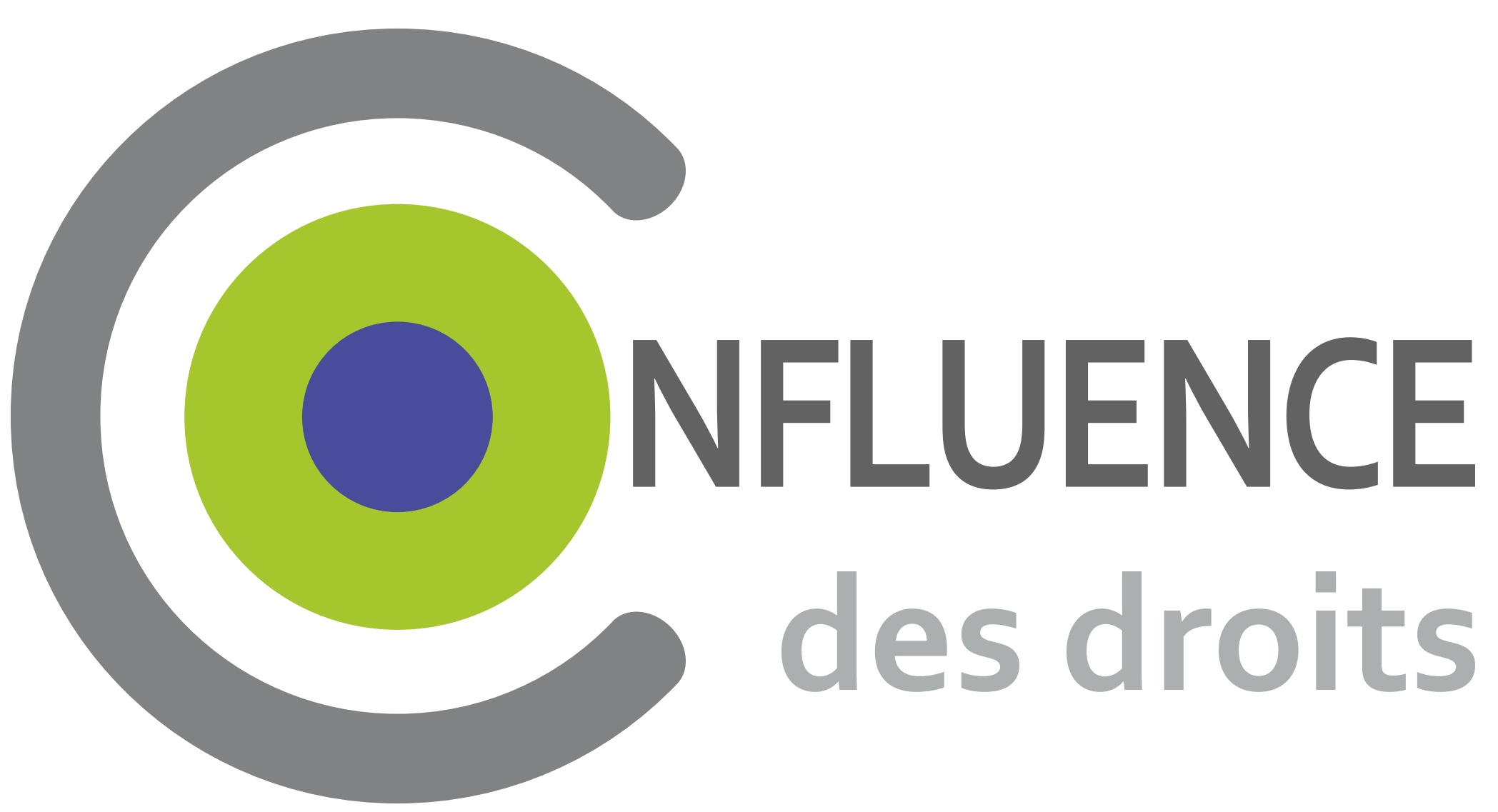

collection d'ouvrages numériques 



\section{NFLUENCE \\ des droits}




\section{Dans la même collection}

MALJEAN-DUBoIS Sandrine (dir.), Circulations de normes et réseaux d'acteurs dans la gouvernance internationale de l'environnement, Confluence des droits [en ligne]. Aix-en-Provence : Droits International, Comparé et européen, 2017. ISBN : 979-10-97578-00-8 http://dice.univ-amu.fr/fr/dice/dice/publications/confluence-droits

ISBN : 979-10-97578-01-5

UMR Droits International, Comparé et Européen (DICE)

Espace René Cassin

3 , avenue Robert Schuman

13628 Aix-en-Provence

dice-editions@univ-amu.fr

Références électroniques :

FATIN-ROUGE STEFANINI Marthe, SEVERINO Caterina (dir.), Le contrôle de constitutionnalité des décisions de justice : Une nouvelle étape après la QPC ?, Confluence des droits [en ligne]. Aix-en-Provence : Droits International, Comparé et européen, 2017. Disponible sur Internet : http://dice.univ-amu.fr/fr/dice/dice/publications/confluence-droits.

ISBN : 979-10-97578-01-5 


\title{
LE CONTRÔLE DE CONSTITUTIONNALITÉ DES DÉCISIONS DE JUSTICE : UNE NOUVELLE ÉTAPE APRÈS LA QPC ?
}

\section{ACtes du Colloque des 23 et 24 JUIN 2016}

\author{
sous la responsabilité scientifique de \\ Marthe Fatin-Rouge StefaninI \\ Directrice de recherches au CNRS \\ UMR 7318, DICE - ILF-GERJC \\ et \\ Caterina SEVERINO \\ Maître de conférences HDR à I'Université de Toulon \\ UMR 7318, DICE - CDPC-JCE \\ Avant propos \\ Sandrine MALJEAN-DUBOIS \\ Directrice de recherches au CNRS, Directrice de I'UMR-DICE, Aix Marseille Univ, \\ Université de Toulon, Univ Pau \& Pays Adour, CNRS, DICE, CERIC
}

Colloque intervenant dans le cadre de la Chaire Louis Favoreu - Fondation AMU et ayant obtenu le soutien de la Communauté du Pays d'Aix et de l'Association française de droit constitutionnel 



\section{SOMMAIRE}

Avant-propos

Sandrine MaljeAn-Dubois, Directrice de recherches au CNRS, Directrice de l'UMR-DICE, Aix Marseille Univ, Université de Toulon, Univ Pau \& Pays Adour, CNRS, DICE, CERIC, Aix-en-Provence, France

Propos introductifs - L'idée d'un contrôle de constitutionnalité des décisions de justice : intérêts et questionnements. .13

Marthe Fatin-Rouge Stefanini, Directrice de recherches au CNRS, Directrice-adjointe de l'UMR DICE, Aix Marseille Univ, Université de Toulon, Univ Pau \& Pays Adour, CNRS, DICE, ILF-GERJC, Aix-en-Provence, France

Partie I. Le contrôle de constitutionnalité des décisions de justice par les Cours suprêmes

Présidence de Monsieur Guy CAnivet, Ancien Membre du Conseil constitutionnel, Ancien Premier Président de la Cour de cassation

\section{Chapitre 1. Un contrôle traditionnel pour les cours suprêmes en France}

Le contrôle par la cour de cassation et le Conseil d'État : perspectives historiques .27

Jean-Louis Mestre, Professeur émérite de l'Université d'Aix-Marseille

Le contrôle par le Conseil d'État aujourd'hui.

Laurent Domingo, Maître des requêtes au Conseil d'État ; Didier Ribes, Maître des requêtes au Conseil d'État

La place de la Constitution dans le contrôle de la Cour de cassation (en dehors de la QPC)......59 Valentine Buck, Magistrate au TGI de Versailles ; Olivier Desaulnay, Professeur à l'Université de la Réunion

Débats, sous la présidence de Monsieur Guy CANIVET .83

Chapitre 2. Un contrôle naturel dans les systèmes diffus

L'unité juridictionnelle et ses conséquences sur les modalités du contrôle de constitutionnalité au Québec et au Canada.

Patrick Taillon, Professeur à la Faculté de droit de l'Université Laval, membre du Centre de recherche interdisciplinaire sur la diversité et la démocratie (CRIDAQ) ; Amélie BinetTe, candidate au doctorat à la Faculté de droit de l'Université Laval, membre du Centre de recherche interdisciplinaire sur la diversité et la démocratie (CRIDAQ) 
Le contrôle de constitutionnalité des décisions de justice en Suisse ou l'exercice d'un contrôle concret des normes

Michel HotTeLIer, Professeur à la Faculté de droit de l’Université de Genève

Débats, sous la présidence de Monsieur Guy CANIVET 129

Partie II. Le contrôle des décisions de justice par les Cours constitutionnelles Présidence de Madame le Professeur Anne LEVADE, Présidente de l'Association française de droit constitutionnel

Chapitre 1. Le contrôle des décisions de justice exercé dans le cadre des recours directs

Le recours individuel dirigé contre une décision de justice pour violation d'un droit fondamental dans la République fédérale d'Allemagne.. .141

Michel Fromont, Ancien professeur des Universités allemandes, professeur émérite à l'Université Paris I Panthéon Sorbonne

Le recours d'amparo contre les décisions juridictionnelles - Le cas de l'Espagne.. 161

Hubert Alcaraz, Maître de conférences HDR, Aix Marseille Univ, Univ Pau \& Pays Adour, CNRS, DICE, IE2IA, Pau, France

Le contrôle de constitutionnalité des décisions de justice en Autriche Marie-Caroline ARreto, ATER à l'Université Paris 1 Panthéon-Sorbonne

Débats, sous la présidence de Madame Anne LEVADE. 197

Chapitre 2. Le contrôle des décisions de justice exercé dans le cadre des questions préjudicielles

Le contrôle des décisions de justice par la Cour constitutionnelle belge 205

Marc Verdussen, Professeur à l'Université de Louvain (UCL), Centre de recherche sur l'État et la Constitution (JUR I-CRECO)

Contrôle de constitutionnalité, interprétation conforme et décisions de justice en Italie : vers une nouvelle configuration des rapports entre la Cour constitutionnelle et les juges ordinaires.

Jean-Jacques PARDini, Professeur, Directeur-adjoint du CDPC Jean-Claude Escarras, Aix Marseille Univ, Université de Toulon, Univ Pau \& Pays Adour, CNRS, DICE, CDPC Jean-Claude Escarras, Toulon, France

Le contrôle des décisions de justice par le Conseil constitutionnel français exercé dans le cadre des questions prioritaires de constitutionnalité. 233 Bertrand Mathieu, Professeur à l'École de droit de la Sorbonne Université Paris 1 


\section{Chapitre 3. L'exemple d'un système mixte : le cas du Portugal}

Le contrôle de constitutionnalité des décisions de justice au Portugal

Vasco Pereira da Silva, Professeur (Professor catedrático) de la Faculté de droit de l'Université de Lisbonne et Professeur invité de l'École de Lisbonne de la Faculté de droit de l'Université catholique portugaise, Directeur de recherche au CIDP - Centro de Investigação de Direito Público ; Rui Tavares Lanceiro, Maître de conférences (Professor Auxiliar) de la Faculté de droit de l'Université de Lisbonne, Consultant auprès du Tribunal constitutionnel, Directeur de recherche au CIDP - Centro de Investigação de Direito Público

Débats, sous la présidence de Madame Anne LEVADE.

\section{Partie III. Coexistence des voies de recours et articulation des contrôles}

Présidence de Madame Nicole Belloubet, Membre du Conseil constitutionnel

Chapitre 1. Le contrôle par les juridictions suprêmes de leur propre jurisprudence

Le cas de la France - Table ronde 267

Le contrôle par les juridictions suprêmes de leur propre jurisprudence - L'exception jurisprudentielle en QPC

Mathieu Disant, Professeur à l'Université Lyon Saint-Étienne, Jean Monnet, Directeur du CERCRID (UMR CNRS 5137)

Le contrôle par les Cours suprêmes de leur propre jurisprudence - Approche critique .......287 Caterina Severino, Maître de conférences HDR, Aix Marseille Univ, Université de Toulon, Univ Pau \& Pays Adour, CNRS, DICE, CDPC Jean-Claude Escarras, Toulon, France

Questions adressées aux juges

Jacques Arrighi de Casanova, Président de section au Conseil d'État; Daniel Ludet, Conseiller à la Chambre sociale de la Cour de cassation; Olivier TALABARDON, Conseiller référendaire à la chambre criminelle de la Cour de cassation

Modèle concentré et ancrage de la Constitution dans l'évolution du contrôle incident en Italie : contribution à l'étude des remèdes contre le refus de soulever la question préjudicielle de constitutionnalité.

Paolo Passaglia, Professeur à l'Université de Pise, Coordonnateur scientifique pour le droit comparé du Service des Études de la Cour constitutionnelle de la République italienne

Débats, sous la présidence de Madame Nicole BELLOUBET

\section{Chapitre 2. Coexistence entre recours direct et question préjudicielle}

La juridiction constitutionnelle en Espagne : un système intégral de justice constitutionnelle? 
La coexistence de la question préjudicielle et du recours direct en Allemagne. 381

Thomas Hochmann, Professeur de droit public à l'Université de Reims Champagne-Ardenne

Chapitre 3. Contrôle de constitutionnalité et contrôle de conventionnalité des décisions de justice

Contrôle de constitutionnalité et contrôle de conventionnalité des décisions de justice - Quelles distinctions dans les contrôles exercés?

Patrick GAÏA, Professeur, Aix Marseille Univ, Université de Toulon, Univ Pau \& Pays Adour,

CNRS, DICE, ILF-GERJC, Aix-en-Provence, France

Contrôle de constitutionnalité et contrôle de conventionnalité des décisions de justice - Quelles fonctions différentes?

Emmanuel PiwnicA, Avocat au Conseil d'État et à la Cour de cassation

Débats, sous la présidence de Madame Nicole BELLOUBET

\section{Partie IV. Les conditions d'une réforme en France, au regard des expériences étrangères}

Table ronde, sous la présidence d'André Roux, Professeur à l'Université

d'Aix-Marseille.

Discussions

Olivier Le Bот, Professeur à l'Université d'Aix-Marseille, Aix-Marseille Univ, Université de Toulon, Univ. Pau \& Pays Adour, CNRS, DICE, ILF, Aix-en-Provence, France ; Michel Fromont, Professeur émérite à l'Université Paris 1 Panthéon-Sorbonne ; Marc Verdussen, Professeur à l'Université de Louvain (UCL), Centre de recherche sur l'État et la Constitution (JUR I-CRECO) ; Julien Bonnet, Professeur à l'Université de Montpellier, CERCOP ; Laurence GAY, Chargée de recherches CNRS, UMR 7318, DICE, Aix-Marseille Univ, Université de Toulon, Univ. Pau \& Pays Adour, CNRS, DICE, ILF-GERJC, Aix-en-Provence, France ; Yasmine Sylvestre, Docteur en droit public à l'Université des Antilles et de la Guyane, Membre associé de LC2S ; Paolo PAssaglia, Professeur à l'Université de Pise ; coordonnateur scientifique pour le droit comparé du Service des Études de la Cour constitutionnelle de la République italienne ; Alexandre VIALA, Professeur à l'Université de Montpellier, Directeur du CERCOP ; Ariane VidAl NAQUeT, Professeur, Aix Marseille Univ, Université de Toulon, Univ Pau \& Pays Adour, CNRS, DICE, ILF-GERJC, Aix-enProvence, France ; Xavier MAgnon, Professeur à l'Université de Toulouse

Propos conclusifs

Marthe Fatin-Rouge Stefanini et Caterina Severino

TABLE DES MATIÈ RES 
À la mémoire de nos deux maîtres Louis Favoreu et Alessandro Pizzorusso, leur vision scientifique et leur grande humanité nous accompagnent toujours 



\title{
Avant-propos
}

\author{
Sandrine MALJEAN-DuBOIs ${ }^{1}$
}

L'introduction de la question prioritaire de constitutionnalité dans le système juridique français a représenté une petite révolution pour le contrôle de constitutionnalité et un indiscutable progrès de l'état de droit. Alors que ce mécanisme est désormais installé dans notre paysage juridique, il est opportun de continuer à réfléchir aux voies et moyens d'amélioration de notre contrôle de constitutionnalité. C'était la motivation de Marthe Fatin-Rouge Stefanini et Caterina Severino lorsqu'elles ont lancé la recherche collective dont cet ouvrage est le fruit. Partant du constat que l'absence de contrôle de constitutionnalité des décisions de justice constitue peut-être l'un des « angles morts »du contrôle de constitutionnalité, n'est-ce pas « ce qui manquerait à notre système de justice constitutionnelle pour le parfaire et se rapprocher d'un système intégral de contrôle de constitutionnalité ? » s'interroge fort justement Marthe Fatin-Rouge Stefanini dans ses propos introductif ${ }^{52}$. Le contrôle de constitutionnalité des décisions de justice pourrait-il contribuer à élargir l'accès au Conseil constitutionnel, et plus largement à offrir une meilleure protection des droits et libertés des justiciables ? Quelles en seraient les modalités pratiques ? Quels en seraient les avantages ? Quels en seraient les risques? Pour répondre à ces différentes questions sur un objet de recherche encore fort peu défriché, Marthe Fatin-Rouge Stefanini et Caterina Severino ont su réunir les meilleurs spécialistes, académiques et praticiens, français et étrangers. L'objectif était d'éclairer le sujet dans toute son épaisseur historique, en s'inscrivant aussi largement dans la prospective.

Il n'est, dans ses conditions, pas étonnant que le contrôle de constitutionnalité des décisions de justice ait donné lieu à des débats aussi passionnés que passionnants lors du colloque organisé à Aix-en-Provence les 23 et 24 juin 2016, colloque dont le lecteur trouvera ci-après les actes. Nul doute que cet ouvrage fera date dans la réflexion sur cette possible nouvelle étape de notre contrôle de constitutionnalité. Nous sommes heureux et honorés de l'accueillir dans la toute nouvelle collection de l'UMR Droits International, Comparé, Européen (UMR DICE 7318, CNRS, Aix-Marseille Université, Université de Toulon, Université de Pau et des pays de l'Adour). Confluence des droits est en effet une collection d'ouvrages entièrement numériques et en libre accès, qui est destinée à publier des

\footnotetext{
$1 \quad$ Directrice de recherche au CNRS, Directrice de l'UMR DICE (Aix-Marseille Université, Université de Toulon, Université de Pau \& des Pays de l'Adour, CNRS, DICE, CERIC, Aix-en-Provence, France)

2 Voir infra, cet auteur, «Propos introductifs. L'idée d'un contrôle de constitutionnalité des décisions de justice, intérêts et questionnements », p. 13.
} 
monographies, thèses, actes de colloques et ouvrages collectifs, en français et en anglais, produits au sein et en dehors de DICE. Confluence des droits s'intéresse à des thématiques montantes ou d'actualité tels que les nouvelles formes de régulation, les nouvelles formes de démocratie ou d'expression démocratique, les changements induits et les nouvelles configurations juridiques et institutionnelles en résultant. La collection accueille les recherches conduites à la croisée des ordres juridiques, aussi bien qu'au carrefour de disciplines différentes, juridiques et extra-juridiques. C'est dire que cet ouvrage y trouve toute sa place. Il fait suite à la parution de Circulations de normes et réseaux d'acteurs dans la gouvernance internationale de l'environnement et précède celle de La démocratie connectée : ambition, enjeux, réalités ?, ainsi que de La fabrication du droit de l'UE dans le contexte du mieux légiférer. Autant d'ouvrages au cœur de débats d'une grande actualité dans notre société, que DICE a pleine vocation à nourrir. 


\title{
Propos introductifs \\ L'IDÉE D'UN CONTRÔLE DE CONSTITUTIONNALITÉ DES DÉCISIONS DE JUSTICE : INTÉRÊTS ET QUESTIONNEMENTS
}

\author{
Marthe Fatin-Rouge Stefanini ${ }^{1}$
}

Pourquoi organiser un colloque en 2016, sur le contrôle de constitutionnalité des décisions de justice ? Pourquoi vouloir se projeter au-delà de la réforme introduite par la révision constitutionnelle du 23 juillet 2008 qui a été soulignée comme un progrès pour l'État de droit français, en particulier pour assurer le respect de la norme fondamentale : la Constitution ? L'introduction de la QPC en France présente, en effet, de nombreux intérêts qui ont pu conduire certains auteurs à parler de révolution : tout d'abord, elle permet progressivement de démarginaliser la Constitution comme norme juridique de contrôle ; ensuite, elle rapproche celle-ci des justiciables et, comme a pu le souligner Ariane Vidal-Naquet lors d'une journée d'étude récente ${ }^{2}$, la QPC a permis de « démocratiser » l'accès au Conseil constitutionnel ; enfin, et surtout, la QPC permet de remettre en cause la constitutionnalité d'une loi entrée en vigueur dont la non-conformité à la Constitution peut se révéler bien des années après son adoption, notamment lors de ses applications concrètes.

Au regard de cette évolution, on pourrait considérer que les avancées notables en matière de contrôle de constitutionnalité constituent un progrès considérable et qu'il n'est pas nécessaire de songer à une nouvelle réforme, d'autant que la mise en place de la QPC est encore très récente. C'est ce qui a d'ailleurs été à peu près constaté dans le rapport présenté par Jean-Jacques Urvoas en 2013 sur le bilan de trois ans d'application de la $\mathrm{QPC}^{3}$. À l'issue de celui-ci, et même s'il soulève un certain nombre de critiques qu'il qualifie «toutefois » d' « hétérogènes », M. Urvoas souligne que : « la procédure fonctionne de manière correcte et n'appelle pas de réforme de grande ampleur $»^{4} \ldots$ Si ce n'est, peut-être, souligne-t-il encore, qu'il faudrait renforcer la juridictionnalisation du Conseil constitutionnel c'est-à-dire donner à celui-ci les véritables moyens de cette réforme ${ }^{5}$.

\footnotetext{
1 Directrice de recherches au CNRS, Directrice-adjointe de l'UMR DICE, Aix Marseille Univ, Université de Toulon, Univ Pau \& Pays Adour, CNRS, DICE, ILF-GERJC, Aix-en-Provence, France.

2 Journée d'étude du 20 juin 2016 organisée par N. Colodrovschi-Danelciuc sur Évolutions et limites du contrôle de constitutionnalité. Regards croisés entre les expériences françaises et Est européennes, Aix-en-Provence.

Assemblée nationale, Rapport d'information, $n^{\circ}$ 842, 27 mars 2013, 157 p.

Précité, Ibidem, p. 60

Précité, Ibidem, p. 65
} 
Cependant, le chercheur a pour habitude de s'interroger constamment et peut-être pour défaut d'être perpétuellement insatisfait. Or, la question prioritaire de constitutionnalité telle qu'elle a été conçue en 2010, et telle qu'elle fonctionne depuis, est le résultat d'un consensus, de compromis au sein des institutions ; s'il l'on s'est entendu sur une modernisation, il n'était pas question de bouleversement ou de renversement des équilibres institutionnels, notamment entre les juridictions. D'un point de vue politique, on peut se satisfaire de ce système et commander la patience. D'un point de vue scientifique, il est naturel de chercher à l'améliorer, d'en identifier les failles, les faiblesses, tout en soulignant également les avantages, les forces, les progrès du système tel qu'il fonctionne. Il est légitime pour les chercheurs d'essayer de voir plus loin, d'imaginer des réformes possibles et de confronter ces réflexions, qui pourraient, d'un premier abord, paraître saugrenues, à d'autres points de vue : ceux d'autres chercheurs, ceux de chercheurs étrangers qui ont déjà peut-être l'expérience d'un contrôle de constitutionnalité des décisions de justice, ceux des praticiens également, de magistrats, de conseillers des juridictions administratives ou judiciaires, de conseillers ou d'anciens conseillers de la juridiction constitutionnelle. L'Université, le CNRS, offrent la liberté de réfléchir et les participants à ce colloque ont été invités durant ces deux jours à saisir cette liberté.

Voir plus loin que ce qui existe actuellement en France, conduit notamment à constater quelques failles ou angles morts du contrôle de constitutionnalité dans notre pays. L'absence de contrôle de constitutionnalité des décisions de justice n'est-elle pas l'un de ces angles morts ? N'est-ce pas ce qui manquerait à notre système de justice constitutionnelle pour le parfaire et se rapprocher d'un système intégral de contrôle de constitutionnalité ?

En outre, après six ans d'application de la QPC, l'objectif affiché par la réforme telle que pensée en 2008 a-t-il bien été atteint ? Si l'un des intérêts de la QPC était de lutter contre la concurrence des normes internationales en matière de protection des droits fondamentaux, et en l'occurrence celle de la Convention européenne des droits de l'Homme par rapport à la Constitution, l'objectif premier de la réforme était d'ouvrir une nouvelle voie de recours aux justiciables pour assurer la protection de leurs droits fondamentaux. Leur permettre d'accéder au juge constitutionnel, gardien de la Constitution et des droits fondamentaux qu'elle recèle. Cependant, après six ans de QPC, force est de constater que si l'accès au prétoire s'est démocratisé, il n'est pas pour autant devenu « populaire ».

Quelles en sont les raisons? Par souci de ne pas engorger le Conseil constitutionnel, tout d'abord, le filtrage peut paraître sévère et, surtout, l'appréciation du caractère sérieux de la question posée n'est pas toujours très compréhensible, en termes de transparence de la motivation, par les justiciables. Ensuite, malgré le succès de la QPC devant le Conseil constitutionnel - et le taux de réussite important ${ }^{6}$ - la QPC semble délaissée par le justiciable lambda, le citoyen ordinaire, au profit d'associations, de grandes entreprises, de syndicats, de groupes de pression, d'individus connus et souvent fortunés. D’ailleurs, ce sont les avocats au Conseil qui détiennent, de fait et au fil du temps, quasiment l'exclusivité de l'accès au prétoire du Conseil constitutionnel.

$6 \quad$ Sans compter les décisions de conformité sous réserve, 23,3\% des QPC qui sont parvenues au Conseil constitutionnel (soit 135 sur les 580 QPC renvoyées au 20 juin 2016) ont donné lieu à des déclarations de non-conformité totale ou partielle. 
La QPC semble donc peu à peu utilisée principalement par ceux qui en ont les moyens, ceux qui sont en mesure de la faire prospérer, au détriment de ceux qui y voient peut-être une perte de temps et d'argent.

Toutefois, la QPC, telle qu'elle a été conçue, avait-elle vraiment pour objectif d'être « populaire » au sens de proche du peuple, proche du citoyen dans sa vie ordinaire? Après tout, si la mise en cause de la loi s'est banalisée, son abrogation ne semble pas avoir vocation à devenir une opération banale dans le système français.

Quoi qu'il en soit, si l'on réfléchit en termes d'accès élargi des citoyens au Conseil constitutionnel, le contrôle de constitutionnalité des décisions de justice pourrait constituer une solution. Toutefois, à son tour, cette proposition donne lieu à une série de questions intrinsèquement liées : qu'entend-on par décision de justice ? Pourquoi ce contrôle ? Par qui serait-il exercé ? Comment serait-il exercé ? Quels seraient les risques d'un tel contrôle?

Tout d'abord, qu'entend-on par décision de justice?

Dans le Vocabulaire juridique de Cornu, la décision de justice est définie comme un «terme juridique englobant tout jugement quel que soit son auteur (arbitre, tribunal de première instance, Cour d'appel, Cour de cassation), son objet (contentieuse ou gracieuse). Dans un sens encore plus large, cela englobe même les décisions d'ordre administratif (et non juridictionnel) émanant d'un juge : les mesures d'administration de la justice ». La question se pose alors de savoir s'il est pertinent, pour notre réflexion, de retenir un sens si large. Qu'en est-il d'ailleurs à l'étranger dans les systèmes qui ont opté pour le contrôle de constitutionnalité des décisions de justice ?

Ensuite, pourquoi ce contrôle?

Un tel contrôle n'existe-t-il pas déjà dans le jeu normal de l'appel et de la cassation ? Un tribunal qui n'aurait pas été impartial, qui n'aurait pas respecté les droits de la défense, ou encore un tribunal qui ne respecterait pas l'autorité de chose jugée attachée à une décision du Conseil constitutionnel, qui n'appliquerait pas une réserve d'interprétation ou qui interpréterait la norme applicable de façon inconstitutionnelle, pourrait être sanctionné par la juridiction supérieure par la voie de l'appel ou de la cassation. Finalement, il n'y aurait plus que les décisions des juridictions suprêmes qui pourraient être concernées par cette réforme, car elles sont insusceptibles de recours en l'état actuel du droit.

La question de l'importance quantitative de ce type de recours mérite également d'être posée. Sur ce point, les expériences étrangères sont susceptibles de fournir des éléments d'appréciation importants puisqu'elles peuvent nous éclairer sur les rapports existants entre le recours direct contre les décisions de justice et les recours par voie incidente. En Allemagne et en Espagne, par exemple, recours direct et question de constitutionnalité coexistent. Cependant, le recours direct est quantitativement beaucoup plus important et concerne majoritairement les décisions de justice, justement. En ce sens, on peut se demander si l'existence de la QPC en France ne conduit pas à exclure la mise en place d'un recours direct contre les décisions de justice. Dès lors, quelles sont dans les autres pays 
et quelles pourraient être en France, les conditions de recevabilité ? Que pensent les comparatistes de cette coexistence entre les deux types de procédure?

Une autre question inévitable concerne le juge susceptible d'exercer ce contrôle : par qui concrètement ce contrôle serait-il exercé ?

On pense bien évidemment au Conseil constitutionnel, mais dans cette hypothèse, ne deviendrait-il pas inéluctable de le réformer? Son rôle et sa place au sein des institutions ne changeraient-ils pas de manière révolutionnaire?

Comment, exercer ce contrôle? Par quelle procédure ?

Sur ce point, plusieurs réponses peuvent être imaginées : un recours direct, si l'on ne veut pas trop bouleverser le système existant ; la mise en place d'un système clairement diffus, si le bouleversement est acté ; ou même une voie intermédiaire qui pourrait s'inspirer, par exemple, du système portugais.

Quel serait, enfin, l'objet du contrôle?

La décision de justice serait l'objet du contrôle, certes, mais à l'intérieur de celle-ci que viserait ce contrôle, précisément ? La motivation ou la décision (le dispositif) en lui-même ? L'appréciation en droit peut-être plus que l'appréciation des faits ? Peut-on parler d'une appréciation de la «norme juridictionnelle »? Et quels seraient, au final, les effets de la décision rendue : un effet sur le procès ou un effet au-delà du procès?

Toutes ces questions et bien d'autres ont été abordées tout au long de ce colloque à travers diverses interventions qui ont permis de nourrir notre réflexion.-

Il nous a semblé opportun de nous interroger tout d'abord sur ce qui a pu exister et sur ce qui existe à l'heure actuelle, concernant le contrôle des décisions de justice, à la fois à travers les juridictions françaises et étrangères, dans le cadre d'un contrôle diffus d'une part (I), et concentré d'autre part (II). Ces diverses expériences ont permis d'apporter des indications essentielles sur les réalités d'un tel contrôle.

La troisième partie du colloque est consacrée à l'analyse de la coexistence des divers types de contrôle présents actuellement en France et à l'étranger, afin de déceler les carences, les limites ou les mécanismes vertueux qui rendraient une telle réforme nécessaire ou pas (III).

Enfin, au regard de tous ces éléments, et pour aller plus loin, une table ronde a été organisée à propos de l'intérêt et des conditions d'une réforme en France pour introduire ce type de contrôle de constitutionnalité (IV).

Pour terminer, Caterina Severino et moi-même souhaitons dédier ce colloque à deux grands maîtres du droit constitutionnel : Louis Favoreu, dont la chaire dans le cadre de laquelle ce colloque a été 
organisé porte le nom, et Alessandro Pizzorusso, également grand professeur de droit constitutionnel et grand comparatiste italien. Tous deux nous ont savamment conduites à nous intéresser à la justice constitutionnelle et nous tenions à leur rendre hommage. En 2001, Louis Favoreu s'était clairement prononcé contre l'introduction d'un recours direct en France qui permettrait aux justiciables de contester directement une loi devant le Conseil constitutionnel ${ }^{7}$. Il soulignait la méconnaissance, souvent source de confusions, des recours directs étrangers lesquels concernent principalement des actes juridictionnels. Nul doute qu'Alessandro Pizzorusso et lui-même, en fins comparatistes, auraient apprécié de débattre avec passion du thème proposé dans le cadre de ce colloque.

7 L. Favoreu, «Sur l'introduction hypothétique du recours individuel direct devant le Conseil constitutionnel », Cahiers du Conseil constitutionnel, $\mathrm{n}^{\circ}$ 10, 2001, accessible en ligne sur le site du Conseil constitutionnel. 

Partie I

\section{LE CONTRÔLE DE CONSTITUTIONNALITÉ DES DÉCISIONS DE JUSTICE PAR LES COURS SUPRÊMES}



Même avant l'instauration de la QPC, la Constitution n'était pas étrangère aux Cours suprêmes de l'ordre administratif et de l'ordre judiciaire en France. Comme le rappelle Jean-Louis Mestre, il s'en est fallu de peu qu'un système diffus de contrôle de constitutionnalité des lois s'établisse. Et même lorsque qu'il fut acquis que les juridictions administratives et judiciaires ne pouvaient pas écarter une loi contraire à la Constitution, la Constitution est restée une norme de référence, non seulement pour le contrôle de dispositions ayant un rang infra-législatif, mais aussi lorsqu'il s'agissait, dans le cadre de la cassation, de vérifier que les juridictions inférieures avaient bien interprété le texte constitutionnel. La norme constitutionnelle est une norme qui, plus globalement, fait partie du contrôle de légalité. De ce fait, le contrôle de la constitutionnalité des décisions de justice, exercé dans le cadre de l'appel ou de la cassation, est apparu comme traditionnel, encore qu'en pratique la norme constitutionnelle soit rarement sollicitée.

De même, dans des systèmes diffus de justice constitutionnelle, tels que le système des États-Unis, celui du Canada ou encore celui de la Suisse, les juridictions supérieures contrôlent «naturellement » la bonne interprétation du droit par les juridictions inférieures et, lors de cette vérification, la norme constitutionnelle apparaît comme une norme de référence parmi d'autres.

Dans les deux cas, le contrôle de constitutionnalité opéré sur les décisions de justice, et leur correcte interprétation ou application du droit, n'est pas « remarquable » en ce sens qu'il se fond dans une opération plus vaste dont l'objectif n'est pas seulement le respect de la Constitution, mais, plus globalement, le respect et la bonne interprétation de la règle de droit.

MFRS et CS 



\section{Présidence de Monsieur Guy Canivet, Ancien Membre du Conseil constitutionnel, Ancien Premier Président de la Cour de cassation}

Guy Canivet remercie Madame Fatin-Rouge Stefanini et Madame Severino de leur invitation. Il ajoute que sa présence aux côtés de Madame Nicole Belloubet, témoigne de la volonté d'associer le passé et le présent du Conseil constitutionnel à la réflexion proposée sur la question prioritaire de constitutionnalité.

Sur le fond du débat, $M$. Canivet remarque que dans les représentations médiatiques dont il est l'objet, le Conseil constitutionnel reflète essentiellement deux images contrastées : l'une du passé de l'institution et de ses acquis, l'autre de son devenir, double vision qui est sous-jacente dans différentes communications et qui est parfaitement exposée par l'introduction de Madame Fatin-Rouge Stefanini. Plus que toute autre institution le Conseil constitutionnel est encore en devenir.

Il ajoute que lorsqu'il s'est agi d'introduire en France un contrôle de constitutionnalité de la loi promulguée, la principale question à résoudre était l'insertion du juge « ordinaire », judiciaire ou administratif, dans l'organisation du recours. Pour des raisons politiques que Madame FatinRouge Stefanini a clairement analysées, la Constitution puis la loi organique ont évité de remettre en cause l'autonomie de ces deux ordres juridictionnels. Le choix a donc été un mécanisme de renvoi au Conseil constitutionnel, à l'initiative de leurs juridictions supérieures respectives, sans la moindre articulation organique entre, le Conseil constitutionnel d'une part, et le Conseil d'État et la Cour de cassation de l'autre. Les conséquences qui en résultent quant aux relations originales et compliquées qu'entretiennent ces trois juridictions sont intéressantes à examiner. C'est l'un des objectifs de ce colloque.

Guy Canivet rappelle que selon le programme établi, la problématique du contrôle de constitutionnalité sera abordée à deux points de vue, l'un dit «traditionnel », comme c'est le cas en France, l'autre dit, « naturel », en vigueur dans les systèmes diffus. Le premier aspect sera traité successivement par MM. Jean-Louis Mestre, Didier Ribes et Laurent Domingo.

Jean-Louis Mestre est Professeur de l'Université d'Aix-Marseille. Ses écrits inspirent beaucoup le Conseil constitutionnel dont il situe le rôle dans une perspective historique. 



\section{Chapitre 1}

\section{UN CONTRÔLE TRADITIONNEL POUR LES COURS SUPRÊMES EN FRANCE}





\title{
Le CONTRôle PAR LA COUR de CASSATION et le Conseil d’État : Perspectives historiQues
}

\author{
Jean-Louis MESTRE ${ }^{1}$
}

Ce contrôle a été opéré dès l'origine, ce qui justifie qu'il ait été qualifié par les deux responsables scientifiques du colloque de « contrôle traditionnel ». Dès le $1^{\text {er }}$ octobre 1791 , le Tribunal de cassation a annulé deux décisions de justice qu'il a jugées contraires à des dispositions de « la loi constitutionnelle de l'État » que l'Assemblée Nationale Constituante venait d'adopter le 3 septembre et Louis XVI d'accepter le 14.

D'emblée, donc, le Tribunal de cassation, qui comprenait plusieurs anciens membres de cette Assemblée, a considéré que le contrôle du respect de la légalité par les juges, contrôle qui lui avait été dévolu par la loi des 27 novembre - $1^{\text {er }}$ décembre 1790 et par les articles 19, 20 et 27 du chapitre de la Constitution consacré au pouvoir judiciaire - le cinquième du titre III - incluait le contrôle du respect des dispositions de la Constitution, à la « fidélité » desquels juges l'Assemblée avait remis le « dépôt » de son œuvre fondamentale et qui juraient précisément, lorsqu'ils entraient en fonction, de «maintenir de tout leur pouvoir la Constitution du Royaume $»^{2}$.

Les deux jugements du $1^{\text {er }}$ octobre 1791 ont été rendus dans des conditions différentes, qu'il convient de relever. Dans la première affaire, le Tribunal a été saisi par des justiciables mécontents d'un arrêt rendu par la cour des aides de Paris, juridiction traditionnellement compétente en matière de fiscalité indirecte. La cour des aides avait refusé de connaître d'un appel qu'ils avaient interjeté devant elle et ordonné que « les parties se retirent par-devant le roi pour leur être fait droit ». Le pourvoi fit valoir que la cour avait « ouvertement violé l'article $1^{\text {er }}$ du chapitre V (du titre III) de la loi constitutionnelle de l'État, qui porte que le pouvoir judiciaire ne pourra, en aucun cas, être exercé par le corps législatif ni par le roi ». Le moyen est admis par le Tribunal de cassation, qui annule « l'arrêt de la ci-devant cour des aides de Paris... et ensemble tout ce qui s'en est ensuivi ».

Professeur émérite de l'Université d'Aix-Marseille.

J.-L. HALPÉRIN, « La Constitution de 1791 appliquée par les Tribunaux », 1791. La première Constitution française (dir. J. BART, J.-J. ClèRE, C. Courvoisier, M. Verpeaux), Paris, Economica, 1993, p. 369-381 ; J.-L. Mestre, « À propos de l'application de la constitution de 1791 par le Tribunal de cassation », Études sur l'ancienne France offertes en hommage à Michel Antoine, Paris, Champion, 2003, p. 243-252. Le serment des juges était imposé par l'article 3 du titre VII de la loi des 16-24 août 1790.

3 Archives Nationales (A.N.), AD/V/4/8. 
De la seconde affaire, le Tribunal de cassation a été saisi sur dénonciation du ministre de la Justice. En vertu de l'article 27 du chapitre de la Constitution consacré au pouvoir judiciaire, ce ministre pouvait demander au Tribunal de cassation, par l'intermédiaire du commissaire du roi près celui-ci, d'annuler « les actes par lesquels les juges auraient excédé les bornes de leurs pouvoirs ». En la circonstance, le tribunal du district de Semur-en-Auxois avait rendu un jugement ordonnant que le commissaire du roi près lui-même s'abstienne de paraître aux audiences pendant un mois et soit remplacé par un juge ! Au nom du ministre, ce jugement est dénoncé comme abusif et, sans précision, comme une «violation évidente de la loi ». Ce Tribunal de cassation l'annule « comme contraire à l'article 2 du chapitre V (du titre III) de la loi constitutionnelle de l'État, qui porte que la suspension ne pourra avoir lieu que pour une accusation admise $»^{4}$.

L'application de cet article n'allait cependant pas de soi, car cette disposition ne mentionnait que les juges élus par le peuple. Or, les commissaires du roi étaient des agents du pouvoir exécutif, selon l'article 1 du titre VIII de la loi des 16-24 août 1790. Ils étaient nommés à vie par le roi, et non élus à temps par les citoyens actifs. C'est vraisemblablement ce problème qui a dû conduire à la réunion des deux sections du Tribunal en audience générale. L'interprétation extensive de la disposition constitutionnelle a été sans doute adoptée pour éviter que des juges ne puissent paralyser l'action du ministère public, alors que commençaient à fonctionner les nouvelles institutions judiciaires. Mais cela confirmait que l'interprétation de la Constitution pouvait poser un problème comme celle des lois, laquelle devait aboutir in fine à l'adoption d'un « décret déclaratoire » de la loi par le Corps législatif.

À partir du 24 novembre 1791, le Tribunal de cassation emploie l'expression « Acte constitutionnel » à la place de celle de « Loi constitutionnelle ». Peut-être parce que ses membres l'estimaient plus solennelle, plus valorisante.

Est-ce qu'on trouve à l'époque la formule « contrôle de constitutionnalité » ? Pas à ma connaissance. Mais l'adjectif « inconstitutionnel » et l'adverbe « inconstitutionnellement » existaient déjà5. Ils avaient même été souvent utilisés avant que les États Généraux ne s'érigent en Assemblée Nationale Constituante. On les rencontre dans des réquisitoires des commissaires du roi, réquisitoires reproduits dans les jugements du Tribunal de cassation. Le premier exemple date du 9 décembre $1791:$ «e ministre de la Justice a fait passer toutes les pièces au commissaire du roi, qui après un mûr examen, a trouvé que la conduite du tribunal de Bergerac était inconstitutionnelle, et que ses jugements et ses délibérations doivent être déférés au Tribunal de cassation $»^{6}$.

Le plus développé de ces réquisitoires émane d'un futur ministre de la Justice, Abrial, dans une affaire jugée le 3 mai 1792, qui posait le problème du pouvoir des juges vis-à-vis d'actes administratifs attaqués pour violation de la Constitution : «Quand bien même l'arrêté de la municipalité de Ségur du 19 janvier 1792 et celui du 26 eussent été inconstitutionnels..., il suffisait qu'ils fussent

$\mathrm{AN}, \mathrm{AD} / \mathrm{V} / 4 / 9$.

A. Vergne, La notion de constitution d'après les Cours et Assemblées à la fin de l'Ancien Régime (1750-1789), Paris, De Boccard, 2006, p. $12-13,427-434$.

6 A.N., $\mathrm{AD} / \mathrm{V} / 4 / 22$. 
émanés des officiers municipaux, comme municipaux, pour que la connaissance et la réformation n'en appartinssent qu'aux corps administratifs ». En l'espèce, le tribunal du district d'Uzerches avait « cassé comme inconstitutionnel » le premier de ces arrêtés. Le réquisitoire d'Abrial a été suivi par les deux sections réunies du Tribunal de cassation : il a annulé les décisions du tribunal d'Uzerches, comme contraires à l'article 3 du chapitre V du titre III de l'Acte constitutionnel, qui défendait aux tribunaux d'entreprendre sur les fonctions administratives. Le jugement du Tribunal de cassation va dans le sens de la décision du Conseil constitutionnel du 23 janvier 1987. Il correspondait à la position de la Constituante, qui avait confié aux autorités administratives départementales, le 12 août 1790 , le soin d'annuler les « actes inconstitutionnels » des corps municipaux. "Chef de l'administration générale du Royaume », Louis XVI a annulé, après délibération du Conseil d'État créé par la loi des 27 avril - 25 mai 1791 et composé des ministres, des actes d'administrations départementales contraires à la Constitution ainsi qu'à des lois'.

On voit bien que l'opération intellectuelle consistant à déterminer si une décision judiciaire ou administrative était ou non contraire à la Constitution apparaissait comme nécessaire au bon fonctionnement de l'État. Thouret, qui avait joué un rôle si important à la Constituante lorsqu'elle avait adopté la loi des 16-24 août 1790 sur l'organisation judiciaire, a même écrit, dans un rapport qu'il a rédigé au sein du Tribunal de cassation dont il était devenu membre, que c'était «pour veiller au maintien d'une des plus importantes parties de la Constitution » - « la distinction faite entre le pouvoir judiciaire et le pouvoir exécutif » - « que la suprême révision de tous les actes des tribunaux » avait été déléguée à ce tribunal suprême ${ }^{9}$. Celui-ci s'estimait donc pleinement dans son rôle quand il examinait si les décisions de justice qui lui étaient soumises étaient ou non contraires à la Constitution, à « l'œuvre régénératrice » de la France, dont le succès apparaissait incertain dans des conditions socio-politiques très tendues.

Son examen des inconstitutionnalités contenues dans les jugements, le Tribunal de cassation a continué de l'exercer après l'abolition de la royauté et l'établissement de la République par la Convention. Ses membres, attachés à l'œuvre de la Constituante au sein de laquelle plusieurs, dont Thouret devenu son président, avaient siégé, devaient craindre les risques de l'abandon de dispositions qui leur paraissaient indispensables pour assurer la séparation du pouvoir judiciaire d'avec les pouvoirs législatif et exécutif, et pour maintenir des garanties procédurales en matière pénale. Simplement, après l'exécution de Louis XVI, l'expression «Acte constitutionnel » est presque toujours remplacée par celle de « loi du 14 septembre $1791 »$. Le Tribunal de cassation présentait ainsi habilement les dispositions de « la ci-devant loi constitutionnelle » qu'il voulait sauver de la caducité, comme de simples dispositions législatives restées en vigueur.

\footnotetext{
7 J.-L. Mestre, «Le Tribunal de cassation et l'inconstitutionnalité des actes administratifs », RFDA 2011, p.117-123 et 842.

8 S. SÉGALA, « Le Conseil d'État de 1791 et l'annulation d'actes administratifs pour illégalité et inconstitutionnalité », RRf, 1993, p. 551-564 ; L'activité des autorités administratives départementales des Bouches-du-Rhône de 1790 à 1792,PUAM, 1997, p. 82-95 (pour des exemples d'annulations de délibérations municipales inconstitutionnelles par les autorités administratives départementales, p. 131, 161, 299).

9 Ce rapport est inséré dans un jugement du 22 mars 1792, qui casse un jugement du tribunal du district d'Hennebon comme contraire à l'article 18 du titre V de la loi des 16-24 août 1790 et à l'article 3 du chapitre V du titre III de l'acte constitutionnel, pour être intervenu sur des « objets d'administration » (A.N., AD/V/4/55).
} 
La Constitution de l'an III (1795), celle du Directoire, a confié à nouveau au Tribunal de cassation la fonction d'annuler les jugements entachés d'une violation des formes procédurales, d'une contravention expresse à la loi ou d'un excès de pouvoir ${ }^{10}$.

Il a continué d'invalider les jugements violant la Constitution. Plus de 120 décisions de cassation sont reproduites au fournal du Palais. Ce chiffre très élevé s'explique par le grand nombre et la minutie des dispositions du titre VIII de cette nouvelle Constitution, consacré au Pouvoir judiciaire. Après la tragique période de la Terreur, les Thermidoriens avaient inséré dans le nouveau texte constitutionnel des dispositions très précises afin de protéger les personnes suspectées de crimes ou de délits. Le Tribunal de cassation veilla à leur respect, comme à celui des dispositions législatives subséquentes ${ }^{11}$. Il a sanctionné aussi des jugements pour violation de la Déclaration des droits et des devoirs de l'homme et du citoyen qui précédait la Constitution elle-même ${ }^{12}$.

La Constitution de l'an III a été vite remplacée par celle du 22 frimaire an VIII (13 décembre 1799), celle du Consulat. Modifiée par des Sénatus-Consultes, elle devient celle de l'Empire. Le Tribunal de cassation profite des changements terminologiques : il est érigé en Cour de cassation en 1804. Celle-ci maintient la position adoptée en 1791 : elle applique les nouveaux textes constitutionnels, qui sont cependant beaucoup moins développés en matière judiciaire.

C'est à l'époque napoléonienne que sont réorganisées les juridictions civiles et pénales, qu'ont été créés le Conseil d'État (par la Constitution de l'an VIII) et les conseils de préfecture. C'est dans ce nouveau cadre institutionnel, qui va persister, qu'il convient d'analyser les modalités des contrôles de constitutionnalité des décisions de justice qu'ont opérés la Cour de cassation et le Conseil d'État.

La Cour de cassation est amenée à procéder à un tel contrôle à l'occasion d'affaires pénales ou civiles, lorsqu'elle connaît de certaines décisions des juges de paix, de certains jugements de tribunaux correctionnels, d'arrêts de Cours d'appel, de Cours criminelles spéciales, de Cours d'assises ou de jugements de Conseils de guerre. Elle peut-être conduite à procéder à un tel contrôle à l'égard de n'importe quelle décision à elle dénoncée par le ministère public dans l'intérêt de la loi, notamment comme entachée d'un excès de pouvoir. Le Conseil d'État, de son côté, peut annuler pour inconstitutionnalité des arrêtés contentieux d'un conseil de préfecture et des décisions rendues par des juridictions judiciaires en cas de conflit d'attribution, et ce, jusqu'aux deux créations successives du Tribunal des conflits ${ }^{13}$.

La diversité des affaires à l'occasion desquelles a été formulé le grief d'inconstitutionnalité, conduit à analyser plusieurs situations.

Articles 255, 262 et 263.

C. SAPHORE, « La Constitution dans la jurisprudence criminelle de la Cour de cassation (1791-1810) », Politeia, n 5, 2004, p. $199-229$.

J. Ferrand, «Aux confins du politique et du juridique... ou du bon usage des Déclarations de droits par les corps administratifs et judiciaires de la Révolution », www.cliothemis.com.

13 J.-L. M., « Les contrôles de constitutionnalité exercés par les juridictions françaises entre 1791 et 1914 », Conférences « Vincent Wright » (Comité d'histoire du Conseil d'État et de la juridiction administrative), vol. 2, Paris, La Documentation française, 2015, p. 87-102. 
I. La première est la plus nette : la Cour de cassation ou le Conseil d'État contrôle si la décision de justice contestée a violé directement une disposition de la Constitution en vigueur applicable en l'espèce. Cet examen conduit soit à valider la décision contestée, soit à l'annuler. Je ne retiens ici que cette seconde possibilité. L'annulation peut provenir de deux causes.

En premier lieu, l'auteur de la décision contestée a donné au litige une solution purement et simplement opposée à la disposition constitutionnelle applicable à la solution de l'espèce. Par exemple, en 1813, un conseil de préfecture ordonne la restitution à son ancienne propriétaire d'un bien qui avait été vendu, comme bien national, à un adjudicataire. La décision est annulée par le Conseil d'État parce que « les actes constitutionnels garantissent l'inviolabilité des adjudications (de biens nationaux) régulièrement consommées $»^{14}$.

Dans d'autres cas, les plus nombreux, la décision est annulée parce qu'elle est considérée comme ayant mal appliqué la disposition constitutionnelle invoquée par l'une des parties ou par le ministère public. Je prends l'exemple de l'article 75 de la Constitution de l'an VIII qui a établi la garantie des fonctionnaires, qu'on qualifiait alors de « garantie constitutionnelle » : « Les agents du gouvernement, autres que les ministres, ne peuvent être poursuivis pour des faits relatifs à leurs fonctions qu'en vertu d'une décision du Conseil d'État : en ce cas, la poursuite a lieu devant les tribunaux ordinaires ». Certaines décisions sont cassées parce qu'elles ont fait bénéficier de cet article 75 des personnes auxquelles elles n'auraient pas dû reconnaître la qualité d'agent du gouvernement ou, à l'inverse, parce qu'elles n'ont pas fait profiter de cet article de véritables agents du gouvernement. $\mathrm{Ou}$ bien, parce qu'elles ont mal apprécié si les faits pour lesquels l'agent du gouvernement était mis en cause se rattachait ou non à l'exercice de ses fonctions. Dans tous ces cas, est sanctionnée la violation de l'article 75, que les juges ont mal appliqué. Ils en ont fait une «fausse application », mais cette expression est moins fréquente que le mot « violation $»^{15}$.

On peut citer aussi, pour donner un autre exemple, un arrêt de la chambre criminelle de la Cour de cassation en date du 18 janvier 1827. Cet arrêt a cassé, pour «violation » de l'article 64 de la « Charte constitutionnelle » de 1814, un arrêt de la Cour d'assises de la Seine-et-Oise qui avait ordonné le huis clos sans « déclarer que la publicité de ces débats serait dangereuse pour l'ordre et les mours $»^{16}$.

II. La seconde situation n'a pas été aussi féconde en annulation que la première. C'est celle du contrôle ou de l'absence de contrôle, par le juge inférieur, de la constitutionnalité initiale d'un texte antérieur à la Constitution en vigueur.

\footnotetext{
1418 janvier 1813, Bruyninckx, Roche et Lebon, VI, p. 403. Il s'agit des Constitutions l'an VIII (article 94) et de l'an III (article 374).

15 J.-L. M., « Les juridictions judiciaires françaises et la garantie des fonctionnaires », RR7, 1990, p. 77-92 ; « La garanties des fonctionnaires », Liberté, libéraux et Constitutions (dir. J.-P. Clément, L. Jaume, M. Verpeaux), Paris, Economica, et Aix, PUAM, 1997, p. 77-96. Sur la problématique de la violation de la Constitution : L. FonTAINE, « La violation de la Constitution : autopsie d'un crime qui n'a jamais été commis », RDP, 2014, p. $1617-1638$.

16 D. 1827.1.374. L'article 64 disposait : «Les débats seront publics en matière criminelle, à moins que cette publicité ne soit dangereuse pour l'ordre et les mœurs ; et, dans ce cas, le tribunal le déclare par un jugement ».
} 
Le problème s'est d'abord posé à propos de décrets qu'avait pris Napoléon sans respecter la Constitution de l'an VIII, en empiétant sur le domaine du législateur, notamment en créant des infractions pénales. Deux cas se sont présentés.

Dans le premier cas, le décret impérial n'a pas été appliqué par les juges inférieurs, qui l'ont estimé entaché d'une inconstitutionnalité ab initio. Mais la Cour de cassation considère que si le décret a été appliqué dès son origine comme une loi, « sans opposition des pouvoirs qui avaient le droit de juger s'il renfermait une usurpation de l'autorité législative », c'est-à-dire sans annulation par le Sénat conservateur de la Constitution de l'an VIII, les juges ne doivent pas prendre en compte l'inconstitutionnalité initiale dudit décret ${ }^{17}$.

Dans le second cas, le décret impérial a été appliqué, les juges n'ayant pas retenu le grief d'inconstitutionnalité $a b$ initio. Mais c'est alors cette application que dénonce le pourvoi en cassation. Le demandeur avance comme moyen la « violation de l'article 25 de la Constitution de l'an VIII », qui ne permettait de promulguer les lois nouvelles qu'après la communication du projet gouvernemental au Tribunat et son adoption par le Corps législatif. La Cour de cassation répond que le décret impérial contesté a été publié et exécuté comme loi de l'État ${ }^{18}$.

Cette jurisprudence, qui donnait force de loi à des décrets impériaux que l'on appelait couramment « décrets impériaux inconstitutionnels », visait, selon des magistrats de la Cour de cassation elle-même, à préserver la stabilité intérieure de l'État, qui risquait d'être affectée par le vide juridique qu'entraînerait la sanction de l'inconstitutionnalité initiale de nombreux décrets impériaux. Elle prêtait le flanc aux critiques, notamment à celles de Dupin aîné, devenu procureur général près la Cour de cassation après la Révolution de 1830 . Ces critiques restèrent cependant vaines ${ }^{19}$.

L'argument tiré de l'inaction de l'organe chargé de veiller au respect de la Constitution n'était évidemment pas transposable lorsqu'était mise en cause, après la Révolution de 1830 et l'entrée en vigueur de la nouvelle Charte constitutionnelle, la constitutionnalité initiale d'une ordonnance royale émanant de Louis XVIII ou de Charles X. Dans un arrêt du 8 janvier 1834, la Cour de Nîmes, chambres réunies, affirme qu'une ordonnance du 27 février 1822 a été rendue " hors des limites du pouvoir exécutif » fixées par la Charte de 1814. Elle le fait après avoir solennellement déclaré que « toutes les fois que l'application d'une ordonnance royale est demandée aux tribunaux, il est de leur devoir d'examiner sa constitutionnalité ; que ce devoir ne cesse pas pour eux, parce qu'ils auraient déjà ordonné l'exécution d'un pareil acte en d'autres circonstances où sa légalité n'aurait

17 Ch. crim., 27 mai 1819, S. 1819.1.347 (Voir C. Durand, « Les décrets-lois napoléoniens devant la jurisprudence de la Restauration », Études offertes à Jean Macqueron, Aix, PUAM, 1970, p. 269-277).

18 Ch. Crim., $1^{\text {er }}$ septembre 1831, S. 1831.1.353. En l'absence d'une publication au Bulletin des lois et décrets, le décret ne se voyait pas reconnaître force législative (Cass. crim., 13 juillet 1855, D.1855.1.360).

19 J.-L. M., « La Cour de cassation et le contrôle de la constitutionnalité. Données historiques », La Cour de cassation et la Constitution de la République, Aix, PUAM, 1995, p. 40-43. Un arrêt des chambres réunies du 13 mars 1832 admit toutefois l'examen de la validité des décrets pris par l'impératrice Marie-Louise pendant sa régence. Il dénia toute valeur à celui qui avait apporté un ajout au Code de commerce, ce qui « excédait évidemment les bornes du pouvoir exécutif » (S. 1832.1.293). Voir aussi G. Bigot, L'autorité judiciaire et le contentieux de l'administration. Vicissitudes d'une ambition. 1800-1872, Paris, LGDI, 1999, p. 209-216. Le Conseil d'État admit aussi l'assimilation des décrets impériaux inconstitutionnels à des lois (par exemple, 6 mai 1858, Giral, R., p. 354). 
pas été mise en question $»^{20}$. Saisie d'un pourvoi, la Cour de cassation, chambres réunies également, affirme au contraire que cette ordonnance " a été constitutionnellement rendue $»^{21}$. Mais elle laisse entendre que, dans le cas contraire, elle n'aurait pas été applicable. Le 28 mai 1842, la chambre criminelle rejette le pourvoi introduit à l'encontre d'un arrêt de la Cour de Caen, qui avait jugé qu'une ordonnance du 14 août 1816 « était impuissante par elle-même pour créer des peines ${ }^{22}$. Un an plus tard, elle confirme cette position : «Les ordonnances royales n'ont pu, depuis la promulgation de la Charte (de 1814) ni rien ajouter aux lois pénales, ni rien en retrancher $»^{23}$.

Le contrôle de la constitutionnalité $a b$ initio de dispositions réglementaires antéconstitutionnelles fut étendu des ordonnances royales à d'autres textes émanant de titulaires du pouvoir réglementaire, notamment aux arrêtés des gouverneurs de colonies. L'exemple le plus remarquable en est fourni par le contentieux relatif à des droits sur les tabacs importés à la Réunion. Trois arrêtés des 17 juillet, 13 et 28 décembre 1850 ont été pris sur la base d'un décret du gouvernement provisoire de la République datant du 27 avril 1848, qui avait attribué diverses compétences au gouverneur de l'île. Un négociant, Lacaussade, refusa de payer les sommes qui lui étaient demandées en excipant de « l'illégalité et de l'inconstitutionnalité » de ces arrêtés. Il fit valoir que ceux-ci avaient établi des droits de douane, même si l'expression « octroi de mer » avait été employée, alors que le décret de 1848 n'avait pas transféré au gouverneur le pouvoir de créer des taxes douanières, pouvoir qu'avait réservé au législateur métropolitain l'article 2 de la loi du 24 avril 1833 sur l'organisation des colonies, loi parfois considérée comme ayant doté les colonies d'une constitution. Après maintes péripéties, la chambre civile de la Cour de cassation jugea, le 11 mars 1885, que l'arrêté du 13 décembre 1850 était « entachée d'illégalité et d'inconstitutionnalité » et cassa l'arrêt faisant l'objet du pourvoi « au chef qui a déclaré légal et constitutionnel l'arrêté susénoncé $»^{24}$.

Le Conseil d'État, qui avait reconnu, dans l'affaire Lacaussade, la compétence de la juridiction judiciaire pour apprécier la validité des arrêtés de 1850, s'agissant de contributions indirectes ${ }^{25}$, a examiné parfois, lui aussi, la question de la constitutionnalité $a b$ initio d'une disposition antéconstitutionnelle. Il le fit le 2 décembre 1853 à propos de la loi du 17 juillet 1819 sur les servitudes militaires : il vérifia qu'elle avait été « votée par les chambres législatives, promulguée et publiée suivant les formes constitutionnelles », celles de la Restauration ${ }^{26}$. Il le fit le 5 juin 1874, en vérifiant que le

\footnotetext{
20 S. 1834.2 .153

8 avril 1837, S. 1837.1.281 et chambre civile, 13 mai 1840. S. 1840.1.536.

S. 1842.1 .855 .

24 mai 1843, S. 1843.1.860. De façon générale, sur la question :J.-L. M., «Les juridictions judiciaires et l'inconstitutionnalité des ordonnances royales de la Restauration au Second Empire », RFDC, 1993, p. 451-461; «L'inconstitutionnalité des actes réglementaires de 1841 à 1851 », Administration et droit (dir. F. Burdeau), Paris, LGDJ, 1996, p. 123-133 ; « La Cour de cassation... », op. cit., p. 44-47 ; G. Bigot, op. cit., p. 176190, 202-209. Il était toutefois admis qu'une ordonnance puisse modifier ou abroger une disposition considérée, de par son contenu, comme réglementaire, alors même qu'elle figurait dans un texte formellement législatif ou dans un décret impérial auquel on reconnaissait force de loi (J.-L. M., « De l'ancien sur l'article 37, alinéa 2, de la Constitution », RFDA, 2001, p. 301-318; « Encore de l'ancien sur l'article 37, alinéa 2, de la Constitution de 1958 », Droit, politique et littérature. Mélanges en l'honneur du Professeur Yves Guchet, Bruxelles, Bruylant, 2008, p. $123-135$. $24 S$ S. 1885.1.425; D. 1885.1.105. Le procureur général Baudouin et le conseiller Ruben de Couder, qui annota cet arrêt de la chambre civile à la fois au Sirey et au Recueil périodique des Pandectes Françaises (1886.5), dont il était le fondateur, ont pris position, à l'inverse, en faveur de la constitutionnalité de l'arrêté incriminé. De façon générale, Jérémy Boutier a soutenu une thèse révélatrice sur La question de l'assimilation politico-juridique de l'île de la Réunion à la Métropole (1815-1906), Aix-Marseille, 2015.

25 C.E., 4 septembre 1856, La Caussade (sic), R. 1856, p. $562 ;$ D.1857.3.30.

26 Veuve Massois, R.1853, p. 1012 ; D. 1854.5 .568 (où l'arrêt est daté par inadvertance du 2 décembre 1854).
} 
décret du 8 août 1870, qui avait déclaré le département du Rhône en état de siège, avait été, «par application de la Constitution du 14 janvier 1852, communiqué le 9 août au Sénat ${ }^{27}$.

III. Les textes antérieurs à la Constitution en vigueur lors du litige, y compris les décrets de Napoléon $I^{\text {er }}$ considérés comme ayant valeur législative et les lois elles-mêmes, n'étaient toutefois applicables qu'à condition de n'avoir pas été abrogés par les textes constitutionnels postérieurs. Le Conseil d'État, dès sa première séance, a fait valoir que « le principe éternel qu'une loi nouvelle fait cesser toute loi précédente ou toute disposition de loi précédente contraire à son texte » était « applicable, à plus forte raison, à la Constitution, qui est la loi fondamentale de l'État ${ }^{28}$.

L'abrogation des dispositions législatives contraires à la nouvelle Constitution découle ensuite directement des dispositions de celle-ci, de l'article 68 de la Charte constitutionnelle de 1814, des articles 59 et 70 de celle de 1830, de l'article 112 de la Constitution de 1848 et de l'article 56 de celle de 1852, puisque ces textes ne maintiennent en vigueur que les dispositions législatives non contraires aux nouvelles dispositions constitutionnelles. Les trois derniers articles qui viennent d'être cités abrogent de la même façon les mesures réglementaires opposées au nouveau texte constitutionnel ${ }^{29}$. De la sorte, appliquer un texte abrogé par la Constitution revient à commettre une inconstitutionnalité.

Deux cas peuvent se présenter. Le premier, c'est celui de l'abrogation dite «nécessaire », la disposition antéconstitutionnelle étant évidemment contraire au texte exprimant la volonté du nouveau constituant. Un arrêt de la chambre criminelle du 15 avril 1819 en fournit un exemple typique. Un faux-monnayeur a été condamné à la confiscation générale de ses biens sur la base de l'article $132 \mathrm{du}$ Code pénal de 1810. Or, l'article 66 de la Charte de 1814 dispose que « la peine de la confiscation des biens est abolie et ne pourra être rétablie ». Cette disposition abrogeant « nécessairement » l'article $132 \mathrm{du}$ Code pénal, l'arrêt de la Cour d'assises est cassé pour violation de cet article $66^{30}$.

L'abrogation peut, dans un second cas, ne pas résulter aussi évidemment du nouveau texte constitutionnel. Les juges sont alors conduits à se livrer à une analyse comparative approfondie entre la disposition législative ou réglementaire antérieure à la Constitution et le texte de celle-ci. Il est donc arrivé que des juges du premier ou du second degré procèdent à une telle analyse et en concluent ou non à l'abrogation de la disposition antéconstitutionnelle. Saisie de pourvois qui reprochaient à un jugement d'un tribunal de police ou à un arrêt d'avoir violé la Constitution en ayant mal résolu la question de l'abrogation implicite qui se posait en l'espèce, la Cour de cassation s'est prononcée à diverses reprises. Il lui est arrivé de faire valoir, pour rejeter un pourvoi, que les lois

27 Chéron, R.1874, p. 515. L'article 12 de la Constitution de 1852 accordait au président de la République le droit de déclarer l'état de siège, « sauf à en référer au Sénat dans le plus bref délai ».

28 Cet avis du Conseil d'État, du 4 nivôse an VIII (25 décembre 1799), a fait l'objet d'un excellent commentaire signé P. de la Gironde (Bernard Pacteau) au Dalloz de 1999 («Que la nouvelle constitution a fait périr les lois anciennes inconciliables avec elle », Jurisprudence, p. 705-710).

29 Les articles 112 et 56 des Constitutions de 1848 et 1852 font mention des « règlements existants », l'article 70 de la Charte de 1830 des « ordonnances ». Mais, même sous la Restauration, il a été admis que l'abrogation par la nouvelle Charte constitutionnelle devait s'appliquer aux actes réglementaires comme aux dispositions législatives, ce qui était logique.

30 S. 1820.1.1. J. Trémeau a écrit que le juge se livre alors à un «contrôle de flagrance » (« La caducité des lois incompatibles avec la Constitution », $A I \mathcal{F} C$, vol. VI, 1990, p. 250). 
invoquées par les demandeurs en cassation étaient « non seulement virtuellement abrogées, par cela seul qu'elles sont inconciliables avec les articles 9 et 10 de la Charte (de 1814), mais qu'elles se trouvent de plus révoquées par l'article 68, qui ne maintient que les lois existantes qui ne sont pas contraires à la Charte ${ }^{31}$. Dans l'ensemble, toutefois, il faut reconnaître que la Cour de cassation s'est montrée beaucoup plus réservée que certaines juridictions inférieures envers l'abrogation implicite de dispositions législatives par les Chartes ou les Constitutions. Elle redoutait les effets potentiels de la disparition de nombreuses mesures législatives protectrices de l'ordre public ou de l'ordre social' ${ }^{32}$.

En ce qui concerne les décrets impériaux, la Cour de cassation a été moins stricte. Certes, elle a refusé de considérer comme abrogés nombre d'entre eux, parfois même en dépit des arguments avancés par un avocat général tel qu'Hello ${ }^{33}$. Mais elle s'est prononcée en faveur de l'abrogation dans des affaires qui ont eu un grand retentissement, à commencer par l'affaire Geoffroy dans les premières années de la Monarchie de Juillet. Condamné à mort pour rebellion à main armée et incitation à la guerre civile, Geoffroy a contesté la compétence du conseil de guerre qui l'a jugé, en excipant de sa qualité de civil. Son avocat, Odilon Barrot, soutient que l'article 103 du décret du 24 décembre 1811, sur lequel reposait la compétence du conseil de guerre, a été abrogé par les articles 53 et 54 de la Charte, qui disposaient que «nul ne pourra être distrait de ses juges naturels » et qui proscrivaient les « tribunaux extraordinaires ». La chambre criminelle lui donne raison, l'article 103 étant « inconciliable avec le texte comme avec l'esprit » des articles 53, 54, 56 et 69 de la Charte de $1830^{34}$. Autre arrêt remarqué sous la Monarchie de Juillet, celui rendu en faveur du lieutenant Marin : il affirme que le décret du $1^{\text {er }}$ mai 1812 a été abrogé par les articles de la Charte de 1830 qui établissent les « garanties constitutionnelles... en ce qui touche la justice criminelle $»^{35}$.

\footnotetext{
31 Cass. civ., 26 décembre 1825. S. 1826.1.270.

32 J.-L. M., « La Cour de cassation », op. cit., p. 48-55 ; G. Bigot, op. cit., p. 217-222. Plus généralement, S. Ferrari, « De l'art du trompe-l'œil : l'abrogation implicite de la loi par la Constitution au service d'un continuum constitutionnel », RFDC, n 83, 2010 , p. 497-521.

33 Par exemple, Cass. crim., 23 juin 1838, S.1838.1.502, note Devilleneuve, favorable aux conclusions non suivies d'Hello. Celui-ci deviendra ensuite conseiller à cette Cour, membre de l'Académie des sciences morales et politiques, et député. Il publia un important ouvrage de droit constitutionnel, d'inspiration libérale. Il y dénonça les « décrets usurpateurs » de Napoléon, tout en assurant que la Cour de cassation avait fait, en assimilant ces décrets inconstitutionnels à des lois, " une chose utile » dans l'intérêt de la société (Du régime constitutionnel dans ses rapports avec l'état actuel de la science sociale et politique, $3^{e}$ édition, Bruxelles, Meline, 1849, p. 288-293). Sur la primauté de la Constitution, il relève que « l'instinct national... fait à merveille la différence de la Charte à la loi ; il y voit une sorte de loi magistrale, la loi par excellence, la loi fondamentale, la loi des lois. Ces appellations sont entrées dans son langage » (p. 242). Il a fait l'objet d'une notice, rédigée par C. CHÊNE, dans le Dictionnaire historique des juristes français (XII ${ }^{e}-X X^{e}$ siècle), dir. P. ArABEYre, J.-L. HAlpérin, J. KRYNEN, $2^{\mathrm{e}}$ éd., Paris, PUF, 2015 , p. $524-525$. 34 Cass. crim., 29 juin 1832, S. 1832.1 .428 ; D. 1832.1.273. L'article 56 de la Charte de 1830 prévoyait le maintien des jurys ; l'article 69 indiquait qu'il serait pourvu par une loi à « l'application du jury aux délits de presse et aux délits politiques ». Dans les jours suivants, la chambre criminelle a rendu des arrêts identiques, dont certains furent publiés au Moniteur Universel, le prédécesseur du fournal Officiel, qui avait déjà publié in extenso la plaidoirie d'Odilon Barrot. À l'inverse, la Cour de Poitiers considéra qu'il ne lui revenait pas de se prononcer sur la validité d'une mesure ordonnée par le général Drouet d’Erlon durant l'état de siège : « Décider que cet ordre a été donné sans droit, qu'il repose sur des lois abolies par la Charte, qu'il est par conséquent inconstitutionnel, c'est juger comme pouvoir judiciaire supérieur un acte administratif, c'est l'annuler, c'est empiéter sur les droits de l'administration » (L'essentiel de l'arrêt, daté du 16 août 1833, est reproduit au Sirey (1834.2.245) et au Dalloz (1834.2.17). Il se trouve aux Archives départementales de la Vienne, dans le registre 2U1897, non paginé, à la date du 23 août 1833). Mais cet arrêt isolé, qui infirmait deux jugements du tribunal de Fontenay-le-Comte en ne distinguant pas entre l'inapplication d'un acte administratif pour inconstitutionnalité et son annulation, reflétait une opposition de nature politique entre magistrats légitimistes vendéens et membres orléanistes de la Cour de Poitiers (J.-L. M., « Une suite judiciaire d'un conflit politique : l'affaire Drouet d'Erlon (1832-1836) », Mélanges en l’honneur du professeur Michel Ganzin, Paris, La Mémoire du Droit, 2016, p. 813-838). La distinction entre inapplication et annulation fut ensuite bien exposée par le doyen de la Faculté de droit de Poitiers, Foucart, lorsqu'il répondit par la négative à la question : «Une ordonnance inconstitutionnelle est-elle obligatoire pour les tribunaux ? » (Éléments de droit public et administratif, $2^{\mathrm{e}}$ éd., Paris, Videcoq, 1839, t. I, p. 80, 93-95). Elle fut bien marquée par Hello (op. cit., p. 290-292). Sur Foucart, M. TouzeIL-DivinA, Éléments d’histoire de l'enseignement du droit public : la contribution du doyen Foucart (1799-1860), Paris, LGDJ, 2007 ; La doctrine publiciste. 1800-1880, Paris, La Mémoire du Droit, 2009, passim.

35 S. 1847.1.465.
} 
Sous la Seconde République, la chambre des requêtes affirme qu'une délégation, contenue dans un décret impérial du 22 mars 1813, « en vertu de laquelle un arrêté ministériel était autorisé à changer la pénalité et l'ordre des juridictions, n'a pu survivre à l'établissement du régime constitutionnel, qui a consacré la séparation entre le pouvoir exécutif et le pouvoir législatif », c'est-à-dire à l'octroi de la Charte de 1814, qui a mis fin à l'usage abusif du pouvoir réglementaire par Napoléon $\mathrm{I}^{\mathrm{er} 36}$.

IV. En pure logique, la substitution d'une Constitution à une autre aurait dû entraîner l'abrogation de l'ensemble des dispositions du « ci-devant » texte constitutionnel. Mais, comme l'avait fait le Tribunal de cassation après le 10 août 1792, la Cour de cassation et le Conseil d'État ont considéré que certaines de ces dispositions pouvaient survivre en tant que dispositions législatives. Tel fut notamment le cas de l'article 75 de la Constitution de l'an VIII sur lequel reposait la garantie des fonctionnaires. En 1821, en 1824, lors des premières décisions favorables au maintien de cette garantie, la Cour de cassation a adapté la rédaction de ses arrêts : elle a invoqué « l'article 75 de la loi du 22 frimaire an VIII $»^{37}$. Mais il lui est arrivé ensuite, au moins sous le Second Empire, d'invoquer « l'article 75 de l'Acte constitutionnel du 22 frimaire an VIII » et de rejeter un pourvoi contre un arrêt ayant fait « une juste application de la disposition constitutionnelle prérappelée $»^{38}$. Elle donnait alors l'impression de procéder à un contrôle de la constitutionnalité de l'arrêt soumis à son examen.

On peut faire une observation semblable à propos de l'arrêt précité du 11 mars 1885 sur l'octroi de mer à la Réunion. La chambre civile reproche à l'arrêt attaqué d'avoir violé l'article 2, paragraphe 5, de la loi du 24 avril 1833, qui réservait au pouvoir législatif métropolitain le régime des douanes dans les colonies, en n'ayant pas déduit de cet article que l'arrêté gubernatorial du 13 décembre 1850 était « entaché d'illégalité et d'inconstitutionnalité ${ }^{39}$. Ce faisant, la chambre civile donnait le sentiment de procéder à un double contrôle, celui de constitutionnalité s'ajoutant à celui de légalitét ${ }^{40}$.

\footnotetext{
$36 \quad 29$ août 1851, S.1851.1.790.

37 Jurisprudence générale Dalloz, tome 32, 1855, verbo « Mise en jugement des fonctionnaires publics », p. 288.

38 Cass. crim., 9 août 1862, Gazette des Tribunaux, 21 août 1862, p. 812.

39 Supra, n. 24.

40 La Cour s'était montrée plus rigoureuse dans son arrêt du 7 mai 1861, déjà relatif aux arrêtés de 1850 : elle n'avait pas retenu le mot inconstitutionnalité qui figurait dans le pourvoi, mais cassé pour «violation de la loi du 24 avril 1833 » (D. 1861.1.205). De même, lorsqu'il avait annulé l'arrêté de conflit dans l'affaire Lacaussade, le Conseil d'État avait remplacé le mot inconstitutionnalité par celui de validité (R., 1856, p. 562). En revanche, la Cour de La Réunion, comme la Cour de cassation en 1885, parlait d'inconstitutionnalité. Dans son arrêt du 30 juillet 1852, elle avait affirmé sa compétence pour « l'examen et l'appréciation des moyens d'inconstitutionnalité et d'illégalité des arrêtés » incriminés, après avoir relevé que « si les magistrats doivent obéissance à la loi, ils prêtent avant tout serment de fidélité et d'obéissance à la Constitution qui est la raison et la fin de toutes les lois, dont la garde et l'application leur est confiée » (arrêt reproduit par Delabarre de Nanteuil, Législation de l'île de la Réunion, tome I, Paris, Donnaud, 1861, verbo « Conflit», p. 587-589). Cette perception de la loi du 24 avril 1833 comme d'un texte d'ordre constitutionnel venait de ce qu'on l'avait souvent présentée comme la «Charte des colonies » ou la « Constitution coloniale ». Cela avait même été soutenu par le rapporteur du projet devant la Chambre des Pairs lors de la séance du 13 février 1833 (Archives Parlementaires, $2^{\mathrm{e}}$ série, tome LXXIX, p. 589-590). Mais juridiquement le texte voté n'était qu'un texte législatif. Un exemple de la perception de la gravité du grief d'inconstitutionnalité est fourni par le rapport du conseiller à la Cour de cassation Mesnard, qui évoque « l'imputation si redoutée d'inconstitutionnalité » et l'estime flétrissante (S. 1844.1.653). Mais le terme d'illégalité était aussi employé pour désigner une violation de la Charte, celle-ci étant considérée comme « la loi fondamentale du royaume » $(S$. 1826.1.268) ou comme « la première de toutes les lois » (S. 1829.1.173). En conséquence, il était possible d'exciper de l'inconstitutionnalité d'un règlement administratif pour échapper à la peine encourue en se fondant sur l'article 471, alinéa 15 du Code pénal, dans sa version issue de la loi du 28 avril 1832 , qui prévoyait la sanction des contraventions aux « règlements légalement faits ». La constitutionnalité de l'octroi de mer fait à nouveau l'objet de débats contentieux (T. M'SAÏDIÉ, « L'octroi de mer face à la Constitution : réflexions à partir de la décision du Conseil constitutionnel du 26 juillet 2013 », RFDC, $\mathrm{n}^{\circ}$ 96, 2013, p. 893-915).
} 
On peut dire encore la même chose à propos d'un autre arrêt de la chambre civile, du 15 mars 1898 , relatif lui aussi à l'octroi de mer, mais cette fois à la Guadeloupe ${ }^{41}$. Cet arrêt qualifie de « disposition législative » l'article 2 du Sénatus-Consulte du 4 juillet 1866, et ce à juste titre, puisque les Sénatus-Consultes ont cessé d'être des dispositions de nature constitutionnelle depuis la fin du Second Empire. Mais il conclut que les arrêtés du gouverneur de la Guadeloupe qui n'ont pas respecté cet article sont « entachés d'illégalité et d'inconstitutionnalité » et prononce la cassation de l'arrêt attaqué.

Dans ces divers cas, on peut parler d'un contrôle fictif de constitutionnalité, puisque la disposition qui a servi de référence n'avait pas ou n'avait plus valeur constitutionnelle, mais seulement valeur législative. Dans sa note sous un arrêt de la Cour d'Alger du 5 mars 1894, Michoud a bien montré qu'il s'agissait d'un contrôle de légalité et non de constitutionnalitée ${ }^{42}$. On peut penser que la persistance de l'emploi du mot inconstitutionnalité, que l'on trouve dans de nombreuses décisions reproduites dans le Recueil de Législation, de doctrine et de jurisprudence coloniales, communément appelé Recueil Dareste, provenait, soit d'une habitude de langage, soit de la volonté des avocats de valoriser, dans l'intérêt de leurs clients, la critique des actes des administrateurs, le grief d'inconstitutionnalité apparaissant plus grave que celui d'illégalitée ${ }^{43}$.

Quoi qu'il en soit, dénoncer l'inconstitutionnalité d'une décision avait pour effet, sous la III ${ }^{\text {e }}$ République, de maintenir l'idée d'un contrôle de constitutionnalité, idée qui avait souffert de l'inaction du Sénat sous le Second Empire. L'affaire Ambroise le fait apparaître. Celui-ci avait demandé au juge de paix de Mahé de déclarer « illégal et inconstitutionnel » le décret du 26 février 1884, qui avait modifié l'établissement des listes électorales dans les comptoirs des Indes, pour n'avoir pas été rendu conformément à l'article 18 du Sénatus-Consulte du 3 mai 1854 et à l'article 4 du décret impérial du 13 décembre 1858. Il avait été débouté, le juge se déclarant incompétent pour « apprécier les actes du pouvoir exécutif ». Par arrêt du 28 octobre 1885, la chambre civile de la Cour de cassation annule le jugement, car « il appartenait au magistrat de l'ordre judiciaire d'examiner la valeur légale dudit décret ». Il en avait même l'obligation. On le voit : la Cour de cassation emploie à juste titre l'expression «valeur légale », puisque le Sénatus-Consulte n'avait plus valeur constitutionnelle. Mais cette affaire a donné au conseiller rapporteur Michaux-Bellaire l'occasion de traiter de la possibilité, pour les juges français, d'exercer un contrôle de constitutionnalité,

\footnotetext{
41 Recueil Dareste, 1898, jurisprudence, p. 73.

42 La délégation au Chef de l'État du pouvoir de légiférer en Algérie au moyen de décrets procède en premier lieu de l'article 25 de la loi du 24 avril 1833, « texte ayant toujours eu le caractère purement législatif », et en second lieu du Sénatus-Consulte du 3 mai 1854, qui ne peut plus avoir que valeur législative depuis la fin du Second Empire. « Il en résulte que le contrôle à exercer sur les décrets algériens, aussi bien que sur les décrets faits par délégation particulière du législateur, est un contrôle de légalité, et non un contrôle de constitutionnalité » (S. 1896.2.89). Sur Michoud, en dernier lieu, Léon Michoud (dir. X. Dupré DE Boulois et P. YolKA), Institut universitaire Varenne, 2014, et, sur la question des décrets coloniaux, la remarquable étude de Bernard Durand, «Les décrets coloniaux étaient-ils des lois ou des règlements ? Une controverse aux frontières du droit et de la politique », Cahiers aixois des droits de l'Outre-Mer français, n 3, 2007, p. 11-54.

43 Comme exemple de décisions discutant de griefs d'inconstitutionnalité alors que n'étaient invoquées que des dispositions de SénatusConsultes, de décrets impériaux ou de lois, voir Cour de la Martinique, 12 janvier 1898 : « Le moyen d'inconstitutionnalité » qui est repoussé pour «manque de base juridique » consistait dans l'invocation de l'irrespect de l'article 1 du décret impérial du 11 août 1866 ; même Cour, 20 mai 1898 : le demandeur faisait valoir qu'une taxe était « doublement inconstitutionnelle », pour violation d'une exigence de forme prévue par l'article 2, paragraphe 2, du Sénatus-Consulte du 4 juillet 1866, et parce que le « droit de statistique » établi avait irrégulièrement le caractère d'une taxe douanière. La Cour a rejeté ces deux arguments (Recueil Dareste, 1898, jurisprudence, p. 142-144, 147-152). On trouve de nombreuses décisions comparables.
} 
non à l'égard des lois, indique-t-il en citant Aucoc, mais à l'égard des décrets pris par le président de la République sur délégation du pouvoir législatif ${ }^{44}$.

V. Une autre problématique mérite toutefois de retenir beaucoup plus d'attention : c'est celle qui a trait à l'application d'un texte réglementaire ou législatif dont la constitutionnalité fait débat alors qu'il est postérieur à la Constitution en vigueur. En général, la juridiction inférieure est saisie de ce débat, de ce contrôle de constitutionnalité qu'on lui demande d'exercer, la Cour de cassation et le Conseil d'État étant amenés ensuite à se prononcer sur la façon dont la juridiction inférieure a résolu le débat.

A. Dès 1792, nous l'avons vu, le Tribunal de cassation a interdit aux juges d'annuler un acte administratif pour inconstitutionnalité. Il leur a dénié, dix ans plus tard, le droit de refuser l'application d'une mesure réglementaire au motif qu'elle serait contraire à la Constitution en vigueur. Il censura une décision du tribunal d'appel de Rennes qui avait refusé d'appliquer un arrêté consulaire ayant établi une contribution ${ }^{45}$. Le Tribunal de cassation reprocha à la juridiction rennaise d'avoir commis « un excès évident de pouvoir », en invoquant à la fois l'interdiction faite aux juges de connaître des actes d'administration par le « décret » du 16 fructidor an III et les articles de la Constitution de l'an VIII conférant au Sénat le pouvoir d'annuler les actes inconstitutionnels ${ }^{46}$. Cette jurisprudence a eu pour effet de faciliter l'usage abusif, par Napoléon, de son pouvoir réglementaire.

Sous la Restauration, la Cour de cassation maintient cette jurisprudence par arrêt du 4 décembre 1823, à propos d'une ordonnance royale du 29 juin 1814. Elle affirme que « les tribunaux ne peuvent la soumettre à leur examen et doivent en maintenir l'exécution ${ }^{47}$. Mais cette position catégorique n'empêche pas diverses juridictions inférieures de se prononcer en sens inverse. Dans un arrêt du 26 juillet 1827, la Cour de Nancy soutient que les tribunaux peuvent apprécier « la légalité constitutionnelle » des ordonnances, car l'obligation d'appliquer des ordonnances contraires à la Charte «serait subversive de leur indépendance, qui est la garantie des justiciables $»^{48}$. Les Cours de Paris et de Metz, confirmant des jugements, se refusent de condamner des personnes poursuivies sur la base d'ordonnances établissant de nouveaux délits et fixant des peines ${ }^{49}$. Saisie de pourvois, la Cour

\footnotetext{
44 S. 1886.1.377. Sur cette juridiction, Leah OTIs, « Les justices de paix à compétence étendue à Mahé et à Yanaon à la fin du XIX siècle », Le juge et l'Outre-Mer, tome 5, (dir. B. Durand, M. Fabre, M. Badji), Montpellier, Publication du Centre d'histoire judiciaire éditeur, 2010, p. 149-170. 45 Jurisprudence générale Dalloz, tome 30, 1853, verbo « Lois », p. 196-197.

46 L'usage traditionnel du mot « décret » peut provoquer une confusion et faire croire qu'il s'agit d'un texte réglementaire (Cass., $1^{\text {re }}$ ch. civ., 8 mars 2012, n 11-24.638, D. 2012.744 ; Constitutions 2012.299, Obs. J. Barthélémy et L. Boré). En réalité, un texte voté par la Convention en tant que « décret » devenait formellement une « loi » dès qu'il avait été revêtu du Sceau de la République. Cela a bien été le cas du décret du 16 fructidor an III. Il est devenu la loi n 1064 publiée dans le n 175 du Bulletin des lois de la République, et, de par son objet, il ne peut être considéré comme « un texte de forme législative » au sens de l'article 37 de la Constitution de 1958 (J.-L. M., « La nature législative du décret du 16 fructidor an III », RFDA, 2012, p. 915-921). Les articles invoqués de la Constitution de l'an VIII sont les articles 21 et 28.

47 S. 1825.1 .48$.

$48 \quad$ S. 1829.1 .172

49 Ces décisions sont reproduites dans le Sirey de 1833.2, p. 599-602 (J.-L. M., « L'inconstitutionnalité des actes réglementaires », op. cit., p. 123-128 ; G. BigOT, op. cit., p. 176-190).
} 
de cassation remet, selon la formule de son futur procureur général Dupin aîné, sa décision « en délibéré indéfini $»^{50}$.

Après la chute de Charles X, provoquée précisément par la révolte parisienne contre des ordonnances entachées d'inconstitutionnalité, et l'entrée en vigueur de la Charte du 14 août 1830, qui interdit expressément au roi de faire des ordonnances suspendant des lois ou dispensant de leur exécution $^{51}$, diverses juridictions prennent à cœur le contrôle de la constitutionnalité des ordonnances $^{52}$. Si, en l'espèce, la Cour de Nîmes, chambres assemblées, se penchait sur l'inconstitutionnalité prétendue d'une ordonnance antéconstitutionnelle, son attendu n'en avait pas moins une portée générale : «Toutes les fois que l'application d'une ordonnance royale est demandée aux tribunaux, il est de leur devoir d'examiner sa constitutionnalité $»^{53}$.

La Cour de cassation est amenée de la sorte à se prononcer sur des décisions qui ont opiné sur la constitutionnalité d'ordonnances prises sous l'empire de la Charte de 1830. Ainsi, en 1844, elle casse un jugement qui n'avait pas écarté l'application d'une ordonnance de 1834 qui n'avait pas été rendue dans la forme réglée par l'article 52 de « l'acte constitutionnel du 22 frimaire an VIII », qui imposait que le Conseil d'État fût entendu ${ }^{54}$. Elle annule une délibération de la Cour de Poitiers qui avait déclaré, en se prévalant de l'article 50 de la Charte, « illégale et inconstitutionnelle » une ordonnance du 5 août 1844 sur le service des magistrats ${ }^{55}$. Peu après, elle rejette le pourvoi formé contre un jugement qui avait déclaré qu'une ordonnance de 1841 avait « excédé les limites du pouvoir réglementaire $»^{56}$. On comprend que Serrigny ait pu écrire : «La règle que les ordonnances inconstitutionnelles ne sont pas obligatoires pour les tribunaux est confirmée par la jurisprudence constante des Cours royales et de la Cour de cassation $»^{57}$.

Le Conseil d'État reconnaissait précisément compétence aux juridictions judiciaires pour se prononcer sur la validité des ordonnances relatives à des contributions indirectes. Il annula l'arrêté de conflit pris par le préfet des Bouches-du-Rhône dans le litige opposant la ville de Marseille à un fabricant qui soutenait qu'une ordonnance du 18 septembre 1832 était « inconstitutionnelle et non obligatoire », reconnaissant ainsi le bien-fondé du jugement du tribunal correctionnel ${ }^{58}$.

On peut remarquer au passage que le débat sur la constitutionnalité d'une ordonnance pouvait être porté devant une Cour d'assises. Tel fut le cas le 28 avril 1838, à l'occasion des poursuites engagées après la publication, par le journal Le National, d'un article attaquant l'ordonnance du 16 mars 1838.

\footnotetext{
50 S. 1836.1.343. Devenu procureur général sous le règne de Louis-Philippe, il cumula sa fonction avec la présidence de la Chambre des Députés (Voir l'ouvrage de F.-J. BrAmi, Dupin aîné (1783-1865), procureur général près la Cour de cassation et jurisconsulte, Paris, Dalloz, 2013). 51 Article 13.

52 J.-L. M., « Les juridictions judiciaires », op. cit., p. 452-459 ; «L'inconstitutionnalité », op. cit., p. 128-133 ; G. BIGOT, op. cit., p. $201-209$. 8 janvier 1834, S. 1834.2.153.

Ch. crim., 14 juin 1844, S. 1844.1 .608

Ch. req., 19 août 1844, S. 1844.1.647. Sur cet arrêt, J.-L. M., « La prétendue inconstitutionnalité d'une ordonnance de Louis-Philippe en 1844 », En hommage à Francis Delpérée. Itinéraires d'un constitutionnaliste, Bruxelles-Paris, Bruylant-LGDJ, 2007, p. 1037-1046.

56 Ch. req., 26 novembre 1844, D. 1845.1.38.

57 Supplément au Traité de l'organisation, de la compétence et de la procédure en matière contentieuse administrative, Paris, Joubert, 1846, p. 3. Sur cette jurisprudence, J.-L. M., « Les juridictions judiciaires », op. cit., p. 455-461 ; « L'inconstitutionnalité », op. cit., p. 128-133 ; G. BigOT, op. cit., p. 201-209.

5830 août 1845 , Rivalz, R. p. 464.
} 
L'avocat et député républicain Michel de Bourges fonda son argumentation sur l'inconstitutionnalité de ladite ordonnance et obtint l'acquittement ${ }^{59}$. Mais, les décisions des Cours d'assises n'étant pas motivées, la Cour de cassation ne pouvait se prononcer sur l'opinion que les jurés, qui avaient délibéré seuls, s'étaient fait de l'argumentation développée par la défense sur « un point important de notre droit constitutionnel ».

Il est arrivé par ailleurs que la Cour de cassation ne soit pas saisie de certains pourvois. Parfois, la Chancellerie ne lui transmettait pas, par crainte qu'ils ne soient pas couronnés de succès, des pourvois émanant d'administrateurs coloniaux qui contestaient le bien-fondé d'arrêts ayant déclaré un arrêté gubernatorial « illégal et inconstitutionnel $»^{60}$.

Mais il est intéressant de relever qu'en 1840 la Cour de cassation, tout en reconnaissant que l'audition d'une esclave était « contraire aux principes de la constitution coloniale », est parvenue à rejeter le pourvoi formé par la personne libre qui contestait la validité de ce témoignage à charge contre elle. Sa décision fait partie de celles qui, sous l'influence de Dupin aîné et du premier président Portalis, visèrent à améliorer la condition des esclaves ${ }^{61}$.

Sous le Second Empire, la Cour de cassation s'est prononcée sur très peu de recours qui invoquaient la Constitution du 14 janvier 1852 à l'encontre de décrets du Chef de l'État. Elle fit une distinction. Elle considéra comme « obligatoire pour les tribunaux » un décret pris par le prince-président entre le 2 décembre 1851 et l'entrée en vigueur de la Constitution, l'article 58 de celle-ci ayant donné force de loi à ces décrets. Elle rejeta donc un pourvoi qui relevait une contradiction entre le décret du 26 mars 1852 et les articles 1 et 56 de la Constitution, en faisant valoir que ce texte avait «la puissance et le caractère d'une loi $»^{62}$.

Elle examina, en revanche, « le moyen tiré de l'inconstitutionnalité » du décret du 23 juillet 1859 à l'encontre d'un arrêt de la Cour de Montpellier qui avait affirmé la constitutionnalité dudit texte, avant de le rejeter ${ }^{63}$.

De son côté, le Conseil d'État connaissait de plusieurs sortes de recours susceptibles de l'amener à exercer un contrôle de constitutionnalité ${ }^{64}$. Une inconstitutionnalité pouvait être invoquée à l'appui d'un recours pour excès de pouvoir à l'encontre d'une décision administrative, comme l'avait indiqué le commissaire du gouvernement Robert dans l'affaire Académie des Beaux-Arts ${ }^{65}$. Mais, puisque le présent colloque est consacré au contrôle de la constitutionnalité des décisions de justice,

59 Michel de Bourges. Plaidoyers et discours réunis par Louis Martin, Paris, Dunod, 1909, p. 181-204.

60 J.-L. M., « Les juridictions de Saint-Louis du Sénégal et l'interdiction d'engager des Africains captifs (1844-1848) », Études offertes à feanLouis Harouel, Paris, Éditions Panthéon-Assas, 2015, p. 905-916.

61 Ch. crim., 31 juillet 1840, M. TANGER, «Le conservatisme des cours coloniales et le rôle réformateur de la Cour de cassation », La Cour de cassation et l'abolition de l'esclavage (dir. P. Ghaleh-Marzban, C. Delplangue, P. Chevalier), Dalloz, 2014 , p. 72.

62 Ch. crim., 27 janvier 1855. S. 1855.1.465 ; G. Bigot, op. cit., p. 223.

63 Montpellier, 3 juin 1861, S. 1861.2.561 ; Cass., req., 11 août 1862, S. 1863.1.39. Voir aussi 16 janvier 1866, S. 1866.1.112 et Cass. civ., 24 février 1886 (Pandectes françaises, 1886.1.113). Il s'agissait de décrets sur le pilotage des navires auxquels on reprochait, sans succès, de déroger au décret impérial du 12 décembre 1806 qui leur servait de fondement, ayant lui-même force de loi.

64 Sur les diverses formes de l'activité du Conseil d'État en matière contentieuse, M. Bouvet, Le Conseil d'État sous la Monarchie de fuillet, Paris, LGDJ, 2001, p. 277-396.

65 «En résumé, le recours pour excès de pouvoirs ne peut se fonder que sur la violation d'un droit privatif dérivant, soit de la propriété, soit de la Constitution dans l'ordre administratif, soit de la possession d'une fonction publique » (21 juillet 1864, R. 1864, p. 685). 
il ne convient pas de s'étendre sur ce point. Une question de constitutionnalité pouvait apparaître aussi lorsque le Conseil tranchait un conflit d'attribution. Il lui arrivait alors d'annuler des décisions rendues par des juridictions judiciaires. On peut citer, à titre d'exemple, l'arrêt Bonnat-Cristave, qui considéra comme non avenus une ordonnance de référé du président du tribunal de Clermont et un arrêt de la Cour d'Amiens. Bonnat-Cristave demandait que le Conseil d'État ne se prononce pas sur l'arrêté de conflit et que la décision soit prise par le Tribunal des conflits prévu par l'article 89 de la Constitution du 4 novembre 1848. Le Conseil se reconnut compétent sur la base de l'article 113 qui disposait que les autorités demeuraient en place jusqu'à la promulgation des lois organiques les concernant et confirma l'arrêté du préfet de l'Oise, sur le fondement, toutefois, d'un texte législatif et non du principe de séparation des fonctions judiciaires et administratives ${ }^{66}$, principe qu'il qualifiera de « constitutionnel » dans l'arrêt Dekeister ${ }^{67}$.

Le Conseil d'État veille au respect des dispositions des Sénatus-Consultes, qui sont compris sous « le terme générique de Constitution ${ }^{68}$. Ainsi, il annule l'arrêté pris par le gouverneur de la Martinique « statuant en conseil privé constitué en conseil administratif » sur une réclamation contre des opérations électorales, parce que, selon les articles 176 et 179 de l'ordonnance du 9 février 1827 et l'article 10 du Sénatus-Consulte du 3 mai 1854, le jugement d'une telle contestation est «attribué au conseil privé constitué en contentieux $»^{69}$.

En tant que juge d'appel des arrêtés des conseils de préfecture, le Conseil d'État contrôle l'application des dispositions constitutionnelles par ceux-ci. Ainsi, il approuve une décision du conseil de préfecture du Morbihan fondée sur l'article 6 de la Constitution de $1852^{70}$. Il lui arrive même de procéder à un contrôle que l'on peut qualifier d'implicite. C'est le cas dans l'arrêt Hachette du 28 février 1866. Le célèbre libraire contestait une décision du conseil de préfecture d'Alger pour des raisons de procédure et de fond. Mais le commissaire du gouvernement de Belbeuf souleva la question de la compétence du conseil de préfecture, en faisant valoir qu'elle avait été basée sur un décret impérial du 2 avril 1854, qui contredisait la loi du 16 juin 1851. De Belbeuf fit valoir, invoquant « un principe de notre droit public » et la Constitution de 1852, qu'un décret ne pouvait contenir des dispositions contraires aux lois en vigueur. Le Conseil suivit ses conclusions, sans toutefois viser la Constitution ${ }^{71}$. Il en fut de même dans l'arrêt Menouillard ${ }^{2}$. De façon comparable, Aucoc invoqua avec succès « le principe constitutionnel de la séparation de l'autorité judiciaire et de l'autorité administrative $\gg^{73}$.

\footnotetext{
6614 février 1849, R. 1849, p. 107.

$67 \quad 6$ août $1861, R .1861$, p. 672.

68 D. 1866.4.105 (Exposé des motifs du Sénatus-Consulte des 18-22 juillet 1866) ; A. Ashworth, « Le contrôle de la constitutionnalité des lois par le Sénat du Second Empire », RDP, 1994, p. 54-56.

695 février 1867, du Plessix, R. 1867, p. 133

30 mars 1870, Glotin, R. 1870, p. 373.

28 février 1866, R. 1866, p. 171

28 mai 1868, R. 1868, p. 592. De Belbeuf invoqua en vain, à l'inverse, «l'égalité des citoyens devant la loi fiscale... sous l'empire d'une Constitution dont le préambule (en réalité l'article 1) reconnaît et consacre expressément les grands principes de 1789 » : sur recours du ministre des Finances, six arrêtés du conseil de préfecture de l'Aube furent annulés, le Conseil s'en tenant à une interprétation rigoureuse de l'article 9 de la loi du 4 juin 1858, interprétation à laquelle de Belbeuf reprochait d'avoir des effets inégalitaires (19 juin 1867, Bizet, R. 1867, p. 569).

7320 février 1869, Pinard, R. 1869, p. 188
} 
Sous la III ${ }^{\text {e }}$ République, la constitutionnalité de divers décrets a été débattue devant les juridictions judiciaires au vu des lois constitutionnelles de 1875. Un exemple remarquable est fourni par l'arrêt de la Chambre civile du 10 juin 1912 rendu dans l'affaire Gour N'Darou Gueye. Il casse pour fausse application de l'article 3 de la loi constitutionnelle du 25 février 1875 l'arrêt rendu par la Cour d'appel de l'Afrique occidentale le 21 mai 1909. Celle-ci avait déclaré « inconstitutionnel et par suite inopérant » le décret du 24 juillet 1906 sur le régime de la propriété foncière en Afrique occidentale, parce qu'il avait été contresigné par le seul ministre des Colonies alors que, selon elle, l'article 4 du décret impérial du 13 décembre 1858 exigeait aussi le contreseing du ministre de la Justice. De plus, elle avait ajouté que la signification du contreseing n'était plus, « sous la Constitution actuelle », ce qu'elle avait été sous le Second Empire ${ }^{74}$. La Cour de cassation annule cet arrêt en lui reprochant d'avoir « faussement appliqué et, par suite, violé l'article 3 de la loi constitutionnelle du 25 février 1875 », qui disposait : "Chacun des actes du Président de la République doit être contresigné par un ministre ». Elle précise que «le Président de la République étant constitutionnellement irresponsable, l'objet de cette disposition est de suppléer à cette irresponsabilité par la responsabilité ministérielle », de telle sorte que, «d'après son texte, comme d'après son esprit, le contreseing d'un seul ministre suffit pour la validité des décrets présidentiels $\gg^{75}$.

Mérite aussi d'être évoquée la contestation de la constitutionnalité du décret du 30 décembre 1898 instituant en Indochine le délit d'atteinte au respect dû à l'autorité française, à l'occasion des poursuites contre un journaliste. Celui-ci avait fait paraître une caricature désobligeante envers le gouverneur général Klobukowski dans le journal Le Pilori, publié à Hanoï. Il fut poursuivi d'une part pour outrage aux bonnes mœurs, d'autre part pour atteinte au respect de l'autorité française. Le tribunal correctionnel de Hanoï le relaxa sur le premier chef en considérant que la caricature n'était pas obscène. Il le relaxa aussi du délit d'atteinte à l'autorité française en développant une argumentation rigoureuse de droit public.

La ville de Hanoï a le statut de colonie française. Elle a été placée sous l'empire du SénatusConsulte du 3 mai 1854. Certes, « la chute de la Constitution de 1852 » a eu « nécessairement pour conséquence l'abrogation des Sénatus-Consultes », mais « la jurisprudence des tribunaux de l'ordre administratif et judiciaire (sic) a toujours admis que le Sénatus-Consulte de 1854 est resté en vigueur, quoiqu'il paraisse, dans plusieurs de ses parties, avoir été virtuellement abrogé par la Constitution de 1875 ». De la sorte, le pouvoir exécutif peut continuer à légiférer en toutes matières par décret pour Hanoï.

74 Recueil Dareste, 1909, jurisprudence, p. 182-187, note anonyme critique ; reproduit au Dalloz périodique, 1913.1.468-469.

75 Recueil Dareste, 1912, jurisprudence, p. 205-206, note anonyme approbative ; D. P. 1913.1.469-470. En explicitant l'objet du contreseing, la Chambre civile répondait à la Cour de l'Afrique occidentale, qui avait assuré que, sous l'empire de la Constitution de 1852, la signature du Chef de l'État, personnellement responsable, se suffisait à elle-même, alors que désormais le contreseing « faisait en quelque sorte partie intégrante de la signature présidentielle », lui permettant d' " acquérir toute sa valeur et toute son autorité légale ». De fait, la Constitution de 1852 ne mentionnait pas l'exigence d'un contreseing ministériel, à la différence de celle de 1848 (article 67). Cette Cour avait aussi mis en avant une citation du Traité de droit politique et parlementaire d'Eugène Pierre ( $\mathrm{n}^{\circ} 103$, p. 116) : «Les Ministres ont pour premier devoir de contresigner tous les actes du Président de la République. Si un acte intéresse plusieurs départements, il doit porter la signature de chacun des Ministres dont la responsabilité est engagée ; le Ministre le plus directement intéressé signe le premier ». Les actes du colloque consacré à Eugène Pierre qui s'est tenu au GERJC-Institut Louis Favoreu le 11 novembre 2016 sont à paraître. 
Mais, « un acte émané du Sénat impérial ne pouvant lier les Assemblée républicaines », celles-ci peuvent légiférer aussi pour les colonies. Si elles le font, « les principes de notre droit public s'opposent de la façon la plus absolue à ce que les matières réglées par la loi soient modifiées par décret ». Or, la loi sur la presse du 29 juillet 1881 est applicable aux colonies. En conséquence, le décret du 30 décembre 1898, qui impose aux citoyens des obligations au détriment des libertés que leur a octroyées cette loi, est « nécessairement illégal » et donc inapplicable.

Le ministère public ne fit appel que sur le second chef d'accusation. La Cour de Hanoï estima que l'atteinte à l'autorité française n'était pas établie, car la personne du gouverneur général d'Indochine ne s'identifiait pas à cette autorité, en ajoutant qu'on « n'arriverait à soutenir le contraire qu'à l'aide d'une sorte de conception monarchique ». Affirmant ensuite que les deux incriminations étaient liées, elle fit valoir que prévalait l'exception de chose jugée au profit du journaliste, ajoutant qu'elle se trouvait donc dans « l'impossibilité d'examiner l'illégalité et l'inconstitutionnalité du décret du 30 décembre 1898, et ce, malgré l'intérêt considérable que cette question présentait ». Son arrêt fut approuvé par la chambre criminelle de la Cour de cassation le 3 mars 1910. Celle-ci affirma même que le tribunal correctionnel avait relaxé le caricaturiste du second chef d'accusation « de ce que le décret du 30 décembre 1898 serait inconstitutionnel », alors pourtant que le jugement ne contenait que l'adjectif « illégal ». Mais le mot inconstitutionnel correspondait au raisonnement tenu dans ce jugement $^{76}$.

Selon Dareste, les juridictions judiciaires procédaient, en contrôlant la régularité formelle de ces décrets ou la validité de leurs dispositions, à un « contrôle de la constitutionnalité des lois » comme les juges américains, puisque ces décrets avaient force de loi dans les colonies. Il s'en réjouissait vivement, de même qu'il saluait l'extension du recours pour excès de pouvoir, dont il disait bien qu'il permettait l'annulation des actes inconstitutionnels, aux règlements d'administration publique ${ }^{77}$. Mais parler de contrôle de la constitutionalité des lois à propos des décrets coloniaux ne pouvait qu'apparaître abusif à ceux qui, tel Lampué, contestaient l'assimilation de ces décrets à des lois ${ }^{78}$.

76 S. 1914.1.337. Même sans la considération d'ordre politique figurant dans le jugement, la compétence du Parlement pour légiférer sur les matières que le Sénatus-Consulte de 1854 avaient réservées au chef de l'État ne pouvait être mise en doute : le pouvoir législatif n'était pas tenu par les Sénatus-Consultes, qui n'avaient plus que valeur législative depuis la fin du Second Empire. Le commentaire du Recueil Dareste sous un arrêt de la chambre civile de la Cour de cassation du 13 juillet 1898 l'indique en renvoyant aux principaux ouvrages de droit colonial (1898, jurisprudence, p. 135). Le décret du 12 novembre 1887 avait retiré au gouverneur général l'exercice du droit de grâce, un sénateur de la Guadeloupe ayant fait valoir que le président de la République bénéficiait, par le biais de l'article 3 de la loi constitutionnelle du 25 février 1875 , d'une délégation du pouvoir constituant qu'il ne pouvait sous-déléguer (E. Gojosso, L'Empire indochinois, LGDJ, 2016, p. 79. Bien accueilli par la presse indochinoise lorsqu'il fut nommé secrétaire général de l’Indochine, Klobukowski suscita vite des polémiques : p. 99-101, 125-126, 130-132, 172, 184. Il en devint cependant gouverneur).

77 «Le législateur colonial », Recueil Dareste, 1915, Doctrine, p. 10-11. Dareste faisait allusion à la jurisprudence Compagnie des chemins de fer de l'Est (C.E., 6 décembre 1907, S. 1908.3.1, concl. TARDIEU, note HAURIOU). Le Conseil d'État visait parfois la loi constitutionnelle du 16 juillet 1875 lorsqu'il examinait de prétendus empiétements du pouvoir réglementaire sur la compétence du pouvoir législatif (19 février 1904, Chambre syndicale des fabricants, $R$. 1904, p. 134), mais il ne le faisait pas systématiquement, même si Romieu avait évoqué la nature constitutionnelle de la question (4 mai 1906, Babin, R. 1906, p. 362 ; de même, à l'occasion d'un recours de plein contentieux, 2 décembre 1892, Mogambury, R. 1892, p. 836 ; S. 1894.3.97, concl. Romieu, note Hauriou). En 1901, le Conseil n'a pas examiné le moyen fondé sur l'inconstitutionnalité d'une taxe lorsqu'il a rejeté un recours contre une décision d'un conseil de préfecture, considérant que cette taxe avait été établie conformément à la loi du 9 avril 1898 (23 mai 1901, Delarue, R. 1901, p. 483). B. Rahal a montré que le Conseil d'État avait fait preuve de prudence dans son contrôle des décrets coloniaux, mais aussi d'audace pour protéger les administrés coloniaux, notamment en étendant aux colonies le principe du double degré de juridiction (« Le contrôle juridictionnel de l'administration coloniale française : entre accompagnement de la haute administration et protection de l'administré », Jahrbuch für europäische verwaltungsgeschichte / Annuaire d'histoire administrative européenne, volume 18, Administration coloniale en Afrique entre politique centrale et réalité locale (dir. E. V. HeYEN et B. DuRAND), 2006, p. 151-186).

78 Se reporter à l'étude approfondie de la controverse par B. Durand (précitée note 42). 
B. Venons-en maintenant à la question du contrôle de la constitutionnalité des lois postconstitutionnelles. Elle s'est posée au Tribunal de cassation lorsqu'il a été saisi d'un recours contre un jugement du Tribunal criminel de la Dyle qui avait écarté l'application de la loi du 7 vendémiaire an IV (29 septembre 1795) en arguant d'une irrégularité de forme. Le Tribunal de cassation a pris une position très nette le 18 fructidor an V (4 septembre 1797). Il a censuré la décision contestée, " considérant que les termes absolus dans lesquels est conçue pour les corps administratifs et judiciaires la défense d'arrêter ou de suspendre l'exécution des lois, ne peuvent admettre ni exception ni prétexte $»^{79}$.

Effectivement, l'article 203 de la Constitution de l'an III, que vise le Tribunal de cassation, interdisait aux juges de «s'immiscer dans l'exercice du Pouvoir législatif » et d' " arrêter ou de suspendre l'exécution d'aucune loi ». Les conventionnels auteurs de la Constitution de l'an III avaient ainsi repris les défenses insérées par l'Assemblée nationale constituante dans les articles 10 et 12 du titre II de la loi des 16-24 août 1790, puis dans l'article 3 du chapitre V du titre III de la Constitution de 1791. Défenses inspirées par le souvenir des problèmes considérables qu'avaient posés au pouvoir royal les interventions des Cours souveraines, des Parlements notamment, en matière législative. Ces Cours s'étaient maintes fois opposées, par leurs refus d'enregistrement, par leurs remontrances, aux mesures que le roi édictait, provoquant de très graves crises politiques. Or, il leur arrivait de reprocher aux mesures législatives royales d'être contraires aux lois fondamentales du royaume ${ }^{80}$.

La question du contrôle de la constitutionnalité des lois s'est reposée devant la Cour de cassation dans les premières années de la Monarchie de Juillet. Le pourvoi en cassation du journaliste Paulin invoque, entre autres arguments, l'inconstitutionnalité de la loi du 8 octobre 1830, dont l'article 3 maintenait la faculté, pour les Cours d'assises stricto sensu - sans le jury - de juger les auteurs des comptes rendus de leurs audiences, alors que l'article 69 de la Charte de 1830 disposait qu'il serait pourvu par une loi, dans le plus court délai possible, à « l'application du jury aux délits de presse ». La chambre criminelle rejette le pourvoi, le 11 mai 1833, après dix heures de délibéré : « La loi du 8 octobre (1830), délibérée et promulguée dans les formes constitutionnelles prescrites par la Charte, fait la règle des tribunaux et ne peut être attaquée devant eux pour cause d'inconstitutionnalité ». Les juges ne peuvent donc vérifier, sous le contrôle de la Cour de cassation, que la régularité formelle de la loi postérieure à la Constitution ${ }^{81}$.

Quelques mois plus tard, le 3 janvier 1834, la chambre criminelle se prononce de même, alors qu'a été contestée devant elle la constitutionnalité de la loi du 22 mars 1831 : «Les lois délibérées et acceptées par le roi et légalement promulguées sont obligatoires pour les citoyens et les tribunaux».

79 Furisprudence générale Dalloz, tome 30, 1853, verbo « Lois », p. 196, note 1.

80 C'est précisément à l'occasion de l'une de ces crises que fut rédigée, par un conseiller d'État qui avait été avocat général au Parlement de Paris, la première synthèse sur les recours en cassation : M. ANToINe, « Le mémoire de Gilbert des Voisins sur les cassations. Un épisode des querelles entre Louis XV et les Parlements (1767) », Revue historique de droit français et étranger, 1958, p. 1-33. Sur les prétentions des Parlements, voir notamment J. Krynen, L'État de justice. France, XIII ${ }^{e}-X X^{e}$ siècle, tome I, L'idéologie de la magistrature ancienne, Paris, Gallimard, 2009, p. 239-279 ; P. Pichot-Bravard, Conserver l'ordre constitutionnel (XVI $T^{e}$ XIX $X^{e}$ siècle). Les discours, les organes et les procédés juridiques, Paris, LGDJ, 2011, p. 239-309.

81 S. 1833.1.358 
Certes, la chambre criminelle ajoute que « l'allégation que la loi du 22 mars 1831, qui a institué les conseils de discipline (de la garde nationale), n'est pas conforme à la Charte, est dénuée de tout fondement $»^{82}$. Mais, on ne saurait voir, dans cette précision, qui apparaît comme un obiter dictum, une véritable prise en compte de l'argumentation portant sur l'inconstitutionnalité prétendue de la loi du 22 mars 1831.

La position de la Cour de cassation a changé sous la Seconde République. À deux reprises, en 1851 - le 15 mars dans l'arrêt Gauthier et le 17 novembre dans l'arrêt Gent - la chambre criminelle a accepté d'examiner des pourvois invoquant l'inconstitutionnalité du contenu même des articles 7 et 8 de la loi du 9 août 1849 sur l'état de siège. Ces articles transféraient aux autorités militaires les pouvoirs des autorités civiles et autorisaient le renvoi des civils devant les conseils de guerre en cas d'état de siège, alors que l'article 4 de la Constitution disposait que nul ne pouvait être distrait de ses juges naturels et interdisait la création de commissions et de tribunaux extraordinaires. Ces pourvois ont été rejetés au motif que l'article 106 de la Constitution laissait au pouvoir législatif la détermination des effets de l'état de siège.

L'extrême brièveté des observations du Sirey ${ }^{83}$, du Dalloz ${ }^{84}$ et du fournal du Palais ${ }^{85}$, recueils publiés après le coup d'État du 2 décembre 1851, a conduit à donner de ces arrêts une lecture minimaliste : les pourvois auraient été déclarés recevables seulement pour affirmer, dans un esprit répressif, la constitutionnalité de la compétence des conseils de guerre à l'égard des civils en cas d'état de siège. Mais, grâce à la Gazette des Tribunaux et au journal Le Droit, il m'a été possible de reconstituer les débats de la seconde affaire, qui présentait une particularité remarquable : le requérant, Gent, son avocat, Martin de Strasbourg, et le conseiller rapporteur, Isambert, avaient fait partie de la Constituante de $1848^{86}$.

Or, ces débats donnent une autre impression, celle de l'abandon de la jurisprudence Paulin, à laquelle ils ne font pas allusion. C'est l'arrêt précité Geoffroy de 1832 qui est commenté, l'arrêt qui avait jugé que la Charte avait abrogé l'article du décret impérial de 1811 qui donnait compétence aux conseils de guerre pour juger les civils en cas d'état de siège. Le rapprochement a été fait évidemment par Martin de Strasbourg, puisque l'article 4 de la Constitution de 1848 reprenait exactement les termes des articles 53 et 54 de la Charte de 1830. Si elle avait été inspirée par une motivation purement politique, la chambre criminelle aurait très bien pu maintenir son refus d'accepter la mise en cause d'une disposition législative pour l'inconstitutionnalité de son contenu, tout en ajoutant, de façon superfétatoire, comme elle l'avait fait en 1834, que la disposition contestée était compatible avec le texte constitutionnel. Cela était d'autant plus facile que, lors de l'adoption de la loi de 1849

\footnotetext{
82 D. 1834.1.73. Plusieurs magistrats de renom ont exprimé une opinion hostile au contrôle de la constitutionnalité matérielle de la loi : Dupin aîné, Tocqueville, Hello (J.-L. M., «La Cour de cassation », op. cit., p. 55-58; V. CATtoire-Jonville, « Tocqueville et le contrôle de la constitutionnalité des lois », La pensée juridique d'Alexis de Tocqueville, Artois Presses Universitaires, 2005, p. 51-62.

$83 \quad$ S. 1851.1.214. et 707.

D. 1851.1 .142 et 333 .

7. P. 1852, tome I, 586 (Gauthier) et 176 (Gent).

«Le contrôle de la constitutionnalité de la loi par la Cour de cassation sous la Seconde République », Renouveau du droit constitutionnel. Mélanges en l'honneur de Louis Favoreu, Paris, Dalloz, 2007, p. 291-310.
} 
sur l'état de siège, l'Assemblée législative avait débattu de la question. Le député Charamaule avait demandé une modification du projet de loi, en invoquant l'article 4 de la Constitution et la jurisprudence Geoffroy. Sa demande avait été discutée, puis rejetée à une très marge majorité.

La teneur des débats donne vraiment l'impression que la Cour de cassation a pensé, dans une période de tensions socio-politiques très vives, à un moment où des avocats invoquaient le droit de résister à l'oppression en cas de violation de la Constitution par le gouvernement ou le législateur, qu'il était préférable qu'elle se prononçât expressément sur la constitutionnalité d'une disposition législative contestée, plutôt que de laisser le débat s'envenimer dans l'opinion publique.

Cette nouvelle jurisprudence, que le procureur général de la Cour d'Aix, Desolliers, désapprouvait, ayant peur qu'elle ne fasse le jeu des « conspirateurs éternels... qui ne craignent pas de profaner ce nom sacré de Constitution pour justifier et autoriser leur mépris et leur résistance à la loi » ${ }^{87}$, n'a pas survécu au coup d'État du 2 décembre 1851 et à la Constitution de $1852^{88}$.

V. La nouvelle Constitution napoléonienne rétablissait le Sénat, érigé par l'article 25 en « gardien du pacte fondamental et des libertés publiques ». Il avait pour fonction de s'opposer à la promulgation des lois inconstitutionnelles, selon l'article 26, et détenait, aux termes de l'article 29, le pouvoir de «maintenir ou annuler tous les actes qui lui sont déférés comme inconstitutionnels par le Gouvernement, ou dénoncés, pour la même cause, par les pétitions des citoyens ». De la sorte, deux questions pouvaient se poser à propos de la constitutionnalité des décisions de justice. Les juridictions judiciaires et administratives devaient-elles renoncer, au profit du Sénat, à examiner la constitutionnalité des textes réglementaires invoqués devant elles ? Le Sénat pouvait-il contrôler la constitutionnalité des arrêts de la Cour de cassation et du Conseil d’État?

La doctrine publiciste de l'époque a répondu à ces deux interrogations. En ce qui concerne la première, elle s'est montrée favorable au maintien de la compétence des juges, en soulignant que cette compétence présentait l'avantage de garantir les droits des citoyens. Dufour et Serrigny l'écrivent

\footnotetext{
87 Ibid., p. 305. Écarté en mars 1848, Desolliers avait été rétabli dans sa fonction au début de 1849 (C. Derobert-Ratel, Les magistrats aixois au cour du XIX siècle, Aix, PUAM, 2003, p. 180-181).

88 L'arrêt précité du 27 janvier 1855, rejetant un pourvoi qui soulevait une contradiction entre le décret du 26 mars 1852 et les articles 1 et 56 de la Constitution du 14 janvier 1852, au motif que l'article 58 de cette Constitution donnait force de loi aux décrets pris entre le 2 décembre 1851 et son entrée en vigueur, laissait entendre que la jurisprudence Gauthier et Gent était abandonnée. Après 1875, dès que les républicains devinrent les maître des nouvelles institutions, la Cour de cassation fit comprendre qu'elle était hostile au contrôle de constitutionnalité des lois par le biais d'un arrêt du 13 juin 1879, qui affirma que les juges ne devaient pas «violer le principe de la séparation des pouvoirs » (Ch. crim., D. 1879.1.277). Cet arrêt, qui sanctionnait un excès de pouvoir commis à l'encontre de la Chambre des députés et du Gouvernement, a été rendu sur réquisitoire du procureur général Bertauld. Celui-ci était un ancien professeur de droit, qui avait été élu comme républicain à l'Assemblée Nationale en 1871 et était devenu sénateur inamovible. C'était un proche de Jules Grévy (Dictionnaire historique des juristes français, op. cit., J.-L. HAlpÉRIN, p. 101-102). En 1871, il avait exprimé son hostilité « à ce que le pouvoir judiciaire fût juge du pouvoir législatif » et reproché aux Parlements de l'Ancien Régime d'avoir paralysé « le pouvoir législatif de la royauté » en se présentant comme « les gardiens des lois fondamentales » (P. Pichot-Bravard, op. cit., p. 462-463). Les arguments avancés pour justifier le refus du contrôle de la constitutionnalité des lois par les juges ont été minutieusement analysés et discutés par J. BonNET, Le juge ordinaire français et le contrôle de la constitutionnalité des lois. Analyse critique d'un refus, Dalloz, 2009. Le refus du Conseil d'État s'est exprimé à l'occasion de recours pour excès de pouvoir (6 novembre 1936, 2 espèces, Coudert et Arrighi, S. 1937.3.32, note A. Mestre ; D. 1938.3.1, note C. EIsenmanN). De façon générale, sur l'histoire du contrôle de constitutionnalité avant 1958, je me permets de renvoyer au Précis Dalloz de Droit constitutionnel (19e éd., 2016, p. 303-327, Bibliographie p. 397-401).
} 
simultanément dans leurs ouvrages en $1854^{89}$, Foucart dans le sien en $1855^{90}$, en pleine période de l'Empire autoritaire. Ils le répéteront par la suite, sans citer toutefois de décisions nouvelles ${ }^{91}$. Il est vrai qu'elles étaient devenues excessivement rares de la part des juridictions judiciaires à l'égard des décrets de Napoléon III, comme on l'a vu.

Cet avantage l'emporte sur le risque encouru, celui, que reconnaît Serrigny, d'une contradiction entre « l'autorité du Sénat reconnaissant la constitutionnalité du décret et la décision de l'autorité judiciaire qui déclarerait l'inconstitutionnalité du même acte ». Mais, il en relativise la portée. Il fait valoir qu'il faut distinguer nettement la pétition adressée par le citoyen au Sénat, qui conduit ce dernier à prononcer directement l'annulation de l'acte inconstitutionnel, annulation ayant effet erga omnes, et le refus d'une juridiction de concourir à l'application d'un acte qu'elle estime contraire à la Constitution, refus qui n'acquiert autorité de chose jugée que dans la décision rendue. Quant à Foucart, il écrit qu'on peut envisager, pour éviter la contrariété de positions entre le Sénat et un tribunal, de faire surseoir à statuer la juridiction devant laquelle la constitutionnalité de l'acte réglementaire est mis en cause, jusqu'à la décision du Sénat. Mais, même ce système de question préjudicielle ne rencontre point son approbation. Foucart est partisan de laisser les magistrats libres de leurs jugements, tout au moins tant que le Sénat, saisi par le gouvernement, ne s'est pas prononcé en faveur de la constitutionnalité de l'acte incriminé.

La faculté, pour le Sénat, d'annuler pour inconstitutionnalité des arrêts de la Cour de cassation et du Conseil d'État, fait en revanche l'objet d'opinions divergentes.

Batbie distingue, en traitant du droit de pétition, entre les juridictions judiciaires et le Conseil d'État. Il admet que « le pouvoir constituant aurait pu faire du Sénat une cour de justice suprême chargée de ramener les cours et tribunaux à l'observation de la loi constitutionnelle ». De même que la Cour de cassation a été établie comme " gardienne de la loi ordinaire », le Sénat aurait pu être « institué gardien de la Constitution, même à l'égard de la Cour de cassation ». La chambre haute n'est-elle pas aussi, en Angleterre, une cour de justice suprême? Mais une telle innovation aurait dû être «formellement et clairement indiquée ». Elle ne peut se fonder sur la simple interprétation d'un texte aussi incomplet que l'article 29 de la Constitution, au prétexte qu'il contient les mots « tous actes ».

Batbie envisage ensuite le cas des décrets contentieux du Conseil d'État. Il reconnaît que le Sénat, saisi d'une pétition d'un justiciable contre un tel décret pour violation de la propriété dans une affaire de délimitation du lit d'une rivière, a nommé une commission pour l'examiner, ce qui impliquait qu'il se sentait compétent pour en connaître. Mais cette commission, qui a beaucoup tardé à rendre son rapport, a éludé la question de compétence, traduisant son embarras et faisant comprendre que la Chambre haute n'entendait pas persévérer dans cette voie, que Batbie condamne

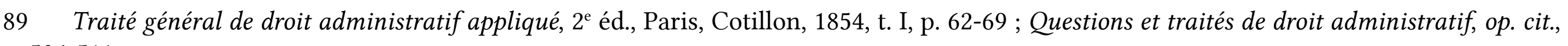
p. 506-511.

90 Éléments de droit public et administratif, $4^{\mathrm{e}}$ éd., Paris, Maresq, 1855, t. I, p. 132-135.

91 D. Serrigny, Traité de l'organisation, de la compétence et de la procédure en matière contentieuse administrative, Paris, Durand, 1865, t. I,

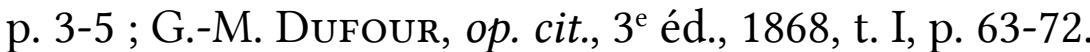


catégoriquement : «Le Sénat n'est pas plus compétent pour annuler les décrets rendus au contentieux que pour annuler les arrêts de cours judiciaires ». Dans tous les cas, fait-il valoir, « il y a chose jugée, droit acquis et, par conséquent, propriété fondée sur le meilleur des titres ». Peu importe que le décret contentieux ait été rendu en faveur de l'État, car « la chose jugée constitue un droit pour l'État comme pour les particuliers » et la fortune publique doit être protégée.

Batbie en vient à critiquer deux opinions. D’abord, celle du Répertoire général de Dalloz - la furisprudence générale - parce qu'il la trouve insuffisamment catégorique au verbo " Pétition ». Certes, elle affirme, comme lui, qu'on ne doit pas demander au Sénat l'annulation d'une décision de justice, puisqu'il n'est pas un tribunal, mais elle affirme que ce n'est là qu'une position « raisonnable et motivée » et non point une « règle obligatoire ». Cette restriction n'apparaît pas pertinente au professeur parisien, qui reproche a fortiori à Firmin Laferrière d'admettre que le Sénat puisse annuler un décret contentieux sans que l'annulation préjudicie aux parties. Pour Batbie, cette position, bien que restrictive quant aux effets de l'annulation, est foncièrement extraordinaire. Elle ne serait admissible que sur la base d'un texte formel ${ }^{92}$.

Cette position de Laferrière est approuvée, en revanche, par Ducrocq. Elle présente l'avantage, à son avis, de concilier le respect dû à la chose jugée avec la disposition générale de l'article 29 de la Constitution. Le successeur de Foucart à Poitiers, qui accordait volontiers de l'intérêt aux considérations historiques ${ }^{93}$, invoque en plus l'article 55 du Sénatus-Consulte du 16 thermidor an X (3 août 1802), qui attribuait au Sénat le pouvoir d' " annuler les jugements des tribunaux, lorsqu'ils sont attentatoires à la sûreté de l'État », lui conférant ainsi une compétence de nature juridictionnelle ${ }^{94}$. La comparaison du Sénat à la Cour de cassation était même officiellement faite : dans le discours de la Couronne à l'ouverture de la session législative de 1861, le Sénat avait été qualifié de « véritable cour de cassation politique $»^{95}$.

Serrigny traite de la question « infiniment délicate » de l'annulation par le Sénat d'un décret contentieux dès le début de son ouvrage ${ }^{96}$. Il met en avant la généralité des termes de l'article 29 de la Constitution, « qui n'excepte rien ». Il ajoute en ce sens l'opinion de Laferrière, le Sénat annulant « dans l'intérêt de la Constitution » comme la Cour de cassation annulant, à l'initiative du ministre de la Justice, des décisions devenues définitives dans l'intérêt de la loi, sans porter atteinte aux droits des parties et des tiers. Il cite aussi l'opinion contraire de Batbie, avant d'exprimer son propre sentiment : il se prononce en faveur de la reconnaissance au Sénat du droit d'annuler pour cause d'inconstitutionnalité un décret «statuant au contentieux ». Il avance aussitôt, pour faire admettre sa position, une supposition : celle de la destitution arbitraire d'un magistrat judiciaire inamovible, auquel l'empereur, en Conseil d'État - c'était encore l'époque de la justice retenue - refuserait de faire droit. Pourquoi le recours de ce magistrat serait-il déclaré irrecevable par le Sénat, auquel il

Traité théorique et pratique de droit public et administratif, Paris, Cotillon, 1862, t. III, p. 298-300.

M. TouzeIL-DivinA, La doctrine publiciste, op. cit., p. 103-104.

Cours théorique et pratique de droit public et administratif, $5^{\mathrm{e}}$ éd., Paris, Cotillon, 1860, tome I, p. 121.

D. 1861.4.27, note 2 .

Traité de l'organisation, de la compétence et de la procédure en matière contentieuse administrative, Paris, Durand, 1865, p. 3-5. 
demanderait à bénéficier du principe constitutionnel de l'inamovibilité, principe qui figure parmi ceux que le Sénat doit faire respecter par le législateur, selon l'article 26 de la Constitution?

Serrigny, dont les opinions républicaines « sentaient le pamphlet » à la Faculté de droit de Dijon $^{97}$, eut toutefois la prudence d'ajouter qu'il s'agissait là d' « un remède extrême et qui ne rencontrera peut-être jamais d'application ». Devenu doyen de sa Faculté, le régime impérial se libéralisant, il put constater que sa prédiction était exacte, puisque le Sénat perdit son rôle de gardien de la Constitution par l'effet du Sénatus-Consulte du 21 mars 1870.

Quoi qu'il en fût, on pourrait retenir de tout cet historique, qui s'est efforcé de dégager la diversité des situations dans lesquelles la Cour de cassation et le Conseil d'État ont exercé un contrôle de la constitutionnalité des décisions de justice, la formule « cassation dans l'intérêt de la Constitution » et la placer à côté de la traditionnelle « cassation dans l'intérêt de la loi ». 



\title{
Le contrôle Par le Conseil d'État aujourd'hui
}

\author{
Laurent Domingo ${ }^{1}$ \\ Didier RIBES ${ }^{2}$
}

Parmi les belles formules du professeur Jean Rivero, celle du « chœur à deux voix $»^{3}$ est appréciée par le Conseil d'État pour exprimer la relation du juge et de la doctrine ${ }^{4}$. Il faut insister sur le fait que, dans ce chœur à deux voix, les partitions qui sont jouées sont différentes. Alors que l'universitaire est conduit à formuler le questionnement le plus large, le plus ouvert, le juge reçoit un litige dont le contenu est délimité par les parties et leurs écritures. Sa réponse et sa capacité de décision sont ellesmêmes conditionnées, enserrées dans un cadre procédural préétabli. La manière d'appréhender le sujet qui nous réunit est nécessairement marquée par ces différences fonctionnelles. À cet égard, il s'agit d'un objet qui ne présente pas, pour le juge administratif, une identité forte et une consistance évidemment perceptible. Cela n'en rend son étude que plus stimulante.

On ne trouvera ainsi aucun développement spécifiquement consacré au contrôle de constitutionnalité des décisions de justice par le Conseil d’État dans le guide du rapporteur utilisé par les membres du Conseil d'État, les rapports annuels ou les écrits du président Odent comme d'ailleurs dans les manuels de contentieux administratif.

S'il constitue un objet doctrinal singulier, le contrôle de constitutionnalité des décisions de justice n'est pas, en l'état de notre droit, une voie de droit spécifique, ni même un moyen particulier, comme c'est le cas de la question prioritaire de constitutionnalité. Et l'autonomisation de ce contrôle nécessiterait de penser la greffe contentieuse, comme cela a été fait pour la question prioritaire de constitutionnalité. Un tel contrôle s’inscrit donc aujourd'hui dans le cadre procédural général.

Le contrôle de constitutionnalité des actes administratifs est bien connu, à Aix-en-Provence tout particulièrement ${ }^{5}$, et toujours pratiqué par le juge administratif, notamment par le Conseil d'État dans le cadre de son contrôle d'excès de pouvoir des décrets et des ordonnances non ratifiées. L'idée d'une invocation de la Constitution à l'égard des actes juridictionnels apparaît moins intuitive.

\footnotetext{
Maître des requêtes au Conseil d'État.

Maître des requêtes au Conseil d'État.

J. Rivero, « Jurisprudence et doctrine dans l'élaboration du droit administratif », EDCE, 1955, p. 36.

J.-M. SAuvé, «L'Université et le Conseil d'État : un dialogue «naturel et bienfaisant» », in J. CaIllosse et O. Renaudie (dir.), Le Conseil d'État et l'Université, Dalloz, coll. « Thèmes et commentaires », Paris, 2015.

5 Cf. notamment l'ouvrage de référence : L. FAvoreu et T. Renoux, Le contentieux constitutionnel des actes administratifs, Sirey, Paris, 1992.
} 
Le Conseil d'État contrôle, comme juge de cassation, les arrêts des cours administratives d'appel et les jugements des tribunaux administratifs rendus en dernier ressort, ainsi que les décisions de dernier ressort des juridictions administratives spécialisées (Conseil supérieur de la magistrature, Cour des comptes, Cour de discipline budgétaire et financière, juridictions ordinales, Cour nationale du droit d'asile, cours des pensions) et, comme juge d'appel, saisi par la voie de l'appel ou en réglant le litige au fond après cassation, il contrôle les jugements des tribunaux administratifs, à l'instar du contrôle exercé par les cours administratives d'appel sur les jugements des tribunaux administratifs.

Comme juge de cassation ou comme juge d'appel, il contrôle la régularité (ou légalité externe) de la décision de justice, c'est-à-dire sa forme, la procédure au terme de laquelle elle a été rendue et la manière dont le juge du fond a exercé ses attributions juridictionnelles.

Comme juge de cassation, il contrôle ensuite le contenu de la décision de justice, son bien-fondé, en particulier l'erreur de droit éventuellement commise par les juges du fond. En revanche, comme juge d'appel, il rejuge le litige par la voie de l'effet dévolutif et en tire les conséquences sur la confirmation, l'annulation ou la réformation du jugement.

Existe-il, dans ce cadre, une place pour le contrôle de constitutionnalité de la décision de justice ? Si un tel contrôle peut éventuellement trouver une place au sein du contrôle de la régularité de la décision de justice (I), il n'en va assurément pas de même dans le contrôle du fond de la décision juridictionnelle (II).

\section{Le contrôle de constitutionnalité et la régularité des décisions des juridictions administratives}

Le contrôle de régularité conduit le juge de cassation ou le juge d'appel, à la demande des parties ou à l'initiative du juge dans le cas des irrégularités soulevées d'office, à sanctionner par l'annulation du jugement ou de l'arrêt la méconnaissance par le juge de première instance ou d'appel des règles de compétence, de forme ou de procédure qui s’imposaient à lui.

Sous l'angle de la régularité, le contrôle de constitutionnalité de la décision de justice peut exister. Mais il faut constater que ce contrôle est rare ${ }^{6}$.

\footnotetext{
$6 \quad$ Notons en revanche que les normes constitutionnelles (comme les normes conventionnelles du reste) ont un impact important sur la détermination des règles relatives au prononcé des décisions du juge administratif. En ce sens, le juge administratif interprète les textes relatifs aux recours et à la procédure à la lumière des droits constitutionnellement garantis en la matière. C'est par exemple le cas des incidences d'une demande d'aide juridictionnelle sur l'office du juge (v. CE, 6 mai 2009, Khan, n 322713, Rec. p. 187 : Sauf irrecevabilité manifeste insusceptible d'être couverte en cours d'instance, la juridiction saisie d'une demande d'aide juridictionnelle doit surseoir à statuer et transmettre sans délai la demande au bureau d'aide juridictionnelle compétent, en raison du droit constitutionnellement garanti à toute personne à un recours effectif devant une juridiction; CE, 30 mars 2015, M. Ghegnagui Diecko, n 369381, à mentionner aux Tables : En vertu de l'article 18 de la loi $\mathrm{n}^{\circ}$ 91-647 du 10 juillet 1991 et de l'article 43-1 du décret n 91-1266 du 19 décembre 1991, l'aide juridictionnelle peut être demandée avant ou pendant l'instance et la juridiction, qui doit être avisée de cette demande, est tenue de surseoir à statuer jusqu'à ce qu'il soit statué sur cette demande. Il résulte en outre du droit constitutionnellement garanti à toute personne à un recours effectif devant une juridiction que, lorsqu'un requérant a formé une demande d'aide juridictionnelle, l'obligation de surseoir à statuer s'impose à la juridiction, que cette dernière ait ou non été avisée de cette demande dans les conditions fixées par le décret du 19 décembre 1991). Le juge administratif peut également déterminer ses obligations en matière de procédure en tenant compte d'un droit constitutionnel de fond. Il est en ainsi par exemple du droit constitutionnel d'asile (v. Section, ${ }^{\text {er }}$ octobre 2014, M. Erden, n 349560, Rec. p. 288 : Il incombe à la Cour nationale du droit d'asile, dans la mise en ouvre de ses pouvoirs d'instruction, de garantir la confidentialité des éléments d'information relatifs aux personnes sollicitant l'asile en France, qui constitue tant une garantie essentielle du droit constitutionnel d'asile qu'une exigence découlant de la convention de Genève relative au statut
} 
Un tel contrôle ne se heurte à aucun obstacle spécifique de recevabilité ou d'opérance. La critique d'une décision de justice par un moyen tiré de la méconnaissance de la Constitution est soumise aux règles générales de recevabilité et d'opérance des moyens devant le juge de cassation et le juge d'appel.

Ce contrôle demeure cependant rare en pratique, pour ne pas dire exceptionnel. Les explications de cette rareté sont multiples.

1) On peut, tout d'abord, mentionner que le contexte juridique ne favorise pas le recours à la constitutionnalité dans le contrôle des décisions du juge administratif.

Le premier élément de contexte juridique, d'ordre général, est que les textes constitutionnels sont relativement pauvres en matière de règles contentieuses. C'est la jurisprudence du Conseil constitutionnel, en se fondant essentiellement sur l'article 16 de la Déclaration des droits de l'homme et du citoyen de 1789, qui a, au cas par cas, consacré au niveau constitutionnel les grands principes contentieux ${ }^{7}$. Cette caractéristique du droit constitutionnel juridictionnel ne favorise pas son développement.

Le second élément de contexte juridique, qui concerne particulièrement le contentieux administratif, est que la matière est principalement réglementaire, ce qui n'est pas un facteur de développement de la jurisprudence constitutionnelle ${ }^{8}$.

Néanmoins, en dépit de ces paramètres plutôt défavorables, il existe bien des principes constitutionnels susceptibles d'être invoqués à l'occasion du contrôle d'une décision du juge administratif.

2) On doit, ensuite, relever la circonstance que le moyen de constitutionnalité est rarement soulevé. En pratique, les parties ne contestent pas, ou si peu, les décisions de justice sous l'angle de la constitutionnalité. Plusieurs raisons peuvent être avancées.

\footnotetext{
des réfugiés. Par suite, s'il lui est loisible de demander la communication de documents nécessaires pour vérifier les allégations des requérants et établir sa conviction tant aux parties que, le cas échéant, à des tiers, en particulier aux administrations compétentes, elle ne peut le faire qu'en suivant des modalités qui assurent pleinement la nécessaire confidentialité des éléments d'information relatifs aux personnes qui sollicitent l'asile).

7 V. en particulier, R. Fraisse, «L'article 16 de la Déclaration, clef de voûte des droits et libertés » in Le Conseil constitutionnel et le procès équitable, Les Nouveaux cahiers du Conseil constitutionnel, 2014, $\mathrm{n}^{\circ} 44$.

8 Le Conseil constitutionnel juge que «les dispositions de la procédure à suivre devant les juridictions relèvent de la compétence réglementaire dès lors qu'elles ne concernent pas la procédure pénale et qu'elles ne mettent en cause aucune des règles, ni aucun des principes fondamentaux placés par la Constitution dans le domaine de la loi » (Décision n 88-153 L du 23 février 1988, Nature juridique de dispositions contenues dans les articles 8, 140 et 143 de la loi n ${ }^{\circ}$ 85-98 du 25 janvier 1985 relative au redressement et à la liquidation judiciaires des entreprises, cons. 2). Ce qui est le cas de la plupart des règles du contentieux administratif. Jugé en ce sens par le CC: «Considérant qu'en vertu de l'article 34 de la Constitution, la loi fixe notamment « les règles concernant... les garanties fondamentales accordées aux citoyens pour l'exercice des libertés publiques... la création de nouveaux ordres de juridiction... »; que les dispositions de la procédure applicable devant les juridictions administratives relèvent de la compétence réglementaire dès lors qu'elles ne mettent en cause aucune des matières réservées au législateur par l'article 34 de la Constitution ou d'autres règles ou principes de valeur constitutionnelle »; tout en précisant bien entendu que « que l'article 37 de la Constitution, selon lequel « les matières autres que celles qui sont du domaine de la loi ont un caractère réglementaire », n'a pas pour effet de dispenser le pouvoir réglementaire du respect des exigences constitutionnelles » (Décision n ${ }^{\circ} 2010-54$ QPC - 14 octobre 2010 Union syndicale des magistrats administratifs, USMA, RFDC 2011 p. 565, note L. DomINGo). C'est le sens également de la jurisprudence du Conseil d'État : « si l'article 34 de la Constitution réserve au législateur le soin de fixer "les règles concernant : - les droits civiques et les garanties fondamentales accordées aux citoyens pour l'exercice des libertés publiques ; [...] - l'assiette, le taux et les modalités de recouvrement des impositions de toutes natures ; [...] - les garanties fondamentales accordées aux fonctionnaires civils et militaires de l'État", les dispositions de la procédure applicable devant les juridictions administratives relèvent de la compétence réglementaire, dès lors qu'elles ne mettent en cause aucune des matières réservées au législateur par l'article 34 de la Constitution ou d'autres règles ou principes de valeur constitutionnelle. » (CE, 17 décembre 2003, Meyet et autres, n’s 258253 et a, AfDA 2004 p. 712 note J-P. MArkus).
} 
C'est, tout d'abord, une question d'habitude, de culture. Le moyen de constitutionnalité n'est pas spontané. Les avocats, parce que la jurisprudence administrative s'est ainsi construite, sont généralement plus enclins à se placer sur le terrain de l'article 6 de la Convention européenne de sauvegarde des droits de l'homme et des libertés fondamentales que sur le terrain constitutionnel'. La question prioritaire de constitutionnalité a eu pour effet de mettre en lumière sur les potentialités contentieuses du moyen de constitutionnalité, mais elle n'a pas pour autant entamé l'attrait des justiciables pour le moyen de conventionnalité.

La faible invocation de la constitutionnalité est aussi et surtout une raison d'intérêt. L'avocat est un stratège et ne laisserait certainement pas passer un moyen de constitutionnalité à son avantage. Or, s'il ne le soulève pas, c'est peut-être parce qu'il n'y trouve pas d'intérêt. Ce que l'on peut comprendre.

Les règles et principes constitutionnels susceptibles d'être invoqués à l'encontre d'une décision de justice ont, parce que ce sont précisément des normes constitutionnelles, un caractère général. Ce ne sont pas des règles techniques. La Constitution, ou la jurisprudence du Conseil constitutionnel, garantit le droit au recours, le principe du caractère contradictoire de la procédure, les droits de la défense, la publicité des audiences, etc... Mais le droit constitutionnel français ne dit que très peu de choses sur les règles pratiques, précises et concrètes du contentieux administratif.

À cet égard, l'invocation de la jurisprudence très factuelle, concrète, de la Cour européenne des droits de l'homme peut présenter pour les avocats un attrait plus grand que celle d'une jurisprudence constitutionnelle qui demeure marquée par un haut degré d'abstraction et donc d'indétermination dans ses conséquences. Cette réalité, qui s'exprime tant en matière procédurale que sur le fond du droit, devient plus sensible encore après la décision récente de l'Assemblée du contentieux ${ }^{10}$ qui a consacré l'exercice successif par le juge administratif de contrôles de conventionnalité de la loi abstrait et concret et alors qu'aucune juridiction ne réalise en France un contrôle de constitutionnalité concret. Les normes constitutionnelles, plus abstraites, ne sont dès lors mobilisées qu'à titre confortatif, voire parfois de manière purement incantatoire.

Dans la très grande majorité des cas, c'est sur le code de justice administrative que l'avocat fondera sa demande, et non sur la Constitution. S'il se plaint qu'un mémoire n'a pas été communiqué ou que la rapporteur public n'a pas régulièrement renseigné le sens de ses conclusions dans l'application Sagace, il invoquera les articles R. $611-1^{11}$ et R. $711-3^{12}$ du code de justice administrative. Le droit constitutionnel ne lui sera d'aucune utilité.

9 En ce sens par exemple, à propos du principe d'impartialité, v. CE, 25 juin 2012, M. Clark, n 336652, inédit ; CE, 6 décembre 2012, Association des topographes géomètres et techniciens d'études, n 341004 aux Tables ou encore CE, 8 juin 2016, Türk, n 394348, à publier au Recueil.

10 CE Ass., 31 mai 2016, $M^{\text {me }}$ Gonzalez-Gomez, n 396848, à publier au Recueil.

11 Par ex. CE, 17 juin 2015, M. et $M^{m e}$ Lefèvre, $\mathrm{n}^{\circ} 365955$, inédit.

12 Par ex. CE, Section, 21 juin 2013, Communauté d'agglomération du pays de Martigues, n 352427, Rec. p. 167. 
3) Les avocats n'ont donc pas une propension particulièrement marquée à critiquer les décisions de justice sous l'angle de leur constitutionnalité mais, et c'est une autre raison que l'on peut avancer pour expliquer la rareté du contrôle de constitutionnalité des décisions du juge administratif, le juge administratif lui-même n'est pas enclin à rattacher d'office les moyens critiquant les décisions de justice aux principes constitutionnels.

Le juge administratif, pour répondre à un moyen, se place sur le terrain juridique approprié.

Par exemple, une partie, qui reproche au tribunal ou à la cour de ne pas lui avoir communiqué un mémoire ou un moyen sur lequel il ou elle se serait fondé en le relevant d'office, peut soulever la méconnaissance du caractère contradictoire de la procédure, sans plus de précisions. Le juge administratif répondra à ce moyen en se fondant sur la règle pertinente applicable, à savoir les articles $\mathrm{R}$. 611-1 ou R. 611-7 du code de justice administrative.

Ou encore, une partie peut critiquer la décision des juges du fond au motif qu'elle méconnait le principe d'impartialité, en raison, par exemple, d'un acte de procédure de la juridiction, d'une prise de position ou du comportement de l'un des magistrats de la formation de jugement. Le juge pourra répondre au moyen tiré de la méconnaissance du principe d'impartialité et l'accueillir ou l'écarter sans avoir besoin de le qualifier de constitutionnel ou de conventionnel, car c'est un principe général du droit ${ }^{13}$.

Si les décisions de justice sont critiquées sur le terrain de règles ou de principes qui ont par ailleurs valeur constitutionnelle (ou conventionnelle), le juge ne statue pas en faisant explicitement référence au fondement constitutionnel (ou conventionnel) du principe. Le contrôle peut matériellement être qualifié de constitutionnel, sans l'être formellement.

Ainsi, l'analyse du juge, comme celle de l'avocat, repose naturellement sur l'utilisation de la « norme de proximité », celle qui, dans le paysage normatif, est la plus précise, la plus concrète et donc plus directement la solution du litige.

4) En réalité, pour le juge administratif, juge de la légalité externe ou de la régularité des décisions de justice, la constitutionnalité n'est pas une fin en soi.

Comme il ne s'agit pas d'un contrôle du contenu, de respect d'une norme par rapport à une norme de valeur supérieure, la question hiérarchique n'est pas primordiale. Ce qui importe, c'est essentiellement que la règle de procédure ou de forme existe et soit applicable. C'est la raison pour laquelle le code de justice administrative, essentiellement dans sa partie règlementaire d'ailleurs, se suffit généralement à lui-même.

13 Par ex., CE, 19 juin 2015, Élections municipales de Saint-Pierre (La Réunion), n 385824, inédit. 
Lorsque le juge administratif a besoin de rechercher l'existence d'une norme plus générale, ce n'est pas parce qu'il a besoin, en soi, d'une norme de valeur supérieure. C'est généralement parce que le code de justice administrative n'est pas applicable (il ne s'applique qu'aux tribunaux administratifs, aux cours administratives d'appel et au Conseil d'État) et qu'il a donc besoin d'une norme d'application plus large (pour les juridictions administratives spécialisées).

Et pour ce faire, le juge administratif fait appel aux principes généraux du droit applicables à l'ensemble des juridictions administratives ou aux « règles générales applicables aux juridictions administratives $»^{14}$.

En pratique, donc, le contrôle des décisions de la justice administrative s'opère le plus souvent en appliquant le code de justice administrative ou en se référant aux principes généraux du droit ou aux règles générales du contentieux administratif.

5) On peut ajouter, enfin, que l'utilité du contrôle de la régularité des décisions de justice sous l'angle de la constitutionnalité n'est pas évidente. La plus-value de ce contrôle, par rapport au contrôle actuellement exercé par le juge administratif sur le fondement du code de justice administrative ou des principes généraux de procédure, n’apparaît pas manifeste.

Ce qui se comprend car, en l'état, le droit constitutionnel n'a pas substantiellement modifié et enrichi le corpus des règles et principes contentieux que le juge administratif applique depuis longtemps ${ }^{15}$. En réalité, la constitutionnalisation du droit processuel en matière de contentieux administratif s'est essentiellement limitée à hisser au niveau constitutionnel des principes déjà existants. Cette constitutionnalisation n'a pas eu pour objet de diffuser dans l'ordre juridique des règles nouvelles. Il s'agit d'une consolidation de l'existant, et non d'une modification ${ }^{16}$.

\footnotetext{
14 Par ex. CE, 24 avril 2013, M. M’Bodji, n³49109, mentionnée aux tables (Dans le silence de ces textes, il appartient aux tribunaux et cours des pensions, en raison de leur caractère de juridictions administratives, de faire application des règles générales de procédure applicables à ces dernières. Aucune des dispositions du code des pensions militaires d'invalidité et des victimes de la guerre, du décret du 20 février 1959 ou de celles du code de procédure civile auxquelles renvoie ce décret ne précise les conditions dans lesquelles le juge des pensions peut opposer d'office le défaut de qualité pour agir d'un requérant. Il y a lieu, en pareil cas, de faire application de la règle générale de procédure applicable aux juridictions administratives selon laquelle le juge ne peut rejeter une demande pour ce motif, dès lors que cette irrecevabilité est régularisable, sans avoir invité son auteur à procéder à cette régularisation. Il en va de même lorsque le juge d'appel entend opposer au requérant l'irrecevabilité de sa demande de première instance) ou CE, 24 avril 2013, M. Boualem, n 350705, à mentionner aux tables (Aucune des dispositions du code des pensions militaires d'invalidité et des victimes de la guerre, du décret du 20 février 1959 ou de celles du code de procédure civile auxquelles renvoie ce décret ne précise les conditions dans lesquelles les décisions de ces juridictions sont rendues publiques. Il y a lieu, en pareil cas, de faire application de la règle générale de procédure applicable aux juridictions administratives, qui ne méconnaît pas les exigences de l'article $6 \S 1$ de la convention européenne de sauvegarde des droits de l'homme et des libertés fondamentales, selon laquelle la décision juridictionnelle est rendue publiquement, soit par lecture publique, soit par tout moyen approprié assurant l'accès au texte de la décision, en particulier sa consultation au greffe de la juridiction qui l'a prononcée).

15 Alors que l'incidence sur le procès administratif de la conception européenne du droit à un procès équitable, telle qu'elle ressort de la jurisprudence de la Cour européenne des droits de l'homme, est plus manifeste.

16 Comme l'expliquait le doyen Vedel, il y a une « antériorité du droit non constitutionnel sur le droit constitutionnel » et l'on peut donc tout autant «parler d'une « civilisation » ou d'une «administrativisation » du droit constitutionnel » (G. VEDEL, « Aspects généraux et théoriques », in L’unité du droit. Mélanges en hommage à Roland Drago, Economica, Paris, 1996, p. 6 et 8).
} 


\section{Le contrôle de constitutionnalité et le bien-fondé des décisions des juridictions administratives}

On pourrait peut-être parler, comme nous y invitent les organisatrices de ce colloque, d'un contrôle traditionnel s'agissant du contrôle par le juge de cassation de la correcte application de la Constitution par les juges du fond. Mais il s'agit là d'un contrôle ordinaire de l'erreur de droit éventuellement commise par le juge du fond dans l'application des règles dont le bénéfice est invoqué par les parties. La seule particularité, qu'il ne convient pas de négliger, est le caractère constitutionnel de la disposition dont il est fait application, notamment lorsqu'il s'agit de tirer les conséquences d'une décision du Conseil constitutionnel.

Mais l'erreur de droit consiste, en cassation, à censurer les cas dans lesquels les juges du fond n'ont pas appliqué la bonne règle de droit ou ont méconnu le contenu ou la portée de la règle de droit applicable. C'est dire que le juge de cassation contrôle la manière dont le juge du fond a appliqué la règle de droit, éventuellement la règle constitutionnelle. Mais il n'évalue pas ou ne confronte pas la décision de justice elle-même au regard des règles constitutionnelles.

Concrètement, la question n'est pas de savoir si le jugement oul'arrêt méconnaît la Constitution.Le cas échéant, le raisonnement suivi par le tribunal ou la cour pourra être censuré au motif qu'il aboutit à une solution qui ne s'accorde pas avec les règles et principes constitutionnels. Mais pour autant, cela ne veut pas dire que la décision des juges du fond a par elle-même généré une violation de la Constitution. Elle a seulement fait une mauvaise application de la règle de droit.

Pour le dire autrement encore, la méconnaissance de la Constitution par le jugement ou l'arrêt n'est pas un moyen spécifique de cassation. Seule la mauvaise application de la Constitution conduit à la cassation. On reste ainsi, d'un point de vue juridictionnel, dans la mise en œuvre par les juridictions administratives d'un contrôle de constitutionnalité des actes administratifs.

Au demeurant, différentes contraintes procédurales s'opposent au développement d'un contrôle de constitutionnalité des décisions de justice par le Conseil d'État. En effet, il convient de rappeler que, sauf lorsqu'elle a une incidence sur la compétence de l'auteur de l'acte litigieux, la méconnaissance de la Constitution n'est pas un moyen d'ordre public qui devrait être relevé d'office par le juge ${ }^{17}$. Le Conseil d'État, juge de cassation, ne peut donc décider de lui-même d'annuler un arrêt au motif qu'il méconnaîtrait la Constitution. Par ailleurs, le litige de cassation constitue un cadre particulier dans lequel sont interdits les moyens nouveaux, entendus comme ceux n'étant pas déjà dans le débat devant les juges du fond ou ne procédant pas de la décision juridictionnelle critiquée en cassation. Les parties ne peuvent donc utilement faire naître en cassation un débat sur la constitutionnalité de la décision de la juridiction du fond qui s'est prononcée en dernier ressort.

17 Dans le prolongement des réflexions du Club des juristes (rapport La régulation des contentieux des Cours suprêmes, octobre 2014, consultable sur son site internet), il est possible de se demander si le passage d'une juridiction de cassation dont l'accès n'est pas limité à une juridiction suprême dont la mission est de trancher un petit nombre de points de droit qu'elle sélectionne ne permettrait pas de lever cette contrainte procédurale. 


\section{En guise de conclusion}

Le Conseil d'État peut exercer un contrôle de la régularité constitutionnelle des décisions des juridictions administratives. En pratique, ce contrôle est toutefois rare. Mais il faut aussi retenir que le contrôle de la régularité des décisions juridictionnelles s'opère sur la base de règles ou de principes qui trouvent leur expression dans des normes générales de valeur constitutionnelle. En revanche, en ce qui concerne le fond, la logique de la cassation exclut un contrôle de constitutionnalité de la décision de justice elle-même. Le contrôle de constitutionnalité porte sur l'application, par les juges du fond, des règles constitutionnelles.

La question, qu'il n'y a pas lieu de développer dans le cadre de cette présentation du contrôle exercé par le Conseil d'État, est de savoir s'il convient, et dans quelles conditions, d'instituer des voies de recours particulières pour contrôler les cas dans lesquels une partie estime qu'une décision de la juridiction administrative méconnait la Constitution ou encore les cas dans lesquels une partie considère que la juridiction administrative a fait une mauvaise interprétation ou application de la Constitution lorsqu'elle a examiné la légalité d'un acte administratif. La nécessité et l'opportunité d'un tel contrôle ne s'imposent pas avec évidence. Mais la question mérite assurément d'être posée. 


\title{
La Place de la Constitution dans le contrôle de LA COUR de CASSATION (EN DEHORS de LA QPC) ${ }^{1}$
}

\author{
Valentine BuCK ${ }^{2}$ \\ Olivier DesaulnaY ${ }^{3}$
}

\section{Introduction}

La Constitution est parfois d'humeur vagabonde. Elle quitte la rue Montpensier, où elle y a trouvé avec le temps son Palais, pour traverser la Seine et s'aventurer Quai de l'Horloge à la Cour de cassation. Le temps de l'examen d'un pourvoi, la norme fondamentale tente de s'épanouir sur le terrain encore trop étranger de la cassation judiciaire et sous les auspices distanciés de ses magistrats.

Pourtant, a priori, il n'y a pas d'obstacle infranchissable à l'accueil au sein du prétoire judiciaire de cette norme venue d'ailleurs. L'article $604 \mathrm{du}$ Code de procédure civile présente ainsi l'objet du pourvoi en cassation comme tendant « à faire censurer par la Cour de cassation la nonconformité du jugement qu'il attaque aux règles de droit ». Pourvu que l'on fasse entrer dans ces « règles de droit » celles de nature constitutionnelle et le contrôle de la constitutionnalité des actes juridictionnels est révélé.

L'invocation de la Constitution à l'encontre des actes juridictionnels est même un phénomène ancien. Comme le rappelle J.-L. Mestre, « dès les origines, [...] le Tribunal de cassation n'est pas seulement une juridiction prévue par la Constitution. C'est aussi une juridiction qui peut censurer les décisions de justice contraire à la Constitution $»^{4}$. Il n'y avait aucune raison de changer le cours de l'histoire et d'empêcher la Cour de cassation d'exercer un contrôle de constitutionnalité des actes des tribunaux dans le cadre de ses attributions légales.

Cette orientation n'est d'ailleurs pas démentie par l'organisation de la justice constitutionnelle telle qu'elle est pensée en France et, de manière générale, dans le modèle européen de cour constitutionnelle. Il n'a jamais été question d'y soustraire un tel contrôle aux juridictions de droit commun pour en attribuer la connaissance à la cour constitutionnelle spécialement investie. De l'aveu même

$1^{\text {er }}$ décembre 2016.

Magistrate au TGI de Versailles.

Professeur à l'Université de la Réunion.

J.-L. Mestre, « Données historiques », in La Cour de cassation et la Constitution de la République, PUAM, 1995, p. 36. 
de H. Kelsen ${ }^{5}$, une telle solution ne reposait sur aucun fondement solide. Par conséquent, le Conseil constitutionnel ne s'est pas vu attribuer un monopole sur l'ensemble des questions constitutionnelles posées dans les litiges ordinaires. De même qu'il n'a jamais été dans son ambition de « cannibaliser » les attributions de la Cour de cassation. Il est remarquable d'ailleurs que la réforme de la question prioritaire de constitutionnalité (QPC), en confiant au Conseil le soin de répondre aux seules questions de constitutionnalité de la loi, conforte la Cour de cassation dans ses attributions traditionnelles quant à la validité juridique, y compris constitutionnelle, des décisions de justice inférieures.

Le doute n'est donc pas permis qu'il revient à la Cour de cassation, en tant que juge suprême de l'ordre juridictionnel judiciaire, de veiller en dernier lieu au respect de la Constitution par les juges du fond et de sanctionner, le cas échéant, la non-conformité de leurs décisions par la voie redoutable de la cassation.

Si le contrôle de constitutionnalité est de l'ordre du permis et du possible dans le contentieux de cassation, il y demeure néanmoins très sporadique, laissant à l'observateur un sentiment d'inachevé.

Il faut dire que l'argument constitutionnel dans les arrêts de la Cour de cassation n'est ni banal ni régulier. En dépit de la poursuite du phénomène de constitutionnalisation du droit sous l'égide du Conseil constitutionnel et d'un surcroît de justiciabilité de la norme constitutionnelle apparaissant encore plus évidente avec la réforme de la QPC, le niveau de référence dans les arrêts demeure encore marginal. Bien qu'il ait progressé depuis les années 1980, pour se situer autour de 100 à 150 références pertinentes dans les arrêts toutes chambres confondues, il n'a guère connu de progression significative depuis ce bond ${ }^{6}$. L' « effet QPC » semble relativement platonique, du moins sur ce point quantitatif de l'invocation et de l'application de la Constitution dans les arrêts de la Cour de cassation ${ }^{7}$.

Si l'on écarte les références superflues dans les moyens des parties non reprises par les juges et si l'on prend garde à ne pas être abusé par celles qui apparaissent dans les motifs ou visa des arrêts, mais qui ne remplissent qu'une fonction $d^{\prime}$ " adjuvant rhétorique $»^{8}$ dans la motivation du juge, il ne reste guère qu'une très petite poignée d'arrêts pertinents dans lesquels s'observe un authentique contrôle de constitutionnalité de la décision de justice objet du pourvoi.

Dans le domaine de la constitutionnalité, le contentieux de cassation n'a pas encore atteint toutes ses potentialités, demeurant ainsi dans une position d'entre-deux. Ce qui ne signifie pas qu'elles ne sont pas perceptibles, s'exprimant par petites touches successives (I). Le mouvement pourrait toutefois s'enrichir à la faveur d'un contexte renouvelé de réflexion du rôle de la Cour de cassation dans la protection des droits et libertés fondamentaux et à l'égard duquel l'introduction de la QPC n'est pas étrangère. Des perspectives de développement d'une plus grande « culture constitutionnelle » au sein de la Cour peuvent alors être tracées (II).

5 H. Kelsen, « La garantie juridictionnelle de la Constitution (la Justice constitutionnelle) », RDP 1928, p. 197, spéc. p. 233.

Qu'il nous soit permis, v. O. Desaulnay, L'application de la Constitution par la Cour de cassation, Dalloz, coll. « Nouvelle Bibliothèque de Thèse », 2009, $\mathrm{n}^{\circ} 84$.

Cf. infra, les perspectives d'avenir ouvertes par la réforme de la QPC.

O. Desaulnay, op. cit., p. 244 et s. 


\section{Les potentialités du contrôle de constitutionnalité des actes juridictionnels devant la Cour de cassation}

Le bilan très mitigé de l'état des lieux du contrôle de constitutionnalité des décisions de justice devant la Cour de cassation ne doit pas conduire à éluder les potentialités qu'il recouvre dans ce domaine. Certes, des contraintes conditionnent l'existence d'un tel contrôle devant le juge judiciaire suprême (A), mais sans qu'elles puissent emporter la conclusion d'une franche inadéquation de la cassation judiciaire à la constitutionnalité. Au contraire, les rares arrêts notables en la matière démontrent que la Cour de cassation parvient pleinement à endosser l'office d'un juge de la constitutionnalité des décisions des juges inférieurs (B).

\section{A. Les conditions existentielles du contrôle de constitutionnalité devant la Cour de cassation}

L'épanouissement du contrôle de constitutionnalité des décisions de justice dans le cadre du pourvoi en cassation s'expose à deux séries de contraintes. Les premières sont d'ordre procédural et demeurent classiques, l'argument constitutionnel s'épanouissant en cassation sans aucun traitement contentieux particulier dans le sens d'une plus grande sévérité ou, au contraire, d'une plus grande souplesse (1). C'est dire que d'autres raisons fondent l'insuccès relatif de la constitutionnalité dans la cassation judiciaire. En effet, des contraintes plus diffuses s'attachent à réduire la compétitivité de l'argument constitutionnel (2).

\section{Les contraintes procédurales commandant la recevabilité des moyens de constitutionnalité en cassation}

Les moyens de constitutionnalité n'échappent pas aux règles procédurales qui encadrent la fonction de cassation judiciaire. Aucun traitement procédural particulier ne s'observe à l'endroit de la norme constitutionnelle et du contrôle de conformité qui s'y attache. D'ailleurs, il ne ressort ni des textes ni de la jurisprudence de la Cour que la violation de la Constitution s'analyse en un moyen d'ordre public auquel s'attacherait une obligation pour le juge suprême de soulever d'office la violation'. De ce point de vue, la Constitution semble presque banale, soumise aux règles traditionnelles de recevabilité des moyens qui se trouve dans la combinaison des articles $619^{10}$ et $620^{11} \mathrm{du}$ Code de procédure civile.

En résumé, les moyens nouveaux sont irrecevables devant la Cour de cassation, à l'exception des moyens de pur droit qui peuvent être invoqués pour la première fois devant la Cour. À cela

\footnotetext{
9 À la différence de ce que certains auteurs ont pu avancer (L. Favoreu, J. Ghestin, B. Mathieu, Boullez, etc.).

10 Art. 619 CPC : « Les moyens nouveaux ne sont pas recevables devant la Cour de cassation.

Peuvent néanmoins être invoqués pour la première fois, sauf disposition contraire :

$1^{\circ}$ Les moyens de pur droit ;

$2^{\circ}$ Les moyens nés de la décision attaquée. »

11 Art. $620 \mathrm{CPC}$ : «La Cour de cassation peut rejeter le pourvoi en substituant un motif de pur droit à un motif erroné ; elle le peut également en faisant abstraction d'un motif de droit erroné mais surabondant.
} 
s'ajoute un tempérament selon lequel le juge de cassation peut d'abord relever d'office, au bénéfice du demandeur, un moyen de cassation de pur droit, que celui-ci a négligé d'invoquer ou, à l'inverse, la Cour peut relever d'office un moyen de défense pour prononcer le rejet du pourvoi en substituant un motif de pur droit à un motif erroné de l'arrêt attaqué (parfois il s'agit d'ajouter un tel motif).

On voit combien il est essentiel pour son épanouissement en cassation que l'argument constitutionnel soit, comme tout argument d'ailleurs, antérieurement invoqué et débattu devant les juges du fond. Le développement du contrôle de conformité à la Constitution dépend donc étroitement de la capacité des juges du fond et des requérants et de leurs conseils à orienter le débat vers la constitutionnalité. Cela suppose une connaissance et une information adaptée sur le droit constitutionnel et ses potentialités ainsi que des usages répétés de la part des professions judiciaires. En deux mots : le réflexe constitutionnel. De ce dernier dépend sans doute pour beaucoup le développement de la constitutionnalité devant les juridictions jusqu'au sommet de la hiérarchie judiciaire devant la Cour de cassation.

Toutefois, deux observations viennent tempérer l'influence de cette contrainte procédurale sur le développement d'un contrôle de constitutionnalité des actes juridictionnels.

D'une part, l'hypothèse du moyen de constitutionnalité irrecevable parce que qualifié par le juge à la fois de nouveaux et de mélangés de fait et de droit ne s'observe guère ${ }^{12}$. La jurisprudence dévoile une alternative bien plus tranchée quant à l'invocation de la norme constitutionnelle : soit celle-ci est totalement superflue et inutile et le juge ne s'y attarde même pas, soit elle s'impose dans le litige sans détour. On perçoit dans cette circonstance, le poids de la rhétorique de la fondamentalité de la Constitution conçue souvent par le juge comme un argument indépassable et indiscutable.

D'autre part, dans le prolongement de cette dernière idée, le juge de cassation ne rechigne pas à soulever d'office la violation de la Constitution lorsque celle-ci lui paraît particulièrement pertinente pour mener à bien son office. De sorte que les plus belles cassations sur le fondement de la Constitution sont souvent le fruit d'une démarche compensatrice du juge de cassation qui a relevé d'office cet argument « massue ».

Cette attitude de la Cour ne doit pas faire oublier que, d'une façon générale, la Constitution ne bénéficie pas toujours aux yeux du juge judiciaire des atouts d'autres normes de protection des droits. De sorte que le caractère marginal de l'invocation de la Constitution dans les arrêts de cassation tient sans doute plus à un déficit de compétitivité qu'aux pesanteurs procédurales de la cassation.

Elle peut, sauf disposition contraire, casser la décision attaquée en relevant d'office un moyen de pur droit. »

12 Pour un exemple récent : Crim., 10 mars 2015, req. $n^{\circ} 14-83329$ : «Attendu que $M^{\text {me }}$ X... n'a pas soutenu devant les juges du fond que la confirmation de la mesure de démolition ordonnée par les premiers juges porterait une atteinte disproportionnée au droit à un logement décent garanti par la Constitution, par la Convention européenne des droits de l'homme et par l'article 300-1 du code de la construction et de l'habitation ; que, dès lors, le moyen, mélangé de fait, est nouveau et comme tel irrecevable ». 


\section{Un déficit de compétitivité de l'instrument constitutionnel}

Sur le marché du droit, la Constitution souffre d'un important déficit de compétitivité qui se manifeste dans la jurisprudence de cassation par une sévère concurrence d'instruments juridiques matériellement équivalents. De sorte que la Cour de cassation (et l'ensemble des juridictions judiciaires) ne consomme la Constitution qu'avec une grande parcimonie, aidée par les pourvois des requérants qui s'orientent volontiers vers d'autres produits juridiques aux qualités protectrices éprouvées.

La concurrence la plus rude, mais la moins controversée, se situe sans doute du côté de la source législative. Cette dernière, codifiée ou non, est préférée aux principes constitutionnels dont elle a vocation à concrétiser fidèlement le contenu et l'esprit dans l'ordonnancement juridique. Ce caractère relai des dispositions législatives à l'égard des droits inscrits dans le bloc de constitutionnalité, associé à une culture judiciaire traditionnellement plus légaliste que constitutionnelle, explique largement cette faveur accordée à la référence législative. Pourquoi aller chercher ailleurs dans la Constitution, souvent méconnue, ce qui se trouve déjà dans le corpus législatif habituel?

Ainsi, il est courant d'observer l'effacement ou la substitution de l'argument constitutionnel au profit de la référence à des dispositions législatives de teneur identique. C'est dire aussi que la Constitution remplit souvent pour la Cour une fonction palliative lorsque la législation demeure trop incomplète ou est devenue obsolète. À ce titre, l'emploi de la référence au droit constitutionnel de grève tiré du septième alinéa du Préambule de 1946 témoigne avec éclat de cette tendance. La Cour de cassation a recouru dans les années cinquante à la référence directe et audacieuse au Préambule pour annuler des jugements et arrêts qui contrevenaient à la nouvelle conception des conflits collectifs de travail dans l'entreprise jusqu'à ce que la législation ultérieure sur la grève dans le secteur privé remplace la référence fondamentale dans les arrêts ${ }^{13}$.

Une autre source de concurrence, souvent présentée et parfois dénoncée pour ses excès, est constituée par les instruments internationaux et européens de protection des droits fondamentaux, avec pour principale figure la Convention européenne des droits de l'homme. Il est inutile de s'étendre longuement sur les facteurs qui contribuent au développement de la conventionalité au détriment de la constitutionnalité dans le prétoire judiciaire. L'antériorité des exigences européennes sur leurs homologues constitutionnelles dans le débat judiciaire portées par un véritable procès, le contrôle diffus de la conventionalité de la loi offrant au juge ordinaire de nouveaux pouvoirs sur la loi et un terrain de contrôle plus étendu, le risque de condamnation par la Cour européenne éprouvée par des juridictions suprêmes vigilantes, sont autant d'atouts pour la norme conventionnelle justifiant cet attrait appuyé voire exclusif pour celle-ci. L'argument constitutionnel est alors souvent négligé tant par les requérants que par le juge ${ }^{14}$. Ce qui fait dire à A. Sauviat-Canin que «le respect récent des termes de la Convention place ces règles d'origine internationale en concurrence avec le respect des

13 V. sur ce point, O. Desaulnay, op.cit., p. 530 et s.

14 Ex. : Civ. 1 ${ }^{\mathrm{er}}, 28$ novembre 1984, Bonnet, Buisson et autres (2 espèces), Bull. civ. I, $\mathrm{n}^{\circ} 321$ (droit de quitter le territoire national) ; Crim., 20 octobre 1987, Bull. crim., n 356 (détention provisoire et atteinte à la liberté individuelle) ; Civ. 3 , 13 juin 2003 , Soc. Arlatex c. Soc. Les Marguerites, D. 2004, p. 367, note C.-M. Benard (liberté d'association issue de l'article 11 de la CEDH). 
normes constitutionnelles qui assurent l'autorité du principe de la liberté des individus en matière pénale $»^{15}$. Pire, il peut être délibérément effacé par le juge au profit de la seule protection européenne et internationale des droits fondamentaux ${ }^{16}$.

Enfin, la Cour de cassation contribue elle-même activement à l'affaiblissement de l'intérêt porté pour l'argument constitutionnel notamment parce qu'elle développe ses propres instruments prétoriens de protection des droits. Différents vecteurs de protections se développent au fil des arrêts sans aucune véritable cohérence d'ensemble permettant de signaler un intérêt particulier pour la source constitutionnelle. La Cour préférera ainsi recourir à un principe jurisprudentiel en lieu et place d'un principe constitutionnel pourtant aisément identifiable ${ }^{17}$. La constitutionnalisation de certains de ces principes sous l'effet de la jurisprudence du Conseil constitutionnel semble n'avoir alors qu'un effet limité sur le juge de cassation. De même, la référence à la nature fondamentale d'un droit ou d'une liberté ${ }^{18}$ dans les arrêts de la Haute juridiction ne s'accompagne jamais d'une référence à la source constitutionnelle de cette fondamentalité, laissant subsister des doutes quant aux intentions véritables des juges suprêmes. Le détour par la notion d'ordre public dans de nombreuses décisions laisse perplexe l'observateur quant à savoir si cette notion plastique intègre véritablement une dimension constitutionnelle ${ }^{19}$.

En définitive, la Constitution ne subit pas particulièrement d'entraves dans son épanouissement en cassation par l'effet de lourdeurs procédurales supplémentaires, pourvu que son invocation dans le litige repose sur de sérieux et solides motifs juridiques et stratégiques propres à convaincre les juges de sa pertinence en comparaison d'autres instruments juridiques dont ils disposent plus couramment. Une fois passé cet obstacle relatif de l'admission du moyen, la constitutionnalité peut alors se réaliser et déployer ses effets, le juge de cassation devenant pour l'occasion juge de la constitutionnalité des actes juridictionnels.

\section{B. La réalisation d'un office judiciaire de la constitutionnalité des actes juridictionnels}

Si les hypothèses de réalisation concrète d'un contrôle de constitutionnalité des décisions des juges du fond empruntent une typologie qui ne déroge guère au contentieux de cassation (1), il est remarquable néanmoins que, par ce canal réduit, la Cour de cassation soit conduite à remplir un véritable office de juge constitutionnel dans l'ordre judiciaire (2).

15 A. Sauviat-Canin, La jurisprudence judiciaire et les décisions du Conseil constitutionnel, thèse limoges, 1993, p. 179.

16 Ex. : Civ. $1^{\text {er }}, 31$ janvier 1989, Bull. civ. I, n 47 (oubli de l'article 11 de la DDHC pourtant invoqué au profit du seul article 10 de la CEDH); Civ. 2', 5 février 1992, Kahn et autres c. Mitterand, D. 1992, J., p. 442 ; note J.-F. Burgelin (oubli de l'article 11 de la DDHC pourtant invoqué au profit des articles $6 \S 1$ et 10 de la CEDH non invoqués par le moyen); Civ. $1^{\text {er }}$, 24 février 1998, Bull. civ. I, n 71; FCP 1998, II, 10175, note Th. Vignal (oubli du principe constitutionnel d'égalité entre époux invoqué dans le moyen au profit de l'article 5 du protocole additionnel ${ }^{\circ} 7$ à la CEDH non invoqué).

17 Ex. : principe « à travail égal, salaire égal »vs le principe constitutionnel d'égalité largement consacré par les textes et la jurisprudence constitutionnelle ; le principe fondamental de libre exercice d'une activité professionnelle vs la liberté constitutionnel du travail que la chambre sociale avait pourtant appliqué avec audace ; le principe des droits de la défense vs l'article 9 de la Déclaration des droits ; le principe de dignité de la personne vs son homologue constitutionnel tiré du Préambule de 1946 par le Conseil constitutionnel, etc.

18 Ex. : la liberté fondamentale du mariage pourtant constitutionnalisée expressément par le Conseil constitutionnel ; la liberté d'expression et d'opinion des salariés dans l'entreprise s'effectue sans jamais recourir aux articles 10 et 11 de la DDHC et au Préambule de 1946, etc.

19 N. Jacouinot, Ordre public et Constitution, thèse Aix-en-Provence, 2000. 


\section{Une typologie du contrôle de constitutionnalité conforme au contentieux de cassation}

La position de la Cour de cassation à l'égard de l'étendue du contrôle de constitutionnalité des actes juridictionnels ne révèle aucune particularité par rapport à celle qu'elle adopte de manière générale dans sa fonction de cassation. La constitutionnalité de la décision des juges du fond s'intègre donc au cadre général de la cassation dans lequel l'étendue de la compétence de contrôle de la Cour est de ne pas connaître du fond des affaires, sauf disposition législative contraire ${ }^{20}$. Le fait de statuer uniquement en tant que Cour régulatrice du droit, donne à la Cour de cassation une mission institutionnelle de veiller à la bonne application de la règle de droit, à laquelle elle intègre le contrôle de sa correcte interprétation. Entendu ainsi, « le contrôle large, que la Cour de cassation assure à l'égard des sources de droit majeures [...], et qui est un contrôle normal, constituant le droit commun de la cassation, s'exerce toujours en effet à partir des constations de fait souveraines des juges du fond, sur lesquelles le juge de cassation n'a de prise que par son contrôle minimum de la motivation. Ce contrôle large ne porte donc que sur des motifs de droit $»^{21}$.

Selon ce cadre général, le juge de cassation peut se porter vers le droit constitutionnel en suivant la voie du contrôle restreint des motifs de fait. Il s'agit alors pour la Cour de sanctionner l'insuffisance dans les constatations des faits qui sont nécessaires pour statuer sur le droit, laquelle est constitutive d'un défaut de base légale. Autrement dit, chaque fois que la Cour de cassation se trouve en présence de constatations de fait incomplètes ou imprécises, qui la mettent dans l'impossibilité d'exercer pleinement son contrôle de la qualification des faits ou de l'application de la règle de droit, la censure pour défaut de base légale s'impose.

Il arrive parfois que les requérants aient à cœur de faire sanctionner par la cassation de l'arrêt la violation de la Constitution lorsqu'elle tire son origine d'une constatation incomplète des faits. Cela se manifeste essentiellement lorsque le juge d'appel a omis de procéder à une appréciation d'ensemble des éléments de preuve ou de faits constatés. C'est donc le raisonnement incomplet ou inachevé des juges du fond qui constitue alors l'inconstitutionnalité de leur motivation.

Ce raisonnement s'observe avec une certaine acuité dans des pourvois qui invoquent le droit constitutionnel de grève à l'occasion de conflits collectifs de travail ayant entraîné le lock out de l'entreprise. Il est alors reproché à la Cour d'appel une prise en considération insuffisante de l'ensemble des éléments de fait ${ }^{22}$ propres à caractériser l'exercice abusif du droit de grève (ex. : grève perlée) et le cas de force majeur consécutif, justifiant la fermeture de l'entreprise pour réorganisation de la production.

20 Art. L. 111-2 du Code de l'organisation judiciaire, reprenant l'art. 3 du décret des 27 novembre et $1^{\text {er }}$ décembre 1790 .

L. BORÉ, La cassation en matière civile, Dalloz, 1997, nº 996.

Ex. : Soc. 2 février 1966, Société « bois africains contreplaques» c. Parrens Président, Bull.civ. V, n 137 ; Soc. 9 novembre 1978, Bull. civ. V, $\mathrm{n}^{\circ} 754$; plus récemment : Soc., 30 juin 2015, req. $\mathrm{n}^{\circ}$ 14-10764 (insuffisante caractérisation d'une désorganisation complète de l'entreprise constitutif d'un abus du droit de grève ; violation de l'alinéa 7 du Préambule de 1946) ; Soc., 25 juin 2015, req. $\mathrm{n}^{\circ} 14-10217$ : viole le droit constitutionnel à la santé et au repos, en privant sa décision de base légale, le juge d'appel qui rejette la demande du salarié au titre des heures 
Une série d'arrêts récents ${ }^{23}$ intervenus dans le domaine de la rétention administrative éclairent également cette hypothèse où la violation de la Constitution est dérivée en quelque sorte d'une appréciation insuffisante des faits par les juges du fond. La Cour de cassation rappelle avec force aux juges des libertés qu'ils ne doivent pas omettre d'effectuer les constatations de faits propres à caractériser l'une des conditions d'application de la loi sous peine de priver leur décision de base légale et de contrevenir aux pouvoirs qu'ils détiennent en tant que gardiens de la liberté individuelle en vertu de l'article 66 de la Constitution. Ainsi, la Cour de cassation veille à ce que les juges du fond exercent en totalité leur pouvoir souverain d'appréciation des faits afin qu'ils s'assurent pleinement que les conditions matérielles de placement en rétention de l'étranger sont conformes aux exigences légales qui garantissent le respect de leur liberté individuelle constitutionnellement reconnue. En l'espèce, il s'agit de s'assurer que le juge des libertés a bien contrôlé non seulement que l'information sur les droits a bien été donnée à l'étranger, mais également que ce dernier a été mis en mesure d'exercer effectivement les droits qui lui sont reconnus. De la sorte, la haute juridiction sanctionne les juges du fond pour ne pas avoir pleinement exercé leur pouvoir de contrôle sur les conditions légales de placement en rétention de l'étranger ce qui, indirectement, lui permet de relever une violation des exigences constitutionnelles tirées de l'article 66.

Le contrôle de constitutionnalité s'exprime davantage avec éclat devant la Cour de cassation lorsque celle-ci empreinte la voie du contrôle étendu des motifs de droit. Le champ d'application des principes constitutionnels, leur sens ou leurs implications les plus concrètes peuvent être alors au cour du débat en cassation. Il s'agit essentiellement pour la Cour de sanctionner une violation de la loi (constitutionnelle) soit pour fausse application ou refus d'application, soit pour fausse interprétation.

Dans un premier temps, les juges du fond ont opéré une nécessaire qualification juridique des faits versés au débat afin de déterminer le ou les règles juridiques applicables au litige parmi lesquelles se trouvent parfois des règles constitutionnelles. L'interruption du travail constatée dans l'entreprise s'analyse-t-elle en une grève constitutionnellement garantie par l'alinéa 7 du Préambule de $1946^{24}$ ? Les propos tenus par un député au téléphone lors d'une émission de radio entrent-ils dans la catégorie des actes en lien direct avec l'exercice de ses fonctions qui bénéficient d'une immunité de fond en vertu de l'article 26 de la Constitution ${ }^{25}$ ? L'interpellation ${ }^{26}$ de l'étranger placé en rétention administrative ou sa garde à vue ${ }^{27}$ sont-elles constitutives d'atteintes à la liberté individuelle dont l'autorité judiciaire est la gardienne en vertu de l'article 66 de la Constitution ? Les juges d'instruction peuvent-ils entendre le Président de la République en tant que témoin assisté dans le cadre de

supplémentaires « sans vérifier, ainsi qu'elle y était invitée, les conditions de mise en œuvre de l'accord collectif prévoyant le recours au forfait en jour ».

23 Civ. $1^{\text {re }}, 31$ janvier 2006, X c. préfet de police de Paris (7 espèces), Bull. civ. I, n 45.

24 Soc., 15 janvier 1991, Conseil départemental de l'Ordre des médecins c. Layet, Bull. civ. IV, n 19 ; LPA 5 juin $1991, \mathrm{n}^{\circ} 67, \mathrm{p} .21$, note

B. Mathieu (cassation pour fausse application du droit constitutionnel de grève au motif qu'il n'y avait pas grève dans les faits).

25 Crim, 7 mars 1988, Forni, Bull. crim., n $113 ;$ FCP 1988, II, 21133, W. Jeandidier.

26 Civ. $2^{\mathrm{e}}, 28$ juin 1995, Préfet de la Haute-Garonne c. Bechta, Bull. civ. II, n 221 ; FCP 1995, II, 22504, concl. J. Saint-Rose ; Civ. $2^{\mathrm{e}}$, 22 mai 1996,

Onder c. préfeet de police de Paris, Bull. civ. II, $\mathrm{n}^{\circ} 101$; Civ. $2^{\mathrm{e}}, 11$ juin 1997, préfet de police de Paris c. Sabeur, Bull. civ. II, $\mathrm{n}^{\circ} 175$.

27 Civ. $2^{\mathrm{e}}, 28$ juin 1995, Mpinga c. préfet de police du Calvados, Bull. civ. II, nº 212. 
poursuites pénales $^{28}$ ? Les exemples ne manquent pas dans la jurisprudence de la Cour de cassation dans lesquels la question de la constitutionnalité du jugement porte en partie ou en totalité sur la qualification juridique des faits qui préside à l'invocation de la norme constitutionnelle. Autrement dit, il s'agit le plus souvent pour le juge de cassation de contrôler si les juges du fond ont correctement circonscrit le champ d'application de la norme constitutionnelle en opérant une juste qualification juridique des faits de l'espèce.

Dès lors, le contrôle de cette opération de qualification est alors décisif tant elle conditionne l'épanouissement des exigences constitutionnelles dans le procès judiciaire et signale à l'adresse de tous les juges du fond les hypothèses pertinentes dans lesquelles il est nécessaire de recourir à l'argument constitutionnel. Une appréciation juridique erronée des faits scelle le sort des exigences constitutionnelles dans le procès judiciaire. Selon les cas, la Constitution aura été omise ou volontairement écartée par les juges sans que cette non-application soit commandée par une juste justification. En sens inverse, mais dans le même ordre d'idée, les juges auront pu décider de mobiliser la norme constitutionnelle à tort à une situation de fait qui ne le justifiait pas. Ainsi, la violation de la Constitution par la décision attaquée pourra être relevée par la Cour de cassation soit, dans le premier cas, pour refus d'application, soit, dans le second cas, pour fausse application. Dans les deux cas, la Cour devra déterminer indirectement, mais nécessairement, le champ d'intervention exact à donner à la norme constitutionnelle.

Dans un deuxième temps, la Cour de cassation peut orienter son contrôle plus directement sur le sens et la portée qui ont été donnés aux règles et principes constitutionnels invoqués dans les motifs des juges du fond, déterminant le sens de leur décision. Les premiers juges auront pu commettre une erreur dans l'appréciation de la signification et de la portée concrète de la disposition constitutionnelle. Cette fausse interprétation, constitutive d'une violation de la Constitution, encourra la sanction de la Cour de cassation qui la jugera manifestement non-conforme au sens réel du texte ou du principe constitutionnel qu'elle entend adopter.

La jurisprudence de la Cour de cassation révèle quelques cas dans lesquels la Cour contrôle et, le cas échéant, sanctionne par la cassation une interprétation constitutionnelle erronée des juges du fond. C'est sans doute lorsque l'étendue de la compétence de la juridiction judiciaire est en jeu que l'on constate les plus belles manifestations de l'emprise interprétative de la Cour régulatrice sur le fondement de la Constitution.

Est-il nécessaire de rappeler la jurisprudence qui s'est établie au fil des arrêts, sur le fondement l'article 66 de la Constitution, dans le sens d'une résurgence ${ }^{29}$ puis d'une extension ${ }^{30}$ du contrôle judiciaire sur la procédure de rétention administrative d'un étranger? À l'inverse, dans le sens d'une

28 Ass. plén., 10 octobre 2001, Breisacher, Bull. civ. A.P., nº 11.

29 Civ. $2^{\text {e }}, 28$ juin 1995, Préfet de la Haute-Garonne c. Bechta, arrêt précit. Depuis près de vingt ans en effet, la Cour de cassation n'a de cesse de rappeler aux juridictions du fond qui omettent l'ampleur de leur compétence en matière de rétention administrative « qu'en vertu de l'article 66 de la Constitution du 4 octobre 1958 et 136 du Code de procédure pénale, il appartient au juge [...] de se prononcer comme gardien de la liberté individuelle sur les irrégularités attentatoires à cette liberté invoquées par l'étranger ».

30 Civ. $1^{\text {re }}, 31$ janvier 2006, X c. préfet de police de Paris (7 espèces), Bull. civ. I, nº 45. 
limitation de la compétence judiciaire, il est permis de citer la cassation de plusieurs ordonnances de référé civil par l'Assemblée plénière ${ }^{31}$ au visa unique de l'article 59 de la Constitution selon lequel « le Conseil constitutionnel statue en cas de contestation sur la régularité de l'élection des députés et des sénateurs ». Il était alors reproché au juge civil de s'être à tort considéré compétent pour connaître de litiges relatifs aux documents électoraux sans tenir compte de la compétence en la matière du Conseil constitutionnel. De même, le juge civil de l'urgence est-il compétent pour ordonner en référé la réquisition de salariés grévistes pour prévenir un «dommage imminent » au sens de l'article 809 du Code de procédure civile sans contrevenir au droit constitutionnel de grève ${ }^{32}$ ?

Sur ce point précis de la compétence juridictionnelle de l'autorité judiciaire, c'est sans doute l'arrêt de l'Assemblée plénière Breisacher ${ }^{33}$ dans le domaine de la responsabilité pénale du Chef de l'État qui a révélé avec éclat la fonction de contrôle de l'interprétation de la Constitution que la Cour de cassation est capable d'endosser. Au-delà de la fausse application de l'article 68 de la Constitution qu'elle relève ${ }^{34}$, la Cour de cassation reproche en effet aux premiers juges d'avoir retenu un sens inexact de cette disposition, profitant de cette occasion pour dicter son interprétation souveraine. Pour statuer sur le sens à donner à l'article 68, les juges du fond avaient considéré qu'ils étaient placés en vertu de l'article 62 de la Constitution dans l'obligation de se référer au considérant $n^{\circ} 16$ de la décision n ${ }^{\circ}$ 98-408 DC du 22 janvier $1999^{35}$ du Conseil constitutionnel. La Cour de cassation précise, en sens contraire, que le juge judiciaire n'était pas tenu, en vertu de l'autorité des décisions du Conseil constitutionnel (art. 62), attachée non seulement au dispositif, mais encore aux motifs qui en sont le soutien nécessaire, de suivre l'interprétation émise par le Conseil constitutionnel, celle-ci n'étant portée que par un simple obiter dictum. Par voie de conséquence, les juges du fond s'étaient déclarés incompétents pour entendre le Président de la République en tant que témoin assisté dans le cadre de poursuites pénales contre X. Leur refus s'appuyait précisément sur le privilège de juridiction constitué par la compétence de la Haute Cour de justice sur les actes du Président en fonction que semblait conférer l'article 68, au dire du Conseil constitutionnel dans le considérant $\mathrm{n}^{\circ} 16$ de sa décision de 1999. Cette lecture de l'article 68, appliqué à tort à la situation de fait, est en définitive écartée explicitement pour fausse interprétation par l'Assemblée plénière au profit de sa propre lecture bien plus constructive : le maintien de la compétence des juridictions pénales pour tous les actes détachables et antérieurs à l'exercice de la fonction présidentielle, moyennant une suspension de la prescription de l'action publique durant l'exercice du mandat.

Enfin, en troisième lieu et dans le prolongement de l'hypothèse précédente, la Cour de cassation peut étendre son contrôle sur les conséquences les plus concrètes que les juges du fond ont pu tirer de l'application des exigences constitutionnelles. Sans contrevenir directement à la substance

31 Ass. plén., 8 mars 1996, Lalonde c. $M^{m e}$ Kerckel et autres (1e espèce) et Landouch et autres c. Perrier et autres ( $2^{e}$ espèce), Bull. civ. A.P., $\mathrm{n}^{\circ} 1$ et 2 ; RFDC 1996, n²5, p. 152, rapp. J.-P. Dorly ; D. 1996, p.373, note R. Ghevontian ; FCP 1996, II, 22621, note E. du Rusquee.

32 Soc., 25 février 2003, CFDT Santé Sociaux de la Haute-Garonne c. Association MAPAD de la Cépière, Bull. civ. V, nº 62 ; DS 2003, p. 621, note Ch. Radé, «le juge des référés et la réquisition des grévistes ».

33 Arrêt précit.

34 Cf. supra. La fausse application de l'article 68 de la Constitution est en réalité le résultat d'une fausse interprétation des termes de cette disposition.

35 Décision n 98-408 DC du 22 janvier 1999, Traité portant statut de la Cour pénale internationale. 
de ces dernières, les juges ont pu omettre d'en tirer toutes les implications utiles pour le litige. L'inconstitutionnalité est plus indirecte, car elle porte davantage sur la portée concrète qu'il convient de donner aux exigences constitutionnelles. La violation de la Constitution relevée par la Cour est alors précisément constituée par les déductions erronées ou insuffisantes opérées par les juges du fond sur la base de constatations de fait complètes.

Il en est ainsi, lorsque la chambre sociale reproche au juge d'appel, sur le fondement du sixième alinéa du Préambule de 1946 (liberté syndicale), de ne pas avoir tiré de la constatation de la nullité absolue du licenciement discriminatoire d'un salarié protégé que ce dernier « [...] a droit au paiement d'une indemnité égale au montant de la rémunération qu'il aurait dû percevoir entre son éviction de l'entreprise et sa réintégration, peu important qu'il ait ou non reçu des salaires ou un revenu de remplacement pendant cette période $»^{36}$.

Dans le même ordre d'idée, la chambre sociale a modifié sa jurisprudence sur les conventions de forfait jour lorsque l'employeur n'en a pas respecté le contenu. Auparavant, elle considérait que le salarié lésé était en droit d'obtenir des dommages et intérêts, sans remettre en cause la validité de la convention ou son efficacité3 ${ }^{37}$. Désormais, au visa inédit du «droit à la santé et au repos qui est au nombre des exigences constitutionnelles » issues de l'alinéa 11 du Préambule de $1946^{38}$, la Cour impose aux juges du fond qu'ils déduisent de la constatation des manquements de l'employeur à ses obligations légales de suivi et de contrôle de l'exécution d'une convention de forfait jour que celle-ci « était privée d'effet et que le salarié pouvait prétendre au paiement d'heures supplémentaires dont elle devait vérifier l'existence et le nombre $»^{39}$.

Il ressort de ce morceau choisi d'hypothèses de contrôle que le juge de cassation, en embrassant tout le prisme des motifs de fait et de droit retenus par les juges du fond, est parfaitement en capacité d'apprécier pleinement si les exigences constitutionnelles ont été effectivement respectées, convenablement appliquées et correctement entendues par les tribunaux inférieurs. Un office complet de juge de la constitutionnalité se dessine alors au fil des arrêts.

\section{L'office d'un juge de la constitutionnalité}

Il est particulièrement remarquable que par l'exercice d'un contrôle complet de la motivation des juges du fond, la Haute juridiction judiciaire soit en capacité de revêtir les habits d'un authentique juge de la constitutionnalité, alors même que son office juridictionnel n'a pas été pensé à l'origine pour remplir une telle fonction.

\footnotetext{
36 Soc., 9 juillet 2014, Bull. civ. V, n 146 ; Soc., 25 novembre 2015, req. n 14-20527.

37 Soc., 13 janvier 2010, Bull. civ. V, $\mathrm{n}^{\circ} 14$.

38 Il n'était pas évident que cette disposition du Préambule de 1946 trouve un jour à s'appliquer concrètement dans un contentieux civil. La Cour de cassation a sans doute été sensible à la voie empruntée par le Conseil constitutionnel lors de l'examen de la constitutionnalité de la loi en faveur des PME qui avait étendu le forfait jour à des salariés non cadres. L'extension avait été validée par le Conseil « sous réserve de ne pas priver de garanties légales les exigences constitutionnelles relatives au droit à la santé et au droit au repos de ces salariés résultant du Préambule de $1946 »$ (Cons. cons., n² 2005-523 DC, 29 juillet 2005, Loi en faveur des PME, cons. 6).

39 Soc., 29 juin 2011, Bull. civ. V, nº 181 ; Soc., 17 décembre 2014, Bull. civ. V, nº 301.
} 
Tout d'abord, son statut de cour suprême au sommet d'un ordre judiciaire hiérarchisé la place dans la situation exceptionnelle de pouvoir remettre en cause de manière définitive les décisions de justice inférieures contrevenant au droit constitutionnel avec une autorité juridique complète. La cassation, avec ou sans renvoi, offre aux exigences constitutionnelles une protection efficace dans la mesure où la résistance des juges inférieurs se solde en définitive toujours par une soumission à la position de la juridiction suprême. Il est d'ailleurs remarquable que, sur ce point, les quelques arrêts ayant été rendus en Assemblée plénière ne l'aient été qu'au regard de l'importance de la question posée et non en réaction à la résistance de la Cour d'appel de renvoi à la première décision de cassation rendue. Tout au plus, la convocation d'une Assemblée plénière voire d'une Chambre mixte se justifie pour se prémunir d'une telle résistance alors que les juridictions inférieures se sont divisées sur l'interprétation à donner aux textes constitutionnels. La volonté de la Cour d'imposer de manière uniforme et rapide sa solution est alors évidente.

Bénéficiant des moyens juridictionnels lui permettant d'imposer sa jurisprudence en matière constitutionnelle, la Cour de cassation est en situation d'assurer l'unité et la primauté de l'ordre constitutionnel dans l'ensemble des branches du droit privé. Au travers du contrôle étendu des motifs de droit retenus par les juges du fond, la Cour de cassation façonne les notions clefs du droit constitutionnel ainsi que le sens et la portée des exigences constitutionnelles qu'elle diffuse ensuite par ses arrêts dans l'ensemble de l'ordre judiciaire privé. Certes, elle doit composer avec la jurisprudence du Conseil constitutionnel dans un esprit de coopération loyale à l'endroit de la constitutionnalité qu'elles ont en partage. Sur ce point précis, il convient d'insister sur la rareté des hypothèses de divergences de jurisprudence, les deux juridictions pratiquant depuis longtemps l'influence réciproque quant à la définition du droit constitutionnel et à l'intensité des exigences qui en découlent. Si ce phénomène s'établit le plus souvent dans le silence des arrêts de la Cour, une observation plus poussée et comparative des jurisprudences judiciaire et constitutionnelle permet néanmoins de conclure à l'existence ancienne d'un véritable dialogue entre les deux juges, dominé par le souci d'une sincère coopération.

Mais, ceci étant dit, la Cour bénéficie avec l'assise de la cassation d'un véritable dernier mot dans l'ordre judiciaire sur le sens du texte constitutionnel. Si la Cour de cassation remplit par la voie de la cassation une fonction essentielle de garantie des droits constitutionnels contre les décisions des juges du fond, en revanche, ses décisions ne sont pas assujetties, à leur tour, à un contrôle direct quelconque de constitutionnalité. Il n'est aucun juge spécial, pas même le Conseil constitutionnel par la voie de la $\mathrm{QPC}^{40}$, qui puisse remettre en cause une décision de la Cour de cassation en matière constitutionnelle.

40 Le Conseil constitutionnel ne peut être saisi par la voie de la QPC que d'une disposition constitutionnelle voire de l'interprétation de cette disposition régulièrement retenue par les juridictions judiciaires. En aucun cas, il ne s'agit de remettre en cause une décision de la Cour de cassation. 
Ainsi confortée dans son rôle d'interprète suprême (interprète authentique), la Cour de cassation ne se contente pas de délivrer ou non un brevet de conformité à la Constitution aux actes juridictionnels dont elle est saisie par la voie du pourvoi en cassation. Elle poursuit au-delà une fonction de relais juridictionnels soutenant la diffusion des exigences constitutionnelles jusque dans les relations de droit privé. Ces dernières se trouvent alors exposées indirectement aux contraintes tirées de la Constitution. Ainsi, à titre d'exemple, la clause de non-concurrence insérée dans le contrat de travail $^{41}$, le licenciement d'un salarié gréviste ${ }^{42}$, la subvention d'un syndicat représentatif par un employeur ${ }^{43} \mathrm{ou}$ encore l'exécution concrète par l'employeur d'une convention de forfait jour ${ }^{44}$ sont des pratiques désormais encadrées par un réseau d'obligations issues directement de l'interprétation de principes constitutionnels effectuée au sein des arrêts de cassation. Autrement dit, la Cour participe activement à la constitutionnalisation de l'ordre juridique privé, c'est-à-dire à la primauté et à la diffusion des exigences constitutionnelles dans les relations interpersonnelles. En assumant son obligation de protection des droits fondamentaux constitutionnels, lorsque les juges du fond ont été défaillants sur ce point, le juge judiciaire suprême en censurant leurs décisions offre un effet horizontal certain à ces droits ${ }^{45}$, sans être embarrassé nullement par la question de l'application de la Constitution aux relations privées.

En définitive, de ce rapide aperçu des manifestations de la constitutionnalité dans le contentieux de cassation, le doute n'est plus permis à l'égard des réelles et importantes capacités que détient la Cour de cassation pour mener à bien une mission de contrôle de la conformité à la Constitution des actes juridictionnels. Pourvu que l'argument constitutionnel soit convoqué dans le débat judiciaire et le contrôle de cassation révèle alors toutes ses potentialités protectrices par l'étendue large de son emprise sur la motivation des juges du fond et l'autorité incontestable sur l'ensemble de l'ordre privé qui s'attache aux décisions de la Cour. La Haute juridiction n'est donc pas un juge de la constitutionnalité par accident, dépendante de l'ingéniosité des pourvois. Elle l'est en revanche par intermittence, demeurant dans une position d'entre-deux, volontiers intéressée mais distante.

Le regard porté à la constitutionnalité par la Cour pourrait-il, voire devrait-il, être plus appuyé et plus régulier lorsque cela s'avère nécessaire ? La question mérite d'être posée dans le contexte renouvelé de la réforme de la QPC dans lequel s'insère désormais cette part judiciaire du contentieux constitutionnel.

\footnotetext{
41 Soc., 19 novembre 1996, Martinez c. Auto Service 34, Bull. civ. IV, nº 392 (encadrement strict de la clause de non concurrence pour protéger la liberté constitutionnelle du travail).

42 Soc., 28 juin 1951, Société d'impression sur étoffes du Grand Lemps c. Geoffroy et Maïseries de la Méditerranée c. Dame Roth, DS 1951 , p. 532 (la consécration du droit constitutionnel de grève par l'alinéa 7 du Préambule de 1946 est incompatible avec la rupture du contrat de travail pour fait de grève).

43 Soc., 29 mai 2001, Union des syndicats CGT-Cégélec, Bull. civ. V, nº 185 (principe constitutionnel d'égalité en matière syndicale).

44 Cf. supra, note 36

45 V. sur ce point D. RiBEs, L État protecteur des droits fondamentaux. Recherche en droit comparé sur les effets des droits fondamentaux entre personnes privées, Thèse Aix-En-Provence, 2005 ; O. Desaulnay, op. cit., p. 129 et $\mathrm{s}$.
} 


\section{Des potentialités renouvelées dans le contexte d'un renforcement de la protection des droits fondamentaux}

Après plus de six années de mise en œuvre, la question prioritaire de constitutionnalité a-t-elle incité la Cour de cassation à puiser dans la Constitution toutes ses potentialités pour censurer un jugement non conforme aux règles de droit, en particulier à la Constitution, au sens de l'article 604 du code de procédure civile, ou rendu en violation de la loi au sens des articles 591 et suivants du code de procédure pénale?

Force est de constater qu'à la lecture des arrêts rendus depuis l'entrée en vigueur de la QPC le $1^{\text {er }}$ mars 2010, aucun changement fondamental n'est apparu dans la manière dont la Cour de cassation examine les pourvois en cassation à l'occasion desquels une atteinte à la Constitution est invoquée(I).

Toutefois, certains signes d'évolution ne doivent pas être négligés parmi lesquels figurent les réflexions menées actuellement au sein de la Cour de cassation sur son office qui offrent un terrain, que la QPC a contribué à préparer, favorable au déploiement d'un contrôle de constitutionnalité (II).

\section{A. Une application encore marginale de la Constitution malgré la procédure QPC}

Malgré l'entrée en vigueur de la procédure QPC, l'utilisation de la Constitution par la Cour de cassation reste encore aujourd'hui marginale. La manière dont la Cour de cassation appréhende la Constitution n'a pas été bouleversée. C'est que la QPC s'inscrit dans un ordonnancement institutionnel et juridictionnel préservant le monopole du contrôle objectif de la conformité de la loi à la Constitution au Conseil constitutionnel (1) et celui de garant ordinaire de l'application des normes conventionnelles à la Cour de cassation(2). Cependant, petit à petit, la QPC contribue à renforcer, au sein de la Cour de cassation, une culture constitutionnelle propice au déploiement d'un contrôle de constitutionnalité (3).

\section{Un cadre strict d'application de la Constitution renforcé par la procédure autonome de la QPC}

Après l'entrée en vigueur de la QPC, à plusieurs reprises, le Conseil constitutionnel a rappelé que le contrôle de la conformité de la loi à la Constitution lui incombe et que le contrôle de la conventionnalité relève de la compétence des juridictions judiciaires et administratives ${ }^{46}$.

Cette répartition des compétences amène alors la Cour de cassation à appliquer la Constitution dans ce cadre strict des articles 61-1 et 62 de la Constitution.

46 Cons. cons., $n^{\circ}$ 2009-595 DC du 3 décembre 2009, Loi organique sur l'application de l'article 61-1 de la Constitution, cons. 14 ; Cons. cons., $\mathrm{n}^{\circ}$ 2010-605 DC du 12 mai 2010, Loi relative à l'ouverture à la concurrence et à la régulation du secteur des jeux d'argent et de hasard en ligne, cons. 11 et 12 ; Cons. cons., n 2014-439 QPC du 23 janvier 2015, cons. 7. 
D'une part, en vertu de l'article 61-1 de la Constitution et des articles 23-1 et suivants de l'ordonnance du 7 novembre 1958, la QPC fait l'objet, par la Cour de cassation, d'un traitement autonome et porte sur un contentieux objectif, abstrait de la norme étranger à l'office de la Cour chargée de contrôler la conformité aux règles de droit d'un jugement tranchant un litige entre justiciables. De ce point de vue, la QPC présente peu d'influence sur le traitement des pourvois.

Ainsi, lorsque les requérants posent une QPC incidente à un pourvoi en cassation, ils réservent un moyen (ou une branche du moyen) de leur pourvoi pris de l'abrogation à intervenir de la disposition législative critiquée. Si la QPC n'est finalement pas transmise au Conseil constitutionnel ou si elle a été jugée irrecevable, soit, lors de l'examen du pourvoi, la Cour répond par exemple « que le moyen tiré de l'abrogation de la loi manque par le fait même qui lui sert de base ${ }^{47}$, soit le plus souvent elle ne reprend tout simplement plus le moyen (ou la branche du moyen) d'inconstitutionnalitée ${ }^{48}$. Ou alors, lorsque le Conseil constitutionnel, saisi de la QPC, a déclaré les dispositions législatives litigieuses conformes à la Constitution, la Cour conclut, au moment de l'examen du pourvoi, que le moyen est devenu sans objet ${ }^{49}$.

En dehors de l'hypothèse de QPC incidentes à un pourvoi, il arrive qu'un moyen ait pour objet de déclarer la disposition législative appliquée dans le litige contraire à la Constitution. Pour la Cour de cassation, ce moyen est tout simplement irrecevable ${ }^{50}$, ou encore elle répond classiquement qu' « il ne lui appartient pas d'apprécier la constitutionnalité » de la loi ${ }^{51}$ ou que le moyen « ne répond pas aux exigences de l'article 978 du code de procédure civile $»^{52}$.

D'autre part, la Cour de cassation fait une application stricte de l'article 62 de la Constitution en vertu duquel les décisions du Conseil constitutionnel s’imposent à elle.

Certes, nombreux sont désormais les arrêts tenant compte des décisions rendues par le Conseil constitutionnel en matière de $\mathrm{QPC}^{53}$.Ainsi, le moyen tiré de l'abrogation d'une disposition législative par le Conseil constitutionnel est de pur droit et est soulevé d'office même si les moyens de cassation reposaient sur la violation de la $\mathrm{CEDH}^{54}$.

La Cour prend en compte, bien entendu, l'effet différé de l'abrogation d'une disposition législative par une décision du Conseil constitutionnel ${ }^{55}$ ou les réserves d'interprétation du Conseil constitutionne ${ }^{56}$. Par exemple, la réserve d'interprétation figurant dans la décision du Conseil constitutionnel

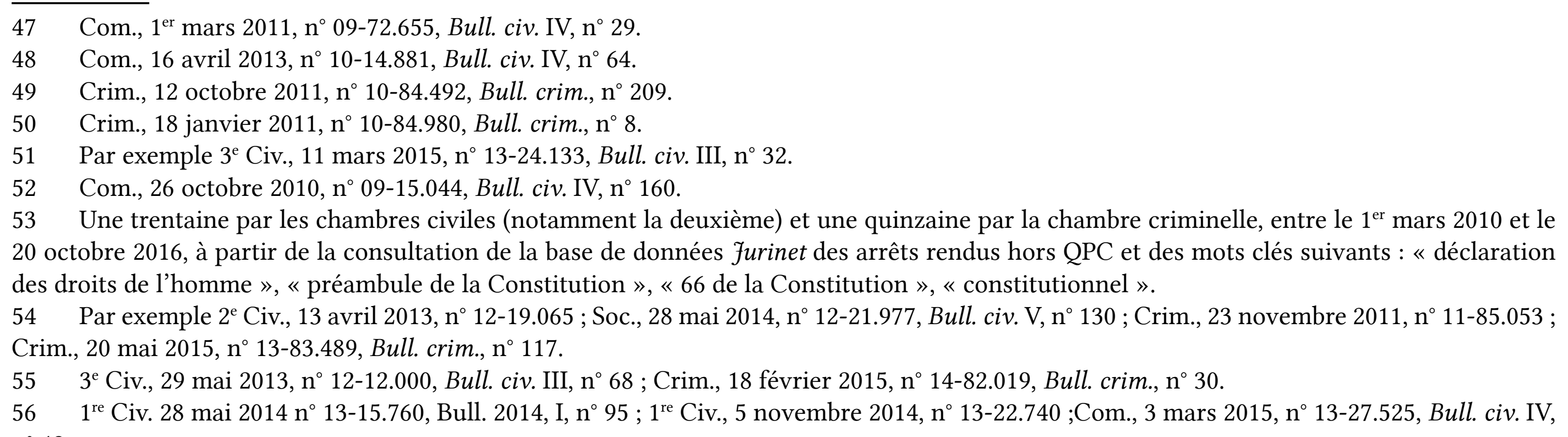

Une trentaine par les chambres civiles (notamment la deuxième) et une quinzaine par la chambre criminelle, entre le $1^{\mathrm{er}}$ mars 2010 et le 20 octobre 2016, à partir de la consultation de la base de données furinet des arrêts rendus hors QPC et des mots clés suivants : « déclaration des droits de l'homme », « préambule de la Constitution », « 66 de la Constitution », « constitutionnel ».

54 Par exemple $2^{\mathrm{e}}$ Civ., 13 avril 2013, $\mathrm{n}^{\circ}$ 12-19.065 ; Soc., 28 mai 2014, $\mathrm{n}^{\circ}$ 12-21.977, Bull. civ. V, $\mathrm{n}^{\circ} 130$; Crim., 23 novembre 2011, $\mathrm{n}^{\circ} 11-85.053$; Crim., 20 mai 2015, $\mathrm{n}^{\circ} 13-83.489$, Bull. crim., $\mathrm{n}^{\circ} 117$.

$55 \quad 3^{\text {e }}$ Civ., 29 mai 2013, n 12-12.000, Bull. civ. III, n 68 ; Crim., 18 février 2015, n 14-82.019, Bull. crim., $\mathrm{n}^{\circ} 30$

$561^{\text {re }}$ Civ. 28 mai $2014 \mathrm{n}^{\circ} 13-15.760$, Bull. 2014, I, $\mathrm{n}^{\circ} 95 ; 1^{\text {re }}$ Civ., 5 novembre 2014, $\mathrm{n}^{\circ} 13-22.740 ;$ Com., 3 mars 2015, $\mathrm{n}^{\circ}$ 13-27.525, Bull. civ. IV, $n^{\circ} 42$. 
$\mathrm{n}^{\circ}$ 2010-8 QPC du 18 juin 2010 sur le contentieux relatif à l'indemnisation des victimes d'une faute inexcusable de l'employeur a donné lieu à un contentieux important de la deuxième chambre civile ${ }^{57}$.

Cependant, la Cour de cassation n'accorde de manière générale aux décisions du Conseil constitutionnel que l'autorité de la chose jugée à la disposition législative examinée et n'étend pas ses effets à des dispositions matériellement similaires ${ }^{58}$. Si elle a reconnu un certain effet dit « horizontal » aux décisions du Conseil constitutionnel, c'est toujours à l'occasion de l'examen de $\mathrm{QPC}^{59}$ et plus rarement à l'occasion d'un pourvoi en cassation ${ }^{60}$. La Cour confirme ainsi son rejet d'une conception matérielle de l'autorité de chose jugée constitutionnelle consistant à étendre celle-ci au-delà de la disposition législative contrôlée par le Conseil constitutionnel pour établir ces effets à l'égard de dispositions législatives dont l'objet est substantiellement analogue ${ }^{61}$.

On le voit, la QPC et le pourvoi en cassation restent cloisonnés dans des zones étanches. La QPC, au même titre par exemple que les demandes d'avis, les recours en révision des affaires pénales, la procédure de récusation, n'est qu'une procédure particulière, confiée à la Cour, indépendante du pourvoi en cassation. Et, comparées aux 30000 pourvois environ examinés chaque année par la Cour de cassation, les 280 QPC examinées en moyenne annuellement pèsent nécessairement peu sur l'activité des magistrats de la Cour.

Les statistiques confirment le peu d'influence de la QPC dans le contentieux ordinaire des pourvois en cassation. Finalement, entre le $1^{\text {er }}$ mars 2010 et le 20 octobre 2016, seule une trentaine de cassations ont été prononcées au visa d'un texte constitutionnel ${ }^{62}$. L'on peut s'étonner que la violation de l'article 66 de la Constitution, abondamment soutenue dans les QPC, n'ait été, durant cette période, invoquée qu'à l'appui d'une trentaine de pourvois devant la chambre criminelle, d'autant plus que celle-ci n'a pas expressément examiné ce moyen à l'inverse des moyens d'illégalité ou d'inconventionnalité souvent simultanément invoqués. Dans le même ordre d'idées, très peu de pourvois devant la chambre criminelle reposent sur les moyens tirés d'une atteinte aux principes de légalité et de présomption d'innocence garantis aux articles 8 et 9 de la Déclaration de $1789^{63}$. Enfin, les moyens d'inconstitutionnalité sont également rarement explicitement rejetés ${ }^{64}$. Les rejets des

57 Par exemple, $2^{\mathrm{e}}$ Civ., 30 juin $2011 \mathrm{n}^{\circ}$ 10-19.475, Bull. civ., II, $\mathrm{n}^{\circ} 148 ; 2^{\mathrm{e}}$ civ., 22 septembre 2011, $\mathrm{n}^{\circ}$ 09-15.756, Bull. civ., II, $\mathrm{n}^{\circ} 171 ; 2^{\mathrm{e}}$ Civ., 4 avril 2012, $\mathrm{n}^{\circ} 11-18.014$, Bull. civ., II, $\mathrm{n}^{\circ} 67$; $2^{\mathrm{e}}$ civ., 4 avril 2012, $\mathrm{n}^{\circ} 11-10.308$, Bull. civ., II, $\mathrm{n}^{\circ} 68 ; 2^{\mathrm{e}}$ civ., 4 avril 2012, $\mathrm{n}^{\circ} 11-14.311$ et $11-14.594$,

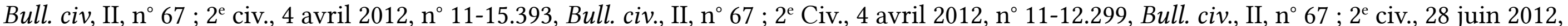
$\mathrm{n}^{\circ}$ 11-16.120, Bull. civ., II, $\mathrm{n}^{\circ} 127$; $2^{\mathrm{e}}$ Civ., 8 novembre 2012, $\mathrm{n}^{\circ} 11-23.516$ et 11-23.524, Bull. civ., II, $\mathrm{n}^{\circ} 182 ; 2^{\mathrm{e}}$ Civ., 20 juin 2013 , ${ }^{\circ} 12-21.548$, Bull. $^{\circ}$ civ., II, $\mathrm{n}^{\circ} 127 ; 2^{\mathrm{e}}$ Civ., 19 septembre 2013, $\mathrm{n}^{\circ} 12 \_18.074$, Bull. civ., II, ${ }^{\circ} 170$.

58 Com., 11 avril 2012, $\mathrm{n}^{\circ}$ 10-25.570, Bull. civ. IV, $\mathrm{n}^{\circ} 81$ et Com., 11 avril 2012, $\mathrm{n}^{\circ}$ 10-27.235, Bull. civ. IV, $\mathrm{n}^{\circ} 79$ au regard de Cons. cons., $\mathrm{n}^{\circ} 2011-$ 212 QPC du 19 janvier 2012, abrogeant l'article L. 624-6 du code de commerce.

$591^{\text {re }}$ Civ., 26 juin 2013, QPC n ${ }^{\circ} 13-40.027 ; 2^{\text {e }}$ Civ., 17 février 2011, QPC n ${ }^{\circ}$ 10-40.060 où, pour refuser de renvoyer une QPC, la Cour a constaté

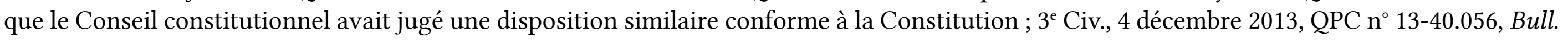
civ. III, $\mathrm{n}^{\circ} 155$.

$60 \quad$ Voir infra note 70.

61 Voir O. Desaulnay, op. cit., p. 675-685.

62 Essentiellement une trentaine d'arrêts rendus par la chambre sociale et 2 arrêts rendus par la chambre criminelle, à partir de la consultation de la base de données furinet des arrêts rendus hors QPC et des mots clés suivants : « déclaration des droits de l'homme », « préambule de la Constitution », « 66 de la Constitution », « constitutionnel ».

63 La chambre criminelle rappelle en effet l'appréciation souveraine des juges du fond (Crim.,16 décembre 2015, $\mathrm{n}^{\circ}$ 14-85.667, Bull. crim., $\mathrm{n}^{\circ} 312$; Crim., 16 février 2016, $\mathrm{n}^{\circ}$ 15-82.402, Bull. crim., $\mathrm{n}^{\circ}$ 50). Voir tout de même une cassation par Crim., 26 février 2014, $\mathrm{n}^{\circ}$ 13-87.888, Bull. crim., $\mathrm{n}^{\circ} 60$.

64 Une dizaine d'arrêts rendus par les chambres civiles (surtout la chambre sociale) ont été répertoriés et 4 par la chambre criminelle entre le $1^{\text {er }}$ mars 2010 et le 20 octobre 2016, à partir de la consultation de la base de données furinet des arrêts rendus hors QPC à partir des mots 
pourvois sont toujours le plus souvent fondés sur une bonne application de la loi, du droit européen ou international. Malgré la QPC, l'instrument constitutionnel continue donc de souffrir d'un déficit de compétitivité.

\section{Le moyen d'inconstitutionnalité fortement concurrencé par le moyen d'inconventionnalité}

L'office de la Cour de cassation étant ainsi strictement encadré, l'introduction de la QPC n'a pas entrainé de déclin du contrôle de conventionnalité, bien au contraire ${ }^{65}$.

Par exemple, une fois que le moyen d'inconstitutionnalité, présenté sous la forme d'une QPC, n'a pas abouti à l'abrogation de la loi, le moyen d'inconventionnalité ${ }^{66}$, très souvent invoqué simultanément, est tout naturellement examiné à l'occasion du pourvoi ${ }^{67}$, voire, compte-tenu de son effet utile, est soulevé d'office ${ }^{68}$.

De même, lorsqu'un requérant invoque au soutien de son pourvoi à la fois des moyens d'inconventionnalité ${ }^{69}$ et d'inconstitutionnalité de la loi, le plus fréquemment la Cour de cassation continue à écarter le moyen d'inconstitutionnalité et à ne répondre que sur le moyen d'inconventionnalité ${ }^{70}$.

Ainsi, la Cour de cassation privilégie le contrôle de la seule violation de la CEDH même si le Conseil constitutionnel avait eu l'occasion de se prononcer sur une question similaire au regard de la Constitution.

Par exemple, dans la décision $n^{\circ}$ 2010-613 DC du 7 octobre 2010 relative à la loi interdisant la dissimulation du visage dans l'espace public, le Conseil constitutionnel avait émis une réserve suivant laquelle l'interdiction de dissimuler son visage dans l'espace public ne saurait, sans porter une atteinte excessive à l'article 10 de la Déclaration de 1789, restreindre l'exercice de la liberté religieuse dans les lieux de culte ouverts au public. Une femme avait été poursuivie sur le fondement de cette loi. Au soutien de son pourvoi, elle avait invoqué le moyen tiré de la violation des articles 9, 10 et 14 de la Convention européenne des droits de l'homme et des articles 10 et 11 de la Déclaration des droits de l'homme et du citoyen de 1789. Or, la Cour s'est contentée d'exposér seulement en quoi la loi est conforme à la CEDH. Ce faisant, elle n'a pas appliqué la Constitution certainement pour ne pas s'engager, dans cette affaire, dans un contrôle sous-jacent de conformité de la loi à la

\footnotetext{
clés suivants : « déclaration des droits de l'homme », «préambule de la Constitution », « 66 de la Constitution », « constitutionnel ». 65 S. Guinchard, F. Ferrand, T. Moussa, «Une chance pour la France et le droit continental : la technique de cassation, vecteur particulièrement approprié au contrôle de conventionnalité »D. 5 février $2015 \mathrm{n}^{\circ} 5$, p. 278 et $\mathrm{s}$. Il en est de même a fortiori du contrôle de légalité.

66 Et/ou d'illégalité.

67 Crim., 19 novembre 2013, QPC n 13-84.909, Bull. crim., nº 233 ; Crim., 14 janvier 2014, n 13-84.909, Bull. crim., nº 8 ; voir aussi par exemple Com., 12 juillet 2011, $\mathrm{n}^{\circ} 10-21.551$.

68 Cons. cons., $\mathrm{n}^{\circ}$ 2012-268 QPC du 27 juillet2012; $1^{\text {re }}$ Civ., 19 avril 2013, $\mathrm{n}^{\circ}$ 11-27.071, Bull. civ. I, $\mathrm{n}^{\circ} 66$.

69 Et/ou d'illégalité.

$70 \quad 3^{\text {e }}$ Civ., 11 mars 2015, n 13-24.133, Bull. civ. III, n³ 32. Il en est de même a fortiori du moyen d'illégalité.
} 
Constitution. Toutefois, un contrôle plus concret de l'application de la loi par les juges du fond lui aurait permis de faire application de la réserve d'interprétation du Conseil constitutionnel ${ }^{71}$.

\section{Le renforcement d'une culture constitutionnelle à la faveur de la QPC}

Malgré ce cloisonnement entre la Constitution et le pourvoi en cassation, certaines fissures apparaissent de sorte que la Constitution s'infiltre peu à peu dans le contentieux judiciaire.

La QPC a accéléré la constitutionnalisation du droit privé par le développement de la jurisprudence constitutionnelle du Conseil constitutionnel ou de la Cour. En effet, un bilan de 5 années de QPC posées devant la Cour de cassation révèle que les droits et libertés garantis par la Constitution les plus invoqués sont l'égalité, le droit au recours, le droit de propriété, les droits de la défense et que les contentieux les plus concernés sont, par chambres, le droit de la famille, l'état des personnes, le droit de la sécurité sociale, le droit de l'expropriation, les procédures collectives, le licenciement, la procédure pénale.

En outre, elle a contribué à développer une véritable culture constitutionnelle que l'on retrouve dans les travaux préparatoires à l'examen des QPC qui procèdent à une analyse approfondie de la jurisprudence constitutionnelle pertinente.

Par ailleurs, plutôt que de renvoyer une QPC sur son interprétation de la loi, la Cour de cassation est conduite à interpréter cette loi dans un sens conforme aux droits et libertés garantis par la Constitution $^{72}$. Elle a été amenée à procéder à des revirements ${ }^{73}$ ou des évolutions de jurisprudence ${ }^{74}$. L'on peut aussi trouver un exemple où, à l'occasion d'un pourvoi en cassation, la Cour de cassation a « complété »une interprétation de la loi déjà interprétée par le Conseil constitutionnel ${ }^{75}$ ou a appliqué une interprétation de la loi par le Conseil constitutionnel dans une situation analogue ${ }^{76}$.

La Cour de cassation formule encore, à l'occasion de l'examen de QPC, des directives d'interprétation conforme à la Constitution à l'attention des juridictions du fond ${ }^{77}$. Elle exerce donc, à

\footnotetext{
71 Crim., 5 mars 2013, n 12-80.891, Bull. crim., nº 54 ; Voir aussi par exemple :Crim., 25 mars 2015, n 13-84.422, Bull. crim., nº 68 (sur la question de la confiscation).

$72 \quad 3^{\mathrm{e}}$ Civ., 13 février 2014, QPC n 13-22.383, Bull. civ. III, nº 22.

73 Soc., 14 septembre 2012, QPC n 11-28.269, Bull. civ. V, nº 229 ; Crim., 12 avril 2012, QPC n 12-90.004, Bull. crim., n 100 ; Crim., 5 octobre 2011, QPC n 11-90.087, Bull. crim., n 196 ; Crim., 26 juin 2012, QPC n 12-80.319, Bull. crim., $\mathrm{n}^{\circ} 158$.

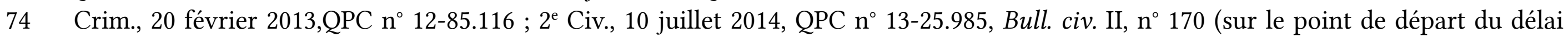
de prescription) ; $3^{\text {e }}$ Civ., 13 février 2014,QPC $n^{\circ} 13-22.383$, Bull. civ. III, $\mathrm{n}^{\circ} 22$ (sur la recevabilité de l'action d'une association syndicale de propriétaire n'ayant pas régularisé sa situation conformément à l'article 60 de l'ordonnance du $1^{\text {er }}$ juillet 2004) ; Com., 5 septembre 2013, QPC $\mathrm{n}^{\circ}$ 13-40.034, Bull. civ. IV, $\mathrm{n}^{\circ} 127$ (en matière de prescription).

75 Par exemple dans Crim., 8 janvier 2013, $\mathrm{n}^{\circ}$ 12-80.465, Bull. crim., ${ }^{\circ}$ 8au sujet d'une personne placée en chambre de dégrisement sur le fondement de l'article L. 3341-1 du code de la santé publique, au visa de l'article préliminaire du code de procédure pénale et du principe suivant lequel la procédure pénale doit être équitable et contradictoire et préserver l'équilibre des droits des parties, elle a censuré un juge de proximité qui, en méconnaissance des droits de la défense, n’avait pas fait joindre à la procédure le document médical dont elle constatait l'existence. Auparavant, le Conseil constitutionnel avait interprété l'article L. 3341-1 du code de la santé publique de sorte que la durée du placement en chambre de sûreté, qui doit être consignée dans tous les cas par les agents de la police ou de la gendarmerie nationales, doit être prise en compte dans la durée de la garde à vue (Cons. cons., n² 2012-253 QPC du 8 juin 2012).

76 Soc., 14 septembre 2012, $\mathrm{n}^{\circ} 11-21.307$, Bull. civ. V, $\mathrm{n}^{\circ} 230$ : une réserve formulée pour une certaine catégorie de salariés protégés a été étendue à une autre catégorie.

77 Par exemple : Soc., 14 septembre 2012, QPC n 11-28.269, Bull. civ. V, n 229 ; Soc., 9 mai 2014, QPC n 14-40.014, Bull. civ. V, $\mathrm{n}^{\circ} 112$; Crim., 15 juin 2011, QPC n 11-83.703, Bull. crim., n 133 ; Crim., 16 juillet 2010, QPC n 10-80.551 ; Crim., 16 avril 2013, QPC n 13-90.006, Bull. crim.,
} 
l'occasion de l'examen des QPC, un rôle de garant de la conformité de l'application et de l'interprétation de la loi conforme à la Constitution ${ }^{78}$.

Quand il s'agit de statuer sur une QPC, la Cour de cassation revêt, on le voit, les attributs d'un juge constitutionnel. Mais, elle rechigne à s'en emparer dès qu'il s'agit d'exercer son rôle de juge de cassation. Les réflexions actuelles au sein de la Cour sur l'office du juge de cassation ouvriraient-elles des perspectives d'évolution?

\section{B. Les perspectives ouvertes par les réflexions actuelles sur la réforme de la Cour de cassation}

À l'initiative du Premier Président, monsieur Bertrand Louvel, une commission de réflexion sur la réforme de la Cour et des sous-groupes se sont constitués depuis le mois de septembre 2015 pour s'interroger notamment sur l'intensité du contrôle de cassation, le filtrage des pourvois, la motivation des arrêts, la place du parquet général et des études d'impact.

La place de la Constitution reste à ce jour faible en comparaison avec celle accordée à la CEDH (1). Pourtant, les réflexions menées sont transposables à la Constitution (2) et pourraient intégrer la riche expérience de six années de traitement des QPC (3).

\section{Une place prépondérante de la CEDH}

D’emblée, le Premier Président Louvel a indiqué que « la réforme de fond à laquelle la Cour de cassation réfléchit est celle de l'intégration dans son champ de contrôle, de manière systématique, de la $\mathrm{CEDH} \gg^{79}$.

La doctrine commentant les réflexions menées par la Cour accorde d'ailleurs peu de place à la Constitution ${ }^{80}$. Certains auteurs y ont même vu une stratégie de la Cour « d'émancipation constitutionnelle par la soumission européenne $»^{81}$.

Ce peu de place laissé à la Constitution s'explique, comme cela a déjà été amplement exposé, pour des raisons de positionnement institutionnel et d'efficacité du contrôle de conventionnalité qui permet à la fois un contrôle abstrait d'un texte et un contrôle concret de son application à l'espèce. Un exemple suffit à caractériser cette efficacité. Alors qu'un moyen de cassation s'appuyait sur le code de procédure pénale, l'article 16 de la Déclaration de 1789, l'article 66 de la Constitution et

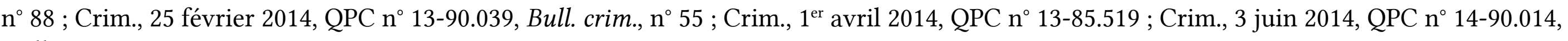
Bull. crim., $\mathrm{n}^{\circ} 144$.

78 Pour une description de ce rôle, voir N. MAZIAU, « L'appréhension de la Constitution au travers de l'analyse de l'évolution de son mode de contrôle : la révolution de la QPC cinq ans après l'entrée en vigueur de la réforme », RFD Const. 2015-2 n 102 p. 453 et s.

79 «Entretien avec Bertrand Louvel» $\mathcal{F C P} \mathrm{n}^{\circ}$ 43, 19 octobre 2015, p. 1906.

80 C. Jamin, « Motivation des arrêts : une alternative », D. 15 octobre 2015, n 35, p. 2001 ; N. Fricero, «L'avenir de la Cour de cassation : la vision originale du Club des juristes. À propos du Rapport Sécurité juridique et initiative économique. Deuxième partie « La Cour de cassation », $\mathcal{F C P ~} \mathrm{n}^{\circ} 26,29$ juin 2015, p. 753 ; Le rapport Sécurité juridique et initiative économique du club des juristes consacré à la Cour de cassation (mai 2015).

81 F. Chenede, « Contre révolution tranquille à la Cour de cassation », D. 14 avril 2016 nº 14, p. 796.
} 
l'article 8 de la CEDH à l'encontre d'une réquisition téléphonique autorisée par le seul procureur, la Cour a répondu que les mesures prévues à l'article 77-1-1 du code de procédure pénale ne sont pas contraires à l'article 8 de la $\mathrm{CEDH}$ (contrôle abstrait de conformité) et que « la chambre de l'instruction a fait une exacte application de l'article 77-1-1 du code de procédure pénale sans méconnaitre les dispositions conventionnelles invoquées $»^{82}$.

\section{La transposition à la Constitution des réflexions actuelles de la Cour de cassation}

Toutes les réflexions actuelles de la Cour fondées sur l'influence de la CEDH sont toutefois transposables à la Constitution.

Parmi elles figurent celles visant à permettre à la Cour de cassation de garantir le respect des droits et libertés fondamentaux. La question de savoir pourquoi la Cour de cassation ne pourrait-elle pas élargir le champ de son contrôle aux droits fondamentaux garantis par la $\mathrm{CEDH}^{83}$ peut s'étendre aussi aux droits fondamentaux garantis par la Constitution.

Par ailleurs, si la CEDH et la CJUE construisent, selon le premier Président de la Cour, « un espace européen des droits fondamentaux », se développe également un espace constitutionnel des droits fondamentaux.

La Constitution et la jurisprudence constitutionnelle ne peuvent donc pas être écartées des réflexions actuelles sur l'office du juge de cassation comme garant des droits fondamentaux. Le rapport Sécurité juridique et initiative économique du Club des juristes consacré à la Cour de cassation de mai 2015, avait proposé justement de mettre en place une commission ad hoc sur la transformation de l'office du juge sous l'influence de la $\mathrm{CEDH}$ et de la Constitution qui puisse envisager une meilleure articulation des contrôles de la loi au regard des droits et libertés fondamentaux (proposition 28).

Au surplus, le premier Président de la Cour craint, qu'en l'absence de réforme, ne se systématise le contrôle des décisions de la Cour de cassation par la CEDH. L'enjeu est donc de préserver « la souveraineté juridictionnelle » et le caractère subsidiaire du contrôle de la CEDH. Cette remarque peut être étendue au Conseil constitutionnel qui, à l'occasion de QPC, contrôle la conformité de l'interprétation de loi faite par les cours suprêmes à la Constitution.

Enfin, si la QPC est cantonnée au contrôle abstrait de la conformité de la loi à la Constitution, rien n'empêche alors la Cour de cassation de développer parallèlement un contrôle concret de constitutionnalité de l'interprétation ou de l'application de la loi, et de la règle de droit, de manière conforme à la Constitution, certes dans la limite que cette interprétation ne devienne pas contra legem ou aboutisse à l'écarter totalement, à défaut de pouvoir l'abroger. L'office du juge de cassation peut en effet comprendre le contrôle in concreto des décisions qui porteraient atteinte aux droits et libertés

$82 \quad$ Crim., 8 juillet 2015, $\mathrm{n}^{\circ}$ 15-81.731, Bull. crim., $\mathrm{n}^{\circ} 174$.

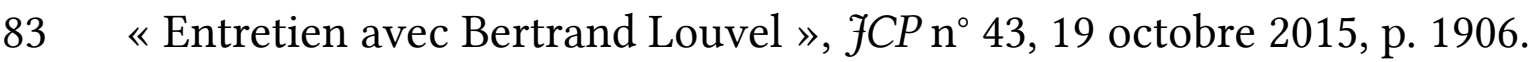


garantis par la Constitution. La Cour de cassation ne se substituerait pas au Conseil constitutionnel, mais appliquerait la Constitution dans un autre contexte, permettant ainsi à la norme suprême de se déployer complètement.

À titre d'exemple, pour un requérant, la sanction de dissolution d'une SCI pour des faits de blanchiment n'était pas nécessaire et proportionnée et portait atteinte à la liberté d'entreprendre. La Cour avait conclu que le moyen d'inconstitutionnalité invoqué n'était pas recevable, car il avait pour objet de juger la loi appliquée contraire à la Constitution. Or, était-ce vraiment la loi qui était critiquée ? N'était-ce pas plutôt l'appréciation faite par la Cour d'appel de l'application de la loi, ce qui entrerait dans le champ du contrôle exercé par la Cour de cassation ${ }^{84}$ ?

À ce jour, un seul arrêt répertorié depuis l'entrée en vigueur de la QPC a, en dehors de toute décision rendue en matière de QPC, interprété expressément la loi visée à la lumière des droits et libertés garantis par la Constitution ${ }^{85}$.

\section{L'apport de la QPC dans les réflexions actuelles de la Cour}

Finalement, les réflexions menées par la Cour doivent tirer profit de l'expérience de la QPC et du développement de la jurisprudence constitutionnelle.

Ainsi, la commission de réflexion s'interroge sur l'opportunité et les modalités d'un filtrage des pourvois. Le rapport Sécurité juridique et initiative économique du Club des juristes consacré à la Cour de cassation avait proposé parmi les critères de sélection des pourvois celui de la difficulté sérieuse ou du moyen sérieux. Or, une étude approfondie de la notion de " question sérieuse », au sens de l'ordonnance $\mathrm{n}^{\circ}$ 58-1067 du 7 novembre 1958 portant loi organique sur le Conseil constitutionnel, pourrait présenter un intérêt pour apprécier ce type de cas d'ouverture d'un pourvoi en cassation.

Parmi les objectifs de la Cour de cassation figure celui de développer le contrôle de proportionnalité ${ }^{86}$. De nombreux arrêts récents témoignent de cette volonté pour la Cour d'étendre ainsi son contrôle. À ce jour, ils reposent tous sur la $\mathrm{CEDH}^{87}$. Pourtant, la Cour exerce aussi un contrôle de proportionnalité plus ou moins intense lorsqu'elle examine le caractère sérieux d'une $\mathrm{QPC}^{88}$. Cette expérience pourrait donc être exploitée dans le cadre d'un contrôle plus systématique de constitutionnalité.

\footnotetext{
84 Crim., 16 décembre 2015, n 14-85.667, Bull. crim., $\mathrm{n}^{\circ} 312$.

85 Soc., 26 mai 2010, n 09-60.393, Bull. civ. V, n 116.

«Entretien avec Bertrand Louvel » $\mathcal{F C P} \mathrm{n}^{\circ} 43,19$ octobre 2015, p. 1906 ; D. 5 février 2015, n 5 ; voir aussi P. Deumier « Repenser la motivation des arrêts de la Cour de cassation? », D. 15 octobre 2015, n' 35, p. 2022 et s.

87 Voir par exemple Civ. $1^{\text {re }}, 4$ décembre 2013, $n^{\circ} 12-26.066$, Bull. civ. I, $\mathrm{n}^{\circ} 234$; Civ. $1^{\text {re }}, 5$ février 2014, $\mathrm{n}^{\circ} 12-20.206$; Civ. $1^{\text {re }}, 10$ juin $2015, \mathrm{n}^{\circ} 14-$ 20.790 ; Civ. $1^{\text {re }}, 30$ septembre 2015, $\mathrm{n}^{\circ}$ 14-16.273, publié ; Civ. $1^{\text {re }}, 25$ février 2016, $\mathrm{n}^{\circ} 15-12.403$ publié ; Civ. $1^{\text {re }}, 6$ juillet 2016, $\mathrm{n}^{\circ} 15-19.853$ publié ; Civ. $3^{\text {e }}, 15$ octobre 2015, n 14-23.612 publié ; $3^{\mathrm{e}}$ Civ., 22 octobre 2015, n 14-11.776 publié ; $3^{\mathrm{e}}$ Civ., 17 décembre 2015, ${ }^{\circ} 14-22.095$ publié ; Com., 15 décembre 2015, n 14-11.500 publié ; Com., 12 janvier 2016, n 14-15.203 publié ; Crim., 16 février 2016, n $15-82.732$ publié.

$881^{\text {re }}$ Civ., 21 mai 2014,QPC n ${ }^{\circ} 13-25.614$; Civ. $2^{\text {e }}, 11$ septembre 2014, $\mathrm{n}^{\circ}$ 14-60.032 ; Civ. $3^{\mathrm{e}}$, 10 juin 2014,QPC $\mathrm{n}^{\circ} 14-40.020$, Bull. civ. III, ${ }^{\circ}$ 79; Com., 2 octobre 2014, QPC nº 14-40.34 ; Com., 9 octobre 2014, n 14-40.036 ; Soc., 18 décembre 2014, n 14-40.043, Bull. civ. V, $\mathrm{n}^{\circ} 311$; Crim., 6 mai $2014, \mathrm{n}^{\circ} 14-90.010$.
} 
En outre, pour le Premier président, « la Cour doit conceptualiser à son niveau la défense des droits fondamentaux et ne plus s'y livrer de manière épisodique, fortuit, ponctuel ${ }^{89}$. Or, elle dispose déjà d'une certaine méthodologie lorsqu'elle apprécie le caractère sérieux d'une QPC. Suivant le raisonnement du Conseil constitutionnel, elle examine, au moins dans ses travaux préparatoires, si la disposition litigieuse porte atteinte à un droit fondamental, si cette atteinte poursuit un but légitime et est proportionnée. Il reste que la méthodologie devra être affinée, encadrée et adaptée à la technique de cassation pour éviter, d'une part, le risque d'arbitraire d'un contrôle de proportionnalité non maîtrisé et, d'autre part, pour distinguer le contrôle in abstracto du contrôle in concreto de constitutionnalité. Enfin, les contours de la notion de «moyen de droit » devront également être précisés au regard des droits fondamentaux ainsi que du développement des contrôles de conventionnalité et de constitutionnalité.

Le Premier président considère que le « contrôle complet a vocation à être fait » au niveau de la Cour de cassation. Pourrait ainsi être confié à la Cour le soin d'exercer un contrôle plus complet, de rendre plus effectifs les droits fondamentaux garantis par la Constitution.

Les réflexions actuelles de la Cour portent également sur la motivation de ses arrêts qui doivent être compris par les justiciables, mais aussi par la CEDH, le Conseil constitutionnel ou les juridictions étrangères ${ }^{90}$. Certains arrêts récents sont rédigés de manière à rendre plus lisible la jurisprudence et citent désormais les références de la jurisprudence ${ }^{91}$. Rappelons que la multiplication des QPC portant sur la « jurisprudence constante de la Cour » avait consacré son rôle normatif et d'interprétation de la loi et l'ont ainsi conduite à s'interroger sur l'identification de sa jurisprudence.

La QPC et les droits fondamentaux garantis par la Constitution ont donc toute leur place dans l'évolution de l'office de la Cour de cassation. Si de nombreux arguments militent vers un développement du contrôle de constitutionnalité, les limites sont connues et ont déjà été présentées. Elles trouvent une illustration dans des arrêts récents de la Cour de cassation renforçant son contrôle de proportionnalité. Si l'on s'en tient au dernier arrêt de la première chambre civile du 9 novembre 2016 le raisonnement de la Cour a suivi deux étapes ${ }^{92}$. Tout d'abord, elle s'est prononcée sur la conventionnalité in abstracto des dispositions législatives appliquées en considérant que « ces dispositions, qui ménagent un juste équilibre entre le droit à la connaissance et à l'établissement de son ascendance, d'une part, les droits des tiers et la sécurité juridique, d'autre part, ne méconnaissent pas les exigences résultant de l'article 8 de la CESDH ». Dans un second temps, elle vérifie que l'application de la loi par le juge ne porte pas concrètement une atteinte disproportionnée au droit fondamental invoqué au regard du but légitime poursuivi par le législateur. Or, la première étape du raisonnement pourraitelle être transposable à un contrôle de constitutionnalité sans empiéter sur les compétences du Conseil constitutionnel?

\footnotetext{
89 «Discours prononcé en ouverture des travaux le 14 septembre 2015 », site internet de la Cour.

P. Deumier, « Repenser la motivation des arrêts de la Cour de cassation ? », D. 15 octobre 2015 n 35, p. 2022 et s.

Crim., 30 mars 2016, QPC n 16-90.001, Bull. crim., nº 113 ; Avis, 4 janvier 2016, n 15-70.004 publié ; Avis, 29 février 2016, n 15-70.005, Bull. civ., Avis, $\mathrm{n}^{\circ} 1$; $1^{\text {re }}$ Civ., 6 avril 2016, $\mathrm{n}^{\circ}$ 15-10.552 publié ; Com., 22 mars 2016, $\mathrm{n}^{\circ} 14-14.218$, publié.

$92 \quad 1^{\text {re }}$ Civ., 9 novembre 2016, $\mathrm{n}^{\circ} 15-25.068$ publié ; voir aussi Civ. $1^{\text {re }}, 5$ octobre 2016, $\mathrm{n}^{\circ} 15-25.507$ publié.
} 


\section{Conclusion}

Des perspectives d'évolution en faveur de l'exercice plus régulier par la Cour de cassation d'un contrôle de constitutionnalité des actes juridictionnels se font jour sous l'effet conjugué du développement d'une plus grande culture constitutionnelle via la QPC et d'une volonté affichée de réforme au sein même de la Cour. Cependant, renforcer le contrôle concret des droits et libertés garantis par la Constitution présenterait le risque de porter atteinte au nouvel équilibre institutionnel encore fragile ${ }^{93}$ qui s'est installé depuis la réforme de la QPC. Il ne faudrait pas que la Cour de cassation en se saisissant plus régulièrement de la constitutionnalité à l'occasion de son contrôle de cassation tende à déborder et marginaliser la QPC et son juge et aboutisse à multiplier les interprétations judiciaires autonomes de la Constitution. Plus que jamais, le dialogue entre les juges doit être préservé.

93 «Entretien avec Bertrand Louvel », $\mathcal{F C P} \mathrm{n}^{\circ}$ 43, 19 octobre 2015, p. 1906 ; B. LouveL, « L’autorité judiciaire, gardienne de la liberté individuelle ou des libertés individuelles ? Réflexion à l'occasion de la rencontre annuelle des premiers présidents de cour d'appel et de la cour de cassation » site internet de la Cour de cassation ; J-M SAUvé, « Quel juge pour les libertés ? » D. 23 juin 2016 , n 23 p. 1320 ; J-M SAUvÉ, «Le Conseil d'État et la protection des droits fondamentaux » intervention à l'Université de Nagoya, 27 octobre 2016, site internet du Conseil d'État ; J-M SAUvÉ, « Le dualisme juridictionnel : synergies et complémentarités », Intervention lors du Cycle approfondi d'études judiciaires (CADEJ) 2016/2017, «L'autorité judiciaire dans l'État», 28 septembre 2016, site internet du Conseil d'État ; P. SARGOS «Il n'y a pour toute la République qu'une seule justice », $\mathcal{F} C P \mathrm{n}^{\circ} 24$ du 13 juin 2010, p. 1193 ; P. WACHSMANN, « De la marginalisation du juge judiciaire en matière de libertés et des moyens d'y remédier », D. 3 mars 2016, n 9 p. 473. 



\section{DÉBATS}

\section{sous la présidence de Monsieur Guy CANIVET}

Guy Canivet remercie les différents intervenants. Il souligne que le professeur Jean-Louis Mestre a parfaitement répondu à la problématique du colloque, à savoir donner un sens « traditionnel » au contrôle de constitutionnalité des lois. Les intervenants suivants ont expliqué comment le Conseil d'État et la Cour de cassation, tout en refusant d'exercer un contrôle de constitutionnalité formel sur la loi, ont néanmoins intégré la Constitution dans leurs fonctions juridictionnelles respectives. Didier Ribes et Laurent Domingo ont notamment posé la question de rôle du Conseil d'État dans l'application de la Constitution sous un angle pratique, en distinguant le recours pour excès de pouvoir et le recours en cassation. Cette dualité ne concerne pas évidemment les juridictions judiciaires où il n'existe qu'un contrôle de la cassation.

Guy Canivet observe par ailleurs, suite à l'exposé du professeur Olivier Desaulnay, que l'espace d'une application résiduelle de la Constitution par les juridictions judiciaires est étroit puisque l'instauration de la question prioritaire de constitutionnalité a fermé toute possibilité de retour sur la jurisprudence refusant aux juridictions judiciaires un contrôle direct de la conformité de la loi à la Constitution. La question est, comme cela a été dit, celle de la subsistance d'un contrôle masqué, soit par le recours aux principes généraux du droit, soit par l'invocation du droit international et notamment de la Convention européenne des droits de l'homme. Sur ce dernier point, la procédure établie par la loi organique a entendu répondre par la « priorité » de la question de constitutionalité. Nous avons tous assisté à la discussion sur la compatibilité de cette notion de " priorité » avec l'ordre juridique de l'Union européenne. La question d'un contrôle résiduel de constitutionnalité des décisions des juridictions judiciaires reste posée. Elle a été abordée de manière nuancée par les intervenants précédents.

À la suite de l'intervention de $\mathrm{M}^{\text {me }}$ Valentine Buck, Monsieur Canivet conclut que le contrôle par la Cour de cassation de la conformité à la Constitution des décisions des juridictions du fond s'opère en référence à la jurisprudence du Conseil constitutionnel lorsqu'une QPC est soulevée devant elle. En appréciant le sérieux de la question, elle met en œuvre les interprétations de la Constitution données par le Conseil constitutionnel. 
Loic Philip pose une question sur les rapports entre la Cour de cassation et le Conseil d'État dans le cadre d'une QPC. Dans le cas où une QPC sur une disposition législative est déposée devant la Cour de cassation par un avocat, est-il possible qu'un autre avocat puisse déposer une QPC sur la même disposition législative avec la même argumentation devant le Conseil d'État?

Répondant par l'affirmative, Didier Ribes prend l'exemple d'une décision rendue au printemps 2016 par laquelle le Conseil d'État a décidé de renvoyer au Conseil constitutionnel une QPC qui portait sur l'auto-saisine du président du tribunal de commerce en cas de non dépôt par une société de ses comptes annuels (CE, 6 avril 2016, Société Famille Michaud apiculteurs et autre, n 396364 , inédit). La même société avait présenté une QPC avec une argumentation légèrement différente devant la Cour de cassation qui avait refusé de transmettre cette QPC. L'argumentation n'était pas parfaitement identique et la société requérante avait tiré les conséquences de la réponse donnée par la Cour de cassation en affinant son argumentation. S'il s'agissait en l'espèce d'un point très spécifique, une telle hypothèse se multiplie, notamment par l'usage, pour ne pas dire l'instrumentalisation, des recours contre des refus d'abrogation de dispositions réglementaires à l'occasion desquels sont présentées, comme dans cette affaire, des QPC. Un litige assez largement artificiel peut ainsi être créé devant le juge administratif par des requérants, personnes physiques comme personnes morales. Didier Ribes souligne que l'idée que la QPC serait aujourd'hui essentiellement utilisée par des personnes morales et, notamment, par des sociétés commerciales, nécessiterait une analyse statistique puisqu'au quotidien, n'est pas perçue une tendance très forte en ce sens-là. Toutefois, un certain nombre de personnes physiques comme certaines personnes morales ont l'idée de créer des contentieux artificiels devant le Conseil d'État pour avoir une sorte de deuxième tour, une deuxième chance de parvenir au Conseil constitutionnel après un refus de transmission de la Cour de cassation. Par conséquent, le Conseil d'État se doit d'être particulièrement attentif aux décisions de la Cour de cassation dans ce cas de figure. Même si chaque juridiction porte sa propre appréciation, le « dialogue » se poursuit, au moins formellement. Concernant la QPC mentionnée ci-dessus, le Conseil d'État avait notamment un doute plus important sur la constitutionnalité de la disposition. Plus précisément, le Conseil d'État a considéré qu'au regard de la jurisprudence du Conseil constitutionnel, il lui fallait transmettre la QPC pour permettre à ce dernier, le cas échéant, de préciser sa jurisprudence sur l'auto-saisine du juge ou d'en délimiter les contours. En effet, des dispositions similaires du Code de commerce, mais de portée différente, avaient déjà été déclarées contraires à la Constitution. La transmission de la QPC pouvait permettre au Conseil constitutionnel de moduler sa jurisprudence selon les configurations procédurales [ndlr : ce qu'il a fait dans sa décision n 2016-548 QPC du $1^{\text {er }}$ juillet 2016 ; le Conseil d'État s'est prononcé sur la conventionnalité des dispositions législatives critiquées dans une décision du 22 février 2017, $\mathrm{n}^{\circ}$ 396364]. Cette hypothèse a donc lieu et ne présente pas en soi un caractère problématique. 
Guy Canivet ajoute qu'il s'agit d'une hypothèse habituelle qui a très vite trouvé sa portée : le refus de renvoyer une question de constitutionnalité par la Cour de cassation peut être contourné par la saisine du Conseil d'État de la même question. Le mécanisme inverse se vérifie tout autant. Cela relativise les divergences entre la Cour de cassation et le Conseil d'État, puisqu'en fin de compte le Conseil constitutionnel finit par être saisi de la question. On compte au moins une vingtaine de décisions rendues dans ce cas de figure.

Bertrand Mathieu souhaite faire quelques remarques générales, notamment à propos des réflexions qui sont menées à la Cour de cassation sur la mission de cette Cour. Le Professeur Mathieu estime que nous avons un réflexe sur lequel il faudrait réfléchir. Il consiste à assimiler le contrôle de constitutionnalité et le contrôle du respect des droits et libertés fondamentaux. Certes, dans le cadre de la QPC il s'agit exclusivement des droits et libertés fondamentaux. Toutefois, le problème, c'est que la mission d'un juge n'est pas exclusivement de veiller au respect des droits et libertés fondamentaux. Elle est de veiller au respect de la Constitution dans son ensemble et notamment à la compétence des organes constitutionnels. Il en est ainsi de celle du législateur qui a pour mission de définir de manière générale ce qui constitue l'intérêt général. Bertrand Mathieu pense que le fait de considérer que le juge est chargé de défendre les droits du citoyen contre le législateur, est une dérive qui peut être dangereuse. Il ne faut pas considérer la Constitution comme étant simplement un énoncé de droits et libertés fondamentaux.

Valentine Buck précise que, dans son intervention, elle se pose la question de l'influence de la QPC et donc ne se focalise que sur les droits et libertés garantis par la Constitution. Quant au respect des compétences entre les pouvoirs publics, c'est une autre question qui n'est pas spécialement abordée et qui ne rentre absolument pas dans les débats actuels au sein de la Cour de cassation.

Olivier Desaulnay adhère à la logique de ses interlocuteurs. Même si la Cour de cassation dans son « contentieux constitutionnel » emploie l'expression ordinaire des droits et libertés fondamentaux, une bonne partie de son contentieux est finalement un contentieux hors droits et libertés. Il s'agit de savoir, par exemple, si le juge judiciaire est compétent en matière électorale, s'il applique l'article 62 de la Constitution, s'il est compétent aux côtés de la Cour de justice de la République, si le juge pénal peut connaître des agissements d'un ministre ou d'un député etc. Ainsi, pratiquement la moitié des affaires qui intéressent la constitutionnalité devant la Cour de cassation sont principalement des questions de compétence. Par ailleurs, il y a également tous les aspects relatifs à la matière pénale, surtout en matière criminelle, l'articulation des articles 34 et 37 de la Constitution. Ces aspects ne sont pas toujours directement liés aux droits et libertés fondamentaux. Par conséquent, il ne faut pas non plus penser que la « jurisprudence constitutionnelle » de la Cour de cassation ne relève que de la matière des droits fondamentaux. 



\title{
Chapitre 2
}

\author{
UN CONTRÔLE NATUREL \\ DANS LES SYSTÈMES DIFFUS
}





\title{
L'UNITÉ JURIDICTIONNELLE ET SES CONSÉQUENCES SUR LES MODALITÉS Du Contrôle de constitutionnalité au Québec et au Canada
}

\author{
Patrick TAILlON \\ Amélie BinetTE ${ }^{1}$
}

Elles sont nombreuses les différences entre le droit public québécois et canadien, d'un côté, et les institutions de la Ve République de l'autre. Figurent parmi les facteurs à l'origine de plusieurs des contrastes entre les deux systèmes, la forme fédérale et monarchique de l'État au Canada, par opposition à la forme républicaine et centralisée en France, mais aussi les modalités du contrôle de constitutionnalité et, plus généralement, l'organisation des organes juridictionnels responsables d'interpréter et d'appliquer le droit. En fait, le fédéralisme canadien s'accompagne d'une fragmentation du pouvoir politique et d'un éparpillement des compétences législatives ${ }^{2}$. Alors que la France dispose d'un seul Parlement, dépositaire d'une pleine souveraineté, il existe au Canada onze parlements spécialisés dans des domaines constitutionnellement protégés ${ }^{3}$.

Cette fragmentation n'a toutefois pas son équivalent dans le domaine judiciaire. Fidèle au modèle britannique d'unité juridictionnelle, la Cour suprême du Canada (et, en première et en deuxième instances, les tribunaux de droit commun que sont les cours supérieures et les cours d'appel) concentre de vastes compétences dans ce que plusieurs appellent un «système intégré » ${ }^{4}$. Elle dispose d'un pouvoir de surveillance et de contrôle sur l'ensemble des juridictions. Qu'il s'agisse d'interpréter le droit fédéral ou le droit provincial, le droit privé, le droit administratif ou le droit constitutionnel, la Cour suprême du Canada cumule, conformément à une conception intégrée et unifiée du pouvoir judiciaire, l'ensemble des compétences interprétatives.

On a donc parfois l'impression d'être en présence d'un reflet inversé : là où le pouvoir législatif se fragmente au Canada en fonction d'un partage des compétences, souvent complexe, entre le fédéral et les dix provinces, les institutions de la $\mathrm{V}^{\mathrm{e}}$ République offrent le portrait unitaire et cohérent d'un

\footnotetext{
1 Les auteurs sont respectivement professeur et candidate au doctorat à la Faculté de droit de l'Université Laval et membres du Centre de recherche interdisciplinaire sur la diversité et la démocratie (CRIDAQ). Ils tiennent à remercier Marthe Fatin-Rouge Stefanini, Caterina Severino et toute l'équipe de l'Institut Louis Favoreu pour leur invitation à participer à cette réflexion.

2 Loi constitutionnelle de 1867, 30 \& 31 Vict., c. 3 (R.-U.), art. 91-92. Henri Brun, Guy Tremblay et Eugénie Brouillet, Droit constitutionnel, 6 éd., Cowansville, Éditions Yvon Blais, 2014, p. 405-618.

3 En vérité, au Parlement fédéral et aux dix parlements des provinces s'ajoutent potentiellement ceux des territoires, dont l'autonomie n'est toutefois pas, dans leur cas, garantie par la Constitution supralégislative.

$4 \quad$ H. Brun, G. Tremblay et E. Brouillet, préc., note 2, p. 830, par. X.67.
} 
Parlement centralisé disposant, en quelque sorte, du monopole de la volonté générale. De même, pendant que l'organisation du pouvoir juridictionnel en France s'articule autour d'un agencement complexe de juridictions spécialisées (Conseil d'État, Conseil constitutionnel, Cour de cassation), chacune étant suprême dans son domaine de compétences, le pouvoir judiciaire au Québec et au Canada se concentre plutôt autour d'un seul tribunal de dernière instance. Bref, le Canada connaît l'unité juridictionnelle, mais sans unité sur le plan des organes politiques alors que la France mise sur une forte unité politique (un seul législateur et un exécutif fort et centralisé), mais sans unité juridictionnelle.

Au Québec et au Canada, les cours supérieures ${ }^{5}$ (Cour supérieure, Cour d'appel et Cour suprême) peuvent évidemment contrôler les décisions prises par l'ensemble des autres instances juridictionnelles. Il s'agit d'un contrôle concret exercé par n'importe quel justiciable disposant d'un intérêt à agir. Ce contrôle est d'autant plus «naturel» qu'il est, en quelque sorte, un pouvoir inhérent à tous les tribunaux de droit commun lesquels, par conséquent, peuvent procéder à la révision judiciaire de l'ensemble des décisions qui leur sont soumises.

Le contraste avec la France est, encore une fois, saisissant. Certes, à la lecture de certaines décisions ${ }^{6}$, on peut timidement entrevoir le début d'un contrôle par un Conseil constitutionnel qui, subtilement, examine la manière dont est interprétée la Constitution par les tribunaux judiciaires ou par les juridictions administratives. Il n'en demeure pas moins que l'étendue de ce contrôle reste sans commune mesure à ce que l'on peut observer au Québec et au Canada.

Évidemment, comparaison n'est pas raison et nous n'oserions en aucun temps trancher entre ces deux types d'organisation du contrôle de constitutionnalité qui comportent, à leur façon, des avantages et des inconvénients. Cela dit, il est important de bien prendre la mesure des contrastes qui existent entre ces deux systèmes. Pour ce faire, nous procéderons en deux temps en examinant d'abord la manière dont le modèle britannique d'unité juridictionnelle, combiné à un contrôle concret et diffus ${ }^{7}$, a favorisé un rôle accru et pratiquement sans limites pour la Cour suprême du Canada dans le contrôle de constitutionnalité des décisions de justice (I) pour, ensuite, analyser, à l'aide de quelques illustrations, toute l'étendue ou l'ampleur de la marge de manœuvre dont disposent les tribunaux à l'occasion de ce type de contrôle (II).

5 Au Canada, chaque province dispose d'une cour supérieure, tribunal de droit commun doté d'un pouvoir de surveillance et de contrôle sur l'ensemble des tribunaux spécialisés (cours inférieures, tribunaux administratifs, etc.).

Décision n 2010-39 QPC du 6 octobre 2010; Décision n² 2010-52 QPC du 14 octobre 2010.

Patrick TAILlon et François HénAult, «Des faits décisifs! Le caractère concret du contrôle de constitutionnalité au Québec et au Canada», dans l'Annuaire international de justice constitutionnelle (AIfC), vol. 29, Paris/Aix-en-Provence, Economica/Presses universitaires d'Aix-Marseille, 2014, p. 25. 


\section{L'unité juridictionnelle, ses sources et ses effets}

La Cour suprême du Canada est en mesure de contrôler la constitutionnalité de toute décision de justice dont elle est saisie. S'il en est ainsi, c'est en grande partie en raison du principe d'unité juridictionnelle, hérité de la tradition britannique (A) et dont les avantages (B) et les inconvénients (C) influencent le fonctionnement du pouvoir judiciaire au Québec et au Canada.

\section{A. Les origines de l'unité juridictionnelle}

Malgré l'existence d'une union fédérale, le Canada, contrairement aux États-Unis, n'a jamais pratiqué le fédéralisme judiciaire ${ }^{8}$. À une exception près", le Québec et le Canada disposent d'un système intégré de cours supérieures qui ne sont ni entièrement fédérales ni entièrement provinciales $^{10}$. En effet, en vertu du partage des compétences législatives prévues à la Loi constitutionnelle de 1867, l'administration de la justice relève des provinces ${ }^{11}$, mais la nomination et la rémunération des juges des cours supérieures dépendent des autorités fédérales ${ }^{12}$. Cette emprise limitée du fédéral et des provinces sur certains aspects précis et circonscrits du fonctionnement des cours supérieures permet, en quelque sorte, d'accroître leur indépendance à l'endroit des organes politiques.

Dotées d'une compétence de droit commun, les cours provinciales «franchissent, pour ainsi dire, la ligne de partage des compétences fédérale et provinciale $»^{13}$, comme le veut la formule du juge Estey. Il en résulte un système intégré comme le définissait déjà, en 1879, le juge en chef Ritchie :

[Traduction] Ces tribunaux [les cours supérieures] sont certainement tenus d'appliquer toutes les lois en vigueur au Canada, qu'elles soient édictées par le Parlement du Canada ou par les législatures locales. Ce ne sont pas de simples tribunaux locaux chargés de l'application des lois locales adoptées par les législatures locales des provinces où ils ont été constitués. Ce sont les

\footnotetext{
8 «While the Canadian founders adopted the logic of federalism for the distribution of legislative authority, they did not apply it to the judiciary. They created a single judicial system to interpret and to apply both federal and provincial laws. » Frederick L. MorTon, Law, Politics

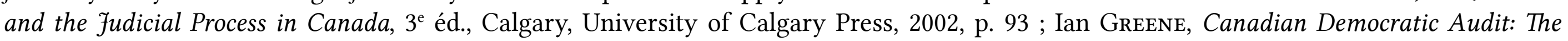
Courts, Vancouver, UBC Press, 2014, p. 8 ; Gil Rémillard, Le fédéralisme canadien, vol. 1, Montréal, Québec/Amérique, 1983, p. 168; JacquesYvan Morin et José Woehrling, Les constitutions du Canada et du Québec : du régime français à nos jours, t. 1, Montréal, Éditions Thémis, 1992, p. 337; Patrick TAILlon et Amélie BinetTe, «Le fédéralisme canadien : sources, pratiques et dysfonctionnement », dans Le fédéralisme : du droit public au droit privé, Lausanne, Association Henri-Capitant et Institut suisse de droit comparé [à paraître en 2017 ], p. 41 de 42.

9 L'article 101 de la Loi constitutionnelle de 1867, préc., note 2, prévoit la possibilité pour le Parlement fédéral d' «établir des tribunaux additionnels pour la meilleure administration des lois du Canada ». C'est en vertu de cette disposition qu'ont été créées, en 1875, la Cour de l'Échiquier (Supreme and Exchequer Court Act, S.C. 1875, c. 11), devenue la Cour fédérale en 1970, puis la Cour fédérale d'appel en 2003. Dans Québec North Shore Paper Company c. Canadian Pacifique Limited ([1977] 2 R.C.S. 1054), la Cour suprême a précisé qu'il ne s'agissait pas d'établir des cours dans les matières de compétences fédérales, mais plutôt pour l'administration de lois fédérales spécifiquement mentionnées, puis de la règlementation et de la common law associées (ITO-International Terminal Operators Ltd. c. Miida Electronics Inc., [1986] 1 R.C.S. 752, 776-777). Jusqu'à présent, leurs compétences s'étendent notamment au droit de la propriété intellectuelle et industrielle, de l'amirauté, de la fiscalité fédérale et du régime de responsabilité civile applicable à la Couronne. En plus, la Cour fédérale dispose du pouvoir de contrôler la légalité de l'action gouvernementale fédérale, compétence dont la constitutionnalité est parfois mise en doute (H. BRUN, G. TREMBLAY et E. Brouillet, préc., note 2, par. X.71). Dérogation au système judiciaire «intégré», certes, ces deux institutions demeurent toutefois sous le contrôle ultime de la Cour suprême du Canada, laquelle entend les appels de la Cour d'appel fédérale (art. 35.1, 37.1, 38 et 40 de la Loi sur la Cour suprême, L.R.C. 1985, c. S-26). Pour un historique détaillé de l'institution, voir : Frank IAcobucci, «Federal Court of Canada: Some Comments on Its Origin, Traditions and Evolution », (1989) 11 The. Advoc. Q. 318.

10 La première reconnaissance jurisprudentielle du principe de l'unité juridictionnelle se trouve dans l'arrêt Valin c. Langlois, [1879] 3 R.C.S. 1, 19 et 20, motifs juge en chef Ritchie. Voir aussi R. c. Thomas Fuller Construction Co. (1958) Ltd. et autres, [1980] 1 R.C.S. 695, 707; Proc. Gén. Can. c. Law Society of B.C., [1982] 2 R.C.S. 307, 327.

11 Loi constitutionnelle de 1867, préc., note 2, par. 92 (14).

$12 I d$., art. 96 et 100.

13 Proc. Gén.Can. c. Law Society of B.C., préc., note 10, 327.
} 
tribunaux qui existaient dans les provinces respectives avant la Confédération [...] Ce sont les tribunaux de la Reine, tenus de prendre connaissance de toutes les lois et de les appliquer, soit qu'elles aient été adoptées par le Parlement du Canada ou par les législatures locales ${ }^{14}$.

Même s'il est une entorse au principe du fédéralisme, ce choix de l'unité juridictionnelle demeure en définitive la conséquence logique d'un attachement «loyaliste» aux traditions et aux institutions britanniques ${ }^{15}$. Cela peut sembler étrange aux yeux de certains de nos contemporains, mais le Canada est en grande partie le résultat d'une expérience coloniale qui - à l'exception de la Conquête de la Nouvelle-France par les Britanniques en 1760 - s'est le plus souvent inscrite sous le signe de la continuité, de la fidélité et de la loyauté à l'endroit du colonisateur.

Au Québec, la double influence coloniale - française et anglaise - se traduit notamment dans la mixité de son système juridique de tradition civiliste pour tout ce qui concerne le droit privé et de common law pour le droit public ${ }^{16}$. Dans le reste du Canada, majoritairement anglophone, la perception de cet héritage se distingue par la manière dont les Canadiens anglais se sont longtemps considérés à la fois comme étant des colonisateurs, tout en étant colonisés ${ }^{17}$. Bien évidemment, cette fidélité à l'héritage britannique trouve de nombreux échos dans le fonctionnement des institutions politiques et judiciaires ${ }^{18}$.

14 Valin c. Langlois, préc., note 10. C'est en vertu de ce même raisonnement que les tribunaux administratifs, constitués par une loi provinciale, peuvent appliquer le droit fédéral : Paul c. Colombie-Britannique (Forest Appeals Commission), 2003 CSC 55, [2003] 2 R.C.S. 585, par. 21; Desputeaux c. Éditions Chouette (1987) inc., 2003 CSC 17, [2003] 1 R.C.S. 178, 208-209.

15 La défaite des loyalistes, au lendemain de la Guerre d'indépendance des États-Unis, encouragea près de 40000 d'entre eux à s'établir dans les colonies britanniques de l'Amérique du Nord, toujours fidèles à l'Empire, bouleversant ainsi l'équilibre démographique, dont celui de la Province of Québec. Pour apaiser les tensions qui en résultèrent avec la population canadienne-française, une colonie distincte, le HautCanada, fut créée par l'Acte constitutionnel de 1791, L.R.C. 1985, app. II, nº 3. Or, l'influence loyaliste persista à travers le temps quant à la conservation des valeurs impériales au Canada et à un ferme attachement aux institutions britanniques. Voir : David V. J. BELL, « The Loyalist Tradition in Canada », (1970) 5 Journal of Canadian Studies 22; Rod PreECE, « The Anglo-Saxon Conservative Tradition », (1980) 13(1) Canadian Journal of Political Science 3. La composition du Sénat canadien fixée en 1867 est un exemple significatif, où les «Pères» de la Confédération ont «copié » le mauvais modèle, soit celui de la Chambre des Lords britannique propre au fonctionnement d'un État unitaire, attaché à ses traditions aristocratiques et fortement centralisé. Ainsi, le Sénat canadien ne constitue pas une véritable chambre fédérale, dont le premier rôle serait de représenter les entités fédérées, et ses membres demeurent formellement nommés par le gouverneur général sur proposition du premier ministre fédéral. Réjean PeLletier, «Le principe fédératif et les institutions fédérales : le Sénat canadien correspond-il au "modèle" d'une Chambre haute dans une fédération?», (2010) 3 R.Q.D.C. 5. Voir, plus généralement : David E. SMITH, «Empire, Crown and Canadian Federalism », (1991) 24 (3) Canadian fournal of Political Science 451 et Marc CHEvRIER, «La genèse de l'idée fédérale chez les pères fondateurs américains et canadiens » dans Alain-G. GAGNON (dir.), Le fédéralisme canadien contemporain. Fondements, traditions, institutions, Montréal, Presses de l'Université de Montréal, 2006, p. 18.

16 «Introduction», dans Mariève LACroIx et Benoit Moore (dir.), Le droit québécois, coll. «Bibliothèque de l'Association Henri Capitant », Paris, LGDJ/Lextenso, 2016. Cela dit, contrairement à ce qui est généralement admis en France, le droit criminel et pénal est considéré au Québec comme étant une branche du droit public.

17 Cette distinction se note dans la manière de nommer les deux peuples coexistant sur le territoire, à l'exception des Autochtones. L'expression «Canadiens» ou, plus familièrement, «Canayens» devint un ethnonyme réservé, au lendemain de la prise de Québec en 1759, aux habitants franco-catholiques, descendants des colons venus s'établir en Nouvelle-France. Par opposition, les anglo-protestants, attachés à la Couronne et à l'Empire britanniques, conservèrent l'appellation d' «Anglais». Alexis de Tocqueville en fait d'ailleurs mention dans Regards sur le Bas-Canada: «Les Anglais et les Français se fondent si peu que les seconds gardent exclusivement le nom de Canadiens, les autres continuant à s'appeler Anglais.» (Montréal, Typo, 2003, p. 163) À partir de l'union du Bas et du Haut-Canada en 1840 en une seule colonie, le Canada-Uni, le terme «Canadiens» fut remplacé par «Canadiens français», pour bien marquer l'attachement à la langue et à la religion, alors que, beaucoup plus lentement toutefois, l'expression «Canadiens anglais» prit progressivement son sens actuel. Voir : Jean TournoN, « The Uneasy Relationship of Ethnicity and Nationalism: The French-Speaking Populations of NorthAmerica », (2006) 12 (2) Nationalism and EhtnicPolitics 239, note 2 ; Chantal Bouchard, «De la "langue du grand siècle" à la "langue humiliée" : les Canadiens français et la langue populaire (1879-1970)», (1988) 29 (1) Recherches sociographiques 7; Ralph SARKonAK, «Accentuating the Differences », (1983) 65 Yale French Studies 3 et supra note 15.

18 Par exemple, Peter Russel écrit : «On the whole, Canadians, professionals and non-professionals alike, have been inclined to regard their courts as one of the unqualified benefits of Canada's British heritage-to be praised rather than examined. » Peter H. RussEL, « The jurisdiction of the Supreme Court of Canada: Present policies and a programme for reform », (1968) 6 Osgoode Hall L. f. 1, 2. 
C'est le cas de l'unité juridictionnelle, bien établie en droit anglais ${ }^{19}$. Conséquence logique du système britannique de rule of law, qui suppose l'application d'un même droit pour tous ${ }^{20}$, l'unité juridictionnelle découle aussi de la logique monarchique de concentration du pouvoir. Fontaine de justice $^{21}$, le Roi délègue à des cours royales ses pouvoirs de surveillance et de contrôle que ces dernières exercent, en son nom, sur l'ensemble des juridictions.

Pour des raisons qui tiennent à leur structure constitutionnelle respective, l'exercice du pouvoir de surveillance et de contrôle a cependant une portée plus restreinte au Royaume-Uni qu'au Canada. Encadrés par le principe de suprématie législative (ou de souveraineté du Parlement), les tribunaux britanniques ont traditionnellement limité leur pouvoir de révision judiciaire (judicial review) à un contrôle de légalité, soit à un contrôle de la conformité aux lois qui s'applique tant aux décisions des tribunaux inférieurs qu'aux actes de l'Administration. Sans normes supralégislatives, du moins à l'exception des engagements européens et du Human Rights Act $1998^{22}$, le contrôle ne peut aller jusqu'à s'étendre à une remise en question des lois adoptées par la «Reine en son Parlement».

Or, même si le système canadien a tenté initialement d'épouser le principe de souveraineté du Parlement ${ }^{23}$, la primauté des lois britanniques sur celles de la colonie ou du dominion ${ }^{24}$ a irrésistiblement favorisé le développement du contrôle de constitutionnalité. Comme aux États-Unis, la colonisation britannique, bien qu'elle s'accompagnait d'une part d'autonomie politique bien réelle, a toujours impliqué une hiérarchisation des normes ayant pour effet de placer l'action des institutions politiques et judiciaires canadiennes sous la tutelle d'un droit britannique doté d'un rang supérieur. Si les États américains ont rompu avec cette tutelle à l'occasion de la Déclaration d'indépendance, le Canada est, encore aujourd'hui, constitué pour l'essentiel par une série de lois du Parlement de Westminster dotées, en droit interne, d'un caractère hiérarchiquement supérieur ${ }^{25}$.

C'est donc au nom de la primauté des lois britanniques que s'est développé un contrôle de constitutionnalité des lois, des actes de l'Administration et de l'ensemble des décisions de justice au Canada. Ce contrôle s'est mis en place à partir des tribunaux existants, calqués sur le modèle britannique d'unité juridictionnelle, et, pendant longtemps, avec pour tribunal de dernière instance,

\footnotetext{
19 Sabino CAssese, La construction du droit administratif. France et Royaume-Uni, coll. «clefs politiques », Paris, Montchrestien, 2000.

20 Et ce, même à la Couronne, sous réserve des droits, privilèges et immunités de cette dernière.

J.-Y. Morin et J. WoEHrLing, préc., note 8, p. 390.

22 En 1998, le Parlement de Londres adopta la Human Rights Act 1998 (1998 c. 42), laquelle est entrée en vigueur en 2000 et incorpore en droit britannique plusieurs aspects de la Convention de sauvegarde des droits de l'homme et des libertés fondamentales, 4 novembre 1950 , S.T.E $\mathrm{n}^{\circ} 5$ (entrée en vigueur le 3 septembre 1953). Dès lors, il existe une forme atténuée de contrôle de la conformité de la loi à la Convention par le biais de la Human Rights Act qui permet aux juges de prononcer une déclaration d'incompatibilité des lois anglaises (art. 4) qui demeure toutefois non contraignante (art. 6). Stephen Gardbaum, «Le nouveau modèle de constitutionnalisme du Commonwealth : théorie et pratique», 13 fus Politicum; JeanFrançois FlAuss, «HumanRightsAct. 1998 : kaléidoscope», (2001) 48 (4) Revue française de droit constitutionnel 695.

23 Ce principe fut admis dès 1854 par la jurisprudence dans l'arrêt Ex parte Gould, (1854) 2 R.J.R.Q. 376 (C.S.), puis suivi, entre autres, dans Hodge c. La Reine, (1883-84) 9 A.C. 117; A.-G. Canada c. Cain, [1906] A.C. 542, 547 et Croft c. Dunphy, [1933] A.C. 156, 163-164. Voir aussi : Albert Venn Dicey, An Introduction to the Study of the Law and the Constitution, 10e éd., Londres, Macmillan, 1967, p. 39 ; Karl DeLwAIDE, « La législature québécoise peut-elle implanter un système complet d'initiative et de référendum », (1981) 22 C. de D. 695 ; H. BRUN, G. TREMBLAY et E. Brouillet, préc., note 2, p. 653-662.

24 Colonial Laws Validity Act 1865, 28-29 Vict., c. 63 (R.-U.).

25 La capacité du Parlement britannique de légiférer pour le Canada a pris fin lors de l'adoption de l'article 2 de la Loi de 1982 sur le Canada (1982, c. 11 [R.-U.]) : « No Act of the Parliament of the United Kingdom passed after the Constitution Act, 1982 comes into force shall extend to Canada as part of its law. » Dorénavant, toute modification formelle à la Constitution canadienne est soumise aux procédures contenues à la partie V de la Loi constitutionnelle de 1982, annexe B de la Loi de 1982 sur le Canada (supra). Cela dit, même si le Canada a désormais la possibilité de modifier sa Constitution, cette dernière demeure composée pour l'essentiel de normes adoptées par les Britanniques «pour le Canada».
} 
une cour suprême étrangère, soit le Comité judiciaire du Conseil privé de Londres. Responsable d'entendre en appel les litiges issus des colonies, cette juridiction impériale fut, jusqu'en $1949^{26}$, en mesure de contrôler les décisions rendues par l'ensemble des tribunaux du Québec et du Canada.

Outre la primauté des lois impériales sur celles des colonies, d'autres considérations ont également renforcé le développement du contrôle de constitutionnalité. Premièrement, le choix en 1867 d'opter pour une union fédérale impliquait forcément l'existence de normes supralégislatives établissant un partage des compétences entre les deux ordres de gouvernement autonomes que sont le fédéral et les provinces ${ }^{27}$. Deuxièmement, le caractère plurinational de la fédération et la nécessité de protéger les droits des minorités qui en découle ont, eux aussi, favorisé le développement d'un contrôle de conformité aux droits collectifs constitutionnellement protégés ${ }^{28}$. Enfin, troisièmement, l'adoption en 1982 d'un catalogue des droits et libertés individuels ${ }^{29}$, constitutionnellement garantis, a résolument confirmé le passage du modèle britannique de souveraineté du Parlement à celui de primauté de la Constitution sur l'ensemble des décisions ou des actes pris par les différents organes de l'État. Cela d'autant plus que le principe de primauté de la Constitution de même que le rôle du juge comme gardien de cette primauté ont été renforcés par l'adoption de dispositions expresses à valeur supralégislative ${ }^{30}$ dans la Loi constitutionnelle de 1982.

\section{B. Les forces du système intégré d'unité juridictionnelle}

L'un des traits importants du pouvoir de surveillance et de contrôle des cours supérieures réside dans son caractère inhérent et non écrit. En effet, au Québec et au Canada, le contrôle de constitutionnalité s'est développé bien longtemps avant que la Loi constitutionnelle de 1982 ne vienne confirmer en des termes explicites le rôle du juge comme gardien de la primauté du droit. Or, par les sources constitutionnelles non écrites, les tribunaux se sont reconnu une compétence inhérente, fondée sur des règles non écrites de common law. Ainsi, ils ont pu refréner toutes les tentatives des législateurs fédéraux et provinciaux de limiter leur pouvoir de surveillance et de contrôle pour se définir une compétence qui transcende la contingence des textes législatifs.

26 L'adoption du Statut de Westminster de 1931 (L.R.C. 1985, ann. II, $\mathrm{n}^{\circ}$ 27) - lequel supprimait l'obligation de compatibilité des lois canadiennes adoptées après 1931 avec les lois impériales - a permis au Canada d'abolir, dès 1933, les appels en matière criminelle au Comité judiciaire du Conseil privé (Criminal Code Amendment Act, SC 1932-33, c. 53, art. 17) responsable d'entendre les causes en provenance des colonies britanniques (Fudicial Committee Act, [1833], 3 \& 4 Will. IV, c. 41; 39. Fudicial Committee Act, [1844], 7 \& 8 Vict., c. 69). Les appels en matière civile furent toutefois maintenus jusqu'en 1949 (An Act to amend the Supreme Court Act, S.C. 1949 [2 ${ }^{\text {nd }}$ Sess.], c. 37, art. 3), moment où la Cour suprême du Canada devint le tribunal de dernière instance au pays, ce que le C.J.C.P. avait d'ores et déjà déclaré valide (Avis sur les appels au Conseil privé, [1947] A.C. 127). Comme le Comité judiciaire termina les causes dont il avait été saisi avant 1949, il rendit son dernier jugement pour le Canada en 1959 (Ponoka-Calmar Oils c. Wakefield, [1960] A.C. 18).

$27 \quad$ Loi constitutionnelle de 1867, préc., note 2, art. 91 et suiv.

28 Au sujet de la minorité anglophone du Québec, voir : Procureur général du Québec c. Blaikie et autres, [1979] 2 R.C.S. 1016; Procureur général du Québec c. Blaikie et autres, [1981] 1 R.C.S. 312; PG (Qué) c. Quebec Association of Protestant School Boards, [1984] 2 R.C.S. 66. Concernant l'éducation confessionnelle : Renvoi relatif au projet de loi 30, An Act to Amend the Education Act (Ont.), [1987] 1 R.C.S. 1; Ontario Home Builders'Association c. Conseil scolaire de la région de York, [1996] 2 R.C.S. 929, 995; quant aux droits garantis aux Autochtones, voir : Delgamuukwc. Colombie-Britannique, [1997] 3 R.C.S. 1010; R. v. Kapp, 2008 CSC 41, [2008] 2 R.C.S. 483.

29 Loi constitutionnelle de 1982, préc., note 25

$30 I d$., préambule et par. 52. (1), lequel se lit ainsi : «La Constitution du Canada est la loi suprême du Canada; elle rend inopérantes les dispositions incompatibles de toute autre règle de droit.» 
Le raisonnement à l'appui de cet affranchissement des tribunaux est le suivant : à titre d'héritières des cours royales anglaises séculaires ${ }^{31}$, les cours supérieures sont dotées d'un pouvoir de surveillance et de contrôle qui n'a pas besoin de s'appuyer sur une habilitation législative expresse, puisqu'il repose, en définitive, sur des règles non écrites de common law. En ce sens, les tribunaux canadiens sont non seulement les interprètes de leur propre compétence, mais ils ont aussi l'avantage d'utiliser des règles non écrites d'origine jurisprudentielle pour faire obstacle à toutes tentatives des parlements du fédéral et des provinces de limiter leur pouvoir en matière de révision judiciaire par le biais d'une clause privative de compétence ${ }^{32}$.

Le pouvoir judiciaire est donc en position de force dans un tel système intégré. La Cour suprême est par défaut compétente en toute matière. Les normes constitutionnelles non écrites qui servent de fondement au pouvoir de surveillance et de contrôle des cours supérieures sont suffisamment flexibles pour offrir, lorsque les circonstances l'exigent, des voies de recours inédites. C'est, dès lors, tout le prestige et toute l'autorité de la fonction judiciaire qui en sortent grandis dans la mesure où les cours supérieures voient leur existence protégée par la Constitution écrite ${ }^{33}$, mais sans que leurs pouvoirs, leurs compétences et leurs attributions soient limités par cette dernière. Elles sont donc en mesure d'agir comme les seules interprètes de leurs compétences, le silence des textes étant comblé par des normes constitutionnelles non écrites ${ }^{34}$ qui, dans la tradition de common law, sont jurisprudentiellement reconnues par les tribunaux eux-mêmes.

Cette grande marge de manœuvre dans l'exercice du pouvoir de surveillance et de contrôle permet aux cours supérieures d'assurer l'unité et la cohésion à l'intérieur de l'ordre juridique ${ }^{35}$. Devant la pluralité des sources et des traditions juridiques (droit fédéral, droit provincial, droit coutumier des peuples autochtones, common law, droit civil), devant les difficultés terminologiques que suppose le fait de concevoir un même droit dans les deux langues officielles (en anglais et en français), bref devant une certaine fragmentation et diversification des sources du droit, l'existence d'un système intégré d'unité juridictionnelle permet aux cours supérieures d'éviter bien des conflits

\footnotetext{
31 Initialement proposée par W.R. Lederman, cette théorie suivant laquelle les cours supérieures seraient les héritières des cours royales anglaises est loin d'être évidente à démontrer sur le plan historique. Cependant, comme le souligne à juste titre Marc Chevrier, la réalité historique semble avoir peu d'importance à partir du moment où les cours supérieures ont repris cette théorie à leur compte de manière à l'officialiser en droit positif, ce qui n'est pas sans rappeler la dimension «performative» du droit. Marc CHEvRIER, «Le juge et la conservation du régime politique au Canada», (2000) 19 (2-3) Politiques et sociétés 65, 68; W.R. LEDERman, The Supreme Court of Canada and the Canadian Fudicial System, Mémoires de la Société royale du Canada, 1975, série IV, 13, p. 209-225.

32 Une clause privative vise à soustraire au contrôle des cours de justice les décisions rendues par un tribunal spécialisé. La jurisprudence est toutefois venue atténuer les effets d'une telle clause en l'assimilant plutôt à un indice, parmi d'autres (mentionnons l'expertise du tribunal, l'objet de la loi et la nature du problème), pour dégager l'intention du législateur concernant le «continuum du degré de retenue judiciaire approprié » que doit suivre le juge. Pushpanathan c. Canada (Ministre de la Citoyenneté et de l'Immigration), [1998] 1 R.C.S. 982, par. 27. Voir aussi : U.E.S., Local 298 c. Bibeault, [1988] 2 R.C.S. 1048; Babcock c. Canada (Procureur général), 2002 CSC 57, [2002] 3 R.C.S. 3 et Patrice GARANT, La justice invisible ou méconnue. Propos sur la justice et la justice administrative, Cowansville, Éditions Yvon Blais, 2014, p. 793. Infra, p. 17.

33 Loi constitutionnelle de 1867, préc., note 2, art. 96-101.

34 Le premier paragraphe du préambule de la Loi constitutionnelle de 1867 (id.) se lit d'ailleurs ainsi : «Considérant que les provinces du Canada, de la Nouvelle-Écosse et du Nouveau-Brunswick ont exprimé le désir de contracter une Union Fédérale pour ne former qu'une seule et même Puissance (Dominion) sous la couronne du Royaume-Uni de la Grande-Bretagne et d'Irlande, avec une constitution reposant sur les mêmes principes que celle du Royaume-Uni» [nos italiques].

35 R. c. Saskatchewan Federation of Labour, 2013 SKCA 43, par. 28-29. S'exprimant à propos du stare decicis, la Cour d'appel de la Saskatchewan pose clairement cette recherche d'unité et de cohérence que procure l'unité juridictionnelle. Elle écrit : «[T]he purpose or rationale of this approach is well understood. It promotes several important values including consistency, certainty and predictability in the law.»
} 
juridictionnels et de préserver, si cela est encore possible, un peu de cohérence à l'intérieur de l'ordre juridique ${ }^{36}$.

La concentration de l'ensemble des fonctions juridictionnelles dans un seul système intégré a aussi l'avantage de la simplicité : la primauté du droit se trouve, en un certain sens, renforcée dans la mesure où elle s'appuie sur un juge capable d'agir en toute circonstance et en toute matière comme gardien de la hiérarchie des normes. Un tel système comporte néanmoins ses désavantages.

\section{Les inconvénients du système intégré d'unité juridictionnelle}

L'unité juridictionnelle s'accompagne de certains effets pervers. Elle entraine la concentration et la centralisation du pouvoir dans une structure intégrée et dominée par une seule Cour suprême dont les compétences connaissent bien peu de limites, si ce n'est l'autolimitation que constitue le principe de la retenue judiciaire ${ }^{37}$.

L'unité appauvrit le dialogue interjuridictionne ${ }^{38}$ dès lors que ce sont toujours les neuf juges de la Cour suprême qui ont le dernier mot. Ils ne sont concurrencés ni par d'autres juridictions suprêmes de droit interne (comme il peut en être le cas en France dans les rapports entre le Conseil d'État, la Cour de cassation et le Conseil constitutionnel) ni par un juge supranational (comme celui de la Cour européenne des droits de l'homme ou de la Cour de justice de l'Union européenne). Les membres de la Cour suprême du Canada sont seuls au sommet. Certes, ces derniers s'expliquent et se justifient dans de longs motifs et le contrôle diffus amène plusieurs autres juridictions inférieures à se prononcer, mais, en définitive, ce sont essentiellement les mêmes juges qui dictent les solutions définitives pour l'ensemble des tribunaux.

\footnotetext{
36 À cet égard, Frederick L. Mortons écrit : «This unitary character of the Canadian judicial system is politically significant because it can mitigate the centrifugal forces of federal-provincial politics [ ... and] it promotes a continuity and uniformity of legal policy across the nation.» F. L. Mortons, préc., note 8, p. 93. Voir aussi Peter McCormick and Ian Greene, fudges and fudging: Inside the Canadian fudicial System, Toronto, Lorimer, p. 212 et Adryan JW Tотн, « Clarifying the Role of Precedent and the Doctrine of Stare Decisis in Trial and Intermediate Appellate Level Charter Analysis », (2013) 22 Dal f. Leg. Stud. 34. Au sujet de la tâche unificatrice de la Cour suprême du Canada, voir : John WiLlis, «Securing uniformity of law in a federal system-Canada», (1944) 5 U.T.L.7. 352, 356; Bora LASkin, "The Supreme Court of Canada: A final court of and for Canadians », (1951) 29 R. du B. can. 1038, 1053 et Luc Huppé, Le regime juridique du pouvoir judiciaire, Montréal, Wilson \& La fleur, 2000, p. 31.

37 «Susceptible de favoriser l'équilibre entre la démocratie parlementaire et l'intervention des tribunaux», la retenue judiciaire est, selon Brun, Tremblay et Brouillet, composée de différentes facettes : préc., note 2, p. 188-191. Sur la retenue quant aux questions constitutionnelles devenues théoriques, voir : Borowski c. Canada (Procureur général), [1989] 1 R.C.S. 342, 354 et suiv. Sur l'importance d'un cadre contextuel dans l'analyse d'une question : R. c. Mills, [1999] 3 R.C.S. 668, Bande Kitkatla c. Colombie-Britannique (ministre des Petites et moyennes Entreprises, du Tourisme et de la Culture), 2002 CSC 31, [2002] 2 R.C.S. 146, par. 46 et P. TAILlon et F. HÉnAult, préc., note 7. Sur l'étendue de la décision à rendre, laquelle doit être strictement nécessaire pour résoudre le conflit ou pour répondre à la question, voir : Gosselin c. Québec (Procureur général), 2002 CSC 84, [2002] 4 R.C.S. 429, 490-492. Le juge Cory de la Cour suprême, dans l'arrêt M. c. H., en 1999, conclut que : «De façon générale, le rôle du législateur exige que les tribunaux fassent preuve de retenue à l'égard des décisions de principe que le législateur est le mieux placé pour prendre.» [1999] 2 R.C.S. 3, par. 78. Il s'attarde, dans les paragraphes suivants de sa décision, aux différents facteurs qui influencent le degré de retenue judiciaire à adopter.

38 Burkhard Hess et Séverine MenÉtrey (dir.), Les dialogues des juges en Europe, Bruxelles, Larcier, 2014; Sionaidh Douglas-Scott, « A Tale of Two of Two Courts: Luxembourg, Strasbourg and the Growing Europe HumanRights Acquis », (2006) 43 Common Market Law Review 629; Arnaud Derrien, «Dialogue et compétition des cours suprêmes ou la construction d'un système juridictionnel», (2003) 105 (2) Pouvoirs 4 et, plus généralement, Louis Favoreu, La Constitution et son juge, Paris, Économica, 2014, p. 1049 et suiv. ; Didier Maus, «Le recours aux précédents étrangers et le dialogue des cours constitutionnelles », (2009) 80 (4) Revue française de droit constitutionnel 675; Xavier MAGNON, "L'exigence d'un standard de protection des droits fondamentaux : un moyen de pacification des rapports entre les cours suprêmes?», dans Marthe Fatin-Rouge StÉFAnini et Guy Scoffoni (dir.), Existe-t-il une exception française en matière de droits fondamentaux?, Les Cahiers de l'Institut Louis Favoreu, n² 2, Aix-en-Provence, Presses Universitaires d'Aix-Marseille, 2013, p. 61.
} 
En outre, dans un système de droit non écrit et de common law, la Cour suprême dispose d'un pouvoir ultime, non seulement sur l'interprétation des normes, mais aussi sur la formulation de certaines d'entre elles. En s'appuyant sur le droit constitutionnel non écrit, de même que sur certaines normes écrites formulées en des termes très généraux, comme celles que l'on retrouve dans les catalogues de droits et libertés, le juge peut dégager de nouvelles normes implicites ${ }^{39}$. Il peut, dès lors, en préciser le contenu et ainsi s'imposer comme un organe agissant à la fois comme interprète, mais aussi comme corédacteur de certaines des normes constitutionnelles ${ }^{40}$.

L'unité juridictionnelle, dans le cadre d'une fédération plurinationale, constitue également une entorse au principe du fédéralisme. En effet, sur le plan de l'organisation des tribunaux, l'absence de fédéralisme judiciaire, privilégié par fidélité au modèle britannique d'unité juridictionnelle combiné au pouvoir du premier ministre fédéral de nommer unilatéralement l'ensemble des juges des tribunaux supérieurs ${ }^{41}$, jettent évidemment un doute sur l'indépendance institutionnelle du pouvoir judiciaire à l'endroit des autorités fédérales. Or, «l'autonomie réciproque du fédéral et des provinces est particulièrement dépendante de l'interprétation judiciaire $»^{42}$. Nommés unilatéralement par l'exécutif fédéral, et ce, sans aucune participation des provinces, les juges des cours supérieures sont indirectement porteurs de la vision idéologique des autorités fédérales qui les ont choisis. Appelés à trancher les litiges entre le fédéral et les provinces, ils peuvent difficilement projeter la nécessaire image d'indépendance lorsqu'ils doivent leur nomination à l'une des deux parties au litige. En ce sens, le processus de nomination des juges au Canada alimente un biais structurel en faveur d'une conception centralisatrice du fédéralisme canadien ${ }^{43}$.

Dans le contexte où les juges des cours supérieures sont tous nommés unilatéralement par l'exécutif fédéral, l'unité juridictionnelle joue en défaveur de l'autonomie des entités fédérées ainsi que de la défense du pluralisme et de la diversité, pourtant inhérents au fédéralisme. Comme le démontre José Woehrling, ce choix en faveur d'un système intégré a des effets uniformisateurs. Il y a, d'une part, le transfert d'un certain pouvoir de décision des organes représentatifs fédérés vers des organes judiciaires dont les membres sont unilatéralement désignés par l'exécutif fédéral et, d'autre part, la consolidation de l'identité pancanadienne au détriment de celle des États membres de la fédération. En ce sens, l'unité juridictionnelle participe au nation building canadien ${ }^{44}$.

\footnotetext{
39 Voir : Patrick TAILlon, «Le gardien ou la plume? Le rôle de la Cour suprême du Canada dans l'interprétation de la Constitution », dans Genoveva VRABIE (dir.), La Cour constitutionnelle - garant de la suprématie de la Constitution, Iasi, Institutul European, 2014 , p. 25. $40 \quad$ Id.

$41 \quad$ Loi constitutionnelle de 1867, préc., note 2, art. 96

42 H. Brun, G. Tremblay et E. Brouillet, préc., note 2, p. 411. Comme le souligne Nicole Duplé, cela fait craindre que « les juges du plus haut tribunal soient, en fait, nommés en raison d'une "qualité" première, soit leur adhésion à la doctrine du parti gouvernemental » qui, au niveau fédéral, est généralement centralisatrice. Nicole Duplé, Droit constitutionnel : principes fondamentaux, Montréal, Wilson \& Lafleur, 2007 , p. 366. Voir également : Eugénie Brouillet, «La légitimité fédérative du processus de nomination des juges à la Cour suprême du Canada», (2011) 41 R.G.D. 5 ; Eugénie Brouillet et Yves TANGUAY, «The legitimacy of the constitutional arbitration process in a multinational federativeregime: the case of the Supreme Court of Canada », (2012) 45 U.B.C.L.R. 47.

43 E. Brouillet et Y. TANguay, id.; E. Brouillet, id.; Andrée Lajoie, « Réformer le processus de nomination des juges de la Cour suprême », dans Nadia Verrelli (dir.), The Democratic Dilemma : Reforming Canada's Supreme Court, Kingston/Montréal, McGill-Queen's Press-MQUP, 2013, p. 145; «Le fédéralisme canadien : science politique fiction pour l'Europe», (2005) 10 (1) LexElectronica, en ligne : <http://www.lexelectronica.org/articles/v10-1/lajoie.pdf > .

44 José Woenrling, « Convergences et divergences entre fédéralisme et protection des droits et libertés : l'exemple des États-Unis et du Canada », (2000-2001) 46 McGill L. f. 21, 49-50.
} 
Cette volonté d'uniformisation et d'aplanissement des différences juridictionnelles est par ailleurs assumée et saluée par plusieurs auteurs canadiens-anglais ${ }^{45}$. Après tout, l'unité permet d'édifier et de consolider l'État central. Cela dit, il y a toujours deux revers à une même médaille ${ }^{46}$. Or, l'interprétation uniforme des droits constitutionnels comme étant «insusceptibles de variations à l'intérieur du territoire d'un même État va à l'encontre des objectifs de diversité et de pluralisme que sous-tend le fédéralisme $»^{47}$.

Dans le cas particulier du Québec, cela est évidemment très problématique, dans la mesure où les tentatives d'uniformiser la manière de penser et d'interpréter le droit représentent le plus souvent une menace à l'intégrité du droit civil québécois. Dans un contexte où la majorité des juges de la Cour suprême n'ont pas de formation en droit civil, plusieurs d'entre eux étant par ailleurs unilingues anglophones, il va de soi que ces juges travaillent avec des méthodes et des catégories conceptuelles qui sont celles de la common law. C'est d'ailleurs pour cette raison que bien des députés québécois se sont opposés, à l'origine, à la création de la Cour suprême du Canada, et ce, jusqu'à ce qu'un compromis soit trouvé afin d'assurer une représentation significative du Québec et de la tradition civiliste au sein de ce tribunal ${ }^{48}$.

Des efforts importants ont donc été déployés pour atténuer ce problème. D’une part, la composition de la Cour suprême garantit qu'un tiers de ses membres doit provenir du Québec. Dans un important avis de 2014, la majorité des juges de la Cour suprême ont considéré que l'objectif de cette surreprésentation du Québec au sein de la Cour avait pour but «(i) de garantir une expertise en droit civil et la représentation des traditions juridiques et des valeurs sociales du Québec à la Cour, et (ii) de renforcer la confiance du Québec envers la Cour. ${ }^{49}$

D’autre part, les autorités fédérales ont mis sur pied, en 1997, la Commission du droit du Canada ${ }^{50}$ responsable d'entreprendre une vaste étude sur les lois fédérales pour mieux refléter dans le droit «les concepts et les institutions des deux systèmes juridiques - le droit civil et la common law - ${ }^{51}$, et pour, à terme, proposer des réformes et une modernisation de l'ordre juridique canadien qui se

45 Comme l'affirme Peter Hogg : «[T]he position of the Supreme Court of Canada, with its plenary jurisdiction, at the top of each provincial hierarchy, has the effect of melding the ten provincial hierarchies into a single national system. » Peter W. HogG, Constitutional Law of Canada, Student Ed., Toronto, Carswell, 2014, p. 7.1 (a) ; F. L. Mortons, préc., note 8, p. 93. Au sujet de la tâche unificatrice de la Cour suprême du Canada, voir : J. WiLlis, préc., note 36, 356; B. LASkin, préc., note 36, 1053.

46 Encore une fois, José Woehrling témoigne de cette double perspective propre à la recherche d'un équilibre des pouvoirs au sein d'une fédération : «Selon les positions de chacun, on pourra estimer un tel résultat souhaitable ou nuisible. Cependant, on devra reconnaitre que la centralisation et l'uniformisation vont à l'encontre de certains objectifs traditionnellement poursuivis par l'entremise du fédéralisme : l'autonomie des entités fédérées et la défense de la diversité. » J. WoEHRLING, préc., note 44.

$47 \quad I d$.

48 Renvoi relatif à la Loi sur la Cour suprême, art. 5 et 6, 2014 CSC 21, [2014] 1 R.C.S. 433, par. 48-56; Peter H. RussELL, The Supreme Court of Canada as a Bilingual and Bicultural Institution, Ottawa, Information Canada, 1969, p. 8.

49 Renvoi relatif à la Loi sur la Cour suprême, art. 5 et 6, id., par. 18, 49, 56, 57, 59 et 69, motifs de la juge en chef pour la majorité.

50 Loi sur la Commission du droit du Canada, L.C. 1996, c. 9.7 (3). Les commissaires devaient représenter les intérêts socio-économiques et culturels divers du Canada, provenir de disciplines variées et avoir collectivement une connaissance des deux systèmes juridiques au Canada, le droit civil et la common law.

51 À son article 7 (3), la Loi sur la Commission du droit, id., énonçait d'ailleurs comme condition de nomination de ses membres : «Les commissaires devraient représenter les intérêts socio-économiques et culturels divers du Canada, provenir de disciplines variées et avoir collectivement une connaissance des deux systèmes juridiques au Canada, le droit civil et la common law». 
voulait équitable et représentatif ${ }^{52}$. Il n'empêche que ces nobles efforts ne suffisent pas toujours à contrebalancer le poids démographique et structurel des juristes de common law.

\section{Un contrôle sans limites des décisions de justice}

L'unité juridictionnelle, avec ses avantages et ses inconvénients, a bien des conséquences sur la manière dont est organisé et pratiqué le contrôle de constitutionnalité au Québec et au Canada. En effet, du moment que l'ensemble des tribunaux ne forme qu'un seul corps, qu'un seul ordonnancement, qu'un seul pouvoir judiciaire, chapeauté par des cours supérieures et une Cour suprême, dont les pouvoirs reposent en grande partie sur des règles constitutionnelles non écrites, il devient difficile de concevoir quelque forme de restriction à la capacité de cette dernière de contrôler la constitutionnalité des décisions de justice. L'étendue de cette compétence, aux contours indéfinis, ne peut aisément faire l'objet d'une description, si ce n'est que par des exemples emblématiques. Nous en mentionnerons trois : premièrement, le sort réservé aux «clauses privatives » édictées par le législateur dans le but d'écarter le pouvoir de surveillance des cours supérieures (A); deuxièmement, la manière dont la Cour suprême a imposé - contre la volonté expresse du législateur le contrôle des avis consultatifs rendus par les cours d'appel des provinces (B) et, enfin, troisièmement, les conditions relativement souples dans lesquelles les tribunaux de première instance peuvent pratiquer «l'overruled» et, à leur tour, contrôler l'interprétation de la Constitution préconisée par les tribunaux de dernière instance (C). À travers ces trois exemples, nous comptons démontrer que la capacité des cours supérieures de définir leur propre compétence connaît bien peu de limites au Canada.

\section{A. L'impossibilité pour le législateur de limiter la compétence des cours supérieures}

N'étant concurrencées par aucun autre ordre juridictionnel, pouvant s'appuyer sur des règles constitutionnelles non écrites dont elles sont les principales interprètes, les cours supérieures au Canada disposent d'une marge de manœuvre considérable dans l'exercice de leurs compétences. Elles peuvent ainsi s'opposer à toutes tentatives des parlements du fédéral ou des provinces de limiter leurs attributions. C'est d'ailleurs ce qu'elles ont fait à quelques reprises.

La création des tribunaux spécialisés ${ }^{53}$, dotés d'une expertise particulière sur des questions précises et circonscrites, s'accompagne généralement de dispositions restreignant la compétence des cours supérieures. Le législateur manifeste alors son intention ferme de faire de ces tribunaux spécialisés

\footnotetext{
52 En 2006, le gouvernement conservateur de Stephen Harper annonça toutefois des coupes budgétaires drastiques dans le budget de la Commission qui ferma ses portes quelques mois plus tard. Pour une revue plus exhaustive des mandats de la Commission, voir Nathalie Des Rosiers, «In Memoriam : La Commission du droit du Canada/The Law Commission of Canada, 1997-2006», (2007) 22 Canadian Journal of Law and Society 145.

53 Au Québec, on note, entre autres, le Tribunal des droits de la personne (Charte des droits et libertés de la personne, RLRQ, c. 12, art. 100), le Tribunal administratif du Québec (Loi sur la justice administrative, RLRQ, c. J-3, art. 14) et le Tribunal des professions (Code des professions, RLRQ, c. C-26, art. 162). Au Canada, on peut mentionner la Cour canadienne de l'impôt (Loi sur la Cour canadienne de l'impôt, L.R.C. 1985, c. T-2), le Tribunal de la concurrence (Loi sur le Tribunal de la concurrence, L.R.C. 1985, c. 19 [2e suppl.]) et le Tribunal canadien des droits de la personne (Loi canadienne sur les droits de la personne, L.R.C. 1985, c. H-6).
} 
des juridictions de dernier ressort, c'est-à-dire d'écarter toute forme d'appel ou de révision judiciaire. Mieux connues sous leur appellation anglaise, statutory privative clauses $^{54}$ (ou clauses privatives), ces dispositions restrictives de compétence prévoient que le tribunal spécialisé a le pouvoir d'entendre et de disposer de certaines affaires à l'exclusion de tout tribunal et que ses décisions sont finales, sans appel et sans autre recours possible.

Par l'adoption de ces dispositions privatives, l'objectif du législateur est de restreindre ou d'écarter le contrôle par les cours supérieures des décisions rendues par les tribunaux spécialisés. Or, les cours supérieures qui ont été amenées à interpréter les «clauses privatives » en ont très rapidement détourné le sens ${ }^{55}$. Refusant d'y donner suite, elles ont tout simplement fait fi des termes de la loi pour préserver leur pouvoir, et ce, en s'appuyant sur des règles non écrites de common law et sur les fondements constitutionnels de leur pouvoir de surveillance et de contrôle. Elles ont, dès lors, considéré que ces dispositions limitatives de compétence ne sont qu'un «indice» - parmi d'autres - qui guide l'analyse «pragmatique et fonctionnelle» de la Cour. Cette dernière vise à déterminer le degré de retenue ou de déférence (ce que l'on désigne, en droit administratif canadien, comme la «norme de contrôle ») qui s'impose au cas par cas, selon le contexte et les circonstances. Autrement dit, en interprétant une intention claire et manifeste du législateur d'écarter leur pouvoir de surveillance et de contrôle et en faisant des clauses restrictives de compétence de simples indications du législateur en faveur d'une plus grande retenue à l'endroit des tribunaux spécialisés, les cours supérieures ont su maintenir et préserver leur capacité à contrôler la conformité de l'ensemble des tribunaux administratifs et des cours spécialisés, lesquels se trouvent ainsi dans une position «inférieure» par rapport aux tribunaux de droit commun.

Plus fondamentalement, c'est la possibilité même pour le législateur de créer des tribunaux spécialisés qui a été remise en question par la jurisprudence. En effet, à force de multiplier, sur des sujets précis et limités, des cours inférieures et des tribunaux administratifs, des contestations judiciaires ont été entreprises pour déclarer inconstitutionnelles ces juridictions. Ces dernières sont apparues potentiellement comme un moyen pour les provinces de vider peu à peu les cours supérieures de leurs compétences. Il faut dire que les provinces disposent de la compétence législative sur l'administration de la justice ${ }^{56}$, mais que cette dernière s'exerce sous réserve du pouvoir de nommer et de rémunérer les juges des cours supérieures ${ }^{57}$. En multipliant ainsi les juridictions spécialisées, les provinces limitent indirectement le domaine d'action des juges nommés par le fédéral au profit de juges provinciaux. Or, à travers toute une série de critères permettant de déterminer si les juridictions spécialisées remettent en question l'équilibre historique que le constituant avait cherché à établir au moment de la Confédération de $1867^{58}$, la Cour suprême du Canada est venue poser des

54 La Cour suprême a défini ces termes, entre autres, dans Pasiechnyk c. Saskatchewan (Worker's Compensation Board), [1997] 2 R.C.S. 890, par. 17.

55 Crevier c. Québec (PG), [1981] 2 R.C.S. 220

Loi constitutionnelle de 1867, préc., note 2, art. 92 (14).

$I d$., art. 96 et 101.

Le test élaboré par la Cour suprême du Canada dans le Renvoi sur la Loi de 1979 sur la location résidentielle est composé de trois étapes : (1) est-ce que la compétence attaquée correspond généralement à celle qu'exerçaient les cours supérieures, de district ou de comté au moment de la Confédération? ; (2) La fonction du tribunal provincial dans son cadre institutionnel est-elle une fonction judiciaire ?; (3) Le cas échéant, 
limites à la capacité des législateurs provinciaux de créer des juridictions spécialisées susceptibles de faire concurrence à la compétence large et supplétive des cours supérieures.

En somme, tant pour la création de tribunaux spécialisés que pour les clauses restrictives de compétence que le législateur a édictées en faveur de ces derniers, les cours supérieures ont su préserver leur pouvoir de surveillance et de contrôle en atténuant la portée des mesures législatives susceptibles de compromettre, de près ou de loin, l’unité juridictionnelle.

\section{B. Le contrôle des avis consultatifs}

Une seconde illustration pour témoigner de l'étendue des pouvoirs de surveillance et de contrôle réside, cette fois, dans les activités «consultatives » de la Cour suprême du Canada. Il s'agit en fait de la manière dont, encore une fois, des dispositions législatives explicites visant à écarter le contrôle par le plus haut tribunal des avis consultatifs rendus par les cours d'appel des provinces ont été surmontées. En effet, il existe au Canada une procédure par laquelle les exécutifs peuvent saisir, par renvoi, le juge de questions de droit ${ }^{59}$. C'est une prérogative de la Couronne héritée des tribunaux anglais $^{60}$ et qui permet à Sa Majesté, ou à ses représentants (gouverneur général et lieutenant-gouverneur), de demander aux tribunaux un «avis consultatif». Cette prérogative a été codifiée en droit canadien en 1833, au moment de la création du Comité judiciaire du Conseil privét ${ }^{61}$ qui a agi comme tribunal de dernier ressort pour le Canada jusqu'en 1949. De même, en 1875, lorsqu'on a mis en place la Cour suprême du Canada, une disposition a été insérée afin de reconnaitre à l'exécutif fédéral le pouvoir de saisir la nouvelle cour générale d'appel d'une demande d'avis consultatif ${ }^{62}$.

Loin d'être anecdotique, le recours aux avis consultatifs a toujours été très important dans les dossiers constitutionnels. Cette procédure permet aux gouvernements de contester la validité d'une loi avant ${ }^{63}$ ou après ${ }^{64}$ son adoption, sans être en présence d'un litige concret, ce qui représente une exception par rapport au modèle anglo-américain de contrôle de constitutionnalité ${ }^{65}$.

\footnotetext{
est-ce que la fonction globale du tribunal provincial dans tout son contexte institutionnel enfreint l'article 96? ([1981] 1 R.C.S. 714, 734-736, précisé dans Sobeys Stores Ltd. c. Yeomans, [1989] 1 R.C.S. 238, 253-255) Ces questions ont pour effet de figer les caractéristiques des cours visées à l'article 96 de la Loi constitutionnelle de 1867 au temps de la Confédération pour éviter qu'elles soient vidées de leur juridiction. Ainsi, «seuls les transferts de compétences jugées complémentaires d'un régime administratif valide ou nécessairement accessoire à la réalisation d'un objectif législatif par ailleurs constitutionnel sont permis. » Renvoi relatif à certaines modifications à la Residential Tenancies Act (N.-É.), [1996] 1 R.C.S. 186, 232; voir aussi Renvoi relatif à la Loi sur les jeunes contrevenants (Î.-P.-É.), [1991] 1 R.C.S. 252, 268-269.

59 P. TAILlon et F. HÉnAult, préc., note 7.

60 Barry L. Strayer, The Canadian Constitution and The Cours. The Function and Scope of Judicial Review, Toronto, Butterworths, 1983, p. 272. In ReCriminal Code, [1910] S.C.R. 434, 451, propos du juge Duff.

61 An Act for better administration of Justice in his Majesty's Privy Council, 3 \& 4 Will. 4, c. 41 (1833), art. 4 : « It shall be lawful for His Majesty to refer to the said Judicial Committee for hearing or consideration any such other matters whatsoever as His Majesty shall think fit; and such Committee shall thereupon hear or consider the same, and shall advise His Majesty thereon in manner aforesaid. ». (Nous soulignons).

62 Supreme and Exchequer Court Act, préc., note 9, art. 52.

63 Renvoi relatif à la réforme du Sénat, 2014 CSC 32, [2014] 1 R.C.S. 704; Renvoi relatif à la Loi sur la Cour suprême, art. 5 et 6, préc., note 48; Renvoi relatif à la Loi sur les valeurs mobilières, 2011 CSC 66, [2011] 3 R.C.S. 837; Renvoi relatif au mariage entre personnes du même sexe, 2004 CSC 79, [2004] 3 R.C.S. 698; Renvoi : Résolution pour modifier la Constitution, [1981] 1 R.C.S. 753.

64 Renvoi relatif à la Loi sur la procréation assistée, 2010 CSC 61, [2010] 3 R.C.S. 457 ; Renvoi relatif à la Loi sur l'assurance-emploi (Can.), art. 22 et 23, 2005 CSC 56, [2005] 2 R.C.S. 669; Renvoi relatif à la Loi sur les armes à feu, [2000] 1 R.C.S. $783 ;$ Renvoi relatif à la rémunération des juges de la Cour provinciale (I.-P.-É.), [1997] 3 R.C.S. 3; Renvoi relatif à la taxe de vente du Québec, [1994] 2 R.C.S. 715; Renvoi sur l'opposition du Québec à une résolution pour modifier la Constitution, [1982] 2 R.C.S. 793.

65 Supra, note 8.
} 
Jacques-Yvan Morin et José Woehrling ont recensé que, durant le premier siècle ayant suivi l'adoption de la Constitution de 1867, «un tiers des décisions portant sur la Constitution furent rendues sous forme d'avis consultatifs $»^{66}$. Or, cette procédure de «renvoi» suscita de vifs désaccords parmi les provinces. Selon Barry L. Strayer ${ }^{67}$, les critiques des provinces étaient confortées par le libellé de la version initiale du projet de loi constitutive de la Cour suprême du Canada. Ce dernier heurtait de front les intérêts des provinces en définissant le renvoi comme une procédure permettant une contestation accélérée de la constitutionnalité des lois provinciales ${ }^{68}$. L'opposition des provinces résidait donc dans le déséquilibre des pouvoirs qui résulte du fait que l'un des membres de la fédération, en l'occurrence le fédéral, puisse être le seul à «obtenir promptement une détermination judiciaire de la validité des lois $»^{69}$. S'appuyant sur ces avis, qui ne sont officiellement que consultatifs, le fédéral risquait ensuite de mobiliser les arguments de la Cour dans les différends politiques et juridiques qui l'opposeraient aux autres membres de la fédération, en l'occurrence les provinces.

Pour bien marquer leur désaccord, les provinces contestèrent la procédure du renvoi jusqu'au Comité judiciaire du Conseil privé de Londres. Celui-ci confirma néanmoins la constitutionnalité de la loi fédérale qui habilite encore aujourd'hui les demandes d'avis consultatif ${ }^{70}$. Ne pouvant empêcher les autorités fédérales de se doter d'une procédure de renvoi auprès de la Cour suprême du Canada ${ }^{71}$, les provinces décidèrent de faire de même et de prévoir des procédures équivalentes leur permettant de saisir leur cour d'appel d'une même demande ${ }^{72}$. Au Québec, une telle loi fut adoptée en $1898^{73}$.

Cette loi québécoise avait cependant une particularité importante : elle empêchait, par son article 4, que l'opinion de la Cour d'appel - rendue dans un simple avis consultatif - ne puisse faire l'objet d'un appel. Ainsi, jusqu'en $1987^{74}$, le contrôle par la Cour suprême d'un avis consultatif rendu

66 J.-Y. Morin et J. Woehrling, préc., note 8, p. 354.

67 Il écrit : «[T]he provinces apparently regarded this reference system as a sinister device intended primarily to enable the federal authorities to attack the provincial legislation in a federally created court before which the province had no automatic right to appear.» B. L. STRAYER, préc., note 60, p. 274.

68 "Dans le premier projet de loi portant création de la Cour suprême et déposé aux Communes par le gouvernement fédéral le 21 mai 1869 , la procédure de l'avis consultatif était prévue, mais, fait remarquable, uniquement en rapport avec la validité des lois provinciales et afin d'éclairer le gouvernement fédéral sur le point de savoir s'il devait exercer sur elles son pouvoir de désaveu. On fit circuler ce projet parmi les juges du pays, espèce d'avis consultatif informel et populaire. La réaction des juges fut fort tiède et de ce projet de loi il ne fut plus question. » Grégoire Webber et François Chevrette, «L'utilisation de la procédure de l'avis consultatif devant la Cour suprême du Canada : Essai de typologie », (2003) 82 (3) Canadian Bar Review 757, 762.

69 G. RÉmillard, préc., note 8, p. 190.

70 Attorney General for Ontario c. Attorney General for Canada, [1912] A.C. 571.

71 Id.

72 Dès 1887, lors de la Conférence interprovinciale tenue à Québec, cinq des sept provinces représentées signèrent une résolution en ce sens : Official Proceedings of the Inter-ProvincialConference, Quebec, 1887, p. 28. Toutefois, il fallut attendre plusieurs années avant qu'une majorité de provinces donnent suite à cette résolution. James L. Huffman et Mardilyn SAAThoff, «Advisory Opinions and Canadian Constitutional Development: The Supreme Court's Reference Jurisdiction», (1989-1990) 74 Minn. L. Rev. 1251, 1259. Aujourd'hui, ce sont toutes les provinces qui disposent d'une procédure d'avis consultatif devant leur cour d'appel : The Constitutional Questions Act, 2012, S.S. 2012, c. C-29.01, art. 2 (Saskatchewan) ; Fudicature Act, R.S.A. 2000, c. J-2, art. 26 (Alberta) ; Constitutional Question Act, R.S.B.C. 1996, c. 68, art. 1 (Colombie-Britannique); Fudicature Act, R.S.N.L. 1990, c. J-4, art. 13 (Terre-Neuve et Labrador) ; Courts of fustice Act, R.S.O. 1990, c. C.43, art. 8 (1) (Ontario); Constitutional Questions Act, R.S.N.S. 1989, c. 89, art. 3 (Nouvelle-Écosse); Fudicature Act, R.S.P.E.I. 1988, c. J-2.1, art. 7 (1) (Île-du-Prince-Édouard) ; Fudicature Act, R.S.N.B. 1973, c. J-2, art. 23 (1) d) (Nouveau-Brunswick); Loi sur les questions constitutionnelles, C.P.L.M. c. C180, art. 1 (Manitoba).

73 Loi autorisant la soumission de certaines questions par le lieutenant-gouverneur en conseil, à la Cour du Banc de la Reine, S.Q. 61, Vict., c. 11. Son article 1 se lit ainsi : «Le lieutenant-gouverneur en conseil peut soumettre à la cour du banc de la reine, juridiction d'appel, pour audition ou examen, toutes questions quelconques qu'il juge à propos, et sur ce, la cour les entend et les examine.»

74 Depuis 1987, par l'adoption de la Loi modifiant la Loi sur les renvois à la Cour d'appel(1987, c. 99.), l'article 5.1 précise que : «L'opinion certifiée de la cour sur les questions ainsi soumises doit être considérée comme un jugement de cette cour et il peut en être interjeter appel à la Cour suprême du Canada comme d'un jugement dans une action. » Loi sur les renvois à la Cour d'appel, RLRQ, c. R -23. 
par la Cour d'appel du Québec était exclu. Malgré cela, le contrôle par la Cour suprême, facilité par une modification à la loi fédérale ${ }^{75}$, s'est néanmoins imposé.

Ce contrôle des avis consultatifs rendus par les cours d'appel des provinces est, à bien des égards, révélateur. Même pour de simples «renvois» qui n'ont pas, dans la tradition anglo-canadienne, de valeur juridique officielle, la Cour suprême conserve encore la possibilité d'intervenir. Pourtant, s'il y a un domaine pour lequel l'intervention du plus haut tribunal n'était pas indispensable, c'est bien celui-là. Comme l'écrivent à l'unanimité les juges du plus haut tribunal, «[d]ans le contexte d'un renvoi, la Cour n'exerce pas sa fonction judiciaire traditionnelle, mais joue un rôle consultatif $»^{76}$. Le renvoi est une exception dans l'univers juridique au Québec et au Canada. Or, en institutionnalisant la possibilité d'en appeler des avis rendus par les cours d'appel des provinces, on a réduit les différences entre l'avis consultatif et la décision exécutoire ce qui a contribué à dénaturer graduellement les avis consultatifs pour en faire, en définitive, une forme non officielle de décision produisant de facto les effets d'un jugement ${ }^{77}$.

\section{Le « réexamen» des décisions judiciaires}

Conformément à la règle du stare decisis qui caractérise les systèmes de common law, les tribunaux sont en principe liés par leurs précédents et par ceux des tribunaux supérieurs ${ }^{78}$. Cela s'explique par un souci de cohérence, de certitude et de prévisibilité qui doit guider les tribunaux dans leur interprétation et dans leur application de la common $\operatorname{law}^{79}$. Par exception à cette règle, la Cour suprême peut néanmoins s'émanciper de sa propre jurisprudence ${ }^{80}$. C'est ce qu'on appelle «l'overruled» ou le réexamen des décisions. La Cour se trouve ainsi à opérer une forme de contrôle de sa jurisprudence antérieure. Cela montre, encore une fois, que, lorsque les circonstances s'y prêtent, il n'y a pratiquement aucune limite à la capacité de la Cour suprême d'examiner l'ensemble des décisions de justice.

Cela dit, le plus étonnant réside ailleurs. Au-delà des revirements à la Cour suprême, il y a de plus en plus de réexamens judiciaires pratiqués par les tribunaux de première instance, et ce, surtout dans des dossiers qui touchent à des questions de constitutionnalité. On assiste en fait à une forme de renversement hiérarchique : ce sont soudainement les tribunaux situés au bas de l'ordonnancement judiciaire qui examinent la conformité à la Constitution de la jurisprudence élaborée par la Cour suprême du Canada, pourtant censée dominer la «pyramide» judiciaire.

75 Un amendement fait en 1922 à la Loi sur la Cour suprême, préc., note 9, a facilité les appels des avis consultatifs initiés par les provinces. L'article 37 de la Loi sur la Cour suprême permet à la Cour suprême de contrôler les avis des cours d'appel provinciales lorsqu'il a été déclaré par une loi de cette province que l'avis doit être considéré comme un jugement de la plus haute cour de la province et qu'on peut interjeter appel comme s'il s'agissait d'un simple jugement dans une action ordinaire. G. RÉMILLARD, préc., note 8, p. 190-191.

76 Renvoi relatif à la sécession du Québec, [1998] 2 R.C.S. 217, par. 25.

77 La Cour suprême le reconnait elle-même : «[B]ien qu'il ne s'agisse pas d'un arrêt au vrai sens du mot, mais simplement de ce que l'on qualifie parfois d'opinion donnée sur une question déférée à cette Cour par le gouverneur général en conseil, conformément à l'article 55 de la Loi sur la Cour suprême et à la juridiction spéciale qu'il confère à cette Cour, nous devons la considérer comme une opinion qui lie cette Cour [...].» R. c. Aziz, [1981] 1 R.C.S. 188, 197.

78 H. Brun, G. Tremblay et E. Brouillet, préc., note 2, p. 201-202, par. I.60.

R. c. Saskatchewan Federation of Labour, préc., note 35, par. 28-29.

Comme l'écrit Janelle Souter : «[T]he doctrine of precedents should not require the courts to follow the wrong path until [they] fall over the edge of the cliff. Following a wrong decision blindly simply makes the law predictably unjust. » Janelle SouTER, «Clearly the Arc Bends: Stare Decisis and Saskatchewan Federation of Labour v. Saskatchewan», (2015) 78 Sask. L. Rev. 397, 404. 
Pour un tribunal de première instance, il peut sembler quelque peu téméraire d'oser un tel réexamen, mais c'est un comportement qui est, en quelque sorte, encouragé par la Cour suprême. En effet, avec le temps, le plus haut tribunal de la fédération a formulé des critères permettant précisément d'encadrer et de baliser le réexamen des interprétations préconisées dans ses décisions antérieures.

D'abord, la Cour suprême considère depuis longtemps que la règle du stare decisis est moins contraignante en droit constitutionnel ${ }^{81}$. Commentant sa propre jurisprudence, elle écrit : «Cette Cour a affirmé clairement que les décisions constitutionnelles ne sont pas immuables, et ce, même en l'absence d'une modification constitutionnelle $»^{82}$. Dans le domaine du partage des compétences, Peter Hogg constate que la Cour «a en fait souvent changé d'avis sur cette doctrine (parfois sans distinguer explicitement ses précédents pertinents), et elle a expressément renversé un nombre disproportionné de précédents constitutionnels $»^{83}$. Le contentieux des droits et libertés de la personne est aussi très propice à de tels réexamens judiciaires ${ }^{84}$.

Dans au moins trois décisions récentes, ce sont donc les tribunaux de première instance qui ont examiné, puis renversé la jurisprudence de la Cour suprême. Dans l'arrêt Bedford ${ }^{85}$, la juge Himel de la Cour supérieure de justice de l'Ontario a, en 2010, réexaminé l'interprétation de la Charte canadienne des droits et libertés préconisée par la Cour suprême dans un renvoi de $1990^{86}$. Auparavant considérées comme conformes à la Constitution, les dispositions du Code criminel $^{87}$ relatives à certaines activités liées à la prostitution ${ }^{88}$ étaient soudainement déclarées ultra vires dès le jugement de première instance. Entretemps, le texte de la Constitution n'avait guère changé, mais le «contexte», lui, avait évolué.

Il en fut de même dans l'arrêt Carter, portant, cette fois, sur l'aide médicale à mourir, où la juge Smith de la Cour suprême de la Colombie-Britannique a, dans sa décision de première instance du mois de juin $2012^{89}$, renversé l'interprétation du droit à la vie, à la liberté et à la sécurité préconisée quelques années auparavant par la Cour suprême du Canada à l'occasion de l'arrêt Rodriguez ${ }^{90}$.

$81 \quad$ Par exemple, dans plusieurs anciennes affaires liées à des questions constitutionnelles, la Cour suprême a jeté les bases de cet abandon progressif du stare decisis en refusant de suivre le précédent établi par le Comité judiciaire du Conseil privé de Londres. Voir, entre autres, le Reference re Loi sur l'organisation du marché des produits agricoles, [1978] 2 R.C.S. 1198, 1234 et 1291, dans lequel elle s'écartera du précédent établi dans Lower Mainland Dairy Products Boardv. Crystal Dairy, [1933] A.C. 168, de même que Referencere The Farm Products Marketing Act, [1957] R.C.S. 198, 212 et 213; Capital Cities Communications Inc. c. Conseil de la Radio-Télévision canadienne, [1978] 2 R.C.S. 141, 161; McNamara Construction (Western) Ltd. c. La Reine, [1977] 2 R.C.S. 654, 661. B. LAskin, préc., note 36, 1073. Voir aussi P. W. HoGG, préc., note 45 , p. 8.7.

82 Clark c. Compagnie des chemins de fer nationaux du Canada, [1988] 2 R.C.S. 680, par. 44 et 45.

83 P. W. HogG, préc., note 45, p. 8.7. L'extrait original en langue anglaise est le suivant : "[H]as in fact often changed its mind on the constitutional doctrine (sometimes without any explicit overruling of the relevant precedents), and has explicitly overruled a disproportionate number of constitutional precedents».

84 Par exemple, l'un des revirements jurisprudentiels les plus spectaculaires des dernières années concerne l'interprétation de la liberté d'association et la question du droit à la négociation d'une convention collective qui a fait l'objet d'importants développements depuis l'arrêt Health Services and Support - Facilities Subsector Bargaining Assn. c. Colombie-Britannique, 2007 CSC 27, [2007] 2 R.C.S. 391. Voir : Ontario (Procureur général) c. Fraser, 2011 CSC 20, [2011] 2 R.C.S. 3; Association de la police montée de l'Ontario c. Canada (Procureur général), 2015 CSC 1, [2015] 1 R.C.S. 3, Saskatchewan Federation of Labour c. Saskatchewan, 2015 CSC 4, [2015] 1 R.C.S. 245.

85 Bedford v. Canada, 2010 ONSC 4264.

86 Renvoi relatif à l'art. 193 et à l'al. 195.1 [1] c) du Code criminel (Man.), [1990] 1 R.C.S. 1123.

87 L.R.C. 1985 , c. C-46.

88 Telles que de tenir une maison de débauche ou de s'y trouver, de vivre des produits de la prostitution d'autrui ou de communiquer, en public, à des fins de prostitution.

89 Carter v. Canada (Attorney General), 2012 BCSC 886.

90 Rodriguez c. Colombie-Britannique (Procureur général), [1993] 3 R.C.S. 519. 
Plus récemment encore, dans l'arrêt Comeau ${ }^{91}$, le juge Ronald Le Blanc de la Cour provinciale de Campbellton au Nouveau-Brunswick a considéré que la jurisprudence relative à l'interprétation de l'article 121 de la Loi constitutionnelle de 1867 devait être écartée au profit d'une interprétation plus favorable au commerce interprovincial.

Fait étonnant, les renversements jurisprudentiels préconisés par les juges de première instance ont, dans le dossier de la prostitution en 2014 comme dans celui de l'aide médicale à mourir en 2015, été confirmés sans réserve par une majorité de juges de la Cour suprême du Canada ${ }^{92}$. Il n'empêche que, d'un dossier à l'autre, les juges ont tenté de préciser les circonstances ou les critères pouvant justifier le réexamen de leurs précédents par des tribunaux de première instance. Ainsi, en 2015, la Cour affirme à l'unanimité :

« Le principe du stare decisis ne constitue pas un carcan qui condamne le droit à l'inertie. Les juridictions inférieures peuvent réexaminer les précédents de tribunaux supérieurs dans deux situations : (1) lorsqu'une nouvelle question juridique se pose ; et (2) lorsqu'une modification de la situation ou de la preuve change radicalement la donne ${ }^{93} »$.

Autrement dit, les tribunaux de première instance sont autorisés à renverser la jurisprudence établie par les tribunaux supérieurs si une nouvelle question de droit se pose ou s'il y a un changement de contexte (ou de preuve) ${ }^{94}$.

Dans le cas de la prostitution et de l'aide médicale à mourir, l'interprétation des dispositions constitutionnelles mobilisées par les parties avait, certes, quelque peu évolué, mais c'est surtout le critère de l'état des connaissances scientifiques qui a été déterminant. Comme l'écrit la Cour dans l'arrêt Carter, «le dossier de preuve est plus étoffé et fait état de résultats de recherches qui n'étaient pas disponibles en $1990 »^{95}$ ce qui fait en sorte «que les données sociales, politiques et économiques sous-jacentes [à la décision de 1990] ne sont plus valables [...] $\gg^{96}$. Bref, au-delà des questions de preuve, se cachent des évolutions des mentalités auxquelles les tribunaux canadiens se montrent assez perméables lorsqu'ils réexaminent leur jurisprudence.

\footnotetext{
$91 \quad$ R c. Comeau, 2016 NBCP 3.

92 Dans le cas de l'affaire Comeau (id.), les juges du plus haut tribunal ne se sont pas encore prononcés, car cette dernière affaire est toujours en attente d'une audition à la Cour suprême du Canada.

93 Carter c. Canada (Procureur général), 2015 CSC 5, par. 44. Nos soulignés.

$94 \quad$ Id.

95 Canada (Procureur général) c. Bedford, 2013 CSC 72, par. 41 (motifs de la juge en chef pour la Cour)

96 Id.
} 


\section{Conclusion}

À la lumière de ces quelques exemples emblématiques, il semble que le système intégré autour d'une Cour suprême unique et toute puissante a favorisé la mise en place du contrôle de constitutionnalité au Québec et au Canada. Si ce système comporte des avantages et des inconvénients, il connaît surtout peu de limites comme en témoignent les exemples qui ont été analysés ici et qui touchaient au sort réservé par les cours supérieures aux clauses privatives et aux appels des avis consultatifs rendus par les cours d'appel des provinces, de même qu'au possible réexamen des précédents et de la jurisprudence.

La principale limite à la capacité des tribunaux de contrôler la constitutionnalité des décisions de justice demeure la retenue dont font preuve les juges - à des degrés variables. En effet, les larges attributions dont disposent les tribunaux n'ont de sens que si elles sont exercées avec retenue, modération et déférence à l'endroit des décisions des instances inférieures et des autres pouvoirs constitués. Cela est d'autant plus important que l'opinion du juge canadien, contrairement à celle du juge constitutionnel français, n'est en définitive pas concurrencée par d'autres juridictions nationales ou supranationales. En somme, parce que l'unité juridictionnelle accroît les pouvoirs et l'influence de la Cour suprême, elle s'accompagne aussi d'un important risque : celui de la concentration du pouvoir qui doit inciter la Cour suprême à s'acquitter convenablement de son devoir de retenue. 


\title{
LE CONTRÔLE DE CONSTITUTIONNALITÉ DES DÉCISIONS DE JUSTICE EN SUISSE OU L'EXERCICE D'UN CONTRÔLE CONCRET DES NORMES
}

\author{
Michel HotTELIER ${ }^{1}$
}

\section{Introduction}

«Selon la jurisprudence, les tribunaux cantonaux ont l'obligation, sur demande du recourant, de contrôler à titre préjudiciel la compatibilité du droit cantonal applicable avec la Constitution fédérale. Si, à l'issue d'un tel contrôle, la norme s'avère inconstitutionnelle, la juridiction compétente ne saurait formellement annuler celle-ci, mais pourrait modifier la décision qui l'applique ${ }^{2}$.»

Ce passage, emprunté à un arrêt récent du Tribunal fédéral suisse, reprend un considérant classique, maintes fois cité dans la jurisprudence de la Haute Cour helvétique. Il exprime clairement, en quelques mots évocateurs, les caractéristiques principales de la juridiction constitutionnelle telle qu'elle a cours en Suisse : celles d'un système de contrôle de la constitutionnalité des normes qui se présente sous une forme diffuse, déconcentrée et concrète ${ }^{3}$.

Avant d'en venir au fondement normatif, puis à l'aménagement et au fonctionnement de ce type particulier de contrôle, il convient de dire quelques mots au sujet de son origine, afin de mieux saisir la manière dont s'opère, dans une perspective globale, le contrôle de la constitutionnalité des décisions de justice en Suisse.

\section{L'origine historique du contrôle concret}

\section{A. La situation lors de la création de l'État fédéral}

L'origine du contrôle concret de la constitutionnalité des lois en Suisse remonte à la création de l'État fédéral, en $1848^{4}$. Cette date reculée fait du système suisse un modèle parmi les plus anciens ${ }^{5}$.

Professeur à la Faculté de droit de l'Université de Genève.

Arrêt du Tribunal fédéral suisse 6B_856/2014 du 10 juillet 2015 dans la cause X. c. Ministère public de la République et canton de Genève, consid. 3.3, cité dans la « Chronique suisse de justice constitutionnelle 2015 », AIFC XXXI-2015, p. 900.

Voir Andreas Auer, Giorgio Malinverni, Michel Hottelier, Droit constitutionnel suisse, vol. I, L'État, 3 éd., Berne 2013 , p. 648.

Robert ZimmermanN, Le contrôle préjudiciel en droit fédéral et dans les cantons suisses, Lausanne 1987, p. 58.

Pierre Bon, Didier Maus (éd.), Les grandes décisions des cours constitutionnelles européennes, Paris 2009, p. XI. 
De fait, le mécanisme mis en place au XIX ${ }^{\mathrm{e}}$ siècle en Suisse se singularise par rapport au contrôle concentré et abstrait tel qu'il a généralement cours en Europe en raison de son apparition nettement antérieure $^{6}$. Le modèle dit européen a en effet été instauré par la Constitution autrichienne du $1^{\text {er }}$ octobre $1920^{7}$, avant d'essaimer et d'être généralisé à la suite du second conflit mondial ${ }^{8}$.

En Suisse, dès la mise en place des nouvelles institutions fédérales au milieu du $19^{\mathrm{e}}$ siècle, des plaintes émanant de particuliers en lien avec le respect de la Constitution ont pu être adressées au Conseil fédéral, gouvernement de la Confédération. Ces plaintes pouvaient être ensuite acheminées, sur recours, à l'Assemblée fédérale. Le Tribunal fédéral, qui ne siégeait pas en permanence, ne disposait alors que d'un rôle secondaire. La Haute Cour ne pouvait en effet statuer que sur les cas qui lui étaient renvoyés par l'Assemblée fédérale?.

L'idée à l'origine de ce système original remonte à la Révolution française et se situe dans le sillage de la théorie de la souveraineté populaire. Elle place dans l'autorité politique élue directement par le peuple la légitimité propre à protéger les droits individuels lors de litiges ${ }^{10}$. Le système n'a toutefois guère fonctionné dans les faits, un seul et unique cas ayant été transmis, en 1852, au Tribunal fédéral ${ }^{11}$. Jusqu'en 1874, l'essentiel de la juridiction constitutionnelle fut ainsi exercé par le Conseil fédéral ${ }^{12}$. Le principe d'une sauvegarde des droits individuels assurée par une instance étatique dotée d'un pouvoir de contrôle effectif était néanmoins posé. Il sera institutionnalisé à l'occasion de la révision totale de la Constitution fédérale du 12 septembre 1848.

\footnotetext{
6 Michel Fromont, Justice constitutionnelle comparée, Paris 2013, p. 26.

Christian Behrendt, Frédéric Bounon, Introduction à la théorie générale de l'État. Manuel, 3 éd., Bruxelles 2014 , p. 259 ; Albrecht WEBER, « Notes sur la justice constitutionnelle comparée: convergences et divergences », AIfC XIX-2003, p. 34 ; Louis FAvOREU, « La notion de Cour constitutionnelle », De la Constitution. Études en l'honneur de fean-François AUBERT, Bâle 1996, p. 15. Sur le sujet, voir également Xavier MAGNON, "Retour sur quelques définitions premières en droit constitutionnel: que sont une « juridiction constitutionnelle », une « cour constitutionnelle » et une « cour suprême »? Propositions de définitions modales et fonctionnelles », Long cours. Mélanges en l'honneur du Professeur Pierre Bon, Paris 2014, p. 305.

8 Fromont (note 6), p. 44 ; voir également Marc Verdussen, Justice constitutionnelle, Bruxelles 2012, p. 50 ; Bon, Maus (note 5), p. XI ; Louis FAVOREU, « Modèle américain et modèle européen de justice constitutionnelle », AIFC IV-1988, p. 52.

9 Voir Goran Seferovic, Das Schweizerische Bundesgericht 1848-1874. Die Bundesgerichtsbarkeit im frühen Bundesstaat, Zurich 2010 , p. 18 s.

10 Alfred Kölz, Histoire constitutionnelle de la Suisse moderne. L'évolution institutionnelle de la Confédération et des cantons depuis 1848, Berne 2013, p. 466, 758 et 803.

11 Jean-François Aubert, Traité de droit constitutionnel suisse, vol. II, Neuchâtel 1967, p. 589.

12 Auer, Malinverni, Hottelier (note 3), p. 680.
} 


\section{B. La révision totale de la Constitution fédérale de 1874}

Le système suisse de juridiction constitutionnelle a évolué dans le sens d'un développement progressif des fonctions exercées par le Tribunal fédéral ${ }^{13}$. Ce dernier organe, jusqu'alors doté de compétences réduites fut, lors de l'adoption de la Constitution fédérale du 29 mai 1874, érigé en instance permanente et composée de magistrats indépendants siégeant à plein temps ${ }^{14}$. Cette évolution a été en particulier dictée par l'accroissement des compétences attribuées à l'État fédéral, accroissement qui appelait un renforcement du contrôle judiciaire. Le Tribunal fédéral ainsi conçu dans sa dimension moderne entra en fonction le $1^{\text {er }}$ janvier $1875^{15}$.

Peu à peu, les compétences judiciaires initialement imparties au Conseil fédéral se virent transférées par voie législative au Tribunal fédéral ${ }^{16}$. Au nombre de celles-ci compta la compétence de connaître des recours fondés sur la violation des « droits constitutionnels des citoyens $»^{17}$. Initialement politique, le curseur de la juridiction constitutionnelle s'est ainsi progressivement déplacé dans le sens de l'instauration d'une forme de contrôle judiciaire, exercé par un organe indépendant et impartial ${ }^{18}$.

\section{L’immunisation des lois fédérales}

À la même époque, en 1874, une restriction affectant de façon majeure l'exercice de la juridiction constitutionnelle fut introduite dans la Constitution fédérale. Une disposition demeurée célèbre (art. 113 al. 3 Cst. 1874) et dont la teneur est demeurée inchangée à ce jour (art. 190 de la Constitution du 18 avril $1999^{19}$ ) précisa que les lois votées par l'Assemblée fédérale devaient être appliquées par le Tribunal fédéral. Plus précisément, le sens historique de la règle signifie, aujourd'hui encore, que les juges ne sauraient refuser d'appliquer une loi fédérale au motif que celle-ci contrevient, par hypothèse, à la Constitution ${ }^{20}$. En droit constitutionnel suisse, l'affirmation du contrôle de la légalité, c'est-à-dire le contrôle qui porte sur la correcte application des lois fédérales, va par conséquent de pair avec l'interdiction de pratiquer la juridiction constitutionnelle à leur égard ${ }^{21}$.

Des impératifs liés aussi bien à la séparation des pouvoirs qu'à l'introduction du référendum populaire facultatif sur le plan fédéral se trouvent à l'origine de la clause d'immunisation des lois fédérales. Pour émaner en effet d'un pouvoir législatif fédéral pratiquant une forme de bicamérisme égalitaire entre la Chambre du peuple et celle des cantons (art. 148 al. 2 Cst.) et être passibles, de surcroît, du scrutin populaire à la demande d'une fraction du corps électoral, soit 50’000 citoyens

\footnotetext{
13 KöLz (note 10), p. 760

14 André Jomini, «Présentation du Tribunal fédéral suisse comme autorité de juridiction constitutionnelle », Cahiers du Conseil constitutionnel 2005 (n 18), p. 134.

15 Alain Wurzburger, Le Tribunal fédéral. Comprendre son fonctionnement, agir devant ses juges, Zurich 2011 , p. 11.

Theodor DE JONCHEERE, Der Rechtsschutz in Verfassungsstreitigkeiten durch die politischen Bundesberhörden, Zurich 1958 , p. 60.

Voir Fromont (note 6), p. 25, qui parle à ce sujet d'une « innovation majeure pour l'Europe »; ZimMERMANN (note 4), p. 62 ; Aubert (note 11), p. 591. Sur la notion de droits constitutionnels, encore employée de nos jours dans la jurisprudence du Tribunal fédéral, voir $A I f C$ XXVII-2011, p. 1013 ; AIFC XXI-2005, p. 720.

18 ZimMERMANN (note 4), p. 66.

19 Ci-après : Cst ; Recueil systématique du droit fédéral suisse 101. Le RS peut être consulté en ligne sur le site www.admin.ch.

$20 \quad$ KöLZ (note 10), p. 543.

21 Voir l'étude de Maya Hertig RANDALL, «L'internationalisation de la juridiction constitutionnelle: défis et perspectives », Revue de droit suisse 2010 II, p. 237 ss et les références citées.
} 
ou huit cantons (art. 141 Cst.), les lois fédérales sont porteuses d'une forte légitimité démocratique. Aussi les Founding Fathers de la Suisse moderne ont-ils voulu que ces lois fussent condamnées, en quelque sorte, à être appliquées, sans pouvoir être remises en cause sur le terrain judiciaire. Dans les rapports qu'elles entretiennent avec la Constitution, seul le terrain politique se prête à leur hypothétique remise en cause, sous l'arbitrage constant du peuple.

La règle traduit la vision historique selon laquelle le pouvoir judiciaire ne saurait s'élever au-dessus du pouvoir législatif exercé par l'Assemblée fédérale, elle-même présentée comme l'autorité suprême de la Confédération au sens de l'article 148 alinéa 1 Cst. ${ }^{22}$. Elle reflète aussi la vision courante, présente en France républicaine comme en Suisse, selon laquelle un pouvoir judiciaire fort serait ressenti historiquement comme monarchique et, par conséquent, suspect sous l'angle démocratique propre à l'expression de la souveraineté populaire ${ }^{23}$.

Voici pourquoi, aujourd'hui encore et pour être certes régulièrement discutée et critiquée sur le terrain doctrinal ${ }^{24}$, la juridiction constitutionnelle en Suisse présente des contours aussi contrastés selon qu'elle est appelée à s'exercer sur des lois cantonales ou sur la législation fédérale.

Très ouvert à l'égard des premières en vue d'assurer une forme de surveillance de la Confédération sur le droit des cantons, le contrôle de la constitutionnalité ne permet par contre nullement au juge de remettre en cause les choix politiques et démocratiques dont sont empreintes les lois fédérales et les autres actes normatifs de rang fédéral qui leur sont directement liés. C'est donc principalement à l'égard des lois cantonales que s'exerce la juridiction constitutionnelle en Suisse.

\section{L'évolution de la clause d'immunisation}

L'interprétation traditionnelle de la clause d'immunité de l'article 190 Cst. a subi une évolution significative au cours des âges, qui témoigne de l'évolution qu'a connue le droit constitutionnel. L'évolution s'est déroulée dans une triple perspective ${ }^{25}$.

En premier lieu, le Tribunal fédéral pratique abondamment, depuis la fin des années 1960, l'interprétation des lois fédérales d'une manière conforme à la Constitution ${ }^{26}$. Cette technique permet

\footnotetext{
22 Auer, Malinverni, Hottelier (note 3), p. 649 ; voir aussi Jean-François Aubert, Traité de droit constitutionnel suisse, vol. I, Neuchâtel 1967, p. 94.

23 Voir Kölz (note 10), p. $545 \mathrm{~s}$ : «La reprise du contrôle des lois tel que l'exerçait la Cour suprême américaine était incompatible avec le fondement démocratique de la Confédération et le principe de la suprématie du parlement. »

24 Pour quelques références empruntées à la doctrine francophone, voir Pascal MAHON, Droit constitutionnel, vol. I, Institutions, juridiction constitutionnelle et procédure, $3^{\mathrm{e}}$ éd., Bâle, 2014, p. 337 ; KöLz (note 10), p. 775 ; William OssıPow, « Les logiques du dernier mot et leur brouillage. Réflexions sur l'avenir incertain du contrôle de constitutionnalité en Suisse », Direkte Demokratie. Herausforderungen zwischen Politik und Recht. Festschrift für Andreas Auer zum 65. Geburtstag, Berne 2013, p. 199 ; Auer, Malinverni, Hottelier (note 3), p. 654 ; Hertig Randall (note 21), p. 227 ; Andreas AuER, La juridiction constitutionnelle en Suisse, Bâle 1983, p. 64.

25 Auer, Malinverni, Hottelier (note 3), p. 655 et s.

26 Recueil officiel des arrêts du Tribunal fédéral suisse (ci-après : ATF) 95 I 330 feckelmann : «Sans doute le Tribunal fédéral ne peut-il examiner la constitutionnalité des lois fédérales (art. 113 al. 3 Cst.), mais on présume que le législateur fédéral ne propose pas des solutions contraires à la constitution, de sorte que les dispositions des lois fédérales doivent être interprétées d'une façon conforme à la constitution, à moins que le contraire ne résulte clairement de la lettre ou de l'esprit d'une loi ». Le texte des arrêts du Tribunal fédéral suisse peut être consulté en ligne sur le site www.bger.ch. Sur le sujet, voir AIFC XVIII-2002, p. 825.
} 
au juge, confronté à plusieurs interprétations d'un texte légal, de retenir celle qui concilie au mieux le sens de la norme avec le respect de la Constitution ${ }^{27}$.

Suivant les propositions d'un courant doctrinal original, le Tribunal fédéral a, en deuxième lieu, imposé une nouvelle interprétation de la règle d'immunité des lois fédérales au début des années $1990^{28}$. Pour certes faire obligation aux juges d'appliquer les lois fédérales, la Constitution ne leur interdit pas pour autant de se prononcer sur le respect de la Constitution. En d'autres termes, la règle de l'article 190 Cst. permet au Tribunal fédéral de pointer d'éventuelles inconstitutionnalités affectant les lois fédérales, en vue de permettre à l'Assemblée fédérale d'y remédier.

Le développement du contrôle de la conventionnalité a en troisième lieu, dès 1993, conduit le Tribunal fédéral à examiner en détail les cas dans lesquels une loi fédérale est susceptible d'entrer en conflit avec un traité international liant la Suisse ${ }^{29}$. Car, pour certes faire obligation au Tribunal fédéral d'appliquer les lois fédérales, l'article 190 Cst. oblige de même la Haute Cour à appliquer le droit international liant la Suisse. Comment, dès lors, régler les cas éventuels d'opposition irréductible entre ces deux catégories d'actes normatifs?

Après avoir, dans un premier temps, fait prévaloir la loi fédérale sur le traité, le Tribunal fédéral a modifié sa jurisprudence au début des années $1990^{30}$. Depuis lors, au nom du principe de la primauté du droit international tel qu'il découle de la Constitution fédérale, du droit international et de sa propre jurisprudence, le Tribunal fédéral fait en principe primer le traité sur la loi en cas de conflit. En Suisse comme ailleurs ${ }^{31}$, le développement du contrôle du respect des traités internationaux a, en quelque sorte, permis de dédoubler la fonction classique impartie à la juridiction constitutionnelle.

Voilà qui explique pourquoi la règle de l'article 190 Cst. permet tout de même, en dépit de sa rigueur apparente, au Tribunal fédéral d'exercer une certaine forme de juridiction constitutionnelle et conventionnelle à l'égard des lois fédérales. Voyons à présent comment le Tribunal fédéral est organisé.

\section{Le Tribunal fédéral}

\section{A. Statut et organisation}

Le Tribunal fédéral, son statut et les compétences dont il dispose sont régis par la Constitution fédérale du 18 avril 1999. L'article 188 Cst. présente l'instance comme l'autorité judiciaire suprême de la Confédération, tout en renvoyant la question de son organisation et celle de la procédure applicable à sa saisine à la loi.

\footnotetext{
27 Sur l'interprétation conforme comme technique générale de mise en oeuvre de la constitution, voir les développements de Massimo Luciani, «L'interprétation conforme et le dialogue des juges. Notes préliminaires », Le dialogue des juges. Mélanges en l’honneur du Président Bruno GeNEVOIS, Paris 2009, p. 695 et s.

$28 \quad$ ATF 117 Ib 367 Eidgenössische Steuerverwaltung.

29 ATF 119 V 171 X. ; 119 V 410 X.

30 Hertig RANDALL (note 21), p. 243 et s

31 Pour le cas de la France, voir par exemple les propos de Marthe FAtin-Rouge STÉFAnini, « La question préjudicielle de constitutionnalité: étude du projet français au regard du droit comparé », AIfC XXIII-2007, p. 14.
} 
Composée de plus de 130 dispositions, la loi sur le Tribunal fédéral détaille le mandat constitutionnel. Cette loi a été adoptée le 17 juin 2005 par l'Assemblée fédérale et elle est entrée en vigueur le $1^{\text {er }}$ janvier $2007^{32}$. C'est cette loi qui aménage, en particulier, les voies de droit et les diverses modalités qui permettent de saisir la Haute Cour, en simplifiant considérablement le système des recours par rapport au système antérieur. Elle est complétée par un règlement qui, adopté le 20 novembre 2006 par le Tribunal fédéral, fournit de précieuses informations sur l'organisation et le fonctionnement de la juridiction ${ }^{33}$.

\section{B. Composition}

À teneur de l'article 1 alinéa 3 LTF, le nombre des juges qui siègent au Tribunal fédéral oscille entre trente-cinq et quarante-cinq. Le nombre exact est actuellement arrêté à trente-huit magistrats et dix-neuf suppléants ${ }^{34}$. Les juges sont, comme leurs suppléants, le président et le vice-président de la juridiction, élus par l'Assemblée fédérale, laquelle siège pour la circonstance en conseils réunis, conformément aux articles 157 alinéa 1 let. a et 168 alinéa 1 Cst.

L'éligibilité au poste de juge fédéral relève de la Constitution fédérale. Profondément imprégnée de considérations démocratiques et, en particulier, du principe d'égalité de traitement qu'énonce l'article 8 alinéa 1 Cst., elle permet à tout citoyen suisse bénéficiant des droits politiques de présenter sa candidature, ainsi que le prévoit l'article 143 Cst. Des compétences spécifiques de nature personnelle, professionnelle ou juridique ne sont expressément requises ni par la Constitution, ni même par la loi. La limite inférieure d'âge correspond à la capacité civique active au sens de l'article 136 alinéa 1 Cst., à savoir dix-huit ans.

Le système électif mis en place par la Constitution fédérale implique que l'accès à la fonction de juge fédéral n'intervient pas d'office, en permettant par exemple à certaines personnalités ayant occupé de hautes fonctions publiques d'y accéder ipso iure comme c'est le cas en France pour les anciens présidents de la République, qui « font de droit partie à vie » du Conseil constitutionnel, conformément à l'article 56 alinéa 2 de la Constitution du 4 octobre 1958. En pratique, seuls des juristes avérés, disposant de compétences pointues et d'une riche expérience, sont éligibles. Le recrutement des juges fédéraux s'opère le plus souvent dans la haute magistrature cantonale, au sein du barreau ou encore dans le milieu académique ${ }^{35}$.

Sur le terrain pratique, l'Assemblée fédérale choisit les juges fédéraux de telle manière que les langues officielles de la Confédération, à savoir l'allemand, le français et l'italien au sens de l'article 70 alinéa 1 Cst. soient représentées ${ }^{36}$. Lors de l'élection des juges au Tribunal fédéral, l'Assemblée fédérale

\footnotetext{
Ci-après : LTF ; RS 173.110. Au sujet de cette loi, voir AIFC XXI-2005, p. 717.

Ci-après : RTF ; RS 173.110.131.Le site du Tribunal fédéral (www.bger.ch/FR/index.htm) présente des informations très intéressantes relatives à l'historique, à l'organisation et au fonctionnement de la Haute Cour.

34 Art. $1^{\text {er }}$ de l'ordonnance de l'Assemblée fédérale sur les postes de juges au Tribunal fédéral, du 30 septembre 2011 (RS 173.110.1).

35 Au sujet du processus de sélection et d'élection des juges fédéraux en Suisse, voir AIfC XXVII-2011, p. 417 et s.

36 Wurzburger (note 15), p. 57.
} 
accorde par ailleurs une représentation équitable aux deux confessions chrétiennes, de même qu'aux principaux partis politiques représentés à l'échelon national ${ }^{37}$.

Les juges fédéraux ne sont pas élus à vie, mais pour des mandats de six ans reconductibles, conformément à l'article 145 Cst. La limite supérieure d'âge est fixée à soixante-huit ans, conformément à l'article 9 alinéa 2 LTF. Ce système frappe par la brièveté de la durée du mandat, de même que par la possibilité d'une reconduction, soit d'un réexamen régulier des candidatures par l'Assemblée fédérale, qui ne permet pas d'exclure tout risque de non-renouvellement ${ }^{38}$.

À teneur de l'article $18 \mathrm{LTF}$, les juges qui composent le Tribunal fédéral sont répartis en plusieurs cours. Cette répartition s'effectue en fonction des domaines du droit, donc par discipline juridique. L'article 26 RTF prévoit ainsi que la juridiction compte sept cours, lesquelles sont constituées pour deux ans : deux cours de droit public, deux cours de droit civil, une cour de droit pénal et deux cours de droit social. Le règlement du Tribunal fédéral arrête le mode de répartition des compétences entre ces diverses formations en fonction de la nature juridique des domaines visés par les recours.

\section{La juridiction constitutionnelle}

\section{A. Le cadre contentieux}

La juridiction constitutionnelle telle que l'exerce le Tribunal fédéral n'intervient que dans un cadre contentieux, c'est-à-dire sur recours. Le contrôle judiciaire préventif des lois, antérieurement à leur promulgation ou même sur une base d'avis consultatif, n'existe pas sur le plan fédéral. L'article 189 alinéa 1 Cst. exprime clairement cette règle, en soulignant que le Tribunal fédéral connaît de contestations, ce qui suppose toujours l'existence d'un litige opposant au moins deux parties. L'article 191b alinéa 1 Cst. pose également l'exigence d'une contestation pour la saisine des autorités judiciaires cantonales dans les domaines relevant du droit civil, pénal ou public. Le jugement rendu sur le plan cantonal précède donc la saisine éventuelle du Tribunal fédéral.

Il convient par conséquent d'épuiser - conformément à l'expression consacrée - les instances et les moyens de droit cantonal avant d'adresser un recours à la Haute Cour ${ }^{39}$. Les instances cantonales devant impérativement avoir été saisies avant que le Tribunal fédéral n'entre en jeu ${ }^{40}$, le contrôle concret de constitutionnalité des normes porte le plus souvent sur des décisions de justice.

37 Jean-François Aubert, Pascal Mahon,Petit commentaire de la Constitution fédérale de la Confédération suisse du 18 avril 1999, Zurich 2003 , p. 1437.

38 Sur le sujet, voir les développements de Hertig Randall (note 21), p. 335 ; voir également Wurzburger (note 15), p. 59 ; Blaise KnAPP, « Le statut constitutionnel des juges du siège et du parquet », AIFC XI-1995, p. 364.

39 Gilbert Kolly, « Le Tribunal fédéral suisse », Les nouveaux Cahiers du Conseil constitutionnel 2016/3 (n 52), p. 50 ; MAHON (note 24), p. 324

40 Pour une illustration, voir ATF 142 I 155 X. S.A. 


\section{B. Le double rôle du Tribunal fédéral}

Le Tribunal fédéral assume un double rôle au sein du système judiciaire helvétique ${ }^{41}$. En sa qualité d'autorité judiciaire de dernière instance au sens de l'article 188 alinéa 1 Cst., il appartient, d'une part, à la Haute Cour d'assurer une interprétation uniforme et de faire respecter la législation fédérale dans son ensemble. Le contrôle de la légalité entre ainsi de plain pied dans ce contexte institutionnel très général, typique du rôle assigné à une cour suprême au sein d'un État organisé sur la base d'une structure fédérale.

Comme juridiction constitutionnelle, le Tribunal fédéral assume, d'autre part, la mission d'assurer le respect des droits fondamentaux de rang fédéral et cantonal, ainsi que des droits de l'homme qui sont contenus dans les instruments internationaux contenant des dispositions directement applicables auxquels la Suisse est partie. Les contrôles de la constitutionnalité et de la conventionnalité s'inscrivent dans ce cadre ${ }^{42}$.

\section{L’aménagement du contrôle concret}

Comme indiqué en introduction, le système suisse de juridiction constitutionnelle repose sur un modèle diffus, déconcentré et concret.

\section{A. Le caractère diffus}

Le système présente un caractère diffus en ce sens que le contrôle de la constitutionnalité n'est pas exercé de manière exclusive et n'est réservé ni une instance, ni à des magistrats spécifiques. En Suisse, la juridiction constitutionnelle est, bien plus, susceptible d'être exercée par toute instance judiciaire $^{43}$.

Sur le plan organique, le contrôle revêt pour ce faire la forme d'une juridiction qui n'est ni organiquement, ni fonctionnellement séparée des autres formes de contentieux que pratiquent les tribunaux. Comme a pu le relever opportunément un auteur, il n'y a pas en Suisse de juges constitutionnels qui seraient désignés d'une manière différente des autres ou qui siégeraient à l'écart des juges dits ordinaires ${ }^{44}$. Bref, en Suisse, il n'est point besoin d'un Palais Royal pour l'exercice de la juridiction constitutionnelle, un palais de justice suffit.

\footnotetext{
Kolly (note 39), p. 47 ; Wurzburger (note 15), p. 35 ; Jomini (note 14), p. 134 ; Aubert, MAhon (note 37), p. 1424 Hertig Randall (note 21), p. 242 ss et les références citées.

Voir Alexandre VON BRÜNNECK, « Le contrôle de constitutionnalité et le législateur dans les démocraties occidentales », AIFC IV-1988, p. 17. Elias Kastanas, Les origines et le fondement du contrôle de la constitutionnalité des lois en Suisse et en Grèce, Bâle 1993 , p. 54.
} 


\section{B. Le caractère déconcentré}

Déconcentré, le système suisse de justice constitutionnelle est pratiqué à l'échelon aussi bien fédéral que cantonal. En pratique, le Tribunal fédéral intervient à la manière d'une cour suprême - à l'américaine, pourrait-on dire ${ }^{45}$.

Devant la Haute Cour, le caractère déconcentré de la juridiction constitutionnelle se caractérise aussi en raison du fait que celle-ci intègre le domaine de compétence de chacune des sept cours qui composent le Tribunal fédéral. Toutes ces juridictions exercent le contrôle de la constitutionnalité des normes à leur magistère à l'occasion des cas d'application qui leur sont déférés.

\section{Le caractère concret}

Le contrôle de constitutionnalité est enfin concret en ce sens qu'il est susceptible d'intervenir à l'occasion de chaque décision d'application de la législation, que celle-ci soit de rang fédéral ou cantonal. L'examen pratiqué à cette occasion, qui se présente comme un contrôle préjudiciel général, constitue la contrepartie logique du système diffus de contrôle des normes ${ }^{46}$.

Le Tribunal fédéral a eu l'occasion de juger et de rappeler aux cantons que leurs autorités judiciaires ont l'obligation de procéder au contrôle préjudiciel de la conformité des normes locales telles qu'appliquées à des cas d'espèce au droit fédéral ${ }^{47}$. En pratique, le contrôle concret s'effectue en premier lieu au niveau des autorités judiciaires des cantons ${ }^{48}$. Statuant sur contrôle abstrait des normes cantonales, la Haute Cour a même annulé, à la faveur d'un arrêt demeuré célèbre, une disposition législative de procédure, qui prétendait exclure du contrôle concret de constitutionnalité les lois votées par le Parlement cantonal ou votées par le peuple ${ }^{49}$.

\section{La pluralité des normes de référence}

Le système suisse de justice constitutionnelle est très développé à un autre égard encore. Non seulement toute instance judiciaire est fondée à le pratiquer, comme nous venons de le voir mais, sur le terrain des normes de référence, il porte sur le respect aussi bien de la Constitution fédérale que de la constitution de chacun des vingt-six cantons ${ }^{50}$.

\footnotetext{
45 Le constituant de 1848 s'est du reste directement inspiré de la Constitution des États-Unis d'Amérique dans l'instauration et l'aménagement du Tribunal fédéral, ainsi que le souligne Seferovic (note 9), p. 13.

46 Voir les développements de Kastanas (note 44), p. 52 et s.

47 Outre la référence citée en tête de la présente contribution, voir ATF 127 I 185 R. ; 117 Ia 262 Y. ; 112 Ia 311 X. ; 106 Ia 383 Gemeinde Zuoz; 104 la 79 S. et les autres références citées.

48 Sur le sujet, voir l'intéressante étude de Jean-Marc VERnIORY, « Le contrôle préjudiciel des normes dans la jurisprudence récente de la chambre administrative genevoise », Direkte Demokratie. Herausforderungen zwischen Politik und Recht. Festschrift für Andreas Auer zum 65. Geburtstag, Berne 2013, p. 275 et s. L'auteur relève en particulier (p. 279 s), s'agissant de la pratique des juges administratifs du canton de Genève, que l'exercice du contrôle concret de la constitutionnalité représente, durant les années 2010 à 2012 , 2\% des arrêts, soit 30 arrêts sur un total de 1900 affaires jugées.

49 Arrêt du Tribunal fédéral du 8 octobre 1986 en la cause L.A., Revue de droit administratif et de droit fiscal 1987 , p. 433.

50 Le texte des constitutions des cantons suisses est disponible en ligne sur le site www.admin.ch/opc/fr/classified-compilation/13.html\#131.
} 
Cette particularité signifie que l'ensemble des actes qui sont pris en application de la législation cantonale peuvent être examinés non seulement sous l'angle de leur conformité au droit fédéral, mais également au regard du respect des droits contenus dans la constitution du canton en cause. Dès lors qu'il arrive que les constitutions cantonales contiennent des droits qui peuvent être conçus d'une manière plus large que ceux que garantit la Constitution fédérale ${ }^{51}$, cette forme de démultiplication du contrôle confère un caractère particulièrement original et vivant au droit constitutionnel des cantons ${ }^{52}$.

\section{Le fondement juridique du contrôle concret}

Le fondement de l'obligation de procéder au contrôle concret de la constitutionnalité a été, de longue date, âprement discuté en doctrine, ce d'autant que la Constitution fédérale ne le mentionne pas de manière explicite ${ }^{53}$. Durant longtemps, on a cru pouvoir le dégager d'une interprétation logique de la clause constitutionnelle immunisant les lois fédérales. Dès lors que la Constitution fait, depuis 1874, obligation à la Haute Cour d'appliquer ces lois, les actes normatifs qui ne sont pas couverts par cette clause d'immunité ne sauraient, a contrario, échapper au contrôle préjudiciel ${ }^{54}$. On a également pu évoquer l'existence d'une coutume constitutionnelle pour fonder le contrôle concret.

De nos jours toutefois, le fondement et la pratique du contrôle préjudiciel général sont réputés découler du principe général de la légalité, qui figure explicitement à l'article 5 alinéa 1 Cst., en tête des principes de l'activité de l'État régi par le droit. Dès lors que l'autorité n'est fondée à agir que sur la base et dans les limites du droit, une norme formellement ou matériellement viciée ne saurait trouver matière à déployer ses effets ${ }^{55}$. Cette vision très puriste n'est pas très éloignée, ici, de la conception classique développée en 1803 par le Chief Justice John Marshall dans l'affaire Marbury v. Madison ${ }^{56}$.

\section{Le fonctionnement du contrôle concret}

\section{A. Le mode de saisine du Tribunal fédéral}

Comme indiqué précédemment, le contrôle concret de la constitutionnalité des normes s'exerce toujours sur recours ${ }^{57}$. Conformément à l'adage nemo iudex sine actore, il n'intervient donc jamais d'office, quelle que soit la nature des droits en cause, le domaine juridique considéré, le type d'acte

\footnotetext{
51 Comme c'est par exemple le cas pour ce qui concerne la Constitution genevoise avec des garanties telles que les droits des personnes handicapées, le droit à un environnement sain ou encore les droits de l'enfant ; voir Michel Hottelier, Thierry TANQuereL, « La Constitution genevoise du 14 octobre $2012 »$, La Semaine judiciaire 2014 II, p. 358 et s.

52 Sur la structure et le contenu des catalogues de droits fondamentaux des constitutions cantonales, voir AIFC XXIX-2013, p. 443.

53 Auer, MALINVERni, Hottelier (note 3), p. 665.

ZimMERMANN (note 4), p. 80.

Voir Auer, MAlinverni, Hottelier (note 3), p. 665 et les références citées.

5 U.S. 137, 177 (1803): "The constitution is either a superior, paramount law, unchangeable by ordinary means, or it is on a level with ordinary legislative acts, and like other acts, is alterable when the legislature shall please to alter it. If the former part of the alternative be true, then a legislative act contrary to the constitution is not law: if the latter part be true, then written constitutions are absurd attempts, on the part of the people, to limit a power in its own nature illimitable. »

57 Kolly (note 39), p. 49
} 
incriminé ou la gravité du vice allégué. Tout au plus, la nature du litige peut-elle influer sur la composition de la cour du Tribunal fédéral habilitée à statuer. En particulier, la procédure du renvoi préjudiciel émanant d'une instance inférieure, telle qu'elle a cours par exemple en Italie, en Allemagne, en Belgique ou en France, dans l'attente d'une prise de position du Tribunal fédéral, n'est pas prévue en droit Suisse ${ }^{58}$.

Il n'existe pas non plus de procédure de sélection préalable des recours, à l'image du mécanisme du writ of certiorari propre à la Cour suprême des États-Unis, par laquelle le Tribunal fédéral déciderait ou non d'entrer en matière sur les recours qui lui sont déférés ${ }^{59}$. Dès lors que les conditions de recevabilité du recours sont réalisées, les juges fédéraux sont tenus d'examiner l'affaire au fond et de la juger.

\section{B. Les types de recours}

Les recours qui permettent de saisir le Tribunal fédéral sont agencés en fonction de la nature juridique des domaines du droit considéré. Il existe ainsi un recours en matière civile (art. 72 à 77 LTF), un recours en matière pénale (art. 78 à 81 LTF) et un recours en matière de droit public (art. 82 à 89 LTF). En fonction des diverses conditions de recevabilité, un recours constitutionnel subsidiaire peut être exercé, exclusivement sur contrôle concret des décisions cantonales, lorsque le recours en matière civile ou le recours en matière de droit public ne sont pas ouverts (art. 113 à 119 $\mathrm{LTF})^{60}$.

Le recours en matière civile, le recours en matière pénale et le recours en matière de droit public sont dits unifiés. L'unification qui caractérise chacune de ces voies de droit tient au fait que chacune d'elles permet aux juges saisis d'exercer le contrôle de la légalité, de la constitutionnalité et de la conventionnalité. Considéré sous cet angle spécifique, le caractère diffus du contrôle de la constitutionnalité réside dans l'intégration institutionnelle et judiciaire de la juridiction constitutionnelle dans les divers chefs de compétence que la Constitution et la législation fédérales attribuent au Tribunal fédéral.

\section{La motivation des griefs}

La loi précise que le Tribunal fédéral applique en principe le droit d'office (art. 106 al. 1 LTF). Il appartient toutefois à la partie recourante d'exposer succinctement en quoi l'acte attaqué viole le droit, de manière à pouvoir d'identifier la nature des vices juridiques invoqués (art. 42 al. 2 LTF). L'exigence suppose que le mémoire de recours ne soit pas excessivement long et qu'il s'en tienne à l'essentiel. L’invocation de griefs de nature constitutionnelle obéit en revanche à un carcan procédural

\footnotetext{
58 Une tentative visant à introduire pareille procédure pour permettre le contrôle des lois fédérales et d'infléchir ainsi la rigueur de la règle d'immunité contenue à l'article 190 Cst. fut certes entreprise dans le cadre de la réforme de la justice fédérale au début des années 2000 , avant d'être rejetée par l'Assemblée fédérale ; voir Aubert, MAHon (note 37), p. 1454 ; AIfC XVIII-2002, p. 828 et les références citées.

59 Voir Wurzburger (note 15), p. 47, qui relève que l'introduction d'une procédure de sélection des recours devant le Tribunal fédéral fut rejetée en votation populaire en 1990 .

60 Auer, Malinverni, Hottelier (note 3), p. 683
} 
plus strict. L'article 106 alinéa 2 LTF fait, en particulier, obligation à la partie recourante d'invoquer et de motiver très précisément les moyens que celle-ci entend faire valoir devant la Haute Cour ${ }^{61}$.

Pour être plus précis, l'exigence de motivation accrue qu'impose l'article 106 alinéa 2 LTF implique que les griefs constitutionnels avancés à l'appui d'un recours soient clairement énoncés, identifiés, avant d'être explicités de manière approfondie. Dans la négative, le recours est déclaré irrecevable. La règle vaut pour le contrôle abstrait comme pour le contrôle concret de constitutionnalité. De surcroît, l'invocation de moyens nouveaux devant le Tribunal fédéral, c'est-à-dire de moyens qui n’auraient pas été soulevés devant les instances précédentes, n’est pas admissible.

Les griefs susceptibles de donner lieu au contrôle de constitutionnalité sont nombreux et variés. Les droits de nature constitutionnelle auxquels l'article 106 alinéa 2 LTF fait référence recouvrent les dispositions de la Constitution fédérale qui présentent des contours suffisamment précis pour être invoqués directement. Sont naturellement visés les droits fondamentaux, mais aussi d'autres normes constitutionnelles auxquelles la jurisprudence confère la qualité de droits directement applicables ${ }^{62}$.

\section{L'instruction et le jugement}

Le président de la cour compétente pour juger la cause dont elle est saisie procède à l'instruction des recours ou désigne un juge à cet effet. Le juge instructeur est chargé de conduire la procédure probatoire et c'est lui qui rédige un projet d'arrêt.

Le magistrat instructeur est habilité à statuer comme juge unique sur la radiation du rôle des procédures devenues sans objet ou sur celles qui se sont achevées par un retrait ou une transaction judiciaire. En outre, le président de la cour ou un juge désigné par lui peut décider, par voie de procédure simplifiée, de ne pas entrer en matière sur les recours manifestement irrecevables, sur ceux dont la motivation est manifestement insuffisante ou encore sur les recours qui présentent un caractère procédurier ou abusif. Les arrêts rendus par un juge unique sur cette base sont sommairement motivés.

La procédure qui se déroule devant le Tribunal fédéral est écrite et ne comprend en principe pas d'audiences. Pour la phase du jugement, les cours du Tribunal fédéral peuvent fonctionner en deux compositions distinctes : à trois juges ou à cinq juges. En règle générale, les cours qui composent le Tribunal fédéral statuent en composition de trois juges. Elles ne siègent en composition de cinq juges que si la cause soulève une question juridique de principe ou si un juge en fait la demande. Les cours statuent également à cinq juges sur les recours dirigés contre un acte normatif cantonal sujet au référendum, ainsi que sur les recours qui concernent une décision cantonale ayant trait à la recevabilité d'une initiative populaire ou à l'exigence d'un référendum.

$61 \quad$ ATF 136 I 49 Hausherr.

62 Voir les références citées supra, note 17 
Sur le terrain pratique, le Tribunal fédéral statue le plus souvent par voie de circulation, c'est-àdire en l'absence de délibération contradictoire ${ }^{63}$. L'article 58 alinéa 1 LTF prévoit toutefois la possibilité d'une délibération publique. En pareille hypothèse, les délibérations et les votes des juges se déroulent lors d'une séance ouverte au public, conformément à l'article 59 alinéa 1 LTF.

Cette procédure particulière présente un caractère exceptionnel et est réservée à trois cas de figure : si le président de la cour l'ordonne, si un juge le demande ou en l'absence d'unanimité. L'objectif poursuivi par cette forme de transparence consiste à permettre au public et aux medias d'exercer un droit de regard sur le fonctionnement de la justice. Elle contribue aussi à élargir le débat judiciaire en permettant aux éventuels magistrats minoritaires de faire publiquement connaître, par oral, leur position personnelle sur la motivation et le dispositif de l'arrêt ${ }^{64}$. L'arrêt finalement notifié aux parties ne comprend toutefois pas d'opinions séparées.

\section{E. Le pouvoir de décision du Tribunal fédéral}

L'objet du recours en cas de contrôle concret de constitutionnalité porte sur une décision d'application d'une loi. C'est, partant, cette décision de mise en œuvre qui est concrètement attaquée. Comme la décision a le plus souvent été prise d'une manière conforme à la loi, le juge examine si elle résiste au grief d'inconstitutionnalité soulevé à son encontre. L'image du contrôle indirect, préjudiciel ou par voie d'exception de la loi trouve ici tout son sens $s^{65}$.

Dans l'exercice de sa fonction de Cour suprême, le Tribunal fédéral est chargé de veiller à la correcte application de la législation fédérale, dans la perspective de conférer à cette dernière un sens identique, valable uniformément dans l'ensemble des régions du pays. La Haute Cour dispose en conséquence du pouvoir de statuer elle-même sur le fond du litige. Elle peut, le cas échéant, remplacer la décision erronée du juge a quo par une nouvelle décision conforme au droit. Si certains éléments font défaut, elle peut aussi renvoyer la cause à l'instance précédente pour permettre à celle-ci de compléter l'instruction avant de rendre une nouvelle décision, ainsi que le précise l'article 107 alinéa 2 LTF.

La situation se présente sous un jour différent lorsque le Tribunal fédéral exerce sa fonction de juge constitutionnel. Ici, la Haute Cour est en effet uniquement chargée de veiller au respect des droits de nature constitutionnelle. C'est, dans ce cas de figure, l'intérêt privé qui prévaut. Si les juges fédéraux parviennent à la conclusion que ces droits sont violés, ils ne peuvent que rarement statuer sur l'affaire au fond. Aussi, le pouvoir qu'exerce le Tribunal fédéral sera le plus souvent de nature cassatoire. L'acte attaqué étant alors annulé, la cause est renvoyée à l'autorité précédente ${ }^{66}$.

\footnotetext{
Kolly (note 39), p. 47.

Auer, Malinverni, Hottelier (note 3), p. 765

Auer, Malinverni, Hottelier (note 3), p. 645.

Auer, Malinverni, Hottelier (note 3), p. 773.
} 
En outre, sur contrôle concret, seul l'acte formant l'objet direct du recours est passible d'annulation par le juge. C'est dire que ce n'est que la décision attaquée qui sera, le cas échéant, annulée. La norme qui sert de support est alors simplement déclarée contraire à la Constitution et ne saurait être appliquée ${ }^{67}$.

\section{Le contrôle abstrait et le contrôle concret}

\section{A. L'étendue du contrôle abstrait}

Le contrôle abstrait de constitutionnalité existe à l'égard des actes normatifs cantonaux, à l'exception des constitutions cantonales, pour lesquelles une procédure spécifique permet à l'Assemblée fédérale d'octroyer sa garantie lors de leur adoption ou de leur modification aux conditions énoncées à l'article 51 Cst.

À teneur de l'article 82 lettre b LTF, les actes normatifs cantonaux de nature infra-constitutionnelle peuvent être déférés au Tribunal fédéral dans un délai de trente jours à compter de leur publication, à moins qu'une procédure de contrôle abstrait n'existe sur le plan local ${ }^{68}$. Si tel est le cas, l'acte normatif doit d'abord être porté devant l'instance cantonale, avant de pouvoir éventuellement être soumis au Tribunal fédéral ${ }^{69}$.

Plusieurs cantons ont institué, à leur niveau, une cour constitutionnelle disposant de la compétence de procéder au contrôle abstrait de la constitutionnalité des normes locales ${ }^{70}$. La création de ce type d'instance et l'intégration de ce type de contentieux sur le plan cantonal ne sont nullement prescrites par le droit fédéral ${ }^{71}$. Comme indiqué précédemment, seul le contrôle concret de la conformité des actes cantonaux au droit fédéral est obligatoire pour les cantons. Aussi, ces derniers disposent-ils d'une marge de manœuvre considérable en matière de contrôle abstrait de la constitutionnalité des normes cantonales.

En outre, le fait qu'un contrôle de constitutionnalité de nature abstraite a déjà pu être exercé à l'égard de l'acte normatif en cause ne saurait avoir pour conséquence de priver le justiciable de l'opportunité de provoquer ultérieurement un contrôle concret. À la suite du contrôle abstrait d'un acte normatif de rang cantonal, l'intéressé conserve en effet la possibilité de faire valoir une inconstitutionnalité de la réglementation à la faveur de l'application de cette dernière à un cas particulier ${ }^{72}$.

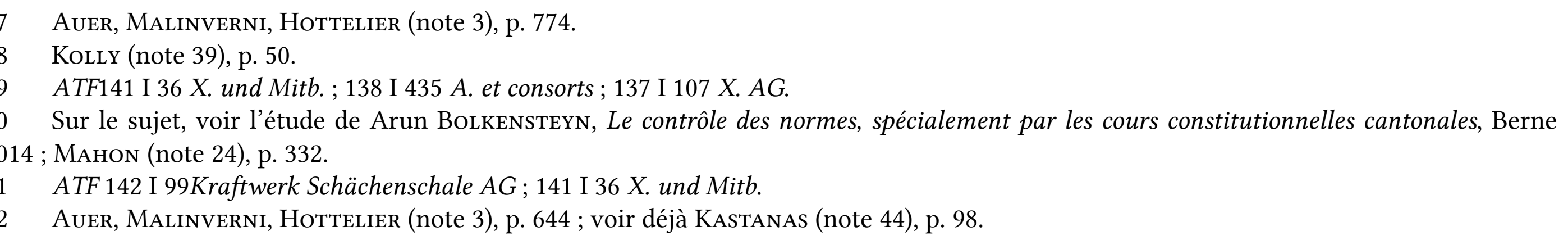




\section{B. Les cas de contrôle concret}

Les cas qui donnent potentiellement lieu au contrôle concret de constitutionnalité sont assurément multiples. Toute décision administrative ou judiciaire est théoriquement passible de la juridiction constitutionnelle. On peut à cet égard envisager deux catégories distinctes, selon qu'une décision reproduit elle-même une inconstitutionnalité contenue dans la loi ou qu'elle s'avère, per se, inconstitutionnelle, indépendamment de son support normatif. La doctrine opère ici une distinction classique, qui se fonde sur le caractère direct ou indirect de la violation de la Constitution ${ }^{73}$.

Le premier cas de figure, celui de la violation directe, concerne l'inconstitutionnalité qui résulte d'une application correcte de la loi, laquelle s'avère en pareille hypothèse elle-même contraire à la Constitution. Dans ce cas, la décision de mise en œuvre de la norme ne fait que reproduire une violation de la Constitution qui figure dans la loi. C'est, partant, la loi qui viole la Constitution.

Un arrêt prononcé en 1985 par le Tribunal fédéral permet d'illustrer le propos. Une disposition normative du canton d'Appenzell Rhodes-Intérieures interdisait la publicité des audiences pénales. À l'occasion d'une procédure, un accusé sollicita la tenue d'une audience publique, laquelle lui fut refusée. Le Tribunal fédéral admit le recours sur la base du principe de la publicité des débats prévu à l'article 6 paragraphe $1 \mathrm{CEDH}^{74}$.

Le second cas révèle une violation indirecte de la Constitution. Il procède d'une inconstitutionnalité qui est liée à la mauvaise application de la loi. Dans cette hypothèse, pour prévoir le principe de la publicité des débats au pénal, le huis-clos est par exemple ordonné sur la base d'une mise en œuvre erronée de la loi. La violation de cette dernière entraîne une violation de la Constitution ${ }^{75}$.

\section{Les enseignements}

\section{A. Généralités}

Le système du contrôle diffus et concret de la constitutionnalité des lois a profondément influencé, dans son ensemble, la structure institutionnelle helvétique. Il n'est en effet guère de chapitre du droit constitutionnel qui n'ait fourni l'occasion d'être lu et interprété, pour ne pas dire réinventé par les tribunaux cantonaux et, en dernière instance, par le Tribunal fédéral. L'apport de la jurisprudence, elle-même irriguée et fécondée par les critiques et les solutions formulées par la doctrine, a conduit à un enrichissement irremplaçable de la perception, la compréhension et l'essor du droit constitutionnel ${ }^{76}$.

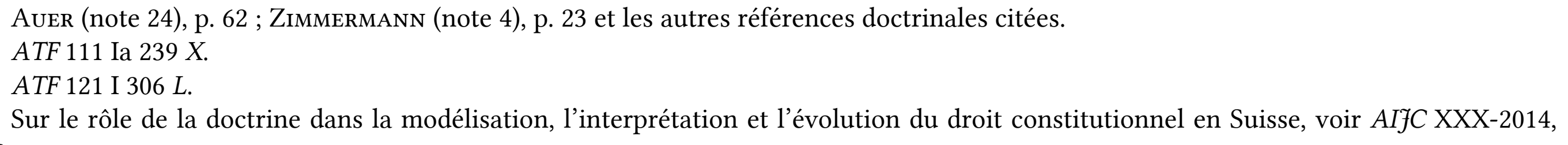


Trois chapitres particulièrement emblématiques de la Constitution fédérale méritent d'être évoqués dans ce contexte, en raison de l'apport auquel la juridiction constitutionnelle a conduit via le contrôle concret : le fédéralisme, la démocratie et les droits fondamentaux.

\section{B. Le fédéralisme}

Les piliers fondateurs de la structure fédérale suisse reposent sur la Constitution. Celle-ci énonce les dispositions qui forment la base, tout à la fois théorique et pratique, du fédéralisme tel qu'il a cours en Suisse depuis 1848. Pour l'essentiel, trois types de normes constitutionnelles fixent ce cadre.

Il y a, d'abord, les règles qui président à l'énonciation de la structure fédérale elle-même et, corrélativement, à la répartition des compétences entre la Confédération et les cantons. Parmi cellesci, l'article 3 Cst. dispose que « les cantons sont souverains en tant que leur souveraineté n'est pas limitée par la Constitution fédérale et exercent tous les droits qui ne sont pas délégués à la Confédération ». La disposition est utilement complétée par l'article 42 Cst., qui prévoit que « la Confédération accomplit les tâches que lui attribue la Constitution », de même que par l'article 43 Cst., qui indique que « les cantons définissent les tâches qu'ils accomplissent dans le cadre de leurs compétences ».

Il y a, ensuite, la règle - assurément fondamentale, elle aussi - qui évoque l'arbitrage en cas de conflit entre compétences fédérales et cantonales. L'article 49 alinéa 1 Cst. dispose à cet égard que «le droit fédéral prime le droit cantonal qui lui est contraire».

Il y a, enfin - last but not least -, l'énumération des diverses compétences que la Confédération est fondée à exercer en application de la règle qu'énoncent les articles 3 et 42 Cst. Un chapitre entier leur est dédié au sein de la loi fondamentale. C'est même le chapitre le plus long de la Constitution, puisqu'il ne compte pas moins d'une centaine de dispositions ${ }^{77}$.

Le cadre ainsi tracé par la Constitution, le système paraît clair et prêt à l'emploi. Tout n'est pas, tant s'en faut, dit pour autant : nombres de questions vitales pour la perception, la compréhension et le fonctionnement effectif du fédéralisme restent en effet ouvertes, en aval si l'on peut dire du texte constitutionnel. Par exemple, comment la répartition des compétences fonctionne-telle effectivement dans la réalité économique, politique, sociale et institutionnelle ? Quelles limites le droit constitutionnel fixe-t-il en la matière ? Ou encore : dans quels cas des conflits de compétences ou de règles entre le niveau fédéral et le niveau fédéré sont-ils susceptibles de survenir? Comment et par l'intervention de quel organe ces conflits sont-ils identifiés puis, le cas échéant, résolus?

La règle de l'article 3 Cst. paraît à première vue claire : soit la Constitution fédérale est compétente pour légiférer sur une matière déterminée, soit ce sont les cantons qui le sont. Mais que se passe-t-il entre le moment où la Constitution fédérale est, par hypothèse, révisée pour permettre aux

77 Voir Auer, Malinverni, Hottelier (note 3), p. 345 et s. 
autorités fédérales d'intervenir et le moment où celle-ci légifère ? Quant à la règle de la primauté du droit fédéral sur le droit cantonal contraire que pose l'article 49 alinéa 1 Cst., que signifie-telle vraiment ? Le doit cantonal éventuellement contraire au droit fédéral est-il nul $a b$ ovo, avec un effet ex tunc ou plutôt annulable, ex nunc?

Voici quelques questions qui sont des classiques de la structure fédérale telle qu'appréhendée par le droit constitutionnel suisse. On se doute bien que la Constitution fédérale n'est pas à même de leur apporter elle-même une réponse claire, définitive et sans appel. Chacun aura compris que c'est au juge constitutionnel que revient la tâche difficile d'aborder les problématiques qu'elles recouvrent et de purger les inévitables litiges qu'elles génèrent.

L'exercice de la juridiction constitutionnelle a, en particulier, permis au Tribunal fédéral de mettre au point une grille méthodologique subtile, complexe et détaillée en vue d'aborder, d'identifier puis de résoudre les conflits de compétence ou de règles opposant les législations des cantons au droit fédéral ${ }^{78}$. C'est d'ailleurs le Tribunal fédéral lui-même qui a historiquement créé et imposé, par voie prétorienne, le principe de la primauté du droit fédéral comme un droit individuel tel qu'il est actuellement codifié à l'article 49 alinéa 1 Cst. $^{79}$.

La Haute Cour a ainsi jugé que le principe de la primauté du droit fédéral que garantit l'article 49 alinéa 1 Cst. fait obstacle à l'adoption ou à l'application de règles cantonales qui éludent des prescriptions de droit fédéral ou qui en contredisent le sens ou l'esprit, notamment par leur but ou par les moyens qu'elles mettent en œuvre, ou qui empiètent sur des matières que le législateur fédéral a réglementées d'une façon exhaustive. Cela étant, même si la législation fédérale est considérée comme exhaustive dans un domaine déterminé, une loi cantonale peut tout de même subsister dans le même domaine, en particulier si elle poursuit un but autre que celui recherché par le droit fédéral. En outre, même si, en raison du caractère exhaustif de la législation fédérale, le canton ne peut plus légiférer dans une matière, il n'est pas toujours privé de toute possibilité d'action. Partant, ce n'est que lorsque la législation fédérale exclut toute réglementation dans un domaine particulier que le canton perd toute compétence pour adopter des dispositions complétives, quand bien même celles-ci ne contrediraient pas le droit fédéral ou seraient même en accord avec celui-ci ${ }^{80}$.

Ces principes jurisprudentiels posent le cadre à l'intérieur duquel les litiges susceptibles d'opposer compétences fédérales et cantonales sont appréhendés. Leur mise en oeuvre au cas par cas permet d'apporter une réponse institutionnelle judiciaire indispensable au bon fonctionnement de la structure fédérale.

\footnotetext{
78 Sur ce point, voir les intéressants exemples cités par Fromont (note 6), p. 375.

79 Kölz (note 10), p. 771 ; AUER, MALINVERni, HotTelier (note 3), p. 371.

La formule est classique dans la jurisprudence, voir ATF 141 V 455 A. ; 140 I 218 A. S.A. ; 138 I 435 A. et consorts ; 137 I 167 Dame X. et X. ; 135 I 106 X. AG; 133 I 110 Slatkine et Pétroz et les autres références citées.
} 


\section{La démocratie}

Le statut de la démocratie représente un chapitre fondateur et structurellement fondamental de l'ordre constitutionnel suisse. La notion de démocratie est mentionnée explicitement dans le préambule de la Constitution fédérale de même que, sous la forme des «droits du peuple », parmi les buts généraux de la Confédération qu'énonce l'article 2 alinéa 1 Cst. L'article 34 Cst. place les droits politiques parmi les droits fondamentaux, soit autant de droits susceptibles d'êtres portés par les citoyens devant le juge. Outre la garantie générale de ces droits (al. 1), la disposition précise en son alinéa second que ceux-ci protègent « la libre formation de l'opinion des citoyens et des citoyennes et l'expression fidèle et sûre de leur volonté ». Le respect des droits politiques fédéraux et cantonaux figure au reste en bonne place parmi les compétences que l'article 189 alinéa 1 Cst. confère au Tribunal fédéral.

Cela dit, la Constitution fédérale ne précise pas davantage la signification, la portée ou les limites des droits politiques au sens de l'article 34 Cst. On voit d'ailleurs mal une loi fondamentale être en mesure d'énumérer les innombrables facettes qui composent une garantie conçue de manière aussi générale. Là également, il revient à la juridiction constitutionnelle de détailler, à travers le contrôle entourant leur mise en œuvre, la notion de droits politiques.

Tout comme c'est le cas dans le domaine du fédéralisme, le Tribunal fédéral a développé au cours des âges une jurisprudence riche et multiforme au sujet des droits politiques tels qu'ils ont cours sur le plan aussi bien fédéral que cantonal et communal ${ }^{81}$. Tel est par exemple le cas en ce qui concerne le droit d'initiative et de référendum populaire ${ }^{82}$. Les arrêts de principe sont ici légion. Nombre d'entre eux ont acquis une dimension historique et même monumentale, contribuant ainsi à concrétiser, à faire évoluer et adapter le statut de la démocratie semi-directe telle qu'elle a cours en Suisse ${ }^{83}$.

Un arrêt prononcé le 27 novembre 1990 a par exemple conduit le Tribunal fédéral à introduire, de lui-même, le suffrage féminin sur le plan cantonal dans un canton qui ne connaissait encore que le suffrage masculin ${ }^{84}$. Etait en cause, en l'occurrence, la tenue d'une Landsgemeinde, soit l'assemblée populaire locale, d'un canton de Suisse centrale (Appenzell Rhodes-Intérieures), au cours de laquelle l'octroi du suffrage féminin fut refusé par une majorité de citoyens. Il faut préciser à ce sujet, que, certes introduit le 7 février 1971 dans la Constitution fédérale, le suffrage féminin était, à l'époque, encore réservé aux seules élections et votations de rang fédéral. Lors du scrutin constitutionnel du 7 février 1971, une clause fut ajoutée dans la Constitution fédérale, précisant que l'agencement du système démocratique sur le plan cantonal et communal n'était pas affecté par l'octroi des droits politiques aux Suissesses. Une dizaine d'années plus tard, la Constitution subit

81 Parmi une doctrine abondante, voir notamment Bénédicte TonNAY, La démocratie directe saisie par le juge. L'empreinte de la jurisprudence sur les droits populaires en Suisse, Zurich 2008.

82 Comme le relève par exemple Fromont (note 6), p. 363

83 Sur le sujet, voir Auer, MALinverni, Hottelier (note 3), p. 274 ss et les références jurisprudentielles citées.

84 ATF 116 Ia 359 Theresa Rohner und Mitbeteiligte. 
une autre révision partielle, au cours de laquelle le principe de l'égalité des droits entre femmes et hommes fut inscrit au titre de droit fondamental.

La question se posait, dès lors, de savoir si les cantons et les communes qui n'avaient pas encore introduit le suffrage féminin à leur niveau pouvaient, au nom de la structure fédérale, continuer sur cette voie ou si, en sens, contraire, le principe d'égalité des droits leur faisait, au nom du respect des droits fondamentaux, obligation de traiter les Suissesses domiciliées sur leur territoire de la même manière que les Suisses. La Haute Cour a tranché cette question par l'arrêt de principe qu'elle a prononcé en séance publique le 27 novembre 1990. Les juges fédéraux ont en l'occurrence précisé que, pour être certes traditionnellement compétents pour agencer leur système politique et démocratique comme ils l'entendent, les cantons sont néanmoins tenus de respecter, au nom de leur dimension objective, les droits fondamentaux, dont la garantie des droits politiques fait naturellement partie. Le Tribunal fédéral a ajouté que la constatation selon laquelle les femmes du canton d'Appenzell Rhodes-Intérieures devaient désormais jouir des droits politiques prenait effet dès le prononcé de son arrêt ${ }^{85}$.

\section{Les droits fondamentaux}

En Suisse comme dans de nombreux États, le domaine des droits fondamentaux occupe une place centrale dans la juridiction constitutionnelle. Cette particularité tient à la nature et à la structure de ces garanties. Les droits fondamentaux se présentent en effet comme des normes très ouvertes et se singularisent par leur concision. Les termes brefs et souvent elliptiques qui caractérisent leur dénomination, leur concrétisation, la détermination de leur champ d'application, tout comme les restrictions qui peuvent leur être apportées supposent, par définition, un processus qui intervient en aval de leur consécration. Sans être exclu, le rôle du législateur, souvent, n’y suffit guère. Il faut, bien plus, la participation ultérieure du juge, au cours d'un processus d'interprétation et de fine tuning typique de leur mise œuvre par voie judiciaire ${ }^{86}$.

Ces caractéristiques générales ne sont pas propres au système constitutionnel suisse. Ce dernier connaît toutefois deux autres particularités, qui permettent de souligner l'importance de la juridiction constitutionnelle.

La première caractéristique tient à la double nature du contrôle qu'exerce le Tribunal fédéral sur les droits fondamentaux. Comme indiqué précédemment, le contrôle abstrait de la législation cantonale de rang infra-constitutionnel coexiste avec le contrôle concret.

La seconde caractéristique s'inscrit dans le prolongement de la structure fédérale helvétique. Dès lors que les cantons sont dotés d'une structure constitutionnelle qui leur est propre, leur constitution contient très souvent un catalogue de droits fondamentaux, qui peut, selon les cas,

85 Sur le sujet, voir l'analyse du Professeur Blaise KNAPP, AIfC VI-1990, p. 855.

86 Auer, Malinverni, Hottelier (note 3), p. 504. 
être riche de garanties inconnues du droit fédéral comme indiqué précédemment ${ }^{87}$. S'agissant du contrôle de la législation et des décisions cantonales, la juridiction constitutionnelle peut par conséquent s'opérer à un double étage, si l'on peut dire : l'étage constitutionnel local, auquel peut s'ajouter l'étage des droits fondamentaux de rang fédéral et celui des droits de la personne humaine consacrés par les instruments internationaux auxquels la Suisse est partie. L'article 189 alinéa 1 lettre d Cst. précise à cet égard que le Tribunal dispose, outre la violation du droit fédéral, de la compétence de statuer sur les droits constitutionnels cantonaux. Le contrôle de la constitutionnalité s'exerce ainsi potentiellement aussi bien sur le respect des droits fondamentaux contenus dans les constitutions cantonales que dans la Constitution fédérale, tous griefs auxquels s'ajoute le respect des droits de l'homme protégés notamment par la $\mathrm{CEDH}$.

La multiplicité des potentialités de contrôle abstrait et concret de constitutionnalité cantonale, fédérale et de conventionnalité offre une palette extrêmement dense et diversifiée d'arrêts d'espèce comme d'arrêts de principe. Incontestablement, le contrôle concret enrichit la signification et la portée des droits fondamentaux tout en offrant l'avantage de permettre d'actualiser, au besoin, la protection qu'offre la Constitution. Toutes les garanties qui ressortissent aux droits fondamentaux et aux droits de la personne humaine en bénéficient en principe, quelle que soit la famille à laquelle celles-ci appartiennent. Outre les doits politiques, c'est le cas pour les libertés, les garanties de l'État de droit ou les droits sociaux.

Le contrôle concret de constitutionnalité a notamment permis au Tribunal fédéral d'enrichir par lui-même, grâce à une jurisprudence avant-gardiste inaugurée au début des années 1960, les droits fondamentaux en complétant le texte de la Constitution fédérale au moyen de la reconnaissance de droits non écrits. Des droits élémentaires comme la garantie de la propriété, la liberté d'expression, la liberté personnelle, la liberté de réunion ou encore, plus récemment, le droit à des conditions minimales d'existence ont ainsi été créées par voie prétorienne, avant d'être formellement intégrées au texte de la loi fondamentale lors du processus de révision totale qui a conduit à l'adoption de la Constitution fédérale du 18 avril $1999^{88}$.

D’autres droits fondamentaux ancrés depuis fort longtemps dans la Constitution fédérale ont également bénéficié de l'œuvre d'interprétation et de concrétisation du Tribunal fédéral au gré des multiples affaires soumises à la Haute Cour dans le cadre de la juridiction constitutionnelle qu'elle exerce. Le principe d'égalité de traitement est particulièrement illustratif à cet égard, tant il est vrai que ce n'est qu'à l'occasion de sa mise en ouvre et du contrôle de son respect que cette garantie fondatrice voit ses contours et sa portée être précisés ${ }^{89}$.

\footnotetext{
$87 \quad$ Supra,note 51.

88 Voir Andreas Auer, Giorgio Malinverni, Michel Hottelier, Droit constitutionnel suisse, vol. II, Les droits fondamentaux, $3^{\mathrm{e}}$ éd., Berne 2013, p. 33 et les références citées.

89 Pour d'autres exemples évocateurs, voir la «Chronique suisse de justice constitutionnelle » publiée chaque année dans l'AIfC.
} 


\section{Conclusion}

Avec l'instauration de la juridiction constitutionnelle, une constitution accède pleinement à la qualité d'acte normatif à part entière, c'est-à-dire un acte appelé à déployer des effets juridiques, à travers un système de contrôle et de sanction organisé de manière institutionnelle. C'est également, dans cette logique, la juridiction constitutionnelle qui permet d'assurer à une constitution la primauté qui lui revient au sein de l'ordre juridique interne ${ }^{90}$. Tout à la fois institution et procédure, organe et fonction, la juridiction constitutionnelle est ainsi au service de la fondamentalité et de la force dérogatoire qui caractérisent la notion de constitution.

L'étude du système suisse, particulièrement original dans le concert européen, révèle que la juridiction constitutionnelle, pour être en mesure de déployer son plein effet utile, ne saurait se limiter au modèle classique du contrôle abstrait de type préventif. Pour intervenir juste après l'adoption d'un acte normatif, au moment même où celui-ci s'apprête à entrer en vigueur, le contrôle abstrait des lois cantonales se présente, en Suisse tout au moins, comme une forme de pari spéculatif qui est posé sur une application future, pronostiquée aussi conforme qu'imaginable à la Constitution, que celle-ci soit fédérale ou cantonale ${ }^{91}$. Mais tout n'est pas dit pour autant.

Commel'a soulignéle Tribunal fédéral au cours d'une jurisprudence constante, pour examiner librement dans le cadre d'un contrôle abstrait des normes la conformité d'un acte normatif aux droits constitutionnels, il s'impose cependant une certaine retenue dans ce contexte, eu égard notamment aux principes qui découlent à la fois du fédéralisme et de la proportionnalité. Il s'avère, à cet égard, décisif que la norme sujette au contrôle puisse, selon les principes d'interprétation traditionnellement reconnus, se voir attribuer un sens compatible avec les droits fondamentaux. Partant, la Haute Cour n'annule une norme cantonale que lorsque celle-ci ne se prête à aucune interprétation conforme à la Constitution. Pour en juger il faut, de jurisprudence constante également, tenir compte notamment de la portée de l'atteinte aux droits fondamentaux en cause, de la possibilité d'obtenir ultérieurement, par un contrôle concret de la norme, une protection juridique suffisante, et des circonstances concrètes dans lesquelles la norme en question sera mise en œuvre. En outre, le juge constitutionnel ne doit pas se borner à traiter le problème de manière purement abstraite. Il lui incombe de prendre en compte la vraisemblance d'une application conforme aux droits fondamentaux. Si une réglementation de portée générale apparaît comme défendable au regard du droit supérieur dans des situations normales, telles que le législateur pouvait les prévoir, alors l'éventualité que, dans certains cas, son application

\footnotetext{
$90 \quad$ Voir sur le sujet les intéressants développements de BEHRENDT, BouHON (note 7), p. 260 et les références citées.

91 Sur le sujet, voir en particulier ZimmermanN (note 4), p. 26 et s. Dans le système français, le procédé de l'interprétation conforme permet également à la Cour de cassation et au Conseil d'État d'aplanir et de désamorcer, à travers la fonction de filtrage des questions prioritaires de constitutionnalité qui est impartie à ces juridictions avant une éventuelle saisine du Conseil constitutionnel, les risques de conflit entre la loi et la Constitution ; voir Marthe Fatin-Rouge STEFAnini, Laurence GAY, « Filtrage des QPC et système de justice constitutionnelle. Réflexions sur la participation des cours suprêmes au contrôle de la constitutionnalité des lois », Long cours. Mélanges en l'honneur du Professeur Pierre Bon, Paris 2014, p. 202 et les références citées.
} 
puisse se révéler inconstitutionnelle ne saurait en principe justifier une intervention du juge au stade du contrôle abstrait des normes ${ }^{92}$.

Mais la Constitution peut changer. Le droit constitutionnel peut aussi subir une évolution susceptible d'affecter son interprétation et sa compréhension. Aussi, une loi déclarée naguère conforme à la Constitution à la faveur d'un contrôle abstrait peut-elle, demain ou après-demain, ne plus l'être. Le contrôle concret des normes permet, à cet égard, d'assurer une forme de suivi et d'adaptation au cours de la mise en ouvre du droit constitutionnel. Davantage que le contrôle abstrait, cette forme de contrôle permet de déceler, d'identifier et de résoudre des questions qui, pour être liées à l'évolution sociale, sont souvent fondamentales d'un point de vue constitutionnel et qui n'ont pu apparaître lors du contrôle portant abstraitement sur la norme en cause ${ }^{93}$.

En Suisse, de longue date, les deux formes de contrôle, abstrait et concret, coexistent et déploient successivement leurs effets à l'égard de l'ensemble de la législation cantonale de rang infra-constitutionnel. La combinaison de ces deux modes de contrôle de la constitutionnalité a été précisément voulue afin de permettre d'assurer une surveillance optimale, par la voie contentieuse, du respect de la Constitution fédérale comme de celle de chaque canton.

Dès lors, si l'utilité du contrôle abstrait de constitutionnalité n'est plus à démontrer, il n'est certainement pas non plus exagéré d'affirmer que le contrôle concret représente un complément tout à la fois incontournable et indispensable en vue de permettre au droit constitutionnel de vivre, d'évoluer bref, de fonctionner. Tant il est vrai que, comme l'a si bien relevé le Professeur Louis Favoreu dans l'éditorial présentant le premier volume de l'Annuaire international de justice constitutionnelle, « c'est qu'en effet, le droit constitutionnel prend une nouvelle dimension dès lors qu'il est lui-même susceptible d'être un droit appliqué par le juge, et plus seulement un droit institutionnel $»^{94}$.

92 La formule est traditionnelle dans la jurisprudence. Voir par exemple l'arrêt du Tribunal fédéral Fondation Armée du Salut suisse et Société coopérative Armée du Salut Oeuvre Sociale c. Grand Conseil et Conseil d'État de la République et canton de Neuchâtel, du 13 septembre 2016 , ATF 142 I 195, consid. 2 et les références citées.

93 Voir Kastanas (note 44), p. 56.

94 AIFC I-1985, p. 12. 


\title{
DÉBATS
}

\author{
sous la présidence de Monsieur Guy CANIVET
}

Guy Canivet observe que la présentation faite par Patrick Taillon du système canadien montre une intégration harmonieuse du rôle respectif des juridictions dans l'application des principes de la Constitution tandis que la culture française procède plutôt par opposition dialectique entre elles. Il relève aussi que dans le système français, comme dans le système canadien, les juridictions peuvent remettre en cause les interprétations de la Constitution par le juge constitutionnel, en invoquant un changement dans les circonstances de droit ou fait. Ce qui permet une interprétation évolutive de la Constitution.

Monsieur Guy Canivet remercie également Monsieur Hottelier de la présentation du système suisse et d'avoir mis en évidence les conséquences juridiques d'un constat de non-conformité de la loi à la Constitution. Il observe qu'à cet égard le système français est assez souple, puisqu'il permet de différer dans le temps les conséquences d'une déclaration de non-conformité de la loi à la Constitution, c'est-à-dire de poursuivre à certaines conditions l'application d'une loi contraire à la Constitution.

Caterina Severino s'interroge sur la suite d'une déclaration d'inconstitutionnalité d'une décision de justice par le Tribunal fédéral suisse.

Michel Hottelier répond que lorsque le Tribunal fédéral invalide la décision dans le cadre du contrôle concret de la constitutionnalité, son verdict déploie en principe un effet cassatoire. Cela signifie qu'en cas de vice de forme par exemple, il faut réentendre les témoins, reprendre la procédure d'instruction, ce qui risque de poser plusieurs problèmes. Si c'est la norme elle-même qui vient à être déclarée contraire à la Constitution dans le cadre du contrôle concret, il incombe aux autorités qui l'ont adoptée de l'abroger ou de la modifier en conséquence. Il n'appartient pas au Tribunal fédéral d'abroger ou de modifier la norme sur contrôle concret, ce qui peut occasionner des problèmes dans l'hypothèse où le législateur n'accomplit pas cette tâche. Au fond, la question du pouvoir de décision de la juridiction constitutionnelle reste un sujet de théorie du droit tout à la fois complexe et relativement peu étudié. Il existe également la théorie de ce que l'on appelle les décisions incitatives. À titre d'exemple, on peut citer une affaire sur le régime des allocations familiales à Genève. Ici, le Tribunal fédéral avait certes admis un recours dirigé contre la loi (il s'agissait d'un cas de contrôle 
abstrait de constitutionnalité d'une loi cantonale), mais il a finalement constaté que l'annulation de la loi serait par trop brutale et aboutirait à des conséquences désastreuses. Autrement dit, à la fin des allocations familiales à Genève. Il faut, en pareille hypothèse, aller par-delà la théorie du droit pour évaluer et comprendre la portée sociale d'une telle décision. Du coup, le recours admis se limite à pointer la violation de la Constitution, mais l'acte incriminé reste néanmoins en vigueur, le temps de permettre le rétablissement d'une situation conforme au droit. La règle est donc la suivante : la décision attaquée est, sur contrôle concret en principe annulée, avec certaines exceptions toutefois, et le rétablissement de la situation conforme au droit incombe à l'autorité compétente dans un délai raisonnable. Que se passe-t-il si les autorités compétentes n'agissent pas ? Il faut alors attendre, envisager de passer par la voie politique pour faire modifier l'acte normatif en cause ou encore tenter de déposer un recours pour refus de statuer devant le Tribunal fédéral sur le fondement du dépassement d'un délai raisonnable. Il importe néanmoins de préciser que ces cas sont rares, en l'absence de véritable procédure juridictionnelle pour omission dans le cadre de la procédure normative.

Guy Canivet, répondant à $\mathbf{M}^{\text {me }}$ Severino, note que la solution est différente dans le cadre de la QPC. Selon l'article 62 de la Constitution, le législateur dispose d'un délai fixé par le Conseil constitutionnel pour modifier la loi et la rendre conforme à la Constitution. S'il ne le fait pas, la déclaration d'inconstitutionnalité produit tous ses effets et la loi est abrogée. En outre, dans ce délai, la Conseil constitutionnel peut aménager les effets de la déclaration d'inconstitutionnalité.

Deux questions sont posées à Patrick Taillon. La première question porte sur le Comité judiciaire du Conseil privé et sur d'éventuelles similitudes avec le cas français et le fait que le juge suprême se trouve inhibé par l'autorité du Conseil constitutionnel dans son contrôle. La seconde porte sur la jurisprudence célèbre de la Cour suprême du Canada dans les années 1980, avec l'affaire Sellars sur la portée contraignante d'un obiter dictum en lien avec le fait que le juge suprême français, dès lors qu'il se prononce, se prononce en droit et pas seulement en fait.

Patrick Taillon répond que jusqu'à 1949, la Cour suprême n'était pas une cour suprême. Il faut aussi préciser que lorsque la Fédération canadienne a été créée, la Cour suprême n'existait pas. Les tribunaux existaient dans chacune des colonies et la compétence de créer éventuellement une cour générale d'appel a été établie. Cette cour générale d'appel, créée en 1875, avait vocation à l'échelle du Canada de rendre des décisions contestables devant ce qu'on pourrait appeler une Cour suprême impériale qui est le Comité judiciaire du Conseil privé. L'abolition en 1949 s'est faite progressivement. Ils avaient maintes attributions : il n'y a pas de sujet pour lesquels l'un était compétent et l'autre ne l'était pas. Le Professeur Taillon a l'impression que cela fait partie du long processus d'émancipation de la tutelle coloniale. Mais est-ce que cela a vraiment changé ? Il est certain que la Cour suprême a acquis une marge de manœuvre. Toutefois, la manière dont le contrôle de constitutionnalité se pratiquait ne représentait a priori pas de révolution immédiate. 
Quant à la deuxième question sur l'obiter dictum, cela fait partie des grandes libertés que se permettent les juridictions canadiennes. Dans un système d'unité juridictionnelle, la Cour est au sommet de la pyramide, elle est totalement libre. Si elle décide de lier les autorités par obiter dictum, elle le fait. Monsieur Taillon estime qu'un common lawer « orthodoxe » est de plus en plus perplexe sur la manière dont la Cour travaille avec les concepts et les méthodes de la common law. Un Obiter dictum ne devrait pas, par définition, être contraignant. Mais, dans un système de common law, la Cour suprême prend les libertés qu'elle veut. Elle s'est même mise à développer des principes. En common law, on travaille avec des cas, des précédents, qui sont précis et on poursuit la logique des principes généraux du droit. On commence à aller vers un raisonnement plus abstrait. Ainsi, au Canada, on travaille beaucoup avec les principes depuis les vingt dernières années et cela dénature un peu les techniques propres à la common law. 

PARTIE II

\section{LE CONTRÔLE DES DÉCISIONS DE JUSTICE PAR LES COURS CONSTITUTIONNELLES}



À la différence des cours suprêmes, les cours constitutionnelles sont généralement saisies du contrôle spécifique de la constitutionnalité des décisions de justice par une attribution de compétence expresse de la Constitution. Dans ce cas, la décision de justice est l'objet direct du recours, comme cela est le cas de la plupart des recours déclenchés par les individus tels que le Verfassungsbeschwerde en Allemagne ou le recours d'Amparo en Espagne.

Dans d'autres systèmes en revanche, tels que le système français, belge ou italien, la cour constitutionnelle peut être amenée - dans le cadre du contrôle de constitutionnalité par voie préjudicielle - à contrôler l'interprétation de la loi donnée par une juridiction ordinaire et, par ce biais, à contrôler la décision de justice elle-même. Dans cette hypothèse, ce contrôle ne constitue qu'un prolongement de l'examen de la constitutionnalité de la loi.

Le Portugal représente, pour sa part, un exemple de système mixte dans lequel un contrôle diffus de constitutionnalité peut aboutir à ce que le Tribunal constitutionnel soit saisi des interprétations délivrées par les juridictions inférieures. 



\section{Présidence de Madame le Professeur Anne Levade, Présidente de l'Association française de droit constitutionnel}

Le Professeur Anne Levade, après avoir rappelé que ce colloque est soutenu par l'association qu'elle préside, tient à en remercier les organisatrices ; elle les remercie de l'y avoir conviée, mais aussi et surtout du choix du thème qui, dit-elle, pour un juriste français suscite l'interrogation d'emblée. Elle dit avoir récemment croisé, en d'autres lieux, certains des intervenants à cette manifestation qui lui ont dit leur surprise en voyant le terrain sur lequel le programme s'engageait. Pour Anne Levade, cela est bon signe et indique en soi que la rencontre de la journée est justifiée.

Madame Levade dit ensuite son sentiment sur les débats du matin qui ont été particulièrement riches ; elle insiste sur le plaisir et l'intérêt qui sont les siens de pouvoir présider cette après-midi, qui invite littéralement à un tour d'Europe.

Elle rappelle que le matin même, une partie de l'Europe a déjà été étudiée, à propos du contrôle diffus. Elle rappelle notamment que cette matinée a permis de comprendre quels étaient les avantages et les vertus du monopôle en termes de contrôle de constitutionnalité. Si certains ont pu, un temps, nourrir le fantasme qu'un jour nous parviendrons à un contrôle diffus en France, elle souligne avoir bien entendu les propos du Président Guy Canivet louant la richesse des échanges et des contradictions, d'où peut parfois surgir la lumière entre les ordres juridictionnels. 



\title{
Chapitre 1
}

\author{
LE CONTRÔLE \\ DES DÉCISIONS DE JUSTICE EXERCÉ \\ DANS LE CADRE DES RECOURS DIRECTS
}





\title{
LE RECOURS INDIVIDUEL DIRIGÉ CONTRE UNE DÉCISION DE JUSTICE POUR VIOLATION D'UN DROIT FONDAMENTAL DANS LA RÉ PUBLIQUE FÉdÉ RALE D’AlLEMAgNe
}

\author{
Michel Fromont ${ }^{1}$
}

Quelques rappels historiques sont nécessaires pour comprendre la situation de l'Allemagne et l'évolution de ses institutions. 1945 : l'Allemagne capitule sans condition, les villes sont rasées, il n'y a rien à manger et la plupart des hommes sont prisonniers de guerre, les femmes déblaient les décombres. 1945-1949 : progressivement, des institutions publiques se reconstituent sous l'impulsion des puissances d'occupation sur le modèle occidental à l'ouest, sur le modèle communiste à l'est (mise en place des communes, puis des Länder), le Plan Marshall, le retour progressif des prisonniers, la réforme monétaire de 1949. 1949 : les puissances d'occupation de l'Ouest décident de susciter la reconstitution d'un État fédéral (Bundesrepublik) à partir des Länder, adoption de la Loi fondamentale le 23 mai 1949 par le Conseil parlementaire (Parlementarischer Rat) composé de délégués des assemblées parlementaires des Länder sous la surveillance des autorités d'occupation². Parmi les innovations les plus notables de la partie IX consacrée au pouvoir judiciaire, figurent la création d'une Cour constitutionnelle fédérale (Bundesverfassungsgericht) et des 5 juridictions fédérales chargées de veiller à l'unité de jurisprudence des tribunaux des Länder dans les différents domaines du droit (droit privé et pénal, droit du travail, droit administratif, droit fiscal, droit social). La Loi fondamentale ne consacre que deux articles à cette nouvelle Cour, l'article 93 énumérant les compétences de celle-ci et l'article 94, très bref, consacré à la composition de celle-ci. Cette brièveté s'explique par le fait que le Parlement hésitait encore entre plusieurs conceptions de la justice constitutionnelle : la juridiction doit-elle faire l'objet d'une partie de la constitution distincte de celle consacrée au pouvoir judiciaire? Les juges doivent-ils être proches du peuple et ne pas être des juristes accomplis ayant les diplômes nécessaires pour être juges (comme c'est le cas partiellement pour les juridictions du travail et les juridictions sociales) ? Les simples particuliers peuvent-ils saisir directement la nouvelle Cour ?, etc... À toutes ces questions, il fut répondu par la négative, les chrétiens-démocrates et leurs alliés, qui avaient la majorité, étant favorables à une juridiction classique.

Ancien professeur des Universités allemandes, professeur émérite à l'Université Paris I Panthéon Sorbonne.

En particulier, les puissances d'occupation insistèrent pour que le fédéralisme soit plus fortement décentralisé dans la nouvelle constitution qu'il ne l'avait été à l'époque de la République de Weimar. 
Cependant, lors de l'adoption de la loi fédérale consacrée à cette nouvelle juridiction deux ans plus tard, la majorité fit une concession majeure à l'opposition social-démocrate souhaitant une juridiction constitutionnelle proche du peuple : les particuliers qui invoquent reçurent le droit de saisir directement la Cour s'ils invoquent la violation d'un de leurs droits garantis par la constitution. Le fameux recours individuel pour violation d'un droit fondamental (Verfassungsbeschwerde) ${ }^{3}$, qui fait aujourd'hui l'orgueil des juristes allemands, fit ainsi son entrée par la petite porte. Cette loi fut d'ailleurs longue à être élaborée puisqu'elle ne fut finalement promulguée que le 12 mars 1951, soit deux ans plus tard ; l'été sera encore nécessaire pour la nomination des premiers juges et la Cour ne commencera à siéger qu'au mois de septembre 1951. Or ce recours fait aujourd'hui l'objet de la majeure partie de l'activité de la Cour et les citoyens y sont très attachés. Compte tenu de son succès, le recours individuel a fait enfin son entrée dans la Loi fondamentale en 1968 à titre de contrepartie à la création de pouvoirs spéciaux dans les situations d'urgence qui fit cette année-là l'objet d'une consécration dans la constitution du fait que les puissances d'occupation renonçaient alors à leurs pouvoirs d'intervention en Allemagne en cas de trouble ou de menace pour la démocratie.

De 1951 à nos jours, soit durant ces 65 ans de fonctionnement, la Cour constitutionnelle fédérale a su devenir une juridiction extrêmement puissante : du 7 septembre 1951 au 31 décembre 2015, 220 353 affaires ont été portées devant la Cour et 216741 ont été jugées (ou réglées d'une autre façon). Les causes de cette puissance tient précisément au nombre considérable de recours individuels qui ont été dirigés par les simples citoyens contre des jugements et autres décisions de justice.

Nous présenterons successivement la place des recours individuels portés devant la Cour constitutionnelle fédérale dans l'ensemble du contentieux constitutionnel allemand, puis la procédure d'examen de ces recours qui est suivie par la Cour constitutionnelle fédérale, enfin la fonction remplie par la Cour constitutionnelle fédérale quand elle statue sur ces recours.

\section{La place des recours individuels dirigés contre les décisions de justice dans le contentieux constitutionnel allemand}

En premier lieu, il convient de rappeler brièvement que les juridictions autres que la Cour constitutionnelle fédérale ont également des compétences pour vérifier la constitutionnalité des décisions de justice.

\footnotetext{
3 Nous évitons systématiquement de traduire «Verfassungsbeschwerde » par recours constitutionnel » pour deux raisons : cette expression est également utilisée pour traduire l'expression espagnole « recurso de inconstitucionalidad» qui ne peut être mis en mouvement que par des autorités publiques et est donc un recours objectif, et surtout, elle est susceptible d'induire en erreur, car elle est insuffisamment explicite. Il est vrai que les juristes français pourraient s'inspirer de la traduction anglaise « constitutional complaint » et parler de plainte constitutionnelle, mais une telle traduction s'inscrit difficilement dans le vocabulaire habituel des juristes francophones.
} 


\section{A. Les recours portés devant les autres juridictions}

\section{Devant les Cours constitutionnelles des Länder}

En premier lieu, les Länder ont tous leur propre Cour constitutionnelle. Ces cours sont chargées de se prononcer non seulement sur les contestations de la conformité des lois et règlements des Länder à leur propre constitution, mais aussi sur de nombreuses décisions prises par les autorités gouvernementales dans leurs relations avec l'assemblée législative du Land.

De plus, les Cours constitutionnelles des Länder sont fréquemment compétentes pour connaître de recours dirigés par des individus prétendant être lésés dans leurs droits fondamentaux par les décisions prises par les différentes autorités judiciaires des Länder (principalement les tribunaux de première et seconde instance, les procureurs et les juges ayant compétence pour statuer seuls). Les Länder qui ont conféré une telle compétence à leur cour constitutionnelle sont la Bavière, Berlin, la Hesse (où le recours s'appelle action pour défendre un droit fondamental, Grundrechtsklage), le MecklembourgPoméranie occidentale, le Rhénanie -Palatinat, la Sarre, la Saxe et la Thuringe, soit au total 8 Länder sur 16, les autres Länder n'ayant créé aucun recours individuel ou l'ayant limité à la contestation d'une loi de Land.

Comme ces recours individuels dirigés contre une décision de justice peuvent être indifféremment portés devant la Cour constitutionnelle fédérale ou devant la Cour constitutionnelle du Land concerné, orsque le droit fondamental invoqué est garanti par la constitution de la Fédération et celle du Land, le nombre d'affaires portées devant les cours constitutionnelles des Länder est assez faible : par exemple, en 2010, la cour de Bavière n'avait été saisie que de 175 affaires, dont 143 recours individuels et 31 actions populaires. Les décisions les plus notables sont analysées dans ma chronique de jurisprudence constitutionnelle paraissant chaque année dans la Revue du droit public, du moins depuis la chronique consacrée aux années 1998 et 1999 (RDP 2001, p. 119)

\section{Le contentieux porté devant une juridiction non constitutionnelle}

Les juridictions ordinaires sont liées à la fois par la constitution et la loi, y compris par les règlements administratifs et gouvernementaux (lesquels sont nécessairement édictés en vertu d'une loi) ${ }^{5}$. En outre, la partie la plus importante des règles contenues dans la Loi fondamentale, celle relative aux droits fondamentaux, est déclarée immédiatement applicable par la constitution de la Fédération ${ }^{6}$.

\footnotetext{
4 La Cour constitutionnelle fédérale, qui est surchargée de recours, encourage les justiciables allemands à saisir la Cour Constitutionnelle de leur Land. Ainsi, depuis 1997 (décision du 15 octobre 1997, analyse Fromont, RDP 1999, p. 505), elle refuse d'examiner un recours individuel dirigé contre une décision de justice prise en vertu d'une loi fédérale dès lors que le requérant fait valoir la violation d'un droit garanti par la constitution du Land. Depuis ce changement de jurisprudence, les recours dirigés contre des décisions de justice devant les Cours constitutionnelles des Länder sont un peu plus nombreux ; c'est pourquoi nous relatons les principales décisions des Cours constitutionnelles des Länder depuis que cette décision a été rendue dans notre chronique annuelle « La jurisprudence constitutionnelle allemande » dans la Revue du droit public.

5 Art. 20, al. 3, Loi fondamentale : « Le pouvoir législatif est lié par l'ordre constitutionnel, les pouvoirs exécutif et judiciaire sont liés par la loi et le droit ».

6 Art. ${ }^{\text {er }}$, al. 3, Loi fondamentale : «Les droits fondamentaux énoncés ci-après lient les pouvoirs législatif, exécutif et judiciaire à titre de droit immédiatement applicable ».
} 
En conséquence, toutes les juridictions allemandes ont le devoir d'appliquer non seulement la loi et les règlements, mais aussi la constitution (celle de la Fédération et celle de leur Land), y compris les droits fondamentaux, et en cas de conflit entre une disposition constitutionnelle et la décision contestée, elles doivent trancher elles-mêmes la question de constitutionnalité : les tribunaux ordinaires allemands sont donc des juges constitutionnels et c'est pourquoi ma chronique annuelle de jurisprudence constitutionnelle allemande à la Revue de droit public contient toujours l'analyse de quelques décisions de justice émanant des juridictions ordinaires, spécialement dans les domaines où les Länder ont des compétences législatives et administratives étendues, comme l'audiovisuel, l'enseignement et le droit administratif.

Il existe toutefois une compétence qui leur a été expressément refusée, celle de déclarer inconstitutionnelle et donc nulle une loi, même si celle-ci a été édictée par un Land, mais seulement si elle a été édictée après l'entrée en vigueur de la Loi fondamentale le 23 mai 1949. En effet, selon la Loi fondamentale, les juridictions ordinaires ne peuvent pas déclarer elles-mêmes inconstitutionnelle une loi postérieure à 1949 et la déclarer inapplicable si celle-ci est postérieure au 23 mai 1949. En effet, selon l'article 100, al. 1 de la Loi fondamentale, « si un tribunal estime qu'une loi dont la validité conditionne sa décision est inconstitutionnelle, il doit soumettre la question à la décision du tribunal compétent pour les litiges constitutionnels du Land s'il s'agit de la violation de la constitution d'un Land, à la décision de la Cour constitutionnelle fédérale s'il s'agit de la violation de la présente Loi fondamentale $\gg^{7}$. Dans la pratique, les cas de saisine de la Cour constitutionnelle fédérale en vue du contrôle de la constitutionnalité d'une loi fédérale, ce que les juristes allemands appellent le contrôle concret des normes (konkrete Normenkontrolle) sont peu nombreux ; ainsi, en 2014 et 2015, seulement 25 et 5 demandes de contrôle concret ont été examinées au fond. Bien sûr, lorsque le tribunal ordinaire juge que la loi ou le règlement applicable au litige est conforme à la constitution, le justiciable qui est mécontent de l'issue du procès, peut contester le jugement rendu pour atteinte à l'un de ses droits fondamentaux, comme nous allons le montrer.

\section{B. Les recours individuels dirigés contre une décision de justice et portés devant la Cour constitutionnelle fédérale}

\section{Les titres de compétence autres que les recours individuels}

Il n'est pas question d'énumérer ici toutes les compétences de la Cour constitutionnelle fédérale : le $\S 13$ de la loi de 1951 sur la Cour énumère au total 17 titres de compétence. D’autant plus que beaucoup sont sans importance ou ne sont exercées que de façon sporadique comme les appels dirigés contre les décisions du Bundestag relatives à l'élection de ses membres ou encore les demandes d'interdiction de partis politiques qui ont d'ailleurs toutes échoué depuis les années 1950. Les seuls titres de compétence méritant d'être mentionnés sont les deux formes de contrôle des normes, le

$\overline{7} \quad$ Il existe deux autres cas, de moindre importance, celui où le tribunal doit saisir la Cour constitutionnelle fédérale selon les alinéas suivant du même article 100 de la Loi fondamentale, celui où « il y a doute sur le point de savoir si une règle de droit international public fait partie du droit fédéral et crée des droits et obligations pour les individus » et celui où une « cour constitutionnelle de Land entend s'écarter d'une interprétation de la Loi fondamentale faite par la Cour constitutionnelle fédérale ». 
contrôle concret et le contrôle abstrait, les litiges entre organes constitutionnels (spécialement entre l'exécutif et le législatif, comme, par exemple au sujet de la décision de dissolution du Bundestag, voire opposant des députés à leurs groupes parlementaires ou aux organes du Bundestag) et enfin les litiges dits fédéraux qui opposent les Länder à la Fédération (ou entre eux).

Même si on les compte tous ensemble, ces titres de compétence ne fournissent que 3\% à 3,5\% des affaires portées devant la Cour constitutionnelle fédérale. Ces titres de compétence présentent cependant une certaine importance, car ils conduisent assez souvent à soumettre à la Cour des questions particulièrement délicates, comme la constitutionnalité de certaines lois ayant mobilisé l'opinion publique ou celle de certaines décisions gouvernementales ou présidentielles, comme la dissolution du Bundestag ou la décision d'envoyer des troupes sur des théâtres d'opération extérieure. À côté de ces titres de compétence qui sont peu importants quantitativement se trouvent les recours individuels pour violation d'un droit fondamental, notamment et principalement les recours individuels qui peuvent être dirigés contre une loi ou une décision du gouvernement ou d'un organe judiciaire qui sont en grand nombre.

\section{Les recours individuels dirigés contre les décisions de justice}

Compte tenu du faible nombre de saisines correspondant à tous les autres titres de compétence, les recours individuels pour violation d'un droit fondamental (Verfassungsbeschwerde) forment la quasi totalité des affaires portées devant la Cour constitutionnelle fédérale. Même si leur nombre a légèrement décru en 2015, il est encore fort élevé : 5739 entrées en 2015 (6606 l'année précédente). Certes beaucoup échouent : en 2015, 5773 ont été rejetés, la plupart par une Section (Kammer) formée de trois juges statuant à l'unanimité selon une procédure écrite, quelques dizaines seulement par l'une des deux Chambres siégeant en séance plénière (Senat). Mais les recours qui réussissent sont en nombre non négligeable : chaque année, plus d'une centaine ont abouti à une déclaration d'inconstitutionnalité ou à l'annulation d'une loi ou d'une décision de justice. Plus précisément, en 2015, il y a eu 98 recours déclarés bien fondés par l'une des sections de trois juges et 13 par l'une des deux chambres statuant en séance plénière. À ces décisions déclarant inconstitutionnelle ou annulant pour inconstitutionnalité une loi ou une décision administrative ou judiciaire, il convient d'ajouter les innombrables décisions fondées sur une interprétation de la loi faite en conformité avec la constitution (verfassungskonforme Auslegung), que la loi ait été contestée directement ou à travers la décision judiciaire qui l'applique ${ }^{8}$.

Mais, parmi ces recours individuels, ceux dirigés contre des décisions de justice sont de beaucoup les plus nombreux. En effet, les recours individuels dirigés directement contre une loi sont tout-à-fait exceptionnels : normalement il faut attendre un acte d'application de la loi pour que le destinataire puisse attaquer la loi, sauf dans les cas où cela paraît inadmissible. La Cour constitutionnelle fédérale ne l'admet pratiquement que dans deux cas : le requérant conteste la constitutionnalité d'une loi

8 Au total, les statistiques de la Cour indiquent qu'en 2015, 120 recours ont été dirigés directement contre une loi ou un règlement et que 248 ont été dirigés indirectement contre une loi ou un règlement. 
pénale ou d'une loi s'appliquant immédiatement à un grand nombre comme, par exemple, une loi prescrivant le recensement de la population. Quant aux recours dirigés contre une décision administrative, ils sont le plus souvent irrecevables, car il faut d'abord épuiser les voies de recours ordinaires et dans ce cas, le recours individuel sera dirigé contre le jugement rendu au sujet de cette décision.

Dans la pratique, on observe une forte prépondérance des recours individuels dirigés contre une décision judiciaire : parmi les 5798 recours individuels jugés en 2015, 5180 d'entre eux ont été dirigés contre des jugements ou des décisions émanant d'un ou plusieurs juges et ils ont abouti à l'annulation pour inconstitutionnalité de 113 décisions de justice, dont 18 émanaient de l'une des juridictions suprêmes placées au sommet de l'un des cinq ordres de juridictions. En outre, ils ont abouti à la déclaration d'inconstitutionnalité ou à l'annulation de 120 dispositions législatives (les interprétations conformes à la constitution étant beaucoup plus nombreuses, mais non recensées par les statistiques de la Cour).

Si l'on compare le nombre de recours individuels dirigés contre des décisions de justice et celui des demandes de contrôle de la constitutionnalité d'une règle de droit, il apparaît que la Cour constitutionnelle fédérale est presque exclusivement un organe de contrôle de la constitutionnalité de l'application des lois, étant rappelé, qu'à cette occasion, la Cour procède fréquemment à des interprétations de la loi en conformité à la constitution qui sont d'ailleurs souvent très audacieuses. En d'autres termes, la Cour constitutionnelle est devenue une véritable cour suprême et est de ce fait, plus proche de la Cour suprême des États-Unis que des cours constitutionnelles bâties sur le modèle kelsénien, à savoir, spécialisées dans le contrôle de la constitutionnalité des lois.

\section{Les problèmes d'organisation posés par les recours individuels dirigés contre les décisions de justice}

L'institution du recours individuel pour violation d'un droit fondamental en 1951 a connu rapidement un grand succès : les règles de recevabilité applicables les premières années étaient très favorables aux individus souhaitant saisir la Cour de Karlsruhe ; en particulier, le recours pouvait être introduit sans ministère d'avocat dès le début des années 1950 (il l'est d'ailleurs toujours quoique les règles à respecter par le requérant soient devenues aujourd'hui très complexes) ${ }^{10}$, et la jurisprudence de la Cour n'avait pas encore alourdi les conditions de recevabilité, comme elle l'a fait par la suite notamment en appliquant de façon sévère la règle selon laquelle toutes les voies de recours ordinaires doivent d'abord être épuisées, ce qui a pour effet de réduire considérablement le nombre des recours dirigés contre des décisions gouvernementales ou administratives. De ce fait, le nombre des recours individuels portés devant la Cour constitutionnelle fédérale a vite dépassé le millier. Cette évolution a produit des effets contradictoires : d'une part, la Cour est devenue pour les citoyens allemands un arbitre incontesté de la vie politique et un protecteur admiré des libertés individuelles, ce qui a

9 Le lecteur trouvera ces statistiques sur le site Internet de la Cour constitutionnelle fédérale : http://bundesverfassungsgericht.de. 10 Dans la pratique, environ la moitié des recours individuels est présentée par un avocat (Lechner/Zuck, Bundesverfassungsgerichtsgesetz, Kommentar, 6 éd., 2011, p. 718). 
contribué au développement de ce qu'on a appelé le patriotisme de la constitution et à faire de la Cour ce qu'on a appelé « le juge des citoyens »(Bürgergericht); d'autre part, la Cour s'est trouvée submergée et elle a très vite réclamé au législateur qu'il prenne des dispositions en vue d'empêcher une véritable submersion de la Cour.

Quels ont été les efforts d'organisation et de réglementation de la procédure en vue d'endiguer le flot des recours tout en laissant aux citoyens et autres justiciables ce droit auquel ils tiennent tant, celui de défendre les droits que la constitution leur reconnaît depuis 1949 ? Ils ont consisté en premier lieu à multiplier les moyens et les formations de jugement ; ils ont consisté, en second lieu, à poser des règles restreignant l'accès au juge et facilitant le rejet des recours mal fondés.

\section{A. L'organisation de l'examen des recours individuels dirigés contre des décisions de justice}

\section{La multiplication des collaborateurs scientifiques}

Le nombre de collaborateurs scientifiques attribués à chaque juge constitutionnel a été progressivement augmenté ; il est aujourd'hui de quatre par juge (il y a, au total, 16 juges constitutionnels répartis entre les deux Chambres). Dans la pratique, ils sont choisis parmi les magistrats qui ont obtenu d'excellentes notes aux deux examens d'État qui clôturent les études universitaires de droit et les années de stage pratique. Aujourd'hui, il y a environ 64 collaborateurs scientifiques qui assistent ainsi les juges. C'est sur leur travail que s'appuient les juges rapporteurs pour rédiger leurs rapports. $\mathrm{Au}$ point que certains juristes allemands considèrent que cette soixantaine de juristes talentueux forment une sorte de troisième Chambre.

\section{La création d'une procédure dite d' "admission à la décision » et de six Sections chargées de l'essentiel du contentieux}

Tout d'abord, le règlement intérieur de la cour autorise les deux présidents de chambre à attirer l'attention des auteurs de recours fantaisistes ou téméraires sur l'absence de chance de voir leur recours examiné au fond et c'est seulement si le signataire du recours maintient sa demande que le recours sera transmis à des organes de jugement ; dans la pratique, la responsabilité de cette correspondance avec les requérants a fait l'objet d'une délégation au profit d'un fonctionnaire de la Cour qui doit avoir l'aptitude à être juge (c'est-à-dire être titulaire des deux examens d'État en droit) ${ }^{11}$. Mais cette mesure ne permet que d'alléger légèrement la charge de travail de la Cour, du moins si l'on ne veut pas confier le soin de rendre la justice à des personnes qui n'ont pas la qualité de juges.

11 Règlement intérieur de la Cour (Geschäftsordnung des Bundesverfassungsgerichts du 19 novembre 2014) : § 63 « ... (2) Dans le Registre général, peuvent être aussi enregistrés a) les recours individuels pour violation d'un droit fondamental, pour lesquels une « admission » à décision ne peut pas être prise en considération parce qu'ils sont manifestement irrecevables ou ne peuvent manifestement avoir aucun succès compte tenu de la jurisprudence de la Cour... » $§ 64:$ : La décision sur l’inscription au Registre général est prise par le Président de la Chambre concernée. Il peut déléguer sa compétence à des collaboratrices ou collaborateurs autorisés à signer le courrier conformément au $§ 16$ ». Or le $\S 16$ dispose : «... (2) Ceux qui sont désignés pour signer le courrier et les décisions relatives au Registre général doivent avoir la capacité d'être juge ». En général, cette compétence est déléguée à une personne qui porte le nom de «Präsidialrat » (conseiller du Président de l'une des deux Chambres). 
L'intervention du législateur a donc été nécessaire. Elle n’a pas été aisée, car il est difficile de conserver au recours individuel son caractère populaire, c'est-à-dire la facilité d'accès, tout en protégeant la Cour constitutionnelle contre une avalanche de recours n'ayant aucune chance de succès. La dispense de ministère d'avocat a donc été maintenue, mais en 1956, le législateur a commencé à mettre en place un système que les juristes français appelleraient « filtrage » et que les juristes allemands appellent d'une expression plus neutre « admission à la décision» (Annahme zur Entscheidung). Depuis 1956, la loi sur la Cour constitutionnelle fédérale a été maintes fois modifiée sans d'ailleurs que les dispositions actuellement en vigueur soient aujourd'hui encore un modèle de précision et de logique, car ces ajouts ont toujours été apportés a minima, phénomène qui est pourtant beaucoup plus rare en Allemagne qu'en France, les juristes allemands ayant généralement le goût du travail bien fait, même lorsque les dispositions adoptées sont le résultat de compromis politiques.

Les Sections sont des formations de jugement constituées de trois juges constitutionnels appartenant à la même Chambre, chaque Chambre étant composée de huit juges et présidée par le Président ou le Vice-président de la Cour. Les juges de chaque Chambre sont ainsi répartis entre trois Sections. La composition des Sections doit changer tous les trois ans afin d'éviter que ne se forment des Sections ayant constamment la même composition.

Selon la loi sur la Cour constitutionnelle fédérale, telle qu'elle est rédigée aujourd'hui, l'examen et le jugement de la quasi totalité des recours individuels sont confiés principalement à ces six Sections (Kammer) ; les deux Chambres en formation plénière (8 juges) ont conservé seulement des compétences que dans deux cas : le recours individuel a été jugé digne d'être examiné au fond ou bien il met indirectement en cause la constitutionnalité d'une loi postérieure à 1949.

Dans la pratique, tous les recours individuels, autres que ceux dirigés directement contre une loi, sont transmis dans un premier temps à l'une des deux Chambres (Senat) selon une grille de répartition par matière établie par le règlement intérieur. Puis, le président de chaque Chambre répartit les recours individuels entre les trois Sections qui sont placées sous sa présidence. Chacune des Sections a alors la charge de procéder au filtrage des recours individuels qu'elle a reçus et doit refuser l'« admission à la décision » (Annahme zur Entscheidung), soit pour irrecevabilité, soit pour absence manifeste de bien fondé ${ }^{12}$.

En outre, depuis 1985, la loi autorise aussi les Sections à admettre le recours et à le déclarer bien fondé « si la Cour constitutionnelle fédérale s'est déjà prononcée sur la question de droit constitutionnel qui détermine l'issue du procès et si le recours est apparemment fondé $»^{13}$; une exception est toutefois faite pour les cas où cette décision déclarerait « qu'une loi est incompatible avec la Loi fondamentale ou tout autre droit fédéral ou est nulle », car une telle décision est expressément réservée par la loi à la Chambre à laquelle appartient la Section qui avait été saisie initialement ${ }^{14}$.

$12 \S 24$ de la loi sur la Cour constitutionnelle fédérale : « Rejet d'une demande a limine.- (1) Les demandes irrecevables ou manifestement non fondées peuvent être rejetées par une décision unanime de la Cour » (rédaction sous cette forme depuis 1970).

$13 \S 93 \mathrm{c}$, al.1, $1^{\text {re }}$ et $2^{\mathrm{e}}$ phrases, loi sur la Cour constitutionnelle fédérale

$14 \S 93 \mathrm{c}$, al.1, $3^{\mathrm{e}}$ phrase, loi sur la Cour constitutionnelle fédérale 
Alors que le premier recueil officiel reproduit seulement les décisions des Chambres de la Cour à l'exclusion des décisions rendues par les Sections, un second recueil publie les plus intéressantes décisions émanant des Sections ${ }^{15}$.

\section{B. Les règles de recevabilité et de fond applicables aux recours dirigés contre une décision de justice}

Pour exposer les règles qui régissent ce filtrage, nous distinguerons les règles qui s'imposent indistinctement aux Sections et aux Chambres, puis celles applicables aux décisions qui sont prises par les Sections et qui sont de beaucoup les plus nombreuses et enfin celles applicables aux décisions prises par l'une des deux Chambres en séance plénière et qui sont relatives aux recours les plus importants.

\section{Les règles s'appliquant indistinctement aux Sections et aux Chambres}

Les règles qui s'appliquent indistinctement aux Sections et aux Chambres sont les règles d'irrecevabilité (Unzulässigkeit) contenues dans les §§ 90, 92 et 93 de la loi sur la Cour constitutionnelle fédérale.

Le $\S 90$, al.1, pose la règle selon laquelle « toute personne peut introduire le recours individuel en prétendant avoir été lésée par la puissance publique dans l'un de ses droits fondamentaux ou dans l'un de ses droits garantis par les articles 20 al. 4, 33, 38, 101, 103 et $104 »^{16}$. Trois conditions de recevabilité sont ici posées : être une personne quelconque (physique ou morale, nationale ou étrangère), être lésée par la puissance publique (l'exigence d'une lésion est toutefois entendue de façon large par la Cour), dans l'un de ses droits fondamentaux ou assimilés ${ }^{17}$ (ce qui souligne le caractère subjectif du recours, du moins à ses origines, voir infra).

Le $\S 90$, al. 2, pose la règle de l'épuisement des voies de recours ordinaires (Erschöpfung des Rechtswegs), ce qui a pour effet d'écarter les recours dirigés contre des jugements ou des décisions judiciaires qui peuvent encore faire l'objet de voies de recours permettant de contester l'atteinte portée au droit fondamental affecté par la décision de justice.

Les $\S \S 92$ et 93 exigent que le recours soit motivé, c'est-à-dire « précise le droit qui aurait été violé et l'action ou l'omission de l'organe ou de l'autorité par laquelle il se sent lésé » et qu'il soit « introduit dans le délai d'un mois », ce délai pouvant être prolongé lorsque le requérant n'est

\footnotetext{
15 Kammerentscheidungen des Bundesverfassungsgerichts, eine Auswahl ou BVerfGK, reproduisant un choix de décisions des Sections rendues depuis le $1^{\text {er }}$ janvier 2003, 20 tomes rassemblant les décisions rendues entre 2003 à 2014, C.F. Müller Verlag, Heidelberg.

16 Noter que le $\S 90$ al.1 de la loi sur la Cour constitutionnelle fédérale reproduit quasiment mot pour mot les dispositions contenues à l'article 93, al.1, 4a de la Loi fondamentale qui est d'ailleurs la seule disposition constitutionnelle consacrée aux recours individuel pour violation d'un droit fondamental.

17 Les droits fondamentaux assimilés, ceux énumérés expressément à l'article 93, al. 1, 4a, de la Loi fondamentale, sont : le droit à agir en justice contre tout acte d'une autorité gouvernementale ou administrative (art. 20), l'égal accès aux fonctions publiques et le droit des fonctionnaires publics à être régis par les règles traditionnelles de la fonction publique (art. 33), le droit de vote (art. 28), le droit au juge légal (art. 101), le droit à être entendu, la légalité des infractions et des peines, le non cumul des peines (art. 103), les garanties juridiques en cas de détention (art. 104).
} 
pas responsable du retard avec lequel le recours a été déposé. La jurisprudence s'est montrée très exigeante au sujet de la motivation du recours : de nombreux recours sont rejetés pour motivation insuffisante ; à cet égard la dispense de ministère d'avocat se révèle le plus souvent illusoire et de fait, plus de la moitié des recours sont présentés avec ministère d'avocat.

\section{Les règles s'imposant aux Sections}

Il convient d'étudier d 'abord les règles applicables à la décision de refuser l'admission à la décision au fond, puis les règles applicables à celle d'accorder l'admission à la décision.

Le refus de l'admission à la décision est normalement prononcé par l'une des Sections de la Chambre qui a été saisie du recours individuel. Selon le $\S 93$ b, al. 1, de la loi sur la Cour constitutionnelle fédérale, « la Section peut refuser l'admission du recours...». Elle peut le faire quand les conditions d'acceptation posées par le $\S 93 \mathrm{a}$, al.2 ne sont pas remplies, c'est-à-dire soit parce que le recours ne présente pas une importance de principe en droit constitutionnel (ce qui est le cas notamment quand il est irrecevable), soit parce qu'il n'est pas indiqué (angezeigt) pour faire respecter un droit fondamental ou pour éviter que le requérant ne supporte un préjudice particulièrement grave ${ }^{18}$. La procédure suivie est assez expéditive puisque, selon le $\S 93 \mathrm{~d}$, al. 1 et 3, la décision de refus est rendue sans que soit entendu le requérant, qu'elle est toujours rendue à l'unanimité, qu'elle n'a pas à être motivée et qu'elle est inattaquable. Dans la pratique, les refus sont très nombreux : environ 96 à $97 \%$ des recours individuels sont rejetés pour cette raison. Cela est d'autant plus choquant que les Sections ne sont pas tenues de les motiver et qu'elles ne les motivent en fait (sommairement ou de façon détaillée) que dans les cas les plus délicats ${ }^{19}$.

L'admission à la décision peut être décidée par une Section dans le cas prévu par le § 93 a, al. 2, lettre a, combiné avec le $\S 93 \mathrm{c}$, al.1, $1^{\text {re }}$ phrase de la loi sur la Cour constitutionnelle fédérale ${ }^{20}$. Dans ce cas, les conditions suivantes doivent être réunies : d'une part, selon le § 93a, al.2, lettre b, il faut que le recours permette de faire respecter un droit fondamental ou que son refus « causerait un préjudice particulièrement grave au requérant »; d'autre part, selon le $\S 93 \mathrm{c}$, al.1, $1^{\text {re }}$ phrase, il faut que « la Cour constitutionnelle fédérale ait déjà statué sur la question de droit constitutionnel qui est déterminante » (pour l'issue du procès initial) et que le recours soit «manifestement fondé ». La Section ne prend d'ailleurs pas une décision formelle d'admission, car elle se contente de justifier

\footnotetext{
18 § 93a, al. 2 : « Le recours individuel est admis à la décision a) s'il présente une importance de principe pour le droit constitutionnel, b) s'il est indiqué (angezeigt) pour faire respecter un des droits énumérés au $§ 90$, al. 1, ; ce peut être aussi le cas si le refus de l'admission causerait un dommage particulièrement grave au requérant $»$.

$19 \S 93 \mathrm{~d}$, al.1 : « La décision conformément aux $\S \S 93 \mathrm{~b}$ et $93 \mathrm{c}$ de la présente loi est rendue sans audition. Elle est inattaquable ». et al. 3 : «Les décisions de la Section sont toujours rendues à l'unanimité ». La Cour constitutionnelle publie sur ce point des statistiques assez sommaires : d'une part, elles valent pour les trois sortes de recours individuels ( (même si la catégorie la plus importante, et de beaucoup, est celle des recours dirigés contre une décision de justice), d'autre part, elles ne distinguent pas entre les décisions de non admission à la décision et celles qui admettent le recours à la décision (et aboutissent le plus souvent à une décision d'inconstitutionnalité). Les voici pour l'année 2015: décisions motivées (décisions positives ou négatives) : 248 ; décisions motivées dans le dispositif : 550 ; non motivées : 4762 (c'est-à-dire $85 \%$ ). Noter que les décisions positives rendues au sujet des trois sortes de recours individuels ont été en 2015 au nombre de 13 émanant de l'une des deux Chambres et de 98 émanant de l'une des 6 Sections.

20 § 93c, al.1, $1^{\text {re }}$ phrase : «Si les conditions posées par le § 93a, al.2, b, sont remplies et que la question de droit constitutionnel dont dépend le jugement du recours a déjà été tranchée par la Cour constitutionnelle fédérale, la Section peut faire droit au recours s'il est manifestement fondé ». Le § 93a, al.2, b, est reproduit à la note 17.
} 
l'admission en des termes brefs au début du jugement au fond qu'elle rend ensuite. Dans l'hypothèse où elle est ainsi amenée à statuer au fond, elle doit donner la possibilité de faire valoir son point de vue à la personne en faveur de laquelle a été rendue la décision de justice contestée (§ 94, al. 3). Dans sa décision rendue sur le fond, elle doit indiquer « quelle disposition de la Loi fondamentale et par quelle action ou inaction elle a été violée » et elle doit annuler la décision de justice déclarée inconstitutionnelle et renvoyer l'affaire à un tribunal compétent (§ 95).

En raison de cette réglementation, les décisions de Section statuant au fond sur des recours individuels dirigés contre des décisions de justice pour violation d'un droit fondamental sont devenues la règle (une centaine par an) et celles émanant de l'une des deux Chambres sont devenues très rares très peu nombreuses (entre 10 à 15 selon les années). Pour justifier ces décisions, les Sections font valoir que la jurisprudence de la Cour est déjà fixée par l'une des deux Chambres et que la procédure expéditive suivie par les Sections permet de gagner un temps précieux.

\section{Les règles s'imposant aux Chambres}

Selon la loi sur la Cour constitutionnelle fédérale, la Chambre peut prononcer «l'admission à la décision » non seulement quand le recours est « indiqué » (angezeigt) pour assurer le respect d'un droit fondamental (qui est le seul cas où la Section peut examiner la question au fond), mais encore, ce qui est d'ailleurs exceptionnel dans la pratique, quand le recours soulève des « questions de principe en droit constitutionnel ». La Chambre n'est pas liée par les propositions du rapporteur de l'affaire au sein de la Section ; mais, en général, elle les suit pour deux raisons : le vote favorable de trois juges de la Chambre suffit pour que l'admission à la décision soit décidée ${ }^{21}$; en outre, cela gagne du temps. Dans la pratique, les Chambres rendent par an environ 10 à 15 décisions positives déclarant les recours bien fondés ; leur compétence est d'ailleurs de droit lorsque le bien-fondé du recours implique que soit déclarée inconstitutionnelle une disposition législativ ${ }^{22}$, ce qui est d'ailleurs relativement rare, car la Cour constitutionnelle préfère le plus souvent éviter l'annulation en procédant à une interprétation qui rend la loi compatible avec la constitution (voir infra).

La décision de la Chambre relative à l'admission à décision peut être positive ou négative. Si la Chambre accepte l'admission que lui a proposée le rapporteur de la Section, elle passe tout de suite à l'examen du fond et, au début de la décision qu'elle rend au fond, elle indique les motifs de son acceptation dans des termes relativement brefs. Si la Chambre refuse d'admettre le recours à la décision, elle expose évidemment seulement les raisons de son refus d'admettre le recours à un examen au fond.

La décision de la Chambre statuant au fond obéit aux règles générales de procédure. En particulier, la Chambre doit donner la « possibilité de s'exprimer » à l'organe constitutionnel ou au ministre compétent de la Fédération ou du Land concerné ou encore à la partie favorisée par le jugement

$21 \S 93 \mathrm{~d}$, al.3, $2^{\mathrm{e}}$ phrase : «L'admission à la décision par la Chambre est décidée quand trois juges au moins l'approuvent ».

$22 \S 93 \mathrm{c}$, al. $1,3^{\mathrm{e}}$ phrase : «Une décision qui déclare une loi compatible ou contraire à la Loi fondamentale ou à une autre règle de droit fédéral avec l'effet prévu au $\S 31$, al. 2 (publication au Journal officiel de la Fédération) est réservée à l'une des deux Chambres (Senat) ». 
contesté (§ 94) $)^{23}$ et, pour les cas les plus importants, une audience publique peut être organisée (§ 93 $\mathrm{d}$ a contrario). Enfin, la décision doit être prise par une Chambre composée d'au moins six juges et si le recours est fondé, la décision doit indiquer quelle disposition de la Loi fondamentale a été violée et par quelle action ou omission elle l'a été, puis annuler la décision de justice qui était contestée et éventuellement renvoyer l'affaire à une juridiction compétente (§ 95). La décision est toujours motivée.

\section{Les conséquences de l'existence d'un contrôle de la constitutionnalité des décisions de justice}

L'existence d'un contrôle de la constitutionnalité des décisions de justice entraîne de grandes conséquences dont certaines peuvent être jugées souhaitables et d'autres non. En premier lieu, de ce fait, la Cour constitutionnelle fédérale a, parmi les institutions étatiques, une place assez différente de celle du Conseil constitutionnel. En second lieu, le développement du contrôle de constitutionnalité des décisions de justice a eu pour effet de donner au droit constitutionnel, et spécialement aux droits fondamentaux, une force et une omniprésence inimaginables en France.

\section{A. La place de la Cour constitutionnelle fédérale parmi les institutions}

\section{La Cour constitutionnelle fédérale, organe constitutionnel}

Dès ses premières années, la Cour constitutionnelle fédérale a revendiqué le droit d'être considéré comme un « organe constitutionnel » (Verfassungsorgan) dans un célèbre Mémorandum (Denkschrift) adressé au Gouvernement fédéral le 27 juin 1952, ce qui lui a permis, tout d'abord, d'avoir un budget distinct de celui du ministère de la justice ainsi qu'un personnel et un patrimoine distincts de ceux de la Fédération, et également d'avoir compétence pour arrêter seule son propre règlement intérieur (Geschäftsordnung).

Mais surtout, cette qualité a permis à la Cour de revendiquer la faculté de ne pas se comporter comme un simple tribunal supérieur. Dans un jugement, elle déclara elle-même : « en vertu de sa qualité générale d'organe constitutionnel et de juridiction pour le droit constitutionnel, elle est beaucoup moins exposée au reproche d'avoir pénétré dans le domaine du pouvoir législatif $»^{24}$. Bien que cette prétention ne soit pas juridiquement justifiée du fait de l'absence de texte constitutionnel en ce sens, cette affirmation de la Cour a suffi pour que les juges se sentent libérés de l'obligation d'appliquer strictement les méthodes classiques d'interprétation de la constitution et des lois.

\footnotetext{
$23 \quad$ L’alinéa $5 \mathrm{du} \S 94$ précise même : « Les organes constitutionnels cités aux alinéas 1, 2 et 4 peuvent se joindre à la procédure. La Cour constitutionnelle fédérale peut renoncer à une audience si on ne peut pas s'attendre à ce qu'elle fasse avancer la procédure et si les organes constitutionnels ayant le droit de s'exprimer et qui se sont joints à la procédure y renoncent ».

24 Cour constitutionnelle fédérale 11 juin 1958 (Jugement sur les pharmacies), BVerfGE, tome 7, p. 377 (413).
} 


\section{La Cour constitutionnelle fédérale, juridiction suprême}

Alors que les constituants de 1949 étaient restés en partie fidèles à l'image d'une juridiction arbitre de la vie politique et des rapports entre les organes constitutionnels et entre les États fédérés et l'État fédéral, le législateur de 1951 fit un pas considérable vers une nouvelle conception de la juridiction constitutionnelle en lui confiant le soin de statuer sur les recours individuels pour violation d'un droit fondamental et spécialement les recours individuels dirigés contre une décision de justice en dernier ressort. En rupture avec les traditions en matière d'organisation de la justice, le législateur institua donc une juridiction placée au sommet de la hiérarchie judiciaire, mais pouvant néanmoins être saisie par de simples personnes privées (physiques ou morales, nationales ou étrangères) sans même que le ministère d'un avocat soit obligatoire, pourvu que le requérant puisse invoquer un droit que lui garantit la constitution fédérale.

Du fait de cette compétence, la Cour constitutionnelle fédérale est devenue une véritable juridiction suprême. En particulier, les 6 Sections sont chargées de veiller au strict respect de la jurisprudence de la Cour constitutionnelle. Les tribunaux ordinaires et les juges statuant seuls savent que leurs décisions seront implacablement cassées par les Sections si elles s'écartent de la jurisprudence constitutionnelle. Rappelons que tout justiciable mécontent d'une décision de justice contre laquelle il ne dispose plus de recours pour la contester a le droit de saisir la Cour constitutionnelle fédérale d'un recours pour obtenir la cassation de cette décision.

\section{La Cour constitutionnelle fédérale, protectrice de tous les justiciables}

Selon les termes mêmes de la Loi fondamentale, « le recours individuel peut être formé par quiconque estime avoir été lésé par la puissance publique dans l'un de ses droits fondamentaux ou dans l'un de ses droits garantis par les articles 20, al. 4, 33, 38, 101, 103 et 104 »(art. 93, al. 1, n 4a) $)^{25}$.

En premier lieu, la Cour constitutionnelle fédérale a pratiquement retiré toute portée à la distinction que fait le texte de la Loi fondamentale entre les droits fondamentaux des Allemands et les droits fondamentaux de tous les êtres humains. En effet, conformément à une tradition remontant au 19e siècle, quelques droits fondamentaux n'appartiennent en principe qu'aux Allemands : la liberté de réunion (art. 8), la liberté d'association (art. 9), la liberté de circulation et d'établissement (art. 11), la liberté de la profession (art. 12). Mais la Cour constitutionnelle fédérale n'a pas hésité à reconnaître aux étrangers ces différents droits en se fondant sur l'article 2, al. 1, de la Loi fondamentale selon lequel « chacun a droit au libre épanouissement de sa personnalité », ce que les juristes allemands appellent la liberté générale d'agir (allgemeine Handlungsfreiheit). Par exemple, le 15 janvier 2002, la

25 Les droits énumérés par l'article 93 sont respectivement le droit de résister « à quiconque entreprendrait de renverser l'ordre constitutionnel », le droit à l'égal accès des Allemands à toutes fonction publiques, le droit d'élire les députés du Bundestag, et divers droits procéduraux (droit à être jugé pr un juge légal, à être entendu par le tribunal, à ne pas être puni plusieurs fois pour le même acte, à n'être privé de sa liberté personnelle que par la décision d'un juge). 
Cour a accueilli favorablement le recours d'un boucher musulman auquel l'administration allemande avait refusé l'autorisation d'abattre ses animaux selon les règles de l'abattage rituel musulman ${ }^{26}$.

En outre, depuis 2011, l'article 19, al. 3 de la Loi fondamentale a reçu de la Cour constitutionnelle fédérale une interprétation conforme au droit de l'Union européenne : désormais, bien que cette disposition énonce clairement que « les droits fondamentaux s'appliquent également aux personnes morales nationales lorsque leur nature le permet », les personnes morales étrangères régies par le droit d'un des États de l'Union européenne, bénéficient des mêmes droits fondamentaux que les personnes morales nationales ${ }^{27}$.

En second lieu, pour ouvrir plus largement l'accès à son prétoire, la Cour constitutionnelle fédérale a créé de nouveaux droits fondamentaux, soit en combinant deux droits fondamentaux entre eux, soit en déduisant le nouveau droit d'un principe de droit objectif consacré par la Loi fondamentale. Le meilleur exemple de combinaison de droits fondamentaux est celle du droit au respect de la dignité humaine et du droit au libre développement de la personnalité : cette combinaison aboutit en effet à la consécration d'un nouveau droit fondamental, le droit général au respect de la personnalité (allgemeines Persönlichkeitsrecht ${ }^{28}$ qui se décompose d'ailleurs lui même en plusieurs droits fondamentaux, le droit à la protection de l'honneur, le droit à l'intimité, le droit à sa propre image et à ses propres paroles, le droit à conserver la maîtrise de ses données personnelles, le droit à connaître sa propre ascendance ${ }^{29}$.

De plus, la Cour constitutionnelle fédérale a déduit de plusieurs règles de droit constitutionnel objectif de véritables droits publics subjectifs susceptibles d'être invoqués à l'appui d'un recours individuel, ce qui a augmenté les possibilité d'introduire un recours individuel. Il en est ainsi de l'interprétation donnée à l'art. 5 de la Loi fondamentale qui affirme que l'art et la science, la recherche et l'enseignement supérieur sont libres : la Cour en a déduit un véritable droit fondamental à la liberté dans son activité professionnelle pour l'homme de science, le chercheur et l'enseignant supérieur ${ }^{30}$. Il en va de même pour l'article 6 de la Loi fondamentale : le principe selon lequel « le mariage et la famille sont placés sous la protection de l’État » (art. 6, al.1, Loi fondamentale) a été interprété comme garantissant la liberté du mariage ${ }^{31}$. Enfin, l'article 14 de la Loi fondamentale a été interprété

\footnotetext{
26 Cour constitutionnelle fédérale, 15 janvier 2002, BVerfGE, tome 104, p. 337 (346), analyse Fromont, RDP 2004, p. 1138.

27 Cour constitutionnelle fédérale 19 juillet 2011, BVerfGE, tome 129, p. 78, analyse Fromont, RDP 2012, p. 1201.

28 Sur l'origine et le développement de cette jurisprudence, voir notre commentaire de la décision du 14 février 1973 de la Cour constitutionnelle au sujet de la publication dans la presse d'un interview inventé de la princesse Soraya in Grandes décisions des cours constitutionnelles européennes (sous la direction de P. Bon et D. MAus), Paris 2008, nº 64.

29 Cour constitutionnelle fédérale, 31 janvier 1989, BVerfGE, tome 79, p. 256 (268), note Fromont, RDP 1992, p.1048; 26 avril 1994 , BVerfGE, tome 90, p. 263 (270), note Fromont, RDP 1997, p. 351.

30 Cour constitutionnelle fédérale 29 mai 1973, BVerfGE, tome 35, p. 79-148 (recours individuel contre la loi relative aux universités de Basse-Saxe), commentaire Fromont in Les grandes décisions des cours constitutionnelles européennes (sous la direction de P. Bon et D. MAus), Paris 2008, n 68 ; Cour constitutionnelle fédérale, 11 janvier 1994, BVerfGE, tome 90, p. 1: «L'article 5, al. 3, phrase 1, déclare que la science, la recherche et l'enseignement sont libres. Ce faisant, il ne consacre pas seulement une règle de droit objectif dans le domaine de la science... Comme droit défensif (Abwehrrecht), il garantit à quiconque a une activité scientifique d'être libre de toute restriction de la part de l'État... Quiconque agit en homme de science bénéficie d'une protection contre toute immixtion de l'État dans le processus d'élaboration et de diffusion de connaissances scientifiques » (p. 11).

31 Cour constitutionnelle fédérale 4 mai 1971, BVerfGE tome 31, p. 58 (mariage d'un espagnol) ; analyse Fromont, RDP 1975, p. 141-142 : la loi allemande sur le droit international privé ne peut pas être appliquée à un Espagnol, car le renvoi à la loi espagnole le priverait de la liberté de se remarier.
} 
comme ne garantissant pas seulement l'existence de l'institution du droit de propriété mais comme conférant un véritable droit fondamental aux titulaires d'un droit de propriété32.

\section{B. L'emprise des droits fondamentaux sur l'ensemble du droit allemand}

\section{L'extension de la portée de certains droits fondamentaux}

Un droit subjectif prend plus d'ampleur lorsqu'il est considéré comme posant une règle de droit objectif. Le meilleur exemple est fourni par la jurisprudence relative au droit de chacun au libre développement de sa personnalité (art. 2, al.1) qui a été interprétée comme imposant au législateur l'obligation d'édicter lui-même les règles régissant toute activité privée en se conformant à l'ensemble des règles constitutionnelles, y compris les règles de droit objectif dégagées par la Cour constitutionnelle fédérale, comme le principe de proportionnalité ou le principe de sécurité juridique. Ainsi, la Cour a donné aux droits fondamentaux une portée très grande dans la mesure où désormais toute activité humaine est protégée au moins par la liberté générale d'agir (garantie par l'article 2 de la Loi fondamentale) et que toute loi restreignant cette liberté générale doit nécessairement respecter non seulement les droits fondamentaux, mais encore l'ensemble des règles découlant de principes très généraux, comme ceux découlant du principe de l'État de droit (art. 20 de la Loi fondamentale).

Du fait de cette jurisprudence, ce droit fondamental est devenu quasiment sans limites ${ }^{33}$. Comme le fait remarquer le professeur Lepsius ${ }^{34}$, le résultat est que le recours pour violation d'un droit fondamental devient une demande de contrôle des normes présentée par un individu, ce qui étend beaucoup les possibilités de saisir la Cour constitutionnelle fédérale par les personnes privées et de mettre à la disposition des personnes privées la possibilité d'invoquer la violation de règles objectives de droit constitutionnel quand elles forment un recours pour violation d'un droit fondamental. Par exemple, on a vu un cavalier amateur de promenades à cheval en forêt former un recours contre une réglementation restreignant le droit des cavaliers de circuler sur certains chemins forestiers ${ }^{35}$.

De même, la Cour constitutionnelle fédérale a donné au droit de propriété une étendue qui excède celle que lui attribue traditionnellement le code civil, puisque, selon la jurisprudence constitutionnelle, le droit fondamental de la propriété couvre tous les droits privés ayant une valeur patrimoniale (notamment les droits du locataire ${ }^{36}$ ) et également les droits publics à recevoir de l'argent, lorsque ceux-ci reposent sur l'épargne de leurs titulaires ${ }^{37}$.

\footnotetext{
32 Art. 14 de la Loi fondamentale : « La propriété et le droit d'héritage sont garantis ».

Cour constitutionnelle fédérale, 6 janvier 1957 (Elfes), BVerfGE, tome 6, p.32.

Lepsius, Die maßstabsetzende Gewalt, in Das entgrenzte Gericht, Eine kritische Bilanz nach sechzig Fahren Bundesverfassungsgericht, Suhrkamp, Berlin 2011, p. 182

35 Cour constitutionnelle fédérale 6 juin 1989 (Reiten im Wald), BVerfGE, tome 80, p. 137. analyse Fromont, RDP 1990, p. 1045.

Cour constitutionnelle fédérale, 21 mai 1993, BVerfGE, tome 89, p. 1 (droits des locataires de logement), analyse Fromont, $R D P 1995$, p. 339.

Cour constitutionnelle fédérale, 28 février 1980, BVerfGE, tome 53, p. 257 ; $1^{\text {er }}$ juillet 1981, BVerfGE, tome 58, p. 1 ; analyse Fromont des deux décisions, $R D P 1982$, p. 1058
} 


\section{L'application des droits fondamentaux aux litiges de droit privé}

Le droit fondamental est conçu normalement comme un droit subjectif, c'est-à-dire un droit qui a nécessairement une personne pour titulaire, mais selon la jurisprudence de la Cour, il peut être considéré comme étant également une règle de droit objectif ayant valeur constitutionnelle et pour cette raison, il peut être invoqué même contre des personnes privées, spécialement contre celles qui disposent d'une position économiquement ou socialement supérieure, car ces règles sont considérées comme « un système de valeurs » (Wertsystem) valable pour tout le monde.

Il est vrai que cette application des droits fondamentaux aux relations de droit privé se fait pour l'instant principalement par l'intermédiaire de ce que les juristes allemands appellent des clauses générales (Generalklauseln), c'est-à-dire des règles législatives posant des règles très générales. Ainsi, en droit civil, la Cour constitutionnelle fédérale s'appuie pour les litiges portant sur la responsabilité civile sur une interprétation des $\S \S 823$ et 826 (responsabilité pour faute, ou pour acte immoral) du code civil ${ }^{38}$ et pour les litiges portant sur des contrats, sur une interprétation des $\S \S 138$ (atteinte à la morale) et 242 (atteinte à la bonne foi) du code civil ${ }^{39}$.

\section{La multiplication des interprétations de la loi faites en conformité avec les droits fondamentaux}

Le plus souvent, la Cour n'annule pas les décisions de justice contestées devant elle en raison de l'inconstitutionnalité de la loi appliquée. La Cour préfère justifier l'annulation de la décision de justice en reprochant au juge ordinaire d'avoir mal interprété la loi et d'avoir ainsi donné de la loi une interprétation inconstitutionnelle ou bien d'avoir exercé son pouvoir d'appréciation sans tenir compte suffisamment de la nécessité de respecter les droits fondamentaux du requérant. Dans la pratique, la Cour ne prononce qu'un nombre limité d'annulations ou de déclarations d'inconstitutionnalité de la loi appliquée et préfère corriger l'interprétation de la loi faite par le juge ordinaire en y substituant sa propre interprétation, c'est-à-dire une interprétation compatible avec les droits fondamentaux en cause (verfassungskonforme Auslegung).

Pourquoi cette préférence ? Selon moi, l'explication est simple : l'élimination de l'inconstitutionnalité est plus sûrement et plus rapidement faite par la Cour constitutionnelle elle-même par une interprétation conforme à la constitution que par une annulation ou une déclaration d'inconstitutionnalité de la loi appliquée dans le procès. L'inconstitutionnalité est ainsi éliminée sans intervention du législateur, que celui-ci soit fédéral ou fédéré. Si un tribunal ordinaire s'enhardissait à ne pas faire sienne l'interprétation imaginée par la Cour pour rendre la loi compatible avec la constitution, il courrait le risque de voir son jugement attaqué par le justiciable mécontent devant

\footnotetext{
38 Cour constitutionnelle fédérale, 15 janvier 1968, BVerfGE, tome 7, p. 198, commentaire Fromont in Les grandes décisions des cours constitutionnelles européennes (sous la direction de P. Bon et D. MAus), Paris 2008, n 24 : l'appel au boycott d'un journal n'engage pas la responsabilité de son auteur car il a simplement fait usage de sa liberté d'expression. Voir aussi l'arrêt Soraya cité à la note 26.

39 Cour constitutionnelle fédérale, 19 octobre 1993, BVerfGE, tome 89, p. 214, commentaire Fromont in Les grandes décisions des cours constitutionnelles européennes (sous la direction de P. Bon et D. MAUs), Paris 2008, $\mathrm{n}^{\circ} 25$ : une banque engage sa responsabilité civile pour faute du fait qu'elle a abusé de la situation d'infériorité de sa cliente.
} 
la Cour constitutionnelle fédérale et évidemment l'une des Sections de la Cour ne manquerait pas de casser ce jugement téméraire. Ainsi la Cour est assurée d'imposer rapidement et pleinement sa propre interprétation de la $\mathrm{loi}^{40}$.

Cette jurisprudence relative au contrôle de la constitutionnalité de l'interprétation des lois faite par les tribunaux ordinaires dans le cadre de recours individuels dirigés contre des décisions de justice peut être résumée à grands traits de la façon suivante. Il faut d'abord examiner si le jugement a accordé une attention suffisante à l'effet de rayonnement des droits fondamentaux (Ausstrahlungswirkung der Grundrechte) dans l'ensemble du droit, y compris dans le droit privé, puis s'il a correctement tenu compte de l'importance et de la portée des droits fondamentaux, notamment des limites de leur champ d'application et s'il a suffisamment pris en compte le poids respectif des droits fondamentaux qui sont antagonistes.

Exceptionnellement, la décision de justice peut être annulée par la Cour, non pas parce que la loi a été mal interprétée, mais parce qu'elle a été mal appliquée, par exemple, parce que le tribunal a agi purement et simplement de façon arbitraire (Willkür), soit en ignorant pratiquement la loi à appliquer, soit en excédant les limites du pouvoir reconnu au juge allemand de combler les lacunes de la loi lorsque la lettre de la loi ne s'y oppose pas et constitue simplement un prolongement des règles posées explicitement par la loi (richterliche Rechtsfortbildung) ${ }^{41}$, soit en violant gravement les règles de procédure qu'imposent le principe de l'État de droit et certains droits fondamentaux, notamment le droit à être entendu (art. 103, al. 1 de la Loi fondamentale) ${ }^{42}$. L'une des difficultés que rencontre ce contrôle tient à ce qu'il faut distinguer la violation des principes constitutionnels qui peut être sanctionnée par la Cour constitutionnelle et celle des règles législatives qui mettent en œuvre ces principes qui ne peut être censurée que par une juridiction ordinaire. Par exemple, la Cour doit se fonder exclusivement sur l'art. 103 de la constitution qui vient d'être cité (droit à être entendu) et il revient au seul juge ordinaire le soin de censurer la violation des règles législatives mettant en œuvre ce principe. Pour effectuer ce partage des responsabilités, la Cour constitutionnelle fédérale a simplement affirmé que les recours individuels dirigés contre une décision de justice ne sont recevables que si le requérant invoque la lésion de « règles spécifiques» au droit constitutionnel ${ }^{43}$.

\footnotetext{
40 Cour constitutionnelle fédérale, 10 juin 1975, BVerfGE, tome 40, p. 88 ; analyse Fromont, RDP 1977, p. 364 (tous les tribunaux sont tenus de respecter une interprétation de la loi par la Cour constitutionnelle fédérale pour que celle-ci soit conforme à la constitution).

41 Cour constitutionnelle fédérale, 15 janvier 2009, BVerfGE, tome 122, p. 248 ; analyse Fromont ; RDP 2010, p. 1190.

42 Voir R. Zippelius/Th. Würtenberger, Deutsches Staatsrecht, Beck, München, $32^{\mathrm{e}}$ éd., München 2008, p. 522.

43 Cour constitutionnelle fédérale, 10 juin 1964, BVerfGE, tome 18, p. 85, commentaire Fromont in Les grandes décisions des cours constitutionnelles européennes (sous la dir. De P. Bon et D.Maus), Paris 2008, n 138.
} 


\section{Conclusion}

\section{Quelques observations comparatives}

En Allemagne, le contrôle de constitutionnalité des décisions de justice, tel qu'il est organisé aujourd'hui, présente de grands avantages, mais aussi de graves inconvénients.

Les avantages sont les suivants. En premier lieu, ce contrôle de constitutionnalité des décisions de justice assure la pénétration du droit constitutionnel et spécialement des différents droits fondamentaux dans l'ensemble du système juridictionnel et du système juridique. Toutes les juridictions doivent prendre en considération l'effet de rayonnement (Ausstrahlung) des droits fondamentaux : aucune juridiction ne peut s'y soustraire. Toutes les branches du droit, y compris le droit privé et même les zones les plus éloignées des préoccupations juridiques, comme les droits des condamnés à une peine de prison ${ }^{44}$, sont désormais dominées par la question du respect des droits fondamentaux. L'unité du système juridictionnel et juridique allemand est ainsi assurée. En second lieu, tous les citoyens et tous les étrangers placés sous l'autorité de l'État allemand disposent d'un recours pour faire respecter leurs droits fondamentaux par leurs juges, qu'ils soient civils, pénaux ou administratifs. De ce fait, il n'existe aucune zone de non-droit constitutionnel.

Les inconvénients sont également évidents : la Cour constitutionnelle fédérale est véritablement submergée par le nombre des recours individuels dirigés contre des décisions de justice. Les remèdes utilisés permettent à la Cour de maintenir la tête hors de l'eau, mais ils condamnent les juges constitutionnels et leurs assistants à un véritable travail à la chaîne pour éviter que les délais de jugement s'allongent dramatiquement ${ }^{45}$. Les remèdes sont insuffisants et, de surcroît, ils sont peu compatibles avec une juridiction qui contribue pourtant au prestige de l'Allemagne dans le monde entier et qui devrait fonctionner d'une façon irréprochable. Rappelons que la procédure suivie par les Sections est très largement écrite, non contradictoire et secrète et que beaucoup de décisions ne sont pas motivées, même sommairement.

En France, plusieurs solutions sont envisageables.

La solution la plus audacieuse consisterait à mettre en place un système généralisé de contrôle de la constitutionnalité des décisions de justice à l'allemande : tout justiciable mécontent devrait pouvoir saisir le Conseil constitutionnel contre une décision de justice contre laquelle plus aucun recours n'est possible. Cette innovation exigerait, tout d'abord, que des modifications soient apportées à la composition et au mode de fonctionnement du Conseil constitutionnel. En ce qui concerne la composition, il serait souhaitable d'exiger que tous les membres aient au moins fait des études universitaires en droit et, si possible qu'ils aient tous acquis soit l'aptitude à être maître de conférences ou professeur en droit, soit l'aptitude aux fonctions de magistrat ou d'avocat. Il est, en effet, impensable

44 Mansuy (Isabelle), La protection des droits des détenus en France et en Allemagne, préface Fromont, Paris 2007, L’Harmattan.

45 Durant les années 2008 à 2015, la durée moyenne des procédures de tous les recours individuels ont été les suivantes : $64 \%: 1$ an ; $22 \%$ : 2 ans ; $7 \%: 3$ et 4 ans ; $7 \%$ : non encore jugées. 
que des non juristes censurent des décisions de justice émanant de juges hautement qualifiés. De plus, le nombre de conseillers devrait être augmenté et passer à 15 membres, ce qui permettrait de constituer trois chambres de 5 juges. Enfin, les conseillers devraient être assistés d'un nombre relativement important de jeunes magistrats placés en situation de détachement. Les décisions du Conseil constitutionnel seraient rendues par l'une des trois chambres selon une procédure qui devrait faire une place au principe du contradictoire et, dans certains cas, à l'oralité.

Une telle réforme risque de se heurter à l'hostilité des deux juridictions suprêmes actuelles, la Cour de cassation et le Conseil d'État, qui ont conservé leur pleine souveraineté puisqu'ils ont obtenu la compétence de décider souverainement de la transmission au Conseil constitutionnel des questions préjudicielles de constitutionnalité, même lorsque la question concerne non pas la loi proprement dite, mais l'interprétation qu'ils en donnent eux-mêmes. C'est pourquoi nous pensons que la réforme la plus urgente à réaliser consisterait, d'une part, à remanier la composition du Conseil constitutionnel d'une façon proche de celle qui est proposée dans le cadre de la réforme qui vient d'être suggérée (augmentation des compétences juridiques et du nombre des membres du Conseil constitutionnel), et, d'autre part, à organiser, soit une procédure solennelle permettant de contester la conformité à la constitution des interprétations que donne de la loi l'une des deux juridictions suprêmes, soit à prévoir simplement qu'un appel au Conseil constitutionnel puisse être formé par l'une des parties au procès en cours contre la décision d'une juridiction suprême de ne pas lui transmettre une question portant sur la constitutionnalité de l'interprétation d'une loi. La dernière solution proposée aurait l'avantage de ne pas trop bousculer les habitudes mentales des juristes français qui ont construit la question prioritaire de constitutionnalité comme le résultat d'une hybridation de deux procédures normalement distinctes, le contrôle concret des normes (ou question préjudicielle) et le recours individuel (donnant l'initiative aux seuls justiciables) et qui ont tendance à raisonner comme si la justice constitutionnelle avait pour fonction quasi exclusive de contrôler la constitutionnalité des lois. 



\title{
LE RECOURS D'AMPARO CONTRE LES DÉCISIONS JURIDICTIONNELLES LE CAS DE L'ESPAGNE
}

\author{
Hubert AlcARAZ ${ }^{1}$
}

Alors que pour beaucoup de Français, dans l'imaginaire collectif, l'Espagne représente le pays de la bonne humeur et du soleil, le tableau qu'il faut dresser ici est non seulement austère mais, peut-être pire encore, décourageant, voire déprimant. Car la vérité au-delà des Pyrénées, sur un sujet comme celui qui nous occupe aujourd'hui, n'est guère enthousiasmante. Plus exactement - et pour faire peut-être des efforts de perspective - elle est paradoxale. Paradoxe entre, d'un côté, le principe de l'existence même d'un recours direct - le recours d'amparo - au sens large, et contre les décisions juridictionnelles en particulier et, de l'autre, une pratique, de l'amparo en général et spécialement de l'amparo contre les décisions de justice. Et soyons franc, c'est là l'une des questions, pour ne pas dire la question la plus problématique du système de justice constitutionnelle espagnol, celle dont dépendent aujourd'hui tous les équilibres, dont procède toute l'économie de ce système.

Pour bien comprendre ce qu'il en est, commençons par dire ce que recouvre l'expression et ce qu'est le recours d'amparo. Littéralement, il s'agit du recours en protection, également présent dans de nombreux États ibéro-américains et qui, en Espagne, est conçu comme le principal instrument de protection des droits fondamentaux. Il suffit, pour en prendre la mesure, de se reporter à l'article 53, alinéa 2, de la Constitution du 27 décembre 1978 : «Tout citoyen pourra demander la protection des libertés et des droits reconnus à l'article 14 et à la section première du chapitre deux devant les tribunaux ordinaires par une action fondée sur les principes de priorité et de la procédure sommaire et, le cas échéant, par le recours individuel d'amparo devant le Tribunal constitutionnel. Ce recours sera applicable à l'objection de conscience, reconnue à l'article $30 »^{2}$.

\footnotetext{
1 Maître de conférences HDR, Aix Marseille Univ, Univ Pau \& Pays Adour, CNRS, DICE, IE2IA, Pau, France.

L'article 53 comporte trois alinéas ainsi rédigés : «1. Les droits et les libertés reconnus au chapitre deux du présent titre sont contraignants pour tous les pouvoirs publics. Seule une loi qui, dans tous les cas, devra respecter leur contenu essentiel, pourra règlementer l'exercice de ces droits et de ces libertés qui seront protégés conformément aux dispositions de l'article 161, paragraphe 1, a). 2. Tout citoyen pourra demander la protection des libertés et des droits reconnus à l'article 14 et à la section première du chapitre deux devant les tribunaux ordinaires par une action fondée sur les principes de priorité et de la procédure sommaire et, le cas échéant, par le recours individuel d'amparo devant le Tribunal constitutionnel. Ce recours sera applicable à l'objection de conscience, reconnue à l'article 30. 3. La reconnaissance, le respect et la protection des principes reconnus au chapitre trois inspireront la législation positive, la pratique judiciaire et l'action des pouvoirs publics. Ils ne pourront être allégués devant la juridiction ordinaire que conformément aux dispositions des lois qui les développeront ».
} 
Toutefois, ainsi qu'on le constate à la lecture de cette disposition, en réalité, la Constitution espagnole ne définit pas un mais deux recours d'amparo: selon la terminologie utilisée par la doctrine, d'une part, l' amparo ordinaire et, d'autre part, l'amparo constitutionnel. Evidemment, ici, c'est le seul recours d'amparo constitutionnel qui nous retiendra, mais un mot sur son pendant « ordinaire » pour bien saisir ce qui nous occupe : l'amparo ordinaire n'est rien d'autre que la procédure qui permet à toute personne physique ou morale qui s'estime lésée, non pas dans l'un quelconque des droits et libertés proclamés par le titre premier de la Constitution (c'est à dire par les articles 14 à 52) mais dans l'un des droits fondamentaux proclamés par les articles 14 à 29 - dits, en général, de premier rang $^{3}$-, de saisir le juge ordinaire d'une action « qui devra être examinée par ce dernier de façon prioritaire et sommaire (principios de preferencia y sumariedad) $»^{4}$.

L'amparo constitutionnel est, alors quant à lui, la voie de droit qui permet à toute personne qui se prétend victime d'une atteinte à l'un des droits fondamentaux, et qui estime ne pas en avoir obtenu la protection par le juge ordinaire, de former directement un recours devant le juge constitutionnel. Cette voie d'accès direct au juge constitutionnel est ouverte à tout justiciable, et peut être rapprochée du recours constitutionnel direct existant en Allemagne ou en Autriche.

Un certain nombre de conditions entourent la formation de ce recours, mais avant d'y venir, pour nous en tenir à l'objet de la recherche, ce sont les actes qui peuvent faire l'objet du recours dont il faut dire un mot car la loi organique 2/1979 relative au Tribunal constitutionnel (désormais LOTC) ${ }^{5}$ ne consacre pas un seul recours d'amparo constitutionnel, mais en réalité plusieurs amparos constitutionnels selon l'auteur de l'acte attentatoire aux droits fondamentaux, c'est à dire selon l'acte susceptible de faire l'objet d'une contestation directe devant le Tribunal constitutionnel. Si l'article 41 de la LOTC pose le cadre général du recours d'amparo constitutionnel ${ }^{6}$, ce sont les articles 42 à 44 qui distinguent, plusieurs recours d'amparo devant le juge constitutionnel.

Ainsi, selon l'article 41, alinéa 2, de la LOTC, ce recours peut être dirigé contre les actes juridiques ou les simples comportements matériels des pouvoirs publics de l'État, des Communautés autonomes et des autres institutions publiques à caractère territorial, professionnel ou institutionnel, ainsi que de leurs fonctionnaires et agents ${ }^{7}$. De sorte que l'acte à l'origine de la violation du droit fondamental peut être d'une quelconque nature, pourvu qu'il émane d'un pouvoir public espagnol. J'ajoute que le recours d'amparo peut être intenté par toute personne physique ou morale ayant un

\footnotetext{
$3 \quad$ Cette expression employée par la doctrine espagnole renvoie à l'idée que ce sont ces droits fondamentaux qui bénéficient des garanties juridictionnelles les plus étendues.

P. Bon, « Amparo » in J. Andriantsimbazovina (dir.), Dictionnaire des droits de l'homme, Paris, PUF, p. 31.

Ley Orgánica 2/1979, de 3 de octubre, del Tribunal Constitucional.

Conformément à l'intitulé du titre III de la LOTC (« Del recurso de amparo constitucional»).

Cette disposition vise, littéralement, « les dispositions, actes juridiques, abstentions ou simple voie de fait des pouvoirs publics de l’État, des Communautés autonomes et des autres entités publiques à caractère territorial, corporatif ou institutionnel, ainsi que de leurs fonctionnaires ou agents » (Art. $41:$ : 1. Los derechos y libertades reconocidos en los artículos catorce a veintinueve de la Constitución serán susceptibles de amparo constitucional, en los casos y formas que esta Ley establece, sin perjuicio de su tutela general encomendada a los Tribunales de fusticia. Igual protección será aplicable a la objeción de conciencia reconocida en el artículo treinta de la Constitución. 2. El recurso de amparo constitucional protege, en los términos que esta ley establece, frente a las violaciones de los derechos y libertades a que se refiere el apartado anterior, originadas por las disposiciones, actos jurídicos, omisiones o simple vía de hecho de los poderes públicos del Estado, las Comunidades Autónomas y demás entes públicos de carácter territorial, corporativo o institucional, así como de sus funcionarios o agentes. 3. En el amparo constitucional no pueden hacerse valer otras pretensiones que las dirigidas a restablecer o preservar los derechos o libertades por razón de los cuales se formuló el recurso »).
} 
intérêt légitime, mais aussi par le Défenseur du peuple ou le Ministère public ${ }^{8}$. La plupart du temps, on s'en doute, les recours émanent de personnes physiques, sans que ceux formés par les personnes morales soient rares pour autant ${ }^{9}$.

Cependant, les articles suivants détaillent le champ d'application de l'amparo en ne l'envisageant précisément qu'à l'égard de trois catégories d'actes : tout d'abord, les actes parlementaires, c'est à dire les actes non législatifs produits par les Cortes generales ou les parlements des Communautés autonomes ${ }^{10}$, ensuite les actes administratifs ${ }^{11}$ et, enfin, les actes juridictionnels ${ }^{12}$. Finalement, ce sont trois catégories de recours d'amparo qui sont définies par la loi organique, qui répondent à des conditions pour partie spécifiques et qui produisent des effets quelque peu différents.

Mais reconnaissons tout de suite, pour nous faire une idée de l'importance de l'amparo contre les décisions de justice en Espagne, que l'essentiel des recours d'amparo est dirigé contre des violations supposées des droits fondamentaux qui trouveraient leur origine dans un acte juridictionnel. Quelques chiffres tirés des dernières statistiques publiées par le Tribunal parlent d'eux-mêmes : en 2015, sur les 7203 recours d'amparo formés, 7190 l'étaient contre des décisions juridictionnelles. 99,8\% des recours d'amparo sont donc actionnés contre des décisions rendues par les juridictions ordinaires. Et dans la majorité des cas, ce sont les décisions du juge pénal qui sont contestées ; viennent ensuite celles du juge administratif, celles du juge civil, celles du juge social et, enfin, celle du juge militaire ${ }^{13}$.

Revenons alors à l'article 44 de la LOTC. Il prévoit que « les violations des droits et libertés susceptibles d'amparo constitutionnel, qui trouveraient leur origine immédiate et directe dans un acte ou une abstention d'un organe juridictionnel, pourront donner lieu à ce recours dès lors que les conditions suivantes sont remplies : a) toutes les voies de droit prévues au sein de l'ordre juridictionnel par les règles processuelles pour l'affaire en cause ont été épuisées ; b) la violation du droit ou de la liberté est imputable de manière immédiate et directe à une action ou à une abstention d'un organe juridictionnel indépendamment des faits qui ont donné lieu au procès au sein duquel cette action ou abstention s'est produite, faits dont, en aucun cas, le Tribunal constitutionnel ne pourra avoir à connaître ; c) que l'atteinte au droit constitutionnel en cause, s'il y a lieu, ait été formellement relevée, aussitôt que possible une fois connue ». Son alinéa 2 rajoute que « le délai pour former le recours d'amparo sera de 30 jours, à compter de la notification de la décision rendue dans la procédure juridictionnelle ${ }^{14}$. Se trouve donc défini, dans cette disposition, le régime du recours

\footnotetext{
En application de l'article 162 b) de la Constitution.

Pour l'année 2015, ce sont 6196 recours d'amparo qui ont été formés par des personnes physiques, 912 par des personnes morales de droit privé, 92 par des entités publiques, 2 par le Ministère public et 1 par le Défenseur des droits.

10 Art. 42 LOTC.

11 Art. 43 LOTC.

12 Art. 44 LOTC.

13 Sur les 7190 recours d'amparo dont a été saisi le Tribunal constitutionnel en 2015 contre des décisions juridictionnelles, 3429 concernaient des décisions du juge pénal (c’est à dire 47, $68 \%$ ), 1898 des décisions du juge administratif (26,39\%), 1184 des décisions du juge civil (16, $46 \%$ ), 409 des décisions du juge social (5,68\%) 169 des décisions du juge pénitentiaire (2, $35 \%)$ et 33 des décisions du juge militaire $(0,45 \%)$.

14 Art. $44:$ : 1. Las violaciones de los derechos y libertades susceptibles de amparo constitucional, que tuvieran su origen inmediato y directo en un acto u omisión de un órgano judicial, podrán dar lugar a este recurso siempre que se cumplan los requisitos siguientes : a) Que se hayan agotado todos los medios de impugnación previstos por las normas procesales para el caso concreto dentro de la vía judicial. b) Que la violación del derecho o libertad sea imputable de modo inmediato y directo a una acción u omisión del órgano judicial con independencia de los hechos que dieron lugar al proceso en que aquellas se produjeron, acerca de los que, en ningún caso, entrará a conocer el Tribunal Constitucional. c) Que se haya denunciado
} 
d'amparo constitutionnel contre les décisions juridictionnelles (I). L'examen de sa mise en œuvre invite, en outre, à porter un regard critique sur l'expérience espagnole en la matière (II), en forme de bilan.

\section{Le régime de l'amparo constitutionnel contre les décisions juridictionnelles}

À sa lecture, il apparaît clairement que l'article 44 de la LOTC poursuit un double but : d'une part, il précise, on l'a dit, l'objet du recours d'amparo. Soulignons, à cet égard, qu'il ouvre concrètement et indiscutablement une voie qui n'était pas prévue de façon tout à fait claire par le texte constitutionnel lui-même ${ }^{15}$. D'autre part, il indique les conditions de forme et de procédure auxquelles sont soumis ces recours lorsqu'ils sont formés contre un acte juridictionnel. Ce faisant, sous couvert de la définition de ce qui apparaît comme des formalités ordinaires, il pose, en réalité, les traits les plus caractéristiques du recours d'amparo et, plus généralement, de la juridiction constitutionnelle en Espagne - nous y reviendrons -. Ce sont les conditions de formation du recours d'amparo (A), d'un côté, et ses modalités d'examen (B) qui sont en cause.

\section{A. Les conditions de formation du recours d'amparo}

Dans l'ordre juridique espagnol, la protection des droits fondamentaux relève en premier lieu des tribunaux ordinaires et, en second lieu, du Tribunal constitutionnel. Ainsi, la protection de ces droits revient à l'ensemble des organes chargés d'exercer la fonction juridictionnelle, à travers un système au sein duquel le recours d'amparo apparaît comme le point final de tout un arsenal de moyens procéduraux orientés vers cette fin, c'est à dire un système mixte dans lequel la juridiction constitutionnelle n'exerce pas de monopole, pas davantage qu'il ne s'appuie exclusivement sur la juridiction ordinaire. Au contraire, l'article 44 de la LOTC considère que les droits fondamentaux peuvent aussi être violés par le juge et il ouvre, en conséquence, une voie de recours face à de telles éventuelles atteintes, faisant du recours d'amparo la solution à toute action anormale ou injustifiée du juge ${ }^{16}$. D'un côté, le dispositif de protection est riche ; de l'autre, l'intervention de la juridiction ordinaire et de la juridiction constitutionnelle peut naturellement faciliter l'apparition de conflits ${ }^{17}$. D'ailleurs, la concurrence entre juridiction constitutionnelle et juridiction ordinaire dans la protection des droits fondamentaux, et la possibilité que la première puisse contrôler l'action de la seconde en la matière peut provoquer et, de fait, a provoqué des prises de position différentes à propos d'une

formalmente en el proceso, si hubo oportunidad, la vulneración del derecho constitucional tan pronto como, una vez conocida, hubiera lugar para ello. 2. El plazo para interponer el recurso de amparo será de 30 días, a partir de la notificación de la resolución recaída en el proceso judicial ».

15 F. Rubio Llorente et M. Aragón Reyes, « La jurisdicción constitucional » in A. Pedrieri et E. García de Enterría (dir.), La Constitución española de 1978, Madrid, Civitas, 1984, p. 877 et s.

16 L. Martín-Retortillo, «Eficacia y garantía de los derechos fundamentales », Estudios sobre la Constitución española. Homenaje al Profesor García de Enterría, II, Madrid, Civitas, 1991, p. 617.

17 R. Bustos Gibert, «Está agotado el modelo de recurso de amparo desiñado en la Constitución ? », Teoría y Realidad consitucional, 1999, 4, p. 278. 
même question, et même parfois le sentiment d'une immixtion dans un champ qui devrait être étranger au juge constitutionnel, celui de la légalité ordinaire ${ }^{18}$.

Ici, à la différence de ce qu'il en est avec les articles 43 et 44 de la LOTC, les pouvoirs publics en cause sont de nature juridictionnelle : le caractère juridictionnel de l'acte litigieux constitue l'élément spécifique dont résultent les différences les plus importantes avec les autres hypothèses de recours d'amparo, même s'il existe évidemment une certaine proximité entre elles. Au premier rang de celle-ci, on pense bien sûr aux droits protégés par cette procédure : l'objet du recours d'amparo - dit autrement, son champ matériel - consiste, comme toujours, dans la protection des droits et libertés consacrés par les articles 14 à 29 de la Constitution, auxquels il faut également ajouter le droit à l'objection de conscience protégé par l'article 30 de la Constitution. De sorte que, même si l'ombre du droit à une protection juridictionnelle effective ne peut manquer de planer, plus que toute autre, sur le recours d'amparo contre les décisions juridictionnelles, il n'épuise pas la liste des droits fondamentaux susceptibles d'être affectés par les agissements juridictionnels.

Mais on doit à la vérité de dire que le droit à une protection juridictionnelle effective ${ }^{19}$ occupe, bien entendu, une place dominante puisqu'il est le droit fondamental qui éveille, de façon tout à fait écrasante, le plus l'intérêt des plaideurs. En effet, bien que l'invocation de droits fondamentaux au contenu proprement substantiel ne soit pas exclue, il va de soi que l'articulation de griefs autour du droit à une protection juridictionnelle effective est souvent le moyen pour les justiciables d'éviter de trancher l'interrogation quant à l'existence d'une véritable atteinte à un droit produite par la juridiction ordinaire, ou celle d'une atteinte qui ne serait que le résultat d'une violation que le juge ordinaire n'a pas été en mesure de réparer. Aussi, les chiffres sont-ils le reflet de ces hésitations : en 2015 , le droit à une protection juridictionnelle effective a fondé $75,19 \%$ des recours formés devant le Tribunal (5 416 recours $)^{20}$. Le principe d'égalité, pour sa part, représente 13,77\% des griefs invoqués, suivi par l'ensemble des autres droits fondamentaux du chapitre II du titre I de la Constitution ${ }^{21}$.

Demeure alors une question essentielle : dans quel cas s'agit-il d'un acte de nature juridictionnelle et, au contraire, dans quel cas l'acte en cause revêt-il une autre nature ? En principe, l'acte ne sera juridictionnel que s'il est adopté par un organe appartenant à l'organisation juridictionnelle de

\footnotetext{
18 F. TOMÁs y VALIEnte, «Poder judicial y Tribunal constitucional », in Escritos sobre y desde el Tribunal constitucional, Madrid, CEC, 1993, p. 77 ; E. Carmona Cuenca, La crisis del recurso de amparo. La proteccción de los derechos fundamentales entre el Poder judicial y el Tribunal constitucional, Universidad de Alcalá, Servicio de publicaciones, 2005 ; P. BoN, « Sur les rapports entre juge constitutionnel et juge ordinaire. Quelques précisions sur le cas espagnol », Constitution et finances publiques. Études en l'honneur de L. Philip, Economica, 2005 , p. 43.

19 Art. 24 de la Constitution : «1. Toute personne a le droit d'obtenir la protection effective des juges et des tribunaux pour exercer ses droits et ses intérêts légitimes, sans qu'en aucun cas cette protection puisse lui être refusée. 2. De même, tous ont droit au juge ordinaire déterminé préalablement par la loi, de se défendre et de se faire assister par un avocat, d'être informés de l'accusation portée contre eux, d'avoir un procès public sans délais indus et avec toutes les garanties, d'utiliser les preuves pertinentes pour leur défense, de ne pas déclarer contre eux-mêmes, de ne pas s'avouer coupables et d'être présumés innocents. La loi règlementera les cas dans lesquels, pour des raisons de parenté ou relevant du secret professionnel, nul ne sera obligé à déclarer sur des faits présumés délictueux ».

20 Au sein de ce pourcentage, l'invocation de l'alinéa 1 de l'article 24 est la plus élevée avec 5325 recours sur les 7596 formés, l'alinéa 2 représentant les 2271 recours restant.

21 Le principe d'égalité est consacré par l'article 14 : « Les Espagnols sont égaux devant la loi ; ils ne peuvent faire l'objet d'aucune discrimination pour des raisons de naissance, de race, de sexe, de religion, d'opinion ou pour n'importe quelle autre condition ou circonstance personnelle ou sociale ».
} 
l'État en vue de solutionner un différend « au moyen de méthodes juridictionnelles ${ }^{22}$. Sont, par conséquent, exclus de cette qualification, les actes d'origine parlementaire, les actes administratifs, les actes adoptés par les organes consultatifs, ceux dont les auteurs sont des organes compétents en matière électorale, ou encore tous les actes qui tranchent des différends mais qui sont adoptés par des organes qui n'appartiennent pas au Pouvoir judiciaire, quelle que soit leur nature, publique ou privée, et cela même s'ils se prononcent sur le fondement de règles juridiques ${ }^{23}$. C'est, le plus souvent, le cas de tous les organes de conciliation, médiation ou d'arbitrage, dès lors qu'ils n'appartiennent pas au Pouvoir judiciaire ${ }^{24}$.

Par ailleurs, il doit s'agir d'une action ou d'une abstention à agir. Comprenons par-là que, d'un côté, les agissements des tribunaux sont envisagés sous un angle positif, à travers le terme « action », renvoyant à une décision qui, dans l'ordre juridique espagnol, peut prendre la forme, essentiellement, de providencia, d'ordonnance (auto), de jugement, d'injonction (requerimiento) ou encore, bien sûr, d'arrêt (sentencia). Tout acte de ce type portant atteinte à un ou plusieurs droits fondamentaux est donc susceptible de recours d'amparo. D'un autre côté, ces agissements peuvent aussi être conçus sous un angle davantage négatif et consister dans des abstentions, c'est à dire toute action qui, utile ou nécessaire à la bonne protection du droit fondamental en cause, n'a pas été réalisée par l'organe juridictionnel compétent. En toute hypothèse, action et abstention peuvent être le résultat d'une interprétation ou d'une application d'une norme, relativement à un droit fondamental déterminé, d'une méconnaissance ou d'une compréhension inexacte de celui-ci. Dit autrement, ce sont toutes les violations de l'intégrité d'un droit fondamental à proprement parler, comme les défauts dans sa protection, qui relèvent du champ du recours d'amparo de l'article 44.

Quant à la défaillance juridictionnelle, elle peut être de deux ordres : d'une part, « quantitative », lorsque le droit n'est pas reconnu avec l'intensité ou la force qu'il mérite, ou avec toutes les conséquences qui devraient lui être attachées. D'autre part, « qualitative », lorsque le droit n'est pas protégé dans tous ses aspects ou ses dimensions, ou que l'un ou l'une d'elle n'est pas reconnu. Finalement, même un léger dérapage dans la garantie du droit suffit pour qu'il y ait place ici pour un recours d'amparo car l'alinéa 2 de l'article 53 de la Constitution exige une protection complète de chacun des droits fondamentaux invocables. Et il va de soi que l'atteinte au droit peut se produire à tous les stades du procès, sous cette réserve qu'elle soit véritable, c'est à dire effective, concrète et actuelle, l'amparo constitutionnel ayant une finalité qui est, essentiellement, réparatrice ${ }^{25}$ et qui exclut donc tout amparo préventif ${ }^{26}$, comme tout jugement abstrait de la constitutionnalité d'une norme ${ }^{27}$. L'amparo constitutionnel est un mécanisme de garantie extraordinaire qui ne peut être

22 J. García Murcia, « Artículo 44 », in J. L. Requejo Pagés (dir.), Comentarios a la Ley orgánica del Tribunal constitucional, Madrid, Coedición del Tribunal constitucional y del Boletín oficial del Estado, 2001, p. 704.

23 STC 288/1993 du 4 octobre, FJ 3. Dans ce dernier cas, toutefois, les actes en cause pourront être considérés comme des actes administratifs et relever, de cette façon, de l'amparo constitutionnel contre les décisions administratives et/ou, ensuite, de l'amparo contre les décisions juridictionnelles.

24 C'est aussi le cas, de ce point de vue, du Tribunal constitutionnel lui-même.

25 STC (arrêt du Tribunal constitutionnel) 77/1982 du 20 décembre, entre autres ; également, ATC (ordonnance) 502/1987 du 22 mars.

26 ATC 201/2003 du 16 juin ; également STC 94/1992 et STC 174/1994.

27 ATC 1064/1988 du 26 septembre. 
mis en œuvre que pour répondre strictement à cet objectif, à l'exclusion de tout autre type de considérations. De sorte qu'il n'y a pas là la voie ouverte afin de corriger des interprétations ou des applications des droits fondamentaux qui ne seraient qu'incorrectes, excessives ou détournées, sans être attentatoires au droit considéré. Pas davantage il ne peut être question de revenir sur une interprétation juridictionnelle supposément inadéquate ou qui aurait des conséquences négatives pour l'une des parties ${ }^{28}$. À l'inverse, cette voie n'est ouverte au juge constitutionnel que dans l'hypothèse où l'intervention juridictionnelle a été insuffisante pour assurer la pleine reconnaissance du droit ; au contraire, elle demeurera fermée lorsque que cette intervention a été au-delà de ce qu'exigeait le droit ou au-delà des critères déterminés par la jurisprudence constitutionnelle ${ }^{29}$. En d'autres termes, le recours d'amparo corrige les carences et non pas les excès ${ }^{30}$.

Afin que le recours soit valablement formé, il convient que les conditions de fond que l'on vient de rappeler soient réunies. Mais, une autre série de conditions est également prévue, relative, cette fois, à la procédure et à la forme du recours : épuisement des voies de recours devant le juge ordinaire, imputabilité immédiate et directe de l'atteinte à un organe juridictionnel et invocation du droit supposément violé le plus tôt possible lors du procès ordinaire sont les trois conditions supplémentaires posées par l'article 44, qui vont être parmi les sources de l'éventuelle non admission du recours. Quant à l'épuisement des voies de recours, il y a là la traduction de ce que l'amparo constitutionnel n'est qu'un recours subsidiaire ${ }^{31}$. C'est le juge ordinaire qui est le juge de droit commun des droits fondamentaux et qui, à ce titre, doit en premier lieu les garantir. Par conséquent, le justiciable qui s'estime lésé dans l'un de ses droits fondamentaux doit d'abord saisir le juge ordinaire et ce n'est que dans l'hypothèse où celui-ci ne lui donne pas satisfaction qu'il pourra alors saisir le Tribunal constitutionnel ${ }^{32}$. Evidemment, cette condition renvoie à la mise en mouvement de recours utiles et « raisonnablement exigibles ${ }^{33}$, et qui sont relatifs à des faits qui parviennent établis devant le juge constitutionnel, c'est à dire d'ores et déjà exposés et prouvés, de sorte qu'ils ne pourront faire l'objet d'aucune appréciation nouvelle de la part du Tribunal constitutionnel. Il ne s'agit pas d'examiner de façon générale les actes du Pouvoir judiciaire mais uniquement d'apprécier leur constitutionnalitée ${ }^{34}$. Et pour ce qui est de l'invocation formelle préalable du droit fondamental lésé, là aussi la jurisprudence constitutionnelle tâche d'adopter une interprétation qui, tout en faisant la place à une certaine souplesse d'appréciation bienvenue pour les requérants, n'ouvre pas pour autant toutes grandes les portes du prétoire constitutionnel : si elle n'exige pas l'invocation expresse et détaillée de la règle supposément violée, elle n'admet pas qu'elle puisse être implicite ou sous-entendue ${ }^{35}$. Pour autant, les modalités d'examen du recours ne sont pas sans susciter des interrogations.

28 Par exemple, STC 86/1985 du 10 juillet, ou STC 136/1987 du 22 juillet.

M. SÁnchez Morón, El recurso de amparo constitucional, Características actuales y crisis, Madrid, CEC, 1987, p. 28 et s.

P. CRuz Villalón, «El recurso de amparo constitucional », in Los procesos constitucionales, Madrid, CEC, 1992, p. 117.

Comme le Tribunal constitutionnel n'a pas manqué de le souligner depuis l'origine : par exemple, et entre autres, SSTC 185/1990 du novembre, et 310/1993 du 25 octobre.

32 Il n'y a pas épuisement des voies de recours lorsque les recours existants ne sont pas actionnés, mais aussi lorsqu'ils le sont incorrectement, provoquant leur irrecevabilité, ou encore lorsqu'ils le sont hors délai : STC 111/2000 du 5 mai.

33 STC 73/1982 du 2 décembre.

34 STC $114 / 1984$ du 29 novembre.

35 SSTC 35/1983, 182/1990 ou encore 66/2009. 


\section{B. Les modalités d'examen du recours d'amparo}

Puisqu'il y a là une voie de droit permettant l'accès direct au juge constitutionnel, ce qui devait se produire est advenu et le recours d'amparo a rencontré, et rencontre toujours, un succès sans précédent, les recours se comptant chaque année par milliers et les chiffres de 2015, bien qu'ils marquent un infléchissement, donnent presque le vertige. Ainsi, quant à l'origine des recours d'amparo, c'est-à-dire les actes contre lesquels ces recours sont formés, conformément aux années passées, ce sont précisément toujours les décisions rendues par les tribunaux qui sont les plus nombreuses, puisqu'elles font l'objet de 7190 des 7203 recours d'amparo dont le Tribunal a été saisi en 2015. Par ailleurs, ce sont avant tout les décisions rendues en appel qui sont contestées (3 116), qu'il s'agisse de celles des Audiencias provinciales ${ }^{36}$ ou de celles des Tribunaux supérieurs de justice ${ }^{37}$. Les décisions du Tribunal suprême représentent, quant à elles, un chiffre de 2067 sur les 7203 recours formés. Si on tourne les yeux vers les plaideurs cette fois, on constate que, dans l'écrasante majorité des cas, les recours sont actionnés par des particuliers ${ }^{38}$; les personnes morales de droit privé ${ }^{39}$ et les personnes morales de droit public ${ }^{40}$ interviennent également, mais dans des proportions beaucoup plus réduites. Et en 2015, même le Défenseur du peuple a formé un recours d'amparo, tandis que le Ministère public deux.

D’où la nécessité de mettre en place des mécanismes de sélection des recours permettant de faire le tri entre ceux qui méritent effectivement un examen approfondi et ceux qui peuvent faire l'objet d'une procédure de rejet sommaire, afin de tenter de désencombrer la juridiction constitutionnelle. À cet égard, l'article 50 de la LOTC prévoit, dans son alinéa $1^{41}$, que le recours doit, tout d'abord, faire l'objet d'une décision d'admission de la demande qui n'intervient que si les conditions posées par les articles 41 à 46 et à l'article 49 de la loi organique sont respectées et que « le contenu $\mathrm{du}$ recours justifie une décision sur le fond de la part du Tribunal constitutionnel en raison de son importance constitutionnelle spéciale, appréciée au regard de son importance pour l'interprétation de la Constitution, pour son application ou pour son efficacité générale et pour la détermination du contenu et de la portée des droits fondamentaux $»^{42}$. Ce sont donc deux hypothèses dans lesquelles le recours peut faire l'objet d'un rejet sommaire : d'une part, si la demande ne remplit pas de façon manifeste l'une quelconque des conditions de formation du recours que nous avons examinées ; d'autre part, la demande manque d'un contenu qui justifie une décision sur le fond de la part du Tribunal car elle est dépourvue d'une importance constitutionnelle spéciale. Cette dernière condition

\footnotetext{
36 Juridictions d'appel siégeant dans chaque Communauté autonome ; 2456 requêtes sur les 7203 enregistrées.

37 Juridictions supérieures siégeant au niveau de chaque Communauté autonome; 1121 recours. Ce sont 1887 décisions rendues en premier ressort ou en juge unique qui font l'objet d'une contestation en amparo.

386196 des 7203 recours enregistrés.

39912 recours.

92 recours.

«1. El recurso de amparo debe ser objeto de una decisión de admisión a trámite. La Sección, por unanimidad de sus miembros, acordará mediante providencia la admisión, en todo o en parte, del recurso solamente cuando concurran todos los siguientes requisitos :a) Que la demanda cumpla con lo dispuesto en los artículos 41 a 46 y 49 ;b) Que el contenido del recurso justifique una decisión sobre el fondo por parte del Tribunal Constitucional en razón de su especial trascendencia constitucional, que se apreciará atendiendo a su importancia para la interpretación de la Constitución, para su aplicación o para su general eficacia, y para la determinación del contenido y alcance de los derechos fundamentales ».

42 Cette condition a été reformulée dans le sens de son objectivisation lors d'une importante modification de la LOTC intervenue en 2007 ;

cf. P. Bon, « Tribunal constitutionnel espagnol : importantes modifications de sa loi organique en 2007 », in Le dialogue des juges - Mélanges en l’honneur du Président Genevois, Paris, Dalloz, 2009, p. 51.
} 
est, on l'aura compris, la plus délicate à interpréter et elle a été introduite en 2007 précisément afin de doter le juge constitutionnel d'un levier efficace lui permettant de faire face rapidement à l'afflux massif de recours d'amparo infondés.

L'article 50 de la loi organique définit ensuite la procédure de rejet sommaire par une section du Tribunal, formation de jugement composée de trois juges. L'admission du recours n'est acquise que si les trois membres de la section, à l'unanimité, considèrent que les conditions de formation du recours sont remplies. Si seule une majorité en faveur de l'admission se dégage, alors c'est à la chambre qu'il revient de trancher cette question. En revanche, s'ils estiment unanimement que ce n'est pas le cas, ils rejettent l'admission du recours par une décision, appelée providencia, qui n'est pas publiée et contre laquelle seul le Ministère public peut agir. Si deux des trois juges estiment qu'il y a lieu à rejet sommaire, ce rejet peut être prononcé par une ordonnance (auto), sommairement motivée, publiée et contre laquelle aucune voie de recours n'est ouverte. Enfin, si un juge ou aucun juge n'est favorable à un rejet sommaire, l'affaire est examinée par l'une des deux chambres du Tribunal ${ }^{43}$, sauf dans le cas où l'affaire soulève des difficultés particulières ce qui justifie qu'elle soit soumise à l'assemblée plénière ${ }^{44}$. Dans un cas comme dans l'autre, le Tribunal rend un arrêt, longuement motivé.

À cet égard, nous aurons l'occasion d'y revenir, une observation s'impose à ce stade : le juge de l'amparo est surtout un juge de la non-admission des recours d'amparo : sur les 8513 affaires d'amparo que le Tribunal a réglé en 2015, 7880 l'ont été par des providencias de inadmisión, c'est-àdire des décisions qui ne procèdent même pas à un examen de l'affaire au fond. Cela représente près de $93 \%$ des litiges résolus. La valeur ajoutée de ce travail pour l'ordre juridique espagnol est quasi nulle. Seuls 96 arrêts, examinant l'affaire au fond, ont été rendus dans le cadre de ce chef de compétence ${ }^{45}$. Ce type de décision soit refuse d'accorder l'amparo, soit au contraire l'accorde, c'est à dire qu'en application de l'article 55, aliéna 1, de la LOTC, l'arrêt indique le droit fondamental qui a été violé, annule les actes qui ont violé ce droit et, le cas échéant, rétablit le requérant dans l'intégrité de

43 Si les trois juges de la section chargée de l'instruction du recours sont unanimes pour considérer que le recours est recevable, ils le décident par ordonnance (providencia de admisión). Les ordonnances d'irrecevabilité, qu'elles résultent de la section (dans l'hypothèse qui vient d'être évoquée) ou de la chambre (lorsque seuls deux juges de la section étaient en faveur de la recevabilité, que la décision a été prise par la chambre et que cette dernière a finalement tranché en faveur de l'irrecevabilité), doivent seulement spécifier la cause de l'irrecevabilité (ce qui veut dire qu'elles ne sont que très sommairement motivées) et sont notifiées au requérant et au ministère public (ce qui veut dire qu'elles ne sont pas publiées). Seul ce dernier a le droit de les attaquer dans un délai de trois jours. Si, à l'inverse, le recours est jugé recevable, l'instruction du recours se poursuit jusqu'à ce qu'il soit en état d'être jugé par la chambre (sauf si l'affaire a été évoquée par l'assemblée plénière du Tribunal constitutionnel, ce qui n'arrive que très exceptionnellement) qui rendra alors un arrêt (sentencia) longuement motivé et évidemment publié. 44 Comme le souligne P. Bon, « Tribunal constitutionnel espagnol : importantes modifications de sa loi organique en 2007 », op. cit. : "Toutefois, dans le cadre du processus de redistribution des litiges entre l'assemblée plénière, les chambres et les sections, il est maintenant permis à la chambre, normalement compétente pour statuer au fond sur un recours d'amparo, de déléguer à la section sa compétence « lorsque, pour sa résolution, est applicable une jurisprudence consolidée du Tribunal constitutionnel » (article 52). Il y a là, nous semble-t-il et comme nous l'avons déjà souligné, un illogisme : nous venons de voir qu'un recours d'amparo ne peut dorénavant être recevable que s'il présente une importance constitutionnelle spéciale, ce qui suffit à fonder l'intervention de la chambre ; au surplus, si le recours présente effectivement une importance constitutionnelle spéciale, il y a tout lieu de penser qu'il n'existe pas en la matière de jurisprudence consolidée du Tribunal constitutionnel ; dès lors, il n'est pas logique de permettre à la section de statuer sur le fond (alors qu'il est logique qu'elle statue, sous certaines conditions, sur la recevabilité) ; en d'autres termes, compte tenu du nouveau système, tous les recours d'amparo devraient, a fortiori, relever de la compétence des chambres pour leur jugement au fond ».

45 Plus généralement, à côté des 7369 affaires enregistrées par le greffe du Tribunal en 2015, ce sont 8486 qui ont été définitivement réglées, la différence de 1313 illustrant les efforts de la juridiction constitutionnelle en vue de réduire le stock des affaires en souffrance. De ce point de vue, restent à trancher au fond 440 affaires, tandis que 3369 sont encore en attente d'une décision quant à leur admission pour un éventuel examen au fond. 
son droit en adoptant toutes les mesures appropriées. Au-delà de ces éléments techniques, le bilan qui peut être tiré de la pratique peut inquiéter.

\section{L'état du recours d'amparo contre les décisions juridictionnelles}

Le recours d'amparo constitutionnel apparaît, depuis l'entrée en vigueur de la Constitution de 1978 et l'entrée en fonction du Tribunal constitutionnel espagnol, comme l'instrument privilégié d'accès des particuliers au prétoire du juge constitutionnel. Il occupe, ainsi, une place essentielle au sein du système de justice constitutionnelle espagnol et, plus généralement, dans l'ordre juridique dans son ensemble, nourrissant même un certain nombre d'évolutions qui le parcourent depuis quelques années.

À cet égard, c'est à la lumière des deux caractéristiques fondamentales du recours d'amparo qu'il convient de tenter de mesurer l'influence qu'il a exercé et qu'il exerce encore sur l'ordre juridique. Subsidiaire et supplétif : voilà les deux traits fondamentaux qui, au moins en théorie, le définissent. Certes l'amparo constitutionnel est subsidiaire, en ce sens qu'il n'est pas possible de le former tant que toutes les voies de recours ne sont pas épuisées; et supplétif en ce sens qu'il est conçu pour réparer les défaillances de justice ordinaire ${ }^{46}$. Cependant, ces deux qualités font surgir, dans le même temps, une interrogation capitale : celle de l'articulation entre juridiction ordinaire et juridiction constitutionnelle (A).

En outre, si le regard est porté cette fois non pas sur le fonctionnement de l'ensemble du système mais simplement sur celui de la juridiction constitutionnelle, une seconde question essentielle se fait jour : celle du poids du recours d'amparo sur l'office du juge constitutionnel (B).

\section{A. L'articulation entre juridiction ordinaire et juridiction constitutionnelle}

D'un point de vue « macro-juridique », observons, en premier lieu, qu'une fois que le juge ordinaire est irrémédiablement impliqué dans la garantie et la réparation des droits fondamentaux, le recours d'amparo (constitutionnel) apparaît, qu'on le veuille ou non, comme une protection face à l'intervention de la justice ordinaire ${ }^{47}$. Et l'existence de l'article 44 de la LOTC ne peut manquer d'être interprétée, au moins pour partie, en ce sens. Jetons alors un regard sur la position du Tribunal constitutionnel, par rapport au juge ordinaire, pour y constater la suprématie de cette juridiction spécialisée sur les organes du Pouvoir judiciaire en matière de garanties constitutionnelles. Une position qui lui permet de contrôler la «forme » selon laquelle les juges et tribunaux ordinaires conçoivent et appliquent les règles constitutionnelles relatives aux droits fondamentaux.

L'intervention du Tribunal constitutionnel par le biais du recours d'amparo met ici en lumière finalement la dimension objective qui est consubstantielle à cette voie de droit. En d'autres termes,

46 F. Rubio Llonente, «Sobre la relación entre Tribunal constitucional y Poder judicial en el ejercicio de la jurisdicción constitucional », Revista española de derecho constitucional, 1982, n 4, p. 65.

47 En ce sens, P. Cruz Villalón, op. cit., p. 117. 
ce n'est pas un simple instrument de protection des justiciables qui se plaignent d'une atteinte à leurs droits ; c'est, au-delà, un instrument de protection de l'ordre constitutionnel lui-même ${ }^{48}$. Bien sûr, le recours se forme à partir d'une plainte individuelle concrète et il revêt un caractère incontestablement subjectif, mais il est tout aussi certain que, à partir de ces éléments, le recours d'amparo participe à la réalisation des droits fondamentaux. Sa finalité n'est autre que celle de fournir la « signification exacte » de ces droits, c'est à dire la signification que leur confère l'interprète authentique de la Constitution. Le recours d'amparo est, en réalité, un instrument d'édification de la jurisprudence relative au contenu et à la portée des droits fondamentaux.

Que le recours d'amparo soit le point final d'une série, plus ou moins longue, d'actions juridictionnelles destinées à protéger les droits fondamentaux traduit également sa nature juridique complexe, en particulier dans son articulation avec la juridiction ordinaire. À ce propos, on peut se demander, très concrètement, s'il s'agit véritablement d'un recours ou, au contraire, s'il suppose plus exactement l'ouverture d'un nouveau procès. On peut également s'interroger sur son caractère « judiciaire », en tant que dernier maillon d'une chaîne d'actions et recours propres au système judiciaire ou si, en réalité, il se situe dans un espace distinct ${ }^{49}$. En effet, il est certain que ce recours déclenche la tenue d'un procès de type juridictionnel, qui se déroule conformément à des règles très semblables à celles du procès judiciaire. De même, il y a là un authentique recours qui ne suppose pas exactement l'exercice d'une action juridictionnelle indépendante et autonome, mais qui s'adosse au contraire sur un procès judiciaire préalable par lequel elle est dans une grande mesure conditionnée. Toutefois, malgré ces éléments, on ne peut que constater sa nature spéciale, compte tenu non seulement de ce que son encadrement relève de normes tout à fait spécifiques, c'est à dire totalement distinctes de celles qui sont applicables à la juridiction judiciaire et dont la LOTC porte le témoignage, mais aussi de ce que l'organe devant lequel il se déroule se situe en dehors du Pouvoir judiciaire ${ }^{50}$. Dit autrement, ce n'est pas une nouvelle instance juridictionnelle mais un instrument spécifique de protection des droits fondamentaux ${ }^{51}$.

Le recours d'amparo n'est comparable, par ailleurs, à aucune autre voie de recours existant dans l'ordre juridictionnel espagnol, tant du point de vue de sa conception normative, dont on a vu qu'elle le plaçait en dehors de l'organisation judiciaire, que du point de vue de son objet qui se limite à la protection des droits fondamentaux. Par hypothèse, ce n'est pas une voie d'appel, compte tenu de sa dimension exclusivement constitutionnelle et de l'impossibilité de connaître des faits. Il ne peut pas davantage être considéré comme un recours en cassation dans la mesure où il relève du monopole du juge constitutionnel, et cela même si un certain parallélisme peut paraître s'établir aisément entre ces deux voies juridictionnelles. De sorte que c'est, sans doute aussi, cette nature mixte qui explique les difficultés proprement factuelles, voire les conflits, qui ont pu voir le jour entre le Tribunal constitutionnel et le Tribunal suprême.

48 J. L. Cascajo Castro et V. Gimeno Sendra, El recurso de amparo, Madrid, Tecnos, 1985, p. 41 et s.

49 Sur cette question : V. GIMENo SENDRA, « Naturaleza jurídica y objeto procesal del recurso de amparo », Revista española de derecho constitucional, 1982, n ${ }^{\circ}$ 6, p. 44.

50 STC 166/1986 du 19 décembre.

51 SSTC 2/1982 du 29 janvier, et 62/1982 du 15 octobre. 
Ainsi, la modification de la LOTC, intervenue en 2007, et qui mérite à plus d'un titre notre intérêt ici, ambitionnait notamment mais précisément de renforcer la position du Tribunal constitutionnel face au pouvoir judiciaire et, plus précisément, face au Tribunal suprême, tant les tensions ont parfois pu se multiplier entre eux. À l'occasion de la réforme de la LOTC opérée en 2007, le législateur organique a donc cru bon de réaffirmer la primauté du premier sur le second en matière de garantie de la Constitution, tout en lui donnant les moyens de la défendre.

Ces conflits sont fréquents, semble-t-il, lorsque, comme en Autriche, en Allemagne et en Espagne, le juge constitutionnel peut être saisi par les individus des violations de leurs droits fondamentaux et, surtout, peut annuler les arrêts rendus par le juge ordinaire qui sont à l'origine ou qui n'ont pas remédiés à ces violations, y compris lorsqu'il s'agit d'arrêts rendus par le juge ordinaire suprême. En effet, ce dernier se trouve alors directement sous l'autorité du juge constitutionnel qui peut censurer ses jugements.

L'Espagne est exemplaire en la matière, où le Tribunal suprême a eu une difficulté certaine à accepter de n'être pas « suprême » en matière de garantie de la Constitution ${ }^{52}$ et de voir, à l'occasion, ses arrêts annulés par le juge constitutionnel ${ }^{53}$. Ce sont deux types d'annulation qui suscitent particulièrement son agacement : d'une part, lorsque le Tribunal constitutionnel annule un de ses arrêts et déclare définitif l'arrêt du juge inférieur ; dans une telle hypothèse, rien de surprenant à ce que le Tribunal suprême s'estime désavoué dans sa mission d'organe juridictionnel suprême de l'ordre judiciaire. D'autre part, lorsque le Tribunal constitutionnel annule un de ses arrêts et retient le montant de l'indemnité accordée par le juge inférieur ; dans un tel cas, l'affront est tout aussi certain et se double, aux yeux du juge suprême, d'une pénétration du juge constitutionnel dans un domaine réservée à la juridiction ordinaire, celui de l'évaluation des préjudices. D'où des critiques vives à l'égard de telles annulations, que le Tribunal suprême n'hésite pas à exposer de manière détaillée à l'occasion de certains de ses arrêts ${ }^{54}$.

Mais il est même allé plus loin : dans un arrêt du 23 janvier 2004, il a purement et simplement engagé la responsabilité civile des membres du Tribunal constitutionnel pour avoir classé, à ses yeux à tort, un recours d'amparo dont ils étaient saisis. Comme on s'en doute, cette condamnation a suscité une émotion considérable, non seulement dans l'immense majorité de la doctrine constitutionnaliste, mais aussi et tout particulièrement au sein du Tribunal constitutionnel. Aussi, le 3 février 2004, le juge constitutionnel a-t-il publié un communiqué adopté par son assemblée plénière rappelant que les décisions rendues par le Tribunal en matière d'examen des recours d'amparo ne peuvent être appréciées par aucun organe du Pouvoir judiciaire et qu'apprécier de telles décisions par le biais de l'examen d'actions en responsabilité civile revient à empiéter sur la compétence exclusive du Tribunal constitutionnel, telle qu'elle lui a été confiée par la Constitution.

52 Article 123-1 de la Constitution : «Le Tribunal suprême, dont la juridiction s'étend à toute l'Espagne, est l'organe juridictionnel suprême, sauf en ce qui concerne les dispositions sur les garanties constitutionnelles ».

53 En 2015, sur les 7203 recours d'a mparo contre des décisions juridictionnelles dont le Tribunal constitutionnel a été saisi, 2067 contestaient des décisions du Tribunal suprême. Mais ce sont seulement 49 décisions juridictionnelles qui ont été finalement annulées.

54 Voir par exemple l'arrêt STC 1064/2001 du 5 novembre 2001. 
Cet épisode est directement à l'origine du volet de la réforme de 2007 qui a pour objectif de renforcer la position du Tribunal constitutionnel par rapport au Tribunal suprême en ajoutant deux précisions à l'article 4 de la LOTC qui définit, en termes généraux, la position institutionnelle du juge constitutionnel. En premier lieu, il est clairement affirmé que les résolutions du Tribunal constitutionnel ne pourront être jugées par aucun organe juridictionnel de l'État. En second lieu, l'alinéa 1 de l'article 4 dispose désormais que le Tribunal constitutionnel délimitera le champ de sa juridiction et adoptera toutes les mesures nécessaires pour la préserver, y compris la déclaration de nullité de ceux des actes ou résolutions qui y portent atteinte ; de la même manière, il pourra apprécier d'office ou à la demande des parties sa compétence ou son incompétence ${ }^{55}$. Décidément, bien curieuse position que celle du Tribunal constitutionnel dans un État de droit, comme l'actualité catalane vient encore de le mettre en lumière ${ }^{56}$ : il en vient à être obligé de se saisir lui-même, pour être, en quelque sorte, juge et partie afin de s'assurer du respect de ses propres décisions, ou à compter sur l'intervention du législateur organique pour rappeler ou redire la place qu'il occupe dans l'ordonnancement juridique. C'est finalement son office lui-même qui se trouve en cause.

\section{B. L'influence du recours d'amparo sur l'office du juge constitutionnel}

L'encombrement du Tribunal constitutionnel est aujourd'hui patent et le constat ne présente plus aucune originalité, bien au contraire. Cet encombrement est allé croissant et il est le résultat de l'évolution exponentielle du nombre de recours d'amparo. De 2006 à 2009, la barre de 10000 recours annuels a été plusieurs fois franchie $e^{57}$, et si depuis 2010, ce chiffre décroit, il s'établit encore en général autour d'un peu plus de 7000 recours annuels ${ }^{58}$. De telle sorte que l'essentiel de l'énergie de la Haute instance est utilisé à juger ces recours d'amparo, au détriment de ses autres chefs de compétence et notamment de ses compétences en matière de contrôle des normes et, plus précisément, de contrôle des actes législatifs, que ce soit sur saisine d'autorités principalement politiques (contrôle abstrait, dénommé en Espagne recours d'inconstitutionnalité) ou du juge (contrôle concret, dénommé question d'inconstitutionnalité). Il en résulte un allongement préoccupant de la durée de jugement (plusieurs années pour les recours d'amparo ; encore plus longtemps pour les procédures de contrôle des normes) qui fait perdre à l'institution une bonne partie de sa crédibilité, dans la mesure où ses décisions en viennent à relever plus de l'histoire du droit que du droit positif ${ }^{59}$.

Pourtant, bien peu de ces recours aboutissent. En effet, sur les milliers de recours d'amparo dont est saisi chaque année le Tribunal constitutionnel, l'immense majorité d'entre eux est rejetée au cours de la phase d'instruction de telle sorte que, finalement, à peine $4 \%$ sont résolus par un arrêt en bonne et due forme et, puisque certains de ces arrêts sont des arrêts de rejet de l'amparo,

\footnotetext{
55 Évidemment dans ce cas, l'annulation doit être motivée et doit être prononcée après audition du ministère public et de l'organe auteur de l'acte ou de la résolution.

56 Songeons à la modification de la LOTC intervenue en 2015 à la suite de la mauvaise volonté, voire du refus, de certains responsables politiques catalans d'appliquer et de faire respecter les décisions du Tribunal constitutionnel.

57 En 2006, 11471 recours. En 2007, 9840 ; en 2008, 10279 ; et en 2009, 10792.

58 En 2010, ce sont 8947 recours d'amparo qui ont été formés. En 2011, 7 098, en 2012, 7 205, en 2013, 7 376, en 2014, 7663 et en $2015,7203$.

59 J. García RocA, cité par F. Fernández Segado, La reforma del régimen jurídico-procesal del recurso de amparo, Dykinson, 2007, p. 16.
} 
le pourcentage des cas de violation des droits fondamentaux relevés par le juge constitutionnel est encore inférieur à ce chiffre. En d'autres termes, le Tribunal déploie une énergie considérable à examiner des recours d'amparo dont, finalement, très peu sont fondés alors que l'exercice de ses autres compétences pâtit du temps qu'il consacre à cette tâche. En 2015, ce sont 8511 décisions qui ont été rendues en cette matière, parmi lesquelles seuls 96 arrêts rendus par l'assemblée plénière et 50 autos par des chambres, la grande majorité étant des providencias rendues par les sections du Tribunal (8 494), c'est à dire des rejets sommaires au stade de l'admission. La mutation de l'office du juge constitutionnel est évidente qui devient avant tout un juge de l'amparo, et plus précisément un juge de la non admission - comprenons par là un rejet qui n'examine et ne traite même pas du fond - de l'amparo.

Aussi, en 2007, la loi organique 6/2007 du 24 mai $2007^{60}$ modifiant la loi organique 2/1979 relative au Tribunal constitutionnel, a-t-elle, comme nous l'avons dit, été adoptée. Sans revenir sur les dispositions qu'elle comportait afin de rétablir des relations plus sereines entre Tribunal suprême et Tribunal constitutionnel, relevons qu'il s'agissait de la sixième modification de la LOTC. Toutefois, elle se distingue de celles qui l'ont précédées, comme de celles qui suivront, par son ambition : alors qu'en général ces modifications n'ont que des objets ponctuels ${ }^{61}$, celle de 2007 est beaucoup plus importante, tant quantitativement - elle modifie plus du tiers des articles de la LOTC - que qualitativement - son objet principal consiste à revoir très sensiblement la procédure d'examen des recours d'amparo, mais sans oublier pour autant d'autres attributions du Tribunal et certaines des règles de base de son organisation ${ }^{62}$.

Afin d' « objectiver » l'amparo constitutionnel, la modification de la procédure d'examen de ce recours est intervenue en amont comme en aval, c'est-à-dire avant et après la saisine du Tribunal constitutionnel. En amont, a été renforcée la possibilité pour le juge ordinaire de protéger les droits fondamentaux en espérant que, de la sorte, les requérants n'auraient pas à saisir le juge constitutionnel. C'est la nouvelle réglementation de l'« incident de nullité des actions », prévu par l'article 241 , alinéa 1, de la loi organique relative au pouvoir judiciaire ${ }^{63}$ et qui se trouve réformé par la disposition finale première de la loi de 2007. Jusqu'alors, cette procédure incidente jouait essentiellement pour remédier à des vices de procédure qui avaient eu pour conséquence d'empêcher quelqu'un de défendre ses intérêts devant le juge ordinaire, de telle sorte qu'elle ne permettait as de garantir que le droit constitutionnel à une protection juridictionnelle effective. Dorénavant, elle peut être utilisée pour défendre n'importe quel droit constitutionnel susceptible de recours d'amparo. En aval, c'est-àdire lorsque le juge constitutionnel a été saisi, la réforme modifie la procédure d'examen des recours

60 Ley orgánica 6/2007, de 24 de mayo, por la que se modifica la Ley orgánica 2/1979, de 3 de octubre, del Tribunal constitucional.

61 La loi organique 8/1984 du 26 décembre 1984 modifie le régime du recours d'amparo contre les violations du droit à l'objection de conscience, la loi organique 4/1985 du 7 juin 1985 (Annuaire international de justice constitutionnelle 1985, p. 350) supprime le recours d'inconstitutionnalité a priori, la loi organique 6/1988 du 9 juin 1988 (Annuaire international de justice constitutionnelle 1988, p. 306) modifie (déjà) la procédure d'examen des recours d'a mparo, la loi organique 7/1999 du 21 avril 1999 (Annuaire international de justice constitutionnelle 1999, p. 496) introduit un nouveau recours devant le Tribunal constitutionnel, le conflit en défense de l'autonomie locale, et la loi organique $1 / 2000 \mathrm{du} 7$ janvier 2000 (Annuaire international de justice constitutionnelle 2000, p. 606) modifie certains délais de recours.

62 G. FERNÁNDEz FARRERES, « La reforma de la ley orgánica del Tribunal constitucional - Comentario a la ley orgánica 6/2007 de 24 de mayo », Revista española de derecho constitucional, 2007, p. 11 ; F. Fernández Segado, La reforma del régimen jurídico-procesal del recurso de amparo, op. cit., p. 19. 63 Ley orgánica 6/1985, de 1 de julio, del Poder judicial. 
d'amparo afin que le filtrage en soit plus efficace parce que plus objectif ${ }^{64}$. Inspirée par le système allemand, la réforme de 2007 a apporté deux changements majeurs.

D'un côté, le recours d'amparo ne sera examiné que s'il fait l'objet d'une décision expresse de recevabilité (décisión de admisión a tramite) alors que, dans le passé, tous les recours étaient examinés sauf s'ils avaient fait l'objet d'une décision expresse de non admission (decisión de inadmisión). Se produit un renversement de perspective, une procédure d'irrecevabilité se substituant à une procédure de recevabilité. D'un autre côté, le recours ne sera recevable que si, en plus de satisfaire aux conditions traditionnelles, il justifie une décision sur le fond de la part du Tribunal constitutionnel en raison de son importance constitutionnelle spéciale (especial trascendencia constitucional). En d'autres termes, une violation présumée des droits fondamentaux d'un individu susceptibles d'amparo ne suffit plus pour que le recours soit recevable. Il faut de plus que le recours présente une importance constitutionnelle spéciale. Il en résulte que le recours d'amparo n'est plus seulement un instrument subjectif de défense des droits des individus. Il devient un élément de défense objective de la suprématie de la Constitution.

Nous avons déjà envisagé les conditions d'admission du recours, sans encore insister sur la novation essentielle apportée par la réforme de 2007, et consistant dans l'ajout d'une condition : « que le contenu du recours justifie une décision sur le fond de la part du Tribunal constitutionnel en raison de son importance constitutionnelle spéciale ». C'est la raison pour laquelle l'article 49 impose dorénavant que le recours résulte d'une demande dans laquelle, non seulement sont exposés avec clarté et concision les faits qui le fondent, sont citées les dispositions constitutionnelles qui sont considérées comme violées par le requérant, est indiqué avec précision l'amparo (protection) qui est demandé pour préserver ou rétablir le droit ou la liberté qui est considéré comme violée, mais aussi dans laquelle figure une justification expresse de l'importance constitutionnelle spéciale du recours.

La volonté du législateur de 2007 consiste à « objectiver » le recours d'amparo : cette voie de droit ne doit pas simplement être un élément de défense des droits subjectifs mais elle doit également être conçue comme un instrument de protection objective de la Constitution. Outre la symbolique dans l'ordre constitutionnel, le législateur organique imaginait là un moyen de limitation du flux de recours d' amparo $0^{65}$. Presque 10 ans après cette modification, les chiffres ne paraissent pas démontrer une baisse drastique du nombre de recours annuellement formés, pas davantage qu'une amélioration de leur valeur. C'est la question de la qualité de la protection des droits fondamentaux dans l'ordre juridique espagnol, presque quarante ans tout juste après l'entrée en vigueur de la Constitution de 1978, qui se trouve alors de nouveau posée.

64 Ce n'est pas la première fois qu'une telle modification a lieu. Déjà, la loi organique 6/1988 du 9 juin 1988 avait modifié le système initialement mis en place par la LOTC sans que, malgré tout, la situation ne s'améliore sensiblement.

65 On se souvient que l'article 50, alinéa $1 \mathrm{~b}$ ), mentionne trois critères qui doivent guider le juge constitutionnel dans l'appréciation de ce critère de l'importance constitutionnelle spéciale : l'importance pour l'interprétation de la Constitution ; l'importance pour l'application de la Constitution ou pour son efficacité générale ; et, enfin, l'importance pour la détermination du contenu et de la portée des droits fondamentaux. 



\title{
LE CONTRÔLE DE CONSTITUTIONNALITÉ DES DÉCISIONS DE JUSTICE en AUTRICHE*
}

\author{
Marie-Caroline ARreto ${ }^{1}$
}

La justice constitutionnelle jouit d'un statut privilégié en Autriche. Avant même l'instauration d'une cour constitutionnelle par l'adoption le $1^{\text {er }}$ octobre 1920 de la Constitution autrichienne, il existait déjà une «première ébauche de juridiction constitutionnelle $»^{2}$ : le Tribunal d'Empire (Reichsgericht), instauré par la Constitution de 1867. Ses compétences étaient loin de rivaliser avec celles que possèdent les juridictions constitutionnelles aujourd'hui. C'est pourquoi, certains auteurs datent plutôt la naissance de la justice constitutionnelle en Europe avec la Constitution de $1920^{3}$. Toute évolution du droit positif autrichien en matière de justice constitutionnelle constitue dès lors une sorte de retour aux sources et peut être témoin d'une évolution présente ou future du modèle européen. Alors que le modèle autrichien de justice constitutionnelle est un des plus anciens en Europe, il est intéressant de voir par ailleurs que ce développement n'a pas touché l'autre branche des recours de droit public : la justice administrative ${ }^{4}$. Et sur ce point, le droit autrichien a vécu un véritable bouleversement entre 2012 et $2014^{5}$ : le législateur a décidé de refonder totalement la justice administrative autrichienne (Verwaltungsgerichtsbarkeit). La raison d'être d'une telle réforme s'explique par l'absence de tout ordre juridictionnel administratif tel que nous pouvons le connaître en France. C'est aussi à cette occasion que fut introduit le contrôle de constitutionnalité des décisions de justice.

Une précision s'impose préalablement. La présente contribution ne porte pas sur un recours à proprement parler mais plutôt sur deux types de recours, deux procédures ouvertes contre les décisions de justice, introduites par la réforme de la justice administrative. Afin d'expliquer le sens et la portée de ces modifications de l'ordonnancement juridique autrichien, il est utile de poser

Ce travail n'aurait pas été possible sans l'aide matérielle apportée par le Prof. Michael Thaler et le Dr. Christina Juhász à l'organisation d'un séjour de recherche complémentaire. Cette contribution a aussi bénéficié des précieux conseils et remarques du $\mathrm{D}^{\mathrm{r}}$ Lucie Sponchiado, Maître de conférences à l'Université de Créteil.

ATER à l'Université Paris 1 Panthéon-Sorbonne.

Charles Eisenmann, La justice constitutionnelle et la Haute Cour constitutionnelle d'Autriche, th., 1928, p. 109.

Louis FAvOREU, « Modèle américain et modèle européen de justice constitutionnelle », AIFC, vol. IV, 1988, p. 51-65 ; Hans KELSEN, « Le contrôle de constitutionnalité des lois. Une étude comparative des Constitutions autrichienne et américaine », RFDC, 1-1990, p. 17-30.

Précisons ici que la Cour constitutionnelle est considérée comme appartenant aux juridictions de droit public.

5 Bundesgesetzblatt (BGBl) I 2012/51 ; BGBl. I 2013/33 ; BGBl I 2013/114 ; BGBl. I 2014/92 ; BGBl. I 2014/99. Il s'agit de la publication au journal officiel autrichien des lois constitutionnelles amendant la Constitution. 
quelques considérations préliminaires sur le système juridique autrichien et de présenter les grandes lignes de cette révision constitutionnelle d'ampleur.

Avant la réforme, le système de justice administrative autrichien était comparable au système de justice administrative français du temps de la justice retenue. L'ensemble des recours s'effectuait devant l'administration elle-même, la Haute Cour administrative (Verwaltungsgerichtshof) ${ }^{6}$ et la Cour constitutionnelle (Verfassungsgerichtshof) se répartissant en dernier ressort le contrôle des décisions prises par l'administration ${ }^{7}$. Les évolutions successives du système de justice administrative ont juridictionnalisé ${ }^{8}$ '’ensemble, alors qu'il s'agissait au départ d'un système de recours hiérarchiques. Le reste des missions de justice administrative était donc assuré directement par l'administration et ses démembrements. À ce titre, apparurent à la fin des années 1980, les Conseils indépendants du contentieux administratif (unabhängige Verwaltungssenate) ${ }^{9}$. Leur création répondait à l'objectif politique de « juguler la surcharge $»^{10}$ de la Haute Cour administrative ${ }^{11}$. Ils ont été institués au niveau des Länder et se sont vu confier le contentieux administratif en premier ressort ; ils contrôlaient donc juridiquement l'administration. Opérationnels à partir du $1^{\text {er }}$ janvier 1991, ils faisaient partie de ces nombreux organes en Autriche qui, sans être une juridiction au sens des articles 87 et 88 de la Constitution autrichienne ${ }^{12}$, étaient néanmoins qualifiés d'autorités administratives des Länder d'une « espèce particulière $»^{13}$. Ils étaient ainsi fonctionnellement compétents en tant qu'autorités du Land et du Bund. Leurs décisions possédaient tout de même un effet juridictionnel et pouvaient être contestées devant la Cour constitutionnelle ou la Haute Cour administrative en appel. À partir de leur création, la Cour constitutionnelle autrichienne ne fut plus compétente qu'en appel des recours formés contre les actes administratifs n'obéissant pas à une procédure formelle d'élaboration ${ }^{14}$.

\footnotetext{
6 Au départ, l'ordre juridictionnel administratif n'était constitué que par la Haute Cour administrative, mais qui est devenue depuis 2014, la juridiction suprême de l'ordre juridictionnel administratif.

Article 144 de la Constitution autrichienne. Voir note 15.

Au fil des réformes, la justice administrative n'est progressivement rendue que par des organes juridictionnels.

Leur création a été constitutionnalisée aux articles 129 a et $129 \mathrm{~b}$ de la Constitution autrichienne. Ils peuvent être comparés aux autorités administratives indépendantes instituées en France.

10 Bertil Cottier (Dir.), Juguler la surcharge des instance supérieures : étude comparative des procédures de recours et des mesures destinées à réduire l'engorgement des tribunaux, Schulthess Polygraphischer Verlag, Publications de l'Institut suisse de droit comparé, Zürich, 1995, 502 p. 11 BGBl 1988/685.

12 Art. 87 alinéa 1 de la Constitution autrichienne : (1) Les juges sont indépendants dans l'exercice de leurs fonctions judiciaires. (Traduction officielle du service de presse fédéral : «(1) Die Richter sind in Ausübung ihres richterlichen Amtes unabhängig. »)

Art. 88 de la Constitution autrichienne : (1) La loi fédérale fixe la limite d’âge à laquelle les juges sont mis à la retraite définitive. (2) Par ailleurs, les juges ne peuvent, contre leur gré, être révoqués, mutés à un autre poste ou mis à la retraite qu'en vertu d'une décision judiciaire en bonne et due forme, et ce uniquement dans les cas et dans les formes prévus par la loi. Toutefois, ces dispositions ne s'appliquent pas aux mutations ou mises à la retraite rendues nécessaires par des modifications de l'organisation judiciaire. Pour de tels cas, la loi fixe un délai au cours duquel les juges peuvent être mutés ou mis à la retraite sans les formalités normalement prescrites. (3) Un juge ne pourra être suspendu temporairement de ses fonctions que par décision de l'administrateur du tribunal ou du président du tribunal ou de l'autorité judiciaire générale qui renverra en même temps l'affaire au tribunal compétent. (Notre traduction pour : «(1) Durch Bundesgesetz wird eine Altersgrenze bestimmt, mit deren Erreichung die Richter in den dauernden Ruhestand treten. (2) Im Übrigen dürfen Richter nur in den vom Gesetz vorgeschriebenen Fällen und Formen und auf Grund eines förmlichen richterlichen Erkenntnisses ihres Amtes entsetzt oder wider ihren Willen an eine andere Stelle oder in den Ruhestand versetzt werden. Diese Bestimmungen finden jedoch auf Übersetzungen und Versetzungen in den Ruhestand keine Anwendung, die durch eine Änderung der Gerichtsorganisation nötig werden. In einem solchen Fall wird durch das Gesetz festgestellt, innerhalb welchen Zeitraumes Richter ohne die sonst vorgeschriebenen Förmlichkeiten übersetzt und in den Ruhestand versetzt werden können. (3) Die zeitweise Enthebung der Richter vom Amt darf nur durch Verfügung des Gerichtsvorstehers oder Gerichtspräsidenten oder der übergeordneten Gerichtsbehörde bei gleichzeitiger Verweisung der Sache an das zuständige ordentliche Gericht stattfinden. »)

13 Theo ÖHLINGER, Verfassungsrecht, $8^{\mathrm{e}}$ éd. remaniée, facultas.wuv, Vienne, 2009, p. 277.

14 Ceci correspond aux actes relatifs à « l'exercice du pouvoir administratif direct d'injonction et de contrainte » (unmittelbarer verwaltungsbehördlicher Befehls- und Zwangsgewalt).
} 
Ce choix en faveur d'organes contentieux de nature non juridictionnelle répondait à la volonté politique de ne pas introduire de recours devant la Cour constitutionnelle contre des décisions juridictionnelles, et cela afin d'empêcher la suprématie de la juridiction constitutionnelle dans le système juridictionnel. Le contrôle de constitutionnalité des décisions de justice a longtemps fait partie des interdits que le constituant autrichien s'était implicitement fixés. Témoin de l'expérience d'autres cours constitutionnelles, ce dernier ne souhaitait pas que le fonctionnement de la Cour constitutionnelle fût autant paralysé que celui de ses homologues en permettant un tel recours. Et la Cour constitutionnelle a confirmé l'impossibilité pour un requérant d'attaquer une décision de justice devant elle ${ }^{15}$, malgré la compétence qu'elle détenait en matière d'appel contre les décisions rendues par les conseils indépendants du contentieux administratif ${ }^{16}$. Cette impossibilité a subsisté, après que ces conseils ont été qualifiés par la Cour européenne des droits de l'homme (CEDH) de « tribunal » au sens de l'article 6 \$1 Convention européenne de sauvegarde des droits de l'homme et des libertés fondamentales (CESDHLF) ${ }^{17}$. L'application de ces dispositions portait surtout sur le contrôle des conditions d'indépendance et d'impartialité de ces conseils. Le terme de «tribunal » de l'article $6 \S 1$ CESDHLF est ainsi plus large que la notion telle qu'elle est prévue par la Constitution autrichienne. C'est pourquoi, sont aussi des tribunaux au sens de l'article 6§1 de la CESDHLF, certaines autorités administratives qui ne reçoivent pas d'instruction et sont donc indépendantes de l'administration (weisungfreie Verwaltungsbehörden) ${ }^{18}$.

Dans le même esprit, et afin de désengorger la Haute Cour administrative d'une partie de son contentieux, une réforme du 4 janvier $2008^{19}$ a créé une Haute Cour d'Asile (Asylgerichtshof) dont la compétence se restreignait aux affaires en dernière instance relatives au droit des étrangers. Cette création permettait ainsi à la Haute Cour administrative d'être délestée de ce contentieux. Cette juridiction a exercé ses fonctions du $1^{\text {er }}$ juillet 2008 au 31 décembre 2013. Depuis cette date, la Haute Cour d'Asile a été transformée et il a été mis un terme à l'existence des Conseils indépendants du contentieux administratif, du fait de l'élaboration d'un nouveau modèle de justice administrative, établi à compter de 2014. Cette dernière réforme a permis d'une part, de supprimer les voies de recours du contentieux administratif et d'introduire onze juridictions administratives et, d'autre part, de transformer la compétence de la Haute Cour administrative : celle-ci n'est plus en mesure, en effet, de connaître des recours contre les décisions adoptées par les autorités administratives mais devient compétente pour une sorte d'appel contre les décisions rendues par les juridictions administratives nouvellement créées.

\footnotetext{
15 VfGH, 26 février 1990, B 1231/89.

16 Article 144 alinéa 1 (dans sa version en vigueur entre le $1^{\text {er }}$ janvier 1991 et le 31 décembre 2013) : «La Cour constitutionnelle statue sur les recours formés contre les décisions des autorités administratives, ainsi que des conseils indépendants du contentieux administratif pour autant que le requérant affirme être atteint par la décision dans un droit constitutionnellement garanti ou être atteint dans ses droits par l'application d'un règlement illégal, d'une loi inconstitutionnelle ou d'un traité non conforme au droit. Le recours ne peut être introduit qu'après l'épuisement des voies de recours. » (Notre traduction pour : « Der Verfassungsgerichtshof erkennt über Beschwerden gegen Bescheide der Verwaltungsbehörden einschließlich der unabhängigen Verwaltungssenate, soweit der Beschwerdeführer durch den Bescheid in einem verfassungsgesetzlich gewährleisteten Recht oder wegen Anwendung einer gesetzwidrigen Verordnung, eines verfassungswidrigen Gesetzes oder eines rechtswidrigen Staatsvertrages in seinen Rechten verletzt zu sein behauptet. Die Beschwerde kann erst nach Erschöpfung des Instanzenzuges erhoben werden. »).

17 CEDH, 16 juillet 1971, Ringeisen, Requête $n^{\circ}$ 2614/65.

18 Theo ÖHLInger, Verfassungsrecht, op. cit., p. 278.

19 BGBl. I 2008/4.
} 
La réforme de la justice administrative a institué un modèle dénommé « $9+2 »$, soit un total de onze juridictions réparties entre le Bund et les Länder. Il existe ainsi une juridiction administrative par Land et deux juridictions administratives au niveau fédéral. Ces deux juridictions fédérales sont de nature différente : l'une s'occupe des affaires financières (Bundesfinanzgericht) et l'autre s'occupe du reste des affaires administratives (Bundesverwaltungsgericht). À ce titre, cette dernière héritera notamment du contentieux des étrangers ${ }^{20}$. Cet ensemble de juridictions constitue le premier degré de juridiction. La compétence de second degré de juridiction revient à la Haute Cour administrative. La répartition des compétences au sein de cette nouvelle architecture juridictionnelle est prévue par les articles 130 et 133 de la Constitution autrichienne. Les juridictions administratives de premier degré et les juridictions administratives de second degré sont saisies de tous les recours exercés contre les décisions des autorités administratives afin de contrôler leur conformité au droit. Aujourd'hui, on peut donc parler d'un système de justice administrative, comparable à celui qui nous connaissons en France (juridictions de premier et second degrés) ${ }^{21}$.

Une comparaison pourrait ainsi être dressée avec la procédure de recours pour excès de pouvoir mais les différences entre ces deux procédures restent substantielles et ce pour trois raisons. En premier lieu, dans une perspective organocentrée ${ }^{22}$, les recours des particuliers autrichiens sont portés devant le juge constitutionnel et non devant le juge administratif. En second lieu, d'un point de vue normocentré23, un nombre plus important de normes générales et abstraites peuvent être contestées par les individus en Autriche et les normes de référence du contrôle sont plus riches. Enfin, l'intérêt à agir dont doit justifier le requérant est plus strict en Autriche, puisqu'il se limite à l'invocation d'un droit subjectif violé. Notons en effet que le titulaire de ce droit de recours peut être une personne physique ou morale, pouvant accéder directement au prétoire de la Cour constitutionnelle autrichienne. L'accès de ces personnes à la Cour constitutionnelle se fait ainsi de manière immédiate, en ce que l'individu devient une partie au « procès constitutionnel » en saisissant lui-même le juge constitutionnel, contrairement à la procédure de question prioritaire de constitutionnalité que nous connaissons en France. Dès lors, il s'agit de structures procédurales qui ne connaissent aucun équivalent dans notre système juridique ${ }^{24}$.

\footnotetext{
20 D'ailleurs ce Tribunal administratif du Bund sera en réalité le produit d'une transformation de l'ancienne Haute Cour d'Asile (Article 151 alinéa 49 phrase 7 de la Constitution autrichienne).

21 Notons que les juridictions du second degré sont en fait les juridictions suprêmes : la Haute Cour administrative possède une compétence de droit commun et la Cour constitutionnelle a une compétence d'attribution. Par rapport à l'organisation juridictionnelle française, elles ne sont toutefois pas des juridictions de cassation mais plutôt des juridictions d'appel.

22 Otto Pfersmann, « Classifications organocentriques et classifications normocentriques de la justice constitutionnelle en droit comparé », in Robert ANDERSEN (Dir.), En hommage à Francis Delpérée : itinéraire d’un constitutionnaliste, Bruylant, LGDJ, 2007, p. $1153-1167$.

23 Eod. loc.

24 Cette considération intervient dans le cadre d'une recherche doctorale en cours, qui a fait l'objet de quelques travaux scientifiques, mais qui reste une procédure peu connue : Les recours individuels devant la Cour constitutionnelle - Étude comparée Allemagne, Autriche, Belgique et Espagne. Cf. les travaux du Colloque international de justice constitutionnelle d'Aix en Provence, « Cours constitutionnelles et droits fondamentaux », Aix-en-Provence, juillet 1991, in Annuaire International de fustice Constitutionnelle, 1991, PUAM Economica, Paris, 1993; Francis DelpéréE (Dir.), Le recours des particuliers devant le juge constitutionnel. Fournée d'études du 9 février 1990, Louvain, Bruylant Économica, Coll. Droit public positif, Bruxelles Paris, 1991, 221 p. ; Otto PfERsmann, « Le recours direct entre protection juridique et constitutionnalité objective », in Les Cahiers du Conseil constitutionnel, 10 (2001), p. 65-71, ainsi que les études réunies sous la direction de cet auteur dans ce numéro.
} 
Afin de mener l'étude de ces recours à bien, il est nécessaire de distinguer l'approche normocentrée de l'approche organocentrée. Cette distinction est en effet cruciale dans une étude de droit comparé, car elle permet de faire le départ entre ce qui relève des dispositions juridiques et ce qui relève de considérations politiques et culturelles. L'approche normocentrée permet également de se prémunir contre la tentation de caractériser de façon hâtive le contentieux constitutionnel autrichien comme un contentieux abstrait ou concret. Il apparaît concret de prime abord, dès lors que tout contrôle de normes est ouvert à un individu qui allègue une violation de ses droits subjectifs devant la Cour constitutionnelle. Mais il est à coup sûr abstrait, dès lors que le contrôle s'exerce tant à l'égard de normes générales et abstraites ${ }^{25}$, que de normes individuelles ${ }^{26}$.

Cette qualification de contentieux abstrait ou concret est souvent utilisée en matière de justice constitutionnelle, mais elle n'emporte pas une définition unique ${ }^{27}$. Ce qui apparaît certain, c'est le « caractère transversal de la distinction $»^{28}$. Plus précisément, cette distinction recouvre trois étapes de tout contentieux constitutionnel ${ }^{29}$. Premièrement, peut être abstrait ou concret le contentieux, qu'il faut entendre comme le moment de l'introduction de l'instance. Il s'agit alors de savoir si le juge constitutionnel est saisi ou pas dans le cadre d'un litige particulier. Deuxièmement, la distinction abstrait/concret s'applique au contrôle strictement entendu, c'est-à-dire au contrôle exercé par le juge constitutionnel dans le cadre de ce contentieux. C'est ce qu'une partie de la doctrine française identifie comme étant la nature du contrôle ${ }^{30}$. Autrement dit, qualifier le contrôle d'abstrait ou de concret permet de se poser la question de l'étendue du contrôle de la norme ${ }^{31}$. Le contrôle abstrait porte sur la norme générale, puisque sa conformité à la constitution dépend de son existence même ; alors que le contrôle concret porte davantage sur le contrôle de la constitutionnalité de l'application de cette norme générale et non sur la norme elle-même. Il s'agit donc à ce stade de considérer d'une part le contentieux et, d'autre part, le contrôle ${ }^{32}$. Troisièmement, enfin, la différence entre abstrait et concret s'applique aussi aux effets de la décision. C'est pourquoi, il importe de distinguer le contrôle strictement entendu, des effets de la décision du juge constitutionnel ${ }^{33}$. Pour le dire autrement, il

25 Il faut entendre par normes générales et abstraites, les lois, les règlements, les traités ou les republications de normes consolidées. 26 Avant la réforme de 2012-2014, les normes individuelles attaquables ne concernaient que les actes administratifs individuels. Depuis l'entrée en vigueur de cette révision constitutionnelle de 2012-2014, les normes individuelles contestables sont les décisions de justice administrative. 27 Cf. notes 27, 31 et 32. Francis Hamon reprend aussi cette distinction sous l'angle par lequel la loi soumise au contrôle est appréciée. L'appréciation dans le contrôle concret est alors nécessairement influencée par les circonstances de l'affaire alors que le contrôle abstrait se caractérise par le fait que le juge examine la loi en elle-même, indépendamment de tous les cas particuliers qui peuvent se présenter : Francis HAMON \& Céline WiEnER, La justice constitutionnelle en France et à l'étranger, LGDJ-Lextenso, 2011, p. 36-37, 62-65.

28 Joseph Pini, Recherches sur le contentieux de constitutionnalité, 1997, Aix-Marseille 3, dactyl., p. 330.

29 Cette présentation n'est que l'ébauche d'une réflexion qui sera développée dans le cadre de notre recherche doctorale.

30 Alexandre VIALA, «L'indifférence de la nature du contrôle de constitutionnalité au contexte de la saisine », in Emmanuel CARTIER, Laurence Gay et Alexandre Viala (Dir.), QPC: Vers une culture constitutionnelle partagée ?, LGDJ - Lextenso éditions, Coll. Colloques \& Essais, Paris, 2015, p. 105-117.

31 Nous reprenons ici les définitions posées par Manfred StELzer, « Die Gesetzesbeschwerde: Ein später, halber Schritt - in die falsche Richtung? », in Susanne ReINDL-KRausKopf (Dir.), Festschrift für Helmut Fuchs, Verlag Österreich, Vienne, 2014 , p. 566-567.

32 L'école d'Aix-en-Provence est de ce point de vue exemplaire puisqu'elle mêle, dans la même distinction, des éléments sur le contrôle exercé au fond et des éléments regardant les conditions d'introduction de l'instance. Elle présente ainsi deux séries de considérations : d'une part, dans le modèle français, le contrôle abstrait se caractérise par une saisine du juge constitutionnel par les autorités publiques quand le contrôle concret consiste en une saisine par question préjudicielle ; d'autre part, et selon la théorie des modèles de justice constitutionnelle, le contrôle abstrait caractérise le modèle européen, à savoir une confrontation entre deux normes générales sans aucune confrontation entre deux parties ou de résolution d'un conflit particulier antérieur alors que le modèle américain est caractérisé par le contrôle concret qui s'exerce à l'occasion de cas concrets et de litiges particuliers. Voir Louis Favoreu et al. (dir.), Droit constitutionnel, 14 édition, Dalloz, Paris, 2011, p. 236-237, 245-246, 268-271.

33 C'est la conception du professeur Fromont qui évoque cette distinction en tant que sanction du contrôle : « La confrontation entre une règle législative et la constitution ne s'opère pas de la même façon selon que la procédure de justice constitutionnelle est de type concret 
s'agit de savoir si le contrôle effectué par le juge constitutionnel aura pour conséquence ou bien de sanctionner la norme générale inconstitutionnelle en l'annulant ou en l'abrogeant, ou bien de mettre seulement à l'écart la norme générale, en refusant de l'appliquer.

S'agissant des effets de la décision du juge constitutionnel, précisons qu'il revient de manière monopolistique à la Cour constitutionnelle autrichienne de sanctionner l'absence de conformité d'une norme par rapport à une autre norme. Ce monopole ne repose pas tant, en effet, sur le contrôle en lui-même, que sur la compétence qui revient au juge constitutionnel de sanctionner l'inconstitutionnalité résultant de ce contrôle - ou plus largement toute absence de conformité de la norme inférieure à la norme immédiatement supérieure - en supprimant la norme fautive de l'ordonnancement juridique. De manière schématique, en Autriche, il revient à la Cour constitutionnelle une compétence d'attribution du contrôle de conformité de normes générales et abstraites à des normes qui leur sont immédiatement supérieures ${ }^{34}$. Cela permet ainsi au juge constitutionnel autrichien de contrôler la constitutionnalité d'une loi ordinaire, la légalité stricto sensu d'un règlement, la conformité de l'introduction des traités dans l'ordonnancement juridique ainsi que la conformité de la republication de normes consolidées ${ }^{35}$. Cette compétence est du Normenkontrolle, concept proprement germanique, qui revient à un pur « contrôle de normes ». Il s'agit donc pour la Cour de résoudre un conflit de normes.

Par exception à ce contrôle pur de normes, en vertu des dispositions de l'article 144 de la Constitution autrichienne, la compétence de la Cour peut porter sur un contrôle «transcendant » l'ordre de production : celui du contrôle de constitutionnalité des décisions de justice. Le juge constitutionnel autrichien est ainsi doté de compétences de deux ordres : d'une part, s'assurer de la concrétisation conforme des normes selon l'ordre de production, d'autre part, vérifier le respect des droits fondamentaux, qui sont directement applicables comme normes de référence du contrôle exercé. Enfin, la compétence de droit commun revient aux autres juridictions, et notamment à la Haute Cour administrative ${ }^{36}$, de contrôler la légalité lato sensu de normes individuelles. C'est la raison pour laquelle une typologie des recours existant contre les décisions de justice en Autriche sera présentée sous l'angle normocentré, c'est-à-dire en se concentrant sur le conflit entre normes ${ }^{37}$.

\footnotetext{
ou abstrait : dans le premier cas, la solution adoptée ne vaut que pour le procès en cours alors que, dans le second cas, elle est normalement susceptible d'aboutir à une modification de l'ordonnancement juridique pour tous. », in Michel Fromont, Fustice constitutionnelle comparée, Dalloz, Paris, 2013, p. 194-195. Cependant, notons que, dans la suite des développements, le professeur Fromont parle de «procédure concrète » et de «procédure abstraite » afin d'englober l'ensemble des catégories que nous abordons dans la présente contribution.

34 Art. 89 alinéa 1 de la Constitution autrichienne : « Le contrôle de la validité [lato sensu] des règlements, de la conformité d'une republication de normes consolidées (traités étatiques), des lois et des traités étatiques promulgués, dans la mesure où les dispositions qui suivent n'en disposent autrement, n'appartient pas aux juridictions ordinaires. » (Notre traduction pour : « Die Prüfung der Gültigkeit gehörig kundgemachter Verordnungen, Kundmachungen über die Wiederverlautbarung eines Gesetzes (Staatsvertrages), Gesetze und Staatsverträge steht, soweit in den folgenden Absätzen nicht anderes bestimmt ist, den ordentlichen Gerichten nicht zu. »).

35 Il s'agit de la Kundmachungen über die Wiederverlautbarung eines Gesetzes : c'est la compétence de certaines autorités du pouvoir exécutif de republier au journal officiel les normes consolidées, et en l'espèce les lois.

36 Article 133 alinéa $11^{\circ}$ de la Constitution autrichienne : «La Haute Cour administrative décide des révisions de décisions des juridictions administratives du fait de leur non-conformité au droit. » (Notre traduction pour : «Der Verwaltungsgerichtshof erkennt über Revisionen gegen das Erkenntnis eines Verwaltungsgerichtes wegen Rechtswidrigkeit. »).

37 Sur l'intérêt d'une telle méthode, voir Otto PfERsmann, « Classifications organocentriques et classifications normocentriques de la justice constitutionnelle en droit comparé », op. cit.
} 
En Autriche, le contrôle des normes a toujours été depuis sa naissance, un contrôle abstrait pour ce qui touche à l'avenir de la norme contestée : il débouche potentiellement sur son annulation. Mais, le recours contre les décisions de justice est concret en ce qui concerne le type de contentieux : ils sont toujours déclenchés par une affaire particulière. Les deux types de recours introduits par la réforme de la justice administrative sont ainsi qualifiables de contentieux concret, parce qu'ils sont possibles en cas de litige déjà examiné par un juge ; et tous les deux sont caractérisés par l'exercice d'un contrôle abstrait. Il s'agira ainsi d'examiner ces deux recours en s'appuyant sur une autre distinction : le fait que le requérant peut contester directement l'acte juridictionnel ou non. Autrement dit, seront examinés d'une part, le recours contre les décisions de justice administrative, qui se caractérise par le fait qu'il est direct (I) ; et, d'autre part, le recours contre les décisions de justice ordinaire, qui se caractérise par le fait qu'il est indirect (II).

\section{Le recours direct contre les décisions de justice administrative : une innovation modérée}

Le recours direct contre les décisions de justice administrative n'est nouveau qu'en ce qui concerne les actes contestables : les dispositions constitutionnelles sont passées d'un recours possible contre les actes administratifs individuels à un recours contre les décisions de justice administrative. Cette modification a donc permis de mettre en cohérence la répartition de compétences entre la Cour constitutionnelle et la Haute Cour administrative en matière de justice administrative (A), de même que les deux types de contrôle qui peuvent être exercés à cette occasion (B).

\section{A. Une mise en cohérence des compétences en matière de justice administrative}

La nouvelle procédure remplace celle qui existait depuis 1867, initialement devant le Reichsgericht, qui permettait de contester la constitutionnalité d'un acte administratif individuel : la procédure de Bescheidbeschwerde. Elle fut reprise par la Constitution de 1920 à l'article 144, qui a alors conféré un pouvoir d'annulation au juge constitutionnel en cas d'inconstitutionnalitée ${ }^{38}$. Puis le contrôle exercé par la Cour constitutionnelle a été étendu : elle peut, depuis le $1^{\mathrm{er}}$ juillet $1976^{39}$, contrôler le fondement normatif de la décision attaquée et s'auto-saisir de la question de la constitutionnalité de la norme générale au fondement de la norme individuelle considérée par le requérant comme illégal. Dans ce cadre, la réforme de la justice administrative de 2012-2014 a procédé à un changement résiduel ${ }^{40}$.

38 En effet, jusqu'alors, le Tribunal d'Empire ne pouvait émettre qu'une simple déclaration d'inconstitutionnalité, pour « prononcer si et dans quelle mesure un droit politique du requérant avait été effectivement violé ». Mais il ne disposait d'aucun pouvoir d'annulation de la décision administrative déclarée inconstitutionnelle. Voir Charles EIsEnmann, La justice constitutionnelle et la Haute Cour constitutionnelle d'Autriche, op. cit., p. 131.

39 Ceci est le jour de l'entrée en vigueur. La réforme date du 10 juin 1975 et a été publiée au BGBl. 1975/302. Cette compétence complémentaire s'est inscrite dans une réforme de plus grande ampleur, introduisant en Autriche le recours individuel direct contre les normes générales et abstraites - l'Individualantrag - qui permet à tout requérant de contester une loi ou un règlement portant une atteinte directe à ses droits, sans que cette norme n'ait fait l'objet d'une application par une décision administrative ou juridictionnelle (Art. 139 et 140 de la Constitution autrichienne).

40 Par le terme « résiduel », nous souhaitons insister sur le fait que c'est en raison du remodelage de la justice administrative autrichienne, que les compétences de la Cour constitutionnelle ont changé. Ce changement est circonscrit à l'objet du recours, à savoir la norme attaquable : les décisions de justice administrative ont été substituées aux actes administratifs individuels. 
Il est à ce propos remarquable que la construction d'un véritable système de justice administrative soit marquée par l'importance centrale du double degré de juridiction ${ }^{41}$. Ainsi, la compétence matérielle des juridictions de droit public change : au lieu d'examiner la conformité des actes juridiques adoptés par l'administration, elles contrôlent aujourd'hui les décisions juridictionnelles, que ce soit des décisions rendues au fond (Erkenntnise) ou des décisions de rejet (Beschlüsse) par les juridictions administratives. Il s'agit donc seulement d'actes juridictionnels; cela suppose que les actes d'administration de ces juridictions n'entrent pas dans cette distinction. Cela suppose aussi que ces actes juridictionnels sont pris par un collège de juges (richterlichen Kollegium). Enfin, cela implique que seuls les actes juridiques individuels et concrets ${ }^{42}$ sont visés par les termes Beschluss ou Erkenntnis. C'est une procédure de recours que l'on peut qualifier de « directe » puisqu'elle permet de contester immédiatement une décision de justice administrative devant la Cour constitutionnelle. Elle porte, depuis la réforme, le nom de Erkenntnis-/Beschlussbeschwerde ${ }^{43}$.

L'originalité de la justice administrative se trouve dans la compétence d'attribution de la Cour constitutionnelle, quand la compétence de droit commun revient à la Haute Cour administrative. Ceci explique que la compétence de la Cour constitutionnelle est généralement qualifiée de « justice administrative spéciale » (Sonderverwaltungsgerichtsbarkeit). Cette compétence complémentaire est en réalité partagée sur le contrôle de ces actes juridictionnels de nature administrative. Même si la systématisation de ce partage des compétences a fait longtemps gloser la doctrine autrichienne, en raison de vives controverses concernant les critères de la distinction des compétences entre les deux juridictions ${ }^{44}$, il semble que l'on puisse proposer des éléments généraux pour l'appréhender.

Schématiquement, la Cour constitutionnelle exerce un Grobprüfung ou contrôle sommaire ${ }^{45}$, sanctionnant les erreurs évidentes de la juridiction, quand la Haute Cour administrative, par le biais de la procédure de Revision ${ }^{46}$, contrôle la légalité des décisions adoptées par les juridictions administratives et notamment l'application des lois ordinaires. Cette dernière exerce plutôt un Feinprüfung, qui est plus précis et surtout caractérisé par le fait qu'il s'agit d'un contrôle par rapport à des normes

41 Elke WildPANner, «Stellung der Parteien im Beschwerdeverfahren nach Art. 144 B-VG », fournal für Rechtspolitik, 21, 2013, p. 364-374. 42 Gerhart HolzingeR, «Verfassungsgerichtsbarkeit und Verwaltungsgerichtsbarkeit erster Instanz », in Michael HoLOuBEK \& Michael LANG (dir.), Die Verwaltungsgerichtsbarkeit erster Instanz, Linde, Vienne, 2013, p. 387 : « nur individuell-konkrete Akte ».

43 Article 144 alinéa 1 de la Constitution autrichienne (BGBl. I 2012/51) : « La Cour constitutionnelle statue sur les recours formés contre la décision d'une juridiction administrative, dans la mesure où le requérant affirme être atteint par la décision dans un droit constitutionnellement garanti ou être atteint dans ses droits par l'application d'un règlement illégal, d'une loi inconstitutionnelle ou d'un traité non conforme au droit. » (Notre traduction pour : « Der Verfassungsgerichtshof erkennt über Beschwerden gegen das Erkenntnis eines Verwaltungsgerichtes, soweit der Beschwerdeführer durch das Erkenntnis in einem verfassungsgesetzlich gewährleisteten Recht oder wegen Anwendung einer gesetzwidrigen Verordnung, einer gesetzwidrigen Kundmachung über die Wiederverlautbarung eines Gesetzes (Staatsvertrages), eines verfassungswidrigen Gesetzes oder eines rechtswidrigen Staatsvertrages in seinen Rechten verletzt zu sein behauptet. »).

44 Josef AzIzI, «Probleme der geteilten Verwaltungsgerichtsbarkeit in Österreich », Österreichische Juristen-Zeitung, 1979 , p. 589 et s. ; Robert WALTER, « Überlegungen zu einer Neuabgrenzung der Zuständigkeit zwischen Verwaltungs- und Verfassungsgerichtshof », Österreichische Juristen-Zeitung, 1979, p. 225 et s.; JosefWalter AICHLREITER, «Zur Abgrenzung von Verwaltungs-und Verfassungsgerichtsbarkeit Wahrung verfassungsgesetzlich gewährleisteter Rechte und Bindung an den Sachverhalt », Furistische Blätter, 1980, p. 406 et s. ; Rene LAURER, «Bemerkungen zu Problemen der Parallelbeschwerde gegen Akte unmittelbarer Befehls- und Zwangsgewalt », Österreichische JuristenZeitung, 1982, p. 202 et s. ; Kurt HeLler, « Rechtsschutz und Ablehnung von Beschwerden an den Verfassungsgerichtshof », Österreichische Juristen-Zeitung, 1987, p. 577 et s. ; Nicolas RAschAuER, « Das Verhältnis zwischen Verwaltungsgerichtsbarkeit und Verfassungsgerichtshof im Gefolge der Verfassungsreform - kritische Anmerkungen », fournal für Rechtspolitik, 2007, p. 311 et s.

45 Ce contrôle se répartit sur plusieurs éléments : contrôle de l'arbitraire/de l'interprétation manifestement fausse, contrôle de manque de base légale, contrôle de la loi au fondement de la décision.

46 Article 133 alinéa 1 de la Constitution autrichienne. Cette décision de Revision ne peut pas faire l'objet d'un recours selon la procédure de l'article 144 alinéa 1, en application de l'article 144 alinéa 5. 
infra-constitutionnelles. C'est donc une compétence de contrôle des décisions juridictionnelles, rendues à la suite d'un recours contre une décision de l'administration devant les juridictions administratives de premier ressort. Cette compétence, équivalente à un appel, est partagée entre ces deux cours suprêmes et demeure inchangée malgré la réforme de la justice administrative. Du fait de cette répartition du contrôle, il est possible pour tout requérant de saisir à la fois la Cour constitutionnelle et la Haute Cour administrative, en joignant à sa plainte devant la première une demande de transmission à la seconde, en application de l'article 144 alinéa 3 de la Constitution autrichienne ${ }^{47}$. Si le requérant ne faisait pas usage de cette possibilité de recours simultané devant les deux juridictions $(\text { Parallelbeschwerde) })^{48}$, la Cour constitutionnelle pourrait toujours renvoyer l'affaire à la Haute Cour administrative (Abtretung ${ }^{49}$ dans l'hypothèse où le recours introduit auprès de la Cour constitutionnelle ne pose aucune question de droit constitutionnel à résoudre et est par conséquent rejeté parce qu'il n'a aucune chance de succès (Ablehnung) ${ }^{50}$. Ceci donnera la possibilité à la Haute Cour administrative de procéder à une révision de la décision juridictionnelle. Malgré les difficultés résultant de ce partage de compétences, une chose est sûre : cette procédure ne permet pas de contester une violation purement objective du droit ${ }^{51}$.

Par l'expression «violation d'un droit garanti par la Constitution », la Cour constitutionnelle entend « la détermination du genre d'irrégularité nécessaire pour qu'une décision [...] puisse être déférée $»^{52}$. Elle a ainsi défini la notion de violation des droits individuels de manière restrictive ${ }^{53}$, pour se prémunir du risque d'attirer à elle la majeure partie du contentieux administratif, au détriment de la compétence de droit commun revenant à la Haute Cour administrative. De ce fait, elle exige que l'acte juridique contesté porte une violation immédiate à la Constitution, et non une simple violation de la loi. Une telle violation est caractérisée, quand la décision juridictionnelle est entièrement dépourvue de base légale réelle ou quand elle a été prise sur le fondement d'une loi inconstitutionnelle.

Dans cette seconde hypothèse, en invoquant la violation de ses droits subjectifs - qui ne se limitent donc pas aux droits fondamentaux - le requérant peut contester une norme individuelle, qui déclenchera un pur contrôle de normes entre la norme générale au fondement de cette norme

\footnotetext{
47 Article 144 alinéa 3 : Si la Cour constitutionnelle conclut que la décision contestée de la juridiction administrative ne constitue pas de violation d'un droit au sens de l'alinéa 1 ci-dessus, elle doit, sur demande du requérant, transmettre le recours à la Haute Cour administrative qui statuera sur le fait de savoir si le requérant a été lésé dans un autre droit par la décision contestée. (Notre traduction pour : « Findet der Verfassungsgerichtshof, dass durch das angefochtene Erkenntnis des Verwaltungsgerichtes ein Recht im Sinne des Abs. 1 nicht verletzt wurde, hat er auf Antrag des Beschwerdeführers die Beschwerde zur Entscheidung darüber, ob der Beschwerdeführer durch das Erkenntnis in einem sonstigen Recht verletzt wurde, dem Verwaltungsgerichtshof abzutreten. Auf Beschlüsse gemäß Abs. 2 ist der erste Satz sinngemäß anzuwenden. »)

48 Marlene KePLINGER, «Parallelbeschwerde und Revision. Verwaltungsgerichtsbarkeitsnovelle 2012 », SPRW, 2013, p. 89 et s.

49 Voir supra, note $\mathrm{n}^{\circ} 46$

50 La condition que le recours ait « une chance de succès » a été introduite par la réforme du 28 juillet 1981 avec la possibilité, dans le cas contraire, de rejeter le recours (BGBl. 1981/350). Dans une révision du 20 juillet 1984, cette condition de chance de succès a été complétée par un critère alternatif : celui selon lequel le recours doit demander la résolution d'une question générale de droit constitutionnel (BGBl. 1984/296). 51 Robert MaYer \& Gabriele Kuscko-Stadlmayer, Bundesverfassungsrecht, 11 éd., Manz, Vienne, 2015, p. 605-606.

52 Avant la réforme de la justice administrative, il s'agissait d'actes administratifs individuels.

53 Par les arrêts des 21 mars 1923 (184), 1 er décembre 1923 (247) et 21 octobre 1924 (337), la Cour constitutionnelle précisait : « toute violation d'un droit garanti par la Constitution ne peut pas être considérée comme une décision inconstitutionnelle au sens de l'art. 144. Il faut que la décision soit elle-même inconstitutionnelle, c'est-à-dire viole les normes de la Constitution qui garantissent le droit [invoqué]. Donc seule l'inconstitutionnalité, et non la simple illégalité, d'une décision administrative permet de former le recours de l'art. 144. C'est ce qui a lieu lorsqu'elle a été prise sans aucune base légale - par exemple sur la base d'une loi qui n'est absolument pas applicable aux faits en question ou sur la base d'une loi inconstitutionnelle. Sinon, la fausse application de la loi à un cas où elle était applicable ne constitue pas une violation d'un droit garanti. »
} 
individuelle et la norme qui lui est immédiatement supérieure. L'adoption de normes individuelles implique en effet nécessairement l'application d'une norme générale et abstraite. Étant donné que la Cour est aussi compétente en matière de contrôle de constitutionnalité des lois, elle n’a logiquement pas eu besoin d'adopter une théorie de la loi écran, comme le Conseil d'État français l'a fait. Toute autre hypothèse, notamment celle du contrôle de légalité de l'acte juridique, ressort ainsi à la compétence de la Haute Cour administrative.

Ces deux hypothèses de contrôle de la Cour constitutionnelle ont amené le constituant à scinder en deux les dispositions portant sur le contrôle susceptible d'être exercé en matière de justice administrative spéciale. Celui-ci a donc modifié les dispositions de l'article 144 de la Constitution, suivant scrupuleusement la jurisprudence de la Cour constitutionnelle, en distinguant explicitement ces deux hypothèses de contrôle.

\section{B. Une évolution de la justice administrative spéciale au seul niveau de l'acte contestable}

L'inconstitutionnalité de la décision de justice administrative peut résulter de deux causes distinctes qui impliquent une différence de contrôle : il peut s'agir, d'une part, d'une atteinte aux droits constitutionnellement garantis du requérant par la décision juridictionnelle même (1) et, d'autre part, de la violation des droits - qui ne se réduisent pas aux droits constitutionnellement garantis - du requérant résultant de l'application d'une norme fautive par la juridiction administrative (2).

\section{La violation caractérisée des droits constitutionnellement garantis par la décision de justice administrative}

Il s'agit d'un recours direct contre la décision de justice administrative car le requérant estime qu'elle porte atteinte à ses droits constitutionnellement garantis. Autrement dit, c'est la décision rendue par les juridictions administratives, depuis la réforme de 2012-2014, qui constitue l'objet du recours.

L'article 144 de la Constitution autrichienne insiste bien sur l'objectif de cette procédure qui consiste à protéger les « droits constitutionnellement garantis ». Comment faut-il comprendre cette notion? La Cour a posé un critère jurisprudentiel pour l'identification d'un droit subjectif, entendant un peu plus largement cette notion que le Tribunal d'Empire : «Il y a droit constitutionnellement garanti au sens de l'art. 144 al. $1^{\text {er }}$, de la Constitution fédérale, lorsqu'il existe un intérêt privé suffisamment individualisé au respect d'une disposition objective de la Constitution. La protection que lui donne [un article de celle-ci] en fait un droit subjectif $\gg^{54}$. Ces droits subjectifs peuvent être

54 VfSlg. 723/1926. Voir Charles Eisenmann, La justice constitutionnelle et la Haute Cour constitutionnelle d'Autriche, op. cit., p. 237. Il répond ainsi à la conception germanique du droit subjectif, dans le sens où une prescription légale confère un droit suffisamment individuel au requérant qui peut alors saisir le juge en cas d'atteinte à son droit. 
prévus par les lois constitutionnelles formelles de l'État fédéral ${ }^{55}$, y compris les droits et libertés fondamentaux et les droits politiques. Cette formule s'est d'ailleurs modernisée, en ce qu'il s'agit de « tout droit subjectif, prévu par une règle du droit objectif de rang constitutionnel $»^{56}$. À ce titre, il faut ajouter aux normes formellement constitutionnelles, les dispositions de la CESDHLF ainsi que les protocoles additionnels ${ }^{57}$. De même, par une décision du 14 mars 2012, la Cour constitutionnelle a élargi le corpus de droits constitutionnellement garantis à la Charte des droits fondamentaux de l'Union européenne. Tous les droits et libertés qui y sont prévus, peuvent valoir comme droits constitutionnellement garantis, lorsque ces droits et libertés connaissent des équivalents dans leur formulation et leur détermination dans le droit fédéral autrichien ${ }^{58}$. Cependant, reste en suspens la question de savoir si les droits prévus par les lois constitutionnelles des Länder peuvent entrer dans cette catégorie.

Si la Cour constitutionnelle reconnaît la violation de droits constitutionnellement garantis, autrement dit l'inconstitutionnalité de la décision de justice administrative, c'est qu'elle résulte de l'absence de toute application de la loi ou que cette dernière a été appliquée de façon insensée par la juridiction administrative. Il s'agit donc de «violations de la loi particulièrement évidentes et graves ${ }^{59}$. En revanche, la Cour constitutionnelle n'est plus compétente lorsqu'il s'agit de savoir si une loi a été correctement appliquée par l'autorité administrative. Cette question revient aux juridictions administratives et, en dernier ressort, à la Haute Cour administrative à l'occasion d'un recours en Revision, pour examiner la conformité au droit des décisions juridictionnelles. D’ailleurs, la Cour constitutionnelle n'a pas compétence pour contrôler les décisions adoptées à l'issue d'une telle procédure. La Cour constitutionnelle n'a en définitive aucun office sur les décisions rendues par la Haute Cour administrative.

Dans le cas où la violation des droits constitutionnellement garantis du requérant ne serait pas avérée, la Cour constitutionnelle se retrouve devant deux possibilités : soit renvoyer à la Haute Cour administrative ce qui semble être une violation des droits du requérant du fait de la violation de la loi appliquée par la décision juridictionnelle, soit s'auto-saisir de la question de la conformité au droit de la norme générale au fondement de cette décision juridictionnelle afin de contrôler si l'atteinte aux droits du requérant résulte de l'application d'une norme générale fautive.

\footnotetext{
$55 \quad$ Ainsi, il y a d'abord les lois héritées de la monarchie (art. 149 de la Constitution), notamment la « Loi fondamentale d'État sur les droits généraux des citoyens » (Staatsgrundgesetz über die allgemeinen Rechte der Staatsbürger) du 21 décembre 1867, la Loi sur la protection de la liberté personnelle (Gesetz zum Schutze der persönlichen Freiheit) du 29 novembre 1988 et la Loi sur la protection du domicile (Gesetz zum Schutze des Hausrechtes) du 27 octobre 1862. Mais aussi les dispositions de la Constitution et plus spécifiquement, des dispositions constitutionnelles sur le droit électoral, le principe d'égalité, le droit à un procès devant le juge légal, l'interdiction de la contrainte à l'auto-accusation, l'interdiction de la peine de mort. Enfin, certains textes supranationaux font également parties des lois constitutionnelles, comme la CESDHLF du 4 novembre 1950 (que le législateur a érigé à ce rang depuis 1964), des dispositions du traité de Saint-Germain-en-Laye (10 septembre 1919), ainsi que du traité de Vienne, mais aussi d'autres textes internationaux plus récents (par exemple : Convention sur les droits politiques des femmes, Convention internationale sur l'élimination de toutes les formes de discrimination raciale et Convention de l'élimination de toutes les formes de discrimination à l'égard des femmes).

56 Gerhart HolzINGER, « Verfassungsgerichtsbarkeit und Verwaltungsgerichtsbarkeit erster Instanz », op. cit., p. 389 : « Verfassungsgesetzlich gewährleistet ist jedes subjektive Recht, das auf einer Vorschrift des objektiven Rechts im Verfassungsrangberuht. 》

57 Cette constitutionnalisation a été adoptée par arrêté exprès du constituant fédéral : Article II phrase 7 de la révision constitutionnelle BGBl. 1964/59.

58 VfSlg. 19.632/2012.

59 Theo ÖHLINGER, « Cour constitutionnelle autrichienne », Revue internationale de droit comparé, vol. 33, n² 2, Avril-juin 1981, p. 554.
} 


\section{Une violation des droits résultant de l'application d'une norme fautive par la décision de justice administrative}

Il s'agit dans ce cas pour le requérant d'attaquer directement devant la Cour constitutionnelle, la décision de justice administrative qui porterait atteinte à ses droits subjectifs, du fait de l'application d'une norme fautive. Il convient d'entendre ici par norme fautive, une norme générale et abstraite non conforme à la norme qui lui est immédiatement supérieure ${ }^{60}$. Dans ce cas, la Cour ne procède pas à un contrôle par rapport aux droits constitutionnellement garantis, comme dans la première hypothèse, mais elle contrôle par rapport aux droits du requérant ${ }^{61}$. C'est pourquoi seront invocables des droits plus largement protégés que dans la première hypothèse, ce qui augmente le nombre de normes de référence du contrôle de la norme générale et abstraite au fondement de l'acte individuel. Autrement dit, il s'agit pour la Cour constitutionnelle de reconnaitre la violation d'un des droits du requérant résultant de l'application par la juridiction administrative d'une norme générale non conforme à la norme qui lui est immédiatement supérieure.

Il s'agit en quelque sorte d'une inconstitutionnalité indirecte de la décision de justice administrative, car celle-ci ne s'explique pas par une erreur commise dans l'application du droit par la juridiction administrative, mais plutôt par l'application d'une norme générale et abstraite elle-même inconstitutionnelle. On constate alors, chose étonnante à des yeux français, que la Cour constitutionnelle peut exercer un contrôle entre des normes générales et abstraites, à tous les degrés de la hiérarchie, en respectant l'ordre de production de normes ${ }^{62}$. Dans le cadre de cette saisine, en effet, la Cour constitutionnelle peut s'auto-saisir de cette question de la conformité de la norme générale au fondement de la décision juridictionnelle, contre laquelle elle est saisie. C'est ce que la doctrine nomme Incidentalverfahren ${ }^{63}$. Si à la suite de cette auto-saisine, la Cour constate le caractère fautif de la norme générale au fondement de l'acte juridictionnel, cela la conduit à annuler également ce dernier.

Ce recours n'a pas beaucoup changé depuis la réforme puisque le mécanisme reste le même. Il s'agit toujours pour la Cour constitutionnelle de soulever elle-même la question de la conformité de la norme générale appliquée par la décision individuelle contestée. Le contrôle de constitutionnalité des décisions de justice administrative prend donc deux formes : l'inconstitutionnalité tenant à l'absence de toute base légale réelle et l'inconstitutionnalité résultant de l'application d'une norme générale non conforme au droit. Il importe ici d'insister sur le fait que ce recours sert à tout requérant en cas de violation de ses droits du fait de l'élaboration d'une décision individuelle, soit parce qu'elle est non conforme à ses droits constitutionnellement garantis, soit parce qu'elle concrétise une norme générale et abstraite qui n'est elle-même pas conforme. Il ne s'agit donc en aucun cas de contester par ce recours l'interprétation d'une norme générale et abstraite effectuée par une juridiction administrative.

\footnotetext{
60 Otto Pfersmann, «La production des normes : production normative et hiérarchie des normes », in Michel Troper, Dominique Chagnollaud (dir.), Traité international de droit constitutionnel : Distribution des pouvoirs, Tome 2, Dalloz, Paris, 2012, p. 499-502.

61 Par cette notion de droits, la Constitution autrichienne garantit les droits plus largement protégés que les droits constitutionnellement garantis, notamment les droits protégés par les dispositions législatives.

62 Il faut entendre par là le fait que la Cour constitutionnelle puisse contrôler la constitutionnalité des lois, mais aussi la légalité des règlements, la conformité au droit des traités et la conformité d'une republication de normes consolidées.

63 Robert Mayer \& Gabriele Kuscko-Stadlmayer, Bundesverfassungsrecht, op. cit., p. 605.
} 
Cette modification d'un recours déjà existant s'est accompagnée d'un deuxième type de recours, qui, lui, a été créé dans une toute autre perspective : c'est le recours, que l'on qualifiera, pour les besoins de la présente étude, d'indirect contre les décisions de justice ordinaire.

\section{L'introduction d'un recours indirect contre les décisions de justice ordinaire : une procédure nouvelle et originale}

Ce nouveau recours vient en réalité compléter la procédure de requête individuelle - Individualantrag - créée en $1975^{64}$ et inscrite aux articles 139 et 140 B-VG, qui permet à un individu de contester la constitutionnalité d'une loi ou la légalité d'un règlement en saisissant lui-même la Cour constitutionnelle, à la seule condition que cette norme générale et abstraite ne fasse l'objet d'aucune concrétisation par une norme de rang inférieur - une décision juridictionnelle ou administrative. Depuis le $1^{\mathrm{er}}$ janvier $2015^{65}$, « la Cour constitutionnelle décide de l'inconstitutionnalité des lois sur demande d'une personne qui, en tant que partie à une affaire jugée par une juridiction ordinaire de première instance, estime, à l'occasion d'un recours formé contre ce jugement, être lésée dans ses droits du fait de l'application d'une loi inconstitutionnelle $»^{66}$. Des dispositions potentiellement inconstitutionnelles, qui auront été appliquées à l'occasion d'un procès devant des juridictions ordinaires, pourront ainsi voir leur conformité à la Constitution contrôlée sur recours d'un individu devant la Cour constitutionnelle. Ce recours contre les décisions de justice ordinaire est qualifiable d'indirect, puisqu'il s'agit avant tout pour le requérant de remettre en cause la constitutionnalité de la norme générale au fondement de la décision de justice devant le juge constitutionnel. Après avoir examiné le mécanisme de ce recours qui vient compléter une protection constitutionnelle de l'individu (A), nous soulignerons quelques différences avec d'autres procédures existantes dans d'autres systèmes juridiques et justifiant la raison d'être de ce recours (B).

\section{A. Une protection constitutionnelle complétée}

Avant de pouvoir être effectivement mise en place, les discussions autour de l'introduction de ce nouveau recours furent longues et vives, conduisant notamment la Cour suprême (Oberste Gerichtshoff $)^{67}$ ̀̀ se mobiliser contre ${ }^{68}$. Examinons, dans le détail, les conditions induites par les règles

\footnotetext{
$64 \quad$ BGBl. $1975 / 302$.

65 BGBl. I 2013/114.

66 Article 140 alinéa 1 phrase $1 \mathrm{~d}$ de la Constitution autrichienne (Notre traduction pour : « Der Verfassungsgerichtshof erkennt über Verfassungswidrigkeit von Gesetzen auf Antrag einer Person, die als Partei einer von einem ordentlichen Gericht in erster Instanz entschiedenen Rechtssache wehen Anwendung eines verfassungswidrigen Gesetzes in ihren Rechten verletzt zu sein behauptet, aus Anlass eines gegen diese Entscheidung erhobenen Rechtsmittels. »).

Il en va de même pour contrôler la légalité des règlements - Article 139 alinéa 1 phrase 4 de la Constitution autrichienne : « La Cour constitutionnelle décide de l'illégalité des règlements sur demande d'une personne qui, en tant que partie à une affaire jugée par une juridiction ordinaire de première instance, estime, à l'occasion d'un recours formé contre ce jugement, être lésée dans ses droits du fait de l'application d'un règlement illégal. » (Notre traduction pour : "Der Verfassungsgerichtshof erkennt über Gesetzwidrigkeit von Verordnungen auf Antrag einer Person, die als Partei von einem ordentlichen Gericht in erster Instanz entschiedenen Rechtssache wegen Anwendung einer gesetzwidrigen Verordnung in ihren Rechten verletzt zu sein behauptet, aus Anlass eines gegen diese Entscheidung erhobenen Rechtsmittels. »)

67 La Cour suprême autrichienne est comparable à la Cour de cassation française, en ce qu'elle remplit le rôle de juridiction ordinaire suprême. 68 Peter Fichtenbauer \& Andreas Hauer, Parteiantrag auf Normenkontrolle, Manz, Vienne, 2015, p. 5-10. L'auteur précise à ce sujet, l'évolution terminologique de la dénomination de la procédure : Normenbeschwerde, Subsidiarantrages, puis seulement Gesetzesbeschwerde (recours contre la loi) et naturellement Verordnungsbeschwerde (recours contre le règlement). Dans une phase ultérieure, dénomination de Parteiantrag auf Normenkontrolle (pouvant être traduit par le fait qu'une partie présente une requête en vue d'un contrôle de normes).
} 
de procédure applicables à la structure procédurale dénommée Parteiantrag auf Normenkontrolle ${ }^{69}$ ou Gesetzebeschwerde $e^{70}$.

Tout d'abord, afin de présenter un Parteiantrag, il faut être un requérant qui bénéficie de droits individuels subjectifs. Mais ce requérant doit aussi être partie à une instance (Partei), c'està-dire demandeur, défendeur, prévenu ou encore partie civile à une instance devant une juridiction ordinaire. Cependant, un tiers intervenant peut agir s'il est légitime en vertu d'un moyen de droit et s'il possède un intérêt processuel à l'issue du procès : la notion de partie à une instance est ainsi largement entendue. Cette instance doit se dérouler devant une juridiction ordinaire, c'est-àdire toute juridiction qui n'appartient pas aux juridictions de droit public. L'aboutissement de cette instance se caractérise par l'adoption d'une décision de justice ordinaire.

Les dispositions encadrant le recours précisent également les conditions entourant la décision ordinaire. Il faut tout d'abord que cette décision ait été rendue à l'issue de la première instance ; c'est une condition minimale. La raison d'être de cette condition s'explique par l'objectif auquel elle répond : il faut qu'au moins une juridiction de premier degré ait la possibilité de saisir la Cour constitutionnelle du problème de constitutionnalité ou de légalité par le biais de la procédure de question préjudicielle. Plus précisément, cette décision de justice ordinaire doit contenir une « chose juridique décidée »(entschiedene Rechtssache). Ainsi, l'acception du terme de décision est large : il peut s'agir d'un jugement définitif (Endurteil), d'un jugement partiel (Teilurteil) ou même d'un jugement avant dire droit (Zwischenurteil) ; l'essentiel est que cette décision est susceptible de faire l'objet d'un recours, c'est-à-dire qu'elle soit contestable. Autrement dit, elle doit être susceptible de faire grief. Cela concerne ainsi le jugement déclaratif, même dans le cas d'une procédure non contentieuse ou accessoire. A contrario tout le contentieux relatif à l'administration de la justice n'est pas concerné. Toujours est-il que la décision doit porter atteinte aux droits individuels du requérant. Cette condition de la violation des droits subjectifs mérite toute notre attention car elle est centrale dans le contentieux du Parteiantrag et plus largement dans les structures procédurales devant la Cour constitutionnelle.

Ce que le législateur autrichien appelle une violation des droits individuels subjectifs résulte de l'application d'une norme inconstitutionnelle ou illégale par la décision de justice ordinaire. Autrement dit, le Parteiantrag est un instrument de protection juridique subjective. L'inconstitutionnalité ou l'illégalité ne doit pas porter directement atteinte aux droits fondamentaux ; il suffit de l'application

69 Maria Bertel, « Der Parteiantrag auf Normenkontrolle », fournal für Rechtspolitik, 21, 2013, p. 269-282 ; Christoph HerBst, Norbert Wess, «Der Parteiantrag auf Normenkontrolle im Bereich der Strafgerichtsbarkeit », Zeitschrift für Wirtschafts- und Finanzstrafrecht, p. 64-68; Michael Rohregger, «Der Parteiantrag auf Normenkontrolle (« Gesetzesbeschwerde »), Anwaltsblatt, 2015, n 4, p. 188 et s. ; Thomas Schoditsch, « Der Parteiantrag auf Normenkontrolle », Ecolex, 2015, n 4, p. 338 et s. ; Walter Brugger, «Einschränkung des Parteiantrags auf Normenkontrolle ist teilweise verfassungswidrig », Anwaltsblatt, 2015, n 12, p. 651 et s. ; Christian Simon, «Partei- und Beteiligtenstellung im verfassungsgerichtlichen Verfahren aus Anlass eines Parteiantrags auf Normenkontrolle », Anwaltsblatt, 2015, n 10, p. 522 et s. ; Hans Peter LeHOFER et Robert FucıK, "VfGH prüft (weitere) Ausnahmeregelungen zum Parteiantrag auf Normenkontrolle », Osterreichische furistenZeitung, 2015, n 23-24, p. 137 et s.

70 Benjamin Kneins, «Die Gesetzesbeschwerde zwischen Entscheidungsbeschwerde und Individualantrag », Fahrbuch Öffentliches Recht, 2014, p. 255 et s. ; Christoph BrenN, « Gegen einen Rechtsmittelausschluss ist eine Gesetzesbeschwerde nicht zulässig », EvBl-LS, 2015/146, n 19, p. 903 et s.; Ulrich PESENDORFER, « Gesetzesbeschwerde beschlossen », iFamZ, 2013, n 4,p. 172 et s. ; Eckart RATZ, «Gesetzesbeschwerde gefährdet funktionierenden Rechtsschutz », RZ, 2013, n 4, p. 77 et s. ; Bernhard MüLLER, « Heiß umfehdet, wild umstritten : die Gesetzesbeschwerde », Ecolex, 2015, n' 1 , p. 30 et $\mathrm{s}$. 
d'une norme générale et abstraite non conforme au droit objectif ou aux droits subjectifs garantis pour caractériser la violation d'un droit du requérant. L'application de cette norme générale et abstraite est donc une condition nécessaire et préalable à tout recours et doit avoir un effet préjudiciable à la sphère juridique (Rechtssphäre) du requérant. Tout d'abord, l'application de la norme générale par la juridiction concerne toute norme contenue de manière immédiate ou indirecte dans la décision de justice ordinaire, même celles qui sont utilisées pour répondre à la question posée à la juridiction de manière préalable. Fondamentalement, il s'agit de toute norme appliquée dans une procédure ordinaire sur laquelle la décision s'appuie plus ou moins explicitement, ce qui revient à considérer aussi les normes qui interviennent au soutien de la motivation de la décision. À l'inverse, toute norme qui ne serait pas appliquée ou qui ne serait pas possiblement appliquée, ne peut pas donner lieu à un Parteiantrag, de telle sorte que la seule affirmation de son application dans un recours ne suffit pas. Mais il faut encore que les effets de cette décision de justice ordinaire portent atteinte à la situation juridique du requérant. Cela signifie qu'a priori seule la partie qui a perdu en première instance, c'est-à-dire qui n'a pas obtenu gain de cause devant la juridiction ordinaire, aura intérêt à agir. La violation doit ainsi être envisageable et défendable. Comment savoir si le Parteiantrag est ouvert au requérant? Si hypothétiquement la norme générale et abstraite n'existait pas, la décision de justice ordinaire aurait été rendue autrement. Il faut également regarder si cette atteinte contrevient à des règles constitutionnelles, des lois ordinaires ou des règles de rang réglementaire. Certains auteurs soulignent le fait qu'il serait également possible d'arguer, de manière complémentaire à une violation d'un droit subjectif, de la violation d'une disposition objective, comme le principe de légalité (Legalitätsprinzip) ou le principe d'efficience (Effizienzprinzip) ${ }^{71}$.

Enfin, il faut souligner l'originalité de ce Parteiantrag. En effet, ce recours contre le fondement d'une décision de justice ordinaire n'est possible qu'à l'occasion d'un « remède », c'est-à-dire lorsque est exercé un moyen juridique opposable (« erhobenen Rechtsmittels »). Il s'agit pour la partie requérante d'introduire un recours juridique contre la décision de justice ordinaire et de saisir à cette occasion la Cour constitutionnelle de l'inconstitutionnalité de la loi ou de l'illégalité du règlement appliqué par cette décision de justice ordinaire, et qui de facto porte une atteinte aux droits subjectifs du requérant. Cette notion de « remède » (Rechtsmittel), traduisible aussi par le terme de «moyen juridique » est assez floue pour un juriste français. Il s'agit apparemment d'un type de recours opposable par le requérant, qu'il exerce contre la décision devant les juridictions ordinaires compétentes. Ainsi, ce nouveau recours suppose l'exercice concomitant de deux voies de droit : une première pour contester directement la décision de justice ordinaire - une sorte d'appel - et la deuxième pour contester directement le fondement légal ou réglementaire de cette décision qui semble inconstitutionnel ou illégal. Cette condition de l'introduction d'un remède est très importante puisque la Cour suprême a notamment précisé que cette voie de recours ne pouvait qu'être ordinaire, excluant de facto les recours ouverts devant la Cour constitutionnelle. C'est d'ailleurs à la suite de cette précision qu'elle a refusé de qualifier une procédure à huit clos de voie de recours,

71 Peter Fichtenbauer \& Andreas Hauer, Parteiantrag auf Normenkontrolle, op. cit., p. 29. 
celle-ci ne permettant pas au requérant d'exercer un Parteiantrag ${ }^{72}$. Par conséquent, si aucun moyen juridique n'est ouvert au requérant contre la décision de justice ordinaire, le Parteiantrag ne peut pas être exercé. Autrement dit, la recevabilité du Parteiantrag est conditionnée par l'existence et l'ouverture d'une voie de droit devant une juridiction ordinaire.

En résumé, ce recours est l'occasion pour le requérant d'invoquer une violation de ses droits subjectifs, résultant de l'application de la norme générale et abstraite inconstitutionnelle ou illégale. Cette procédure se trouve à mi-chemin entre le recours contre un acte individuel devant la Cour constitutionnelle et la question prioritaire de constitutionnalité. Il convient désormais, ces éléments de procédure ayant été précisés, de souligner l'originalité d'un tel mécanisme en s'aidant du droit comparé pour mieux le comprendre.

\section{B. Une architecture juridictionnelle préservée}

L'introduction de ce recours indirect contre les décisions de justice ordinaires n'a en rien modifié l'architecture juridictionnelle autrichienne. Ceci tient tant à la raison d'être de cette nouvelle procédure, qu'à l'idée profondément ancrée dans la culture juridique autrichienne de ne pas créer un degré de juridiction supplémentaire.

Tout d'abord, précisons la raison d'être de cette réforme, qui visait à combler une lacune ${ }^{73}$. Avant la réforme de 2012-2014, la procédure d'Individualantrag ne permettait pas effectivement à tous les requérants d'agir contre les normes générales et abstraites qui pouvaient porter atteinte directement à leurs droits. Ce recours est conditionné par deux éléments qui réduisent considérablement la probabilité de voir son recours examiné au fond. D’une part, la norme générale et abstraite contestée ne doit avoir fait l'objet d'aucune concrétisation - que ce soit par une décision administrative ou juridictionnelle, et d'autre part le requérant doit épuiser toutes les voies de recours ordinaires. L'ajout d'une nouvelle procédure complémentaire par la réforme de la justice administrative de 2012-2014, vise ainsi à remédier à ce défaut structurel de l'Individualantrag : comment en effet peut-on parvenir à articuler ces deux exigences ? Combiné à une clause de subsidiarité, ce recours s'avérait en réalité peu propice à être exercé par les requérants, la norme générale pouvant rarement porter atteinte aux droits du requérant sans qu'elle ne soit concrétisée par une norme plus particulière. Cette clause de subsidiarité résulte pour la Cour constitutionnelle directement de la formulation des dispositions constitutionnelles encadrant cette procédure. La logique de la subsidiarité entrait cependant directement en contradiction avec l'exigence selon laquelle le recours ne pouvait être exercé que si la norme générale ne faisait l'objet d'aucune concrétisation individuelle ${ }^{74}$. C'est la raison pour laquelle le législateur a introduit ce nouveau recours de Parteiantrag, complémentaire au mécanisme de l'Individualantrag.

OGH 15.7.2015, 3 Ob 130/15m

Il faut entendre ici une lacune politique ; ce terme ne préjuge en rien la complétude du système juridique.

Manfred StElzER, « Die Gesetzesbeschwerde: Ein später, halber Schritt - in die falsche Richtung? », op. cit., p. 557-574. 
La complémentarité de ce nouveau recours vient du fait que les normes générales qui ont fait l'objet d'une application par une décision individuelle - en l'espèce la décision de justice ordinaire pourront tout de même être contestées devant la Cour constitutionnelle. La procédure de Parteiantrag auf Normenkontrolle, de la même façon que pour le recours contre les décisions de justice administrative, est un moyen juridique pour le requérant de faire sanctionner l'atteinte à ses droits du fait de l'application d'une loi en elle-même inconstitutionnelle ou d'un règlement en lui-même illégal. Il ne s'agit donc pas d'un recours contre l'interprétation qui a pu être donnée à cette norme générale et abstraite par la décision juridictionnelle, mais plutôt d'un recours contre la norme elle-même ${ }^{75}$. À cette occasion, le contrôle opéré par la Cour constitutionnelle est nécessairement abstrait, puisque la norme appliquée par le juge ordinaire est inconstitutionnelle ; celle-ci sera donc annulée par le juge constitutionnel.

Ce type de procédure est à la fois très proche dans la structure du recours, mais également plus éloigné dans le type de contrôle effectué par rapport au modèle existant en Italie ou en France. Dans ces ordres juridiques, le contrôle des normes par le juge constitutionnel a lieu à l'occasion d'une question préjudicielle, ce qui n'est pas sans rappeler la condition selon laquelle le requérant doit agir simultanément contre la norme générale au fondement de la décision juridictionnelle devant la Cour constitutionnelle et contre la décision ordinaire selon une voie de recours qui lui est ouverte. Cependant, la comparaison s'arrête là puisque les juridictions constitutionnelles italienne et française prennent en compte le « droit vivant », c'est-à-dire l'interprétation donnée par le juge ordinaire des normes contrôlées ${ }^{76}$. Le traitement de l'inconstitutionnalité d'une loi ou de l'illégalité d'un règlement résultant de l'interprétation seule de cette norme générale par le juge ordinaire demeure incertain en Autriche. À défaut d'une prise en compte du droit vivant par le juge constitutionnel, il est tout à fait concevable que le juge constitutionnel puisse alors substituer son application à celle de la juridiction ordinaire, en raison du fait que la norme générale elle-même est constitutionnelle. La seule question non clairement tranchée est de savoir si cela sera fait dans le cadre de ce recours ${ }^{77}$.

L'originalité de cette procédure traduit une différence de conception majeure avec les recours contre les décisions juridictionnelles que l'on observe ailleurs en Europe. En effet, en Espagne ou en Allemagne, l'introduction d'un recours contre les décisions juridictionnelles couplée au principe de subsidiarité, conduit nécessairement à la création d'un nouveau degré de juridiction devant la Cour constitutionnelle ${ }^{78}$. Or, les autrichiens sont très attentifs à ne pas soumettre les juridictions ordinaires,

\footnotetext{
75 La loi ou le règlement ainsi contestés s'avèrent non conformes à la constitution en raison de leur existence même.

76 Pour l'Italie, dès l'arrêt $n^{\circ} 3$ de 1956, la Cour constitutionnelle affirme « qu'elle ne [pouvait] faire autrement que tenir compte d'une interprétation jurisprudentielle constante conférant au précepte législatif sa valeur effective dans la vie juridique, s'il est vrai - et cela est vrai que les normes ne sont pas telles qu'elles apparaissent fixées dans l'abstrait, mais telles qu'elles sont appliquées dans l'œuvre quotidienne du juge, qui s'attache à les rendre concrètes et efficaces » (Source : Caterina SEverino, La doctrine du droit vivant, PUAM-Economica, coll. Droit public positif, Aix-en-Provence Paris, 2003, p. 14). Pour la France, le Conseil constitutionnel a jugé par une décision n²010-39 QPC du 6 octobre 2010, $M^{\text {mes }}$ Isabelle D. et Isabelle B., « qu'en posant une question prioritaire de constitutionnalité, tout justiciable a le droit de contester la constitutionnalité de la portée effective qu'une interprétation jurisprudentielle constante confère à cette disposition ». (Source : Commentaire aux Cahiers du Conseil constitutionnel, $\left.\mathrm{n}^{\circ} 30\right)$

77 Peter Fichtenbauer \& Andreas Hauer, Parteiantrag auf Normenkontrolle, op. cit., p. 14.

$78 \quad$ Cf. infra, note $\mathrm{n}^{\circ} 81$.
} 
et surtout la Cour suprême, à la Cour constitutionnelle ${ }^{79}$. Contrairement au « Pyramidalmodell » allemand, dans lequel la Cour constitutionnelle fédérale possède une compétence juridictionnelle sur les cinq juridictions suprêmes de l'ordre juridictionnel, l'Autriche a plutôt opté pour un modèle mettant sur le même plan, l'ensemble des trois cours suprêmes ${ }^{80}$. Ainsi, la Cour constitutionnelle, la Cour suprême et la Haute Cour administrative n'ont aucune compétence juridictionnelle l'une sur l'autre. Afin de respecter cette architecture juridictionnelle, le constituant autrichien a imposé une condition stricte au recours, qui en représente un aspect essentiel : seules les décisions de première instance peuvent faire l'objet d'un recours devant la Cour constitutionnelle. Et cette règle est indérogeable ${ }^{81}$.

Il convient d'insister sur le fait que la Cour suprême a accepté l'introduction de ce nouveau recours puisque l'office de la Cour constitutionnelle se limite aux décisions de première instance. Sans cette précaution, il apparaît très probable que l'introduction d'un recours direct contre les décisions juridictionnelles ait deux conséquences substantielles sur le système juridique.

Premièrement, un tel recours conduit nécessairement à la création d'un degré de juridiction supplémentaire. En effet, le professeur Pfersmann observe que : « Le recours contre les actes juridictionnels, certes limités aux questions de constitutionnalité, devient fonctionnellement l'ouverture d'un nouveau degré de juridiction $»^{82}$. L'exemple allemand de Verfassungsbeschwerde est de ce point de vue éclairant : plus de $90 \%$ des recours constitutionnels introduits devant la Cour constitutionnelle fédérale allemande portent sur des décisions juridictionnelles (Urteilsverfassungsbeschwerde), alors que «tout acte de puissance publique » est susceptible de faire l'objet d'un tel recours ${ }^{83}$. Si les requérants n'obtiennent pas gain de cause à l'issue des voies de recours ordinaires, et en application du strict principe de subsidiarité du recours, ils tentent nécessairement d'aller devant la Cour constitutionnelle fédérale allemande pour contester une décision juridictionnelle. Et cela conduit alors à l'engorgement de la dernière juridiction compétente, puisque c'est elle qui aura le dernier mot et qui corrélativement connaîtra un afflux massif de recours. Le recours indirect contre les décisions ordinaires de première instance en Autriche n'est donc pas assimilable au recours allemand, ce dernier permettant d'attaquer la constitutionnalité d'une décision de justice, quelle que soit sa nature. Bien au contraire, le recours autrichien est avant tout dirigé contre la norme générale et abstraite appliquée par la décision de justice ordinaire, du moins en ce qui concerne le contentieux intéressant le juge constitutionnel. Ces deux structures procédurales ne peuvent pas être assimilées l'une à l'autre et incarnent ainsi deux formes différentes de recours individuel.

\footnotetext{
79 Matthias JestaedT, « Gleichordnung der Grenzgerichte oder Überordnung des Verfassungsgerichts ? Zur Frage einer Übernahme des deutschen „Pyramidenmodells“ in Österreich », Journal für Rechtspolitik, 2008, n 16, p. 17-22.

80 Eod. loc.; Matthias JestAEDT, « Die Gesetzesbeschwerde an den Verfassungsgerichtshof - Verfassungspolitische Anmerkungen », fournal für Rechtspolitik, 2013, n²1, p. 112.

81 Harald Stolzlechner, Einführung in das öffentliche Recht, $8^{\mathrm{e}}$ éd., Manz, Vienne, 2013, p. 250.

82 Otto Pfersmann, «Le recours direct entre protection juridique et constitutionnalité objective », op. cit., p. 117.

83 Article 93 alinéa 1 4a de la Loi fondamentale allemande : « La Cour constitutionnelle fédérale statue sur les recours constitutionnels qui peuvent être formés par quiconque estime avoir été lésé par la puissance publique dans l'un de ses droits fondamentaux ou dans l'un de ses droits garantis par les articles 20, alinéa 4, 33, 38, 101, 103 et 104. » (Traduction d'octobre 2010, par les professeurs Autexier, Fromont, Grewe, Jouanjan)
} 
Deuxièmement, l'introduction d'un tel recours conduit mécaniquement à une « hiérarchisation » de celui qui a le dernier mot sur celui qui ne l'a pas. Autrement dit, les décisions du juge constitutionnel primeront les décisions du juge ordinaire. Dans le cas d'un Parteiantrag, la Cour suprême serait alors automatiquement «subordonnée » à la Cour constitutionnelle, cette dernière vérifiant l'application du droit à laquelle la première procéderait. Et une telle situation est clairement refusée par la principale concernée ${ }^{84}$, le constituant ${ }^{85}$ et la doctrine ${ }^{86}$ en Autriche. De même, dans le cas des recours directs contre une décision juridictionnelle administrative devant la Cour constitutionnelle, les décisions en Revision de la Haute Cour administrative dont l'objet est de contrôler les décisions des autorités administratives, ne sont pas recevables ${ }^{87}$. Le législateur autrichien a ainsi rendu impossible tant le recours contre les décisions de la Haute Cour administrative, que le recours contre les décisions de la Cour suprême, laissant perdurer le modèle de trois juridictions suprêmes sur un pied d'égalité.

$\mathrm{Au}$ surplus, soulignons que la protection des droits fondamentaux n'est pas détenue de façon monopolistique par la Cour constitutionnelle ; la Cour suprême possède aussi une compétence en cette matière. Sur ce fondement, un requérant peut invoquer une violation de ses droits fondamentaux lors de l'exercice du recours relatif aux droits fondamentaux (Grundrechtsbeschwerde), et plus particulièrement pour invoquer la violation de son droit à la liberté personnelle ${ }^{88}$. La Cour suprême, et plus généralement les juridictions ordinaires, se sont donc senties dangereusement menacées par le nouveau recours : elles ont probablement craint que ce contentieux ne leur échappe dans l'hypothèse où in fine le requérant aurait pu saisir la Cour constitutionnelle des décisions rendues au titre de cette compétence de la protection individuelle.

En conclusion, on peut constater la richesse de la gamme des recours contre les décisions juridictionnelles ouverts en Autriche. Il peut y avoir des recours différents en fonction de la nature de la décision juridictionnelle - administrative ou ordinaire - ou de la façon dont s'articule la procédure : le requérant peut attaquer directement la décision elle-même ou seulement le fondement de la décision. Enfin, ces différents recours présentent un point commun fondamental : l'institution d'un contrôle abstrait de normes tout en garantissant simultanément la protection effective des droits subjectifs des requérants.

\footnotetext{
84 La Cour suprême a publié une tribune dans une revue juridique spécialisée contre l'introduction du Gesetzesbeschwerde: Stellungsnahme des Obersten Gerichtshofs gegen die Einführung einer Gesetzesbeschwerde, « Die Gesetzesbeschwerde aus Sicht des Obersten Gerichtshofs », Österreichische Richterzeitung, 2012, p. 130-131.

85 L'originalité de ce recours, qui consiste à pouvoir contester la norme générale au fondement de la décision de justice et non la décision juridictionnelle elle-même, s'explique par le refus purement politique de soumettre la Cour suprême de l'ordre juridictionnel à la Cour constitutionnelle.

86 Matthias JESTAEDT, « Gleichordnung der Grenzgerichte oder Überordnung des Verfassungsgerichts ? Zur Frage einer Übernahme des deutschen „Pyramidenmodells“ in Österreich », op. cit. ; Peter Fichtenbauer \& Andreas Hauer, Parteiantrag auf Normenkontrolle, op. cit., p. 21-23 ; Klaus SchrÖDER, « Vom Rechtsstaat zum Rechtsmittelstaat », Ósterreichische Richterzeitung, 2012, n 7-8, p. 157 et s. ; Eckart RATZ, « Der Oberste Gerichtshof in Österreich als Grundrechtsgericht », Anwaltsblatt, 2013, n 5, p. 274 et s. ; Ronald RoHrer \& Gerhard KurAs, «Gesetzesbeschwerde gegen Entscheidungen der ordentlichen Gerichte? », Österreichische Furisten-Zeitung, 2012 , n 12, p. 529.

$87 \quad$ Article 144 alinéa 5.

88 Loi du 27 octobre 1862 pour la protection de la liberté personnelle (Gesetz zum Schutz der persönlichen Freiheit) et révisée le 29 novembre 1988, qui est une loi de rang constitutionnel.
} 



\title{
DÉBATS
}

\author{
sous la présidence de Madame Anne LEvade
}

Marthe Stefanini demande à Monsieur Fromont quelles sont les conséquences de l'inconstitutionnalité d'une loi dans le cadre d'un recours contre les décisions de justice.

Le Professeur Michel Fromont répond que la première conséquence concerne l'organe compétent. Si le recours ne met pas en cause la constitutionnalité de la loi appliquée par le juge, le recours sera jugé par une section formée de trois juges de la Cour constitutionnelle fédérale statuant à l'unanimité ; il le sera même si la décision de justice attaquée émane d'une Cour de cassation. Si le recours contre la décision de justice met en cause indirectement la constitutionnalité d'une loi, deux cas se présentent. Le premier cas est celui où la section estime que la loi appliquée est conforme à la Constitution et, dans ce cas, elle peut constater elle-même la conformité à la Constitution de la décision de justice et juger ensuite, soit que la loi n'a pas été appliquée (notamment interprétée) par le juge ordinaire de façon conforme à la Constitution, soit que l'application de la loi est conforme à la Constitution. Le second cas est celui où tout ou partie de la section estime que la loi appliquée est inconstitutionnelle; dans ce cas, la section ne peut pas statuer elle-même et elle doit transmettre immédiatement le dossier à la Chambre à laquelle elle appartient ; cette Chambre, qui comprend huit juges (y compris les membres de la section qui a transmis le dossier) pourra constater l'inconstitutionnalité de la loi appliquée si elle partage l'avis de tout ou partie de la section.

Marthe Stefanini demande si l'effet de la décision de la Cour constitutionnelle, qui contrôle la constitutionnalité d'une décision de justice, est relatif et ne vaut donc que pour les parties.

Michel Fromont répond alors que, lorsqu'une décision de justice est jugée inconstitutionnelle en raison de l'inconstitutionnalité de la loi appliquée, non seulement la décision individuelle en cause est annulée, mais encore les dispositions législatives jugées inconstitutionnelles doivent être déclarées inconstitutionnelles, à charge pour le législateur de les modifier dans un délai déterminé ou bien être annulées purement et simplement. Ces déclarations ou annulations s'imposent au respect de tous ( $\$ 31$ de la loi sur la Cour constitutionnelle fédérale).

Une personne dans la salle demande à Madame Arreto ce qu'elle appelle un « recours indirect » dans son intervention. 
Marie-Caroline Arreto répond qu'il faut distinguer deux choses : l'inconstitutionnalité indirecte d'une décision de justice administrative et le recours indirect contre les décisions de justice ordinaire. L'inconstitutionnalité est indirecte puisqu'il ne s'agit pas d'une mauvaise application du droit ou d'une application erronée par la juridiction administrative, mais plutôt de l'application d'une norme elle-même non conforme à la norme qui lui est immédiatement supérieure. D'une part, l'inconstitutionnalité de la décision de justice administrative résulte du fait qu'elle se fonde sur une norme elle-même inconstitutionnelle. Avant même l'institution de la Cour constitutionnelle, la Constitution prévoyait seulement un recours en contestation de la constitutionnalité des actes administratifs individuels et l'on voyait déjà cela poindre à travers l'idée d'une certaine concrétisation. Pour Madame Arreto, il existe en effet une idée qui est présentée, par son directeur de thèse, Otto Pfersmann, et qui dit la chose suivante : plus l'on concrétise les normes et plus il y a de risque que ces normes individuelles soient non conformes à la Constitution. L'idée d'introduire ce genre de recours est donc justement de permettre de surveiller la concrétisation et de résoudre ce paradoxe de la concrétisation qui veut qu'il y a plus de risque d'inconstitutionnalité dans les normes individuelles que dans les normes générales et abstraites. Suivant ce modèle, la pratique du recours par la Cour constitutionnelle a nécessairement évolué dans le sens d'une prise en compte de la constitutionnalité des actes intermédiaires entre la Constitution et l'acte administratif individuel, et notamment de la loi. D'autre part, le recours contre les décisions de justice ordinaire est qualifiable d'indirect puisque devant la Cour constitutionnelle autrichienne, ce n'est pas la décision juridictionnelle qui fait l'objet d'un recours mais c'est un grief d'inconstitutionnalité de la loi dont est saisi le juge constitutionnel. Plus précisément, à l'occasion du recours exercé contre la décision juridictionnelle devant les juridictions ordinaires, le requérant peut en même temps contester la constitutionnalité de la loi au fondement de la décision juridictionnelle en saisissant la Cour constitutionnelle.

Concernant les effets des décisions ensuite, Madame Arreto estime qu'il s'agit d'un problème particulièrement épineux en Autriche. Concernant les jugements d'inconstitutionnalité des normes générales et abstraites, l'annulation ex nunc est de rigueur. Il est ainsi difficile de savoir si c'est la loi antérieure qui doit revenir en vigueur ou si un vide juridique subsiste jusqu'à ce que le législateur adopte de nouvelles dispositions. La question de l'annulation des normes générales et abstraites a toujours posé problème. Toutefois, la Cour constitutionnelle possède la compétence de moduler les effets de ses décisions. Elle peut moduler de façon temporelle les effets de ses décisions sur dix-huit mois. Du reste, les deux procédures que Madame Arreto a présentées lors de son intervention sont assez récentes et le contentieux qui est publié de temps à autre sur le site de la juridiction ne permet pas, pour l'instant, d'en dire grand chose. Ce qui est certain pour elle, c'est que la Cour constitutionnelle n'a pas de pouvoir de réformation de l'acte individuel contesté, contrairement au Conseil d'État français par exemple. Elle estime que l'on comprend mieux pourquoi en Autriche, la possibilité de sanctionner l'inconstitutionnalité des actes individuels a été instaurée seulement en 1920 alors que depuis 1867 le Tribunal de l'Empire ne pouvait que déclarer les actes administratifs individuels comme inconstitutionnels. 
Michel Fromont souhaite ajouter une précision concernant son intervention. Il considère que le plus souvent la Cour constitutionnelle allemande préfère procéder à ce que la doctrine appelle une interprétation de la loi en conformité à la Constitution plutôt qu'à une annulation. Pour lui, c'est très curieux car en France, en général, si la loi est inconstitutionnelle, elle est abrogée. Très souvent la Cour constitutionnelle allemande préfère interpréter, ainsi elle corrige elle-même le sens du texte afin qu'il soit conforme à la Constitution. Michel Fromont soupçonne les juristes allemands de le faire de façon assez systématique parce qu'il y a beaucoup plus d'interprétations conformes que d'annulations. Il pense aussi que cela permet d'aller beaucoup plus vite parce que le système juridique est alors nettoyé sur le champ. Dès que la décision de la Cour est publiée, tout le monde sait comment il faut appliquer la loi sans commettre de violation de la Constitution. Sinon, il faut déclarer la loi inconstitutionnelle, imposer un délai - en général de dix-huit mois voire plus - et la constitutionnalité ne serait effacée qu'à l'expiration de ce délai. Michel Fromont pense que ce genre de considérations joue aussi et estime que les juges trouvent cela moins brutal. Il trouve cela assez extraordinaire et dit n'avoir jamais lu d'explications dans les écrits allemands sur ce point-là.

Pauline Giraud, doctorante, s'adresse à Hubert Alcaraz. Elle souhaite rebondir sur ce que Madame Arreto vient d'expliquer sur la distinction entre les cas où l'inconstitutionnalité réside dans la décision de justice elle-même et les cas où l'inconstitutionnalité est à imputer à la norme que le juge a appliquée. Pour rebondir sur ce point donc, elle demande si la statistique présentée par Monsieur Alcaraz (selon laquelle 99\% des décisions du juge constitutionnel espagnol sont des contestations d'une décision de justice), ne doit pas conduire à relativiser l'importance du contrôle de constitutionnalité des décisions de justice. Dans ces $99 \%$, elle demande quelle est la part des cas où l'inconstitutionnalité réside dans la décision de justice. Elle s'interroge sur le point de savoir si derrière la contestation de la décision de justice ce ne serait pas finalement un acte administratif ou même une loi qui serait contestée le plus souvent.

Hubert Alcaraz répond que les choses sont assez simples en Espagne. Si jamais le problème, dans le cadre du recours d'Amparo, est en réalité un problème à l'égard d'un acte administratif, alors est engagé un recours d'Amparo contre un acte administratif, mais la voie de la contestation de la décision juridictionnelle n'est pas empruntée. Ce qui se produit le plus souvent est l'hypothèse selon laquelle les plaideurs invoquent à la fois la violation de l'un et de l'autre, ou choisissent la bonne voie. Pour Hubert Alcaraz, on ne fait toutefois pas vraiment cette distinction car si la section qui examine l'admission du recours d'Amparo constate qu'il existe un vrai problème de constitutionnalité, elle transmet à la chambre qui, elle, tranchera le recours d'Amparo sur le fond. Et si à l'occasion de l'examen de ce recours d'Amparo la chambre constate que le problème ne vient pas de la décision qui a été prise par le juge mais de la norme que le juge avait appliquée, il existe une procédure qui s'appelle «l'auto-question d'inconstitutionnalité » et qui permet que la chambre transmette à l'assemblée plénière du Tribunal une question d'inconstitutionnalité. Elle règle donc le recours d'Amparo mais elle énonce qu'à cette occasion est apparu un problème plus général de constitutionnalité et elle transmet. Monsieur Alcaraz estime qu'il y a finalement peu d'annulations mais qu'il ne 
faut pas oublier aussi que le contentieux actuel existe depuis plus de trente ans - depuis l'entrée en vigueur de la Constitution - et que les préoccupations qui étaient liées au régime franquiste ont été largement épurées. Il estime que l'essentiel des décisions sont tournées contre les arrêts du Tribunal suprême, et que les plaideurs ont aussi tendance à voir cela comme un ultime recours lorsqu'ils sont insatisfaits.

Une personne dans la salle demande à Monsieur Alcaraz comment il envisage l'évolution en France, au vu de l'expérience espagnole.

Hubert Alcaraz constate qu'en Espagne dans un premier temps (comme pour la QPC en France) il y a eu beaucoup de décisions qui constataient une inconstitutionnalité et que, par la suite, la tendance a décliné. Aujourd'hui, il y a peu d'annulations en Espagne. Il est donc difficile de dire ce qu'il en serait en France. Pour lui, ce qui ne plaide pas en faveur de ce contentieux est le temps que prend le Tribunal constitutionnel pour l'examen d'admission des recours d'Amparo.

Itziar Gomez Fernandez souhaite ajouter une précision. Elle estime qu'il est nécessaire de s'interroger sur le point de savoir quel type de Tribunal constitutionnel la société désire. Pour sa part, elle préfère un Tribunal qui garantisse les droits de l'homme.

Hubert Alcaraz abonde dans le sens de Madame Gomez Fernandez ; il estime qu'il existe aujourd'hui des tensions internes liées à l'État espagnol et au fonctionnement de la juridiction constitutionnelle. Il considère que le débat sur ce registre se pose en ces termes : veut-on un Tribunal des droits fondamentaux ou un Tribunal des normes générales ? Pour lui, tout dépend en partie de la présidence du Tribunal constitutionnel espagnol qui peut parfois imprimer plus de sévérité à l'examen de la recevabilité des recours d'Amparo. Par ailleurs, avec l'aide de ce levier qui a été la révision constitutionnelle de 2007, il est plus facile d'écarter des problématiques délicates dont le Tribunal constitutionnel ne veut pas se saisir. À la décharge du Tribunal, il considère cependant que ce dernier se retrouve aujourd'hui avec les problèmes les plus insolubles à régler (organisation territoriale, procréation médicalement assistée, mariage des couples de même sexe). Par ailleurs, un recours d'inconstitutionnalité ou une question d'inconstitutionnalité demandent parfois sept ou huit ans pour aboutir à une décision. Il n'est pas question de sacrifier l'un à l'autre mais, il est très compliqué aujourd'hui de parvenir à un système totalement satisfaisant.

Caterina Severino demande à Monsieur Alcaraz si une modification de la composition du Tribunal constitutionnel est envisageable afin d'améliorer le système.

Hubert Alcaraz répond qu'une révision de la Constitution espagnole serait nécessaire et que cela poserait encore un problème supplémentaire. En effet, la composition du Tribunal et la façon dont les douze magistrats sont désignés ne relève pas de la loi organique, mais du texte constitutionnel.

Madame Severino demande également si ces magistrats possèdent chacun un service juridique ou des assistants. 
Monsieur Alcaraz répond que le Tribunal constitutionnel compte de nombreux conseillers référendaires (comme Madame Gomez ci-présente). Parmi ces conseillers, il y a ceux qui y travaillent en permanence et ceux qui viennent de façon plus ponctuelle. Toutefois, en ce qui concerne plus précisément la question posée par Madame Severino, il faut dire que seul le Président dispose d'un service juridique qui lui est attribué.

Hubert Alcaraz revient par ailleurs sur les condamnations de l'Espagne par la Cour européenne des droits de l'homme. Il estime que l'on a sans doute trop peu de recul pour comprendre si c'est exclusivement la faute à la manière dont le Tribunal constitutionnel rejette sommairement des recours qui a conduit à huit condamnations depuis le début de l'année pour l'Espagne. Il s'interroge sur le point de savoir si ce ne serait pas, en plus de la situation devant le Tribunal, d'autres éléments qui contribueraient à cette situation. Il pense notamment aux contentieux liés aux étrangers. Il souligne en effet que l'on parle plus de la jungle de Calais que de Melilla ou de Ceuta, alors qu'il existe aussi des problèmes importants dans ces enclaves qui conduisent à faire condamner l'Espagne. Mais sans doute manque-t-on de recul actuellement pour arriver à formuler un jugement tranché.

Michel Fromont ajoute une précision en ce qui concerne l'Allemagne. Concernant la durée d'examen des recours individuels, toutes catégories confondues, on note les chiffres suivants : les deux tiers sont examinés en un an, un quart en deux ans, $5 \%$ en trois ans et presque $2 \%$ en quatre ans. 

Chapitre 2

\author{
LE CONTRÔLE DES DÉCISIONS \\ DE JUSTICE EXERCÉ DANS LE CADRE \\ DES QUESTIONS PRÉJUDICIELLES
}





\title{
LE CONTRÔLE DES DÉCISIONS DE JUSTICE PAR LA Cour Constitutionnelle belge
}

\author{
Marc VERDUSSEN ${ }^{1}$
}

On ne répétera jamais assez que la justice constitutionnelle procède primordialement du souci de rencontrer le risque d'une « omnipotence parlementaire $»^{2}$. Voilà pourquoi il ne saurait y avoir de justice constitutionnelle « sans cette attribution centrale qu'est le contrôle de constitutionnalité des lois, c'est-à-dire la soumission de la volonté du Parlement au respect de la règle de droit $»^{3}$.

Toutes les juridictions constitutionnelles européennes contrôlent donc la constitutionnalité des lois et autres normes législatives. C'est là leur core business, pour utiliser un langage économique propre au monde de l'entreprise.

Cependant, certaines d'entre elles, et pas des moindres, sont également compétentes pour contrôler la constitutionnalité des actes, administratifs ou juridictionnels, d'application des normes législatives. L'exemple le plus marquant est celui de la tentaculaire Cour constitutionnelle fédérale allemande, qui peut étendre son contrôle à l'égard de tout acte de la " puissance publique », selon l'article 93-1-4-a de la Loi fondamentale, ce qui recouvre les normes législatives, mais aussi les actes administratifs, règlementaires et individuels, et les décisions juridictionnelles. On retrouve ici la distinction opérée par Francisco Fernández Segado entre le contrôle de constitutionnalité de la loi exercé en marge de son application et le contrôle de constitutionnalité de la loi exercé à l'occasion de l'application de celle-ci'.

Comment se situe, à cet égard, la justice constitutionnelle belge ? Plus particulièrement, la Cour constitutionnelle contrôle-t-elle, d'une manière ou d'une autre, les décisions de justice ? Quelles sont les perspectives envisageables, spécialement au regard des évolutions du contentieux sur renvoi préjudiciel ? On distingue donc la situation actuelle (I) et les perspectives envisageables (II).

Professeur à l'Université de Louvain (UCL), Centre de recherche sur l'État et la Constitution (JUR I-CRECO).

J. FAzy, De l'intelligence collective des sociétés - Cours de législation constitutionnelle [1873], Université de Genève, Schulthess, 2010 , p. 187.

L. Favoreu et W. Mastor, Les Cours constitutionnelles, $2^{\mathrm{e}}$ éd., Paris, Dalloz, 2016, p. 25.

F. FERNÁNDEZ SEGADO, « La faillite de la bipolarité 'modèle américain-modèle européen' en tant que critère analytique du contrôle de la constitutionnalité et la recherche d'une nouvelle typologie explicative », Fahrbuch des öffentlichenRechts der Gegenwart, 2004, vol. 52, p. 471-503. 


\section{La situation actuelle}

Le mot « contrôle » est ambigu. On peut l'entendre de deux manières différentes. Contrôler, c'est vérifier. Contrôler, c'est aussi maîtriser. On distingue donc le contrôle-vérification et le contrôle-maîtrise.

Le contrôle-vérification. Si contrôler, c'est vérifier, force est alors de constater qu'en Belgique, à la différence de l'Allemagne, ou encore de l'Espagne, ni les jugements et arrêts rendus par les juridictions - cours et tribunaux - de l'ordre judiciaire, ni les décisions rendues par les juridictions administratives ne peuvent faire l'objet de recours auprès de la Cour constitutionnelle. À plusieurs reprises, cette dernière a rappelé qu'elle est compétente pour contrôler la constitutionnalité des lois, voire des autres normes ayant force de loi, mais pas davantage. Ainsi, dans l'arrêt n n 6/89 du 15 mars 1989, elle constate que le requérant demande l'annulation du jugement rendu le 5 octobre 1987 par la $45^{\mathrm{e}}$ chambre correctionnelle du Tribunal de première instance de Bruxelles, de telle sorte que le recours ne relève pas de sa compétence.

Pour autant, les décisions des juridictions ne sont pas exonérées de tout contrôle direct de constitutionnalité. Pour ce qui concerne les juridictions judiciaires, ce contrôle s'exerce dans le cadre des voies de recours, ordinaires (appel ou opposition) et extraordinaires (cassation par exemple). Quant aux griefs d'inconstitutionnalité, ils peuvent concerner tantôt la compétence de la juridiction en cause (dans la mesure où cette compétence est déterminée par la Constitution), tantôt la motivation formelle de la décision querellée (le droit à la motivation des décisions de justice est un droit constitutionnel), tantôt encore l'application qui est procurée par la juridiction à une règle de droit constitutionnel matériel. En ce sens, les cours et tribunaux de l'ordre judiciaire sont des juges constitutionnels et, en dernière instance, c'est à la Cour de cassation de trancher les éventuelles divergences d'interprétation. Mutatis mutandis, la situation de la section du contentieux administratif du Conseil d'État est comparable.

La seule limite concerne l'objet du grief d'inconstitutionnalité : s'il porte sur une norme législative, la juridiction saisie ne peut l'examiner, mais doit s'adresser, par la voie d'une question préjudicielle, à la Cour constitutionnelle lorsque l'inconstitutionnalité suspectée entre dans les attributions de cette dernière. Sur ce dernier point, on rappelle que la Cour constitutionnelle a pour mission essentielle de contrôler la compatibilité des normes législatives à l'égard des règles qui sont établies par la Constitution ou vertu de celles-ci pour déterminer les compétences respectives de la collectivité fédérale et des collectivités fédérées, de tous les droits fondamentaux consacrés par le Titre II et par les articles 170, 172 et 191 de la Constitution et, depuis 2014, du principe de loyauté fédérale consacré par l'article 143 de la Constitution. Elle exerce donc un contrôle de constitutionnalité qui vise toutes les normes législatives, mais qui ne s'étend pas à l'ensemble du texte constitutionnel. 
Le contrôle-maîtrise. Si contrôler, c'est maitriser, à tout le moins exercer une certaine maîtrise, au sens d'une influence prépondérante, le seul fait qu'ayant été saisie d'une question préjudicielle, la Cour constitutionnelle puisse interdire à un juge, la juridiction de renvoi, de faire application d'une loi inconstitutionnelle traduit déjà, en soi, une forme de suprématie de la juridiction constitutionnelle.

On objectera que cette suprématie est toute relative, car au-delà de l'interdiction formulée par la Cour, la juridiction de renvoi reste maître de la solution qu'elle estime devoir apporter au litige dont elle est saisie. Mais l'est-elle vraiment dans tous les cas ? En répondant à une question préjudicielle sur la constitutionalité d'une loi, la Cour constitutionnelle n'est-elle pas amenée à influer de manière plus déterminante sur l'issue du litige a quo? Quatre observations nous paraissent s'imposer ici.

1. En vertu de l'article 26, § 2, alinéa 3, de la loi spéciale du 6 janvier 1989 sur la Cour constitutionnelle (LSCC), à l'exception de la Cour de cassation et de la section du contentieux administratif du Conseil d'État, toute juridiction qui envisage de poser une question préjudicielle doit préalablement se prononcer sur la pertinence de cette question dans le litige dont elle est saisie, dans l'idée que, si la réponse à la question n'est pas indispensable pour rendre sa décision, elle s'abstiendra de la poser $^{5}$. La Cour constitutionnelle, tout en reconnaissant que cette appréciation appartient au premier chef à la juridiction de renvoi, considère que, lorsque la question n'est manifestement pas (ou plus) pertinente, il ne lui appartient pas d'y répondre ${ }^{6}$. Elle dit pour droit que « la question préjudicielle n'appelle pas de réponse ${ }^{7}$. C'est une forme de contrôle-maîtrise qu'on retrouve dans d'autres États, comme l'Italie par exemple ${ }^{8}$. Il arrive aussi que la Cour constitutionnelle renvoie l'affaire à la juridiction de renvoi « afin de lui permettre d'apprécier si la question préjudicielle nécessite encore une réponse $»^{9}$.

2. Quand une juridiction pose une question préjudicielle à la Cour constitutionnelle, elle peut la libeller de manière très neutre, mais elle peut aussi lui donner une formulation fondée sur une lecture particulière de la loi mise en cause. Dans ce cas, la Cour doit bien sûr répondre à la question posée dans l'interprétation retenue par la juridiction de renvoi : si elle tient la norme pour inconstitutionnelle dans cette interprétation, elle doit le dire pour droit à la juridiction qui l'a interrogée. Cependant, la Cour se reconnaît la possibilité de remettre en cause l'interprétation retenue par la juridiction de renvoi, lorsqu'elle estime pouvoir tirer de la loi une autre interprétation - une interprétation alternative -, le but étant d'ajuster la loi à la Constitution et ainsi d'en préserver la constitutionnalité. La Cour formule alors une réponse « bipolaire », dans un arrêt « interprétatif $»^{10}$.

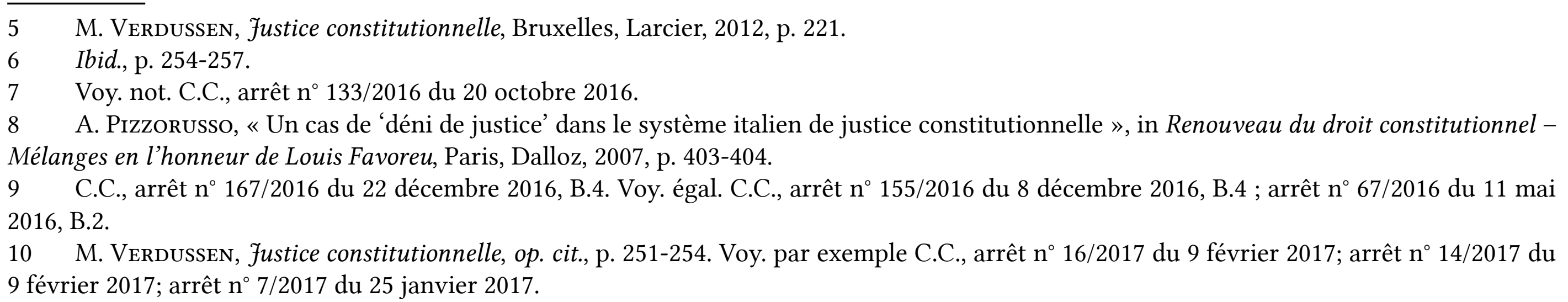


Dans la mesure où elle contribue au maintien de la sécurité juridique, cette méthode doit être approuvée. Mais elle n'est pas sans se heurter à quelques écueils. D’une part, il arrive que la juridiction de renvoi éprouve de sérieuses difficultés à déterminer avec précision les conséquences d'une interprétation conciliante. D'autre part, une telle méthode peut être ressentie par la juridiction de renvoi comme une ingérence dans ses « affaires intérieures », spécialement lorsque l'interprétation condamnée est une interprétation consolidée. Car, à la différence de la Cour constitutionnelle italienne, la Cour constitutionnelle belge, lorsqu'elle condamne une interprétation consolidée, n'hésite jamais à proposer une interprétation alternative. Dans certaines affaires retentissantes, ce procédé a pu froisser la susceptibilité de la section du contentieux administratif du Conseil d'État et, surtout, de la Cour de cassation ${ }^{11}$.

Confrontée à un arrêt interprétatif, la juridiction de renvoi a deux possibilités : soit elle retient l'interprétation conciliante et applique la loi mise en cause ; soit elle s'obstine à retenir l'interprétation condamnée et elle n'a d'autre choix alors que de refuser d'appliquer la loi mise en cause. La Cour constitutionnelle n'a donc pas le pouvoir d'imposer son interprétation à la juridiction de renvoi. À supposer qu'on puisse malgré tout considérer les arrêts interprétatifs comme une forme de contrôle-maîtrise, il n'y a rien dans cette méthode de très original, la plupart des juridictions constitutionnelles européennes recourant au même procédé.

3. La Cour constitutionnelle a été plus loin encore, en procédant - dans quelques arrêts - à des substitutions de qualifications. Très brièvement et pour la bonne compréhension des choses, on rappelle que tout contrôle de constitutionnalité d'une loi suppose une opération préalable de qualification qui met en présence la loi contrôlée et une disposition tirée de la Constitution ; qualifier, c'est vérifier que la disposition constitutionnelle invoquée est bien applicable à la loi querellée. La juridiction de renvoi est présumée avoir opéré cette vérification. Une substitution de qualification, c'est donc cette opération qui consiste pour la Cour à modifier la qualification donnée par la juridiction de renvoi à la loi faisant l'objet de la question préjudicielle et, en conséquence, à refuser de se prononcer sur la constitutionnalité de cette loi, à tout le moins dans la qualification retenue par la juridiction ${ }^{12}$. On est déjà plus dans l'idée d'un contrôle-maîtrise, mais il n'est pas certain que le procédé soit très atypique.

4. En Belgique, le contrôle exercé par la Cour constitutionnelle lorsqu'elle répond à une question préjudicielle est de plus en plus souvent concret ${ }^{13}$. Qu'entend-t-on par « concret »? On a souvent écrit que le contrôle de constitutionnalité revêt un caractère concret lorsqu'il est déclenché par une

\footnotetext{
11 Voy. J. van Compernolle et M. Verdussen, « La guerre des juges aura-t-elle lieu ? À propos de l'autorité des arrêts préjudiciels de la Cour d'arbitrage », fournal des tribunaux, 2000, p. 297-304 ; ID., « La réception des décisions d'une Cour constitutionnelle sur renvoi préjudiciel. L'exemple de la Cour d'arbitrage de Belgique », Les Cahiers du Conseil constitutionnel, 2003, n 14, p. 87-89.

12 M. VERDUSSEN, Justice constitutionnelle, op. cit., p. 257-262.

13 Voy. P. Martens, «Le contrôle préjudiciel de constitutionnalité est-il un art abstrait ? », in Mélanges en hommage à Robert Andersen, Bruxelles, Bruylant, 2009, p. 423-450 ; M. Verdussen, « La Cour constitutionnelle belge exerce-t-elle un contrôle concret ? », AIfC, 2013, vol. XXIX, p. 17-23. Voy. égal. l'intervention de M. Verdussen, « Table ronde. Le contrôle de constitutionnalité a posteriori sur renvoi est-il concret ? », in L. GAY (dir.), La question prioritaire de constitutionnalité - Approche de droit comparé, Bruxelles, Bruylant, 2014, p. 667-670 ; M. Verdussen, « La Cour constitutionnelle de Belgique : une juridiction politique ? », in G. GrandjEAN et J. WiLDEMEERsCH (dir.), Les juges : décideurs politiques? - Essais sur le pouvoir politique des juges dans l'exercice de leur fonction, Bruxelles, Bruylant, 2016, p. 340-342.
} 
question préjudicielle de constitutionnalité. Ce n'est pas dans ce sens que nous l'entendons. Dans l'acception retenue ici, le contrôle de constitutionnalité revêt un caractère concret lorsque l'examen de la question conduit la juridiction constitutionnelle à contrôler, non pas la norme comme telle - en ce qu'elle a vocation à s'appliquer à toutes les situations qu'elle appréhende abstraitement -, mais la norme en tant qu'elle s'applique à une situation particulière, celle à laquelle est confrontée la juridiction de renvoi. Ce n'est donc pas la norme qui est contrôlée, c'est la norme en situation. Et c'est cette mise en situation de la norme qui conduit la juridiction constitutionnelle à contextualiser, donc moduler, son jugement de constitutionnalité ${ }^{14}$. Pour autant que de besoin, on précise qu'il ne faut pas confondre cette contextualisation particulière de la norme avec la contextualisation générale de la norme, la prise en compte de circonstances factuelles générales pouvant en effet amener les juges constitutionnels à réinterroger une norme législative qui, au moment de son adoption, était exempte de tout vice de constitutionnalité.

Les juridictions belges se privent de moins en moins de poser des questions contextualisées et la Cour constitutionnelle de leur apporter les réponses qu'elles attendent : à question circonstanciée, réponse circonstanciée ${ }^{15}$. Plutôt que de condamner la norme législative comme telle, la Cour censure l'inconstitutionnalité de cette norme en tant qu'elle s'applique à la situation à laquelle est confrontée la juridiction de renvoi. Le développement de ces questions contextualisées et du contrôle ciblé qu'elles génèrent - « case by case » - est très significatif de la volonté des juges ordinaires et des juges constitutionnels, non seulement de révéler toutes les virtualités du mécanisme de renvoi préjudiciel, mais aussi de protéger le plus efficacement possible les droits fondamentaux des citoyens.

Cela peut aller très loin, en ce sens que la contextualisation de la question posée est parfois à ce point précise que la réponse que la Cour constitutionnelle donne à cette question détermine directement la solution à apporter au litige $a$ quo. Il arrive, à cet égard, que le dispositif de l'arrêt de la Cour soit une reproduction de la question dont elle a été saisie, la forme interrogative étant remplacée par une forme affirmative. Dans ces conditions, peut-on encore soutenir que la juridiction de renvoi reste maître de la solution qu'elle juge devoir apporter au litige dont elle est saisie ?

\section{Les perspectives envisageables}

Faut-il aller plus loin, en étendant les compétences de la Cour constitutionnelle à l'ensemble des décisions de justice, sur le modèle allemand ou espagnol, en passant d'un contrôle-maîtrise à un contrôle-vérification? On entreprend ici une première approche de cette question, en précisant, d'une part, qu'on reste dans le cadre belge et, d'autre part, qu'en Belgique, une telle extension de compétence n'a jamais été sérieusement envisagée par le monde politique, pas plus que la question n'a été approfondie dans le milieu scientifique. On se risque donc à quelques éléments de réponse très personnels.

14 Il ne faut pas confondre cette contextualisation particulière de la norme avec la contextualisation générale de la norme. La prise en compte de circonstances factuelles générales peut en effet amener les juges constitutionnels à réinterroger une norme législative qui, au moment de son adoption, était exempte de tout vice de constitutionnalité.

15 Pour deux exemples significatifs, voy. C.C., arrêt n 65/200 du 30 mai 2000 ; arrêt n 167/2006 du 18 octobre 2006. Pour un exemple récent, voy. C.C., arrêt n 25/2017 du 16 février 2017. 
On peut sérieusement douter de la faisabilité d'une telle réforme en Belgique, tout au moins dans l'état actuel des choses. Il serait difficilement justifiable d'étendre le périmètre d'action de la Cour constitutionnelle aux décisions juridictionnelles sans englober les autres actes d'application de la loi, à savoir les décisions des administrations. Par la force des choses, une telle extension de compétence aurait pour effet d'élever la Cour constitutionnelle au rang de seule et unique juridiction suprême. Or, la Cour constitutionnelle n'a pas une légitimité suffisamment solide pour être placée dans une position aussi hiérarchiquement supérieure à la Cour de cassation et au Conseil d'État, qui ont été créés bien des années avant la création en 1980 de la Cour constitutionnelle : 1831 pour la Cour de cassation et 1946 pour le Conseil d'État.

Surtout, le déroulement chronologique de la création des trois hautes juridictions a abouti à mettre en place un système où l'interprétation de la Constitution n'est pas monopolisée par quelques juges, mais est partagée entre trois ordres juridictionnels et donc entre trois hautes juridictions, qui par la force des choses sont obligées de s'engager dans un dialogue constitutionnel. Le concept de « dialogue constitutionnel » - est-il besoin de préciser qu'il est dépourvu de tout caractère normatif? renvoie à l'idée que l'interprétation du texte constitutionnel ne peut être être réservée à un organe juridictionnel, car elle concerne toutes les juridictions et, au delà, les législateurs, les administrations et, bien sûr, le citoyen lui-même. Ce n'est pas sans quelques effets collatéraux, mais c'est tellement plus enrichissant si on veut bien admettre que la Constitution doit être interprétée quotidiennement à travers des échanges continus auxquels participent tous les segments de la société. Avec lucidité, Dominique Rousseau observe que la juridiction constitutionnelle « est, seulement, un élément de la chaîne argumentative qui intervient, à un moment donné, pour sanctionner par sa décision le sens d'un énoncé constitutionnel, sans pour autant arrêter par sa sanction cette chaîne ; elle continue de vivre, car le sens produit ouvre, dans les assemblées, dans les juridictions, dans la doctrine... de nouveaux débats, de nouvelles réflexions qui peuvent produire, quelques temps plus tard, une nouvelle interprétation $»^{16}$.

On peut également douter de l'utilité, et même de la pertinence, d'une telle réforme en Belgique. Les divergences entre les trois hautes juridictions sur l'interprétation de la Constitution ne sont pas suffisamment significatives pour justifier une réforme aussi appréciable, qui serait vécue par la Cour de cassation et le Conseil d'État comme un désaveu aussi injuste qu'injustifié.

Par ailleurs, si un contrôle de constitutionnalité des décisions de justice devait être confié à la Cour constitutionnelle, il va de soi, selon nous, que les griefs dirigés contre ces décisions pourraient aussi concerner l'inconstitutionnalité d'une loi appliquée par un juge. Or, le système actuel des questions préjudicielles est conçu de telle manière que, lorsqu'existe un doute sur la constitutionnalité d'une loi applicable au litige, il est vidé à un stade ou un autre de la procédure. En effet, à ce jour, les juges peuvent de leur propre initiative saisir la Cour constitutionnelle d'une question préjudicielle de constitutionnalité et, en toute hypothèse, lorsqu'une partie interroge la constitutionnalité d'une loi,

16 D. Rousseau, « La jurisprudence constitutionnelle : quelle 'nécessité démocratique' ? », in G. Drago, B. FrançOIS et N. MolfEssis (dir.), La légitimité de la jurisprudence du Conseil constitutionnel, Paris, Economica, 1999, p. 376. 
le juge a en principe l'obligation de renvoyer une question préjudicielle à la Cour constitutionnelle. L'utilité d'un recours postérieur serait donc limitée à deux hypothèses. Soit personne - ni les juges ni les parties - n'ont songé à soulever le problème, et ce tous les degrés de l'instance. Soit une des parties au moins y a songé, mais le juge n'a pas fait droit à la demande de cette partie de renvoyer la question à la Cour constitutionnelle, ce qui en dernière instance n'est légalement possible que si la Cour de cassation ou la section du contentieux administratif du Conseil d'État constate que la Cour a déjà répondu à une question ayant un objet identique.

Pour autant, devons-nous exclure toute évaluation du système existant ? Pas nécessairement. Trois constats sont ici formulés.

Le premier constat touche à la temporalité du procès constitutionnel. En Belgique, la juridiction qui interroge la Cour constitutionnelle doit attendre une année, en moyenne, pour recevoir une réponse. Et lorsque la Cour pose une question en interprétation ou en validité à la Cour de justice de l'Union européenne - ce qui n'est pas rare ${ }^{17}$-, l'instance se prolonge au-delà de ce qu'on peut considérer comme un délai convenable. N'est-il pas contraire aux exigences d'une bonne administration de la justice d'imposer un tel délai aux justiciables? N'est-ce pas d'autant plus incompréhensible dans le cas de questions concrètes de constitutionnalité - au sens indiqué ci-dessus -qui, parce qu'elles sont contextualisées, se révèlent fortement imbriquées dans le litige a quo et relèvent davantage de la «micro-constitutionnalité »? À la lecture de certaines réponses données par la Cour constitutionnelle à des questions concrètes, on ne peut manquer de penser que le juge de renvoi aurait pu fournir lui-même la réponse. Au lieu de cela, il doit y renoncer. Ce renoncement peut générer des frustrations. Surtout il contraint le juge à attendre trop longtemps une réponse que, le plus souvent, il devine avec succès.

Le deuxième constat est lié au premier. Un contrôle concret de constitutionnalité exige de la part de la juridiction constitutionnelle des spécialisations dans toutes les branches du droit. Si le manque d'expertise dans telle ou telle matière est un problème qui concerne le contrôle de constitutionnalité des lois en général, il se pose avec une acuité particulière s'agissant des contrôles concrets. Or, dans un pays comme la Belgique, les règles relatives à la composition de la Cour constitutionnelle et au choix des juges et des référendaires ne garantissent pas que chaque question concrète puisse être traitée par des juges et des référendaires ayant une expertise suffisante. Le problème concerne-t-il uniquement la Belgique? Sans doute touche-t-il d'autres cours constitutionnelles. En revanche, dans les États du modèle déconcentré de justice constitutionnelle, comme les États-Unis et le Canada, les affaires dont est saisie la Cour suprême ont fait l'objet d'un examen préalable par des juges spécialisés, en premier et en deuxième ressort. Elles ont en quelque sorte été prétraitées par des juges et des avocats ayant une maîtrise de la discipline.

17 M. VERDUSSEN, « Le renvoi par les cours constitutionnelles de questions préjudicielles à la Cour de justice de l'Union européenne », in E. CARTIER, L. GAY et A. Viala (dir.), La QPC : vers une culture constitutionnelle partagée ?, Paris, Institut Universitaire Varenne, 2015, p. 261-270. 
Le risque est grand de développer une jurisprudence qui suscite, à tort ou à raison, l'incompréhension - et, partant, des reproches d'incompétence - dans le chef de celles et ceux, scientifiques ou praticiens, qui ont une expertise dans la matière concernée. On retient un exemple. La Cour constitutionnelle belge a été saisie de nombreuses questions préjudicielles très concrètes en droit de la filiation. Or, dans cette matière, les arrêts de la Cour ont suscité de vives réactions de la part des «familiaristes ». Dans une étude récente, deux professeurs de droit familial ont écrit que la Cour «a posé des choix pas toujours inspirés » et qu' « un malaise s'est installé et a grandi entre la Cour qui distillait ses enseignements au gré d'arrêts de moins en moins limpides et les auteurs chargés de tirer de ces enseignements des normes juridiques applicables par les praticiens du droit $»^{18}$.

Le troisième constat découle de l'émergence des ordres juridiques européens. Il devient de plus en plus difficile de justifier sérieusement que les juridictions ordinaires n'aient ni le pouvoir ni la capacité d'exercer un contrôle de constitutionnalité des lois alors qu'elles ont l'obligation d'écarter toute loi qui serait incompatible avec le droit de l'Union européenne ${ }^{19}$. Dans certains États, dont la Belgique fait partie, elles ont aussi le pouvoir d'écarter les lois qui ne seraient pas compatibles avec d'autres traités, telle la Convention européenne des droits de l'homme. En effet, selon l'arrêt Le Ski rendu par la Cour de cassation le 27 mai 197120, lorsqu'un conflit oppose une norme législative de droit interne et une norme de droit international conventionnel, la règle établie par le traité international doit prévaloir, la prééminence de celle-ci résultant « de la nature même du droit international conventionnel », et toutes les juridictions sont habilitées à le constater à titre incident. L'arrêt Le Ski est l'équivalent des arrêts Société des cafés facques Vabre et Nicolo rendus respectivement par la Cour de cassation de France le 24 mai 1975 et par le Conseil d'État de France le 20 octobre 1989.

Ces constats, tirés de l'expérience belge, conduisent à penser que la distinction traditionnelle entre le modèle concentré et le modèle déconcentré de justice constitutionnelle a atteint ses limites. Alors, bien sûr, la Belgique n'abandonnera pas de sitôt le modèle concentré. Et c'est heureux, pour toutes les raisons qui ont justifié sa création. Il n'en reste pas moins que les constats faits ici justifient un requestionnement du modèle concentré.

Une piste mérite d'être creusée, celle d'un partage du contrôle de constitutionnalité des lois entre la Cour constitutionnelle et les juridictions ordinaires, par une « hybridation ${ }^{21}$, limitée mais réelle, des modèles concentré et déconcentré. Compte tenu des constats brièvement esquissés, on

18 N. Massager et J. Sosson, « Filiation et Cour constitutionnelle», in N. MAssager et J. Sosson (dir.), Cour constitutionnelle et droit familial, Limal, Anthemis, 2015, p. 33 et 34.Voy. égal. J. Sosson, « Un enfant majeur a-t-ilundroitinconditionnel à contester sa filiation? Les enseignements de l'arrêt dit 'Boël' de la Cour constitutionnelle», fournal des tribunaux, 2016, p. 289-294.

19 Depuis l'arrêt Simmenthal, la Cour de justice de l'Union européenne considère que « tout juge national, saisi dans le cadre de sa compétence, a l'obligation d'appliquer intégralement le droit communautaire et de protéger les droits que celui-ci confère aux particuliers, en laissant inappliquée toute disposition éventuellement contraire de la loi nationale », de telle sorte que serait « incompatible avec les exigences inhérentes à la nature même du droit communautaire toute disposition d'un ordre juridique national ou toute pratique, législative, administrative ou judiciaire, qui aurait pour effet de diminuer l'efficacité du droit communautaire par le fait de refuser au juge compétent pour appliquer ce droit, le pouvoir de faire, au moment même de cette application, tout ce qui est nécessaire pour écarter les dispositions législatives nationales formant éventuellement obstacle à la pleine efficacité des normes communautaires » (CJCE, 9 mars 1978, Simmenthal, aff. 106/77, $\S \S 21-22)$. Voy. L.F.M.Besselink, « The Proliferation of Constitutional Law and Constitutional Adjudication, or How American JudicialReview Came to Europe After All », Utrecht L. Rev., 2013, vol. 9, p. 24.

20 Cass., 27 mai 1971, Pas., 1971, I, p. 887, concl. W.-J. Ganshof van der Meersch.

21 A. Harding, P. Leylandet T. Groppi, «Constitutional Courts : Forms, Functions and Practice in Comparative Perspective », fournal of Comparative Law, 2008, vol. 3, p. 3. 
se risque à envisager de laisser aux juridictions ordinaires la possibilité de trancher elles-mêmes les exceptions concrètes d'inconstitutionnalités ou, pour le dire autrement, ce qui relève de la microconstitutionnalité.

Ces derniers mots doivent être bien compris. L'expression« micro-constitutionnalité» a été utilisée par une partie de la doctrine avec une connotation négative. On peut lire ainsi, sous la plume d'un des plus grands constitutionnalistes italiens, que « le régime judiciaire des affaires constitutionnelles met souvent le juge, qui prend l'initiative, au contact des problèmes de constitutionnalité des lois dans une perspective de micro-constitutionnalité (c'est-à-dire que pour la solution d'un tout petit problème, on évoque, sans médiations, par exemple le grand principe d'égalité) », avec la conséquence «que souvent les grands principes de la Constitution sont 'sollicités' dans des cas négligeables $»^{22}$. Selon nous, un micro-problème de constitutionalité est un problème qui épouse les contours d'un litige particulier et dont l'enjeu est, par la force des choses, limité aux particularités de ce litige. Ce n'est pas pour autant un problème négligeable. Car, pour le justiciable confronté à un problème de constitutionnalité, peu lui chaut que ce problème concerne une généralité de situations ou une situation spécifique - la sienne -, dès le moment où il est pour lui source d'injustice.

Quel serait, dans ce schéma, le rôle de la Cour constitutionnelle ? Son rôle serait potentiellement double. Tout d'abord, elle continuerait à être saisie de questions abstraites de constitutionnalité, des questions de «macroconstitutionnalité » en quelque sorte. Ensuite, s'agissant de ce qui relève de la microconstitutionnalité, la Cour n'interviendrait qu'au bout de la chaine juridictionnelle, sur recours introduit contre le jugement ou l'arrêt final. Dans ces conditions, on pourrait imaginer la possibilité d'un recours auprès de la Cour constitutionnelle qui serait dirigé contre la décision prise en dernière instance. Elle aurait ainsi, dans ce cadre, la possibilité de contrôler des décisions de justice? Il s'agirait d'un contrôle-vérification, et non plus d'un contrôle-maîtrise.

Une telle piste suscite moult interrogations et se heurte à de sérieux écueils. Parmi ces difficultés, la distinction entre une question concrète et une question abstraite de constitutionnalité n'est pas la moindre. Elle débouche sur une autre difficulté, celle de savoir à qui il revient de décider du caractère concret ou abstrait d'une question. Mais ces difficultés ne méritent-t-elle pas d'être à tout le moins explorées? Il y a assurément place pour un débat sur ce point.

Un tel réaménagement du contrôle de constitutionnalité des lois renforcerait l'idée que la Constitution est l'affaire de tous, et pas uniquement de douze juges. Une Constitution n'est légitime que si chacun, autorité publique ou personne privée, peut se l'approprier. Comme l'écrit si bien Mark Tushnet, professeur de droit constitutionnel à la Harvard Law School, « the Constitution belongs to us collectively, as we act together in political dialogue with each other - whether we act in the streets, in the voting booths, or in legislatures as representatives of others $»^{23}$.

22 G. ZAGREBELSKY, « La multiplication des recours en Italie. Encombrement et micro-constitutionnalité », AIFC, 1985, vol. I, p. 113-114

23 M. Tushnet, Taking the Constitution away from the Courts, Princeton University Press, 1999, p. 181. 
Ce réaménagement aurait, par ailleurs, pour effet de permettre à la Cour constitutionnelle de jouer un rôle plus « principiel », terme retenu par référence à la notion de « forum de principes » qu'a utilisée Ronald Dworkin ${ }^{24}$.

Plus la question qui leur est posée est abstraite et générale, plus les juges constitutionnels tranchent un problème constitutionnel qui intéresse la communauté des citoyens et qui, soit dit en passant, a pu susciter des opinions à travers les canaux traditionnels d'expression démocratique, dans le cadre d'une délibération constitutionnelle collective.

Plus la question qui leur est posée est abstraite et générale, plus les juges constitutionnels seront amenés à dégager des principes, et pas seulement des solutions. Pour citer une fois encore Dominique Rousseau, « le droit se fabrique aussi avec des principes $»^{25}$. Et, dans l'élaboration de ces principes, les juges constitutionnels jouent un rôle prépondérant.

24 R. BAdinter et S. Breyer (dir.), Les entretiens de Provence - Le juge dans la société contemporaine, Paris, Fayard, 2003, p. 130. 


\title{
CONTRÔLE DE CONSTITUTIONNALITÉ, INTERPRÉTATION CONFORME ET DÉCISIONS DE JUSTICE EN ITALIE : VERS UNE NOUVELLE CONFIGURATION DES RAPPORTS ENTRE LA COUR CONSTITUTIONNELLE ET LES JUGES ORDINAIRES
}

\author{
Jean-Jacques PARDINI ${ }^{1}$
}

En Italie, il est bien entendu que le contrôle de constitutionnalité ne s'étend pas aux décisions de justice. Tout au plus, ces dernières peuvent-elles, en théorie, être annulées par la Cour constitutionnelle dans l'exercice d'autres compétences dont elle dispose : celle, d'abord, relative à la solution des conflits d'attribution entre l'État et les régions et entre les régions '2 ; celle, ensuite, qui concerne les conflits entre les pouvoirs de l'État'. Ce sont là des questions qui, malgré l'intérêt qu'elles présentent, ne seront évoquées dans la présente contribution que de manière allusive et en tant que de besoin. De fait, au regard de la logique retenue par les organisatrices du colloque, mon propos se concentrera exclusivement sur le contentieux préjudiciel de constitutionnalité des lois et des actes ayant force de loi, renvoyant au procès incident de constitutionnalité qui, on le verra, peut, à certains égards, rejoindre le thème en discussion.

Ce sont les articles 134 et 137 de la Constitution italienne, complétés et mis en œuvre par la loi constitutionnelle $\mathrm{n}^{\circ} 1 \mathrm{du} 9$ février $1948^{4}$ (article $1^{\text {er }}$ ) et la loi ordinaire $\mathrm{n}^{\circ} 87 \mathrm{du} 11$ mars $1953^{5}$ (article 23 et s.), qui ont prévu l'exercice, par la Cour constitutionnelle, d'un contrôle concret et a posteriori de constitutionnalité des lois et des actes ayant force de loi de l'État et des Régions. Comme l'observait le Doyen Jean-Claude Escarras, les citoyens, dans ce cadre, « «ne peuvent pas agir directement devant la Cour constitutionnelle, mais doivent suivre un chemin indirect et tortueux» pour saisir cette dernière ${ }^{6}$. Ce chemin indirect et tortueux, on s'en doute, passe par l'office des juges ordinaires (les juges a quibus) qui, pour reprendre une formule qui a fait florès, sont qualifiés de « portiers $»^{7}$ de la Cour constitutionnelle.

\footnotetext{
1 Professeur, Directeur-adjoint du CDPC Jean-Claude Escarras, Aix Marseille Univ, Université de Toulon, Univ Pau \& Pays Adour, CNRS, DICE, CDPC Jean-Claude Escarras, Toulon, France.

2 Sur cette compétence, voir I. CIOLLI, « La Cour constitutionnelle italienne et les conflits d'attribution entre État et régions et entre régions », www.scienzegiuridiche.uniroma1.it.

À propos de cette compétence, voir notre article « Les conflits entre pouvoirs de l'État en 1997 », AIfC, XIII, 1998 , p. 727 et s.

Loi constitutionnelle $\mathrm{n}^{\circ} 1$ du 9 février 1948 portant normes relatives aux jugements de constitutionnalité et aux garanties d'indépendance de la Cour constitutionnelle, $G U \mathrm{n}^{\circ} 43$ du 20 février 1948

Loi n 87 du 11 mars 1953 portant normes sur la constitution et le fonctionnement de la Cour constitutionnelle, GUn ${ }^{\circ} 62$ du 14 mars 1953. J.-C. Escarras, «Éléments de référence », Cahiers du CDPC, vol. n 1, 1987, p. 30 (l'auteur citant U. Rescigno, Corso di diritto pubblico,

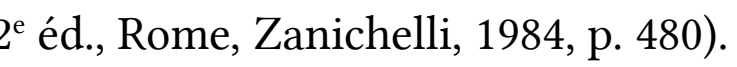

7 On doit cette expression au grand juriste italien P. CALAmandreI, La illegitimità delle leggi nel processo civile, Padoue, Cedam, 1950, p. XII.
} 
On sait, en effet, que lorsque, au cours d'un procès, un juge [le juge a quo] régulièrement saisi, par une partie ${ }^{8}$, d'une question de constitutionnalité décide que cette question satisfait à certaines conditions ${ }^{9}$, il l'accueille et rédige une ordonnance de renvoi qui, pour être recevable, doit comporter des indications très précises ${ }^{10}$. C'est précisément sur cette ordonnance de renvoi que porte le contrôle de la Cour constitutionnelle. Il va sans dire que ce contrôle n'est pas à proprement parler un contrôle de constitutionnalité de décisions de justice au sens retenu par certains États. Pour autant, il s'agit bien d'un contrôle qui concerne une décision de justice ${ }^{11}$, mais une décision de justice très particulière qui s'analyse comme une « courroie de transmission » qui mène au jugement constitutionnel.

En ce sens, et à l'évidence, un tel contrôle participe, certes de manière indirecte, à l'examen de constitutionnalité. D'abord, parce qu'il porte sur la manière dont le juge a quo assure la liaison du contentieux constitutionnel; à ce titre, le contrôle de la Cour constitutionnelle concerne, d'une part, la régularité des conditions de formation et de présentation de la question incidente et, d'autre part, l'appréciation, par le juge a quo, de la rilevanza de la question ${ }^{12}$. Ensuite, parce que le juge constitutionnel accepte sans ambages de contrôler l'examen, par le juge a quo, du doute de constitutionnalité, le fumus boni juris. Ce faisant, la Cour s'engage, s'il y a lieu - c'est-à-dire si les conditions précitées sont remplies - dans l'examen au fond de la question de constitutionnalité, réévaluant ainsi, le cas échéant, l'appréciation faite, par le juge a quo, de sa non manifesta infondatezza ${ }^{13}$.

Pour intéressantes et subtiles (peut-être trop d'ailleurs) qu'elles soient, ces questions ne seront pas ici évoquées, car, à l'évidence, elles ne constituent pas le cœur de nos préoccupations. L'analyse se concentrera en revanche sur l'adjonction, par la Cour constitutionnelle elle-même - donc par voie

8 On sait aussi que, autre hypothèse, le juge peut, en Italie, soulever d'office une question de constitutionnalité. Quoi qu'il en soit, le pouvoir de saisir la Cour constitutionnelle relève, en tout état de cause, de la compétence exclusive du juge. L'invocation, par les parties, d'un vice de constitutionnalité n'est en effet pas suffisante puisque, in fine, c'est le juge qui, au regard des conditions de recevabilité prescrites, décide que la question doit ou pas être transmise à la Cour.

9 Si ces conditions ne sont pas remplies, le juge opposera un refus aux parties et ne transmettra donc pas la question de constitutionnalité à la Cour constitutionnelle. Sur la possibilité (très restreinte) de contester les refus de soulever la question de constitutionnalité et certaines difficultés tenant à la forme que prennent ces refus, voir P. Passaglia (cet ouvrage), « Modèle concentré et ancrage de la Constitution dans l'évolution du contrôle incident en Italie : contribution à l'étude des remèdes contre le refus de soulever la question préjudicielle de constitutionnalité ». L'auteur met l'accent sur l'absence de recours direct des particuliers contre les décisions de justice et sur le caractère très théorique de l'utilisation des conflits d'attribution évoqués supra.

10 Cette ordonnance de renvoi (ordinanza di rimessione) a un double effet prévu par l'alinéa 2 de la loi $\mathrm{n}^{\circ} 87$ de 1953 : la transmission immédiate des actes à la Cour constitutionnelle et la suspension du procès en cours. Il faut, par ailleurs, distinguer la forme et le contenu de l'ordonnance de renvoi : a) La Cour constitutionnelle estime que la forme n'est pas déterminante pour l'instauration du jugement de constitutionnalité : par l'ordonnance $\mathrm{n}^{\circ} 124 \mathrm{du} 5$ mai 2014 (Giur. cost., 2014, p. 2140 et s.), elle précise qu' « en soulevant la question de constitutionnalité, les juges a quibus, après avoir apprécié la rilevanza et la non manifesta infondatezza de celle-ci, ont prescrit la suspension de l'instance principale et la transmission du fascicule à la chancellerie de la Cour », en sorte que « l'on doit reconnaître à ces actes, même s'ils ont pris la forme d'un decreto, la nature d'une véritable ordonnance » (la question n'est donc pas irrecevable) ; b) S'agissant du contenu, en revanche, l'ordonnance doit comporter, aux termes de l'article 23 de la loi n 87 de 1953 et d'une jurisprudence constitutionnelle constante, la description correcte du cas concret soumis à l'examen du juge, la motivation complète de la rilevanza et de la non manifesta infondatezza de la question de constitutionnalité, l'identification adéquate de l'objet de cette question, d'un petitum univoque et suffisamment défini et, on le verra, rendre compte de l'impossibilité de résoudre par voie interprétative le doute présumé de constitutionnalité. Le caractère exhaustif du contenu de l'ordonnance de renvoi est fondé sur le principe dit d' « autosuffisance » consacré par la jurisprudence de la Cour constitutionnelle. Sur la portée de ce principe d'autosuffisance de l'ordonnance de renvoi, voir, notamment, F. CASTALDI, « Il principio dell'autosufficienza dell'atto introduttivo del giudizio dinanzi la Corte costituzionale », www.extranet.dbi.it.

11 A. CERRI précise que l'acte introductif d'instance est l'expression d'un jugement complet, in Corso di giustizia costituzionale, $4^{\mathrm{e}}$ éd.,Milan, Giuffrè, 2004, p. 147.

12 Il faut préciser que si les conditions requises à ce titre ne sont pas remplies, la Cour constitutionnelle adopte des « décisions de procédure » ou « procédurales » ou, encore, « processuelles » (irrecevabilité ou irrecevabilité manifeste) en déclarant qu'un (ou des) vice(s) entache(nt) tel ou tel élément conditionnant la liaison du contentieux constitutionnel, ce qui empêche l'examen au fond de la question de constitutionnalité. 13 Pour des précisions sur tous ces points en langue française, J.-C. EscARRAs, «Éléments de référence », op. cit., spéc.p. 61 et s. Sur un essai de comparaison entre la question italienne et la QPC, voir notre article « Question prioritaire de constitutionnalité et question incidente de constitutionnalité italienne : ab origine fidelis », Pouvoirs, n 37, 2011, p. 101 et s. 
purement prétorienne - d'une autre condition de recevabilité de la question incidente de constitutionnalité qui réside dans l'obligation, pour le juge a quo, de rechercher une interprétation de la loi conforme (in accordance) $)^{14}$ à la Constitution. Que cette «nouveauté » soit largement discutée par la doctrine $^{15}$ - sans, d'ailleurs, que ces discussions soient encore totalement apaisées - ne doit pas surprendre. Car, enfin, en attribuant ainsi au juge de renvoi la fonction d'interprète obligé de la loi afin d'en dégager un sens conforme à la Constitution (I), la Cour constitutionnelle, alors même qu'elle ne dispose d'aucun instrument de contrôle efficace quant à l'exercice de cette fonction, assume consciemment le « risque » d'une altération du contrôle incident de constitutionnalité ${ }^{16}$ (II).

\section{Le juge de renvoi, interprète obligé de la loi : l'interprétation conforme à la Constitution $^{17}$}

Aux deux conditions classiques de recevabilité que l'on a évoqué, la Cour constitutionnelle a, en effet, par voie purement prétorienne, ajouté une nouvelle condition tenant à l'obligation, pour

14 La doctrine italienne, à ce propos, évoque indifféremment les expressions interpretazione conforme et interpretazione adeguatrice. Il faut dire que la Cour constitutionnelle utilise elle-même les deux formules sans, d'ailleurs, que l'on puisse clairement identifier une différence conceptuelle entre elles. Pourtant, certains membres de la doctrine italienne ont tenté de faire le départ entre les deux types d'interprétation. Pour des précisions sur cette question, A. Vignudelli, La Corte delle leggi. Osservazioni sulla cosidetta efficacia «normativa» delle sentenze della Corte costituzionale, Rimini, Maggioli Editore, 1988, spéc. p. 66. En substance, selon l'auteur, l'interprétation adeguatrice renvoie à une interprétation de la loi en harmonie avec la norme constitutionnelle mais qui est erronée, alors que l'interprétation conforme est celle qui renvoie à une lecture en adéquation avec les exigences constitutionnelles et qui n'est pas erronée. On dira notre perplexité relativement aux hypothèses ainsi avancées, tenant à la difficulté de cerner avec précision la frontière entre une interprétation erronée et une interprétation non erronée de la loi toutes deux conformes à la Constitution. Pour une autre conception de l'interprétation adeguatrice, voir V. ONIDA, «L'attuazione della Costituzione tra Magistratura e Corte costituzionale », in Scritti in onore di C. Mortati, vol. $\mathrm{n}^{\circ}$ IV, $1977, \mathrm{p} .537$ et s. 15 Les écrits portant sur l'interprétation conforme de la loi à la Constitution sont très nombreux et renvoient à des opinions qui ne sont pas toujours concordantes relativement à sa nature et à sa portée. Sans prétendre à l'exhaustivité, on citera toutefois G. SoRRENTI, L'interpretazione conforme a Costituzione, Milan, Giuffrè, 2006 ; M. LuciANI, « Le funzioni sistemiche della Corte costituzionale, oggi, e l'interpretazione «conforme a» », Federalismi.it,, 2007 ; R. RombolI, « Qualcosa di nuovo ... anzi d'antico : la contesa sull'interpretazione conforme della legge », archivio. rivistaaic.it, 2006 ; M. D’Amico, B. RANDAzzo (dir.), Interpretazione conforme e tecniche argomentative, Actes du colloque de Milan, 6-7 juin 2008, Turin, Giappichelli, 2009 ; M. Ruotolo, «Interpretazione conforme e tecniche decisorie della Corte costituzionale », www.gruppodipisa.it ; Actes du Séminaire de la Cour constitutionnelle, Corte costituzionale, giudici comuni e interpretazione adeguatrice, 6 novembre 2009, Milan, Giuffrè, 2010 ; A. Ciervo, Saggio sull'interpretazione adeguatrice, Rome, Aracne, 2011 ; G. SERGES, «L'interpretazione conforme a Costituzione tra tecniche processuali e collaborazione dei giudici », in Scritti in onore di Franco Modugno, IV, Naples, Editoriale scientifica, 2011, p. 3380 et s. ; I. CIOLLI, «Brevi note in tema d'interpretazione conforme a Costituzione », AIC, wwwrivistaaic.it., 2012 ; M.-A. GLIATTA, L'interpretazione conforme a Costituzione. Aspetti teorici e applicazione pratiche, 2012-2013, feoda.unina.it ; G. LANEve, La giustiziacostituzionale nel sistema dei poteri, vol. I, Interpretazionee giustizia costituzionale : profili ricostruttivi, Bari, Cacuci, 2014 ; M. Ruotolo, Interpretare : nel segno della Costituzione, Naples, Editoriale Scientifica, 2014 ; F. Modugno, « Al fondo della teoria dell'»interpretazione conforme alla Costituzione» », Diritto e società, 2015, p. 461 et s. ; M. Nistico, L'interpretazione giudiziale nella tensione tra i poteri dello Stato. Contributo al dibattito sui confini della giurisdizione, Turin, Giappichelli, 2015. Voir également en langue française, Th. Di MANNo, « L'impossibilité de l'interprétation conforme de la loi à la Constitution, condition de recevabilité de la question incidente de constitutionnalité italienne », in La question prioritaire de constitutionnalité. Approche de droit comparé, Actes du colloque d'Aix-en-Provence, 21-22 mars 2013, Bruxelles, Bruylant, coll. À la croisée des droits, 2014, p. 123 et s. 16 Comme il a été justement observé, « la question qui concerne l'interprétation conforme ne renvoie pas [...] au choix entre une application constitutionnelle ou inconstitutionnelle de la loi. Si tel était le cas, la décision serait évidente. La question renvoie plus exactement au choix entre application de la loi secundum Constitutionem et activation du contrôle de constitutionnalité et met donc en cause les rapports entre juridiction ordinaire et juges constitutionnels et la définition de leurs fonctions respectives [...] », in M.-A. GLIATTA, L'interpretazione conforme a Costituzione. Aspetti teorici e applicazione pratiche, op. cit., p. 58. Elle estime aussi que l'interprétation conforme n'est pas une question de «méthode juridique » pouvant se résoudre par une réponse prescriptive en termes d'interprétation de la loi. Du reste, dit-elle, « toute méthode sous-entend une idée différente du droit en sorte qu'une analyse qui porterait seulement sur le problème de la méthode serait nécessairement incomplète ». En ce sens, G. ZAgrebelsky, Il diritto mite. Legge, diritti, giustizia, Turin, Einaudi, 1992, p. 185. L’idée est également exprimée, en doctrine, que plusieurs interprétations conformes sont possibles eu égard au caractère ouvert des normes constitutionnelles ; en ce sens, G. SORRENTI, L'interpretazione conforme a Costituzione, op. cit.,p. 82 et s. qui prend quelque distance avec la thèse de la one right answer de Dworkin. 17 La notion d'interprétation conforme de la loi à la Constitution est également présente dans le filtrage des questions prioritaires de constitutionnalité (ci-après QPC) françaises, ce qui, d'ailleurs, n'a pas laissé d'inquiéter certains auteurs. On a pu en effet évoquer un « détournement de l'interprétation conforme » à cet égard, car « tout se passe comme si le juge ordinaire, usurpant le procédé de l'interprétation conforme dans le dessein d'arrêter le chemin d'une QPC, volait au Conseil constitutionnel sa traditionnelle fonction qui est, non pas d'interpréter la loi, mais d'encadrer l'interprétation de la loi dans les limites de la constitutionnalité », A. VIALA, « De la puissance à l'acte : la QPC et les nouveaux horizons de l'interprétation conforme », $R D P, 2011$, p. 979 et $\mathrm{s}$. La distinction est donc établie entre une interprétation nécessaire à l'application de la loi et une interprétation nécessaire à l'examen de sa constitutionnalité [la frontière étant sans doute poreuse], de sorte que le fait que le juge ordinaire « indique, par une argumentation sur mesure, comment une disposition doit être interprétée pour demeurer conforme à la Constitution le porte à s'immiscer indûment dans les prérogatives herméneutiques du Conseil constitutionnel » (ibid. p. 982). 
le juge de renvoi, de rechercher l'éventuelle interprétation conforme des dispositions législatives. Même si maints débats ont eu lieu à ce sujet ${ }^{18}$, cette condition nouvelle se présente en réalité comme un préalable (un prius) à l'appréciation des deux conditions classiques plus haut envisagées. Il faut donc comprendre que le juge a quo procède à son examen avant de s'atteler à celui des conditions tenant à la rilevanza et à la non manifesta infondatezza de la question de constitutionnalité ${ }^{19}$. La consistance de l'obligation, pour le juge a quo, de rechercher l'interprétation conforme de la loi à la Constitution doit d'abord être évoquée (A). La question se posera ensuite de l'articulation entre cette obligation et la doctrine du droit vivant (B).

\section{A. La consistance de l'obligation, pour le juge a quo, de rechercher l'interprétation conforme de la loi}

C'est par l'arrêt nº 356 du 14 octobre $1996^{20}$ que la Cour constitutionnelle, après quelques tentatives ponctuelles ${ }^{21}$, a forgé ce préalable, en précisant qu' " en principe, les lois ne doivent pas être déclarées contraires à la Constitution parce qu'il est possible d'en dégager des interprétations contraires [...], mais parce qu'il est impossible d'en dégager des interprétations conformes [...] $\gg^{22}$. La jurisprudence est constante depuis cette date et les affirmations de la Cour, on le verra, toujours plus résolues.

Une telle assertion n'a certes rien de bien original, le critère de l'interprétation conforme ayant déjà été utilisé par elle dans le passé2 ${ }^{33}$ avec cette conséquence qu'elle rendait, dans le cas où une loi contestée était susceptible d'être interprétée conformément à la Constitution, une décision interprétative de rejet ${ }^{24}$. Dans cette hypothèse, le juge de renvoi appliquait la loi en cause au litige concret

18 L'introduction de cette nouvelle condition de recevabilité a suscité bien des débats en Italie. Pour une synthèse complète des positions doctrinales, voir M.-A. GliatTA, L'interpretazione conforme a Costituzione. Aspetti teorici e applicazione pratiche, op. cit.,p. 64 et s. qui distingue trois thèses : celle qui voit, dans l'interprétation conforme, un critère qui influe, en la modifiant, sur la non manifesta infondatezza; celle qui estime que l'interprétation conforme entre dans le jugement de rilevanza; celle, enfin, qui voit dans l'interprétation conforme une troisième condition d'ordre processuel - logique - introduite iure pretorio. Ceci dit, quelle que soit la pertinence de telle ou telle thèse, en cas de non-respect de l'obligation, c'est toujours par une décision d'irrecevabilité (manifeste) ou, plus rarement, d'infondatezza que ce non-respect est sanctionné par la Cour constitutionnelle. En ce sens, R. BIN, «L'applicazione diretta della Costituzione, le sentenze interpretative, l'interpretazione conforme a Costituzione della legge », www.robertobin, p. 4 et s.

19 En ce sens, P. PAsSAglia, « Modèle concentré et ancrage... », op. cit. (cet ouvrage).

20 Corte cost., sent. n 356 du 14 octobre 1996, Giur. cost., 1996, p. 3096 et s. avec note de E. LAMARQUE, « Una sentenza «interpretativa di inamissibilità» », Giur. cost., 1996, p. 3107 et s.

21 Voir notamment l'arrêt nº 456 du 19 juillet 1989, Giur. cost., 1989, p. 2086 (cons. en droit n 2 ).

22 Cons. en droit $n^{\circ} 4$. On comprend que cette formule ait pu conduire certains auteurs à penser que, dès lors, le juge $a$ quo, ne pouvant rendre la loi conforme à la Constitution,devait être convaincu de l'inconstitutionnalité de celle-ci. Comme l'observe Th. Di Manno, reprenant une proposition de rectification émise par F. Modugno, « peut-être la Cour constitutionnelle aurait-elle dû plutôt affirmer [...] que les lois doivent être déclarées contraires à la Constitution, «parce qu'il est difficile (improbable) d'en dégager des interprétations conformes à la Constitution». Une telle formulation aurait permis de laisser entendre que le juge ordinaire doute de la constitutionnalité de la loi, parce qu'il lui est difficile ou qu'il lui paraît improbable d'en dégager une interprétation constitutionnellement conforme », in "L'impossibilité de l'interprétation conforme de la loi... », op. cit. p. 142.

23 Sur l'identification de trois grandes phases dans l'expérience italienne de l'interprétation conforme de la loi à la Constitution, voir Th. Di Manno, «L'impossibilité de l'interprétation conforme de la loi... », ibid., p. 125 et s. Pour une analyse de l'évolution jurisprudentielle sur l'interprétation conforme, voir les références bibliographiques in M. BoNI (dir.), Le pronunce di inamissibilità della Corte costituzionale, www.cortecostituzionale.it, p. 58, note $\mathrm{n}^{\circ}$ 262. On signalera que, lors du discours prononcé dans le cadre de l'Audience inaugurale de la Cour, constitutionnelle le 23 avril 1956, E. di Nicola, alors Président de la Consulta, avait indiqué que la Cour et l'Autorité judiciaire « doivent, avec une unité d'intentions et d'actions, tendre au même objectif : la Cour, gardienne de la Constitution ; la Magistrature, gardienne de la Loi » et que le rapport pouvait être «maintenu dans ces frontières naturelles, c'est-à-dire sans excès inutilement extensifs et sans excès injustement restrictifs ». Dans la même veine, C. MEzzAnotTe avait utilisé une formule qui a ensuite fait florès : « aux juges la loi, à la Cour la Constitution », in «La Corte costituzionale : esperienze e prospettiva », in Attualità e attuazione della Costituzione, Rome-Bari, Laterza, 1979 , p. 160.

24 La littérature portant sur les décisions interprétatives de rejet (premier type de décisions interprétatives « créé » par la Cour) est foisonnante. On consultera notamment G. Sorrenti, L’interpretazione conforme a Costituzione, op. cit. p. 177 et s. et R. RomBoli, « Qualcosa di 
dans l'interprétation retenue par elle. Au contraire - et en cela l'arrêt de la Cour est innovatoire - elle décide, par cette décision, de prononcer l'irrecevabilité de la question incidente de constitutionnalité, en confiant au juge ordinaire la mission d'identifier lui-même la possible interprétation conforme de la loi à la Constitution. Ainsi, ce qui, pour le juge ordinaire, n'était jusque-là qu'une facultée ${ }^{25}$ devient désormais une obligation qui, en cas de non-respect, donne lieu à une décision dite de procédure ${ }^{26}$ (ce qui montre bien qu'il s'agit d'une condition autonome de recevabilité de la question qui, si elle n'est pas respectée, empêche qu'elle puisse être examinée au fond par la Cour). En quelque sorte, le recours à la Cour constitutionnelle devient subsidiaire - une "possibilité résiduelle ${ }^{27}$ selon le Président Zagrebelsky - et ce n'est que dans la mesure où le juge ordinaire ne parvient pas à dégager une interprétation conforme de la loi à la Constitution qu'il pourra valablement la saisir ${ }^{28}$.

nuovo... », op. cit.p. 3 et s. Apparue dès l'arrêt n 1 du 16 janvier 1957 (Giur. cost., 1957, p. 1), cette technique a permis à la Cour constitutionnelle de s'abstraire de l'alternative rigide entre admission et rejet de la question, entre déclaration d'inconstitutionnnalité et déclaration d'infondatezza. S'arrogeant ainsi le pouvoir d'interpréter de manière autonome les dispositions législatives soumises à son examen - et remettant ainsi en cause la distinction légalité/constitutionnalité - la Cour, par ce procédé, prononce le rejet de la question en fournissant une interprétation de la disposition législative contestée devant elle permettant de la « sauver » et d'éviter un vide normatif. On trouve différentes formules dans le dispositif de ces décisions qui permettent de les identifier, la Cour déclarant la question infondée nei modi (dans la mesure où), in quanto (en tant que), nei sensi (dans le sens où), di cui in motivazione (référence aux motifs de la décision). Sur la réception, par les juges ordinaires, des premières décisions interprétatives de rejet, voir C. MoRTATı, «Effetti pratici delle sentenze interpretative della Corte costituzionale », Giur. cost., 1959, p. 550 et s. Sur les difficultés liées aux effets de ces décisions, voir P. PASSAGLIA, « Modèle concentré et ancrage... », cet ouvrage. 25 Le fait qu'il ne s'agisse que d'une faculté ou d'une éventualité permettait de tenir à distance la crainte de l'invasion de la sphère de compétence de la Cour (ce qui aurait été le cas s'il s'était agi d'une obligation). G. GrotTANelli expliquait ainsi que « seule la Cour peut juger, en appréciant le degré d'ambiguïté, donc de danger, de la norme, s'il est ou non opportun d'en déclarer l'inconstitutionnalité ou de tenter d'imposer, par un arrêt interprétatif de rejet, un sens donné de la norme », in « Manifesta infondatezza e interpretazione adeguatrice », Giur. cost., 1963, p. 417. Par ailleurs, une telle position se justifiait par des raisons de politique constitutionnelle « afin de permettre la concentration entre les mains de la Consulta de l'harmonisation des lois par rapport à la Constitution », G. ZAGREBELSKy, V. MARCENò, Giustizia costituzionale, Bologne, Il Mulino, 2012, p. 293. Ainsi, la Cour jugeait recevables les questions soulevées par le juge a quo qui, par une ordonnance correctement motivée, exprimait seulement un doute sur l'interprétation qu'il retenait de la norme à appliquer. La Cour constitutionnelle, par l'arrêt ${ }^{\circ} 58$ du 20 février 1995 (Giur. cost., 1995, p. 493) par exemple, précisait que pour qu' « une question de constitutionnalité soit correctement posée, il suffit que le juge a quo donne à la disposition contestée une interprétation non improbable (non implausible) qu'il estime applicable au jugement principal [...] mais dont il doute, de manière non arbitraire ou à titre de pur prétexte, de la conformité à certaines normes constitutionnelles » (cons. en droit $\left.\mathrm{n}^{\circ} 2\right)$.

26 La conséquence est donc que le nombre de décisions interprétatives de rejet est en régression : il a été observé que de 1986 à 1996 , le rapport entre décisions interprétatives de rejet et décisions d'irrecevabilité pour absence d'interprétation conforme était de 58 à 9 , alors que pour la période 1997-2012 (premier quadimestre), il était de 42 à 180 ; statitisques fournies par M. Fierro, R. NevolA, I. Morelli, M. FulgENZi (dir.), L'interpretazione adeguatrice e l'obbligo del rimettente di ricercare un'interpretazione costituzionalmente orientata della norma censurata, Service des études de la Cour constitutionnelle, (STU 235), 2012, p. 8 et s. Ceci dit, la forte réduction de cette catégorie décisoire ne doit pas occulter le fait que, parfois, la Cour constitutionnelle adopte des décisions interprétatives de rejet « occultes », donc définitives du fait de « leur caractéristique typique qui consiste à maintenir la réinterprétation de la Cour «dietro le quinte» (dans la clandestinité) »(G. SoRRENTI, «La Costituzione «sottintesa»», in Corte costituzionale, giudici comuni e interpretazioni adeguatrice, Actes du séminaires d'études de la Cour constitutionnelle du 6 novembre 2009, op. cit. spéc. p. 36. L’hypothèse ici visée est celle dans laquelle la Cour constitutionnelle, dans la décision d'irrecevabilité (parfois manifeste) qu'elle adopte, ne se limite pas à constater le défaut de motivation relativement à la recherche de l'interprétation conforme de la loi, mais fournit des indications au juge a quo pour appliquer la loi dans un sens conforme à la Constitution, indications qui n'apparaissent que dans les motifs de la décision. On voit bien que, par là, la décision d'irrecevabilité révèle un examen au fond. Cela rend d'ailleurs illusoire la reproposition - en théorie possible - de la question par le même juge $a$ quo qui aura du mal à s'abstraire des orientations interprétatives de la Cour. Par ailleurs, la question a été posée de la pertinence de la décision d'irrecevabilité dans cette hypothèse dans la mesure où celle-ci, dans ses effets, ne concerne que le procès principal à l'origine de la question. Il faut bien voir, en effet, que, ainsi, l'interprétation conforme de la loi à la Constitution n'est pas relayée en sorte que, pour certains, l'instrument de la décision interprétative de rejet ou d'admission serait d'utilisation plus opportune. En ce sens, G. GEMMA, « Inamissibilità delle sentenze «interpretative» di inamissibilità », in M. D’Amico, B. Randazzo, (dir.), Interpretazione conforme e tecniche argomentative, op. cit., p. 276 et s. M. BonI considère par ailleurs que « la distinction entre décision interprétative de rejet et décision d'irrecevabilité n'est pas encore entièrement claire » dans la mesure où la Cour fait une utilisation ductile de ces décisions, ce qui témoigne de son intention "de maintenir fluides les limites des compétences de l'autorité judiciaire et de la Cour en adaptant la formule de la décision aux circonstances” », in « Le pronunce.... », op. cit., p. 65-66. Certains estiment que dans la mesure où la décision interprétative de rejet ne possède pas une force entièrement contraignante pour le juge $a$ quo, l'utilisation de la décision d'irrecevabilité pourrait permettre à la Cour de trouver un moyen plus persuasif envers celui-ci afin qu'il fournisse l'effort interprétatif nécessaire. Il ne faut pas non plus exclure le fait que les décisions d'irrecevabilité sont généralement adoptées en chambre du conseil, donc plus rapidement. Enfin, certains auteurs ont mis l'accent sur le fait que l'irrecevabilité pour effort interprétatif insuffisant ou absent se traduit, selon les cas, par une ordonnance d'irrecevabilité simple ou manifeste ou par un arrêt, ce qui déroge à la catégorisation binaire de l'article 18 de la loi $\mathrm{n}^{\circ} 87$ de 1953 qui distingue les arrêts des ordonnances, ces dernières, aux termes du dernier alinéa, étant « motivées de manière succincte ». 27 Conférence de presse du 2 avril 2004, www.cortecostituzionale.it.

28 On ne s'étonnera donc pas que le nombre d'ordonnances de renvoi soit en forte baisse : alors, par exemple, qu'en 2003, étaient recensées 1196 ordonnances de renvoi, ce sont seulement 348 ordonnances qui ont été transmises à la Cour constitutionnelle en 2015. 
Par là - et c'est l'avantage principal généralement reconnu par la doctrine ${ }^{29}$ - la " légalité constitutionnelle $»^{30}$ tend assurément à pénétrer dans l'ordonnancement juridique au moment de l'application de la loi au cas concret.

Le contrôle, par la Cour constitutionnelle, de l'ordonnance de renvoi se manifeste ainsi par le fait qu'elle exige que démonstration soit faite, dans cette ordonnance, non seulement de la recherche, par le juge a quo, d'une interprétation conforme de la loi, mais encore de l'impossibilité, pour lui, d'identifier une telle interprétation. De fait, ce contrôle est particulièrement « tatillon » et l'on « recense aujourd'hui de nombreuses décisions d'irrecevabilité (parfois manifestes) ou d'infondatezza (parfois manifestes) ${ }^{31}$ rendues au motif que le juge a quo a omis ou s'est insuffisamment efforcé de dégager une interprétation conforme de la loi en cause à la Constitution $»^{32}$. Certains auteurs, de manière significative, sont allés jusqu'à évoquer une « radicalisation de la doctrine de l'interprétation conforme $»^{33}$ au regard de l'ampleur du phénomène.

Il est néanmoins évident qu'il arrive à la Cour constitutionnelle de reconnaître l'impossibilité d'une interprétation conforme de la loi à la Constitution : dans ce cas, elle estime que la tentative vaine d'interpréter la loi conformément à la Constitution doit « céder le pas au contrôle de constitutionnalité $»^{34}$. Dans cette hypothèse - non introuvable - la Cour décharge donc le juge a quo de sa mission, considérant que les efforts consentis par lui n’ont pu déboucher sur une lecture en harmonie avec les exigences constitutionnelles.

En revanche, elle n'admet pas que les juges puissent la saisir de manière à « s'appuyer » sur elle. Elle estime en effet que pouvoir-devoir de l'autorité judiciaire d'interpréter la loi à la lumière des principes constitutionnels exclut que l'on puisse lui soumettre un pur et simple doute interprétatif, puisque la recherche de solutions herméneutiques constitutionnellement orientées ne peut se traduire en une sorte de « protection » en faveur du juge commun. La Cour refuse donc, de manière

29 En ce sens, notamment, I. Ciolli, « Brevi note... », op. cit., p. 4.

30 M. Luciani, « Su legalità costituzionale, legalità legale e unità dell'ordinamento », in Scritti in onore di G. Ferrara, Turin, Giappichelli, 2005, vol. II, p. 501 et s.

31 Il arrive, en effet, que la Cour censure l'effort interprétatif insuffisant du juge de renvoi par l'infondatezza (voir, par exemple, arrêts $\mathrm{n}^{\circ} 18$ du 28 janvier, n ${ }^{\circ} 60$ du 24 mars et n 64 du 26 mars 2014 notamment, Giur. cost., 2014, p. 260 et s., p. 1292 et s., p. 1368 et s.), ou par la manifesta infondatezza (ord. n 124 du 5 mai, n 179 du 11 juin 2014 notamment, Giur. cost., 2014, p. 2140 et s., p. 2820 et s.). Dans ces cas (à l'inverse d'hypothèses où elle n'examine pas au fond l'affaire), elle adopte une décision de rejet de questions susceptibles d'être résolues sur le plan herméneutique. Par l'ordonnance $\mathrm{n}^{\circ} 25$ du 10 février 2014, par exemple, elle a jugé manifestement infondée une question qui avait déjà été déclarée infondée « au motif de la possibilité constatée d'une interprétation conforme à la Constitution de la norme dénoncée dans les termes indiqués par l'organe de nomofilachia » (Giur. cost., 2014, p. 403 et s.). Il en est de même dans l'arrêt n ${ }^{\circ} 51$ du 12 mars 2014 où elle souligne que « la disposition contestée peut être interprétée de manière à dépasser les doutes de constitutionnalité proposés »(Giur. cost., 2014, p. 1204 et s., cons. en droit n 2).

32 Th. Di Manno, La régulation des contentieux devant les cours suprêmes, sous l'égide du Club des juristes, commission Constitution et institutions, octobre 2014, p. 80. La formule retenue par V. MARCENÒ est celle de « l'effort interprétatif insuffisant », in « Le ordinanze di manifesta inammissibilità per «insufficiente sforzo interpretativo» : una tecniche che può coesistere con le decisioni manipolativi (di norme) e con la dottrina del diritto vivente ? », Giur. cost., 2005, p. 785 et s. Dans l'ordonnance n 220 du 9 juillet 2014 par exemple, la Cour précise bien que « l'utilisation non adaptée des pouvoirs interprétatifs que confère la loi au juge de renvoi et l'absence de recherche de solutions herméneutiques différentes et praticables constituent des omissions justifiant l'irrecevabilité de la question » (Giur. cost., 2014, p. 3503 et s., cons. en droit $n^{\circ} 5.1$ ).

33 G. Sorrenti, L'interpretazione conforme a Costituzione, op. cit., p. 209. Il n'est pas rare, d'ailleurs, que l'Avocat général de l'État, défenseur de la loi dans le procès constitutionnel, invoque, entre autres arguments, celui de l'interprétation conforme pour voler au secours des dispositions législatives et inciter la Cour constitutionnelle à rejeter la question.

34 Cour const., sent. $\mathrm{n}^{\circ} 26$ du 25 janvier 2010, Giur. cost., 2010, p. 337 et s. (cons. en droit $\mathrm{n}^{\circ}$ 2). De manière générale, la Cour procède à l'examen au fond de la question lorsque les juges a quibus ont estimé, par une motivation adaptée, que les efforts interprétatifs pour rendre la norme contestée conforme au prescrit constitutionnel dépassent les limites que l'ordonnancement pose à l'activité herméneutique. Ainsi, par l'arrêt nº 216 du 9 juillet 2014, la Cour relève « le caractère correct de la reconstruction du cadre normatif de la part du Tribunal administratif de renvoi et l'impossibilité conséquente de fournir une interprétation différente des dispositions en vigueur » (Giur. cost., 2014, p. 3440 et s., cons. en droit n 5). 
traditionnelle, d'accueillir des requêtes propres à obtenir un avis sur l'option herméneutique proposée par le juge de renvoi, car, pour elle, cette démarche révèle une « utilisation impropre et dévoyée de l'incident de constitutionnalité qui vise non pas fournir une solution à un problème de préjudicialité au regard de la définition du thema decidendum du cas d'espèce, mais à tenter d'obtenir de la Cour un avis interprétatif $»^{35}$.

Reste à savoir comment la Cour constitutionnelle appréhende la situation lorsque la loi fait l'objet d'une interprétation consolidée et qu'elle est appliquée de manière constante dans le sens qui lui est attribué. C'est ici aborder la question de l'articulation entre l'obligation d'interprétation conforme de la loi à la Constitution et la doctrine du droit vivant.

\section{B. L'articulation entre l'obligation d'interprétation conforme de la loi à la Constitution et la doctrine du droit vivant}

La question de l'articulation du critère de l'interprétation conforme avec la doctrine dite du « droit vivant ${ }^{36}$ (l'interprétation consolidée de la loi provenant d'une orientation jurisprudentielle constante) ne pouvait pas ne pas se poser. La Cour constitutionnelle - qui elle est liée par le droit vivant, lorsqu'il existe, et ne peut proposer une interprétation différente, en sorte que l'objet du jugement de constitutionnalité est nécessairement l'interprétation consolidée de la loi ${ }^{37}$ - a été amenée à se prononcer sur cette articulation. De manière générale, elle précise certes que le juge a quo doit apprécier tous précédents utiles, alors même qu'ils ne révèleraient pas encore une orientation interprétative consolidée. Dans l'ordonnance $\mathrm{n}^{\circ} 222$ du 4 juillet 2011, par exemple, elle observe que «le juge de renvoi n'a pas pris en considération une autre orientation de la jurisprudence administrative, abstraction faite de savoir s'il s'agit ou pas d'un droit vivant, omettant ainsi d'envisager la possibilité de parvenir, par voie interprétative, à la solution qu'il aurait pu estimer conforme à la Constitution $»^{38}$.

L'hypothèse est différente si l'existence d'un droit vivant ne fait aucun doute. Dans son arrêt n 350 du 13 novembre 1997, la Cour constitutionnelle a, en effet, estimé que le juge de renvoi pouvait certes accueillir cette interprétation consolidée de la loi. Toutefois, elle l'incite à s'en abstraire dans l'hypothèse où il estime qu'elle est contraire à la Constitution et l'encourage ainsi à dégager de la loi une interprétation différente et conforme aux exigences constitutionnelles. Elle précise en effet que s'il est vrai qu'il « n'existe, dans le système en vigueur, aucune obligation, pour le juge du fond, de se conformer aux orientations de la Cour de cassation (sauf hypothèse où sont en cause des jugements de renvoi), il est également vrai que lorsque des orientations sont consolidées de manière stable dans

\footnotetext{
35 Cour const., ord., n 322 du 11 décembre 2013, Giur. cost., 2013, p. 5075 et s. Voir aussi les ordonnances n 205 du 9 juillet 2014 , Giur. cost., 2014, p. 3301 et s., n 92 du 19 avril 2015, Giur. cost., 2015, p. 784 et s., et nº 161 du 24 juin 2015, Giur. cost., 2015, p. 1315 et s..

36 C. Severino, La doctrine du droit vivant, Paris-Aix-en-Provence, PUAM-Economica, 2003. G. ZAGREBELSKY, « La doctrine du droit vivant », $A I f C$, vol. II, 1986, p. 55 et s.

37 On sait que cette auto-limitation de la Cour constitutionnelle a fait suite à ce que l'on a appelé la " guerre des deux cours », due à la concurrence entre la Consulta et la Cour de cassation dans l'interprétation des lois ; voir N. Assini, L'ogetto del giudizio di costituzionalità e la « guerra delle due Corti », Milan, Giuffrè, 1973. Pour des précisions sur ce point, G. ZAGREBELSKY, « La doctrine du droit vivant », op .cit., évoquant les « interprétations militantes » de la Cour constitutionnelle (p. 68). En renonçant, dans les années 1970, à adopter des interprétations de lois qui auraient été en contraste avec celles issues de la jurisprudence dominante, spécialement celles de la Cour de cassation, la Cour constitutionnelle a ainsi signé un armistice salutaire pour les rapports entre elle et les juges ordinaires.

38 Cour const., ord. $\mathrm{n}^{\circ} 222 \mathrm{du} 4$ juillet 2011, Giur. cost., 2011, p. 2876 et s.
} 
la jurisprudence - au point de revêtir les traits d'un «droit vivant» - il est possible que la norme telle qu'interprétée par la Cour de cassation et les juges du fond soit soumise à l'examen de constitutionnalité, puisque, ainsi enracinée dans l'ordonnancement, elle ne peut être modifiée sans l'intervention du législateur ou de cette Cour. En d'autres termes, poursuit-elle, en présence d'un droit vivant, non accueilli par le juge a quo qui le considère inconstitutionnel, celui-ci a la faculté de choisir entre l'adoption, toujours permise, d'une interprétation différente [et conforme à la Constitution] ou - retenant le droit vivant - la transmission de la question à la Cour ; en revanche, en l'absence d'un doit vivant, le juge de renvoi a le devoir d'adopter l'interprétation conforme aux principes constitutionnels ${ }^{39}$.

Dès lors, il faut bien comprendre que si le juge a quo estime que le droit vivant est en contradiction avec la Constitution, il dispose d'une faculté clairement et, depuis lors, constamment exprimée par la Cour constitutionnelle. L'obligation d'interprétation conforme de la loi à la Constitution laisse donc place dans cette hypothèse à un choix dont dispose le juge de renvoi. C'est ce que la Cour rappelle, en termes généraux, dans l'arrêt n 242 du 22 octobre 2014 en précisant « qu'en présence d'une orientation jurisprudentielle consolidée, le juge a quo - s'il est libre de ne pas la partager et de proposer une exégèse différente, le caractère vivant de la norme étant un phénomène par définition ouvert - $a$, de manière alternative, la faculté d'assumer l'interprétation contestée en termes de «droit vivant» et de demander sur cette base le contrôle de compatibilité avec les paramètres de constitutionnalité $»^{40}$. Elle rejette ainsi l'exception d'irrecevabilité soulevée par le président du Conseil des ministres tenant à l'inexistence d'un droit vivant, en précisant que « la jurisprudence administrative s'est désormais fermement consolidée [...] au point d'assumer les caractères d'un vrai et propre droit vivant, comme le démontre une série importante de décisions du Conseil d'État, toutes de même signe $»^{41}$.

En revanche, on devine aisément que lorsque, dans cette hypothèse, l'interprétation conforme de la loi à la Constitution n'est pas possible, malgré les efforts entrepris par le juge de renvoi pour la dégager, ce dernier n'aura d'autres ressources que de transmettre à la Cour la question de constitutionnalité portant sur le droit vivant qu'il estime inconstitutionnel. Dès lors, tertium non datur : soit la disposition législative ne fait l'objet d'aucune interprétation consolidée ou véritablement consolidée (il n'y a donc pas de droit vivant ou de droit vivant incontestable) et le juge a quo est alors dans l'obligation de fournir - si possible - une interprétation conforme de la loi sous peine d'être « sanctionné » par la Cour constitutionnelle ; soit, à l'inverse, le droit vivant existe indubitablement et le juge a quo, s'il estime que ce droit vivant est inconstitutionnel, dispose alors d'un choix : soit s'efforcer de proposer une interprétation différente de la loi conforme à la Constitution (si elle est possible), soit transmettre à la Cour la question de constitutionnalité de ce droit vivant. Ainsi, la Consulta semble trouver un point d'équilibre entre interprétation conforme et respect du droit vivant même si, on le constate, l'existence d'un droit vivant peut être contournée par le juge ordinaire.

\footnotetext{
39 Cour const., sent. $\mathrm{n}^{\circ} 350 \mathrm{du} 13$ novembre 1997, Giur. cost., 1997, p. 3435 et s.

40 Cour const, ord. n 242 du 22 octobre 2014, Giur. cost., 2014, p. 4004 et s. (cons. en droit n 2). Idem dans l'arrêt nº 11 du 9 février 2015 , Giur. cost., 2015, 108 et s. (cons. en droit n ${ }^{\circ}$ 3) et dans l'ordonnance n ${ }^{\circ} 201$ du 23 septembre 2015, Giur. cost., 2015, p. 1627 et s.

41 Cons. en droit $n^{\circ} 2$.
} 
On ajoutera que, évidemment, l'inexacte reconstruction du droit vivant par le juge a quo provoque l'irrecevabilité de la question. Ainsi, par l'ordonnance n 96 du 9 avril 2014, la Cour précise que « le juge de renvoi a élevé au rang de «droit vivant» une orientation interprétative exprimée par deux décisions des sections isolées de la Cour de cassation, adoptées dans un intervalle de plusieurs années [...] : orientation, dit-elle, dont les postulats sont en contradiction ouverte avec le courant interprétatif consolidé $»^{42}$.

Finalement, le choix opéré en 1996 par la Cour constitutionnelle se traduit par une jurisprudence aujourd'hui stabilisée, mais qui, assurément, reste largement commentée en doctrine. Il ne faut d'ailleurs point s'en étonner si l'on considère que, par son contrôle incisif de l'ordonnance de renvoi, la Cour rend possible, sans avoir aucune prise sur le résultat interprétatif issu de l'esprit des juges, une altération du contrôle incident de constitutionnalité.

\section{L'altération possible du contrôle incident de constitutionnalité}

Force est de constater que le changement de route opéré par la Cour constitutionnelle a suscité de nombreuses préoccupations et moult réflexions doctrinales portant sur la possible altération du cadre général du système. La question du sens à assigner à l'obligation de l'interprétation conforme de la loi à la Constitution a été largement discutée avant que la Cour constitutionnelle elle-même indique, sans surprise, que le principe de suprématie constitutionnelle était au fondement d'une telle obligation (A). Pour aussi logique et attendue qu'elle soit, la consécration d'un tel principe conduit, à l'évidence, à une nouvelle configuration des rapports entre des juges (ordinaires) dont, assurément, la responsabilité interprétative est renforcée et les juges constitutionnels. De ce point de vue, et au regard de certains risques liés aux excès possibles dans la lecture des textes, la question se pose des moyens dont dispose la Cour constitutionnelle pour assurer la régulation des interprétations conformes (B).

\section{A. Le sens de l'obligation de l'interprétation conforme de la loi à la Constitution : le principe de suprématie constitutionnelle}

La Cour constitutionnelle, dans l'arrêt n ${ }^{\circ} 356$ de 1996, n'apporte aucune explication sur la nouvelle «politique » qu'elle entend mettre en place. De fait, plusieurs thèses, plus ou moins pertinentes, ont été avancées sur le plan doctrinal dont la finalité était de fournir un sens, en même temps qu'un fondement ${ }^{43}$, à l'obligation pesant sur les juges d'identifier une interprétation conforme de la loi à la Constitution.

Une partie de la doctrine a considéré que le changement de perspective opéré par la Cour était lié à des exigences purement contingentes, la Consulta, en imposant l'obligation en cause,

42 Cour const., ord., n ${ }^{\circ} 96$ du 9 avril 2014, Giur. cost., 2014, p. 1703 et s. Idem dans l'arrêt nº 11 du 9 février 2015 précité où la Cour juge infondée une question de constitutionnalité pour «interprétation erronée de la norme contestée par le juge de renvoi » qui a présupposé un droit vivant introuvable dans la jurisprudence de nomofilachia (cons. en droit $\mathrm{n}^{\circ} 4$ ).

43 Sur ce point, A. RUGGERI, «Alla ricerca del fondamento dell'interpretazione conforme », in Interpretazione conforme e tecniche argomentative, in M. D’Amico, B. RANDAzzo (dir.), op. cit., p. 388 et s. 
ayant cherché à obtenir une « déflation »du contentieux pesant sur elle ${ }^{44}$. Dès lors, en effet, que le juge a quo omet ou s'efforce insuffisamment de dégager une interprétation conforme de la loi à la Constitution, elle rend des décisions d'irrecevabilité (éventuellement manifestes) pour « effort interprétatif insuffisant », se « débarrassant » ainsi, en chambre du conseil, du problème sans autres formalités. Force est cependant de constater que cette thèse est fragile et n'est en aucun cas partagée par ceux qui observent que, dans les années 90, l'arriéré de la Cour, dû au procès Lockheed, était tout à fait stabilisé ${ }^{45}$. En réalité, ce sont sans doute des motivations d'ordre substantiel qui ont conduit la Cour constitutionnelle à opérer ce changement d'orientation. De ce point de vue, plusieurs thèses explicatives ont, là encore, été avancées par la doctrine avant que la Cour constitutionnelle vienne elle-même fournir la «solution » au problème.

Il a d'abord été observé que, certes sans le dire, la Haute Instance, en 1996, s'était appuyée sur le principe de conservation des actes juridiques, dérivant de l'adage latin Actus interpretandus est potius ut valeat quam ut pereat ${ }^{46}$, et qui, inscrit à l'article 1367 du code civil - équivalent de l'article 1157 du code civil français - porte sur la matière contractuelle ${ }^{47}$. Ce principe serait ainsi au fondement de l'interprétation conforme en même temps que, pour certains, il en constituerait la limite ${ }^{48}$. De fait, ce principe - fondant assurément une méthode d'interprétation - est régulièrement sollicité par la Cour constitutionnelle ${ }^{49}$ qui le considère comme faisant partie des " canons herméneutiques généraux » auxquels elle a recours. Ainsi lit-on, dans l'arrêt n 368 du 9 juillet 1992, que « cette Cour a, en effet, constamment affirmé que le principe de conservation des valeurs juridiques [...] impose le maintien en vie d'une disposition de loi, lorsque l'on peut reconnaître à celle-ci au moins une signification conforme à la Constitution $»^{50}$. Le continuum jurisprudentiel est ainsi établi et l'on perçoit assurément les liens intimes qui unissent le principe de conservation des actes juridiques (en l'occurrence les lois) et l'interprétation conforme à la Constitution.

D'autres membres de la doctrine ont mis l'accent sur l'existence d'un principe de présomption de constitutionnalité des lois pour expliquer le canon de l'interprétation conforme ${ }^{51}$. Selon cette thèse, proche d'ailleurs de celle impliquée par le principe de conservation des actes juridiques, la

\footnotetext{
44 M. Fierro, R. Nevola, I. Morelli, M. Fulgenzi (dir.), L'interpretazione adeguatrice e l'obbligo del rimettente di ricercare un'interpretazione costituzionalmente orientata della norma censurata, op. cit., p. 7.

45 En ce sens, M. Boni, « Le pronunce... », op. cit., p. 59-60. Sur le procès Lockheed impliquant la responsabilité pénale de deux ministres italiens, voir Processo Lockheed, suppl. Giur. cost., $\mathrm{n}^{\circ} 10,1979$.

46 L'adage utile per inutile non vitiatur renvoie à la même idée.

47 Article 1367 du code civil (« Conservation du contrat ») : «En cas de doute, le contrat ou les clauses particulières doivent être interprétés de manière à produire leurs effets et non de façon à n'en produire aucun ». De cet avis, A. PACE, «I limiti dell'interpretazione «adeguatrice», Giur. cost., 1963, p. 1070 et s. ; G. Sorrenti qui, toutefois, considère que c'est seulement dans le cas où la signification de la norme-paramètre est univoque et où il y a une orientation jurisprudentielle uniforme sur la disposition contestée que cette hypothèse serait valide (ce qui pose la question des normes constitutionnelles dont l'ouverture interdit les solutions univoques puisque, par hypothèse, plusieurs interprétations conformes à une seule norme constitutionnelle seraient envisageables, ce qui mettrait à mal le principe de certitude juridique et le souci d'unification jurisprudentielle), L'interpretazione conforme... op. cit., p. 143.

48 Sur les limites évoquées, A. PAcE qui s'appuie sur le fait que les décisions des juges a quibus n'ont pas d'effets erga omnes, in «I limiti dell'interpretazione «adeguatrice»», Giur. cost., 1963, p. 1073.

49 En ce sens, Th. Di MANno, « L'impossibilité de l'interprétation conforme de la loi... », op. cit., p. 131.

50 Cour const., sent., n 368 du 9 juillet 1992, Giur. cost., 1992, p. 2935 (cons. en droit n 3).

51 En ce sens, M. Ruotolo, Interpretazione conforme e tecniche decisorie, op. cit. p. 14 et s. qui met l'accent sur l'opportunité d'une valorisation de la pratique de l'interprétation conforme « dans la mesure où elle permet une meilleure conscience de la part du juge de la possibilité d'appliquer directement la Constitution, lorsque c'est tehniquement envisageable, soit pour combler les lacunes de l'ordonnancement - comme cela est arrivé, par exemple, dans la récente affaire Englaro - soit pour interpréter les lois selon les préceptes que l'on peut en déduire ».
} 
validité de la loi, jusqu'à preuve du contraire, sous-tend l'idée que « la déclaration d'inconstitutionnalité pure et simple ne peut être qu'une extrema ratio, ne pouvant être envisagée que lorsqu'il n'est pas possible de «sauvegarder la loi» au moyen d'interprétations ou «manipulations» [...] $»^{52}$. L'idée, à la base de ce raisonnement, est simple, qui consiste à considérer que lorsque la lecture de la loi offre deux sens possibles, il convient de présumer que l'intention du législateur correspond au sens qui est en harmonie avec les dispositions constitutionnelles et non au sens contraire.

Enfin, il y a ceux qui, considérant que l'interprétation conforme est une composante de l'interprétation systématique ${ }^{53}$, fondent cette hypothèse sur le principe de cohérence de l'ordonnancement $^{54}$. Cette position de principe n'exclut cependant pas certaines nuances, portant principalement sur la manière d'envisager le rapport entre interprétation et respect de la hiérarchie formelle, la question étant de savoir si la logique hiérarchique est présente au moment de la « soudure » que réalise l'interprétation conforme entre légalité légale et légalité constitutionnelle ${ }^{55}$.

À ce stade, toutefois, les explications avancées ne permettent pas de justifier que la Cour constitutionnelle ait rendu obligatoire, pour le juge a quo, la recherche d'une interprétation de la loi conforme à la Constitution. Le «saut qualitatif » entre la faculté et l'obligation devait donc trouver une raison plus convaincante que, finalement, la Cour constitutionnelle a décidé de fournir dans l'arrêt n 113 du 13 avril 2000. À cette occasion, elle affirme solennellement que « doit être retenu comme un canon herméneutique prééminent le principe de la suprématie constitutionnelle [...] qui impose [...] à l'interprète d'opter, parmi plusieurs solutions abstraitement possibles, pour celle qui rend la disposition conforme à la Constitution $»^{56}$. La Cour indique donc que l'interprétation conforme à la Constitution trouve son origine dans le principe de suprématie constitutionnelle et que ce canon herméneutique prééminent concerne tout interprète, en premier lieu les juges ordinaires. Tout bien considéré, cette prise de position rejoint celle exprimée par G. Zagrebelsky selon lequel « si les normes de la Constitution forment un système avec les normes législatives avec une valeur de condition [...], il n' y a alors aucune raison d'exclure que le juge ordinaire, avant de soulever la question, soumette la loi à son interprétation selon le critère systématique », en sorte que si peut

\footnotetext{
$52 \quad$ Ibid. p. 15. En ce sens, G. Zagrebelsky, La legge e la sua giustizia, Bologne, Il Mulino, 2009, p. 257 et s., pour lequel « la "faillite de l'interprétation" se constate lorsqu'il n'est pas possible de trouver dans l'ordonnancement, tel qu'il existe, une norme propre à répondre aux attentes constitutionnelles de régulation du cas concret ». Ainsi, « l'inconstitutionnalité est la faillite de l'interprétation et la déclaration d'inconstitutionnalité se fait en fonction du succès de l'interprétation. La juridiction constitutionnelle sur les lois apparaît dès lors, dans sa lumière essentiellement interprétative, comme fonction de secours à l'interprétation lorsqu'elle est accrochée dans des normes inadéquates desquelles il faut la libérer ».

53 L'interprétation systématique permet d'attribuer à une disposition un sens à la lumière de sa place dans le système des normes. Certains auteurs considèrent que l'interprétation systématique n'est pas nécessairement en contradiction avec l'interprétation littérale. Ainsi, E. DicıotTi pour qui « dans un document, la signification littérale de chaque énoncé dépend de celle des autres énoncés qui le précèdent et le suivent. Dès lors, on peut affirmer que ce principe légitime également certaines opérations que l'on inclut d'ordinaire dans la méthode systématique de l'interprétation », in Interpretazione della legge e discorso razionale, Turin, Giappichelli, 1999, p. 303. En d'autres termes, l'interprétation littérale et l'interprétation systématique se caractérisent par différentes particularités (non opposées) du même processus de signification : « par la locution "interprétation littérale", on insiste sur la condition (méthodologique) de la textualité [...] du processus de signification, mais aussi sur l'importance primaire (et préjudicielle) de cette dernière sur un énoncé normatif spécifique ; par l'expression "interprétation systématique”, à l'inverse, on souligne la condition (méthodologique) d'une considération adéquate du contexte (relatif au document et à l'ordonnancement), au sein des mesures respectives et du même processus » (A. VIGnUdELLI, Interpretazione e Costituzione, Turin, Giappichelli, 2011, p. 246).

54 R. BIN, «L'applicazione diretta della Costituzione [...] », op. cit., p. 4 et s. ; O. ChessA, « Non manifesta infondatezza versus interpretazione adeguatrice? », in M. D’Amico, B . RANDAZzo (dir.), Interpretazione conforme e tecniche argomentative, op. cit. p. 266 et s.

55 Sur ce point, O. Chessa, « Drittwirkung e interpretazione : brevi osservazioni su un caso emblematico », in Il giudizio sulle leggi e la sua «diffusione», (dir.) E. Malfatti, R. Romboli, E. Rossi, Turin, Giappichelli, 2002, p. 425.

56 Cour const., sent., $\mathrm{n}^{\circ} 113 \mathrm{du} 13$ avril 2000, Giur. cost., 2000, p. 2000 (cons. en droit n 3).
} 
être envisagée « une interprétation conforme de la loi de la part du juge a quo, il ne s'agira pas alors d'une vraie question de constitutionnalité, mais plutôt d'une question d'interprétation faisant partie des pouvoirs normaux (et devoirs) de l'autorité judiciaire $»^{57}$.

Ainsi entendue, la force prescriptive de la contrainte de l'interprétation conforme est liée à l'idée selon laquelle la source supérieure - le texte constitutionnel, acte normatif à part entière - doit prévaloir sur la source inférieure, laquelle doit être interprétée en conformité avec la première afin d'éviter l'antinomie entre elles. Partant, l'interprète - le juge ordinaire en l'occurrence - n'est plus libre de choisir, il doit appliquer le critère de l'interprétation conforme ${ }^{58}$. La conséquence évidente est que « l'interprétation conforme à la Constitution, parce qu'elle découle de la supériorité de la Constitution, se présente [...] comme un outil efficace qui permet d'assurer l'unité du droit à partir et autour de la Constitution [...]. La Constitution n'apparaît pas seulement comme une limite à la loi, mais également comme une norme véhiculant des valeurs irradiant l'ensemble du système normatif. Dès lors, la technique de l'interprétation conforme à la Constitution apparaît comme le meilleur outil de diffusion de la Constitution dans toutes les branches du droit $»^{59}$.

Mais ce n'est pas tout, dans la mesure où l'interprétation conforme de la loi à la Constitution, parce qu'elle est aujourd'hui une obligation pour les juges ordinaires, engendre sans contredit une « responsabilisation interprétative ${ }^{60}$ accrue de ceux-ci, investis qu'ils sont du rôle impérieux d'interprètes constitutionnellement obligés. On comprend ainsi que les traits du contrôle incident de constitutionnalité des lois aient été substantiellement redessinés par le choix opéré par la Cour, ce qui, à l'évidence, emporte une nouvelle configuration des rapports entre les juges et la Cour constitutionnelle. La question se pose cependant des risques toujours possibles d'abus dans la lecture que font les juges ordinaires des textes législatifs, partant des moyens dont dispose la Cour constitutionnelle pour assurer la régulation des interprétations conformes.

\section{B. La régulation des interprétations conformes par la Cour constitutionnelle}

On ne s'étonnera pas du fait que, par ses importantes implications, le choix de la Cour constitutionnelle ait fait l'objet de nombreuses interprétations, interprétations dont la substance doit être évoquée à grands traits.

\footnotetext{
57 G. Zagrebelsky, V. MARCenò, Giustizia costituzionale, op. cit., p. 293.

58 En ce sens, R. Bin, « L'applicazione diretta della Costituzione », op. cit., spéc. p. 5. L'auteur constate donc que « le résultat est que la "norme du cas" que le juge applique dans sa décision pourra avoir une origine complexe, c'est-à-dire être formée de "sens" déduits tant de la loi ordinaire que de la Constitution [...] ». Ce n'est que lorsque la « soudure » entre les deux sources n'est pas possible [...] que « l'intervention "demolitorio" de la Cour constitutionnelle est indispensable ». Considérant qu'il n'est pas envisageable de distinguer entre droit constitutionnel par principes et droit législatif par règles aux fins d'identification de la norme propre à régir le cas concret, G. ZAGREBELSKY, Il diritto mite [...], op. cit., p. 147 et s. Contra, G. GuASTIni, L’interpretazione dei documenti normativi, Milano, Giuffrè 2004, spéc. p. 295, qui estime qu'entre l'interprétation de la loi et l'interprétation de la Constitution, il existe un rapport de spécialité.

59 Th. Di MAnno, « L'impossibilité... », op. cit., p. 132-133.

60 Selon la formule de V. MARCENò, « Le ordinanze di manifesta inamissibilità per «insufficiente sforzo interpretativo» [...], op. cit., p . 795. Cette idée de responsabilisation des juges ordinaires avait déjà été exprimée par M. LuciAni in Le decisioni processuali e la logica del giudizio costituzionale incidentale, Padoue, Cedam, 1984, p. 271-272 qui se référait à la production du droit vivant, à la contribution à l'interprétation conforme des lois à la Constitution et à la fixation plus précise que par le passé du thema decidendum du jugement incident.
} 
Selon E. Lamarque, l'irrecevabilité des questions posées sans « effort interprétatif suffisant » de la part du juge a quo « traduit la conception selon laquelle l'interprétation conforme à la Constitution est le monopole exclusif des juges et, de manière spéculative, emporte négation du fait qu'une telle activité puisse relever de la compétence de la Cour $»^{61}$. Ne pouvant se résoudre à cette situation, l'auteur juge qu'il serait préférable que la Cour ait recours à une décision d'infondatezza dans la mesure où celle-ci, à la différence de la décision d'irrecevabilité, suppose que « ce devoir d'interprétation conforme incombe aussi à la Cour de manière subsidiaire étant entendu qu'il doit certes se concilier avec celui des juges $»^{62}$. D'autres auteurs ont pu considérer qu'avec l'obligation en cause, la Cour a « introduit dans notre système un type de contrôle diffus de constitutionnalité, qui ne redevient concentré que lorsqu'il est impossible de manipuler les textes du législateur et qu'il ne reste dès lors qu'à les démolir $»^{63}$. Certains enfin, adoptant une lecture moins radicale, considèrent qu'il n'existe pas une différence dogmatique fondamentale entre une décision d'irrecevabilité pour effort interprétatif insuffisant et une décision interprétative d'infondatezza. Certes, ces derniers reconnaissent que l'on assiste à une « atténuation du monopole du contrôle (concentré) de constitutionnalité des lois attribué à la (seule) Cour constitutionnelle, atténuation fondée [...] sur la conciliation entre deux principes constitutionnels fondamentaux, celui de supériorité globale de la Constitution sur l'entier univers normatif [...] et celui du «monopole» du contrôle des lois attribué à la Cour ». Mais ils nient avec force que l'on puisse se trouver face à un contrôle diffus, en considérant qu'il s'agit plus probablement d'un « contrôle de type collaboratif $»^{64}$.

En réalité, et quelle que soit la pertinence de ces opinions, les termes du débat peuvent être résumés de la manière suivante : la Cour constitutionnelle conserve sans contredit le monopole du contrôle de constitutionnalité des lois, mais, du fait de son choix, elle ne détient pas (ou plus) celui de l'interprétation conforme à la Constitution. Partant, l'obligation imposée au juge ordinaire d'interpréter les lois conformément à la Constitution a pour effet (constaté) de « décentraliser » le contrôle de constitutionnalité et de faire de ce juge un concurrent sérieux de la Cour constitutionnelle. La question (redoutable) qui n'a pas manqué d'être posée ${ }^{65}$ est alors de savoir si l'on peut faire le départ, dans l'activité des juges a quibus, entre une interprétation conforme " raisonnable » et une interprétation conforme qui ne le serait pas, parce que, dépassant certaines limites, elle confinerait à un contrôle diffus qui, au surplus, irait « au-delà du possible », c'est-à-dire au-delà de la lettre du texte ${ }^{66}$ :

61 E. LAMARQUE, « Una sentenza «interpretativa di inamissibilità»», op. cit., p. 3118 (les italiques sont dans le texte).

62 Ibid.

63 G.-U. Rescigno, « Del preteso principio secondo cui spetta ai giudici ricavare principi dalle sentenze della Corte e manipolare essi stessi direttamente le disposizione di legge per renderle conformi a tali principi », Giur. cost., 2009, p. 2413.

64 F. Modugno, «Inammissibilità della quaestio legitimatis per omessa interpretazione costituzionalmente conforme e bilanciamento in concreto di diverse esigenze costituzionali », Giur. cost., 2009, p. 2405 et s. (les italiques sont dans le texte). L'auteur considère d'ailleurs, en substance, que la décision d'irrecevabilité est plus pertinente et plus significative que la décision interprétative de rejet dans la mesure où, alors que cette dernière identifie l'interprétation qui permet de ne pas considérer la norme inconstitutionnelle, la première, en déclarant la question irrecevable, traduit l'idée selon laquelle la Cour n'a pas été correctement interpellée.

65 M. LUCIANI, estimant incompatible l'activité d'interprétation conforme avec le caractère concentré de la justice constitutionnelle italienne, observait que « l'extrême rigueur de la jurisprudence sur la (manifeste !) irrecevabilité des questions soulevées sans qu'il ait été procédé à une interprétation conforme à la Constitution a implicitement poussé les juges ordinaires à faire un usage assez incisif (pour ne pas dire excessif) de ce paradigme, ce qui a provoqué la crise du caractère incident du contrôle et coloré de forts éléments diffus notre système de contrôle concentré », in «Le funzione sistemiche [...] », op. cit., p.9.

66 Pour l'identification de certains cas d'excès dans l'interprétation conforme, M. Ruotolo, « Oltre i confini dell'interpretazione costituzionalmente conforme ? A proposito della pronuncia della Cassazione sulla presunzione di adeguatezza della custodia cautelare in carcere per il delitto di violenza sessuale di gruppo », www.rivistaaic.it, n. 2, 2012. G. Pistorio, notamment, considère que la lettre de la loi fait 
dans ce cas, il y aurait manipulation du droit pour le rendre conforme à la Constitution ou, pour le dire comme R. Bin, l'interprétation littérale serait supplantée par «l'interprétation artificielle » ${ }^{67}$. Or, la détermination de cette frontière (poreuse) ne peut, dans un système concentré de constitutionnalité des lois, revenir qu'à la Cour constitutionnelle elle-même, organe de « clôture » du système. C'est elle en effet qui, en théorie, doit pousser le curseur jusqu'au point au-delà duquel l'interprétation conforme retenue par le juge ordinaire ne serait pas admissible. Ainsi, « [...] la Cour constitutionnelle doit $[\ldots]$ toujours pouvoir intervenir pour redresser des interprétations constitutionnellement conformes qui manifesteraient l'usurpation par les juges ordinaires du contrôle de constitutionnalité des lois $»^{68}$.

Le problème est néanmoins de savoir si, en l'absence de recours direct ouvert aux particuliers ${ }^{69}$, la Cour constitutionnelle a les moyens de « contrer » l'usage abusif, par les juges ordinaires, de l'interprétation conforme de la loi à la Constitution ${ }^{70}$. Certes, la question reste sans doute assez théorique lorsque c'est un juge « inférieur » qui abuse du «pouvoir » d'interprétation : dans ce cas, en effet, on imagine aisément que les juridictions supérieures - notamment la Cour de cassation ne manqueraient pas de redresser cet abus. Mais la question devient très sensible si c'est la Cour de cassation elle-même, organe qui détient la fonction nomofilattica ${ }^{71}$ (ou nomofilachia), qui abuse du pouvoir d'interprétation conforme. Dans ce cas, si l'on met de côté l'hypothèse d'un juge du fond audacieux qui défierait la juridiction suprême ${ }^{72}$, seule la procédure - d'application incertaine en

fonction de limite explicite à l'interprétation conforme de la loi à la Constitution, in Interpretazioni e giudici. Il caso dell'interpretazione conforme al diritto dell'Unione Europea, Naples, Editoriale scientifica, 2012, p. 55 et s. En ce sens, Th. Di ManNo qui, pour répondre à cette question, considère que « la technique de l'interprétation conforme doit nécessairement être cantonnée dans des limites qui tiennent à la «texture» de la disposition législative en cause ». Selon lui, « la technique de l'interprétation conforme ne peut servir à dégager de la loi que ce qui s'y trouve, même à l'état latent, et non pas ce qu'il serait souhaitable d'y trouver, pour répondre aux exigences constitutionnelles. En d'autres termes, la technique de l'interprétation conforme ne saurait permettre, sous couvert de favoriser le respect du principe de suprématie constitutionnelle, de réécrire la loi » (les italiques sont dans le texte). Il observe qu'en France, c'est « un autre critère qui a été mis en avant pour fixer la frontière entre l'interprétation constitutionnellement conforme permise et l'interprétation constitutionnellement conforme interdite aux juridictions ordinaires suprêmes dans le filtrage des QPC. Ce critère serait celui du caractère inédit ou non de l'interprétation conforme dégagée par le juge ordinaire. En d'autres termes, le juge ordinaire pourrait pratiquer l'interprétation conforme de la loi et, donc s'abstenir de renvoyer une QPC au Conseil constitutionnel, tant qu'il s'appuierait sur sa jurisprudence déjà éprouvée relativement à cette loi ou tant qu'il s'inspirerait fidèlement d'une jurisprudence constante du Conseil constitutionnel », in « L'impossibilité... », op. cit. p. 145.

67 R. BIN, «L'interpretazione conforme. Due o tre cose che so di lei », www.robertobin.it., p. 2.

68 Th. Di MAnno, «L'impossibilité... », op. cit., p. 146. L'auteur remarquant que c'est ainsi que le système allemand de la question préjudicielle de constitutionnalité a été conçu. «En effet, si le juge ordinaire allemand doit être convaincu de l'inconstitutionnalité de la loi pour déclencher le mécanisme de la question préjudicielle de constitutionnalité, il peut être conduit, d'une manière abusive, à ne pas saisir la Cour constitutionnelle fédérale, alors même que la loi en cause pose un sérieux problème de constitutionnalité. Une telle situation peut alors être aisément compensée par une garantie procédurale qui existe dans le système allemand de justice constitutionnelle, le recours constitutionnel direct (le Bundesverfassungbeschewerde), qui permet alors à la Cour constitutionnelle de contrôler, le cas échéant, la décision par laquelle le juge ordinaire a manifesté un usage abusif de l'interprétation conforme de la loi à la Constitution ». Ainsi, « le recours direct en protection des droits fondamentaux qui est ouvert contre les décisions de justice en Allemagne permet [...] de contrebalancer le poids qui est donné aux juges ordinaires dans le déclenchement de la question préjudicielle de constitutionnalité ».

69 Pour des précisions sur cette question et, de manière générale, sur les défaillances du système des voies de recours contre le refus de soulever une question de constitutionnalité, voir P. PAssaglia, « Modèle concentré et ancrage de la Constitution [...] », op. cit., cet ouvrage.

70 On sait que le Conseil constitutionnel français est totalement démuni de ce point de vue puisque, à ce jour et malgré certaines propositions en ce sens, les décisions de non-renvoi des QPC ne sont susceptibles d'aucun recours.

71 Selon l'article 65 alinéa 1 du décret royal n 12 du 30 janvier 1941 sur l'organisation judiciaire (GU n 28 du 4 février 1941$)$, « la Cour suprême de cassation, en tant qu'organe suprême de la justice, garantit le respect et l'interprétation uniforme de la loi, l'unité du droit objectif national [...] ». L'adjectif nomofilattico dérive du grec vó $\mu$ os, qui signifie «norme », lié au verbe $\varphi v \lambda \alpha ́ \alpha \sigma \omega$, qui indique l'action de la « protéger avec le regard ».

72 L'hypothèse renvoie à la saisine, par ce juge audacieux, de la Cour constitutionnelle à laquelle il poserait la question de constitutionnalité d'une loi qui aurait fait l'objet d'une interprétation conforme de la part de la Cour de cassation, qu'il estimerait abusive. Il faut préciser, à cet égard, que la Cour constitutionnelle indique régulièrement, dans ses décisions, que, sauf hypothèse de renvoi, la jurisprudence de la Cour de cassation ne s'impose pas aux juges du fond. 
l'espèce - des conflits entre les pouvoirs de l'État pourrait être utilisée $e^{73}$, mais avec le risque de créer des tensions importantes entre les deux Cours et de réactiver une « guerre » entre elles.

Une chose est sûre et tient au fait que la Cour constitutionnelle a conscience du risque de « débordement » qui menace son rôle institutionnel. D'une manière certes sporadique, en effet, elle semble vouloir mettre un frein aux possibles ardeurs des juges ordinaires en indiquant que « la teneur univoque de la norme marque la limite en présence de laquelle l'effort interprétatif doit céder le pas au contrôle de constitutionnalité ${ }^{74} \mathrm{ou}$, dans la même veine, que « l'obligation de l'interprétation conforme pèse sur le juge dans les limites dans lesquelles elle est permise par les textes des normes $»^{75}$. De manière encore plus imagée - ce qui est peut-être le signe d'une rigueur croissante de sa part - elle n'hésite pas à traquer les interprétations « excentriques et bizarres ${ }^{76}$.

Finalement, c'est la parole du juge constitutionnel lui-même qui peut et doit permettre à l'observateur de forger sa propre opinion sur cette situation. Lors de l'important séminaire d'études organisé à la Cour constitutionnelle en $2009^{77}$, Sabino Cassesse évoquait trois pistes de réflexions pouvant justifier l'obligation de l'interprétation conforme ${ }^{78}$ : soit, disait-il, il pourrait s'agir d'une atténuation, «dans la culture européenne, du positivisme juridique », l'interprétation des juges entrant ainsi en concurrence avec la logique mécanique du normativisme ; soit, serait en cours une évolution «naturelle » des tribunaux constitutionnels - des Cours kelséniennes aux Cours marshalliennes - évolution qui renverrait au besoin d'introduire dans les systèmes concentrés de contrôle de constitutionnalité un certain degré de décentralisation »; soit, plus prosaïquement, s'exprimerait ainsi la volonté d'alléger la charge de travail de la Cour, « les juges constitutionnels [étant] surchargés de travail et [cherchant] à se libérer d'une partie de celui-ci en direction des autres juges (fonction deflattiva) ». Gaetano Silvestri, quant à lui, se fondant sur l'idée majeure de légalité constitutionnelle, défendait la thèse selon laquelle, la Constitution devenant immanente au système, l'interprétation conforme est rendue nécessaire par une lecture différente de la Constitution qui « imprègne le système selon une logique moléculaire, entre dans toutes les mailles de celui-ci et donc le caractérise, le conforme, permet et impose cette interprétation qui tient compte de cette Constitution $[\ldots] »^{79}$.

\footnotetext{
73 Deux situations potentielles ont été proposées par la doctrine. Soit, le pouvoir législatif peut, dans ce cas, élever un conflit d'attribution contre la Cour de cassation relativement à la décision juridictionnelle en cause. Cette proposition, toutefois, semble vouée à l'insuccès car si la Cour constitutionnelle admet, dans ce cadre, qu'un acte juridictionnel puisse être l'objet d'un conflit, elle pose une limite en ce qu'elle exclut que l'on puisse lui demander de censurer une error in iudicando (erreur dans l'exercice de la fonction juridictionnelle) dans la mesure où cela reviendrait à instituer un nouveau degré de juridiction (voir, en ce sens, l'ordonnance $\mathrm{n}^{\circ} 334$ du 8 octobre 2008 rendue sur le cas Englaro avec note de R. Romboli, « Il conflitto tra poteri dello Stato sulla vicenda Englaro: un caso di evidente inammissibilità », Foro it., 2009 , I, p. 49 et s.). Soit, c'est la Cour constitutionnelle elle-même qui soulève, devant elle, un tel conflit contre la Cour de cassation, arguant que celle-ci, en abusant de son pouvoir, se comporte comme un juge constitutionnel. Là encore, mais pour d'autres raisons - tenant à la logique institutionnelle - cette proposition est manifestement d'application délicate.

74 Cour const., sent., n 26 du 25 janvier 2010, Giur. cost., 2010, p. 337 et s. (cons. en droit n 2).

Cour. const., sent. $\mathrm{n}^{\circ} 150$ du 26 mai 2015, Giur. cost., 2015, p. 1284 et s. (cons. en droit nº 2.1).

Formule que la Cour constitutionnelle emploie dans l'arrêt n 36 du 13 janvier 2016, Giur. cost., 2016, p. 209 et s. (cons. en droit n 4 ).

« Corte costituzionale, giudici comuni e interpretazioni adeguatrici », Séminaire du 6 novembre 2009, op. cit.

Ibid., p. 321.

Ibid., p. 324. En ce sens, M. Luciani qui observe qu' « à travers le canon de l'interprétation constitutionnellement orientée, on permet à la Constitution de pénétrer en profondeur dans l'ordonnancement qui, par là, est imprégné de valeurs constitutionnelles, lesquelles, ainsi, ne restent pas reléguées in apicibus [au sommet] mais entrent entièrement dans le bagage culturel des opérateurs juridiques », in « Le funzioni... », op. cit., p 6.
} 
On ne saurait conclure ce propos sans exprimer, de manière synthétique, deux idées, l'une plutôt optimiste, l'autre nuançant quelque peu cet élan positif, idées qui, réflexion faite, débouchent sur un paradoxe. En premier lieu, on a largement vérifié que la Cour constitutionnelle italienne n'était plus, par sa volonté même, « dépositaire de la vérité constitutionnelle ${ }^{80}$, ayant « délaissé », pour les raisons et selon les modalités rappelées, le monopole de l'interprétation de la Constitution en la déléguant aux juges ordinaires. Sans doute, au-delà des interrogations et des inquiétudes évoquées, doit-on voir dans ce renoncement le signe d'une maturité qui, aujourd'hui, imprègne les rapports entre les juges constitutionnels et les juges ordinaires et d'une confiance des premiers envers les seconds (et réciproquement). Que des « ajustements » puissent, à l'occasion, être nécessaires afin d'assurer la régulation des interprétations conformes à la Constitution ne doit pas masquer le fait qu'il s'agit là, en théorie, d'un progrès culturel qui permet, dans l'équilibre et la collaboration qu'il suppose, une meilleure diffusion des valeurs constitutionnelles. Corrélativement, l'intrication légalité légale/légalité constitutionnelle qu'une telle évolution favorise ne fait que fragiliser encore davantage ce qu'un auteur a pu qualifier, de manière imagée, de "séparation acoustique $»^{81}$ entre juridiction ordinaire et juridiction constitutionnelle dont on sait qu'à l'évidence elle ne révèle qu'une césure artificielle et beaucoup de perméabilité. Malgré tout, en second lieu, la question peut se poser de savoir si le corps judiciaire (i.e. les juges ordinaires), à travers l'interprétation conforme, n'est pas amené, parfois, à « relégitimer » la loi en « forçant »le constat de sa constitutionnalité. Cette interrogation va au-delà de l'hypothèse déjà évoquée d'interprétations conformes qui se détacheraient par trop du texte législatif. Elle pourrait aussi - peu d'auteurs le relèvent - concerner des interprétations qui instrumentaliseraient la Constitution en lisant dans ses dispositions ce qui n'y figure guère ou pas nécessairement ${ }^{82}$ ou en dilatant à l'excès les principes constitutionnels pour satisfaire aux exigences du cas concret ${ }^{83}$. Le " prétexte de constitutionnalité » pourrait alors servir d'alibi, fût-il inconscient, aux interprétations conformes peu fondées et, par là, de verrou obstruant l'accès au juge constitutionnel. Si iconoclaste qu'une telle réflexion puisse paraître, on ne peut cependant, trop rapidement, exclure le risque au moins marginal que la spécificité de l'interprétation constitutionnelle s'accorde mal avec l'office du juge ordinaire chargé, avant tout, d'apporter une solution « raisonnable » à un litige concret ${ }^{84}$. La possibilité, pour les parties, de saisir la Cour constitutionnelle d'un recours contre les interprétations conformes des juges ordinaires serait alors sans doute nécessaire pour éviter toute

\footnotetext{
80 Selon l'expression utilisée par M.-C. Ponthoreau, « Réflexions sur le pouvoir normatif du juge constitutionnel en Europe continentale sur la base des cas allemand et italien », Les Cahiers du Conseil constitutionnel, n² 24, 2008, p. 99.

81 F. Michelman, « The interplay of constitutional and ordinary jurisdictions », in T. Ginsburg et R. Dixon (dir.), Comparative Constitutional Law, Cheltenham, Elgar Publishing, 2011, p. 279-282. M. Carpentier explique que « deux juridictions sont acoustiquement séparées dès lors qu'elles appliquent des ensembles de règles rigoureusement distincts », précisant, à l'évidence, que « les cas de séparation acoustique parfaite ne se réalisent jamais », in «Pour de nouveaux «modèles» de justice constitutionnelle », RIDC, 1-2016, p. 32.

82 Nous reprenons, en la modifiant quelque peu, la formule de M. Luciani qui écrivait que « l'interprétation conforme ne peut aller jusqu'au point de lire dans la disposition ce qui n'y figure pas, alors même que la Constitution souhaiterait cette lecture », in « Le funzioni... », op. cit., p. 7. 83 Sur ce point, G. Sorrenti, « La Costituzione «sottintesa» ... », op. cit., p. 45 et s., qui cite plusieurs exemples de décisions qui traduisent ces excès.

84 Sur cette question délicate renvoyant à une supposée division fonctionnelle du travail entre les juges ordinaires et la Cour constitutionnelle, R. Romboli, «Qualcosa di nuovo... », op. cit., p. 13. L'auteur précise que les premiers se situent sur le plan de l'application de la loi et sont donc sensibles au cas concret, alors que la seconde est placée sur le plan plus général de la constitutionnalité de la loi. Une telle division du travail tend sans doute, au moins en partie, à influer sur les canons interprétatifs utilisés par les uns et par l'autre. Dans le même sens, à propos du système allemand, P. HÄBERLE, La verfassungsbeschwerde nel sistema della giustizia costituzionale tedesca, Milan, Giuffrè, 2000 , p. 63.
} 
distorsion dans la concrétisation maladroite, désinvolte ou audacieuse des principes constitutionnels. Finalement, le paradoxe tient au fait que le contrôle pointilleux opéré par la Cour constitutionnelle sur l'obligation, pour le juge, d'interpréter la loi conformément à la Constitution ne se double d'aucun contrôle susceptible d'écarter les interprétations éventuellement peu conformes à la Constitution. On peut sans doute le regretter. 



\title{
LE CONTRÔLE DES DÉCISIONS DE JUSTICE

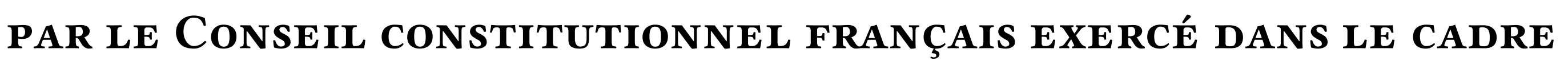 DES QUESTIONS PRIORITAIRES DE CONSTITUTIONNALITÉ
}

\author{
Bertrand MATHIEU ${ }^{1}$
}

Introduite non sans difficulté dans l'ordre juridique national, la Question prioritaire de constitutionnalité se met en place dans un contexte où l'importance accordée aux droits fondamentaux contribue à renforcer le pouvoir des juges. Ce renforcement s'accompagne, comme dans d'autres domaines $^{2}$, de conflits, plus ou moins ouverts entre les ordres juridictionnels (judiciaire, administratif et constitutionnel) s'agissant de la détermination de leur domaine de compétence.

Cette nouvelle procédure bouscule des situations acquises. La répartition des compétences s'agissant du contrôle de la loi au regard des droits et libertés fondamentaux, est alors ainsi figée : Le Conseil constitutionnel borne son intervention à un contrôle a priori de constitutionnalité de la loi, les juges, judiciaires et administratifs, s'interdisent de juger de la constitutionnalité de la loi et en revanche, ils jugent tant la loi que son application au regard des exigences conventionnelles et tout particulièrement celles de la Convention européenne des droits de l'homme.

Ainsi, la Cour de cassation, comme le Conseil d'État exercent de fait un monopole s'agissant du respect des droits et libertés fondamentaux à l'occasion de l'application de la loi. C'est cette exclusivité du contrôle de conventionnalité que la procédure de la Question prioritaire de constitutionnalité vise à remettre en cause. En recentrant d'abord, prioritairement, le contrôle sur le respect des exigences constitutionnelles, elle place le Conseil constitutionnel au centre du mécanisme. Réduits à une fonction de filtrage les juridictions les plus hautes de l'ordre judiciaire et de l'ordre administratif se trouvent de facto placées sous le contrôle du Conseil constitutionnel.

En première ligne, la Cour de cassation a estimé que cette nouvelle procédure était susceptible de remettre en cause son monopole d'interprétation de la loi et de soumettre son appréciation à celle du Conseil constitutionnel. Face aux réticences manifestées par cette même Cour à renvoyer certaines questions, ont été envisagées des procédures de contrôle de cette opération de filtrage, soit par appel

\footnotetext{
$1 \quad$ Professeur à l'École de droit de la Sorbonne Université Paris 1.

2 Cf. la question des conflits de compétence entre la Cour de cassation et le Conseil d'État à propos des mesures de police administrative prises dans le cadre de l'état d'urgence.
} 
de ses décisions, soit par autosaisine du Conseil constitutionnel, soit par « contournement » de son monopole de renvoi ${ }^{3}$.

Au delà des inévitables différences d'appréciation qui peuvent persister, la situation s'est apaisée et un équilibre a abouti à ce que l'on peut appeler une « interprétation harmonisée de la loi » .

Cet équilibre résulte d'une limitation du champ du contrôle exercé par le Conseil constitutionnel sur l'opération de filtrage opérée par le juge de renvoi. Il n'en reste pas moins qu'inévitablement le Conseil constitutionnel est conduit à exercer certaines formes de contrôles sur les décisions des juridictions de renvoi. Enfin il sera soutenu qu'un contrôle sur le caractère rétroactif de l'interprétation donnée à la loi par les juges judiciaires et administratifs s'impose.

\section{La limitation du champ du contrôle exercé sur les décisions des juridictions de renvoi}

L'équilibre tel qu'il résulte de la mise en œuvre de la procédure de la Question prioritaire de constitutionnalité (QPC), résulte à la fois d'une absence de contrôle subie par le Conseil constitutionnel et d'une absence de contrôle acceptée par le Conseil constitutionnel. La première tient au fait que le Conseil constitutionnel ne peut pas faire porter son contrôle sur l'appréciation du juge de renvoi (Conseil d'État ou Cour de cassation) selon laquelle, la question est dépourvue de caractère sérieux. La seconde résulte du fait que le Conseil constitutionnel a accepté de ne pas substituer sa propre interprétation de la disposition législative contestée à celle retenue par les juridictions de renvoi.

\section{A. Une absence de contrôle subie : le contrôle de constitutionnalité «négatif » exercé par le juge de renvoi}

La QPC a fait des juges judiciaires et administratifs des juges de la constitutionnalité de la loi. Ayant à juger du caractère sérieux de la question (ou de son caractère nouveau), le juge exerce nécessairement un premier contrôle de constitutionnalité de la loi. Superficiel (en principe) s'il s'agit de censurer l'absence de caractère sérieux pour les juges du fond, un peu plus approfondi, s'il s'agit de juger du caractère sérieux, pour les juges de renvoi. Lorsqu'il estime la question sérieuse, le juge de renvoi ne fait que transmettre une question au Conseil constitutionnel qui, seul, pourra tirer les conséquences d'une éventuelle inconstitutionnalité. En revanche, lorsqu'il estime que la question, est dépourvue de caractère sérieux, le juge de renvoi tranche lui même la question en jugeant la disposition législative contestée conforme à la Constitution. Dans ce cas, le Conseil constitutionnel ne peut intervenir qu'indirectement à l'occasion de l'examen d'une disposition législative similaire

3 C'est ainsi que peu de temps avant son départ du Conseil constitutionnel, le Président Debré avait suggéré que le Conseil puisse être saisi d'une question de constitutionnalité par le défenseur des droits.

4 Cf. B. Mathieu, « Neuf mois de jurisprudence relative à la QPC : un bilan », Pouvoirs, n 137, 2011, p. 57. 
dont il serait saisi, ou d'une précision apportée sur la portée d'une disposition constitutionnelle. Mais il ne s'agit pas à proprement parler d'un contrôle sur la décision du juge de renvoi.

Cette absence de contrôle est d'autant plus remarquable que le contrôle de constitutionnalité négatif opéré par le juge de renvoi peut être approfondi.

Il en est, notamment, ainsi, lorsque le juge de renvoi se livre à un contrôle de proportionnalité entre différentes exigences constitutionnelles. De nombreuses décisions témoignent de cette propension du juge de renvoi.

La Cour de cassation exerce directement un contrôle de proportionnalité, c'est à dire qu'elle s'immisce au cœur du mécanisme même du contrôle de constitutionnalité, lorsqu'elle juge qu'une disposition législative « ne porte pas une atteinte disproportionnée à l'objectif de valeur constitutionnelle que constitue le droit au logement » (Cass civ. 3, 16 avril 2015, n 14-25381). Le contrôle de proportionnalité exercé par la Cour de cassation est clairement illustré par la décision du 4 février 2016 (soc. $\mathrm{N}^{\circ}$ 15-21536). La Cour juge relativement à certaines dispositions du code du travail, telles qu'interprétées par elle, (art L2411-22, L 2421-1 et L 2421-2 $4^{\circ}$ concernant les incidences d'un licenciement d'un salarié protégé prononcé aux torts de l'employeur) qu'elles ne portent pas « une atteinte disproportionnée ni à la liberté d'entreprendre, ni au droit de propriété, non plus qu'au droit au maintien de l'économie des contrats légalement formés » au regard du fait que les dispositions contestées «ne visent qu'à assurer l'effectivité du droit syndical et du principe de participation justifiant que les représentants du personnel bénéficient dans l'intérêt de l'ensemble des travailleurs qu'ils représentent, d'une protection exceptionnelle ». La Cour exerce ainsi un contrôle de constitutionnalité approfondi sur sa propre jurisprudence.

Ce contrôle de proportionnalité peut prendre la forme d'un contrôle de « raisonnabilité » Ainsi dans une décision du 10 avril 2014 (soc. $\mathrm{n}^{\circ}$ 14-4008) la Cour de cassation considère que la mise à disposition par certaines entreprises d'un local commun pour les syndicats (art. L2142-8 al 1 code du travail) « constitue un équilibre raisonnable entre le besoin, pour les organisations syndicales, de disposer d'un local syndical, et la charge économique imposée à l'employeur compte tenu de la taille de l'entreprise, sans que cet équilibre ne porte atteinte à la liberté syndicale... ». Il ne s'agit pas discuter ici, au fond la solution retenue, mais sa formulation rapproche le contrôle opéré d'un contrôle d'opportunité.

De même le recours à la notion «d'atteinte substantielle » constitue de la même manière que le contrôle proportionnalité un moyen d'exercice approfondi d'un contrôle de proportionnalité. Ainsi le Conseil d'État (29 avril 2015, n 387773) pour juger que la question portant sur la constitutionnalité d'une disposition législative (art. L 1434-3-1 du code de la santé publique) assortissant le droit au recours contre le projet régional de santé, n'est pas sérieuse, au regard de la prise en compte de la complexité de la procédure d'adoption des documents en cause, des risques de multiplication de contestations sources d'insécurité juridique, et des garanties néanmoins mises place ne porte pas « une atteinte substantielle du droit des intéressés d'exercer un recours ». 
En fait, l'exercice d'un contrôle de constitutionnalité négatif est justifié lorsque le juge de renvoi estime que le principe invoqué n'est pas en cause ou que, conformément à l'autorité de chose interprétée par le Conseil constitutionnel, le principe constitutionnel n'a pas la portée que lui prête le requérant ou lorsque dans une affaire similaire le Conseil a jugé qu'il n'y avait pas violation de la Constitution. Il peut éventuellement être justifié dans l'hypothèse où le Conseil d'État observe qu'eu égard aux motifs d'intérêt général poursuivis des dispositions législatives relatives aux agents de la Polynésie française ne violent pas la liberté contractuelle des collectivités territoriales (CE 17 juillet 2013, n $\mathrm{n}^{\circ}$ 368789). Dans cette hypothèse, le juge n'opère pas, à proprement parler, une conciliation entre des exigences constitutionnelles, ce qui constitue le cœur de l'opération de contrôle de constitutionnalité, mais prend en compte la portée du principe de la liberté contractuelle qui comporte, en lui même une réserve tenant à la poursuite d'un intérêt général suffisant. En revanche, l'exercice d'un tel contrôle est plus contestable lorsque le juge de renvoi opère lui-même un contrôle du caractère justifié de l'atteinte à un principe constitutionnel et qu'il se livre alors à un véritable contrôle de proportionnalité concernant, soit la conciliation entre plusieurs exigences constitutionnelles, soit la limitation d'un principe au nom de l'intérêt général.

\section{B. Une absence de contrôle acceptée : l'interprétation de la loi par les juridictions de renvoi}

La question de la remise en cause du monopole des « Cours suprêmes », et tout particulièrement de la Cour de cassation dans l'interprétation de la loi, a été à la fois un enjeu important de la QPC et sujet de conflit, notamment entre la Cour de cassation et le Conseil constitutionnel.

Dans un premier temps, la Cour de cassation a rejeté toute question dont elle estimait qu'elle porte non sur la loi elle-même mais sur l'interprétation qu'elle lui a donnée ${ }^{5}$. Cette position aurait pu conduire la Cour de cassation à refuser de transmettre toute question portant sur une loi qu'elle a interprétée. En fait, la Cour de cassation considérait qu'elle dispose d'un monopole de l'interprétation de la loi ${ }^{6}$. Elle estimait qu'une disposition législative ne peut être critiquée en ce qu'elle laisse place à une interprétation, laquelle relève de l'office du juge.

Le Conseil constitutionnel a fait litière de l'analyse de la Cour de cassation relative à l'impossibilité de contester une disposition législative telle qu'elle l'a interprétée, en précisant dans un considérant de principe « qu'en posant une question prioritaire de constitutionnalité, tout justiciable a le droit de contester la constitutionnalité de la portée effective qu'une interprétation jurisprudentielle constante confère à cette disposition $»^{7}$.

Aujourd'hui, la jurisprudence manifeste en l'état un relatif consensus quant à la répartition des rôles entre le juge de renvoi et le Conseil constitutionnel s'agissant de l'interprétation de la loi. Dans

\footnotetext{
Cass., 19 mai 2010, arrêt n 12009

Cf. Cass.,31 mai 2010, Fédération française de rugby.

Cons. const., déc. $\mathrm{n}^{\circ}$ 2010-96 QPC.
} 
sa décision du 27 septembre $2011^{8}$, la Cour de cassation reprend la jurisprudence du Conseil constitutionnel, en précisant que «s'il a été décidé que « tout justiciable a le droit de contester la constitutionnalité de la portée effective qu'une interprétation jurisprudentielle constante confère à une disposition législative », sous la réserve que cette jurisprudence ait été soumise à la Cour suprême compétente, il résulte, tant des dispositions de l'article 61-1 de la Constitution et de l'article 23-5 de l'ordonnance $\mathrm{n}^{\circ}$ 58-1067 du 7 novembre 1958 modifiée que des décisions du Conseil constitutionnel, que la contestation doit concerner la portée que donne à une disposition législative précise l'interprétation qu'en fait la juridiction suprême de l'un ou l'autre ordre de juridiction ». En revanche, lorsque le justiciable invoque la jurisprudence elle-même de la Cour de cassation, sans dénoncer de dispositions textuelles précises, la Cour de cassation rejette la question.

On relèvera cependant que dans quelques occurrences, la Cour de cassation a refusé de renvoyer une question au regard du fait qu'elle visait une règle jurisprudentielle ne découlant pas directement d'un dispositif législatif $f^{9}$. Cette position est contestable, d'une part, en ce qu'elle interdit au justiciable de contester la règle qui lui est appliquée et en ce qu'elle manifeste une volonté de la cour de s'ériger en autorité normative autonome. En ce sens la nouvelle motivation des décisions de la Cour de cassation s'appuyant sur les précédents jurisprudentiels peut conduire à ce que la Cour prenne « le risque de s'éloigner de la loi $»^{10}$ et ainsi de justifier des non renvois.

En parallèle, le Conseil constitutionnel a renoncé à substituer sa propre interprétation à celle du législateur. Le Conseil constitutionnel s'est référé à la doctrine italienne du « droit vivant », comme le démontre le commentaire destiné à être publié aux Cahiers du Conseil de la décision 2010-39 DC ${ }^{11}$. Ainsi, dans cette décision, le Conseil constitutionnel examine la constitutionnalité de la loi « dans la portée que lui donne la jurisprudence constante de la Cour de cassation ». Le considérant de principe est le suivant : « en posant une question prioritaire de constitutionnalité, tout justiciable a le droit de contester la constitutionnalité de la portée effective qu'une interprétation jurisprudentielle constante confère à cette disposition ». Le rôle éminent de la Cour de cassation en tant qu'interprète de la loi est ainsi reconnu. En cas d'interprétation constante, ou consolidée, de la loi, le Conseil constitutionnel ne substitue pas sa propre interprétation à celle de la Cour de cassation mais apprécie la constitutionnalité de la loi telle qu'interprétée par la Cour de cassation.

On relèvera cependant que l'affirmation selon laquelle la loi est conforme à la Constitution dans l'interprétation qu'en retient le juge de renvoi permet au Conseil constitutionnel de « geler » une jurisprudence de la Cour de cassation en la constitutionnalisant.

Il n'en reste pas moins que, au delà de la rivalité qui a pu exister entre les juridictions intervenant dans le cadre de la QPC, cette procédure a renforcé l'harmonisation des jurisprudences et l'autorité des décisions du Conseil constitutionnel. De manière schématique, et sans ignorer des points

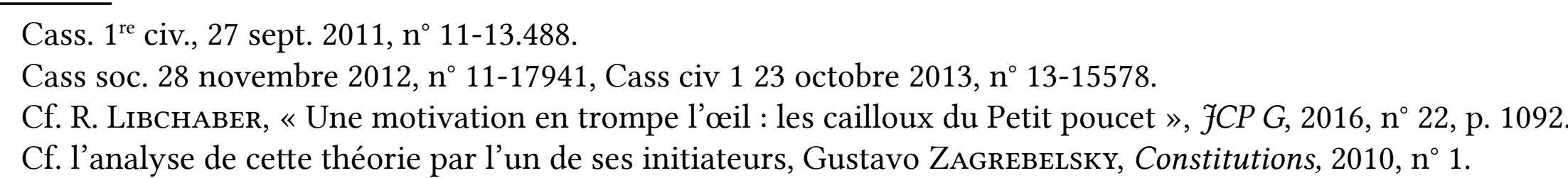


de friction, il me semble que, globalement, nous sommes passés de la querelle de l'interprétation de la loi à une interprétation harmonisée. La Cour de cassation ayant accepté de renvoyer des questions portant sur des dispositions législatives qu'elle a interprétées et le Conseil constitutionnel examinant la portée de cette disposition dans l'interprétation que lui donne le juge de l'application de la loi. Le juge judiciaire ou administratif peut lui même procéder, préventivement, à un alignement de sa jurisprudence sur les exigences constitutionnelles. Ce mécanisme « auto-correcteur » répond à l'objectif de cette nouvelle procédure qui vise à empêcher une application inconstitutionnelle de dispositions législatives. Tout cela participe à une harmonisation de l'interprétation de la loi favorisant la sécurité juridique.

\section{L'existence de contrôles indirects sur les décisions des juridictions de renvoi}

Le Conseil constitutionnel est cependant conduit à exercer un contrôle plus ou moins direct sur la jurisprudence de la Cour de cassation et du Conseil d'État. Ce contrôle résulte d'abord de l'autorité de chose interprétée reconnue aux décisions du Conseil constitutionnel. Nous ne développerons pas cette question ici $^{12}$.

Moins indirectement, elle peut résulter d'un contrôle de la qualification de l'acte pris sur la base de la disposition contestée opérée par la juridiction de renvoi. Elle peut également porter sur l'appréciation du changement de circonstances qui justifierait un réexamen de dispositions jugées conformes à la Constitution par le Conseil constitutionnel. Enfin, bien qu'il en fasse un usage relativement limité le Conseil constitutionnel peut exercer un contrôle préventif sur les décisions des juges judiciaires et administratifs au moyen de réserves d'application de la disposition contestée.

\section{A. Le contrôle de la qualification opérée par le juge de renvoi}

Le respect de l'interprétation retenue par le juge de renvoi de l'acte ou de l'opération prise sur le fondement de la disposition législative contestée pourrait, dans certains cas, faire obstacle aux droits que le justiciable se voit reconnaitre en vertu de la procédure de la question prioritaire de constitutionnalité.

Cette remarque peut être illustrée au regard de la décision 2010-23 QPC par laquelle le Conseil constitutionnel a abrogé une disposition législative prévoyant la faculté d'imposer au bénéficiaire d'une autorisation de construire, des cessions gratuites de terrain, dans la limité de $10 \%$ de la superficie du terrain auquel s'applique la demande. Le Conseil d'État avait considéré que les dispositions en cause constituent « une réglementation du droit de construire » qui limite l'exercice du droit de propriété sans priver une personne de la propriété d'un bien, (décis. 11 février 2004, Schiocchet). C'est pourtant essentiellement sur le fondement d'une violation de l'article 17 DDHC que les requérants avaient mis en cause la constitutionnalité de cette disposition. Ainsi, ils demandaient au Conseil

Cf. B. MATHIEU, QPC, La jurisprudence, Lexis-nexis, 2013. 
constitutionnel d'écarter l'interprétation de la loi retenue par le Conseil d'État. Or Le Conseil constitutionnel considère que cette disposition porte potentiellement atteinte à l'article 17 DDHC et qu'elle constitue donc une dépossession. Certes, habilement, le Conseil se situe sur le terrain de l'incompétence du législateur, qui n'assure pas lui même la protection des exigences de l'article 17 DDHC. C'est alors une violation médiate des exigences de cet article qui justifie son abrogation. Il n'en reste pas moins que ce sont les exigences de l'article 17 DDHC qui sont en cause.

Si le Conseil constitutionnel avait strictement respecté l'interprétation du juge de renvoi, il aurait été conduit à considérer que les dispositions contestées ne devaient pas être interprétées comme permettant une dépossession, mais une simple réglementation du droit de construire. On peut alors supposer que l'inconstitutionnalité aurait été plus difficile à démontrer et que le justiciable n'aurait pas nécessairement obtenu satisfaction.

\section{B. Le contrôle de l'appréciation du changement de circonstances justifiant un réexamen de la constitutionnalité d'une disposition législative}

La logique de la QPC tend à faire du contrôle opéré dans ce cadre un contrôle objectif, c'est à dire un contrôle de la loi et non de son application. Ainsi, en cas de déclaration d'inconstitutionnalité, la disposition législative n'est pas seulement écartée mais elle est abrogée. De même, l'extinction, pour quelle que cause que ce soit, de l'instance à l'occasion de laquelle la question a été posée est sans conséquence sur l'examen de la question (L. org. $n^{\circ}$ 2009-1523, art. 23-8).

Cependant le filtrage opéré par le juge saisi peut conduire à une appréciation in concreto de la question de constitutionnalité. Il est en effet prévu que la juridiction saisie doit transmettre la question au Conseil d'État et à la Cour de cassation si certaines conditions sont remplies parmi lesquelles : la disposition contestée n'a pas déjà été déclarée conforme à la Constitution dans les motifs et le dispositif d'une décision du Conseil constitutionnel, sauf changement des circonstances.

La réserve tenant à ce que cette condition ne joue pas en cas de changement de circonstances a des implications importantes. En effet, elle ne vise pas seulement les circonstances de droit, mais aussi le changement des circonstances de fait. Elle permet ainsi au juge de renvoi, sous le contrôle du Conseil constitutionnel, de prendre en compte les conditions, ou le contexte, de l'application de la loi. En effet le renvoi au changement de circonstances de fait constitue une forte incitation à prendre en compte les circonstances dans lesquelles la loi a été appliquée, même si tel n'est pas l'objet direct de cette réserve.

C'est en fait non seulement la mission du législateur consistant à adapter, ou non, le droit aux évolutions de la société, c'est à dire à définir l'intérêt général qui est en cause, mais aussi la mission du juge ordinaire qui est sur ce point contrôlé par le Conseil constitutionnel. 
Il en est ainsi également lorsque le juge de renvoi prend en compte des faits sociaux pour juger du caractère nouveau de la question ${ }^{13}$. En ce sens la Cour de cassation (Civ 3, n ${ }^{\circ}$ 14-40006 du 3 avril 2014) reformule les conditions de ce critère, en précisant qu'il s'agit non seulement de l'invocation d'une disposition constitutionnelle dont le Conseil constitutionnel n'aurait pas eu encore l'occasion de faire application, mais aussi d'une question « dont il y aurait intérêt à le saisir ». Cette formulation élargit sensiblement l'appréciation en opportunité du renvoi. Mais ce pouvoir s'exerce également sous le contrôle du Conseil constitutionnel.

\section{Le contrôle préventif au moyen de réserves d'interprétation}

L'utilisation de réserves d'interprétation par le Conseil constitutionnel a été considérée, notamment par la Cour de cassation, comme menaçant son pouvoir d'interprétation de la loi. Le Conseil constitutionnel en use cependant avec modération. Une interprétation par le Conseil constitutionnel d'une disposition législative ne poserait problème que si elle mettait en cause une interprétation constante d'une disposition législative par la Cour de cassation, ce qui ne semble pas avoir été le cas.

Pourtant, les réserves d'interprétation peuvent constituer des directives d'interprétation ou d'application de la loi qui s'imposent au juge avec l'autorité de l'article 62 de la Constitution au titre des motifs qui sont le soutien nécessaire du dispositif de la décision ${ }^{14}$. Elles sont relativement fréquentes. Certaines ont pu être analysées comme constituant une intervention du Conseil constitutionnel dans le pouvoir d'interprétation de la Cour de cassation ${ }^{15}$.

Mais une réserve d'interprétation peut également être le fruit d'un dialogue constructif entre la Cour de cassation, le Conseil constitutionnel et, médiatement, la Cour européenne des droits de l'homme et conduire à palier une lacune législative. Tel est le cas dans la décision 2014-446 QPC. En matière de détention provisoire la Cour de cassation juge que la Chambre de l'instruction n'est pas tenue par le délai prévu par l'article 194CPP lorsqu'elle est saisie après cassation de l'arrêt de la première chambre de l'instruction, mais qu'elle doit cependant se prononcer dans un bref délai, en se fondant sur la Convention EDH. Dans son rapport annuel 2013, la Cour de cassation invite le législateur à étendre l'application des dispositions de l'article 194CPP à cette hypothèse. Faute d'obtenir l'intervention du législateur, la Cour de cassation renvoie au Conseil constitutionnel une QPC portant sur cette lacune de l'article $194 \mathrm{CPP}$ (c'est à dire que la disposition est contestée « en tant que ne pas »). Reprenant, sans la citer, la jurisprudence de la Cour EDH, le Conseil constitutionnel estime qu'en matière de privation de liberté, le juge doit se prononcer dans les plus brefs délais et, par une réserve d'interprétation, étend, de fait, le champ d'application de l'article 194 CPP, remédiant, sans censure, à la carence législative.

\footnotetext{
13 À propos de la définition du mariage Cass. $1^{\text {re }}$ civ., 16 nov. 2010, $\mathrm{n}^{\circ} 10-40.042$.

14 CE, 2 mars $2011, n^{\circ} 323830$.

15 Cf. E. Dreyer, JCP G 2011, 1247, p. 2238.à propos de la décision 2011-164 QPC dans laquelle le Conseil constitutionnel valide une disposition législative relative à la responsabilité des créateurs ou animateurs de sites de communication au public en ligne à raison du contenu d'un message à condition qu'elle soit interprétée comme ne permettant pas l'engagement de responsabilité si le producteur n'avait pas eu connaissance du message avant sa mise en ligne.
} 


\section{Un contrôle potentiel et nécessaire : la portée rétroactive de la loi résultant de l'interprétation jurisprudentielle}

Dans sa décision du 10 juin 2013, n 366880, le Conseil d'État renvoie au Conseil constitutionnel une question portant sur la portée de rétroactive de l'interprétation de la loi par la Cour de cassation qui, du fait de sa tardivité aurait porté atteinte à des situations légalement acquises. Le rapporteur public précise ${ }^{16}$ qu'il s'agit «d'admettre que lorsque le juge donne d'une loi une interprétation qui prend à contrepied les anticipations légitimes des acteurs, ces derniers puissent contrôler la constitutionnalité de la loi pour la période antérieure et, le cas échéant, en paralyser les effets inattendus ». Le juge constitutionnel pourrait ainsi moduler dans le temps les effets de cette interprétation au moyen d'une réserve d'interprétation. Cette jurisprudence, qui pose ainsi que l'a jugé le Conseil d'État, une question nouvelle, est pertinente. En effet la rétroactivité de la jurisprudence, tout autant que la rétroactivité de la loi peut porter atteinte à la garantie des droits affirmée par l'article 16 DDHC.

Le Conseil constitutionnel (2013-336 QPC) ne tranche en fait pas la question posée en considérant que l'interprétation jurisprudentielle contestée n'opère pas un revirement de jurisprudence et que le fait pour la société requérante de ne pas être soumise à une obligation légale ne constituait pas un droit acquis dont elle pouvait se prévaloir. La question du contrôle de la constitutionnalité des revirements de jurisprudence portant atteinte a des droits acquis reste donc posée.

Il devrait y être apporté une réponse positive. En effet, la possibilité pour le justiciable de contester la loi dans l'interprétation constante de la Cour de cassation, et à l'occasion de l'application qui lui en est faite, implique que la contestation puisse porter sur la portée rétroactive de l'interprétation jurisprudentielle, indépendamment de la substance de cette interprétation. Il ne s'agit pas de contester directement l'effet rétroactif de la jurisprudence, mais la portée rétroactive de la loi qui résulte de l'interprétation retenue par la Cour de cassation ou le Conseil d'État

Certes, il convient de considérer que nul n'a droit au maintien du droit existant et que l'immutabilité de la jurisprudence, pas plus que celle de la loi, ne relève d'aucune exigence constitutionnelle. Mais mutatis mutandis, l'analyse du Conseil constitutionnel relative à la rétroactivité de la loi, et même à son application immédiate, lorsqu'elle met en cause des conventions régulièrement conclues, des situations régulièrement acquises ou la confiance légitime, doit être ici transposée. Ainsi l'application rétroactive de la loi, comme de la jurisprudence, ne doit pas priver de garanties des exigences constitutionnelles, sur le fondement de l'article 16 de la DDHC. Le fait que cette rétroactivité ne résulte pas directement de la loi mais de la loi telle qu'interprétée par une jurisprudence constante de la Cour de cassation ne doit pas faire obstacle à l'examen de sa constitutionnalité.

16 L'auteur remercie Alexandre Lallet, rapporteur public, d'avoir bien voulu lui transmettre ses éclairantes conclusions. 
Il résulte de l'objet même de la procédure de QPC que le constituant et le législateur organique ont entendu permettre à tout justiciable de contester la disposition législative qui est effectivement applicable à son litige. Il ne s'agit ainsi ni de contester l'office du juge ni son interprétation, mais seulement de «paralyser les effets inattendus » de cette jurisprudence, pour reprendre les termes du rapporteur public sur la décision précitée du 10 juin 2013.

Dans sa décision 2013-336 QPC, le Conseil constitutionnel, tout en considérant qu'en l'espèce, la jurisprudence n'avait pas un caractère rétroactif, confirme cette analyse. Selon le commentaire de cette décision, publié sur le site du Conseil constitutionnel, «si la création de la QPC a institué un contrôle a posteriori abstrait des dispositions législatives, elle a reconnu aux justiciables le droit de contester la constitutionnalité d'une disposition législative « applicable au litige ». Ainsi, le justiciable ne s'est pas vu reconnaitre le droit de contester une norme dans une abstraction théorique qui serait distincte de l'application qui est susceptible d'en être faite dans le litige où il est partie : le requérant qui pose une QPC a le droit que soit examinée la constitutionnalité d'une disposition législative telle qu'elle est appliquée, c'est-à-dire compte tenu de la portée effective que lui confère une interprétation jurisprudentielle constante ».

Le contrôle de la portée rétroactive de la loi résultant d'une interprétation jurisprudentielle, portant elle-même un effet rétroactif, s'impose également lorsque sont en cause les principes de légalité des délits et des peines et le principe de non rétroactivité de la loi pénale. On relèvera d'ailleurs, qu'au visa de la CEDH, la Cour de cassation a considéré que dans certaines circonstances «le juge doit procéder à une évaluation des inconvénients justifiant qu'il soit fait exception au principe de la rétroactivité de la jurisprudence et rechercher, au cas par cas, s'il existe, entre les avantages qui y sont attachés et les inconvénients, une disproportion manifeste ${ }^{17}$. Lorsque ces "inconvénients relèvent d'exigences constitutionnelle, la solution retenue par la Cour de cassation, c'est à dire la portée donnée à la loi devait pouvoir faire l'objet d'une QPC.

Il résulte de l'ensemble de ces observations rapides que la notion de contrôle ne peut être univoque. Le débat sur la possibilité de faire du Conseil constitutionnel une Cour suprême, outre les approximations auxquelles il renvoie, fausse le débat. Deux facteurs jouent un rôle essentiel en la matière. D'une part la circularité de la jurisprudence qui induit un système d'influence, d'autre part le positionnement institutionnel des juridictions qui induit un mécanisme de concurrence. En réalité le «big brother » des droits fondamentaux s'incarne de plus en plus dans la Cour européenne des droits de l'homme dont la jurisprudence se veut à la fois fédératrice, subsidiaire et pourtant intégratrice. Elle génère à son tour des phénomènes de soumission et de résistance.

17 Cass civ 16 avril 2016, n 15-10552, cf. art. précité de R. LiBChaBER, p. 1093. 


\section{Chapitre 3}

\section{L'EXEMPLE D'UN SYSTÈME MIXTE : LE CAS DU PORTUGAL}





\title{
LE CONTRÔLE DE CONSTITUTIONNALITÉ des décisions de justice au Portugal
}

\author{
Vasco PEREIRA DA Silva ${ }^{1}$ \\ Rui TAVARES LANCEIRO ${ }^{2}$
}

\section{Considérations générales}

Le système de contrôle de constitutionnalité des décisions de justice consacré par la Constitution de la République portugaise présente un degré de complexité élevé car il comprend plusieurs modalités de contrôle : a) le contrôle a priori ; $b$ ) le contrôle abstrait successif ou a posteriori ; $c$ ) le contrôle concret ; $d$ ) le contrôle de l'inconstitutionnalité par omission ${ }^{3}$. Chacune de ces modalités de contrôle est le propre de modèles distincts de contrôle de constitutionnalité (notamment le contrôle a priori du modèle français, le contrôle a posteriori du modèle autrichien, le contrôle a posteriori concret du modèle américain, le contrôle de l'inconstitutionnalité par omission du modèle de l'ancienne Yougoslavie) que le législateur constitutionnel a combiné de façon originale, en mélangeant des apports tirés de tous les modèles et en le faisant d'une forme qui lui est propre, donnant ainsi naissance à un modèle autonome.

Si on voulait ironiser là-dessus, on dirait que le législateur constitutionnel a suivi la recette culinaire du « cozido à portuguesa », le pot-au-feu caractéristique de la cuisine portugaise où l'on cuit ensemble dans un même récipient plusieurs sortes de viandes et de charcuteries, ainsi qu'une grande variété de légumes, auxquels vient encore s'ajouter le riz, le résultat en étant une combinaison de goûts et de saveurs réellement originales et «typiques ».

En ce qui concerne les contrôles a priori, abstrait a posterioriet d'inconstitutionnalité par omission, il appartient exclusivement au Tribunal constitutionnel de les opérer. Quant au contrôle concret de constitutionnalité, la Constitution portugaise a trouvé une solution originale qui représente un

\footnotetext{
1 Professeur (Professor catedrático) de la Faculté de droit de l'Université de Lisbonne et Professeur invité de l'École de Lisbonne de la Faculté de droit de l'Université catholique portugaise, Directeur de recherche au CIDP - Centro de Investigação de Direito Público.

Maître de conférences (Professor Auxiliar) de la Faculté de droit de l'Université de Lisbonne, Consultant auprès du Tribunal constitutionnel, Directeur de recherche au CIDP - Centro de Investigação de Direito Público.

3 Voir à ce sujet, par ex., et pour tous, J. M. CARdoso DA Costa, A furisdição Constitucional em Portugal, 3. ${ }^{a}$ ed., Almedina, 2007 ; J. J. Gomes Canotilho, Direito Constitucional e Teoria da Constituição, Almedina, 7. a ed., 2003, p. 887 et s. ; J. J. Gomes CANotilho/ V. Moreira, Constituição da República Portuguesa Anotada, vol. II, 4. ${ }^{a}$ ed. revista, Coimbra Editora, p. 879 et s. ; R. MEdeIros, Constituição Portuguesa Anotada, t. III, Coimbra Editora, 2007, p. 738 et s. ; J. MirandA, Manual de Direito Constitucional, t. VI, Coimbra Editora, 4. ${ }^{a}$ ed., 2013 , p. 11 et 50 et s. ; Idem, Constituição Portuguesa Anotada, t. III, Coimbra Editora, 2007, p. 702 et s. ; C. BlanCo De Morais, Justiça Constitucional, t. II, Coimbra Editora, $2^{\text {a }}$ ed., 2002, p. 22 et s.
} 
compromis entre le modèle des États-Unis de contrôle diffus (judicial review of legislation) et le modèle « autrichien » de contrôle concentré (Verfassungsgerichtsbarkeit). La caractéristique de ce système est d'être « mixte » ou « diffus » à la «base » et « concentré » au « sommet » ${ }^{4} / 5$. La première partie (« diffus à la base ») s'explique par la compétence qui est conférée à tous les juges de tous les tribunaux portugais de contrôler la constitutionnalité des lois. En effet, l'article 204 de la Constitution établit que dans les affaires soumises au jugement des tribunaux, les juges doivent s'abstenir d'appliquer des normes qui violent ce que dispose la Constitution ou les principes qui y sont inscrits. Il s'ensuit que tous les juges de tous les tribunaux portugais sont, en vertu de la Constitution, des « organes de justice constitutionnelle $»^{6}$. La seconde partie de la qualification du système portugais («concentré au sommet ») découle du fait que les décisions des tribunaux en matière de constitutionnalité sont susceptibles de recours devant le Tribunal constitutionnel ${ }^{7}$, lequel décide en dernier ressort. En certains cas, le ministère public est tenu obligatoirement de déposer un recours (article 280-3 et 5 de la Constitution).

Il n'existe pas au Portugal de mécanisme de « renvoi préjudiciel » pour accéder au Tribunal constitutionnel ${ }^{9}$. Les questions de constitutionnalité lui sont soumises par le biais de recours contre les décisions rendues par les tribunaux, déposés par des particuliers (parties au procès) etou par le ministère public, le juge n'étant pas compétent pour saisir ex officio le Tribunal constitutionnel de questions de constitutionnalitééti11.

Le système de contrôle de constitutionnalité repose donc, au Portugal, sur les organes juridictionnels ${ }^{12}$. Ceux-ci comprennent, aux termes de l'article 209 de la Constitution, outre le Tribunal constitutionnel, les catégories suivantes de tribunaux : a) le Tribunal suprême de justice et les tribunaux judiciaires de première et de seconde instance, ce qui correspond à la « juridiction ordinaire » (civile, pénale et du travail) ; b) le Tribunal suprême administratif et les tribunaux administratifs et fiscaux restants, ce qui correspond à la juridiction « administrative et fiscale »; et la Cour des comptes. Le paragraphe 2 de la précitée disposition constitutionnelle prévoit aussi que puissent exister des tribunaux maritimes, des tribunaux arbitraux et des justices de paix ${ }^{13}$. Le devoir de non application d'une norme inconstitutionnelle s'impose à tous ces tribunaux au titre de l'article 204 de la

\footnotetext{
4 Voir M. Lúcia Amaral, "Problemas da Judicial Review em Portugal", in Themis, ano VI, n. o 10, 2005, p. 67-90, p. 74; C. Blanco DE Morais, Fustiça Constitucional, II, p. 329-330; V. MoreIRA, "A fiscalização concreta no quadro do sistema misto de justiça constitucional”, in Boletim da Faculdade de Direito, Volume Comemorativo, 2003, p. 846.

$5 \quad$ Voir les arrêts du Tribunal constitutionnel n. ${ }^{\circ}$ s 169-92, § 8, 200-98, § 10, et 195-2010, §13.

Voir J. J. Gomes Canotilho, Direito Constitucional, p. 917.

Voir J. J. Gomes Canotilho, Direito Constitucional, p. 1014-1015.

Voir J. Miranda, Manual, VI, p. 268.

Voir M. dos Prazeres Beleza, "Subsistência do controlo difuso ou migração para um sistema concentrado de reenvio prejudicial", in Perspectivas de Reforma da fustiça Constitucional em Portugal e no Brasil, Almedina, 2012, p. 89-99 ; R. MedeIRos, Constituição Portuguesa Anotada, III, p. 742.

10 Voir M. Galvão Teles, "A competência da competência do Tribunal Constitutional”, in Legitimidade e legistimação da justiça constitucional, Colóquio no 10o Aniversário do Tribunal Constitucional, Coimbra Editora,1995, p. 105 et s., p. 112-113.

11 Cf. Arrêt du Tribunal constitutionnel No 569-2003, § 6.

12 Voir J. J. Gomes Canotilho/ V. Moreira, Constituição da República Portuguesa Anotada, II, p. 941-942 ; C. Lopes Do Rego, Os Recursos de Fiscalização Concreta na Lei e na Jurisprudência do Tribunal Constitucional, Almedina, 2010, p. 22 et s., p. 112-113.

13 En outre, il est établi que, pendant la durée de l'état de guerre, doivent être constitués des tribunaux militaires chargés de juger les crimes de nature strictement militaire.
} 
Constitution. Et il est possible de saisir le Tribunal constitutionnel de recours contre leurs décisions en la matière.

Le Tribunal constitutionnel est placé de la sorte au sommet de la hiérarchie des tribunaux pour ce qui est du contrôle de constitutionnalité et la Constitution lui réserve une place autonome au regard des autres tribunaux ${ }^{14}$, dans un titre dédié uniquement à lui (le Titre VI) de la Partie III (qui traite de «L'organisation du pouvoir politique » $)^{15}$.

Au Portugal, le contrôle de constitutionnalité est un contrôle de normes juridiques aux termes notamment de l'article 277-1 de la Constitution. C'est ainsi que les différentes modalités de contrôle de constitutionnalité ont pour objet les dispositions des actes législatifs (lois adoptées par l'Assemblée de la République, décrets-lois pris par le gouvernement, et décrets législatifs régionaux adoptés par les assemblées législatives des régions autonomes) ou d'autres actes normatifs des pouvoirs publics, y compris les conventions internationales (traités et accords), susceptibles d'en être dégagées en procédant à leur interprétation.

Pour déterminer l'objet du contrôle, le Tribunal se sert d'un concept élargi de « norme », ayant recours à un critère fonctionnel et formel. Ledit concept ne comprend pas uniquement les dispositions d'une nature générale et abstraite, mais également toutes les normes publiques dotées d'efficacité externe, même celles qui ont un caractère individuel et concret, dès lors qu'elles sont inscrites dans un acte législatif (puisque, dans ce dernier cas, la norme de référence du contrôle est la Constitution elle-même). En outre, sont également des «normes », comme le Tribunal ne cesse de le répéter dans une jurisprudence uniforme et constante, tout et chaque acte des pouvoirs publics contenant une « règle de conduite » pour les particuliers ou pour l'administration, un « critère de décision » pour cette dernière ou pour le juge, ou encore, de manière plus générale, un « paramètre à l'aune duquel un comportement doit être jugé ».

\section{Les décisions judiciaires et le contrôle du Tribunal constitutionnel portugais}

Le Tribunal constitutionnel a affirmé à plusieurs reprises dans sa jurisprudence que le contrôle de constitutionnalité est un contrôle de normes et non un contentieux de décisions, quelle qu'en soit la nature ${ }^{16}$. En ce sens-là, il n'y a pas, au Portugal, un contrôle de la constitutionnalité des décisions judiciaires en soi, mais uniquement celui des normes appliquées par les tribunaux dans leurs décisions ou, vu sous un autre angle, des normes instituées par la jurisprudence ${ }^{17}$.

\footnotetext{
14 L'article 209-1 de la Constitution établit que «outre le Tribunal constitutionnel, il existe les catégories suivantes de tribunaux [...] ». Voir J. Miranda, Manual, VI, p. 185-188, 203.

Voir J. Miranda, Manual, VI, p. 58 et 251.

Voir J. Miranda, Manual, VI, p. 244 ; Idem, Constituição Portuguesa Anotada, III, p. 715 ; C. Blanco DE MoraIs, fustiça Constitucional, II, p. 562 ; C. Lopes Do Rego, Os Recvursos, p. 26-27.
} 
Le Tribunal a accepté de contrôler la constitutionnalité des « assentos » (décisions du Tribunal suprême destinées à uniformiser sa jurisprudence et ayant force de loi ${ }^{18}$ et des arrêts uniformisant la jurisprudence du Tribunal suprême de justice ${ }^{19}$ ou encore de normes créées par le juge interprète « dans l'esprit du système » (article 10-3 du code civil) afin de combler les lacunes de la loi ${ }^{20}$.

Dans ce contexte, la norme instituée par la juridiction peut faire l'objet d'un contrôle de constitutionnalité abstrait a posteriori ou d'un contrôle concret. La norme appliquée par le juge ordinaire dans la décision judiciaire est, cependant, susceptible d'appréciation par le Tribunal constitutionnel dans le cadre du contrôle concret. Il ne s'agit pas, dans ce cas, de réexaminer la décision judiciaire du tribunal en question mais de contrôler la constitutionnalité des normes appliquées en l'espèce par ledit tribunal ${ }^{21} / 22$.

Dans le cadre du contrôle concret, le Tribunal constitutionnel contrôle toujours, en vertu de la nature même de cette modalité de contrôle, non seulement la conformité à la Constitution de la loi, mais encore celle de l'interprétation qu'en a fait le juge a quo, comme il résulte au demeurant de l'article 80-3 de la LTC (Loi du Tribunal constitutionnel). Il va de soi que cette caractéristique du contrôle concret n'est pas exempte de difficultés relativement à la distinction entre l'interprétation de la loi, contrôlée par le Tribunal constitutionnel, et l'application de la loi, laquelle échappe à ce contrôle. Il est permis d'affirmer, de façon générale, que la distinction entre une question d'interprétation de la loi et une question d'application de la loi ne soulève pas de grandes difficultés quand il s'agit de normes juridiques susceptibles d'une application littérale fondée sur le modèle du syllogisme juridique ; toutefois, la distinction devient plus compliquée lorsqu'est en cause l'application d'un principe juridique, d'une norme au contenu indéterminé ou d'une clause générale telle que la bonne foi.

Quoi qu'il en soit, c'est le Tribunal constitutionnel lui-même qui a la charge de décider de façon définitive quant aux termes de ladite distinction entre interprétation et application de la norme. Ceci n'est pas sans rapport avec la place qu'occupe le Tribunal constitutionnel dans l'ordonnancement juridique portugais, non seulement en tant que tribunal suprême - dans le sens que ses décisions sont insusceptibles de recours -, mais encore en tant que suprême des suprêmes (bien que son pouvoir soit spécifique et qu'il soit placé en dehors des divers types de juridictions) - dans le sens où il est investi du pouvoir de connaître des recours relatifs à la manière dont sont mises en ouvre ses décisions, grâce à la faculté de décider de la recevabilité des recours qui lui sont déférés, sous forme

\footnotetext{
18 Cf. les arrêts du Tribunal constitutionnel N. ${ }^{\circ}$ s 40-84, § 5 ; 68-86, II ; et 104-86, II. Cette institution a été déclarée partiellement inconstitutionnelle - pour ce qui concerne l'attribution de compétence aux tribunaux pour fixer la doctrine avec force obligatoire générale non conforme à la Constitution par les arrêts du Tribunal constitutionnel : $\mathrm{n}^{\circ}$ 810-93, § 3 de la motivation ; 407-94, § II ; 410-94, § III. Elle a également été considérée inconstitutionnelle, avec force obligatoire générale, dans la même mesure, par l'arrêt n. ${ }^{\circ} 743-96$. Tout en prenant en compte la précitée délimitation, le Tribunal constitutionnel a postérieurement connu des assentos, cf. par ex. les arrêts n. ${ }^{\circ}$ s 299-95, III.1 et $2 ; 1197-96, \S 6$.

19 Cf. les arrêts du Tribunal Constitutionnel n. ${ }^{\circ}$ 110-2007, § 6; 361-2016, § 2. La doctrine n'est pas unanime quant à savoir si, actuellement, les arrêts visant à unifier la jurisprudence ont une nature normative (voir C. Lopes Do C. Lopes Do Rego, Os Recursos, p. 30).

20 Cf. les arrêts du Tribunal constitutionnel n. ${ }^{\circ}$ s $264-98$; § 12.2; 116-2002, II.

21 Voir C. Blanco de Morais, Justiça Constitucional, II, p. 653.

22 Voir, par ex. les arrêts du Tribunal constitutionnel n. ${ }^{\circ}$ S 587-2014, § 8.2 et s. ; 79-2015, § 7-8; 614-2016, § 7 ; 655-2016, § 5.
} 
de réclamation, ainsi que de la possibilité de connaître des recours portant sur la manière dont sont exécutées ses décisions ${ }^{23}$.

\section{A. Le contrôle concret de constitutionnalité et les recours devant le Tribunal constitutionnel}

L'ordonnancement constitutionnel portugais reconnaît à tous les tribunaux le droit d'exercer (d'office) le contrôle de constitutionnalité de toutes les normes juridiques en vertu de l'article 204 de la Constitution. Ceux-ci sont tenus de s'abstenir d'appliquer, dans les cas concrets soumis à leur juridiction, les dispositions qu'ils estiment inconstitutionnelles. L'exercice du contrôle normatif concret incombe, par conséquent, en première ligne, aux tribunaux en général ${ }^{24}$. Cependant, leurs décisions portant sur une question de constitutionnalité sont susceptibles de recours devant le Tribunal constitutionnel. En effet, dans le système portugais, les particuliers peuvent accéder au Tribunal constitutionnel dans le cadre du contrôle concret de constitutionnalité par le biais d'un recours contre les décisions rendues par d'autres juridictions ${ }^{25}$.

Le réexamen de décisions judiciaires dans le cadre du contrôle concret constitue la partie centrale, en termes de volume de travail, de l'activité du Tribunal constitutionnel. En consultant le rapport annuel d'activité du Tribunal constitutionnel pour 2015, on s'aperçoit que le Tribunal, cette année-là̀ ${ }^{26}$, a rendu 700 arrêts dont 635 (environ 90\%) furent émis dans le cadre du contrôle concret ${ }^{27}$. Plus génériquement, sur les 1510 décisions du Tribunal constitutionnel rendues au cours de l'année 2015, 1445 (soit 95 \%) le furent dans le cadre du contrôle concret - ce qui représente la somme des 810 décisions sommaires et des 635 arrêts rendus dans ce domaine.

Ces chiffres montrent le volume atteint par le contrôle concret dans le cadre des activités du Tribunal constitutionnel. Il convient, au demeurant, de souligner que ces chiffres ne divergent pas de ceux des années antérieures, ce qui veut dire qu'ils expriment une tendance structurelle de la justice constitutionnelle portugaise. On peut dire que le contrôle concret, pris dans son ensemble, représente grosso modo, depuis l'entrée en fonctionnement du Tribunal constitutionnel portugais, qui eut lieu en 1983, plus de 90\% du total des décisions rendues.

\footnotetext{
23 Voir M. Galvão Teles, “A Competência da Competência do Tribunal Constitucional”, précité, p. 120.

Voir C. Blanco de Morais, Fustiça Constitucional, II, p. 550.

La définition de tribunal en vue de la saisine du Tribunal constitutionnel comprend tout et chaque tribunal public ou de l'État et tout et chaque tribunal arbitral alors qu'il juge stricto jure, mais non quand il juge ex aequo et bono. Voir J. J. Gomes CANOtilHo / V. Moreira, Constituição da República Portuguesa Anotada, II, p. 1015 et s.

26 Disponible sur le site http://www.tribunalconstitucional.pt/tc/content/files/tc_ebook_relactiv2015/index.html\#3, (consulté le 1 ${ }^{\text {er }}$ décembre 2016). 27 Parmi ces arrêts, on compte 365 arrêts rendus en conférence de chambres, conformément aux articles 78-A-3, LTC (dont 87 sont interlocutoires), 141 arrêts rendus par une chambre, 2 arrêts rendus par l'assemblée plénière, au titre des articles 79-A et 79-D LTC, et 127 arrêts rendus sur des réclamations aux termes de l'article 77 de la LTC (dont 21 interlocutoires).
} 
Il existe, essentiellement, trois grands types de recours en matière de constitutionnalitééc: a) les recours contre les décisions des tribunaux qui refusent d'appliquer des normes au motif qu'elles seraient contraires à la Constitution [article 280-1 a] de la Constitution] ; b) les recours contre les décisions des tribunaux qui appliquent des normes attaquées pour inconstitutionnalité par les parties [article 280-1 b] de la Constitution] ; ou c) les recours des décisions des tribunaux qui appliquent des dispositions déjà déclarées précédemment contraires à la Constitution par le Tribunal constitutionnel (article 280-5 de la Constitution) ${ }^{29}$.

Les recours contre les décisions qui refusent l'application de normes pour un motif d'inconstitutionnalité sont déférés directement au Tribunal constitutionnel et ils sont obligatoires. C'est au ministère public qu'il incombe de saisir ledit Tribunal pour les cas énoncés à l'alinéa $a$ ) précité, lorsque la norme refusée est inscrite dans un traité international, une loi ou un règlement promulgué par le président de la République, ou bien, pour les cas mentionnés à l'alinéa c) précité, si les autres tribunaux n'ont pas respecté la jurisprudence du Tribunal constitutionnel.

Si la question de constitutionnalité a été soulevée, en cours de procès, par l'une des parties mais que le tribunal devant lequel il se déroule l'a ignorée, la partie en question peut saisir le Tribunal constitutionnel dès lors que l'ensemble des voies de recours ordinaires ont été épuisées (article 70-2, LTC $)^{30}$. Cette exigence d'épuisement est nécessaire afin que le Tribunal soit uniquement appelé à apprécier à nouveau les décisions qui constituent le dernier mot dans l'organisation judiciaire du tribunal qui les a rendues, ce qui évitera de faciliter le soulèvement injustifié de questions de constitutionnalité et épargnera donc les interventions du Tribunal ${ }^{31}$.

Il incombe alors au Tribunal constitutionnel de réexaminer, dans le cadre du recours, la constitutionnalité de la norme que les tribunaux ont appliquée, celle-ci étant soit retirée littéralement du précepte légal, soit le résultat d'une interprétation juridictionnelle.

\footnotetext{
28 En parallèle avec les recours en inconstitutionnalité, il existe aussi les recours de contrôle de légalité. En la matière, la Constitution, à son article 280-2, prévoit le recours devant le Tribunal constitutionnel contre les décisions des tribunaux : a) qui refusent l'application d'une disposition légale au motif de son illégalité fondée sur la violation d'une loi à valeur renforcée ; $b$ ) qui refusent l'application d'une disposition d'une loi régionale au motif de son illégalité fondée sur la violation du statut de la région autonome ou de la loi générale de la République portugaise ; c) qui refusent d'appliquer une disposition d'un acte législatif émanant d'un organe de l'État au motif de son illégalité pour violation du statut d'une région autonome ; $d$ ) qui appliquent une disposition dont l'illégalité pour l'un des vices mentionnés aux alinéas précédents a été soulevée en cours d'instance.

29 Voir J. J. Gomes Canotilho / V. Moreira, Constituição da República Portuguesa Anotada, II, p. 942-943; J. Miranda, Manual, VI, p. 204 et $\mathrm{s}$.

30 Quant à cette nécessité d'épuisement des voies de recours, il convient d'ajouter quelques précisions. On estime que tous les recours ordinaires ont été épuisés quand il y a eu renoncement, que les délais respectifs ont expiré sans qu'ils aient été déposés, ou qu'il n'ait pas été possible de donner suite aux recours introduits pour des motifs d'ordre procédural (article 70-4, LTC). Les réclamations auprès des présidents des instances supérieures, dans les cas de non-admission ou de rétention des recours, ainsi que les réclamations auprès de la conférence contre les ordonnances des juges rapporteurs ou des juges de la mise en état sont assimilées à des recours ordinaires (article 70-3, LTC). N'est pas admise la saisine du Tribunal constitutionnel dans les cas de décisions pour lesquelles le recours ordinaire est obligatoire aux termes de la loi procédurale (article 70-5, LTC). Si la décision est susceptible de recours ordinaire, même si cela vise à uniformiser la jurisprudence, le fait de ne pas déposer un recours auprès du Tribunal constitutionnel n'exclut pas le droit à une décision postérieure qui vienne confirmer la première (article 70-6, LTC).

31 Voir C. Lopes do Rego, Os Recursos, p. 113 et s.
} 


\section{B. Les conditions et exigences procédurales du recours en inconstitutionnalité et son contrôle par le Tribunal constitutionnel}

Le recours doit porter sur une décision judiciaire définitive ${ }^{32} / 33$, et il est tenu d'avoir un objet normatif $^{34}$ et de présenter de l'utilité pour le procès ${ }^{35}$. Sont également des exigences formelles du recours en inconstitutionnalité, la nécessité pour le requérant de citer l'alinéa du paragraphe 1 de l'article 70 en vertu duquel le recours est interposé, ainsi que la norme dont il prétend que le Tribunal constitutionnel apprécie la conformité à la Constitution (article 75-A-1, LTC).

Il existe des exigences additionnelles selon les divers types de recours. Pour le premier type de recours susmentionné à l'alinéa $a$ ) : i) que le refus d'application ait lieu dans le cadre d'une décision judiciaire ; ii) que le refus d'application ait pour objet des normes juridiques ; iii) que le jugement contesté ait effectivement refusé d'appliquer une norme (ou des normes) en invoquant son (leur) inconstitutionnalité3 ${ }^{36}$. Quant au second type de recours susmentionné à l'alinéa $b$ ), les conditions additionnelles qui s'y appliquent sont $: i$ ) qu'il s'agisse de l'application effective d'une norme juridique par une décision judiciaire ; ii) que le requérant, en cours d'instance, ait soulevé la question de constitutionnalité devant le tribunal a quo, de façon adéquate et dans les délais impartis (article 280-4 de la Constitution et article72-2 de la LTC ${ }^{37}$; iii) qu'il s'agisse d'une décision non susceptible de recours ordinaire (article 70-2 de la LTC) ; $i v$ ) que le requérant indique la disposition ou le principe constitutionnel qu'il estime violé ainsi que le moment du procès où la question de l'inconstitutionnalité a été soulevée (article $75 .^{\circ}$-A-2, LTC) ${ }^{38}$. En ce qui concerne le troisième type de recours susmentionné à l'alinéa $c$ ), le requérant est tenu d'identifier le jugement du Tribunal constitutionnel qui a, précédemment, déclaré contraire à la Constitution la norme appliquée par la décision attaquée ${ }^{39}$.

Si la requête d'introduction du recours ne contient pas tous les éléments exigés, le juge rapporteur (juge de mise en état) devra inviter le requérant à présenter les éléments manquants (article 75-A-5, 6 et 7, LTC).

Le Tribunal constitutionnel a estimé à plusieurs reprises dans sa jurisprudence que le recours en inconstitutionnalité a une fonction instrumentale vis-à-vis du procès principal jugé par les tribunaux inférieurs ${ }^{40}$. Comme il est écrit dans l'arrêt no. 86-90, paragraphe 5 , « le jugement de la question d'inconstitutionnalité a toujours une fonction instrumentale, et il se justifie uniquement s'il est utile pour décider de la question de fond. Ceci veut dire que le sens du jugement de la question d'inconstitutionnalité doit pouvoir influencer la décision de la question car, autrement, on se trouverait à trancher une question purement académique ». Cette orientation s'est maintenue jusqu'à ce jour ${ }^{41}$.

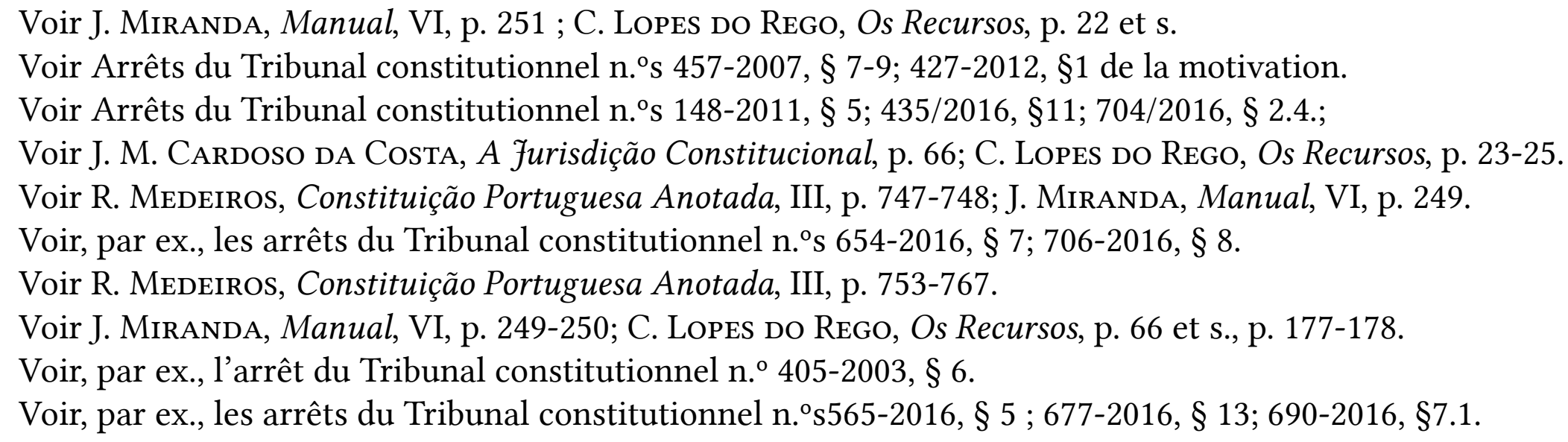


Pour cette raison, le Tribunal considère qu'il ne doit connaître d'une question d'inconstitutionnalité et se prononcer à son sujet que si celle-ci est susceptible de se répercuter utilement sur le jugement du procès dans lequel ledit recours a émergé. Si ce n'est pas le cas, il manque l'intérêt procédural de la partie.

Finalement, si le juge a quo a fait allusion à une question de constitutionnalité normative, mais qu'une telle mention ne constituait pas le fondement de sa décision, sa ratio decidendi, et représentait plutôt un obiter dictum ou un argument ad ostentationem, dans ce cas-là, il n'est pas non plus utile que le Tribunal connaisse de la question ${ }^{42}$. De même, si le juge a quo a invoqué deux fondements différents pour trancher une certaine question - et que seul l'un d'entre eux était étayé par des motifs relevant de la constitutionnalité -, la connaissance du recours n'a pas d'utilité puisque la décision attaquée resterait immuable quel que fût le jugement du Tribunal, compte tenu du fait qu'elle se basait sur un autre fondement.

Le Tribunal constitutionnel portugais ne dispose pas d'une discretionary jurisdiction qui lui permettrait de filtrer les affaires dont il est saisi selon des critères d'importance substantive. Il n'a notamment pas un instrument équivalent au writ of certiorari de la Cour suprême des États-Unis ${ }^{43}$.

Il existe, nonobstant, certaines formes de contrôle procédural permettant de sélectionner les procès qui remplissent les conditions précitées et le rejet de ceux qui ne les remplissent pas. En effet, la modification de la LTC, opérée en 1998 (loi no. 13-A-98 du 26 février), allait introduire un nouveau et important dispositif en matière de recours en inconstitutionnalité : « la décision sommaire » du juge rapporteur ${ }^{44}$. Conformément à l'article 78-A-1 de la LTC, le rapporteur rend une décision sommaire quand il estime que le Tribunal n'est pas habilité à connaître de l'objet du recours ou quand il entend que la question est simple du fait, notamment, qu'elle a déjà fait l'objet d'une décision du Tribunal ou qu'elle s'avère manifestement infondée.

La décision sommaire peut consister simplement dans l'invocation de la jurisprudence antérieure du Tribunal. Le juge rapporteur peut aussi rendre une décision sommaire lorsque le requérant ne fournit pas tous les éléments auxquels se réfère l'article 75-A de la LTC (article 78-A-2). Il est possible de faire une réclamation contre une décision sommaire auprès de la conférence, laquelle est composée du président ou du vice-président du Tribunal, du rapporteur et d'un autre juge de la formation pertinente. La conférence tranche définitivement la question de la recevabilité du recours dès lors qu'il existe unanimité des juges qui en font partie. Quand l'unanimité n'est pas atteinte, c'est au plénum de la chambre de décider (article 78-A-3 et 4 de la LTC).

\footnotetext{
42 Voir, par ex. les arrêts du Tribunal constitutionnel 366-2015, § 8 ; 693-2015, dernier paragraphe de la motivation ; 376-2016, § 2; 578-2016, § 4.1. 43 Voir M. Lúcia Amaral, "Problemas da Judicial review em Portugal", in Themis, Ano VI, n. ${ }^{\circ} 10,2005$, p. 88.

44 Jusqu'en 1998, le juge rapporteur était habilité à produire un exposé préliminaire de non-connaissance du recours (ou de simple invocation de la jurisprudence antérieure). Il était, toutefois, toujours nécessaire de rendre un arrêt, émis par tous les juges de la formation. À partir de la modification de la LTC, introduite par la loi 13-A-98, il est devenu possible de clore définitivement le procès au moyen de la décision d'un seul juge et sans que soit nécessaire l'intervention de ses pairs.
} 


\section{Le contrôle concret de constitutionnalité et le réexamen des décisions judiciaires par le Tribunal constitutionnel}

Le juge $a$ quo a le pouvoirdevoir de se prononcer et de décider, en première ligne, de la question de constitutionnalité, comme il a été mentionné ci-dessus. Ainsi, si le juge refuse d'appliquer une norme en alléguant son inconstitutionnalité, il est évident qu'il se prononce sur la question de la conformité de ladite norme à la Constitution. Par ailleurs, quand le juge applique une norme, nonobstant le fait que l'une des parties l'a estimée inconstitutionnelle, il se prononce également sur la question de constitutionnalité. Qui plus est, si la partie lui a posé une question de constitutionnalité, le juge est tenu de se pencher sur elle, sous peine d'omission de se prononcer, ce qui constitue, selon le code de procédure civile, une cause de nullité de la décision judiciaire. L'action du Tribunal constitutionnel dans le cadre du contrôle concret implique, par conséquent, que les décisions des tribunaux $a$ quo en matière de constitutionnalité soient réexaminées.

Comme il a été mentionné plus haut, le contrôle exercé par le Tribunal constitutionnel est purement un contrôle de normes et non des décisions de justice en elles-mêmes. Il convient, quand même, de souligner que, malgré le fait qu'il n'existe pas au Portugal de dispositifs équivalents à la «plainte constitutionnelle » (Verfassungsbeschwerde), au « recurso de amparo » ou encore à «l'action constitutionnelle de défense » contre des actes non normatifs potentiellement inconstitutionnels ${ }^{45}$, la jurisprudence du Tribunal a permis, quoique latéralement ou d'une façon mitigée, d'obtenir quelques-uns des effets de ces institutions, notamment lorsqu'elle admet le contrôle des normes dans une interprétation donnée- l'interprétation retenue dans la décision contestée ${ }^{46}$. En effet, et comme le Tribunal l'a maintes fois affirmé, dans une jurisprudence abondante et répétée, la question de constitutionnalité peut aussi bien porter sur une partie de la norme, que sur l'interprétation ou sens dans lequel elle a été rendue dans le cas d'espèce et appliquée ou non appliquée ${ }^{47}$.

Cette ouverture à la possibilité de contrôle des normes dans une interprétation donnée amène le Tribunal à exercer un contrôle qui, tout en n'abandonnant pas le référent normatif, peut impliquer l'examen des éléments de fait du procès. En effet, lorsqu'il apprécie la conformité à la Constitution d'une norme avec le sens qui lui a été donné dans la décision attaquée, le Tribunal constitutionnel finit souvent par procéder aussi à l'analyse du cadre factuel dans lequel se situe ladite décision. Quoi qu'il en soit, il faut répéter encore une fois que ceci n'implique nullement et en aucune façon que le contrôle opéré par le Tribunal cesse d'être un contrôle purement normatif, comme il a été signalé ci-dessus.

\footnotetext{
45 Voir J. De Mello Alexandrino, "Sim ou não ao recurso de amparo", in fulgar, 11, 2010, p. 41 et s. ; M. Lúcia Amaral, Problemas da fudicial Review em Portugal, p. 70-71; J. ReIs DE Novais, "Em Defesa do Recurso de Amparo Constitucional (ou uma Avaliação Crítica do Sistema Português de Fiscalização Concreta da Constitucionalidade)", in Themis, ano VI, n. o 10, 2005, p. 91 et p. $97-117$.

46 Voir M. Lúcia Amaral, "Queixas Constitucionais e Recursos de Constitucionalidade (uma Lição de Direito Público Comparado)", in Estudos Comemorativos dos 10 anos da Faculdade de Direito da Universidade Nova de Lisboa, vol. I, Almedina, 2008 , p. 473-501.

47 Voir, par ex. les arrêts du Tribunal constitutionnel n. ${ }^{\circ}$ 652-2016, § 11; 677-2016, § 9; 691-2016, § 6.2.
} 
Indépendamment de cette question, le droit constitutionnel portugais consacre des mécanismes visant à assurer, dans le cadre des procédures de contrôle concret, l'uniformisation de la jurisprudence relative aux jugements d'inconstitutionnalité rendus par les divers tribunaux et par le Tribunal constitutionnel lui-même.

C'est ainsi que, dans le cadre du contrôle concret, peuvent donner lieu à la saisine du Tribunal constitutionnel, obligatoire pour le ministère public, les décisions des tribunaux : (i) qui appliquent une norme déjà déclarée inconstitutionnelle ou illégale par le Tribunal constitutionnel lui-même ; (ii) qui appliquent une norme déjà déclarée inconstitutionnelle par la commission constitutionnelle dans les termes précis où son appréciation est requise par le Tribunal constitutionnel ; (iii) qui refusent l'application d'une norme d'une loi ou d'un acte ayant force de loi au motif qu'elle contrarierait une convention internationale, ou bien qui l'appliquent en contrariant ce qui a été précédemment décidé par le Tribunal constitutionnel. Il importe encore de noter que, dans ce dernier cas, le recours est restreint aux questions de nature juridico-constitutionnelle et juridico-internationale impliquées dans la décision attaquée, tandis que dans tous les autres cas les recours sont limités à la question d'inconstitutionnalité soulevée au cours du procès (cf. articles 280-5 de la Constitution, et 70-1, alinéas g), h) et i), 71 et 72-3, de la LTC).

Outre ces mécanismes d'uniformisation de la jurisprudence constitutionnelle dans son ensemble, il existe aussi un mécanisme qui vise à l'uniformisation de la jurisprudence à l'intérieur du Tribunal constitutionnel lui-même. Dans ce contexte, il y a lieu à déférer au plénum du Tribunal constitutionnel (obligatoirement dans le cas du ministère public lorsqu'il intervient dans le procès en tant que requérant ou recouru) les décisions des chambres de ce même Tribunal où celui-ci, à travers l'une de ses chambres, a jugé la question d'inconstitutionnalité ou d'illégalité dans un sens divergent de celui qui avait était précédemment adopté relativement à la même norme (cf. article 79-D-1 de la LTC).

En dernier lieu, il faudrait encore mentionner que le Tribunal a le pouvoir d'apprécier et de déclarer, avec force obligatoire générale, l'inconstitutionnalité de quelconque norme du moment que celle-ci a été jugée non conforme dans trois cas concrets, c'est-à-dire, dans le cadre du contrôle concret de constitutionnalité.

Il est interdit au Tribunal constitutionnel de reformuler la question de constitutionnalité telle qu'elle a été soulevée par les requérants ; ceci signifie qu'il ne lui est pas permis de modifier l'objet du recours. Il peut, cependant, délimiter cet objet en excluant, par exemple, de son appréciation -du fait qu'il estime une telle appréciation inutile ou parce que les conditions précitées ne sont pas remplies - des normes dont il lui est demandé d'examiner la conformité à la Constitution.

De plus, tel que mentionné précédemment, en vertu de l'article 79-C de la LTC visant les pouvoirs de connaître des recours du Tribunal, ce dernier peut uniquement déclarer inconstitutionnelle ou illégale la norme que la décision contestée a, selon les cas, appliquée ou dont elle a refusé l'application. Il peut le faire en se fondant sur la violation de normes ou de principes constitutionnels ou légaux différents de ceux dont la violation a été invoquée. Le Tribunal dispose, par conséquent, 
d'une large marge de pouvoir discrétionnaire relativement à la motivation de sa décision, mais il se trouve limité par le principe «non ultra petita »; partant, il est uniquement habilité à apprécier la constitutionnalité des normes mentionnées par les requérants ${ }^{48} / 49$.

Ainsi, lorsque le Tribunal constitutionnel examine un recours d'inconstitutionnalité ayant pour objet une norme dans une interprétation donnée (l'interprétation qu'en a fait la décision attaquée), il est lié, par rapport à l'objet du recours, par ladite interprétation. Cependant, le même raisonnement n'est pas vrai pour la motivation de la décision recourue, ni pour la question de constitutionnalité dont il a été saisi. Même s'il confirme la décision du tribunal a quo, le Tribunal constitutionnel n'est pas lié par les raisons qui fondent la décision de celui-ci. Il est absolument libre quant à la détermination des fondements de la décision de constitutionnalité.

Il importe aussi de souligner que, conformément au paragraphe 3 de l'article 80 de la LTC, si le jugement de constitutionnalité au sujet de la norme que la décision a appliquée ou a refusée d'appliquer s'appuie sur une appréciation donnée de ladite norme, celle-ci devra être appliquée dans l'affaire en question selon cette même interprétation.

\section{Effets des décisions du Tribunal constitutionnel sur le contrôle concret}

Les décisions rendues dans les recours appréciés dans le cadre du contrôle concret n'ont ni force obligatoire générale, ni effets erga omnes. Elles n'ont d'effet qu'entre les parties et pour des tierces personnes qui peuvent en profiter (article 74-1, 2 et 3 de la LTC). C'est ainsi que la décision du recours a, dans le procès, force de chose jugée en ce qui concerne la question d'inconstitutionnalité ou d'illégalité soulevée.

S'il est fait droit entièrement ou partiellement au recours, le Tribunal constitutionnel annule la décision attaquée (système de cassation) et le tribunal qui a statué est tenu de reformuler la décision de la question principale - ou bien d'ordonner sa reformulation à un tribunal de hiérarchie inférieure - en conformité avec le jugement sur la question d'inconstitutionnalité - article 80-2 de la LTC.

L'article 80-3 de la LTC prévoit la possibilité pour le Tribunal constitutionnel lui-même de fixer une interprétation de la norme appliquée par le tribunal dont la décision a été attaquée ou de la norme que celui-ci a refusé d'appliquer, afin d'éviter qu'il n'y ait inconstitutionnalité (ou illégalité). Une telle interprétation conforme à la Constitution lie ce tribunal.

48 Voir J. Miranda, Manual, VI, p. 57-58; C. Blanco de Morais, Fustiça Constitucional, II, p. 568-571, 574.

49 Voir les arrêts du Tribunal constitutionnel n. ${ }^{\circ}$ s 107-2011, § 7.3. ; 400-2015, § 4. 


\section{Le lien entre le Tribunal constitutionnel et les autres juridictions}

Il n'existe pas de lien organique au sens propre du terme entre le Tribunal constitutionnel et les autres juridictions, bien que ce dernier fonctionne, en ce qui concerne les matières de nature juridico-constitutionnelle, comme l'organe le plus haut placé de la hiérarchie des tribunaux ${ }^{50}$. En effet, les décisions du Tribunal constitutionnel rendues sur des recours de décisions d'autres tribunaux ont à l'égard de ceux-ci, et par rapport aux matières de nature juridico-constitutionnelle, les mêmes effets typiques des décisions d'un tribunal supérieur relativement à un tribunal inférieur.

Le Tribunal constitutionnel est donc un tribunal qui se trouve simultanément à l'intérieur et au dehors de la hiérarchie des tribunaux portugais. Il est à l'intérieur de la hiérarchie, plus précisément à son sommet, puisque, du fait que tous les tribunaux ont le pouvoir-devoir de contrôler la constitutionnalité des normes (article 204 de la Constitution), tous sont liés aux décisions rendues en la matière et celles-ci, dans le cadre du contrôle concret de constitutionnalité et de légalité, sont toujours en dernier ressort le fait du Tribunal constitutionnel. Et ils sont également liés par les décisions positives d'inconstitutionnalité ou d'illégalité rendues par ledit Tribunal dans le cadre du contrôle abstrait. En même temps, il se trouve en dehors de la hiérarchie, soit du point de vue du contrôle abstrait a priori et a posteriori, soit dans la perspective du contrôle de l'inconstitutionnalité par omission, soit encore du point de vue de plusieurs autres compétences qui lui sont attribuées par la Constitution, un grand nombre d'entre elles n'étant même pas de nature juridictionnelle (article 223 de la Constitution).

Il est, toutefois, loisible de parler d'un lien personnel entre le Tribunal constitutionnel et les autres juridictions pour ce qui est de la procédure de désignation des juges constitutionnels. Quoiqu'il ne soit pas possible d'acquérir la qualité de juge du Tribunal constitutionnel par les voies normales de progression dans la carrière de magistrat judiciaire ou par inhérence des fonctions exercées auprès d'autres juridictions, le Tribunal constitutionnel se compose de treize juges (dix désignés par l'Assemblée de la République et trois cooptés par les premiers), six des juges désignés par l'Assemblée de la République étant obligatoirement choisis parmi les juges des autres juridictions et ceux qui restent parmi les juristes (article 222-1 de la Constitution) ${ }^{51}$.

Le Tribunal constitutionnel n'a de contact avec d'autres juridictions que dans le seul cadre du contrôle concret. Or, dans ce cadre, comme il a été noté plus haut, les questions de constitutionnalité sont déférées au Tribunal constitutionnel en tant que voie de recours des décisions judiciaires. Ces recours sont formés par des particuliers ou par le ministère public, le juge du procès n'étant pas compétent pour soulever d'office une quelconque question de constitutionnalité devant le Tribunal constitutionnel. Étant donné que le recours adressé au Tribunal constitutionnel est déposé auprès du tribunal ayant rendu la décision contestée et que c'est à ce dernier qu'il incombe d'apprécier la

50 Cf. J. Miranda, Manual, VI, p. 185-188.

51 Cf. J. Miranda, Manual, VI, p. 148. 
recevabilité dudit recours (article 76 de la LTC), la possibilité pour le requérant d'introduire auprès du Tribunal constitutionnel une réclamation contre une ordonnance rejetant la demande de recours (cf. article 77 de la LTC) est également prévue (cf. article 77 de la LTC). Il est à noter ici, tout particulièrement, que la décision du Tribunal constitutionnel a force de chose jugée en ce qui concerne la question de recevabilité du recours (cf. article 77-4 de la LTC).

Finalement, il importe de savoir si les décisions du Tribunal constitutionnel sont généralement respectées par les autres juridictions dans le cadre du contrôle concret.

En matière de contrôle concret, les autres tribunaux doivent suivre les décisions du Tribunal constitutionnel, reformulant leurs décisions selon ce qui a été décidé par celui-ci relativement à la question de constitutionnalité. En effet, les décisions du Tribunal constitutionnel ont, dans le procès, force de chose jugée relativement à la question de constitutionnalité qui y a été soulevée. Bien qu'il soit permis d'affirmer, en général, que la jurisprudence du Tribunal constitutionnel n'a pas rencontré de grandes difficultés à se faire accepter et que la même chose vaut pour la suite donnée à ses décisions de la part des tribunaux contestés ${ }^{52}$, on ne peut ignorer qu'il existe des situations où cela se passe autrement, surtout lorsque le Tribunal fixe l'interprétation de la loi qui est conforme à la Constitution dans un cas d'espèce ${ }^{53}$.

Quant à la question du respect des décisions du Tribunal constitutionnel de la part du tribunal contesté, dans le cadre d'une procédure de contrôle concret de constitutionnalité, le Tribunal a connu des recours de constitutionnalité dans le cas suivant : lorsque, après qu'il eut annulé la décision du tribunal $a$ quo et ordonné sa reformulation conformément à sa propre décision sur la question de constitutionnalité, il constate que cette dernière décision n’a pas été respectée. Il existe, par conséquent, la possibilité de saisir le Tribunal constitutionnel en alléguant une violation de l'autorité de la chose jugée découlant d'une décision précédemment rendue par ledit Tribunal ${ }^{54} / 55$.

La question peut, toutefois, être écartée du cadre du contrôle, puisque les jugements du Tribunal constitutionnel ne constituent pas un précédent qui lie les autres juridictions. Quant au respect des décisions du juge constitutionnel par les autres juridictions hors du procès qu'elles concernent, il est important de mentionner que les décisions du Tribunal constitutionnel constituent un argument parfois décisif pour les autres tribunaux ${ }^{56}$.

\footnotetext{
52 Voir A. Rocha Marques, «O Tribunal Constitucional e os outros Tribunais: A Execução das Decisões do Tribunal Constitucional», in Estudos sobre a Jurisprudência do Tribunal Constitucional, Editorial Notícias, 1993, p. 470; C. Blanco De MoraIs, Justiça Constitucional, II, p. 345 et $\mathrm{s}$.

53 Voir à ce propos, citant un cas où les tribunaux ordinaires refusèrent, à plusieurs reprises, de suivre l'interprétation de la loi adoptée par le Tribunal constitutionnel, ce qui aboutit à la saisine du Tribunal constitutionnel de cinq recours sur la même question, Luís Nunes de Almeida, «La compétence d'appel du Tribunal Constitutionnel du Portugal sur les décisions des cours ordinaires », in Conférence internationale - Relations entre les cours constitutionnelles et les autres juridictions (Sarajevo, les 18 et 19 mars 2000), Sarajevo, 2001, p. 63-64.

54 En ce sens, voir les arrêts du Tribunal constitutionnel n 532-99, § 6 ; et 340-2000, § 8 .

55 Cf. M. Dos Prazeres Beleza, "Admissibilidade de um recurso autónomo para o Tribunal Constitucional por violação do caso julgado", in Estudos em Homenagem à Professora Doutora Isabel Magalhães Colaço, vol. II, Coimbra Editora, 2002, p. 479 et s. Cf. aussi M. GALvẽo Teles, "A Competência da Competência do Tribunal Constitucional", in Legitimidade e legitimação da fustiça Constitucional, Coimbra, 1995 , p. 120.

56 Cf. C. Blanco De Morais, fustiça Constitucional, II, p. 400.
} 



\title{
DÉBATS
}

\author{
sous la présidence de Madame Anne LEvade
}

Caterina Severino réagit aux propos de MarcVerdussen et de Bertrand Mathieu concernant leurs réserves sur l'introduction d'un éventuel contrôle de la conformité des décisions de justice devant le juge constitutionnel. Elle s'interroge d'abord sur la Cour constitutionnelle belge et le contrôle de microconstitutionnalité que Marc Verdussen attribuerait aux juges ordinaires, en laissant à la Cour constitutionnelle le seul contrôle de la macroconstitutionnalité. Elle pose la question de savoir si le juge ordinaire est le plus indiqué pour réaliser le contrôle de microconstitutionnalité. Elle note que la Cour constitutionnelle belge est composée majoritairement de parlementaires ce qui laisse supposer que ce ne sont pas forcément des juristes. Si cette Cour était composée essentiellement de juristes, alors elle serait peut-être mieux armée pour vérifier également des questions de microconstitutionnalité, c'est-à-dire de questions très techniques. Pour Caterina Severino, la différence entre la microconstitutionnalité et la macroconstitutionnalité est très subtile et n'est pas forcément pertinente : la Constitution est la norme fondamentale d'où tout devrait découler. Les juges constitutionnels devraient être capables de se pencher sur la microconstitutionnalité, concernant des questions très techniques, tout comme ils peuvent se pencher sur des questions de macroconstitutionnalité.

Puis, Caterina Severino s'interroge sur les propos de Bertrand Mathieu. Elle précise que bien que, apparemment, personne n'ait le dernier mot, au final un acteur a véritablement le dernier mot : la Cour européenne des droits de l'homme. La Cour EDH, pour reprendre les propos de Bertrand Mathieu, est un «big brother » et tout peut passer par elle. Or, la QPC a été mise en place pour éviter de se tourner sans cesse vers la Cour EDH qui donne des leçons aux différents juges et aux différents législateurs étatiques. Tout cela laisse donc planer un doute : est-ce que l'on continue avec la QPC en France en en développant toutes les potentialités ou bien se tourne-t-on, encore une fois, vers la Cour EDH, qui a le dernier mot et qui est capable, elle, de sanctionner les décisions de justice, les interprétations jurisprudentielles ainsi que les législations qui vont à l'encontre des principes de la Convention?

Anne Levade apporte quelques précisions sur la Cour EDH. La Cour EDH subit le même type de mutation que le Tribunal constitutionnel avec le recours d'Amparo. Elle est elle-même débordée par les événements. Elle est amenée à développer des mécanismes d'examen de la recevabilité qui vont conduire à ce que cela soit beaucoup plus sélectif et donc qu'elle ne puisse plus toujours avoir le dernier mot tout le temps. C'est peut-être une incitation à ce que les cours constitutionnelles développent un contrôle d'un genre nouveau. 
Marc Verdussen ne souhaite pas entrer dans le débat sur la composition de la Cour constitutionnelle belge. Il est parmi ceux, d'ailleurs, qui soulèvent des critiques quant à la composition de cette Cour et il a de grandes réserves sur la question. Pour lui, les parlementaires n'y ont pas leur place. Sur ce point, il est assez isolé par rapport aux autres constitutionnalistes en Belgique. Marc Verdussen revient, par ailleurs, sur le contrôle concret de constitutionnalité des lois. Pour lui, un État de droit constitutionnel réclame un contrôle concret de constitutionnalité. En effet, la violation d'un droit fondamental se fait le plus souvent dans l'application de la loi. Ce contrôle est le plus adéquat pour contrôler les inconstitutionnalités. En revanche, il n'est pas certain que le juge constitutionnel soit le plus apte à le réaliser, et ce pour plusieurs raisons. La première raison concerne la capacité technique de ce juge à réaliser un tel type de contrôle. Dans certains domaines, le juge constitutionnel belge a pu développer une jurisprudence sur des questions extrêmement concrètes, une jurisprudence qui s'est retrouvée déphasée par rapport à la manière dont les disciplines sont conçues par les spécialistes mêmes de celles-ci. Les juges constitutionnels et les référendaires sont recrutés de façons différentes, ce qui fait que les différentes disciplines ne sont pas forcément représentées au sein de la Cour constitutionnelle, comme c'est le cas actuellement du droit de la famille et de la filiation. Certes, les juges constitutionnels et les référendaires sont assez intelligents pour se documenter, mais ils ne sont pas des spécialistes de la matière. En deuxième lieu, Marc Verdussen craint qu'en accentuant le rôle du juge constitutionnel dans les contrôles concrets, on éloigne le juge du cœur de sa mission c'est-à-dire d'avoir un rôle principiel. Le risque, avec le contrôle de la microconstitutionnalité, est que le juge ne puisse plus jouer ce rôle qui consiste à dégager des principes et non seulement des solutions, selon l'idée de Dominique Rousseau. Lorsqu'on demande au juge constitutionnel de faire de la microconstitutionnalité, il développe lui-même des principes protecteurs, voire des mécanismes d'autodéfense. Ainsi en Italie, selon Jean-Jacques Pardini, la Cour constitutionnelle oblige les juges à faire des efforts d'interprétation et s'ils ne le font pas, le recours peut être considéré comme irrecevable. En Espagne, un recours d'Amparo peut être considéré comme étant irrecevable si on ne démontre pas qu'il y a une importance constitutionnelle spéciale. La violation présumée du droit fondamental ne suffit pas. Ainsi, il existe des mécanismes auto-protecteurs des juges constitutionnels. Cela ne manifeste-t-il pas une préoccupation du juge qu'il faille revenir à l'essentiel ?

Marc Verdussen souhaite répondre enfin à une affirmation de Bertrand Mathieu selon laquelle le contrôle concret serait une forme d'empiétement sur l'autonomie du législateur. Marc Verdussen n'est pas d'accord. Pour lui, la normativité législative doit rester abstraite et les juges constitutionnels qui font du contrôle concret le rappellent. On ne peut pas exiger que le législateur fasse du concret. C'est là le rôle du juge. Le juge ne vient pas se substituer au législateur mais le compléter et l'affiner. Ainsi il n'y a pas de risques de gouvernement des juges et encore moins quand il y a un contrôle concret. La difficulté « contre-majoritaire » est moins épineuse lorsqu'il s'agit d'un contrôle concret. Marc Verdussen ajoute qu'en Belgique, lorsque la Cour constitutionnelle répond à une question préjudicielle, concrète ou abstraite, la décision n'abroge pas et n'annule pas la norme. La norme est juste inappliquée. Ensuite, le législateur doit en tirer les conséquences. Ici, le législateur est peut-être davantage préservé que si la norme devait être abrogée ou annulée. 
Bertrand Mathieu souhaite rebondir sur les propos de Caterina Severino. Il est vrai que la QPC a été créée pour rapatrier le contrôle du respect des droits et libertés fondamentaux. Mais la Cour européenne des droits de l'homme est gagnante dans le système. Elle n'a peut-être pas toujours le dernier mot, mais elle a le dernier mot quand elle veut avoir le dernier mot. Le principe de subsidiarité l'arrange. Une question subsidiaire est une question que la Cour européenne laisse au juge national le soin de trancher et une question non subsidiaire est une question qui l'intéresse. Ceci se constate à travers un certain nombre de décisions. Fréderic Sudre, qui n'est pas un adversaire farouche de la Cour EDH, démontre que le principe de subsidiarité est appliqué de manière aléatoire. La seule solution est d'appliquer à la Convention EDH la notion de «principe inhérent à l'identité constitutionnelle de la France ». De quoi s'agit t-il ? Déterminer ce qui relève de ces principes inhérents ne doit pas nécessairement être établi a priori. Il s'agit d'une arme de dissuasion. Elle offre au législateur et au juge national une possibilité de résister. En réalité nous assistons à un théâtre d'ombres. Dans les commentaires du Conseil constitutionnel sur son site internet, on constate que, parfois, la moitié du commentaire est consacré à la jurisprudence de la Cour européenne des droits de l'homme. Pourquoi ? Parce que le Conseil constitutionnel craint fondamentalement de se faire désavouer par la Cour. Ainsi, c'est un mécanisme de soumission qui est à l'œuvre.

Sur la notion de contrôle concret, Bertrand Mathieu est d'accord avec Marc Verdussen, sauf qu'il y a des cas ou le juge ordinaire français décide de ne pas appliquer la loi en allant ainsi contre la volonté même du législateur. Cela a été le cas, par exemple, s'agissant de la décision du Conseil d'État sur l'insémination post mortem, dans laquelle le Conseil d'État dit que la loi n'est pas contraire à la CEDH mais que, pour des raisons diverses et pratiques, il ne l'applique pas tout de même, car il prend en compte le cas concret. Ici, il y a une violation de la volonté même du législateur. Le législateur n'a pas voulu laisser d'angle mort ni laisser d'exception. La Cour de cassation a eu la même interprétation concernant des gestations pour autrui réalisées à l'étranger. Dans ces cas-là, il y a des empiétements clairs, nets, voulus et assumés par le juge sur la compétence du législateur.

Jean-Jacques Pardini revient sur la question soulevée par Caterina Severino et souhaite apporter une précision concernant le juge constitutionnel italien. Par un arrêt n ${ }^{\circ} 49$ de 2015, dans son considérant $n^{\circ} 4$, la Cour constitutionnelle affirme que le raisonnement du juge de renvoi est erroné de deux points de vue. D'abord, le juge de renvoi suppose que c'est au juge de Strasbourg de déterminer le sens de la loi nationale. Or, ce n'est pas le cas. Le juge européen doit apprécier si la loi, telle qu'appliquée par les autorités nationales, a généré des violations de la Convention EDH. La Convention EDH et non la loi vit dans sa dimension herméneutique. Cela signifie que rien n'empêche l'interprétation conforme à la Convention EDH de la loi, mais qu'il faut également et prioritairement une lecture conforme à la Constitution et cela ressort des arrêts n ${ }^{\text {os }} 348$ et 349 de 2007. La Cour constitutionnelle est l'organe de clôture au regard de la supériorité axiologique de la Constitution sur la Convention européenne des droits de l'homme. 
Bertrand Mathieu est persuadé que le grand oublié de ces procédures est le justiciable. Le justiciable est seulement celui qui lance le processus. Bertrand Mathieu est favorable à ce qu'il y n'ait pas uniquement des professeurs de droit dans une Cour constitutionnelle comme en Allemagne car le risque est de trop théoriser le débat. Faut-il intégrer des justiciables dans le système ? Il faudrait un mélange au sein des conseils et ce mélange permettrait de ne pas oublier le justiciable. On ne peut pas toujours critiquer les hommes politiques. Un homme politique, quand bien même fusse-t-il éloigné du justiciable, est toujours plus proche du justiciable qu'un professeur de droit ou qu'un juge. Un bon système constitutionnel et juridictionnel est un système qui répond aux besoins des citoyens et non un système qui répond aux critères abstraits des professeurs de droits.

Anne Levade conclut la séance et clôture la première journée du colloque. 
Partie III

\section{Coexistence des VOIES DE RECOURS ET ARTICULATION DES CONTRÔLES}



$\mathrm{Si}$, comme nous l'avons vu, le contrôle de constitutionnalité des décisions de justice a pu faire son entrée devant le prétoire des juges de la constitutionnalité des normes (y compris celui des juges suprêmes) par le biais des procédures analysées dans les deux premières parties de cet ouvrage, la question fondamentale de l'articulation entre les différents types de contrôle et des effets que cette articulation produit à l'égard de la protection des droits fondamentaux reste à explorer. Trois hypothèses peuvent ainsi être retenues.

Tout d'abord, l'hypothèse qui peut se produire dans les systèmes connaissant la voie préjudicielle, comme les systèmes français ou italien, dans lesquels la coexistence d'un recours devant le juge du filtre et d'un éventuel recours devant le juge constitutionnel concernant la même question de constitutionnalité peut conduire à des conflits entre ces juges, voire à une véritable appropriation, par les juges du filtre, du contrôle de constitutionnalité de leur propre jurisprudence. Par ailleurs, par le biais de l'interprétation conforme, les juges du filtre peuvent également faire évoluer leur propre jurisprudence et l' « assainir » ainsi du point de vue de sa constitutionnalité, sans l'intervention du juge constitutionnel. Quelles sont les conséquences de ces chevauchements ? Cela comporte-t-il des risques pour les droits du justiciable?

Concernant, ensuite, les systèmes dans lesquels il existe à la fois un recours individuel de constitutionnalité des décisions de justice et un recours de constitutionnalité de la loi par la voie préjudicielle, comme cela est le cas en Espagne ou en Allemagne, la question se pose de savoir quels sont les effets concrets produits par cette coexistence et si des effets pervers peuvent être décelés, en termes de protection des droits fondamentaux. Des spécificités qui font que passer par l'un s'avère être mieux que passer par l'autre sont-elles notables ? Et qu'en est-il, dans des systèmes si " perfectionnés » et si «poussés » d'un point de vue du contrôle de la constitutionnalité des normes, de la jurisprudence des juges européens à leur égard?

Enfin, dans le système français, la coexistence entre le contrôle de conventionnalité et le contrôle de constitutionnalité des décisions de justice doit être analysée, pour comprendre, dans cette hypothèse aussi, si des spécificités peuvent être constatées et pour comparer ces deux types de contrôle d'un point de vue de l'efficacité de la protection des droits du justiciable. 



\section{Présidence de Madame Nicole Belloubet, Membre du Conseil constitutionnel}

$\mathrm{M}^{\text {me }}$ Belloubet indique qu'alors même que les réformes concernant le système constitutionnel français sont relativement récentes, ce colloque s'interroge déjà sur leur dépassement. La question posée est tout à fait légitime car tout système est destiné à évoluer. Si la question prioritaire de constitutionnalité (QPC) constitue indiscutablement un progrès, cela n'exclut nullement que l'on se penche sur ses acquis pour les évaluer et que des améliorations puissent être envisagées, pour le futur, au bénéfice des justiciables.

Les statistiques montrent en effet que, dans la plupart des cas, ce ne sont pas les simples particuliers, les justiciables ordinaires qui ont accès au Conseil constitutionnel (CC), par le biais de la QPC. Ces questions sont déposées par des requérants qui sont soit des associations ayant pignon sur rue, soit des entreprises, soit des plaignants singuliers comme Monsieur Cahuzac dans le cadre de litiges emblématiques ${ }^{1}$. Les interventions qui portent sur environ $25 \%$ des dossiers reçus, revêtent les mêmes caractéristiques².

Les statistiques démontrent également qu'un peu moins de 5\% des parties n'ont pas d'avocat et, en conséquence, ne plaident pas ; 62 à $63 \%$ des parties font appel à un avocat au Conseil d'État (CE) ou à la Cour de cassation (C. Cass) ; $35 \%$ font appel à un avocat à la cour : parmi ces derniers le nombre des avocats au barreau de Paris augmente progressivement (49 \% en 2011 mais 71 \% en 2016) au détriment des barreaux de province.

Ces éléments chiffrés témoignent de l'ouverture du prétoire du Conseil constitutionnel aux justiciables mais il est toujours possible de réfléchir intellectuellement à élargir les voies d'accès à la justice constitutionnelle. Il est toutefois essentiel de garder à l'esprit que toute modification procédurale aurait nécessairement des incidences sur les deux cours suprêmes que sont la Cour de cassation et le Conseil d'État. Tout cela doit donc être envisagé d'une manière cohérente et globale, d'autant plus que toute évolution systémique de cette nature est une question politique. Elle a des incidences complexes, à la fois en termes de régulation du contentieux devant les cours suprêmes et devant le Conseil constitutionnel.

\footnotetext{
1 Au 31 mai 2016, sur 545 dossiers QPC, 259 ont été portés par des personnes physiques, 268 par des personnes morales (entreprises et associations) et 28 par des collectivités territoriales.

2 Au 31 mai 2016, sur 500 interventions, 78 sont le fait d'associations, 89 de collectivités territoriales, 78 d'entreprises, 29 de syndicats, 32 de diverses personnes et 194 de particuliers. Mais on trouve dans ce dernier chiffre les interventions dites de séries comme, par exemple, 40 intervenants dans la QPC 2013-363 : limitation du droit d'appel de la partie civile à ses intérêts civils ou 50 pour la QPC 2012-297 QPC : traitement des pasteurs des églises consistoriales..
} 
L'organisation de la QPC a bouleversé, nous l'analyserons amplement, le rapport de l'ensemble des juridictions au contrôle de constitutionnalité. À l'heure actuelle, le Conseil constitutionnel juge une centaine de QPC par an. Si l'accès devait en être élargi, cela supposerait sans doute une autre organisation, une autre composition, d'autres modalités de travail. Une telle réforme devrait également être mise en perspective avec les modèles existants devant les juridictions constitutionnelles étrangères dont les organisations diffèrent selon les États. Plusieurs systèmes pourraient être imaginés : une section d'instruction au sein du Conseil constitutionnel, une QPC avec un filtre élargi, un système laissant au Conseil la possibilité d'évoquer des questions principielles au regard de leur constitutionnalité ... Toutefois, aucune de ces voies d'accès n'est sans incidence sur le système de justice qui fonctionne actuellement en France. C'est donc un sujet qui doit être nécessairement tranché au niveau du Parlement.

Les rapports entre contrôle de constitutionnalité et contrôle de conventionnalité seront également abordés. C'est un thème éminemment sensible qui conjugue la question de l'office des juges, celle des modalités d'exercice de leur contrôle, celle enfin de la primauté du droit international et notamment du droit de l'Union européenne (UE). Les jurisprudences récemment intervenues en ce domaine ouvrent de nouveaux chemins de réflexion.

L'ensemble de ces éléments conduit à une réflexion sur le positionnement du Conseil constitutionnel en tant que cour suprême. L'office du Conseil constitutionnel le situe aujourd'hui dans une relation juridictionnalisée tant à l'égard des justiciables qui se présentent devant lui pour faire trancher, par la QPC, un procès dans le procès, qu'à l'égard des diverses juridictions avec lesquelles s'établit un rapport d'étroite interdépendance. Il n'est pas interdit que l'aboutissement de ce processus vers une réelle juridictionnalisation du Conseil constitutionnel fasse l'objet de questionnements sur l'ensemble du système français et sur la manière dont s'y insère non seulement la « cour constitutionnelle » mais peut-être la « cour suprême » qui serait en germe dans ces évolutions.

$\mathrm{M}^{\mathrm{me}}$ Belloubet indique cependant qu'elle n'est pas certaine que ces voies doivent nécessairement être ouvertes dès aujourd'hui tant le système de contrôle a posteriori mis en place en France est jeune et doit s'apprécier sur un temps long. Mais aiguiser l'esprit critique n'est jamais inutile pour les inflexions futures! 


\title{
Chapitre 1
}

\author{
LE CONTRÔLE \\ PAR LES JURIDICTIONS SUPRÊMES \\ DE LEUR PROPRE JURISPRUDENCE
}





\section{Madame Nicole Belloubet, Membre du Conseil constitutionnel}

À l'intervention réelle des cours suprêmes dans le contrôle de constitutionnalité de la loi, répond la prise en compte par le Conseil constitutionnel de la jurisprudence par elles appliquée.

Les cours suprêmes effectuent un contrôle de constitutionnalité de la loi appliquée en tant que juges du filtre. Les critères nécessaires à la transmission de la QPC sont connus : applicabilité au litige, absence de déclaration préalable de conformité à la Constitution et question nouvelle ou présentant un caractère sérieux. Ces critères, et notamment le troisième, permettent à la Cour de cassation et au Conseil d'État de vérifier que l'examen des conditions cumulatives a bien été réalisé par le juge $\mathrm{du}$ fond mais surtout d'effectuer un véritable tri entre les questions constitutionnelles sur la base de leur caractère sérieux. Ce faisant elles exercent un véritable contrôle de constitutionnalité de la loi appliquée. Les statistiques témoignent d'une certaine stabilité dans la transmission des QPC avec des variations entre Conseil d'État et Cour de cassation voire même selon les chambres au sein de la Cour de cassation. Le maintien d'un taux à peu près constant de renvoi ${ }^{1}(21,15 \%$ et $78,85 \%$ de nonrenvoi) est toutefois un indice de fonctionnement correct du système !

Les cours suprêmes assurent également la diffusion de la doctrine constitutionnelle. Dans une jurisprudence récente, le Conseil d'État juge que « les réserves d'interprétation dont une décision du Conseil constitutionnel assortit la déclaration de conformité à la Constitution d'une disposition législative sont revêtues de l'autorité absolue de la chose jugée et lient le juge administratif pour l'application et l'interprétation de cette disposition ${ }^{2} »$. Cet arrêt témoigne de l'effectivité des décisions QPC dont la teneur est prise en compte par les juridictions administratives et judiciaires, en dépit de quelques contournements à l'exemple de la Cour de cassation qui a parfois pris appui sur le droit européen pour anticiper l'abrogation d'une disposition législative décidée par le Conseil constitutionnel.

\footnotetext{
1 Le taux de renvoi évolue chaque année : de 24,72\% en 2010 à $27,88 \%$ en 2016. Corrélativement le taux de non-renvoi est passé de $75,28 \%$ en 2010 à $72,12 \%$ en 2016.

2 CE, 8 juin 2016, n 383259 : «Considérant qu'il résulte de ce qui précède que les commentaires attaqués doivent être annulés en tant qu'ils concernent l'imposition des dividendes ; qu'ils doivent l'être également en tant qu'ils concernent les plus-values de cession, dès lors que, eu égard à l'objectif de sécurité juridique poursuivi par l'article L. 80A du livre des procédures fiscales, les instructions ou circulaires fiscales dont un contribuable peut, dans les conditions définies par cet article, se prévaloir doivent être appliquées littéralement et ne sauraient donc faire l'objet d'une interprétation permettant d'en faire une application conforme aux normes qu'elles doivent respecter ; qu'il suit de là, sans qu'il soit besoin d'examiner les autres moyens de la requête, que les requérantes sont fondées à demander l'annulation de l'ensemble des commentaires qu'elles attaquent ; ».
} 
De son côté, le Conseil constitutionnel réalise au moyen de la QPC un contrôle de la jurisprudence appliquée. Ce contrôle des décisions de justice n'a lieu que de manière occasionnelle lorsque la question soulevée s'y prête.

Tantôt, pour effectuer son contrôle de la disposition contestée, le Conseil prend appui sur la jurisprudence constante des cours suprêmes. Il a ainsi très rapidement admis qu'il devait apprécier la validité de la loi appliquée en tenant compte de l'interprétation jurisprudentielle constante de celle-ci par les juridictions suprêmes. En effet, « en posant une question prioritaire de constitutionnalité, tout justiciable a le droit de contester la constitutionnalité de la portée effective qu'une interprétation jurisprudentielle constante confère à la disposition législative contestée ${ }^{3} »$. Il s'agit, en réalité, d'un contrôle incident de la constitutionnalité de la jurisprudence suivie.

Tantôt le Conseil constitutionnel invoque un changement de circonstances de droit pour réinterroger sa propre jurisprudence. Cette théorie du changement des circonstances prend appui sur les décisions de justice. Dans une décision QPC de Juillet 2013, Société Numéricâble SAS ${ }^{5}$, le Conseil constitutionnel a reconnu un double changement des circonstances de droit. Il a tout d'abord considéré que des modifications textuelles introduites postérieurement à une disposition déjà jugée interdisaient de considérer que les dispositions contestées avaient déjà été jugées conformes à la Constitution. Il a par ailleurs relevé que l'évolution de sa propre jurisprudence constituait un changement des circonstances de droit ${ }^{6}$. Il s'agit moins d'un contrôle en tant que tel que de la reconnaissance de la validité constitutionnelle d'une décision de justice fondatrice d'un changement de circonstances ${ }^{7}$.

Par ces deux techniques, la prise en compte de la jurisprudence constante des cours suprêmes et la théorie du changement des circonstances, le Conseil constitutionnel prend appui sur les décisions de la Cour de cassation et Conseil d'État. Il rejoint ainsi la théorie du droit vivant proposée par le juge italien selon laquelle c'est la constitutionnalité de loi, telle qu'elle est effectivement interprétée constamment et appliquée par le juge ordinaire, qui doit être contrôlée par le juge constitutionnel.

C'est la nature même de ce trilogisme qui va maintenant être analysée par les différents intervenants.

\footnotetext{
3 Décision n 2011-127 QPC du 6 mai 2011, Consorts C. [Faute inexcusable de l'employeur : régime spécial des accidents du travail des marins], cons. 5.

Michel Fromont, fustice constitutionnelle comparée, Dalloz, 2013, p. 220.

Décision n²013-331 QPC du 5 juillet 2013, Société Numéricâble SASet autre [Pouvoir de sanction del'Autorité de régulation des communications électroniques et des postes], cons. 8.

6 Sa décision $\mathrm{n}^{\circ}$ 2012-280 QPC du 12 octobre 2012 dans laquelle il a jugé « que, lorsqu'elles prononcent des sanctions ayant le caractère d'une punition, les autorités administratives indépendantes doivent respecter notamment le principe d'impartialité découlant de l'article 16 de la Déclaration de $1789 »$ constituait un changement de circonstances de droit. Dans le même sens voir :

Décision n ${ }^{\circ}$ 2016-545 QPC M. Alec W. et autre [Pénalités fiscales pour insuffisance de déclaration et sanctions pénales pour fraude fiscale] du 24 juin 2016 : la décision du 18 mars 2015 EADS constitue un changement de circonstances de droit.

Décision n 2011-120 QPC du 8 avril 2011 M. Ismaël A. [Recours devant la Cour nationale du droit d'asile] «9. Considérant, en dernier lieu, que, si, en posant une question prioritaire de constitutionnalité, tout justiciable a le droit de contester la constitutionnalité de la portée effective qu'une interprétation jurisprudentielle constante confère à cette disposition, la jurisprudence dégagée par la Cour nationale du droit d'asile n'a pas été soumise au Conseil d'État; qu'il appartient à ce dernier, placé au sommet de l'ordre juridictionnel administratif, de s'assurer que cette jurisprudence garantit le droit au recours rappelé au considérant 87 de la décision du Conseil constitutionnel du 13 août 1993 ; que, dans ces conditions, cette jurisprudence ne peut être regardée comme un changement de circonstances de nature à remettre en cause la constitutionnalité des dispositions contestées »;

7 Décision n ${ }^{\circ}$ 2015-512 QPC du 8 janvier 2016, M. Vincent R. [Délit de contestation de l'existence de certains crimes contre l’humanité].
} 


\section{LE CAS de LA France}

\section{TABLE RONDE}

Afin de traiter la question du contrôle, par les Cours suprêmes, de leur propre jurisprudence, dans le cadre du filtre des QPC, et des problèmes que cela pose, une table ronde a été organisée en présence de Mathieu Disant, Professeur à l'Université de Lyon Saint-Etienne, Caterina Severino, Maître de conférences HDR à l'Université de Toulon, Jacques Arrighi de Casanova, Président de section au Conseil d'État, Daniel Ludet, Conseiller à la Chambre sociale de la Cour de cassation et Olivier Talabardon, Conseiller référendaire à la Chambre criminelle de la Cour de cassation.

Monsieur Disant et Madame Severino ont introduit la table ronde par deux interventions. Mathieu Disant a dressé un état des lieux, en analysant le cadre et les modalités concrètes de ce contrôle. Caterina Severino s'est interrogée sur les avantages et les risques d'un tel contrôle, notamment à l'égard de la problématique centrale du colloque qui est celle d'une meilleure protection des droits et libertés des justiciables.

Les juges ont apporté leurs réponses aux questions posées par les deux intervenants. 



\title{
LE CONTRÔLE PAR LES JURIDICTIONS SUPRÊMES DE LEUR PROPRE JURISPRUDENCE L'EXCEPTION JURISPRUDENTIELLE EN QPC
}

\author{
Mathieu DisANT ${ }^{1}$
}

La question du contrôle, par les Cours suprêmes, de leur propre jurisprudence, lors du filtre des QPC est un sujet peu étudié en tant que tel, très difficile à dépouiller dans la mesure où il rassemble, en les combinant, les différents problèmes, tant théoriques que pratiques, relatifs à l'office du juge de renvoi, que ce soit en matière d'interprétation ou plus largement d'implication dans le contrôle de constitutionnalité.

Dans la présente contribution ${ }^{2}$, il s'agit de dresser un état des lieux « analytique » en présentant le cadre restreint et les modalités singulières de ce contrôle, sur la base d'une analyse des décisions de non-renvoi - cette matière brute dont il est parfois difficile de percer tous les mystères, plus encore dans le sujet qui nous occupe dans ces lignes ${ }^{3}$. Comment situer ce contrôle dans le mécanisme particulier de la QPC ? Quelles sont les principales questions qu'il soulève ? Peut-on établir certaines pratiques ou orientations?

À vrai dire, la manière de formuler le sujet est elle-même problématique. Que faut-il entendre par « jurisprudence »? S'agit-il d'un véritable « contrôle » de constitutionnalité qui serait (ou devrait être) exercé sur elle ? En définitive, comment nommer l'ambiguïté de cet office autocentré ?

Cela fait beaucoup de questions à traiter. Il faut se contenter de pointer quelques situations critiques pour mieux comprendre ce que signifie « contrôler » sa propre « jurisprudence » et ce que cela implique dans et pour l'équilibre contentieux de la QPC.

Professeur à l’Université Lyon Saint-Étienne, Jean Monnet, Directeur du CERCRID (UMR CNRS 5137).

On se reportera à la contribution de Caterina Severino pour une perspective dynamique voire programmatique, sur les avantages et les risques d'un tel contrôle.

3 L'étude jurisprudentielle s'arrête à juin 2016. 


\section{Sur la notion de « jurisprudence », objet du contrôle}

Le Conseil d'État et la Cour de cassation reprennent les conditions posées par le Conseil constitutionnel en la matière ${ }^{4}$. Le critère pertinent est « la portée effective qu'une interprétation jurisprudentielle constante » confère à la disposition législative, sous la réserve que cette jurisprudence ait été soumise à la cour suprême compétente.

Le Conseil d'État retient « qu'en posant une QPC, tout justiciable a le droit de contester la constitutionnalité de la portée effective qu'une interprétation jurisprudentielle constante confère à cette disposition ». La Cour de cassation précise que « la contestation doit concerner la portée que donne à une disposition législative précise l'interprétation qu'en fait la juridiction suprême de l'un ou l'autre ordre $»^{5}$.

Trois conditions doivent donc être réunies : l'interprétation doit porter sur une disposition législative précise ; l'interprétation doit émaner de la cour suprême compétente ; l'interprétation jurisprudentielle doit être constante.

1. Chacune de ces conditions appelle des observations. À plusieurs reprises, Conseil d'État et Cour de cassation ont livré des précisions sur ce que l'on doit entendre par ces différents critères. Leurs frontières sont perméables. Leur maniement n'est pas toujours clair. On peut retenir que le champ du contrôle est strictement délimité.

Que l'interprétation doive émaner de la cour suprême compétente, cela exclut notamment l'interprétation «prêtée » par le demandeur au jugement de tribunaux 6 . Pas plus qu'il n' " existe » d'interprétation jurisprudentielle constante issue, par exemple, de la Caisse nationale assurance vieillesse $^{7}$ ou des instructions fiscales ${ }^{8}$.

Que l'interprétation jurisprudentielle doive être constante, cela conduit la Cour à vérifier que l'auteur de la QPC n'a pas fait une interprétation erronée de la jurisprudence qu'il critique9. La cour de cassation est régulièrement amenée à juger que, contrairement aux affirmations des requérants, il n'y a pas de jurisprudence constante posant la règle contestée. C'est souvent le contenu même de l'interprétation qui est jugé erroné, sans que la Cour ne profite toujours de cette occasion pour clarifier cette interprétation.

La situation est quelque peu différente lorsque la question posée ne conteste qu'une interprétation supposée ou projetée que ferait la Cour lors de l'examen d'un pourvoi ${ }^{10}$. Dans une telle hypothèse,

Cons. const., $\mathrm{n}^{\circ} 2011-120$ QPC du 8 avril 2011.

Soc., 28 novembre 2012, $\mathrm{n}^{\circ} 11-17.941$ et 3 juillet 2014, $\mathrm{n}^{\circ}$ 14-40.026 ; Com., 24 avril 2013, $\mathrm{n}^{\circ}$ 12-23.486 et 27 novembre $2014, \mathrm{n}^{\circ} 14-16.644$; $1^{\text {re }}$ civ, 8 décembre $2011, \mathrm{n}^{\circ} 11-40.070$ et 13 février $2013, \mathrm{n}^{\circ} 12-19.354$ et 27 février $2013, \mathrm{n}^{\circ} 12-40.100 ; 2^{\mathrm{e}}$ civ., 12 juin $2014, \mathrm{n}^{\circ} 14-40.022$.

Soc. 31 mai 2011, $\mathrm{n}^{\circ} 11-13.256$

Par ex. $2^{\text {e }}$ civ., 12 juin $2014, \mathrm{n}^{\circ} 14-40.022$

$3^{\text {e }}$ civ., 25 septembre $2013, \mathrm{n}^{\circ} 13-40.046$.

Soc. 16 novembre $2011, \mathrm{n}^{\circ} 11-40.071 ; 1^{\text {re }}$ civ., 6 juin $2012, \mathrm{n}^{\circ} 12-40.028$

$10 \quad$ Par ex. $1^{\text {re }}$ civ., 13 février 2013, $n^{\circ} 12-19.354$. 
la QPC se borne en réalité à poser tout bonnement la question de l'interprétation de la loi ${ }^{11}$. La Cour juge alors la QPC sans objet.

On ajoutera que la Cour vérifie s'il existe bien « en l'état » une interprétation jurisprudentielle constante de la disposition législative critiquée ${ }^{12}$. Dans le cas contraire, la question est soit non sérieuse ${ }^{13}$, soit sans objet ${ }^{14}$, soit irrecevable ${ }^{15}$. Ainsi, par exemple, un seul arrêt de rejet n'a pas constitué une jurisprudence constante ${ }^{16}$. La multiplicité des situations de fait laissées à l'appréciation souveraine des juges du fond et l'absence d'un arrêt cassant une cour d'appel du fait d'une application erronée de la disposition contestée conduit la Cour à considérer qu'il n'existe pas de jurisprudence constante ${ }^{17}$.

2. Plus important encore, l'interprétation doit porter sur une disposition législative précise.

Une série de balises ont été posées sur ce point. Par exemple, la Cour de cassation ne renvoie pas les QPC qui ne critiquent pas la disposition législative en elle-même, singulièrement lorsque la QPC 《 ajoute » au texte « une restriction qu'il ne comporte pas ${ }^{18}$. Est tout autant jugé irrecevable une QPC qui porte, sous couvert de la critique des dispositions législatives, à contester l'interprétation des dispositions réglementaires ${ }^{19}$.

Trois paramètres parmi les plus délicats méritent attention.

En premier lieu, est exclue - comme irrecevable - la critique de la seule jurisprudence, c'està-dire la contestation $\mathrm{d}^{\prime}$ ' une règle jurisprudentielle sans préciser le texte législatif dont la portée serait, en application de cette règle, de nature à porter atteinte » au principe constitutionnel invoqué ${ }^{20}$. Le refus de contrôler la règle jurisprudentielle « nue »ou « pure », c'est-à-dire non rattachable à une disposition législative, a fait l'objet d'un récent arrêt de la chambre sociale, du 17 février 2016, publié au bulletin, qui refuse de renvoyer une QPC fondée sur l'interdiction d'édicter des arrêts de règlement ${ }^{21}$. Ne sont donc pas examinées les QPC portant sur une règle de source uniquement jurisprudentielle, autrement dit la « jurisprudence prétorienne » dénuée de fondement législatif. Par exemple, la $1^{\text {re }}$ chambre civile a écarté une QPC qui « porte exclusivement sur la soumission jurisprudentielle au droit civil commun procédural des actions auxquelles (l'article 9 du code civil) donne lieu, en l'absence de textes spécifiques, sans dénoncer de dispositions précises régissant le

11 Par exemple, dans l'affaire $1^{\text {re }}$ civ., 13 février 2013, $\mathrm{n}^{\circ}$ 12-19.354, il s'agit, sous couvert d'une critique de constitutionnalité, de poser la question de ce qu'il faut entendre par « le tribunal statue sur les contestations subsistant entre les parties »... et c'est précisément la question posée par le pourvoi.

12 Com. 21 février 2012, n 11-23.097; 29 janvier 2013, nº 12-40.089; 24 avril 2013, n 12-23.486 et 12-23.487 ; 27 novembre 2014 , n $14-16.644$.

Com. 21 février $2012, \mathrm{n}^{\circ} 11-23.097 ; 24$ avril $2013, \mathrm{n}^{\circ} 12-23.486$ et $12-23.487$

Com. 29 janvier $2013, \mathrm{n}^{\circ} 12-40.089 ; 1^{\text {re }}$ civ. 13 février $2013, \mathrm{n}^{\circ} 12-19.354$

Com. 27 novembre $2014, \mathrm{n}^{\circ} 14-16.644$.

Com. 23 mars $2013, n^{\circ} 12-23.486$ et $12-23.487$

Par ex., $3^{\mathrm{e}}$ civ., 20 mars 2014, $\mathrm{n}^{\circ} 13-24.439$.

$2^{\mathrm{e}}$ civ., 22 mai $2014, \mathrm{n}^{\circ} 14-40.019$.

Soc. 11 juillet $2013, \mathrm{n}^{\circ} 13-40.022 ; 2^{\mathrm{e}}$ civ. 12 octobre $2011, \mathrm{n}^{\circ} 11-14.490$

$1^{\text {re }}$ civ., 27 septembre $2011, \mathrm{n}^{\circ} 11-13.488 ; 1^{\text {re }}$ civ., 27 février $2013, \mathrm{n}^{\circ} 12-40.100$; Soc. 3 juillet $2014, \mathrm{n}^{\circ} 14-40.026$

Soc., 17 février 2016, n 15-40042, Bull. 
délai de leur prescription $»^{22}$. La chose est entendue : la possibilité de contester le texte tel qu'interprété ne transforme pas la QPC en procédure de contrôle des décisions jurisprudentielles ${ }^{23}$. Prendre à la lettre cette position, c'est considérer que l'examen de constitutionnalité qui prend pour objet la règle jurisprudentielle - sous-entendu « détachable » - soit bénéficie paradoxalement d'une sorte d'immunité (alors que son fondement est par hypothèse le moins assurée ${ }^{24}$ ), soit pourrait s'exercer hors QPC par le biais d'une exception d'inconstitutionnalité ${ }^{25}$. Le sujet rejoint alors la problématique plus générale de la place de la Constitution dans le contrôle opéré par le Conseil d'État et la Cour de cassation. Dans ces conditions, faudrait-il composer avec un double statut contentieux de la jurisprudence selon son identité normative et son degré de mixité textuelle ? Et dans l'application de cette distinction, comment dissocier l'entre-deux jurisprudentiel et établir une échelle objectivée d'ancrage textuel alors que, nous le savons, « la construction de la règle repose souvent sur l'action conjuguée de différentes sources $»^{26}$ ?

La question se complique si l'on tient compte d'un second paramètre. Les cours refusent de renvoyer des QPC qui critiquent, d'une façon ou d'une autre, l'office du juge consistant à appliquer la loi. C'est-à-dire lorsque la QPC est considérée comme critiquant « des arrêts qui (ne font) que tirer les conséquences s'inférant (de l'application de la loi) $»^{27}$. La Cour de cassation vérifie à cet égard que la critique porte bien sur l'interprétation de la loi et non sur sa simple application (par la cour d'appel ${ }^{28}$. Par exemple, a été jugée non sérieuse une QPC qui critiquait « une méthode d'évaluation des biens expropriés que les juges du fond peuvent souverainement retenir $»^{29}$. Dans le même esprit, la question n'est pas jugée sérieuse si « sous couvert d'une prétendue atteinte à la Constitution qui serait portée par un texte de loi ou par son application jurisprudentielle ancienne et constante [...], la question ne tend qu'à contester l'application de cette jurisprudence à des circonstances particulières de fait $»^{30}$. Tout comme est jugée irrecevable par la chambre criminelle une QPC qui « ne revient [...] qu'à contester la conformité de l'interprétation avec le libellé du texte législatif en cause $»^{31}$. Ou encore le refus, par les chambres civiles, de transmettre des QPC qui critiquent l'interprétation faite de la disposition législative dans l'instance en $\operatorname{cours}^{32}$, notamment à l'occasion d'un deuxième pourvoi ${ }^{33}$. Toutes ces solutions rappellent, qu'on l'approuve ou pas, que le contrôle de constitutionnalité à la française est un contrôle abstrait des normes générales, pas des normes particulières que sont les décisions, sans pour autant être un contrôle de la règle jurisprudentielle.

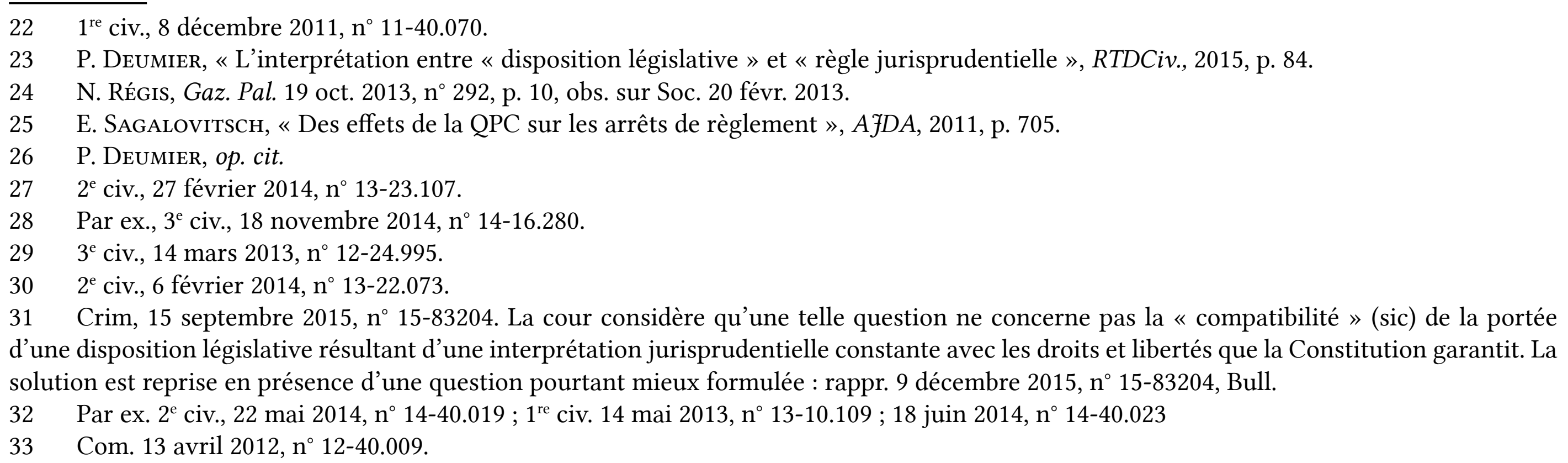

Crim, 15 septembre 2015, $\mathrm{n}^{\circ}$ 15-83204. La cour considère qu'une telle question ne concerne pas la « compatibilité » (sic) de la portée d'une disposition législative résultant d'une interprétation jurisprudentielle constante avec les droits et libertés que la Constitution garantit. La solution est reprise en présence d'une question pourtant mieux formulée : rappr. 9 décembre 2015, $\mathrm{n}^{\circ}$ 15-83204, Bull.

32 Par ex. $2^{\text {e }}$ civ., 22 mai $2014, \mathrm{n}^{\circ} 14-40.019 ; 1^{\text {re }}$ civ. 14 mai $2013, \mathrm{n}^{\circ} 13-10.109 ; 18$ juin $2014, \mathrm{n}^{\circ} 14-40.023$

33 Com. 13 avril 2012, n 12-40.009. 
Ajoutons à cela, en troisième lieu, que sont jugées irrecevables - par la Cour de cassation au moins - les QPC qui critiquent une interprétation de plusieurs dispositions législatives ou principes combinés. Ce qui concerne aussi l'articulation qui peut être faite entre plusieurs dispositions par la jurisprudence critiquée. Il en été jugé ainsi par la chambre sociale à propos de la règle jurisprudentielle selon laquelle les dispositions d'une clause de non-concurrence qui minorent la contrepartie financière en cas de rupture imputable au salarié sont réputées non écrites ${ }^{34}$. Dans cette affaire, des dispositions législatives étaient bien visées (article 1134 du code civil et L. 1121-1 du code du travail), et la jurisprudence était bien énoncée au visa de ces textes. Mais la Cour, suivant son rapporteur, a considéré que la jurisprudence contestée n’avait pas été énoncée au seul visa des dispositions critiquées - elle reposait aussi sur plusieurs autres combinaisons normatives impliquant le principe fondamental de libre exercice d'une activité professionnelle. La contestation d'une règle jurisprudentielle énoncée «notamment » au visa des textes contestés est donc jugée irrecevable. Seule une relation d'exclusivité donne prise à la QPC ! On peut, là encore, s'interroger sur cette restriction, alors que la jurisprudence est de plus en plus appelée à assurer une mise en cohérence des textes par la détermination de leur applicabilité respective.

Bilan : pas de critique de la seule jurisprudence, mais pas non plus de critique des décisions de justice en tant que norme juridictionnelle, et pas de critique de l'interprétation combinée des dispositions législatives. On admettra que la fenêtre de tir, sans être inexistante, est assez étroite. Et que les requérants doivent y fonder des espoirs très mesurés.

\section{Le non-lieu à renvoi de la jurisprudence}

La critique de la jurisprudence par le biais des QPC n'est pas toujours examinée par la Cour de cassation ou le Conseil d'État lorsque celle-ci constate que la QPC n'est pas recevable, par exemple pour défaut de motivation ${ }^{35}$, ou que la disposition n'est pas applicable au litige ${ }^{36}$. Il arrive d'ailleurs qu'une évolution de la jurisprudence de la Cour conduise à ce que la QPC ne soit plus applicable au litige en raison d'un nouvel aménagement des champs d'application d'un dispositif ${ }^{37}$.

Ceci étant, l'analyse des non-lieux à renvoi de la « jurisprudence » permet de livrer quelques observations sur l'hypothèse d'une rétention de ce contrôle par les cours suprêmes.

Il est frappant d'observer des modalités différentes d'examen, notamment au sein de la Cour de cassation.

\footnotetext{
$34 \quad$ Soc., 28 novembre $2012, \mathrm{n}^{\circ} 11-17.941$.

35 Civ. 3, 4 février 2016, $\mathrm{n}^{\circ}$ 15-21381, Bull.

36 Par ex., Crim. 4 mai 2011, $\mathrm{n}^{\circ} 11-80.618 ; 21$ juin 2011, $\mathrm{n}^{\circ} 11-90.036 ; 6$ décembre 2011, $\mathrm{n}^{\circ} 11-86.795 ; 20$ juin $2012, \mathrm{n}^{\circ} 12-81.474 ; 19$ septembre $2012, \mathrm{n}^{\circ} 12-84.800 ; 21$ novembre $2012, \mathrm{n}^{\circ} 12-90.057 ; 26$ novembre $2012, \mathrm{n}^{\circ} 12-86.539$ et $12-86540 ; 12$ décembre $2012, \mathrm{n}^{\circ} 12-86.585 ; 21$ décembre $2012, \mathrm{n}^{\circ} 12-86.645 ; 26$ juin $2013, \mathrm{n}^{\circ} 13-83.498 ; 7$ août $2013, \mathrm{n}^{\circ} 13-90.016$ à 13-90.019; 25 septembre $2013, \mathrm{n}^{\circ} 13-85.023 ; 1^{\text {er }}$ octobre 2014 , $\mathrm{n}^{\circ} 14-85.722 ; 22$ octobre $2014, \mathrm{n}^{\circ} 14-82.082$; civ. 3, 11 février 2016, $\mathrm{n}^{\circ} 15-21949$, Bull.

37 Crim., 10 mai 2016, n 15-86600 (à propos des expressions diffamatoires ou injurieuses et de l'incrimination d'outrage à magistrat).
} 
1. Parfois, la Cour examine expressément la conformité de la jurisprudence critiquée à la Constitution. La chambre sociale est à cet égard exemplaire, et dans une moindre mesure, en raison d'une pratique plus aléatoire, la $3^{\text {e }}$ chambre civile.

Dans cette hypothèse, les arrêts de non-renvoi indiquent expressément que la question de la conformité de la jurisprudence n'est pas sérieuse. Il est alors jugé que l'interprétation jurisprudentielle « ne heurte aucun principe constitutionnel dès lors que...» ${ }^{38}$, qu'elle « ne prive pas $»^{39}$, «n'impose pas $»^{40}$, «n'opère pas $»^{41}$, «n'empêche pas $»^{42}$, qu'elle « se borne à préciser $»^{43}$, « ne fait que tirer les conséquences $»^{44}$, ou encore qu'elle doit « être mise en corrélation avec... $»^{45}$, ou qu'elle «ne fait que traduire la conciliation voulue par le législateur ${ }^{46}$.

Le grief peut être rejeté au motif, utilisé par la chambre criminelle, que « la Cour de cassation applique strictement les termes clairs et précis » de la $\operatorname{loi}^{47}$, autrement dit par une sorte de négation du pouvoir jurisprudentiel lui-même ou plus exactement par la dissociation poussiéreuse interprétation/application. On notera que dans de nombreuses autres affaires, singulièrement devant la chambre criminelle, le refus de renvoyer trouve une justification argumentative fondée sur ce que l'interprétation du texte - «suffisamment clair et précis »- entre dans l'office du juge ${ }^{48}$, lequel se trouve chargé d'apprécier la nécessité de l'atteinte portée aux droits constitutionnels ${ }^{49}$.

Parfois, la « jurisprudence constante de la Cour de cassation » est avancée comme majeure du contrôle, par exemple en matière de cumul des sanctions pénales et fiscales où on observe une duplication implicite de la jurisprudence constitutionnelle ${ }^{50}$.

2. Mais le plus souvent, et sans qu'il soit possible - pour l'observateur extérieur - d'établir objectivement les circonstances qui le justifieraient, la Cour estime que la question n'est pas sérieuse sans se prononcer expressément sur sa jurisprudence, c'est-à-dire sans faire état de ce que sa jurisprudence était contestée. À quelques exceptions près, c'est la règle pour la chambre criminelle ${ }^{51}$ et les chambres civiles ${ }^{52}$. On peut dénombrer plus d'une cinquantaine d'arrêts pour la chambre

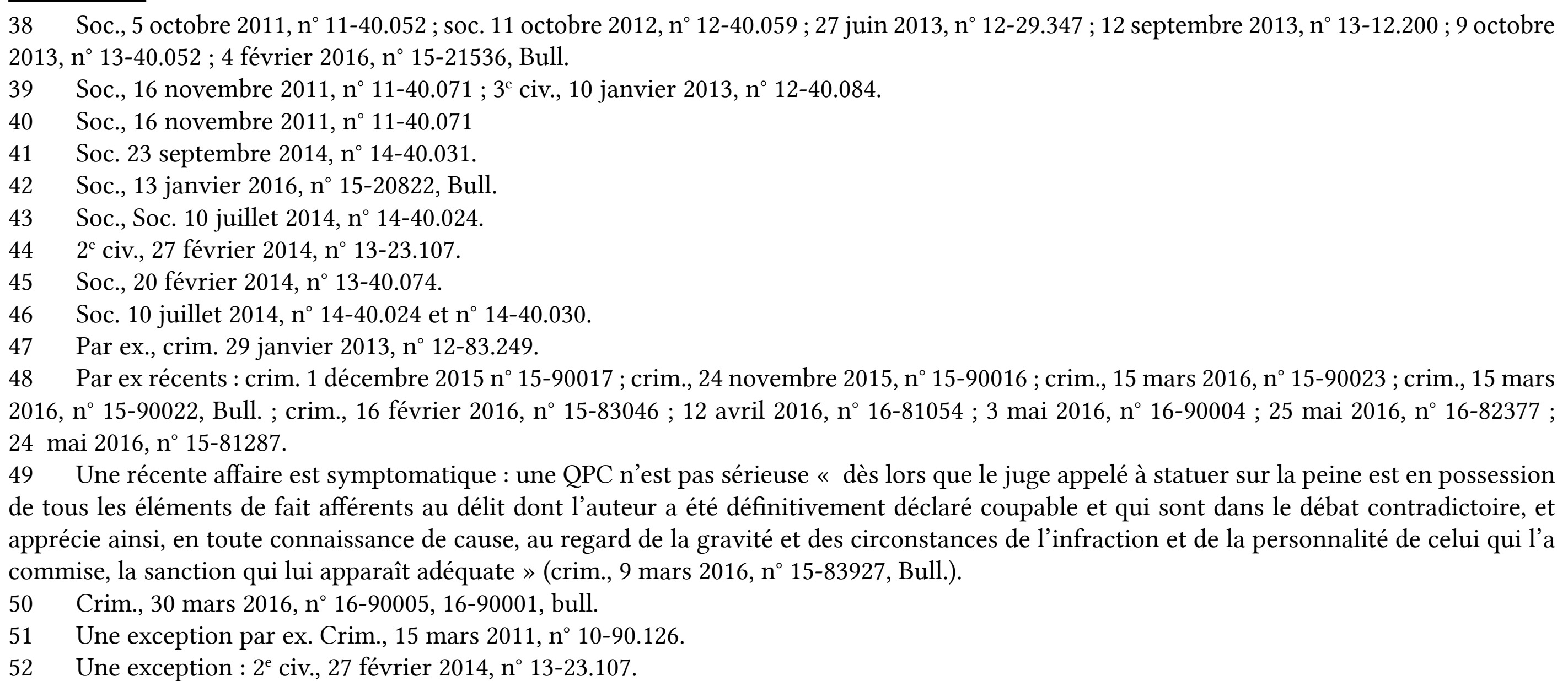


criminelle $^{53}$; une vingtaine pour la chambre sociale ${ }^{54}$; à peu près autant pour les trois chambres civiles (une dizaine pour la $1^{\text {re }}$ chambre civile ${ }^{55}$ et la $2^{\text {e }}$ chambre civile ${ }^{56}$ ). Et plusieurs autres cas significatifs du côté de la chambre commerciale ${ }^{57}$.

Le constat est clair. Le non-renvoi d'une jurisprudence de la Cour est rarement - trop rarement explicite (c'est d'ailleurs vrai aussi en cas de renvoi au Conseil constitutionnel de la jurisprudence, mais cela n'est pas préjudiciable au droit d'accès au juge constitutionnel). La motivation ne permet pas toujours de vérifier que la jurisprudence a été confrontée aux griefs invoqués. C'est au mieux la lecture croisée des rapports, avis et différents commentaires qui permettent de constater que la jurisprudence était en cause dans une QPC.

Deux questions immédiates se posent :

D’une part, peut-on en déduire implicitement que la jurisprudence a été jugée conforme à la Constitution? Parfois, et singulièrement dans les cas plus récents, la lecture du rapport et de l'avis permet de constater que l'ensemble du dispositif légal et jurisprudentiel encadrant la disposition critiquée a été examinés8.

D'autre part, dans quelle mesure envisager une clarification et comment sortir pleinement de la clandestinité ce contrôle - plus exactement, cet anti-contrôle - de la jurisprudence, devant lequel l'observateur et, plus gravement, le justiciable - qui pourtant le sollicite de plus en plus dans la formulation des QPC - se trouvent souvent démunis?

On doit, à cet égard, souligner les différences d'approches entre les différentes chambres de la Cour de cassation qui renvoient plus ou moins volontiers les questions portant sur leur jurisprudence. Il semble que les chambres ne souhaitent pas harmoniser leurs pratiques sur ce point, déjà mis à l'ordre du jour de précédentes réunions du groupe de travail sur les divergences de jurisprudence. Est-il satisfaisant de considérer, comme c'est le cas aujourd'hui, qu'une telle question relève de la politique jurisprudentielle de chaque chambre?

\footnotetext{
53 Par ex. crim., 6 avril 2011, $\mathrm{n}^{\circ} 10-85.470 ; 10$ mai 2011, $\mathrm{n}^{\circ} 11-90.019 ; 7$ juin $2011, \mathrm{n}^{\circ} 11-90.043 ; 16$ juin 2011, $\mathrm{n}^{\circ} 11-81-628$; 21 juin $2011, \mathrm{n}^{\circ} 11-$ $90.046 ; 1^{\text {er }}$ septembre $2011, \mathrm{n}^{\circ} 11-84.268 ; 6$ septembre $2011, \mathrm{n}^{\circ} 11-90.074 ; 13$ septembre $2011, \mathrm{n}^{\circ} 11-90.077 ; 30$ mars $2016, \mathrm{n}^{\circ} 15-84320 ; 6$ avril 2016, n ${ }^{\circ}$ 15-86043, Bull.

54 Quelques exemples : Soc., 25 janvier 2012, $\mathrm{n}^{\circ} 11-40.088 ; 11$ juin 2012, $\mathrm{n}^{\circ} 12-40.024 ; 20$ février 2013, $\mathrm{n}^{\circ} 12-40.095 ; 10$ juillet 2013 , $\mathrm{n}^{\circ} 13-10.759$ et $13-10.760 ; 12$ mars $2014, \mathrm{n}^{\circ} 13-23.174 ; 13$ juin $2014, \mathrm{n}^{\circ} 13-26.353$ à 13-26.357; 29 octobre 2015, $\mathrm{n}^{\circ} 15-12525$, Bull.

55 Par ex. $1^{\text {re }}$ civ., 6 juin $2012, \mathrm{n}^{\circ} 12-40.027 ; 11$ septembre $2012, \mathrm{n}^{\circ} 12-14.135 ; 5$ février $2014, \mathrm{n}^{\circ} 13-21.929 ; 3$ septembre $2014, \mathrm{n}^{\circ} 14-12.200$; 12 février 2014, $\mathrm{n}^{\circ} 13-22.602 ; 18$ septembre 2014, $\mathrm{n}^{\circ} 14-18.944 ; 25$ novembre 2015, $\mathrm{n}^{\circ}$ 14-25109, Bull. ; civ. 1, 25 novembre 2015, $\mathrm{n}^{\circ}$ 15-40035, Bull.

56 Par ex. $2^{\text {e }}$ civ., 16 décembre 2010, $\mathrm{n}^{\circ} 10-17.096 ; 31$ mars 2011, $\mathrm{n}^{\circ}$ 10-25.281; 7 juillet 2011, $\mathrm{n}^{\circ} 11-40.028 ; 19$ octobre $2011, \mathrm{n}^{\circ} 11-40.063$; 12 juillet, $2012, \mathrm{n}^{\circ} 12-14.220 ; 5$ septembre $2013, \mathrm{n}^{\circ} 13-40.037 ; 5$ septembre $2013, \mathrm{n}^{\circ} 13-40.038$.

57 Com. 18 septembre 2012, $\mathrm{n}^{\circ}$ 12-14.584, 12-14.401, 12-14.632, 12-14.595, 12-14.597, $\mathrm{n}^{\circ} 12-14.598,12-14.624,12-14.625,12-14.648 ; 12$ janvier $2016, \mathrm{n}^{\circ} 15-40036$

58 Crim., 7 mai 2014, n 14-90.011; 18 juin 2014, n 14-90.015 et 14-90.016.
} 
3. Sur le fond, on observe que les Cours se livrent parfois à un véritable contrôle de constitutionnalité de leur propre jurisprudence, révélé par l'intensité et le caractère approfondi du contrôle, lequel peut, au surplus, prendre en compte une définition législative ${ }^{59}$.

Du côté du Conseil d'État, un exemple récent concerne le contrôle de la jurisprudence relative à l'obligation pour les titulaires d'officine de pharmacie de se faire assister par un nombre de pharmaciens en fonction de leur chiffre d'affaires. Dans le chiffre d'affaires à prendre en compte pour l'application des dispositions de l'article L. 5125-20 du code de la santé publique, la jurisprudence retient qu'il n'y a pas lieu de distinguer entre les activités liées à la préparation et à la vente de médicaments et les activités commerciales annexes. Cette jurisprudence a été directement analysée et «validée » sur le terrain de la liberté d'entreprendre et celui du principe d'égalitée ${ }^{60}$.

Par ailleurs, la cour suprême paraît réticente à recevoir des griefs « en tant que ne pas » à l'égard de sa propre jurisprudence. Un exemple récent peut en témoigner. Le Conseil d'État a jugé que « la circonstance que le juge administratif n'imposerait pas à l'employeur d'un salarié protégé déclaré inapte à son emploi d'autres obligations de reclassement que celle fixée par les dispositions de l'article L. 1226-2 du code du travail ne caractérise, en tout état de cause, aucune atteinte portée par ces dispositions à la liberté syndicale ou au principe de participation des travailleurs à la détermination collective de leurs conditions de travail $»^{61}$.

Sans pouvoir ici approfondir, on soulignera que l'examen d'une QPC est aussi l'occasion de préciser les modalités, le champ d'application ${ }^{62}$ ou même les objectifs de la jurisprudence contestée ${ }^{63}$.

\section{Les évolutions du contrôle}

Parmi les évolutions les plus marquantes concernant le contrôle par les deux cours suprêmes de leur jurisprudence, deux retiennent l'attention : d'une part, le recours à l'interprétation conforme à la Constitution et, d'autre part, la mise en ouvre d'un revirement de jurisprudence ou du moins une technique proche de mise en conformité avec la jurisprudence constitutionnelle.

1. En premier lieu, plutôt que de renvoyer une QPC portant sur l'interprétation de la loi, le Conseil d'État - même si c'est rare ${ }^{64}$ - et certaines chambres de la Cour de cassation ont parfois décidé que

59 Crim., 30 septembre 2015, n 15-90.014 : il est jugé que l'article 11 du Code de procédure pénale qui, tel qu'interprété de façon constante par la Cour de cassation, permet au ministère public de produire, dans une instance civile, des pièces tirées d'une information judiciaire en cours, sans que puisse lui être opposé le secret de l'instruction, ne porte pas atteinte, notamment, aux principes des droits de la défense, car cette faculté relève des missions spécifiques d'intérêt général que la loi lui attribue notamment en matière civile, et que le secret de l'instruction ne s'impose, en application de l'article 11, qu'aux personnes concourant à cette procédure, que sous la réserve des nécessités des droits de la défense, et que les informations transmises par le ministère public sont communiquées et soumises au respect du contradictoire.

60 CE, 6 avril 2016, n 396247 : «la prise en compte, dans le chiffre d'affaires retenu pour déterminer le nombre minimal de pharmaciens assistants, du produit des activités commerciales annexes que le titulaire de l'officine fait, le cas échéant, le choix d'adjoindre à son activité sous monopole légal, ainsi qu'il y est autorisé par la loi, et qui sont nécessairement exercées au sein de la même entreprise et dans un même lieu, n'a pas davantage pour effet d'entraîner des sujétions constituant une atteinte disproportionnée à la liberté d'entreprendre des pharmaciens d'officine au regard de l'objectif de protection de la santé publique poursuivi »

61 CE, ch. réunies, 30 mai 2016, n 387338, Leb.

62 civ. 3, 14 janvier 2016, $\mathrm{n}^{\circ}$ 15-20286, Bull. s'agissant du régime de la propriété des chemins d'exploitation

63 soc., 4 février 2016, n 15-21536, Bull.

64 Par ex. récemment, CE, 6 avril 2016, n 394240, Leb. tables ; CE, ch. réunies, 18 mai 2016, n 386810, Tables. 
l'examen de la QPC pouvait être l'occasion d'une interprétation de la loi dans un sens conforme à la Constitution. Le recours à l'interprétation conforme comme obstacle au renvoi d'une QPC demeure problématique à différents égards ${ }^{65}$. Il n'est pas propre à la jurisprudence bien entendu.

La méthode est parfois clairement perceptible, en particulier lorsque la Cour mentionne que les dispositions contestées « doivent être interprétées en ce sens que... » ou « qu'ainsi interprétées (elles) ne sont pas contraires (à la Constitution) $»^{66}$. On observe cette inclinaison lorsque la question, au-delà de la disposition législative ciblée, touche en réalité de nombreux autres textes, ce qui incite la Cour à répondre de manière générale par une sorte de réserve d'interprétation auto-directive ${ }^{67}$. Du coté des parties, on voit se développer, parfois expressément dans la formulation des $\mathrm{QPC}^{68}$, des demandes d'interprétation conforme auprès du juge de renvoi.

Cette méthode prend une forme particulière lorsque la Cour s'appuie sur la jurisprudence existante relative à la disposition contestée pour y déceler des directives d'interprétation que le juge doit mettre en œuvre. Ainsi, par exemple, s'agissant d'une disposition qui prévoit que le juge de l'expropriation doit tenir compte des accords amiables conclus entre l'expropriant et les divers titulaires de droits à l'intérieur du périmètre des opérations faisant l'objet d'une déclaration d'utilité publique, la Cour précise que le juge n'est pas lié par le prix résultant de ces accords et qu'il apprécie, dans l'exercice de son pouvoir souverain, l'ensemble des éléments de référence et les caractéristiques matérielles et juridiques du bien à évaluer et de ces accords ${ }^{69}$.

Reste ouverte la question des interprétations divergentes que donneraient, de manière constante, les jurisprudences administrative et judiciaire. Une telle divergence peut légitimement être analysée comme un grief sérieux d'atteinte à l'égalité devant la loi. Le Conseil d'État a été récemment saisi d'une telle situation, en jugeant toutefois, au cas d'espèce, que la divergence ne portait pas sur l'objet précis du litige qui lui était soumis ${ }^{70}$. Quant à la Cour de cassation, elle semble très attachée à ce que la critique porte exclusivement sur une interprétation de la loi et non sur une «contrariété de jurisprudence $»^{71}$.

2. En second lieu, il semble désormais admis qu'une QPC puisse permettre à la Cour de cassation de faire évoluer sa propre jurisprudence, à droit constitutionnel constant. Elle peut ainsi, à l'occasion de l'examen d'une QPC, adapter l'interprétation qu'elle avait de la loi afin que cette nouvelle interprétation soit conforme aux exigences constitutionnelles et à la jurisprudence du Conseil constitutionnel.

65 Sur la question, voir not. nos observations in La question prioritaire de constitutionnalité. Approche de droit comparé, Bruylant, coll. À la croisée des droits, 2014. Egal. A. VIALA, « De la puissance à l'acte : la QPC et les nouveaux horizons de l'interprétation conforme », RDP, 2011, $\mathrm{n}^{\circ}$ 4, p. 979, critiquant les réserves d'interprétation « à usage inversé » qui, pour les juges, ne sont « rien d'autre qu'une interprétation adressée à [eux-mêmes] ».

66 Par ex. Soc., 14 septembre 2012, $\mathrm{n}^{\circ}$ 11-28.269.

67 Par ex. Soc., 9 mai 2014, $\mathrm{n}^{\circ}$ 14-40.014, s'agissant des dispositions qui permettent au juge d'ordonner des mesures d'investigation ou d'instruction. Il est jugé que « la question posée ne présente pas un caractère sérieux en ce qu'elle remet en cause [...] le droit pour le juge judiciaire de procéder à des mesures d'instruction lesquelles sont nécessairement soumises à un contrôle, par le juge qui les prononce, de leur utilité et de leur proportionnalité ».

$68 \quad 2^{\mathrm{e}}$ civ., 27 février $2014, \mathrm{n}^{\circ} 13-23.107$.

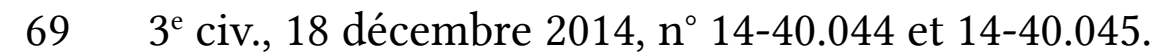

70 CE, ch. réunies, 30 mai 2016, n 387338, Leb.

71 Crim, 25 juin 2014, $\mathrm{n}^{\circ}$ 13-87.224 
Cette lecture «dynamique » de la doctrine du droit vivant repose sur la doctrine développée notamment par le Conseiller Nicolas Maziau ${ }^{72}$. Plusieurs exemples témoignent de l'efficacité de la technique. Elle avait été initiée par la chambre criminelle en 2011, elle est aujourd'hui généralisée à toutes les chambres, sauf la première chambre civile qui semble préférer renvoyer au Conseil constitutionnel.

Une évolution de jurisprudence en matière commerciale est à relever concernant un problème de prescription ${ }^{73}$ où la chambre commerciale admet, dans un arrêt de non-renvoi, un principe général qui empêche de faire courir un délai, fût-il préfix, contre une personne dans l'impossibilité d'agir. Or, jusque-là, sans s'être expressément prononcée sur ce point, la Cour semblait hostile à cette exception $^{74}$.

Une autre évolution jurisprudentielle a été actionnée par la $2^{\mathrm{e}}$ chambre civile concernant sa jurisprudence relative au point de départ du délai de prescription de l'action en restitution de cotisations. Il a été précisé que ce délai «ne peut commencer à courir avant la naissance de l'obligation de remboursement $»^{75}$.

Plus récemment, on peut mentionner un arrêt de la $1^{\text {re }}$ chambre civile qui prend acte d'une nouvelle computation du délai de prescription en matière de crédit immobilier, issue de sa propre jurisprudence, ce qui vide la question de constitutionnalité posée ${ }^{76}$. On peut aussi mentionner le mouvement convergent - du Conseil d'État et de la Cour de cassation - qui élimine, dans l'interprétation qui en avait pu être retenue, tout automatisme en matière de sanction et présomption irréfragable de culpabilité ${ }^{77}$.

Une QPC a été l'occasion pour la $3^{\text {e }}$ chambre civile d'apporter une précision, sinon de compléter l'interprétation faite d'un de ses précédents arrêts qui, concernant la recevabilité à agir d'une association syndicale, n'avait pas tranché la question de savoir si la publication des statuts pouvait intervenir postérieurement à l'expiration du délai de régularisation de deux ans prévu par la loi (ce qui, à l'époque, n'était pas nécessaire à la résolution de l'arrêt). Précisant en ce sens sa jurisprudence antérieure, la Cour « valide » son interprétation de la disposition litigieuse au regard du droit à un recours juridictionnel effectif ${ }^{78}$.

Autre formule à relever, la cour peut transposer une réserve d'interprétation formulée par le Conseil constitutionnel pour un article analogue. Elle a ainsi modifié sa jurisprudence et sa propre interprétation du texte à l'occasion de l'examen d'une QPC dont la nouvelle interprétation

\footnotetext{
72 N. MAzIAu, Le revirement de jurisprudence dans la procédure de QPC. Comment la Cour de cassation, dans son interprétation de la loi, s'inspire du Conseil constitutionnel dans son rôle d'interprète de la Constitution”, D., p. 1833.

Com., 5 septembre 2013, $\mathrm{n}^{\circ}$ 13-40.034.

A. Lienhard, « Relevé de forclusion : impossibilité d'agir dans le délai d'un an », Dalloz Actualité, 11 septembre 2013.

$2^{\mathrm{e}}$ civ., 10 juillet $2014, \mathrm{n}^{\circ} 13-25.985$

Civ.1, 17 février $2016, \mathrm{n}^{\circ} 15-19803$

CE, 22 avril 2016, n 398087 ; Cass., crim., 5 avril 2016, n 16-90002

$3^{\mathrm{e}}$ civ., 13 février $2014, \mathrm{n}^{\circ} 13-22.383$.
} 
rendant vaine la transmission ${ }^{79}$. Ce phénomène s'appuie sur l'autorité substantielle des décisions du Conseil constitutionnel, ou l'autorité de chose interprétée qui irrigue de façon générale l'appréciation du sérieux du renvoi.

\section{La fusion du juge de renvoi avec le juge interprète?}

Tout ce qui vient d'être évoqué soulève l'inévitable interrogation de la fusion du juge de renvoi avec le juge interprète. Le juge du renvoi est-il un juge plein ? Autrement dit, Conseil d'État et Cour de cassation sont-ils « juge et partie » lorsqu'ils se prononcent sur la question de constitutionnalité de leur propre « jurisprudence »? Etant précisé que la question se pose dans la mesure où les deux cours - «portiers » obligés et ultimes des QPC - disposent du monopole de renvoi, ce qui est une différence notable avec, par exemple, le système italien. Il leur revient en dernière analyse de transmettre ou pas l'interprétation qu'elles ont pu elles-mêmes donner.

La question est accrue avec le recours à l'interprétation conforme de la loi contestée en l'absence de toute interprétation précédente, alors que l'interprétation conduit à écarter la QPC en la neutralisant ${ }^{80}$. Le juge peut-il créer de l'interprétation en sa qualité de juge de renvoi ? Le juge de renvoi, déjà maître de l'interprétation digne d'être contestée, est-il créateur de droit ? On peut au moins douter de ce que le filtrage des QPC ait vocation à développer de la jurisprudence, ce qui procède d'un environnement technique et chronologique différent, au risque aussi de dénaturer la procédure QPC et de prendre en traitre le justiciable. Mais, d'un autre côté, jusqu'où peut-on reprocher aux juges de vouloir rendre leur jurisprudence conforme à la Constitution?

Si l'on admet la thèse de la fusion, la question de l'objectivité se pose ${ }^{81}$. On sait que, dans la suite des positions des deux cours suprêmes ${ }^{82}$ qui repose sur l'invocation de leur qualité de juge constitutionnel, la Cour EDH a jugé conforme à la Convention le mécanisme du filtre des juridictions suprêmes propre à la procédure de la QPC. Dans l'arrêt « Renard c. France »" que le refus d'un renvoi motivé au regard des exigences organiques vise à réguler l'accès au Conseil constitutionnel et que sont donc non fondés les griefs tenant, notamment, au fait que l'examen par la Cour de cassation d'une QPC portant sur sa propre jurisprudence serait contraire à l'exigence d'impartialité. Pour autant, est-il satisfaisant que l'auteur de l'interprétation jurisprudentielle en soit le contrôleur habituel?

\footnotetext{
79 Soc. 14 septembre 2012, $\mathrm{n}^{\circ}$ 11-28.269 (visant l'article L. 2411-16 du code du travail) ; rappr. Cons. const., $\mathrm{n}^{\circ} 2012-242$ QPC du 14 mai 2012 (concernant l'article L. 2411-13 ${ }^{\circ}$ du code du travail), s'agissant de la réserve selon laquelle la protection assurée au salarié titulaire de mandats de représentation ne saurait permettre au salarié protégé de se prévaloir d'une telle protection dès lors qu'il est établi qu'il n'en a pas informé son employeur au plus tard lors de l'entretien préalable au licenciement. La transposition de la réserve concerne une autre catégorie de salariés protégés. 80 CE, 19 mai 2010, Théron, $n^{\circ}$ 33025. Le Conseil d'État interprète la disposition législative en cause au regard du droit de propriété, alors qu'elle était contestée sur le terrain de la présomption d'innocence. Voir égal. Cass, 14 septembre 2012, n $11-28269$ (interprétation conforme fondée sur une décision du Conseil constitutionnel) ; CE, 12 juin 2013, n 367004.

81 Voir la contribution de Caterina Severino dans le présent ouvrage.

82 CE, 12 septembre 2011, $M^{m e}$ Dion : « contrairement à ce que soutiennent les requérants, la circonstance que le Conseil d'État a, dans ses formations contentieuses, fixé sur certains points l'interprétation à donner des dispositions législatives en litige, ne fait pas obstacle à ce qu'il statue, ainsi que le lui prescrit l'article 61-1 de la Constitution, sur le bien-fondé du renvoi au Conseil constitutionnel de la question de constitutionnalité qu'ils soulèvent et n'est, en tout état de cause, pas incompatible avec les stipulations des articles 6 et 13 de la Convention européenne de sauvegarde des droits de l'homme et des libertés fondamentales ».

$83 \mathrm{CEDH}, \mathrm{n}^{\circ} 3569 / 12, \mathrm{n}^{\circ}$ 9145/12, n 9161/12 et n 37791/13, 25 août 2015, Renard et a. c/ France.
} 
L'admettre revient à enrailler la mécanique de la QPC. Certes la procédure de QPC a été pensée pour et à travers la loi. Le contrôle de la jurisprudence n'a pas été un déterminant équivalent lors de sa conception, et cela explique en partie la polémique d'hier à l'égard de l'examen de l'interprétation jurisprudentielle et aujourd'hui les difficultés qui viennent d'être évoquées. Mais cela ne saurait signifier qu'elle ne peut, ni ne devrait, avoir la jurisprudence pour objet. Que le fonctionnement de cette procédure se soit établi pour se saisir d'une source politique (la loi) n'aide pas à lever définitivement le malaise qu'il y a, auprès de certains acteurs, à suspecter la jurisprudence d'être non conforme à la Constitution. En la matière, plus que des formules à inventer... inspirées des (contre-) expériences étrangères, il s'agit de prendre au sérieux la connaissance sur les sources du droit.

De même, le choix de renvoyer ou non les QPC portant sur la jurisprudence ne repose pas et ne saurait reposer seulement sur l'opposition entre volonté de respecter le rôle du Conseil constitutionnel et volonté de préserver l'indépendance jurisprudentielle du juge, mais également sur l'idée très pragmatique qu'il n'est pas opportun d'opérer un revirement par crainte d'une censure de sa jurisprudence alors que l'on n'est pas certain de la solution qu'adoptera le Conseil constitutionnel. 


\title{
LE CONTRÔle PAR LES COURS SUPRÊMES DE LEUR PROPRE JURISPRUDENCE APPROCHE CRITIQUE
}

\author{
Caterina SEVERINO ${ }^{1}$
}

Le constat réalisé par Mathieu Disant ${ }^{2}$, concernant la jurisprudence relative au filtrage des questions prioritaires de constitutionnalité (QPC), confirme la tendance du Conseil d'État et de la Cour de cassation à réaliser, même lorsqu'est en cause leur propre interprétation de la loi, un « contrôle de constitutionnalité » de cette interprétation, à l'instar de ce qu'elles font lorsqu'elles doivent filtrer une question qui porte uniquement sur une disposition législative.

Or, en analysant cette tendance dans l'optique d'une amélioration de la protection des droits et libertés du justiciable, il est possible d'identifier des avantages, mais aussi certains risques qui nous conduisent à émettre des réserves sur le mécanisme actuel de la QPC.

\section{Les avantages}

Au-delà de l'aspect positif du dialogue qui se met en place entre les juges, le contrôle par les juges suprêmes de leur propre jurisprudence paraît logique et conforme à certains principes fondamentaux de notre ordonnancement juridique, et ce même sous l'angle du droit comparé. Il pourrait bien aussi constituer un gage d'efficacité quant à la diffusion des valeurs constitutionnelles au sein de l'ordonnancement juridique. Il représente également un gain de temps pour que la justice soit rendue.

1. Un contrôle logique. Le contrôle par les Cours suprêmes de leur propre jurisprudence, ainsi que l'interprétation conforme qui peut s'ensuivre parait, en premier lieu, logique, au sein d'un système de justice constitutionnelle par voie incidente.

En effet, dans ce système, tous les juges du renvoi (et pas seulement les Cours suprêmes) devraient pouvoir réaliser un contrôle de la jurisprudence qui s'est formée autour de la loi contestée

1 Maître de conférences HDR, Aix Marseille Univ, Université de Toulon, Univ Pau \& Pays Adour, CNRS, DICE, CDPC Jean-Claude Escarras, Toulon, France.

2 Voir la contribution de Mathieu Disant ci-dessus. 
et tenter d'en dégager une interprétation conforme à la Constitution avant de soulever une QPC. Ceci semble être la conséquence logique du caractère unitaire de l'ordre juridique - entièrement soumis à la norme constitutionnelle - ainsi que du principe de conservation des actes juridiques qui commande que l'acte juridique soit conservé tant que possible et ne soit annulé que s'il est impossible de faire autrement. Ces deux principes devraient donc conduire logiquement à ce que tous les juges, et pas seulement le juge constitutionnel, puissent appliquer directement la Constitution et puissent interpréter les actes juridiques conformément à la norme fondamentale.

Le droit comparé vient conforter cette idée. En effet, en regardant d'autres systèmes similaires, comme le système italien qui, comme on le sait, a largement inspiré la réforme de 2008, on constate que les juges du filtrage sont tout naturellement conduits à effectuer un tel type de contrôle. En effet, la Cour constitutionnelle italienne les y oblige depuis longue date ${ }^{3}$, en les contraignant à tenter de réaliser une interprétation conforme de la loi avant de soulever la question de constitutionnalité, sous peine d'irrecevabilité de cette question ${ }^{4}$; et ce, même lorsqu'il existe une interprétation jurisprudentielle consolidée qui semble être contraire à la Constitution ${ }^{5}$. Dans ce système, où tous les juges peuvent accéder au prétoire de la Cour constitutionnelle en soulevant une question de constitutionnalité, le contrôle par les juges du renvoi de leur propre jurisprudence et la technique de l'interprétation conforme constituent une opération logique et nécessaire, correspondant aux principes fondamentaux de l'ordonnancement juridique.

2. Un contrôle efficace. En plus d'être logique, en deuxième lieu, cette attitude des Cours suprêmes consistant à contrôler leur propre jurisprudence présente l'avantage d'une très grande efficacité, $\mathrm{du}$ point de vue de la diffusion des valeurs constitutionnelles, de la constitutionnalisation de l'ordonnancement juridique et, bien évidemment, du point de vue de l'appropriation par les juges de la Constitution.

En ce sens, elle conduit tout naturellement à faire évoluer la jurisprudence des Cours suprêmes dans un sens conforme aux paramètres constitutionnels. Certes, nous savons pertinemment que depuis toujours la Cour de Cassation et le Conseil d'État ont fait évoluer leur jurisprudence pour l'adapter aux normes constitutionnelles. Mais ici la nouveauté est qu'elles l'adaptent à travers le

\footnotetext{
3 La Cour constitutionnelle a affirmé pour la première fois cette idée dans une décision isolée de 1989 (arrêt $n^{\circ} 456$ de 1989 ) consacrée, à partir de 1994, par une longue série d'arrêts (arrêts $n^{\text {os }} 121,149,255,410,443$ et 451 de 1994 et notamment arrêt n 356 de 1996 et suivants). Sur cette jurisprudence de la Cour constitutionnelle italienne, voir notamment T. Di MANNO, «L'impossibilité de l'interprétation conforme de la loi à la Constitution, condition de recevabilité de la question incidente de constitutionnalité en Italie », in L. GAY (dir.), La question prioritaire de constitutionnalité. Approche de droit comparé, Bruylant, Coll. À la croisée des droits, 2014, p. 123 et s.

Si bien qu'une partie de la doctrine italienne a parlé d'une véritable « troisième condition de recevabilité » qui est venue s'ajouter, par la voie prétorienne, aux deux autres conditions de recevabilité prévus par les textes, à savoir la rilevanza et la non manifesta infondatezza (en se sens, G. Amoroso, «L'interpretazione «adeguatrice» nella giurisprudenza costituzionale tra canone ermeneutico e tecnica di sindacato di costituzionalità », Foro italiano, 1998, V, p. 92 ; R. RombolI, « Il giudizio di costituzionalità delle leggi in via incidentale », in R. Romboli (dir.), Aggiornamenti in tema di processo costituzionale (1987-1989), Giappichelli, 1990, p. 202.

5 Sur les rapports entre la «doctrine» du droit vivant et la «doctrine» de l'interprétation conforme, voir notamment C. SEVERINO, La doctrine du droit vivant, Economica-PUAM, Coll. Droit Public Positif, 2003, p. 102 et s. ; Id., " La jurisprudence des juridictions suprêmes face à la Constitution : du contrôle à l'autocensure », in L. GAY (dir.), La question prioritaire de constitutionnalité. Approche de droit comparé, op. cit., p. 158 et $\mathrm{s}$.
} 
mécanisme de la $\mathrm{QPC}^{6}$ : on peut supposer qu'elles le font notamment pour éviter que leur interprétation jurisprudentielle soit sanctionnée, a posteriori, par le Conseil constitutionnel. Ce qui fait une différence de taille, car ici le rapport entre le juge constitutionnel et les Cours suprêmes, concernant l'interprétation de la loi, est plus direct, il s'instaure à l'intérieur d'un même mécanisme de contrôle. Par ailleurs, cette mise en adéquation de l'interprétation des juges suprêmes par rapport à la Constitution est ici «spontanée » et pas « imposée » par le Conseil constitutionnel par le biais d'une censure de leur jurisprudence, ce qui pourrait constituer un gage de consolidation de l'interprétation conforme et de stabilité de celle-ci pour le futur ${ }^{7}$.

En raisonnant sur ce point, on pourrait affirmer que même si, en définitive, le fait de soulever une question de constitutionnalité sur une interprétation douteuse du juge suprême ne sert qu'à remettre en cause cette interprétation et à la faire évoluer, il s'agit déjà d'un résultat positif du mécanisme de la QPC tout entier. Il semble même que l'on atteigne un résultat proche de celui obtenu si le Conseil constitutionnel avait été saisi.

3. Un gain de temps. Le contrôle par les Cours suprêmes de leur propre jurisprudence présente un troisième avantage. Il s'agit d'un intérêt concret, qui touche de près les justiciables et leurs procès : c'est la rapidité, le gain de temps, l'intérêt de résoudre la question de constitutionnalité dans des délais plus brefs et avec moins de frais que s'il avait fallu attendre une décision du Conseil constitutionnel.

Du point de vue du Conseil constitutionnel, il s'agit aussi d'éviter son engorgement.

Toutefois, concernant la volonté de ne pas surcharger le Conseil constitutionnel, et en raisonnant en termes de bonne administration de la justice, on peut se poser la question de savoir dans quelle mesure l'activité de filtrage effectuée par les juges suprêmes contribue à aggraver leur propre engorgement qui, comme on le sait, est bien réel et revêt une certaine importance ${ }^{8}$.

Par ailleurs, pour ce qui est de la rapidité de la procédure, nous pouvons nous demander où se situe le véritable intérêt du justiciable. Il se peut très bien que le justiciable préfère atteindre le Conseil constitutionnel pour voir véritablement la jurisprudence de la cour suprême être censurée, plutôt que d'assister à un contrôle effectué par cette cour elle-même sur sa propre jurisprudence.

\footnotetext{
$6 \quad$ Parmi les exemples jurisprudentiels relevant de cette attitude consistant, pour les Cours suprêmes, grâce à une QPC, à faire évoluer leur propre interprétation de la loi pour la rendre conforme aux paramètres constitutionnels, en précisant l'interprétation précédente, ou en la complétant, voire en la modifiant par un véritable revirement de jurisprudence, voir notamment Cass. (Soc.), 16 novembre 2011, $\mathrm{n}^{\circ} 11-40.071$; CE, 14 septembre 2011, M. Pierre, $\mathrm{n}^{\circ} 348394$; Cass. (Crim.), 5 octobre 2011, $\mathrm{n}^{\circ}$ 11-90.087 ; Cass. (Crim.), 12 avril 2012, $\mathrm{n}^{\circ}$ 12-90.004 (cf. N. MAZIAU, « Le revirement de jurisprudence dans la procédure de QPC », D., 2012, p. 1833 et s.) ; Cass. (Crim.), 26 juin 2012, n 12-80.319 ; Cass. (3 Civ.), 13 février 2014, $\mathrm{n}^{\circ} 13-$ 22.383. Plus récemment, voir CE, 6 avril 2016, nº 394240 ; CE, 22 avril 2016, n 398087 ; Cass. (1 ${ }^{\text {re }}$ Civ.), 17 février 2016, n 15-19.803 (voir B. MATHIEU, «Jurisprudence relative à la Question prioritaire de constitutionnalité », $\mathcal{F} C P, \mathrm{G} ., 2016, \mathrm{n}^{\circ}$ 30-35, 901, qui définit le mécanisme utilisé ici par la Cour de cassation comme un mécanisme « d'autocorrection » de la jurisprudence judiciaire) ; Cass. (Crim.), 5 avril 2016, $\mathrm{n}^{\circ}$ 16-90002.

7 Bien qu'il ne faille pas occulter ici les zones d'ombre que présente cet usage par les juges suprêmes de la technique de l'interprétation conforme. En ce sens, voir notamment les observations critiques d'A. VIALA, « De la puissance à l'acte : la QPC et les nouveaux horizons de l'interprétation conforme », $R D P, 2011, \mathrm{n}^{\circ} 4$, p. 979, soulignant le fait que ces réserves d'interprétation «à usage inversé » ne sont rien d'autre que des directives adressées par les juges à eux-mêmes.

8 Selon les dernières statistiques disponibles, fin 2015, le stock du contentieux civil de la Cour de cassation était de 23.442 affaires, avec un délai moyen de jugement de 402 jours, ces chiffres étant en hausse depuis 2010 (https://www.courdecassation.fr/IMG///Statistiques\%202016. pdf) ; tandis que pour le Conseil d'État, en 2015, la part d'affaires pendantes de plus de 2 ans était de 4,5\% (bien qu'en diminution par rapport aux années passées) et le délai prévisible moyen de jugement pour les affaires en 2015 était de 6 mois et 23 jours (bien qu'en en baisse par rapport aux années précédentes) (http://www.conseil-etat.fr/Decisions-Avis-Publications/Etudes-Publications/Rapports-Etudes/Rapport-public-2015).
} 
Ces questions nous invitent à pousser la réflexion plus loin et à considérer aussi « l'autre face de la médaille », c'est-à-dire les risques que comporte le contrôle par les Cours suprêmes de leur propre interprétation jurisprudentielle.

\section{Les risques}

Concernant ces risques, on a pu relever, en premier lieu, celui qui concerne l'objectivité voire l'impartialité des juges qui réalisent ce contrôle. En deuxième lieu, le risque consistant à rendre l'accès au juge constitutionnel plus difficile, compte tenu aussi de l'impossibilité de passer outre une décision de non-renvoi des Cours suprêmes. Enfin, les risques de divergences d'interprétation conduisant à un manque de cohérence de l'ordonnancement juridique.

1. Un manque d'impartialité ? En premier lieu, il existerait selon certains un risque que les Cours suprêmes ne soient pas considérées comme des organes satisfaisant pleinement l'exigence d'impartialité objective au sens de l'article $6 \S 1$ de la Convention européenne des droits de l'homme, dès lors que la question prioritaire de constitutionnalité porte sur une interprétation jurisprudentielle dont elles sont l'auteur.

C'est la question qui a trait à l'objectivité et à l'impartialité des juges qui opèrent ce contrôle, et, donc, à la subjectivité d'un tel contrôle. C'est, en d'autres termes, la question de savoir si les Cours suprêmes sont les mieux placées pour opérer un tel contrôle ou si elles ne devraient pas plutôt, dans ces hypothèses, transmettre la question de manière automatique au Conseil constitutionnel ou, du moins, réaliser un filtrage très allégé, c'est-à-dire moins strict ${ }^{9}$.

La Cour de cassation et le Conseil d'État ont été questionnés sur ce point dans plusieurs affaires où était mise en cause l'interprétation jurisprudentielle de la $\operatorname{loi}^{10}$. Mais elles ont repoussé cette critique de manière ferme, en s'appuyant sur deux raisonnements différents. La Cour de cassation s'est fondée sur les dispositions législatives du Code de l'organisation judiciaire ${ }^{11}$ (qui disposent qu'il n'y a qu'une Cour de cassation pour toute la République) pour rappeler sa position hiérarchique au sein de l'ordre judiciaire et écarter, ainsi, le grief. Le Conseil d'État s'est quant à lui fondé sur l'article 61-1 de la Constitution (qui prescrit un filtrage des questions de constitutionnalité par les juridictions suprêmes) pour considérer qu'il n'y a aucune incompatibilité entre le fait d'avoir préalablement

\footnotetext{
9 En ce sens, M. Fatin-Rouge Stefanini, «L'appréciation, par les Cours suprêmes, du caractère sérieux de la question de constitutionnalité », in E. CARTIER, L. GAY, A. VIAlA (dir.), La QPC : vers une culture constitutionnelle partagée, LGDJ, Institut Universitaire Varennes, Coll. Colloques \& Essais, 2016, p. 39.

10 Voir, par exemple, l'argument développé dans les renvois devant la Cour de cassation décidés par les arrêts n 11-90.025, 11-90.032 et n 11-90.033 du 20 mai 2011, dans lequel le requérant affirme qu' « il existe un risque que la Cour de cassation ne soit pas considérée comme un organe satisfaisant pleinement l'exigence d'impartialité objective au sens de l'article $6 \S 1$ de la Convention européenne de sauvegarde des droits de l'homme et des libertés fondamentales, dès lors que la question prioritaire de constitutionnalité porte sur une interprétation jurisprudentielle dont la Cour de cassation est l'auteur et qu'elle a appliqué constamment et à de très nombreuses reprises ». En ce qui concerne le Conseil d'État, voir l'arrêt M. et $M^{m e}$ Dion, 12 septembre 2011, n 347444.

11 Article L. 4111 du Code de l'organisation judiciaire.
} 
donné une interprétation de la loi dans ses formations contentieuses et le fait de statuer ensuite sur le bien-fondé du renvoi au Conseil constitutionnel ${ }^{12}$.

Quant à la Cour européenne des droits de l'homme, saisie de cette question à la suite des réponses données par les deux juges suprêmes français, elle a estimé qu'il n'y avait pas de violation de l'article $6 \S 1$ de la CEDH. Dans un arrêt Renard c. France du 25 août $2015^{13}$, elle a en effet considéré que le refus d'une Cour suprême de renvoyer au Conseil constitutionnel une QPC qui porte sur sa propre jurisprudence fait partie du mécanisme même de filtrage des QPC, mécanisme qui a justement été mis en place afin de réguler l'accès au juge constitutionnel. Par ailleurs, selon la Cour européenne, le fait que la question porte sur la propre jurisprudence de la Cour suprême n'est pas contraire, en soi, à l'exigence d'impartialité, puisque pour en être ainsi, il faudrait que la décision de refus de la Cour suprême ne soit pas suffisamment motivée ou relève véritablement de l'arbitraire.

Cependant, malgré ces réponses, la question demeure. Sans aller jusqu'à soupçonner les Cours suprêmes de partialité, le problème réside au moins dans l'impression donnée aux justiciables et aux observateurs : l'impression qu'il puisse y avoir (en puissance) une certaine subjectivité dans le jugement provenant d'un juge appelé à statuer sur la constitutionnalité de sa propre interprétation jurisprudentielle. Et puisque dans un système juridique les apparences comptent, il n'est pas insensé d'éprouver un certain malaise face à cette situation.

Certes, on pourrait répondre à cela que cette question devrait alors se poser à chaque fois qu'un juge, en particulier un juge suprême, est appelé, en dehors des QPC, à évaluer sa propre orientation jurisprudentielle, sa propre interprétation des textes, et décide éventuellement de la faire évoluer, ou même d'opérer un véritable revirement. En d'autres termes, le contrôle de sa propre jurisprudence serait inhérent à la fonction du juge, dans n'importe quelle situation et ne soulèverait aucun problème particulier de manque d'objectivité de sa part lorsqu'il est réalisé dans le cadre d'une QPC. Pourtant, il nous semble qu'une différence notable existe entre ces deux cas de figure : dans le cadre du contrôle réalisé à l'occasion d'une QPC, la jurisprudence en examen est susceptible d'être censurée ou modifiée par le Conseil constitutionnel, les juges suprêmes en perdant en quelque sorte la maîtrise ${ }^{14}$

2. Le risque de bloquer l'accès au juge constitutionnel. Le problème est d'autant plus épineux qu'il n'existe aucun moyen dans le système juridique français de remettre en cause le refus de la part des Cours suprêmes de transmettre une QPC qui porte sur leur propre jurisprudence.

12 CE, $M$. et $M^{m e}$ Dion, 12 septembre 2011, cit. Sur ce point, v. A. Roblot-Troizier, « Les Cours suprêmes et l'interprétation de la loi », in Question sur la question : la QPC façonnée par ses acteurs: quelle(s) tendance(s)?, NCCC, 2013, n. 38, qui estime pour sa part que « le raisonnement n'est pas parfaitement convaincant dès lors qu'on aurait pu imaginer le maintien d'un filtrage sans appréciation du caractère sérieux de la $\mathrm{QPC}$ et limité aux seules conditions d'applicabilité de la disposition législative au litige et d'absence de déclaration préalable de constitutionnalité dans une décision du Conseil constitutionnel ».

$13 \mathrm{CEDH}$, requêtes n ${ }^{\text {os }}$ 3569/12, 9145/12, 9161/12 et 37791/13, 25 août 2015, Renard c. France (http://hudoc.echr.coe.int/eng\#\{«itemid»:[«001-157418»]\}). 14 Les « résistances » initiales de la Cour de Cassation face à des QPC portant sur sa propre jurisprudence semblent, du reste, conforter cette impression. 
On touche ici à la question de l'accès au juge constitutionnel et des possibilités ouvertes au justiciable d'aller au-delà d'un blocage de la part des Cours suprêmes lorsqu'est mise en cause leur propre jurisprudence.

Dans le système de la QPC, l'accès au Conseil constitutionnel dépend entièrement, in fine, de la volonté des Cours suprêmes et, donc, de leur appréciation du caractère sérieux d'une question qui aurait pour objet leur propre interprétation jurisprudentielle ; alors que dans les autres pays où il y a un contrôle par voie incidente, comme en Allemagne, en Italie, ou en Espagne, compte tenu de l'absence de double filtre, les autres juges, tous les autres juges, peuvent saisir le juge constitutionnel et court-circuiter ainsi une décision de non-renvoi de la Cour suprême.

Ainsi, si on mobilise à nouveau le droit comparé, qui montrait, dans les lignes qui précèdent, la logique d'un tel contrôle des Cours suprêmes dans un système par voie incidente, on s'aperçoit que le double filtre, lui, ne rentre peut-être pas dans la logique d'un tel type de système, surtout si on considère le double filtre à la lumière de ce contrôle. Cette logique voudrait en effet que tous les juges puissent filtrer la question de constitutionnalité et puissent accéder ainsi au prétoire du juge constitutionnel et ce, également et surtout, lorsqu'est mise en cause une jurisprudence provenant d'une Cour suprême.

On pourrait objecter à cette observation que les décisions de non-renvoi des Cours suprêmes n'ont qu'une autorité relative de la chose jugée, ce qui laisse ouverte la possibilité de soulever la même question portant sur la constitutionnalité de la même interprétation dans d'autres espèces (à la condition, toutefois, que les parties ou les normes paramètres soient différentes) ${ }^{15}$.

Il nous semble, toutefois, que l'accès au juge constitutionnel (qui représentait tout de même le but premier de la réforme de 2008) n'est pas forcément garanti si on doit espérer que dans d'autres espèces se présente une question qui a pour objet la même interprétation jurisprudentielle de la loi et que les filtres mis en place laissent passer cette question jusqu'au Conseil constitutionnel.

Par ailleurs, puisque les Cours suprêmes ont la pleine maîtrise du filtrage des QPC, si elles décident, par un choix stratégique, de ne pas transmettre la QPC au Conseil constitutionnel, elles peuvent opposer une résistance et bloquer, au bout de la procédure, toute saisine du Conseil constitutionnel ${ }^{16}$.

15 Devant la juridiction administrative, l'autorité de chose jugée produit ses effets (pas de nouvelle proposition de la question de constitutionnalité) seulement dans le cas de la triple identité (mêmes parties, mêmes dispositions attaquées et mêmes normes constitutionnelles paramètre). En revanche, devant la juridiction judiciaire, en raison de la transposition de la jurisprudence Césaréo (Cass. (Plén.), 7 juillet 2006 , Césaréo, $\mathrm{n}^{\circ}$ 05-10672 : impossibilité pour la même partie de recommencer le procès en invoquant un fondement juridique différent. Transposition en matière de QPC : Cass. (Crim.), 17 janvier 2012, $\mathrm{n}^{\circ}$ 11-90112), l'identité des normes constitutionnelles invoquées ne joue pas : la même partie ne peut donc invoquer une nouvelle QPC pour le même litige, avec les mêmes parties, à l'encontre de la même disposition législative, mais à l'aune de normes constitutionnelles non invoquées précédemment (sur ce point, voir N. JACQUiNOT, «L'utilisation par les juges du fond des arrêts de non-renvoi d'une QPC », AFDA, 2012, 2097).

16 Il faut songer également au fait que, même si les décisions de non-renvoi possèdent simplement une autorité relative, celles dans lesquelles il y a une interprétation de la loi de la part du juge suprême sont capables de restreindre le renouvellement du contrôle de constitutionnalité. Ces décisions ont un impact sur les juges du fond. Voir notamment, N. Jacquinot, «L'utilisation par les juges du fond des arrêts de non-renvoi d'une QPC », op. cit., p. 2097, estimant que ces arrêts possèdent une autorité de chose interprétée dans la mesure où la cour suprême pourra censurer, à l'occasion d'un pourvoi, la décision d'un juge du fond ayant refusé de tenir compte de sa nouvelle jurisprudence. 
Et même, in fine, si d'autres plaideurs, dans d'autres instances, réussissent à soulever la question devant le Conseil constitutionnel et que celui-ci rend une décision d'inconstitutionnalité ou émet des réserves, le premier plaideur fera de toute façon figure « de dindon de la farce $»^{17}$, puisqu'il n'aura pas réussi, lui, à atteindre le Conseil constitutionnel.

3. Les risques de divergences d'interprétation. Enfin, le contrôle par les Cours suprêmes de leur propre jurisprudence risque de conduire à des divergences d'interprétation et donc à un manque de cohérence et de sécurité de l'ordonnancement juridique ainsi qu'à une violation de l'égalité devant la loi.

À vrai dire, il s'agit là d'un risque lié à toute opération d'interprétation conforme de la loi réalisée par le juge suprême, il ne concerne pas uniquement le cas où est contestée (et réinterprétée) une interprétation constante de celui-ci. Toutefois, dans cette hypothèse, le risque semble accru.

En effet, d'une part, même si l'analyse de la jurisprudence "constitutionnelle" de la Cour de cassation et du Conseil d'État donne l'impression que ces deux juridictions cherchent à prolonger, à suivre, la ligne jurisprudentielle du Conseil constitutionnel, des divergences d'interprétations entre ces juges sur une même disposition législative peuvent exister, et ce, en particulier, lorsqu'il y a déjà, à la base, une interprétation constante provenant d'une Cour suprême. Par ailleurs, il peut y avoir des divergences entre l'interprétation donnée par la Cour de cassation et celle donnée par le Conseil d'État ${ }^{18}$ et même au sein d'une même juridiction (par exemple, entre différentes chambres de la Cour de cassation... $)^{19}$.

D’autre part, le risque d'une certaine insécurité juridique peut naître du fait que, contrairement à une véritable censure ou à une décision de conformité du juge constitutionnel, l'interprétation conforme réalisée par les juges suprêmes peut toujours évoluer, elle n’est pas figée.

On peut alors se poser la question de savoir si, lorsqu'on est en présence d'une disposition législative qui porte en son sein des lourds germes d'inconstitutionnalité, à savoir une disposition qui peut faire l'objet de plusieurs interprétations, dont au moins une contestée ou contestable, ne vaudrait-il mieux pas que le juge transmette la question au Conseil constitutionnel et que ce dernier censure la disposition, en renvoyant ainsi la balle au législateur pour qu'il réécrive le texte, plutôt que de donner des interprétations conformes qui sont toujours susceptibles d'être inappliquées ou modifiées. Dans ces hypothèses, il nous semble que le principe de conservation des actes juridiques devrait peut-être céder le pas à celui de la sécurité juridique, principe essentiel dans un État de droit.

17 J. DubARry, « QPC portant sur l'interprétation d'une disposition législative et stratégie contentieuse », $\mathcal{F C P , ~ G . , ~} 2014, \mathrm{n}^{\circ} 26, \mathrm{p} .743$. 18 Pour une illustration significative d'une divergence entre les Cours suprêmes concernant l'interprétation d'une disposition législative, voir « l'affaire GECOP » (Cass. (2 civ.), 8 février 2012, URSSAF du Rhône c/ Sté Jumfil, n 11-40.094 ; Cass. (2e civ.), 28 févr. 2013 , SA Sté Star Sécurité c/ URSSAF Paris région parisienne, $\mathrm{n}^{\circ}$ 12-40.099 QPC ; Conseil d'État "Société GECOP », 5 juin 2015 ; Conseil constitutionnel, décision $\mathrm{n}^{\circ}$ 2015-479 QPC du 31 juillet 2015).

19 Voir la contribution de Mathieu Disant dans le présent ouvrage. 



\section{QUESTIONS ADRESSÉES AUX JUGES}

Pour ouvrir la discussion, $\mathrm{M}$. Disant et $\mathrm{M}^{\mathrm{me}}$ Severino ont soumis les questions suivantes aux juges invités à la table ronde :

- La première question concerne la notion de « jurisprudence constante » et son appréciation par les Cours suprêmes. Il est demandé aux juges de nous éclairer sur les critères leur permettant d'apprécier cette notion.

- L'analyse des décisions montre par ailleurs que le non renvoi (comme le renvoi) de la jurisprudence au Conseil constitutionnel est rarement explicite : est-il possible d'envisager une clarification ? Et si oui, dans quelle mesure?

- Souvent le juge suprême considère que la question n'est pas sérieuse sans se prononcer expressément sur la jurisprudence qui était en cause : peut-on alors considérer que cette jurisprudence est implicitement jugée conforme à la Constitution?

- Quelle méthode d'analyse est utilisée lorsqu'est en cause la "jurisprudence"? Y a-t-il un traitement spécifique ? Des évolutions méthodologiques sont-elles envisagées?

- Quelles sont les conditions de recours à l'interprétation conforme à la Constitution (comme obstacle au renvoi)?

- Concernant les dangers liés à ce contrôle des Cours suprêmes sur leur propre jurisprudence, il existe selon certains un risque que les Cours suprêmes ne soient pas considérées comme des organes satisfaisant pleinement l'exigence d'impartialité objective au sens de l'article $6 \S 1$ de la Convention européenne de sauvegarde des droits de l'homme et des libertés fondamentales, dès lors que la question prioritaire de constitutionnalité porte sur une interprétation jurisprudentielle dont elles sont l'auteur. Il est demandé aux juges de nous éclairer sur les raisons qui ont conduit leur juridiction d'appartenance à repousser ce grief.

- L'un des avantages de ce contrôle réalisé par les Cours suprêmes consiste indéniablement dans le fait d'éviter l'engorgement du Conseil constitutionnel. Les juges sont invités à nous dire dans quelle mesure celui-ci contribue éventuellement à aggraver celui de leur juridiction d'appartenance.

- L'analyse de la jurisprudence "constitutionnelle" de la Cour de cassation et du Conseil d'État donne l'impression que ces deux juridictions cherchent à prolonger la ligne jurisprudentielle du Conseil 
constitutionnel. Peut-on, en revanche, envisager l'hypothèse d'interprétations constitutionnelles divergeant de celles élaborées par le Conseil constitutionnel ? Par ailleurs, chacune des Cours suprêmes est-elle attentive aux interprétations formulées par l'autre?

\author{
Jacques ArRighi de CASANova \\ Président de section au Conseil d'État
}

Pour répondre aux questions mises en évidence par les deux précédents intervenants, j'essaierai d'exposer la manière dont elles se présentent du point de vue du Conseil d'État. À la différence de la Cour de cassation, dont parfois la ligne jurisprudentielle peut difficilement être décelée, il n'y a - pour paraphraser une disposition célèbre concernant la Cour de cassation - qu'un seul Conseil d'État qui assure l'unité de la jurisprudence administrative et il n'y a donc pas matière à présenter plusieurs lignes jurisprudentielles différentes. Quant aux questions évoquées, il convient d'en aborder deux principales. L'une porte sur l'interprétation conforme et l'autre sur la question de la légitimité des filtres.

Le Conseil d'État a toujours eu recours au procédé de l'interprétation conforme, avant même l'apparition du contrôle de constitutionnalité qui n'a fait que renforcer cette tendance. Ainsi, en interprétant la loi à la lumière des principes généraux du droit qu'il a dégagés à partir de la fin de la dernière guerre, notamment en 1950 dans l'affaire Dame Lamotte, le Conseil d'État n'hésite pas à imposer une réserve et à affirmer, dans cette affaire, que l'expression « aucun recours » ne concerne pas le recours pour excès de pouvoir contre une décision administrative. C'était une époque un peu incertaine avec l'insertion récente des principes généraux du droit dans la hiérarchie des normes. Néanmoins, cette tendance s'est poursuivie ensuite avec l'apparition du contrôle de constitutionnalité des lois, notamment la reconnaissance de la place du Préambule et des principes constitutionnels dans la hiérarchie des normes.

Les arrêts du Conseil d'État se fondent donc, quand il s'agit d'interpréter un texte, notamment législatif, sur des exigences inhérentes à la hiérarchie des normes. Il le fait d'autant plus naturellement que la loi s'interprète conformément à sa lettre ou, le cas échéant, à l'intention de ses auteurs, mais aussi en tenant compte de ce que le Parlement est expressément soumis au respect de la Constitution sous la Ve République. Et même si la question se pose en termes différents par rapport au respect des engagements internationaux de la France au titre de l'article 55 de la Constitution, le Parlement doit, de manière générale, être réputé ne pas avoir entendu méconnaitre la hiérarchie des normes et, par conséquent, avoir voté une loi conforme aux normes supérieures. De sorte qu'en cas de doute sur l'interprétation, il est possible de faire dire à la loi un peu autre chose de ce qu'elle a écrit, afin de l'interpréter à la lumière de la hiérarchie des normes, c'est-dire conformément à la Constitution et aux traités. 
Parmi de nombreux exemples de cette démarche, il convient d'en citer un, particulièrement significatif. Il s'agit de l'arrêt Bitouzet de 1998 où était en discussion une vieille loi remontant au régime de Vichy, codifiée à l'article L. 160-5 du code de l'urbanisme, et selon laquelle les servitudes d'urbanisme ne sont pas indemnisables. Le Conseil d'État a interprété cette loi avec le souci d'éviter une condamnation de la France à Strasbourg, par la Cour européenne des droits de l'homme, sans oublier les exigences constitutionnelles qui sont en arrière-plan. Le Conseil d'État n'a donc pas hésité à interpréter un texte qui disait qu'il n'y avait pas d'indemnisation de ces servitudes en jugeant que le droit à réparation existait quand même dans certains cas.

L'interprétation conforme est donc un exercice classique, même si le problème du respect par la loi de la hiérarchie des normes ne se pose pas si fréquemment. Cet exercice est d'autant plus familier au Conseil d'État qu'il exerce par ailleurs une fonction consultative. En effet, le Conseil d'État examine toutes les semaines les projets de textes qui lui sont soumis et, en particulier, donne des avis au Gouvernement sur la conformité des projets de lois à la Constitution. Ce contrôle préventif s'est nécessairement renforcé dans les années soixante-dix, après la décision sur la liberté d'association et la réforme de 1974 élargissant la saisine du Conseil constitutionnel, afin d'éviter le risque de censure constitutionnelle. Autrement dit, ces questions sont assez familières aux membres du Conseil d'État qui siègent au contentieux tout en ayant exercé aussi la fonction consultative et qui, à ce titre, ont déjà été confrontés à ce type de questions.

Ainsi, le Conseil d'État peut naturellement être conduit à reconsidérer la jurisprudence pour la mettre en conformité avec les normes supérieures, notamment avec les normes constitutionnelles. On peut mentionner à ce propos l'évolution de la jurisprudence sur la responsabilité de l'État du fait des lois pour rupture d'égalité devant les charges publiques. Sans trouver aucun encrage dans aucun texte, ce régime purement jurisprudentiel a été dégagé par l'arrêt Société La Fleurette de 1938, qui a admis la possibilité d'une telle responsabilité, mais a pendant longtemps été mis en œuvre en admettant que, dans certaines matières, la loi pouvait être présumée avoir entendu exclure toute indemnité. Cependant, ayant été conduit à statuer de nouveau sur la question, le Conseil d'État a reconsidéré sa jurisprudence. Depuis un arrêt société coopérative Ax'ion rendu en 2005 au visa de la Constitution et du premier Protocole additionnel à la Convention européenne des droits de l'homme, le Conseil d'État a affirmé que la responsabilité du fait d'une loi pour rupture d'égalité devant les charges publiques ne pouvait être écartée que si cela résultait des termes de la loi qui aurait explicitement exclu toute indemnité. Par ailleurs, il est toujours possible de contester la loi à cet égard dans un tel cas : soit directement dans le litige soumis au juge, au titre du contrôle de conventionnalité de la loi par rapport à la Convention européenne des droits de l'homme, soit par le biais d'une QPC depuis 2010 .

Il est nécessaire de noter à ce propos qu'à partir du moment où la QPC a été mise en œuvre, le Conseil d'État a aussitôt été confronté à l'article L. 160-5 du Code de l'urbanisme. Il n'a pas renvoyé la QPC. Cette décision de non-renvoi n'a pas été fondée sur une nouvelle interprétation de l'article en question le mettant à l'abri de critiques constitutionnelles et conventionnelles, mais sur le constat 
que l'interprétation jurisprudentielle de cet article par l'arrêt Bitouzet ne posait pas un problème constitutionnel. De plus, le Conseil constitutionnel, saisi par la suite d'une question analogue à propos des cessions gratuites des terrains dans des opérations d'urbanisme, a emprunté la même réserve d'interprétation pour assurer la conformité de la loi qui lui avait été déférée à la Constitution.

Il convient donc de conclure, quant au premier point, que l'interprétation de la loi conformément à la hiérarchie des normes et notamment, bien sûr, à la Constitution, est une méthode à laquelle le Conseil d'État avait classiquement recours et qui désormais s'inscrit également dans le cadre du contrôle a posteriori, qu'il s'agisse du contrôle de conventionnalité ou de la QPC.

S'agissant de la question de la légitimité, de l'objectivité et de l'impartialité des filtres, il me semble que l'importance du problème soulevé par les intervenants précédents ne doit pas être exagérée. Par définition, une juridiction suprême n'est pas le Gouvernement, qui défend son projet de loi, ni le Parlement, qui défendrait sa proposition de loi. Une juridiction a objectivement un statut qui la porte naturellement à statuer en toute indépendance. Étant saisie d'une argumentation, elle est habilitée à remettre en cause sa jurisprudence pour quelque motif que ce soit, pas uniquement d'ailleurs pour en assurer la conformité à la Constitution. S'il y avait de bonnes raisons de suspecter les juridictions de partialité au motif qu'elles seraient mal placées pour juger le bien-fondé de leur propre jurisprudence, elles ne procéderaient jamais à des revirements de la jurisprudence. Cela ne se passe pas de cette manière.

Par ailleurs, le choix du constituant d'instaurer le filtrage par des deux juridictions suprêmes semble raisonnable. Il me semble qu'on ne peut pas reprocher au Conseil d'État de ne pas transmettre au Conseil constitutionnel un texte qui mériterait un débat constitutionnel. D’après les statistiques, le Conseil d'État a un taux de renvoi assez constant, environ une QPC sur quatre. Initialement, on s'attendait à une diminution du taux de renvoi dans le temps grâce à la censure des dispositions qui devaient l'être, et à une meilleure connaissance de la jurisprudence du Conseil constitutionnel permettant aux juges suprêmes d'être mieux en mesure d'apprécier le sérieux de la question. Or, en réalité, le taux de renvoi reste à peu près le même.

Il faut aussi rappeler que le système des filtres a été également choisi afin d'éviter l'engorgement du Conseil constitutionnel. C'est pourquoi on ne s'est pas aventuré à permettre sa saisine par toute juridiction sans aucun filtre, ou directement par les particuliers. Par ailleurs, on ne peut pas dire qu'il existe un engorgement du Conseil d'État en raison de la mise en place de la QPC.

En conclusion, malgré les interrogations sur le rôle de juge constitutionnel « négatif » joué en quelque sorte par les juridictions suprêmes, il me semble qu'elles ne dépassent pas ce rôle du filtre en allant jusqu'à affirmer la constitutionnalité d'une disposition législative. Au total, le système me paraît donc plutôt satisfaisant. 


\section{Daniel LUDET \\ Conseiller à la Chambre sociale de la Cour de cassation}

À titre préliminaire, Monsieur Ludet tient à remercier les organisatrices de ce colloque : c'est toujours un très grand honneur de venir à Aix-en-Provence pour des colloques portant sur des questions de constitutionnalité qui lui rappellent le souvenir de Louis Favoreu. Il précise également qu'il n'est pas mandaté par la Cour de cassation. C'est donc à titre personnel que Monsieur Ludet prend part à la discussion.

Tout d'abord, il souhaite s'arrêter sur la question de la définition de l'interprétation constante, ainsi que sur celle de sa portée et de son point de départ. Il existe des décisions rendues sur ce point. Il faut remarquer qu'il y a une certaine souplesse sur l'évaluation et la détermination de l'interprétation constante. Ainsi, un seul arrêt de l'Assemblée Plénière de la Cour de cassation peut représenter une interprétation constante. Les juges de la Cour de cassation (les conseillers), lors de leur travail, cherchent très fréquemment à savoir s'il y a une jurisprudence sur le point à traiter. En ce qui concerne la chambre sociale par exemple, elle cherche souvent à savoir s'il y a plusieurs arrêts dans le même sens et s'il y en a au moins un qui est publié. Ceci est en effet un élément important pour déterminer s'il y a une jurisprudence derrière laquelle le conseiller peut se retrancher, sur laquelle il peut se fonder. Donc, sans avoir à graver dans le marbre une caractérisation de l'interprétation constante, on peut dire que lorsqu'il existe plusieurs décisions - dont au moins une ou deux publiées - qui vont dans le même sens, alors il est fort probable qu'il y ait une interprétation constante qui pourra être prise en considération lors d'une QPC.

Une deuxième observation peut être faite. Elle concerne le regret manifesté à l'égard du caractère laconique des décisions de la Cour. Il faut souligner que le laconisme est peut-être plus grand dans les décisions de transmission que dans celles de non-transmission. Toutefois, il faut bien le préciser, il ne s'agit pas d'un aspect spécifique aux décisions QPC. Nous savons, en effet, que ce laconisme fait fréquemment l'objet de critiques et il s'agit d'ailleurs d'un sujet d'interrogation au sein même de la Cour de cassation. Le style de la Cour de cassation est un style qui privilégie une très grande brièveté dans les rejets, c'est la mise en œuvre du syllogisme judiciaire dans sa conception la plus rude. Derrière le laconisme, il y a la brièveté. En ce moment, au sein de la Cour de cassation, un travail de réflexion est en cours sur la question de la motivation des décisions, dans le but de rendre la motivation plus claire. Cela dit, il apparaît que dans les décisions de non-transmission il y a quand même un effort minimal d'explicitation. Ceci est peut-être regardé par certains comme insuffisant, mais il y a un effort tout de même - bien que la motivation reste brève - d'expliquer pourquoi il n'y a pas transmission au Conseil constitutionnel. S'agit-il d'une sorte de prudence de la part de la Cour, qui préfère éviter de trop s'avancer en prenant position et en explicitant de façon trop importante le doute de constitutionnalité ? 
Il faudrait préciser ici les méthodes de travail employées à la Cour de cassation pour le traitement des QPC : lors de l'entrée en vigueur de la réforme, un bureau du droit constitutionnel a été mis en place au sein de la Cour. Ce bureau met à disposition du rapporteur tout un ensemble de matériaux, d'analyses précises et de jurisprudences constitutionnelles. Ensuite, le rapporteur, à l'aide de cette documentation, établit son rapport qui ouvre la discussion avec l'ensemble de la chambre. Donc certes, au final, il n'y a peut-être pas grand-chose dans la motivation de la décision, mais il est certain que le travail en amont est très approfondi.

Une autre question semble faire débat : la non-transmission d'une QPC portant sur une interprétation constante recèle-t-elle un jugement implicite de constitutionnalité de cette interprétation? Les juges de la Cour de cassation ainsi que ceux du Conseil d'État ont été chargés par la Constitution et par la loi organique d'exercer un filtrage, de vérifier si la question était sérieuse ou non. Si les juges ne transmettent pas, c'est parce qu'ils considèrent que la question de constitutionnalité n'est pas sérieuse. Ainsi, il y a bien la considération selon laquelle la disposition est conforme à la Constitution.

En ce qui concerne, ensuite, les interrogations et les mises en cause de la Cour de cassation pour les cas où elle se risque à prendre les devants, soit en apportant une précision sur une interprétation précédente, soit en modifiant sa propre interprétation, il faut dire qu'au regard d'une QPC, la Cour de cassation reste fidèle à elle-même. La question des inconvénients que cela pourrait provoquer a été évoquée, et notamment le fait que cette attitude constituerait un obstacle au jeu normal du renvoi. Or, les juges ne le voient pas comme cela. Il ne s'agit pas assurément d'une obstruction au renvoi, mais il faudrait plutôt regarder cela comme la nécessité de résoudre un problème en peu de temps et de façon concrète. Les juges, c'est leur fonction, apportent des solutions à un problème. Alors, est-ce qu'il y a derrière cela, comme il est parfois suggéré à partir de la lecture de décisions des chambres civiles, un non-respect de l'esprit de la QPC ? Au fond, que se passe-t-il si la Cour de cassation modifie sa jurisprudence au regard de la QPC ? La question est de savoir si elle empiète ainsi sur les pouvoirs de quelqu'un d'autre. Faut-il entendre ce mécanisme de QPC utilisé de cette manière comme un mécanisme qui empiète ? Faut-il considérer que seul le Conseil constitutionnel a l'autorité de dire s'il y a inconstitutionnalité ou pas ? Il faut soulever le débat. Le souci de la Cour de Cassation est de résoudre le problème par une solution pragmatique. La Cour de cassation n'a peut-être pas reçu de la Constitution la compétence expresse de le faire à l'instar du Conseil constitutionnel mais la question se pose de savoir si la Cour de cassation est compétente techniquement pour le faire. Avec la jurisprudence facques Vabres, la Cour a déjà eu à s'interroger sur la confrontation de normes législatives à des normes supérieures. À titre personnel, Monsieur Ludet ne pense pas que la Cour de cassation empiète sur les compétences de quelqu'un d'autre, et qu'il faut, dans le regard porté sur sa pratique, prendre en considération son souci d'une bonne administration de la justice.

Pour terminer, concernant la question de l'impartialité de la Cour de cassation, la question de savoir si cette juridiction peut se prononcer elle-même sur sa propre jurisprudence, Monsieur 
Ludet pense que ce débat est, certes, intellectuellement intéressant au regard de l'exigence d'apparence d'impartialité, mais qu'il est juridiquement et pratiquement sans issue. Comment éviter cela? On a évoqué la solution de la transmission automatique au Conseil constitutionnel, mais cela n'est pas prévu par les textes. Par ailleurs, des interrogations demeurent sur la pertinence, de lege ferenda, d'un tel automatisme. D'après Monsieur Ludet, il n'y a pas de solution procédurale originale pour remédier à un supposé défaut d'impartialité de la Cour de cassation à l'égard de sa propre jurisprudence.

De manière générale, dans des affaires où des magistrats de la Cour de cassation ont déjà eu à connaître de situations concernant les mêmes justiciables pour le même litige et ne peuvent donc pas siéger, la solution est d'aller chercher d'autres membres de la juridiction pour remplacer ces magistrats. Ceci peut être transposable à l'hypothèse qui nous intéresse, pour garantir l'impartialité supposée fragilisée : faire siéger des conseillers qui n'ont pas eu auparavant à appliquer la jurisprudence visée par une QPC. Toutefois, cela peut s'avérer difficile en pratique, sauf à soumettre dans une telle hypothèse la QPC à une chambre de la Cour autre que celle qui serait normalement compétente ratione materiae. Une telle solution aurait aussi ses inconvénients. Ce débat semble donc sans solution à coup sûr commode, mais la transmission automatique de la QPC ne semble pas pour autant être une bonne solution, au regard des dispositions actuelles de la Constitution et de la loi organique qui mettent en place un filtrage des QPC par les juridictions suprêmes des deux ordres.

\section{Olivier TALABARDON \\ Conseiller référendaire à la chambre criminelle de la Cour de cassation}

Je m'associe aux remerciements qui ont été adressés aux organisatrices du colloque car cette invitation est pour nous l'occasion de répondre aux interrogations que peut susciter la pratique de nos cours en matière de question prioritaire de constitutionnalité.

Pas plus que Monsieur Ludet, je ne prétends m'exprimer ici au nom de la Cour de cassation car il ne me revient pas tant de présenter la jurisprudence de sa chambre criminelle en lien avec l'objet de la présente table ronde, que de tenter de répondre à des questions qui, pour certaines, ont un caractère prospectif et sur lesquelles je ne peux donc me prononcer qu'à titre personnel. J'ajoute que nous avons jugé utile d'être deux pour représenter la cour suprême judiciaire en raison des spécificités que présente le contentieux de la cassation en matière pénale, et partant le rôle de la chambre criminelle comme filtre des questions prioritaires de constitutionnalité en cette matière. Ce sont ces spécificités que je voudrais commencer par vous exposer brièvement.

En premier lieu, la chambre criminelle connait, à elle seule, de plus de la moitié des QPC dont la Cour de cassation est saisie. Ainsi, entre le $1^{\text {er }}$ mars 2010 et le 31 décembre 2015, 1150 questions ont été enregistrées en matière pénale, laquelle relève par principe du domaine de la loi, contre 870 
pour l'ensemble de la matière civile, commerciale et sociale. Ce chiffre peut toutefois paraître limité au regard de l'activité traditionnelle d'examen des pourvois en cassation, qui est singulièrement lourde pour une juridiction suprême chargée d'assurer l'unité de la jurisprudence, si l'on songe que la chambre criminelle rend chaque semaine, en moyenne, une soixantaine d'arrêts motivés, auxquels s'ajoutent les décisions de non-admission prises en formation restreinte sur les rapports et avis circonstanciés d'un conseiller et d'un avocat général. Mais, précisément, le traitement, en sus de cette activité déjà soutenue, d'un nombre élevé de QPC et ce, sur des sujets particulièrement sensibles comme la procédure pénale (66 \% des questions posées de 2010 à 2015), a représenté pour la chambre criminelle un défi matériel autant qu'intellectuel, qu'elle peut s'enorgueillir d'avoir relevé, et ce, avec l'assistance du bureau du droit constitutionnel du Service de documentation, des études et du rapport (SDER) de la Cour.

En deuxième lieu, le taux des QPC irrecevables est plus élevé en matière pénale qu'en matière civile, constituant un quart des causes de non-renvoi au Conseil constitutionnel. Cette situation s'explique principalement par l'absence de représentation obligatoire devant la chambre criminelle et la possibilité offerte aux parties de présenter des QPC dans des mémoires personnels. Or les questions ainsi posées sont plus souvent déclarées irrecevables que les autres, soit parce que le mémoire qui les comporte n'a pas été présenté dans les formes et délais prévus par le code de procédure pénale, soit parce que la formulation de la question elle-même est inadéquate.

En troisième lieu, les QPC soumises à la chambre criminelle le sont davantage par voie incidente à un pourvoi en cassation (61\% sur la période 2010-2015) que par voie de transmission par une juridiction du fond (39\%), alors que c'est l'inverse devant les chambres civiles. Les causes de cette différence, qui mériteraient une étude approfondie, sont sans doute à rechercher dans les conditions dans lesquelles s'exerce la défense devant, respectivement, les juridictions pénales du fond et la chambre criminelle.

En quatrième et dernier lieu, cette chambre a longtemps présenté le taux de renvoi au Conseil constitutionnel le plus faible, puisqu'il n'a été que de $10 \%$ sur la période 2010-2015, alors qu'il était de $16 \%$ pour les chambres civiles - avec cependant de fortes disparités d'une chambre à l'autre en fonction de la nature du contentieux qu'elle traite - et que, ainsi que le Président Arrighi de Casanova l'a indiqué, il se maintient autour de $25 \%$ au Conseil d'État.

D'aucuns y ont vu une réticence particulière de la chambre criminelle à partager avec le Conseil constitutionnel la connaissance de la matière pénale. D’autres raisons plus objectives peuvent cependant être avancées : un taux d'irrecevabilité des QPC qui, comme il vient d'être dit, est sensiblement plus élevé en matière pénale ; le fait qu'une même question, bien que jugée non sérieuse, puisse être de nouveau soumise à la chambre criminelle dans de nombreuses affaires similaires, parfois dans une intention dilatoire ; le fait que, notamment après les décisions n ${ }^{\circ}$ 2011-163 QPC du 16 septembre 2011 et $\mathrm{n}^{\circ}$ 2012-240 QPC du 4 mai 2012 relatives, respectivement, aux délits et crimes incestueux et au délit de harcèlement sexuel, l'atteinte au principe de légalité des délits et des peines 
a été très fréquemment invoquée, mais à mauvais escient, contre les textes d'incrimination, au motif d'un prétendu manque de clarté et de précision de la définition de l'infraction poursuivie, ce qui a conduit la chambre criminelle à répondre à de nombreuses reprises que les termes en cause étaient « suffisamment clairs et précis pour que l'interprétation de ce texte, qui entre dans l'office du juge pénal, puisse se faire sans risque d'arbitraire », conformément au principe cardinal selon lequel le droit pénal est d'interprétation stricte.

On peut ajouter que la procédure pénale présente cette particularité de ménager des droits différents selon la qualité de la partie en cause : ministère public, mis en examen ou prévenu, partie civile, civilement responsable, etc., par exemple au regard des conditions, notamment de délai, dans lesquelles un mémoire peut être présenté devant la chambre criminelle au soutien d'un pourvoi en cassation. Or, les distinctions édictées par la loi, qui tiennent compte de la situation propre à chaque partie, constituent un équilibre que toute remise en cause peut déstabiliser. C'est une réalité dont la chambre criminelle doit tenir compte lorsqu'elle examine le caractère sérieux d'une QPC tendant à faire réexaminer les droits de telle ou telle partie par rapport à telle ou telle autre.

Quoiqu'il en soit, il me semble que le taux de renvoi des QPC soumises à la chambre criminelle a vocation à augmenter car, à mesure que le nombre global de ces questions diminue, celui de celles présentant un caractère sérieux apparaît proportionnellement plus élevé. Ainsi, à la dernière audience de la section à laquelle j'appartiens, nous avons examiné trois QPC, que nous avons renvoyées au Conseil constitutionnel, deux portant sur l'article 11 de la loi n 55-385 du 3 avril 1955 relative à l'état d'urgence, la troisième sur l'article 197 du code de procédure pénale à propos du droit des parties se défendant sans avocat d'accéder aux réquisitions du procureur général dans les dossiers soumis à la chambre de l'instruction (trois décisions du 21 juin 2016).

Après cette présentation des spécificités de la question prioritaire de constitutionnalité en matière pénale, j'en viens à l'objet même de notre table ronde.

Tout d'abord, je souscris pleinement à ce qu'ont indiqué les intervenants précédents sur le rôle des juridictions suprêmes des deux ordres dans l'interprétation conforme des textes qui leur sont soumis, sur la notion de « jurisprudence constante», sur la légitimité de ces cours à réexaminer une telle jurisprudence à l'occasion du filtre des QPC dont elles sont saisies et sur l'absence d'engorgement spécifique susceptible d'en résulter pour elles.

S'agissant de l'interprétation conforme, je voudrais en illustrer l'intérêt en donnant l'exemple de la décision Crim., 16 septembre 2014, QPC n 14-90.036, Bull. crim. 2014, nº 188.

La question, transmise par une juridiction correctionnelle, soulevait une difficulté d'articulation entre les dispositions spéciales de l'article L. 3421-1 du code de la santé publique, incriminant l'usage illicite de produits stupéfiants, et celles de l'article 222-37 du code pénal, incriminant la détention de tels produits. En effet, selon une pratique judiciaire ancienne, l'usage de stupéfiant était fréquemment poursuivi sous les deux qualifications, l'usager étant considéré de facto comme détenteur des 
substances consommées. Or, tant la procédure que les peines applicables aux deux incriminations sont sensiblement différentes, le texte du code de la santé publique poursuivant un objectif sanitaire, tandis que celui du code pénal vise à réprimer le trafic de stupéfiants. Il y avait donc un risque d'arbitraire en ce que des faits similaires pouvaient être poursuivis et sanctionnés sur le fondement, indifféremment, de l'un ou l'autre de ces textes. La QPC, qui pointait en substance l'existence de ce risque, était donc a priori sérieuse. Toutefois, la chambre criminelle a dit n'y avoir lieu de la renvoyer au Conseil constitutionnel en posant pour principe que : « les dispositions spéciales de l'article L. 3421-1 du code de la santé publique, incriminant l'usage illicite de produits stupéfiants, excluent l'application de l'article 222-37 du code pénal, incriminant la détention de tels produits, s'il est établi que les substances détenues étaient exclusivement destinées à la consommation personnelle du prévenu ». Pour ce faire, elle s'est inspirée d'une solution qu'elle avait déjà dégagée par un arrêt Crim., 22 juin 2005, pourvoi n ${ }^{\circ}$ 05-80.395, Bull. crim. 2005, n 193, en vue de régler un conflit de qualification entre le délit de cession ou offre illicites de stupéfiants à une personne en vue de sa consommation personnelle, prévu par l'article 222-39 du code pénal, et celui de détention des produits cédés, prévu par l'article 222-37.

Ne peut-on légitimement penser qu'en posant ainsi un principe d'interprétation conforme de textes entrant en concurrence, elle a pleinement et efficacement joué le rôle qui lui revient d'assurer l'unité du droit pénal et son application conforme aux normes supérieures et qu'un renvoi de la QPC au Conseil constitutionnel aurait vraisemblablement abouti à un résultat similaire, mais différé, par une déclaration de conformité de la loi assortie d'une réserve d'interprétation du même ordre?

S'agissant ensuite de la manière dont la chambre criminelle procède lorsqu'une QPC met en cause une disposition législative dans l'interprétation qu'en donne sa jurisprudence constante, il me semble que le libellé des questions 2 à 4 repose sur un présupposé, quelque peu théorique, selon lequel la lettre du texte et la lecture qu'en donne la jurisprudence pourraient toujours être examinés distinctement. Or, il me semble que ce n'est pas la démarche que suit la chambre criminelle lorsqu'elle est saisie d'une QPC à l'encontre d'un tel texte : elle examine généralement ce dernier dans la lecture qu'elle en a toujours donnée et qui est communément admise. Il ne s'agit donc pas, pour elle, de renvoyer ou non au Conseil constitutionnel l'examen, en tant que telle, de sa jurisprudence. C'est la raison pour laquelle sa décision, de renvoi comme de non-renvoi, peut apparaittre peu explicite sur un éventuel contrôle de cette jurisprudence.

$\mathrm{Au}$ demeurant, le plus souvent la chambre criminelle examine le texte au regard non pas tant d'une interprétation constante qu'elle en donnerait que de la manière dont ce texte a vocation à s'articuler avec d'autres dispositions ou principes. C'est ainsi que, par une décision récente et spécialement motivée (Crim., 24 mai 2016, QPC n 16-90.007, Bull. crim. 2016, n 157), elle a dit n’y avoir lieu de renvoyer au Conseil constitutionnel une QPC portant sur l'article 56 du code de procédure pénale relatif aux perquisitions en matière de crimes et délits flagrants, en se fondant sur les garanties offertes non seulement par le texte lui-même, mais également par d'autres dispositions avec lesquelles il doit se combiner. 
S'agissant, d'une manière générale, de la question de la motivation des décisions en matière de QPC, il est vrai que certaines réponses, dans le style cursif propre à la Cour de cassation, peuvent donner le sentiment d'être par trop péremptoires, spécialement lorsqu'elles se concluent sur un non-lieu à renvoi. Cependant, cette concision ne doit pas occulter l'importance du travail réalisé en amont par le rapporteur, le cas échéant avec l'assistance du SDER. Le rapport du conseiller, qui est communiqué aux parties, comporte en effet une analyse de la jurisprudence du Conseil constitutionnel en rapport avec les griefs soulevés, de la jurisprudence de la Cour elle-même ou de celle d'autres juridictions comme le Conseil d'État, ainsi qu'un exposé de la doctrine sur la question, et il permet bien souvent d'éclairer la décision ultérieurement prise par la chambre. Par ailleurs, les réflexions au sein de la Cour de cassation sur le renforcement de la motivation des arrêts, qui se traduit d'ores et déjà devant la chambre criminelle par le renoncement aux réponses stéréotypées aux moyens dénués de pertinence, ont vocation à se traduire également dans la motivation des décisions en matière de QPC (cf. deux décisions du 30 mars 2016, QPC n 16-90.001, Bull. crim. 2016, n 113, et QPC n 16-90.005, Bull. crim. 2016, n 114, portant renvoi de QPC sur la dualité de poursuites, pénales et fiscales).

Et il ne faut pas perdre de vue que, lorsque la chambre criminelle dit n'y avoir lieu de renvoyer une QPC invoquant, par exemple, une atteinte au principe de légalité des délits et des peines, au motif qu'elle estime que le texte d'incrimination est suffisamment clair et précis pour que sa mise en œuvre échappe à l'arbitraire du juge du fond, elle prend l'engagement d'exercer, en tant que juge de cassation, un contrôle étroit sur cette application.

Ainsi, par sa décision Crim., 8 avril 2014, QPC n 14-90.008, elle a dit n’y avoir lieu à renvoi d'une question prise de ce que l'article $431-9,1^{\circ}$, du code pénal, qui incrimine l'organisation d'une manifestation sur la voie publique sans déclaration préalable, ne déterminerait pas suffisamment clairement et précisément les caractéristiques d'un tel rassemblement et ce, en retenant au contraire que les termes du texte sont suffisamment explicites pour que son interprétation puisse se faire sans risque d'arbitraire. Pourtant, à la différence de l'attroupement, dont le premier alinéa de l'article 431-3 du même code donne une définition ${ }^{1}$, la notion de manifestation n'est pas explicitée par le code pénal et la jurisprudence y afférente, y compris constitutionnelle, est rare. En revanche, les articles L. 211-1 et suivants du code de la sécurité intérieure, qui codifient les dispositions de l'ancien décret-loi du 23 octobre 1935 dans une section spécifiquement consacrée aux « Manifestations sur la voie publique », comportent des indications utiles sur cette notion.

Or, il se trouve que la chambre criminelle a pu elle-même en donner une définition quelques mois plus tard, à l'occasion de l'examen d'un pourvoi en cassation dans une autre affaire, par son arrêt Crim., 9 février 2016, pourvoi $\mathrm{n}^{\circ}$ 14-82.234, Bull. crim. 2016, $\mathrm{n}^{\circ} 35$, dont le sommaire énonce : "Constitue une manifestation, au sens et pour l'application des articles L. 211-1 du code de la sécurité intérieure et 431-9 du code pénal, tout rassemblement, statique ou mobile, sur la voie publique d'un groupe organisé de personnes aux fins d'exprimer collectivement et publiquement une opinion ou une volonté commune ».

1 «Constitue un attroupement tout rassemblement de personnes sur la voie publique ou dans un lieu public susceptible de troubler l'ordre public ». 
À travers cet exemple, on perçoit comment une décision de non-lieu à renvoi d'une QPC peut esquisser les contours d'une jurisprudence à venir.

S'agissant, enfin, de la question des revirements de jurisprudence auxquels il est arrivé à la chambre criminelle de procéder à la faveur d'une QPC, il importe de souligner combien l'introduction de cette procédure, et les normes de contrôle qui la sous-tendent, a eu un impact sur le développement de la jurisprudence en matière pénale.

En effet, jusqu'alors, la chambre était familière du contrôle de conventionnalité, d'autant que les principes de la Convention européenne de sauvegarde des droits de l'homme applicables à la matière pénale sont repris, en droit interne, à l'article préliminaire du code de procédure pénale, au visa duquel nombre d'arrêts de cassation sont pris. Toutefois, la contrainte induite par ce contrôle de conventionnalité n'est pas immédiate, la jurisprudence de la chambre n'étant susceptible d'être discutée devant la Cour de Strasbourg que plusieurs années après le jugement de l'affaire à l'occasion de laquelle elle a été fixée ou simplement appliquée. Le mérite de la QPC est, au contraire, de confronter directement la chambre criminelle à sa jurisprudence constante. Or, dans l'hypothèse où la question révèle que cette jurisprudence n'est plus en phase avec l'évolution du droit ou l'état de la société, faut-il priver la chambre criminelle de la possibilité de la redresser au motif que le revirement n'intervenant pas à l'occasion d'un pourvoi en cassation mais d'une question prioritaire de constitutionnalité, il serait suspect de partialité, voire de procéder d'une stratégie d'évitement du Conseil constitutionnel ? Il me semble que la réponse se trouve dans la question lorsque l'on examine l'une des affaires emblématiques d'un tel recadrage, par la chambre criminelle, de sa jurisprudence.

Ainsi, par sa décision Crim., 12 avril 2012, QPC n 12-90.004, Bull. crim. 2012, n 100, cette chambre a dit n'y avoir lieu de renvoyer au Conseil constitutionnel une QPC portant sur l'article 132-5 du code pénal, relatif au régime de confusion des peines, tel qu'il était interprété de manière constante depuis un arrêt du 24 janvier 2007. Pour faire court, la chambre criminelle avait, par cet arrêt pris sous l'empire du nouveau code pénal, modifié dans un sens plus sévère la jurisprudence prévalant sous l'empire de l'ancien code, sans avoir conscience que, dans certaines hypothèses, la nouvelle règle posée pouvait conduire à une rupture d'égalité devant la loi pénale. Or, un cas topique de cette difficulté lui a été soumis par une QPC transmise par un juge du premier degré. Prenant ainsi conscience des inconvénients de sa jurisprudence, la chambre criminelle a décidé de procéder à un revirement, revenant à la solution antérieure, et posé le principe désormais applicable dans sa décision de non-lieu à renvoi, avant de le réaffirmer un mois plus tard dans un arrêt Crim., 10 mai 2012, pourvoi n 11-87.301, Bull. crim. 2012, nº 117 (sur ce point, voir la chronique de Nicolas Maziau au Recueil Dalloz 2012 p. 1833).

Une telle manière de procéder, qui reste au demeurant rare, me paraît présenter de sérieux avantages pour le justiciable qui a posé la QPC, comme à tous ceux qui sont concernés par l'objet de cette question, puisque, d'une part, il est donné satisfaction à l'intéressé sans délai, ce qui en matière pénale a souvent un prix, d'autre part, la modification de l'état du droit apportée par le revirement 
de jurisprudence lui profite nécessairement, alors qu'une abrogation du texte, tel qu'interprété par la chambre criminelle, pourrait ne pas lui profiter si le Conseil constitutionnel reporte les effets dans le temps de la censure.

En tout état de cause, un tel exercice a ses limites car il suppose que la difficulté d'application du texte législatif tienne à l'interprétation qu'en donne la chambre criminelle et que celle-ci puisse aisément y remédier par un revirement de sa jurisprudence.

Mais l'expérience montre que sont plus souvent invoquées des lacunes dans les textes, notamment dans l'organisation de voies de recours, par exemple contre des autorisations en matière de saisie ou de confiscation. Or, il s'agit de situations dans lesquelles la chambre criminelle ne peut pallier la carence de la loi et où le renvoi au Conseil constitutionnel s'impose afin qu'une censure conduise le législateur à adopter des dispositions plus conformes aux principes constitutionnels.

Pour conclure, il me semble qu'un dialogue satisfaisant s'est établi entre la chambre criminelle et le Conseil constitutionnel et que la manière dont la première peut être conduite à réexaminer sa jurisprudence à l'occasion d'une QPC n'appelle pas de réserves particulières de la part du second. 



\title{
Modèle CONCENTRÉ et ANCRAge de la Constitution DANS L'ÉVOLUTION DU CONTRÔLE INCIDENT EN ITALIE : CONTRIBUTION À L'ÉTUDE DES REMÈDES CONTRE LE REFUS DE SOULEVER LA QUESTION PRÉJUDICIELLE DE CONSTITUTIONNALITÉ
}

\author{
Paolo PASSAgLiA ${ }^{1}$
}

\section{Introduction}

La doctrine constitutionnaliste et comparatiste classe, sans trop d'hésitations, le système italien de justice constitutionnelle parmi les systèmes concentrés inspirés du modèle kelsenien : l'existence d'une Cour constitutionnelle est la manifestation la plus évidente et, en même temps, la plus indiscutable de l'option en faveur d'un modèle qui s'oppose aux systèmes diffus dont le prototype est celui des États-Unis.

On ne saurait contester une telle définition, qui peut compter sur trop d'arguments à l'appui et sur trop de partisans. Cependant, compte tenu de la pratique la plus récente (notamment celle des vingt dernières années) et des remarques que la doctrine en a déduit, il n'est peut-être pas trop aventureux de proposer quelques nuances à la définition courante, eu égard à l'origine du système et à l'évolution qu'il a connu.

Les connaissances de l'auteur de cette contribution rendent l'objectif trop ambitieux pour qu'il puisse être poursuivi en adoptant une approche visant à l'étude du système de justice constitutionnelle dans son ensemble, d'où l'opportunité, voire la nécessité, de choisir un point de vue spécifique qui puisse réduire la focale d'analyse. Le choix est délicat, car il s'agit de sélectionner un sujet qui soit à la fois suffisamment limité pour être maitrisable et suffisamment révélateur pour suggérer, en guise de paradigme, des pistes de réflexion susceptibles de généralisation. Eu égard à l'objectif poursuivi, la question des fondements et des moyens offerts par le système afin de contester les décisions des juridictions ordinaires qui refusent de soulever devant la Cour constitutionnelle la question préjudicielle de constitutionnalité semble répondre à ces exigences. D’un côté, parce qu'il s'agit d'un aspect qui se situe au carrefour des domaines d'action respectifs du juge constitutionnel

1 Professeur à l'Université de Pise, Coordonnateur scientifique pour le droit comparé du Service des Études de la Cour constitutionnelle de la République italienne. L'auteur tient à remercier le Professeur Roberto Romboli, pour ses suggestions et pour les échanges qui lui a accordé, et $\mathrm{M}^{\mathrm{me}}$ Céline Torrisi, pour ses conseils et pour sa relecture du texte. 
et des autres juges et, de l'autre, parce qu'il s'agit d'un élément-clef pour comprendre le fonctionnement du contrôle de constitutionnalité incident, qui, à son tour, représente la pierre angulaire de la protection de la Constitution dans le système juridique italien.

Ainsi, dans le but d'identifier, ou tout du moins de chercher à identifier les nuances évoquées, nous traiterons du sujet des « remèdes » susdits dans une perspective générale, qui est - bien sûr celle du système de justice constitutionnelle, mais qui implique, en amont, quelques éclairages sur la position et la perception de la Constitution au sein de l'ordre juridique.

Une telle approche, intégrant la question des remèdes contre le refus de soulever la question de constitutionnalité aux traits essentiels du système de justice constitutionnelle, nous permettra, non seulement de mettre en exergue les particularités (croissantes) du système italien, mais aussi de s'interroger sur l'impact que l'émergence de ces particularités produit sur la perception des remèdes et, plus généralement, sur la définition même du contrôle incident.

Tandis que le retour sur les fondements théoriques et textuels qui ont conduit les Constituants dans leur choix en faveur d'un système concentré et d'un contrôle incident de la constitutionnalité des lois comme modalité ordinaire de protection de la Constitution nous permettra de souligner la nature imparfaite de la protection d'un acte sui generis (I), l'analyse de la pratique nous conduira, quant à elle, à interroger les changements qui ont affecté le système de mise en œuvre du principe de constitutionnalité (II).

\section{L'établissement du contrôle incident, protection imparfaite d'un acte sui generis}

Lorsque l'État de droit devait être rebâti sur les ruines morales et matérielles laissées par les deux décennies de la dictature fasciste, les députés de l'Assemblée constituante ont, avant tout, rejeté les oppositions venant de deux grands courants de pensée bien présents au sein de l'Assemblée : d'un côté, le modèle légicentriste de la tradition libérale, soutenu, à droite, par un bon nombre de députés cherchant à instituer une continuité avec les institutions antérieures à 1922 ; de l'autre, le modèle légicentriste issu du jacobinisme d'inspiration marxiste, qui avait, à gauche, un grand nombre de partisans, au sein des Partis socialiste et communiste. Une fois opéré le premier choix, fondamental, en faveur d'un système de justice constitutionnelle, une deuxième option était requise, car il s'agissait de déterminer le type de système à mettre en place. À cet égard, la majorité des députés s'est prononcée en faveur d'un système de justice constitutionnelle fondé sur un organe spécifique unique détenteur du pouvoir d'annuler les actes du législateur qui méconnaissaient la Constitution. Afin de rendre effectif un tel pouvoir, l'accès à la Cour par le biais d'une question préjudicielle a été conçu comme le moyen ordinaire de saisine (A), ce qui a fait du « circuit juges-Cour » l'axe fondamental autour duquel le système a été façonné. Par conséquent, c'est principalement au moment où le fonctionnement de ce circuit s'enraye que l'efficacité du système de justice constitutionnelle et les moyens de secours prévus pour les cas d'un blocage doivent être interrogés (B). 


\section{A. Le contrôle concentré et le renvoi des questions préjudicielles à la Cour constitutionnelle}

L'acceptation par les Constituants de la nécessité d'une protection juridictionnelle de la Constitution a été concrétisée avec les choix concernant le système de justice constitutionnelle à mettre en place. Ces choix ont abouti à l'adoption du modèle kelsenien, sans pour autant renoncer à une « hybridation » du modèle avec des caractères assez originaux, relatifs, notamment, au rôle central joué par les juges ordinaires (1). L'importance des originalités du système sont telles que l'effectivité du contrôle de la constitutionnalité des actes législatifs dépend en large mesure des conditions requises pour que les juridictions ordinaires puissent ou doivent saisir la Cour (2).

\section{Un contrôle concentré à l'initiative diffuse}

La prévision d'une Cour constitutionnelle, chargée - entre autres - du contrôle de la constitutionnalité des actes législatifs, a permis la mise en place d'un système concentré, marquant, de facto, le refus d'un système diffus (a). Une telle option, toutefois, n'a pas empêché que la Cour constitutionnelle dépende largement, pour l'accomplissement de sa mission principale, des saisines provenant des juridictions ordinaires (b).

\section{a. L'option en faveur d'un contrôle concentré de la constitutionnalité des lois}

Les débats au sein de l'Assemblée constituante montrent des attitudes diverses vis-à-vis de la création d'un système de justice constitutionnelle. Si une partie considérable des députés, notamment issus de la gauche marxiste, contestaient l'idée même d'un organe chargé de contrôler le législateur, les partisans du contrôle étaient partagés entre une minorité qui prônait d'adoption d'un système diffus à l'américaine (dont un embryon avait été entrevu avant le fascisme ${ }^{2}$ ) et une majorité qui plaidait pour la création d'un organe spécialisé.

Cette solution s'est très vite imposée, eu égard, aussi, à son caractère flou : la mise en place d'un organe nouveau, laissant ouverte la question de sa configuration juridictionnelle ou politique, était acceptable, comme un moindre mal, même pour les députés communistes et socialistes.

La confrontation sur la nature de l'organe a conduit à l'élaboration de normes reflétant très clairement les suggestions de Kelsen, visant à confier la mission de contrôler les lois à un organe ne relevant ni du pouvoir législatif ni du pouvoir juridictionnel, mais indépendant de tout autre pouvoir $^{3}$ : «la protection des principes de la Constitution [devait être] assurée par un organe qui, bien qu'indépendant du Parlement, considère les lois non seulement du point de vue des droits subjectifs

\footnotetext{
2 Sur la justice constitutionnelle italienne précédant l'avènement de la République et l'entrée en fonction de la Cour constitutionnelle, voir F. RACIOPPI, «Il sindacato giudiziario sulla costituzionalità delle leggi », La legge, 1905, p. 705 et suiv. ; A. Pizzorusso, « Garanzie costituzionali », Commentario della Costituzione, sous la direction de G. Branca, article 134, Bologne - Rome, Zanichelli - Il Foro italiano, 1981, p. 43 et suiv. ; F. Roselli, « Giudici e limiti al potere legislativo vigente lo Statuto albertino », Rivista trimestrale di diritto e procedura civile, 1986, p. 476 et suiv. ; J. LuTHER, Idee e storie di giustizia costituzionale nell'Ottocento, Turin, Giappichelli, 1990, p. 190 et suiv. ; M. BIGNAMI, Costituzione flessibile, Costituzione rigida e controllo di costituzionalità in Italia (1848-1956), Milan, Giuffrè, 1997, p. 27 et suiv.

3 Cf. H. Kelsen, « La Garantie juridictionnelle de la constitution (la Justice constitutionnelle) », Rev. dr. publ. et sc. pol., 1928, p. 197 et suiv. (voir, notamment, le paragraphe IV).
} 
du citoyen, mais qui se situe au sein de la logique législative même, sans ne jamais perdre de vue la « raison politique »; un organe, en définitive, lui-même situé dans une position intermédiaire entre les nécessités opposées de la constitutionnalité et de l'autorité légitime de la loi ordinaire ${ }^{4}$.

La recherche d'un équilibre est bien représentée, en premier lieu, par les normes constitutionnelles relatives à la composition de la Cour, qui en font une instance dont les compétences juridiques des membres sont bien assurées, sans pour autant négliger leurs aptitudes à tenir compte de la situation politique dans laquelle les actes législatifs sont adoptés et celle dans laquelle ils sont contrôlés. D’un côté, la qualification juridique des membres de la Cour se traduit par des conditions assez sévères requises pour la nomination ou l'élection : « [1] es juges de la Cour constitutionnelle sont choisis parmi les magistrats, même en retraite, des juridictions supérieures, ordinaires et administratives, les professeurs d'université titulaires de chaires de droit et les avocats ayant vingt ans d'exercice professionnel » (article 135, alinéa 2, de la Constitution) ; de l'autre, la diversité des approches à l'égard du droit et de la législation, qui est en partie le résultat de la présence au sein de l'organe de magistrats, juristes universitaires et avocats, est renforcée par les autorités chargées de les nommer ou de les élire : « [1]a Cour constitutionnelle est composée de quinze juges nommés pour un tiers par le président de la République, pour un tiers par le Parlement réuni en congrès et pour un tiers par les magistratures suprêmes judiciaire et administratives » (article 135, alinéa $1^{\mathrm{er}}$ ).

Le refus d'une Cour qui soit trop proche de la politique et, en même temps, l'opportunité de la laisser assez distancée des juridictions ordinaires se manifeste, en second lieu, dans les dispositions concernant les attributions qui lui sont confiées.

Pour que la Cour constitutionnelle puisse accomplir la mission qu'on lui confiait, la prévision de voies d'accès efficaces était la première des conditions. À ce propos, les Constituants ont fait preuve d'une prudence extrême, qui a donné lieu à l'introduction d'un nombre très restreint du moins si on le compare à celui d'autres cours et tribunaux constitutionnels européens - de recours dont la Cour peut être saisie. La Cour, en effet, n'exerce que quatre catégories de compétences : le contrôle de constitutionnalité « des lois et de actes, ayant force de loi, de l'État et des Régions » (article 134 de la Constitution) ; la résolution « des conflits d'attribution entre les pouvoirs de l'État, entre l'État et les Régions, et entre les Régions » (article 134) ; la résolution des litiges concernant les « accusations portées, aux termes de la Constitution, contre le Président de la République » (article 134 : avant la réforme apportée par la loi constitutionnelle $\mathrm{n}^{\circ} 1$ de 1989,

4 Cf. C. Mezzanotte, Il giudizio sulle leggi. Le ideologie del Costituente (1979), Naples, Editoriale Scientifica, 2014, p. 75. À propos de l'élaboration des dispositions constitutionnelles concernant la Cour constitutionnelle, voir aussi G. D'OrAzIO, La genesi della Corte costituzionale, Milan, Giuffrè, 1981 ; G. Ferrari, «La difficile nascita della Corte costituzionale », Studi parlamentari e di politica costituzionale, 1988, ${ }^{\text {os }} 81-82$, p. 5 et suiv. ; P. CostANzo, «L'organizzazione e il funzionamento della Corte costituzionale nei lavori preparatori dell'assemblea costituente », in P. Costanzo (sous la direction de), L'organizzazione e il funzionamento della Corte costituzionale, Atti del Convegno di Imperia, 12-13 maggio 1995, Turin, Giappichelli, 1996, p. 7 et suiv. ; C. MArgiotTA Broglio, « La Corte costituzionale italiana e il modello kelseniano », Quaderni costituzionali, 2000, p. 333 et suiv.; G. VolPE, «L'accesso alla giustizia costituzionale : le origini di un modello », in R. RomBOLI (sous la direction de), L'accesso alla giustizia costituzionale : caratteri, limiti, prospettive di un modello, Naples, Esi, 2006, p. 3 et suiv. ; G. BIsogNI, Teoria giuridica e giustizia costituzionale in Italia. Un profilo storico-filosofico, Milan, Mimesis, 2012. 
la compétence s'étendait aussi aux ministres) ; enfin, le contrôle de l'admissibilité des requêtes de référendum abrogatif (article 2 de la loi constitutionnelle du 11 mars 1953, nº 1$)^{5}$.

Des quatre catégories, seule la première concerne le contrôle de la constitutionnalité des lois ${ }^{6}$. Sans que l'on puisse négliger l'importance des autres, c'est évidemment à cette catégorie que l'on doit réserver une attention particulière, eu égard à son impact dans la mise en œuvre du principe de constitutionnalité et au nombre de saisines qu'elle a engendré.

L'encadrement du contentieux des actes législatifs par la Constitution est pour le moins lacunaire: dans le texte constitutionnel on a pris soin de préciser la qualification des pouvoirs propres à la Cour, sans pour autant entrer dans les détails de la procédure de contrôle et des voies d'accès.

Sur le premier aspect, l'influence de Kelsen est bien présente, notamment à l'article 136, alinéa $1^{\mathrm{er}}$, de la Constitution, aux termes duquel « [1] orsque la Cour déclare l'inconstitutionnalité d'une norme d'une loi ou d'un acte ayant force de loi, la norme cesse de produire effet dès le lendemain de la publication de la décision ». Il en résulte que la mission de la Cour n'est pas celle de légiférer, car aucune activité « créatrice » n'est prévue : l'influence sur la législation ne se produit que par l'annulation, d'où la qualification de « législateur négatif » qui est propre à la Cour et qui en caractérise l'activité, en la distinguant de celle du législateur : pour reprendre les mots de Kelsen, « [a]lors que le législateur n'est lié par la Constitution que relativement à sa procédure, d'une façon exceptionnelle seulement quant au contenu des lois qu'il doit édicter et seulement par des principes ou directions générales, l'activité du législateur négatif au contraire, de la juridiction constitutionnelle, est absolument déterminée par la Constitution $»^{7}$.

En ce qui concerne la procédure du contrôle, la Constitution s'est limitée à deux renvois, l'un à une loi constitutionnelle qui « fixe les conditions, les formes, les délais dans lesquels des recours en inconstitutionnalité peuvent être introduits » (article 137, alinéa $1^{\mathrm{er}}$ ) et l'autre à la loi ordinaire pour qu'elle « fixe les autres règles nécessaires à l'organisation et au fonctionnement de la Cour » (article 137, alinéa 2).

Même pour ce qui est des voies d'accès à la Cour, la réglementation est loin d'être détaillée : dans son texte original, la Charte, à l'article 127, ne prévoyait que le recours abstrait et a priori du Gouvernement contre les lois régionales. À la suite de la loi constitutionnelle $\mathrm{n}^{\circ} 3$ du 18 octobre 2001, portant révision du Titre $\mathrm{V}^{\mathrm{e}}$ de la Partie $\mathrm{II}^{\mathrm{e}}$ de la Constitution, l'article 127 a été modifié. Il

\footnotetext{
5 Les compétences propres à la Cour constitutionnelle font l'objet d'une bibliographie qui est désormais impossible à maîtriser, tant le nombre de contributions est élevé. Pour ne mentionner que quelques ouvrages généraux parmi les plus récents, voir F. TEREsI, I giudizi della Corte costituzionale, Bari, Cacucci, 2010 ; A. CERRI, Corso di giustizia costituzionale plurale, Milan, Giuffrè, 2012 ; G. ZAGREBELSKY - V. MARCENò,

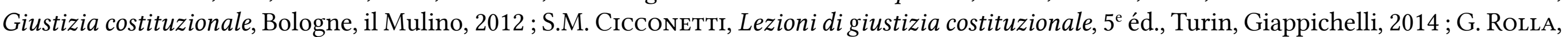
La giustizia costituzionale, Milan, Giuffrè, 2014 ; A. RugGeri - A. SpadAro, Lineamenti di giustizia costituzionale, 5 éd., Turin, Giappichelli, 2014 ; G. Amoroso - G. PArodi, Il giudizio costituzionale, Milan, Giuffrè, 2015 ; E. Malfatti - S. PAnizzA - R. Romboli, Giustizia costituzionale, $5^{\mathrm{e}}$ éd., Turin, Giappichelli, 2016. Ces ouvrages et manuels pourront offrir des références bibliographiques supplémentaires.

6 À l'issue d'une évolution jurisprudentielle marquée, notamment, par l'arrêt n 457 de 1999 de la Cour constitutionnelle, les actes législatifs peuvent faire l'objet de conflits d'attribution entre les pouvoirs de l'État, sous certaines conditions et réserves. Le sujet ne rentrant pas dans le domaine de cette intervention, on se contentera d'y avoir fait allusion. Pour plus de détails, voir, en français, P. PAssAGLIA, Le fuge constitutionnel et le Législateur. L'expérience italienne, Saarbrücken, Éditions Universitaires Européennes, 2011, p. 66 et suiv.

7 Cf. H. Kelsen, op. cit., p. 226.
} 
prévoit, désormais, tant le recours (non plus a priori, mais a posteriori) du Gouvernement contre les lois régionales que le recours des régions contre un acte législatif de l'État.

Il est sans doute paradoxal qu'aucune mention ne soit faite de l'autre voie d'accès qui a toujours été et qui reste - malgré un recul significatif dans les quinze dernières années ${ }^{8}$ - le mode le plus utilisé pour saisir la Cour constitutionnelle du contrôle de la constitutionnalité des actes législatifs, à savoir la question préjudicielle de constitutionnalité.

\section{b. La question préjudicielle de constitutionnalité, voie d'accès privilégiée à la Cour}

L'absence de toute référence au contrôle incident au sein du texte constitutionnel est peut-être le résultat de la méfiance, voire de l'aversion d'une partie considérable des députés à l'Assemblée constituante, vis-à-vis d'un organe qui serait appelé à contrôler l'œuvre du législateur. La difficulté d'arriver à un compromis sur les dispositions portant sur la Cour constitutionnelle est, d'ailleurs, très bien illustrée par les deux renvois précités à la loi constitutionnelle et à la loi ordinaire, opérés par l'article 137, issus d'un amendement présenté par Giuseppe Arata, député communiste, dont l'objectif était de bloquer ou, du moins, de retarder autant que possible l'entrée en fonction d'une institution que le secrétaire de son parti, Palmiro Togliatti, définissait comme une « bizarrerie ».

Ce n'est donc que par une loi constitutionnelle complémentaire adoptée par l'Assemblée constituante que le contrôle incident de la constitutionnalité des lois a été introduit. Il s'agit de l'article $1^{\text {er }}$ de la loi constitutionnelle du 9 février 1948, $\mathrm{n}^{\circ}$ 1, ainsi rédigé : " La question de constitutionnalité d'une loi ou d'un acte ayant force de loi [...] soulevée d'office ou par une des parties au cours du procès et non considérée par le juge manifestement à rejeter, est renvoyée à la Cour constitutionnelle pour qu'elle rende sa décision ».

La disposition était assez laconique pour laisser sans réponse un certain nombre de questions fondamentales, parmi lesquelles, notamment, celle qui concernait le rapport entre le procès en cours et la question de constitutionnalité : le caractère préjudiciel de celle-ci n'ayant pas été expressément reconnu, on aurait pu imaginer les solutions les plus diverses ; même l'idée du procès ordinaire comme simple occasion pour saisir la Cour de n'importe quelle question, indépendamment de tout lien avec le litige en cours, ne pouvait être exclue $a$ priori. Trois aspects étaient néanmoins bien clairs : en premier lieu, l'initiative visant à soulever la question pouvait dériver de tout acteur du procès, et donc du juge comme des justiciables comme du parquet ; en deuxième lieu, le juge se voyait quand même réserver une compétence de filtrage, car c'était à lui que revenait le premier contrôle sur le fond de la question ; enfin - et surtout - la nature du contrôle était très particulière car le juge devait se limiter à constater que la question n'était pas dépourvue de tout fondement.

La nécessité qu'une loi (cette fois de rang ordinaire) précise les principes et les normes régissant le déclenchement du contrôle par voie d'une question préjudicielle n'était donc pas contestable. Ce sera la loi du 11 mars 1953, n 87, qui mettra en œuvre les dispositions constitutionnelles portant sur

8 Sur ce recul, voir infra, II, A.2.a. 
la Cour. Et, pour ce qui a trait au contrôle incident, l'article 23 mettra en exergue le caractère préjudiciel de la question de constitutionnalité par rapport à l'issue du litige en cours, qui « ne [pourra] être défini indépendamment de la décision sur la question de constitutionnalité » et qui sera suspendu à partir du renvoi de celle-ci jusqu'à ce que la décision de la Cour constitutionnelle soit rendue 9

Or, même si la loi de 1953 revêt une importance non négligeable, justement pour ces précisions et pour la consécration du caractère préjudiciel de la question de constitutionnalité (ainsi que pour la réglementation d'autres aspects de détail), il est clair que, dès 1948, le choix fondamental avait été fait : en l'absence d'un recours direct du particulier, le système italien de justice constitutionnelle connaîtra une seule voie d'accès ouverte à la généralité des justiciables et cette voie passera par la juridiction ordinaire ${ }^{10}$. En d'autres termes, le contentieux constitutionnel italien a été mis en place de manière à faire des juges (judiciaires ou administratifs) les « concierges » du Palais de la Consulta ${ }^{11}$.

En effet, ce sont les juges qui ont, eux seuls, le pouvoir de soulever la question préjudicielle de constitutionnalité : les justiciables doivent se limiter à évoquer, parmi les moyens introduits dans un litige devant le juge, celui ou ceux qui sont tirés de l'antinomie entre une ou plusieurs dispositions législatives et une ou plusieurs dispositions constitutionnelles ; mais il revient tout de même au juge de décider si l'antinomie dénoncée peut donner lieu à une question susceptible d'être soulevée devant la Cour constitutionnelle. L'activité des justiciables n'est donc pas suffisante, ni même nécessaire, compte tenu du fait que le juge peut soulever la question soit sur requête des parties soit d'office.

Or, afin que la question puisse être soulevée, le droit positif énonce deux conditions ${ }^{12}$. L'article 23 de la loi n 87 de 1953 prévoit, en premier lieu, que le procès en cours ne puisse pas être résolu

9 Sur le caractère préjudiciel du procès constitutionnel et sur la condition de « rilevanza » qui en dérive, voir M. CAPPELLETTI, La pregiudizialità costituzionale nel processo civile, Milan, Giuffrè, 1957 ; G. ZAGREBELSKY, «La rilevanza, un carattere normale ma non necessario della questione incidentale di legittimità costituzionale », Giurisprudenza costituzionale, 1969, p. 1001 et suiv. ; F. PizzETTi - G. ZAGREBELSKY, "Non manifesta infondatezza" e "rilevanza" nell'instaurazione incidentale del giudizio sulle leggi, Milan, Giuffrè, 1972 ; V. OnIDA, « Note su un dibattito in tema di "rilevanza" delle questioni di costituzionalità delle leggi », Giurisprudenza costituzionale, 1978, p. 997 et suiv. ; N. Trocker, «La pregiudizialità costituzionale », Rivista trimestrale di diritto e procedura civile, 1988, p. 796 et suiv. ; F. DAL CANTO, « La rilevanza e il valore del fatto nel giudizio di costituzionalità delle leggi in via incidentale », in E. MALFATTI - R. Romboli - E. Rossi (sous la direction de), Il giudizio sulle leggi e la sua "diffusione”, Atti del seminario di Pisa svoltosi il 25-26 maggio 2001, Turin, Giappichelli, 2001, p. 145 et suiv. ; G.P. Dolso, Giudici e Corte alle soglie del giudizio di costituzionalità, Milan, Giuffrè, 2003 ; L. AzzenA, La rilevanza nel sindacato di costituzionalità dalle origini alla dimensione europea, Naples, Jovene, 2012.

10 Le contrôle incident de la constitutionnalité des lois fait l'objet d'un grand nombre d'ouvrages et de contributions de la part de la doctrine italienne. Sans pouvoir présenter une bibliographie exhaustive, on doit mentionner, du moins, les suivants : G. ABBAMONTE, Il processo costituzionale italiano. Il sindacato incidentale, Naples, Jovene, 1957 ; F. Modugno, "Riflessioni interlocutorie sull'autonomia del giudizio costituzionale », Rassegna di diritto pubblico, 1966, p. 221 et suiv. ; A. GARdino CARLI, Giudici e Corte costituzionale. Gli elementi diffusi del nostro sistema di giustizia costituzionale, Milan, Giuffrè, 1988 ; CoRTe costrtuzionale, Giudice a quo e promovimento del processo costituzionale, Milan, Giuffrè, 1990 ; A. Spadaro, Limiti del giudizio costituzionale in via incidentale e ruolo dei giudici, Naples, Edizioni Scientifiche Italiane, 1990 ; P. BIANCHI - E. MAlfatti, «L'accesso in via incidentale », in A. Anzon - P. CARetti - S. Grassi (sous la direction de), Prospettive di accesso alla giustizia costituzionale, Atti del seminario di Firenze svoltosi il 28-29 maggio 1999, Turin, Giappichelli, 2000, p. 13 et suiv. ; A.M. Nico, L'accentramento e la diffusione nel giudizio sulle leggi, Turin, Giappichelli, 2007 ; S. BAGNI, La questione incidentale nel controllo di costituzionalità. I sistemi italiano e spagnolo a confronto nel quadro dei modelli elaborati dalla dottrina, Bologne, Clueb, 2007 ; L. DeLli Priscoli - P.G. DemARCHI, L'eccezione di incostituzionalità: profili processuali, Bologne, Zanichelli, 2008 ; N. PIGNATELLI, Le "interazioni” tra processo amministrativo e processo costituzionale in via incidentale, Turin, Giappichelli, 2008; G.L. ConTI, « Mantenere nel tempo il valore del giudizio incidentale di legittimità costituzionale », in C. Decaro - N. Lupo - G. Rivosecchi (sous la direction de), La "manutenzione" della giustizia costituzionale. Il giudizio sulle leggi in Italia, Spagna e Francia, Atti del seminario tenutosi a Roma, alla Luiss Guido Carli, il 18 novembre 2011, Turin, Giappichelli, 2012 , p. 31 et suiv. ; A. PATroni Griffi, Accesso incidentale e legittimazione degli «organi a quo», Naples, Jovene, 2012 ; R. RomBolI, « Natura incidentale del giudizio incidentale e tutela dei diritti: in margine alla sentenza n. 10 del $2015 »$, Quaderni costituzionali, 2015, p. 607 et suiv.

11 La définition, devenue célèbre, est de Piero Calamandrei (La illegittimità costituzionale delle leggi nel processo civile, Padoue, Cedam, 1950, p. XII), éminent juriste qui a été membre de l'Assemblée constituante.

12 À ces conditions, une troisième s'ajoute. Il s'agit d'une création de la jurisprudence constitutionnelle, qui l'a déduite du système (cf. infra, II, A.2.a.). 
indépendamment de la décision relative à la question de légitimité constitutionnelle. En d'autres termes, pour qu'elle puisse être soulevée, la question doit conditionner la solution du litige ou de la poursuite en cours. Il s'agit de la condition de «rilevanza », notion qui identifie directement le caractère préjudiciel des questions de constitutionnalité dont la Cour constitutionnelle est saisie, mais qui, au-delà de cette qualification générale, est assez difficile à traduire, car la jurisprudence constitutionnelle a elle-même proposé plusieurs définitions, allant de la nécessité que l'éventuelle déclaration d'inconstitutionnalité dérivant de la question préjudicielle ait une « influence nécessaire » sur l'issue du litige en cours jusqu'à l'exigence que la disposition législative contestée soit applicable au procès devant le juge commun (ou, du moins, que le juge estime que la disposition s'y applique). Si la pratique la plus récente semble pencher vers cette dernière définition ${ }^{13}$, ce qui intéresse à présent est, surtout, que l'appréciation de la « rilevanza» de la question revient au juge commun, sans pour autant que la Cour constitutionnelle soit dépourvue du pouvoir de contrôler la décision du juge et, pour les cas les plus évidents d'erreur, même opposer une « irrecevabilité » de la question de constitutionnalité justement pour défaut de son caractère préjudiciel.

L'article 23 précité évoque aussi une seconde condition, qui réside dans la «non manifesta infondatezza ». Il s'agit d'une condition qui n'a pas toujours attiré l'attention qu'elle mérite, peut-être parce que l'intérêt s'est souvent concentré sur l'autre condition, qui paraît plus déterminante dans la définition des traits essentiels du système. Or, dans le but qui est propre à cette contribution, toutefois, une place tout à fait centrale est - semble-t-il - à reconnaître à la condition de "non manifesta infondatezza», ne serait-ce parce qu'elle contribue de manière décisive à mettre en lumière les particularités du système italien dans le contexte comparatiste et parce qu'elle pose des questions qui appellent des réponses permettant de donner des précisions importantes à l'égard des rapports entre la juridiction constitutionnelle et les juges ordinaires.

\section{Les conditions de fond requises pour soulever une question préjudicielle de constitutionnalité}

Le contrôle incident de la constitutionnalité des lois est fondé sur un filtrage préliminaire opéré par les juges ordinaires, impliquant, entre autres, un examen du fond de la question à soulever. Cet examen a été conçu comme rien plus qu'une appréciation très sommaire (a), ce qui peut poser, au niveau de la pratique, quelques difficultés à l'égard de la mission propre aux juges d'interpréter le droit positif (b).

\section{a. Le caractère «non-futile » de la question}

La «non manifesta infondatezza», condition de fond que le juge ordinaire doit prendre en considération afin de statuer sur le renvoi de la question de constitutionnalité, se traduit par l'exigence

13 L'assouplissement de la rigueur de la condition de « rilevanza » s'est très clairement manifesté lors du contrôle par la Cour de la loi électorale : cf. l'arrêt du 13 janvier 2014, $\mathrm{n}^{\circ}$ 1, et le débat au sein de la doctrine qui en est dérivé (voir « Dibattito sulla sentenza della Corte costituzionale n. 1 del 2014 dichiarativa dell'incostituzionalità di talune disposizioni della l. n. 270 del 2005 », Giurisprudenza costituzionale, 2014, p. 629 et suiv. ; voir aussi R. RomBoLI, « La riforma della legge elettorale ad opera della Corte costituzionale : attenti ai limiti », Foro italiano, 2014, I, c. 677 et suiv. ; sur la question qui a déclenché le contrôle de la Cour, voir R. RomBoLI, « La costituzionalità della legge elettorale 270/05: la Cassazione introduce, in via giurisprudenziale, un ricorso quasi diretto alla Corte costituzionale ? », Foro italiano, 2013, I, c. 1836 et suiv.). 
que la question ne soit pas manifestement dépourvue de chances de donner lieu à une décision sur le fond qui déclare l'inconstitutionnalité des dispositions législatives dénoncées. En principe, l'exclusion des questions qui sont manifestement dépourvues de tout fondement implique que, pour pouvoir saisir à juste titre la Cour constitutionnelle, il suffit que le juge ait un doute - un simple doute à l'égard de la conformité entre les dispositions constitutionnelles et les dispositions législatives applicables à l'espèce (ou, selon la définition que l'on donne à la « rilevanza », les dispositions dont l'inconstitutionnalité éventuelle influence l'issue du litige).

En d'autres termes, la loi no 87 de 1953 avait pris le soin d'éviter que des questions « futiles », «frivoles » ou « téméraires » soient posées ${ }^{14}$. Il s'agit d'un choix assez particulier, d'un point de vue comparatiste, qui s'explique - semble-t-il - par le fait que lorsqu'on introduisait le contrôle incident comme le mode ordinaire de saisine de la Cour, on ne savait pas vraiment ce que celui-ci aurait pu devenir. Ceci augmentait considérablement les risques d'un échec, qui aurait mis à mal, non seulement le contrôle de la constitutionnalité des lois, mais aussi le système de justice constitutionnelle en général, d'autant plus que dans la situation italienne de l'après-guerre, l'éventail restreint des voies d'accès, combiné au quasi-monopole des juges ordinaires du pouvoir de saisine, cachait le risque que la justice constitutionnelle n'arrive pas à jouer un rôle significatif au sein de l'ordre juridique : l'œuvre d'épuration ayant été très partielle et superficielle ${ }^{15}$, un certain nombre de juges ordinaires se révélaient compromis avec le fascisme et, en tout état de cause, la grande majorité d'entre eux (dont surtout ceux qui siégeaient dans les plus hautes instances) avait achevé leurs études et s'était formé bien avant que les principes inspirateurs de la République se répandent dans l'ordre juridique en se substituant à la législation adoptée pendant la dictature. Autrement dit, le choix de laisser aux juges le pouvoir de saisir la Cour pouvait bien se révéler le moyen par lequel raréfier les questions soulevées, jusqu'à les rendre trop peu nombreuses pour que la Cour constitutionnelle puisse donner son empreinte au nouveau régime. La tradition hostile à tout empiétement des juges sur le domaine politique et même un passé caractérisé par des tendances légicentristes (atténuées seulement en raison du développement considérable des pouvoirs normatifs de l'Exécutif) autorisaient un certain pessimisme. Le fait même que l'article 101, alinéa 2, de la Constitution énonce le principe selon lequel « les juges ne sont soumis qu'à la loi » pouvait se prêter à des interprétations stérilisantes, quoique l'emploi du terme « loi » ne soit pas à rapporter à l'acte législatif, étant évidemment le vestige d'un positivisme radical qui définissait le droit en se référant uniquement au droit positif et qui assimilait l'essentiel de celui-ci à la production législative ${ }^{16}$.

14 Sur la condition de "non manifesta infondatezza », voir P. CALAMANDREI, "Sulla nozione di "manifesta infondatezza" », Rivista di diritto processuale, 1956, II, p. 164 et suiv. ; F. PizzetTi - G. ZAgrebelsky, op. cit.; plus récemment, voir M. Luciani, "La non manifesta infondatezza come caratteristica oggettiva della questione di costituzionalità », Giurisprudenza costituzionale, 1992, p. 3975 et suiv. ; G. SorRENTI, « La "manifesta infondatezza" delle questioni di legittimità costituzionale e l'applicazione diretta della Costituzione nella prassi giudiziaria. Ovvero : una ricerca empirica su una risalente ipotesi, di rinnovata attualità », in E. MALFATTI - R. RomBOLI - E. Rossi (sous la direction de), op. cit., p. 76 et suiv. Au cours des dernières années, la condition de «non manifesta infondatezza » a été étudiée par la doctrine en liaison avec l'interprétation conforme, sur laquelle voir infra, II, A.2.a.

15 Cf. P. CAnosA, Storia dell'epurazione in Italia. Le sanzioni contro il fascismo 1943-1948, Milan, Baldini \& Castoldi, 1999 ; H. Woller, I conti con il fascismo. L'epurazione in Italia 1943-1948, Bologne, il Mulino, 2008.

16 Cf. D. Bifulco, Il giudice è soggetto soltanto al diritto: contributo allo studio dell'articolo 101, comma 2 della Costituzione italiana, Naples, Jovene, 2008. 
L'expérience des premières années de «Constitution ... sans Cour »-que le législateur de 1953 ne pouvait évidemment pas négliger - offrait plus qu'un argument à l'appui des réserves concernant l'attitude des juges vis-à-vis des nouveaux principes constitutionnels ${ }^{17}$.

L'élasticité de la condition de «non-futilité » de la question de constitutionnalité était donc conçue, vraisemblablement, comme une soupape de sécurité, dans la mesure où elle augmentait les chances que des questions préjudicielles de constitutionnalité soient soulevées. Autant dire qu'en mettant en place le système de justice constitutionnelle, le législateur de 1953, eu égard au nombre limité des voies d'accès à la Cour (et notamment au défaut de tout recours direct des particuliers), comptait garantir le fonctionnement du système en facilitant, autant que possible, la tâche des seuls « concierges » du Palais de la Consulta.

Si la prévision permettant de soulever de questions de constitutionnalité qui puissent être qualifiées simplement de «non-futiles » a eu un impact majeur sur la pratique, en contribuant de manière déterminante à faire de l'Italie « la terre d'élection » du contrôle incident ${ }^{18}$, ses effets sur la structure du système de justice constitutionnelle ne sauraient être négligés.

Pour dégager une analyse sommaire de ceux-ci, il est peut-être utile de faire recours à la comparaison avec d'autres systèmes caractérisés par l'existence d'un contrôle incident.

L'exemple que l'on cite le plus fréquemment est celui de l'Allemagne, où la mise en place du système de justice constitutionnelle est à peu près contemporaine à l'Italie ${ }^{19}$. C'est directement la Loi fondamentale allemande qui esquisse - à l'article 100, paragraphe 1 - les traits essentiels du contrôle concret des normes, en réservant le renvoi de questions préjudicielles de constitutionnalité au cas où « un tribunal estime qu'une loi dont la validité conditionne sa décision est inconstitutionnelle ». Le juge ordinaire allemand est donc censé saisir le Tribunal constitutionnel fédéral (dans le cas d'une antinomie se manifestant avec la Loi fondamentale) ou le tribunal constitutionnel du Land (si c'est la constitution du Land à être en question) uniquement lorsque son examen des rapports entre l'acte législatif et les dispositions constitutionnelles aboutit à la constatation d'une méconnaissance de celles-ci par celui-là.

La comparaison avec le cas italien est apparemment assez simple : alors que pour le juge italien un doute est suffisant pour soulever la question préjudicielle, le juge allemand doit être persuadé de l'inconstitutionnalité des dispositions législatives qu'il soumet au contrôle du Tribunal constitutionnel. Une différence majeure résulte ainsi de ce qu'il aux juges ordinaires est demandé et, en même temps, est permis.

\footnotetext{
17 À ce propos, voir P. CostANZo, « Disposizioni transitorie e finali I-XVIII. Leggi costituzionali e di revisione costituzionale (1948-1993) », Commentario della Costituzione, sous la direction de G. Branca et de A. Pizzorusso, disp. trans. VII, Bologne - Rome, Zanichelli - Il Foro italiano, 1995, p. 143 et suiv. ; M. BignAmi, op. cit.

18 Cf. M. Fromont, La justice constitutionnelle dans le monde, Paris, Dalloz, 1996, p. 58.

19 En raison de la quasi-contemporanéité de la mise en place de la justice constitutionnelle en Allemagne et en Italie, l'exemple allemand fera l'objet d'une attention particulière. Â des remarques similaires se prête le système espagnol et même, du moins pour ce qui est des conditions pour soulever la question prioritaire de constitutionnalité, le système français. On fait référence, évidemment, au fait que la question ne doit pas être « dépourvue de caractère sérieux » (article 23-2 de l'ordonnance n ${ }^{\circ}$ 58-1067 du 7 novembre 1958 portant loi organique sur le Conseil constitutionnel français, dans sa rédaction issue de la loi organique $n^{\circ}$ 2009-1523 du 10 décembre 2009, relative à l'application de l'article 61-1 de la Constitution).
} 
L'approche différente a des répercussions qui ne sont pas uniquement « quantitatives », eu égard au nombre des questions qui sont soulevées. L'effet inévitable est que le nombre de questions préjudicielles est beaucoup plus important en Italie qu'en Allemagne. Cela est loin d'impliquer, pour l'Allemagne, une limitation de l'empreinte du juge constitutionnel : on a tendance à mettre en évidence le fait que le nombre restreint de questions de constitutionnalité se justifie par la possibilité offerte au justiciable allemand de saisir directement le Tribunal constitutionnel, une fois épuisés les remèdes juridictionnels ordinaires. Bien évidemment, par cette voie, la décision même par laquelle le juge refuse de soulever une question de constitutionnalité peut faire l'objet du contrôle du Tribunal constitutionnel ${ }^{20}$.

Les remarques suggérées par la comparaison avec l'Allemagne pourraient assez facilement être généralisées à tous les systèmes ayant tant un contrôle incident des lois qu'un recours direct des particuliers contre les décisions de justice. Le cas espagnol, par exemple, est très révélateur, car même le Tribunal de Madrid, tout en ne pouvant pas contrôler la constitutionnalité des lois à la suite d'un recours d'amparo, est quand-même en mesure de vérifier si le refus de soulever la question de constitutionnalité a conduit à la méconnaissance d'un droit fondamental, et notamment de celui d'obtenir une protection juridictionnelle effective ${ }^{21}$.

\section{b. Les rapports entre le renvoi et l'interprétation : un sujet initialement négligé}

Le choix de subordonner le renvoi des questions préjudicielles de constitutionnalité à la condition qu'elles ne soient pas «futiles» poursuivait un objectif qui était sans doute méritoire. Dans la pratique, le moyen pour poursuivre l'objectif allait très vite manifester une efficacité incontestable ; cependant, sur le plan de la théorie, il ne pouvait pas cacher des difficultés qui n'auraient cessé de s'aggraver au fil des ans.

La comparaison avec le système allemand peut, à nouveau, aider à dégager les aspects principaux de cette difficulté.

Le juge ordinaire qui - comme est le cas du juge allemand - ne peut saisir le juge constitutionnel que lorsqu'il est persuadé de l'inconstitutionnalité de la disposition législative est un sujet auquel le système demande d'exercer à fond sa mission de sélection des dispositions et d'interprétation des dispositions sélectionnées ${ }^{22}$. Par conséquent, la question préjudicielle se situe à la fin de la phase qui

20 Une telle possibilité est à l'origine d'une différence majeure entre système italien et système allemand, sur laquelle, cependant, il n'est peut-être encore temps de s'arrêter : la possibilité pour la juridiction constitutionnelle de contrôler le bien-fondé du refus de soulever la question de constitutionnalité sera au cœur de l'analyse des particularités qui sont propres au système italien qui sera entreprise par la suite (sous-partie B). Le sujet ne sera pas, toutefois, abordé d'un point de vue comparatiste, car, justement en raison des particularités du système italien, la comparaison avec un système plus « complet », tel que celui de l'Allemagne, risquerait de n'avoir qu'un intérêt purement théorique. 21 Article 24, alinéa $1^{\text {er }}$, de la Constitution : « Toute personne a le droit d'obtenir la protection effective des juges et des tribunaux dans l'exercice de ses droits et intérêts légitimes. En aucun cas, ce recours ne peut être refusé ».

22 Les rapports entre l'activité herméneutique et celle de sélection des dispositions (par le biais de l'application des critères de résolution des antinomies normatives) font l'objet d'une attention constante de la part de la doctrine italienne, notamment en raison du fait que la détermination de la disposition qui s'impose (en vertu des critères hiérarchique, de compétence, chronologique et de spécialité) requiert une interprétation de la disposition même qui puisse dégager des énoncés normatifs un contenu susceptible d'être analysé en rapport avec celui des autres dispositions susceptibles, en théorie, d'application. Cf., en ce sens, G. SorREnTı, L'interpretazione conforme a Costituzione, Milan, Giuffrè, 2006, p. 9 et suiv. ; R. BIN, « L'applicazione diretta della Costituzione, le sentenze interpretative, l'interpretazione conforme a Costituzione della legge », in La circolazione dei modelli e delle tecniche del giudizio di costituzionalità in Europa, Atti del XX Convegno annuale dell'AIC (Roma 27-28 ottobre 2006), Naples, Jovene, 2010, p. 201 et suiv. ; F Modugno, Interpretazione giuridica, $2^{\mathrm{e}}$ éd., Padoue, Cedam, 2012 , p. 135 et suiv. 
précède l'application ${ }^{23}$ et ne se concrétise qu'à la condition que le juge ne soit pas arrivé à éviter l'antinomie entre la loi et la Constitution à travers une interprétation de la loi, et notamment à travers une interprétation visant à rendre la loi conforme à la Constitution. Le texte de l'article 100 de la Loi fondamentale, précité, est loin de susciter des doutes à ce propos, justement parce que la locution utilisée (auf dessen Gültigkeit es bei der Entscheidung ankommt, für verfassungswidrig), évoquant le fait d'être parvenu à une décision, implique l'achèvement par le juge de l'analyse juridique aboutissant à la détermination de la norme, c'est-à-dire de la règle à appliquer dans le cas d'espèce ${ }^{24}$.

Par contre, si on demande au juge ordinaire, comme cela est le cas du système italien, de simplement constater que la question de constitutionnalité n'est pas futile, on évoque l'idée d'un jugement sommaire, qui se contente d'une appréciation au premier abord de la question, sans qu'on l'analyse en profondeur.

Or, « juger, c'est interpréter la loi » : l'adage, dont la formulation est vieille de quelques siècles ${ }^{25}$, est sans doute évocateur de l'impossibilité de séparer n'importe quelle juridiction d'un pouvoir qui est inhérent à la mission du juge. Sans qu'il soit question, ici, de s'arrêter sur la critique des théories prônant une application mécanique de la loi, qui arrivaient à n'identifier dans le juge qu'un instrument de la loi, et notamment la bouche qui en prononçait les mots ${ }^{26}$, ce qui est à constater est que la « superficialité relative » de l'activité requise au juge italien se répercute sur ce qu'on lui demande à propos de l'interprétation des dispositions législatives susceptibles de faire l'objet de la question préjudicielle.

Dans une perspective purement spéculative, en négligeant le caractère indéfectible de l'interprétation, on pourrait même être tenté d'exclure des tâches du juge ordinaire celle d'interpréter les dispositions : l'idée même d'un jugement purement sommaire, associée à l'objectif (ou, du moins, à l'opportunité) de faciliter l'accès à la Cour constitutionnelle, pourrait se traduire par la requête minimale de sélectionner les dispositions à appliquer au cours litige (ce qui est requis par la condition de «rilevanza») et de s'assurer de ne pas faire «perdre du temps » à la Cour constitutionnelle en la saisissant de questions dont la solution est trop évidente pour ne pas être formulée sans aucune intermédiation.

Un tel encadrement, s'il peut paraître conforme à la structure d'un contrôle incident mis en place en substitution d'un recours direct, n'est toutefois pas défendable du point de vue strictement juridique. La décision même de soulever une question de constitutionnalité implique, en effet, que

\footnotetext{
23 Sur les rapports entre interprétation et application des dispositions, voir F. MANNELLA, Giudici comuni e applicazione della Costituzione, Naples, Editoriale Scientifica, 2011, p. 31 et suiv. ; F Modugno, op. cit., p. 272 et suiv.

24 Dans la doctrine italienne, notamment sur la base du magistère de Vezio Crisafulli (« Disposizione (e norma) », in Enciclopedia del diritto, volume XIII, Milan, Giuffrè, 1964, p. 195 et suiv.), la distinction est bien établie entre la disposition et la norme : par la première on fait référence au texte de l'énoncé normatif, tandis que la seconde est le résultat de l'interprétation dont la disposition fait l'objet. Dans la suite, les deux termes seront utilisés « à l'italienne ».

25 Une attestation explicite est celle du sermon prononcé par William Dickinson en 1619: The Kings Right: Briefely Set Downe in a Sermon Preached Before the Reuerend Iudges at the Assizes Held in Reading for the County of Berks. Iune 28. 1619. Cf. J.-F. SPITZ, Fohn Locke et les fondements de la liberté moderne, Paris, Presses Universitaires de France, 2001, p. 157 et suiv.

26 La référence est, bien évidemment, à la définition de MontesQuieu (De l'Esprit des Lois, Genève, 1748, Livre XI, Chapitre VI), sur laquelle nous aurons l'occasion de revenir (cf. infra, II, B.1.a.).
} 
le juge ne se contente pas de sélectionner la disposition législative, car il devra nécessairement lui attribuer des contenus, pour qu'il puisse la qualifier d'applicable au litige. Encore (et surtout), le renvoi d'une question préjudicielle ne peut se faire qu'une fois que l'antinomie entre la loi et la Constitution a été pour le moins entrevue car, autrement, la question serait sans objet ; et pour que l'antinomie soit entrevue, le juge ne saurait éviter de déduire des contenus de la disposition qui fait l'objet potentiel de la question. Or, l'activité par laquelle le juge donne des contenus aux dispositions est tout simplement l'interprétation. De ce fait, avant de soulever n'importe quelle question de constitutionnalité, le juge italien est tenu d'interpréter les dispositions législatives, à l'instar de son homologue allemand. C'est justement à ce stade de l'argumentation que la solution pragmatique italienne s'avère porteuse de difficultés, car il est impossible de déterminer le moment où l'interprétation qui permet le simple jugement sommaire devient autre chose et fonde un jugement complet du fond de la question de constitutionnalité à soulever.

Force est de constater, donc, que l'impact du filtrage très élastique assuré par la condition de « non-futilité » s'apprécie moins du point de vue concret que sur le plan de la «philosophie du système ».

En d'autres termes, pour que le juge puisse déclarer la question «non-futile », il doit interpréter la disposition législative, mais comme l'activité interprétative n'est pas susceptible d'être segmentée (car l'alternative qui se pose est rigide entre, d'un côté, éviter la lecture même de l'énoncé normatif et, de l'autre, lui donner des contenus), avant de saisir la Cour constitutionnelle le juge doit arriver au bout de la phase interprétative, ce qui veut dire qu'il doit faire ni plus ni moins que ce que fait le juge allemand. La véritable différence n'est donc pas d'ordre « quantitatif » (c'est-à-dire liée au degré de profondeur requis pour soulever la question), mais plutôt d'ordre « qualitatif » : si en Allemagne rien ne s'oppose à ce que le juge expérimente n'importe quel canon d'interprétation, car le système requiert que la question de constitutionnalité soit le résultat de l'impossibilité d'arriver à une interprétation qui évite l'antinomie entre la loi et la constitution, en Italie le sujet n'est pas tranché de manière incontestable par le droit positif. Par conséquent, des théories diverses pourraient très bien se confronter. Le problème s'est présenté surtout à l'égard de l'alternative entre le renvoi de la question préjudicielle et l'interprétation de la disposition pouvant faire l'objet de la question de manière à la rendre conforme à la Constitution. C'est donc le domaine de l' " interprétation conforme » celui où les difficultés d'encadrement de la notion de «non-futilité » par rapport aux pouvoirs interprétatifs des juges ont imposé des solutions prétoriennes visant à orienter l'alternative entre « soulever » et « interpréter ». Et, du point de vue comparatiste, les solutions qui ont été élaborées ne sont pas dépourvues d'originalité.

Avant d'aborder ce sujet, il convient, cependant, de terminer l'ébauche du tableau illustrant le contrôle incident tel qu'il se présentait au moment où la Cour constitutionnelle était mise en place, en soulignant notamment la défaillance du système des remèdes contre le refus de soulever une question de constitutionnalité. 


\section{B. Le système défaillant des remèdes contre le refus de soulever une question de constitutionnalité}

Le rôle décisif qui est joué par les juges ordinaires dans le fonctionnement du contrôle de constitutionnalité fait en sorte que la mise en œuvre du principe de constitutionnalité implique une collaboration étroite entre les juges et la Cour constitutionnelle. Le point sensible du système réside justement dans ces rapports, et en particulier dans la disponibilité des juges à saisir la Cour. Dans ce cadre, il est clair que le refus de soulever une question préjudicielle peut toujours constituer, en principe, une atteinte au bon fonctionnement du système. Par conséquent, on pourrait s'attendre un éventail de remèdes contre de tel refus. En fait, les remèdes s'avèrent assez peu performants, eu égard tant aux possibilités de saisir la Cour (1) qu'à celles de saisir d'autres juridictions (2).

\section{Les contestations devant la Cour constitutionnelle : les remèdes introuvables}

Organe député à protéger la Constitution, la Cour constitutionnelle est dépourvue de moyens pour se protéger elle-même vis-à-vis de décisions judiciaires qui la privent du pouvoir de contrôler la constitutionnalité des lois. Ce paradoxe dérive, d'un côté, des limitations des voies d'accès à la Cour (a) et, de l'autre, d'une jurisprudence constitutionnelle qui est extrêmement prudente vis-à-vis du contrôle des actes juridictionnels (b).

\section{a. Les limitations par le droit positif : l'absence d'un recours direct des particuliers}

La notion même de système concentré de justice constitutionnelle paraît évoquer l'idée que la Cour constitutionnelle soit en mesure d'avoir le dernier mot dans les questions relatives à la constitutionnalité des $\operatorname{lois}^{27}$. Cela impliquerait, vraisemblablement, le pouvoir de contrôler l'exercice par les juges de missions rebondissant sur les tâches de la Cour. C'est, du moins, ce qui arrive dans les systèmes où une voie d'accès directe à la juridiction constitutionnelle est offerte aux particuliers qui contestent les décisions des juridictions ordinaires. En effet, le recours direct permet à la Cour ou au Tribunal constitutionnel de vérifier si et dans quelle mesure les instances judiciaires, y compris les cours suprêmes, ont fait une application correcte de la Constitution, ce qui revêt un intérêt tout particulier lorsque parmi les griefs figure le refus de soulever une question de constitutionnalité. Le contrôle incident est ainsi complété par l'accès direct à la juridiction constitutionnelle, de manière à préserver l'indépendance des juges ordinaires tout en l'encadrant, grâce à la possibilité toujours ouverte de contrôler tout usage abusif de cette autonomie. Certes, dans un tel système la juridiction constitutionnelle risque de devenir une cour suprême supplémentaire, chargée de rendre la justice en dernier ressort, ce qui n'est peut-être pas tout à fait cohérent avec l'idée d'une juridiction spéciale pour la Constitution (en supposant qu'une distinction rigide soit réellement possible, sur ce point, entre la juridiction ordinaire et la juridiction constitutionnelle) : n'est peut-être pas sans

27 On fait (et on fera) emploi de la notion de « dernier mot » dans un sens différent de celui qu'on lui attribue généralement : au lieu de faire allusion aux rapports entre la juridiction constitutionnelle et le législateur (ou le pouvoir constituant dérivé : cf., par exemple, L. FAvorEU, « La légitimité du juge constitutionnel », Revue internationale de droit comparé, 1994, p. 578, qui explique que « [1]a légitimité du juge constitutionnel tient à ce qu'il n'a pas le dernier mot »), ici le dernier mot a trait aux rapports entre la juridiction constitutionnelle et les juridictions ordinaires, notamment pour ce qui est de la possibilité de soumettre les dispositions législatives au contrôle de constitutionnalité. 
intérêt le fait que, dans les États ayant une taille démographique significative (et donc un nombre considérable de justiciables potentiels), les juridictions constitutionnelles qui sont appelées à juger les recours directs des particuliers doivent souvent gérer un contentieux très lourd, jusqu'à ce que des procédures spécifiques sont mises en place pour permettre des décisions en forme simplifiée des recours irrecevables ${ }^{28}$. En contrepartie, le bénéfice le plus évident tient au fait que, dans la logique qui anime le système concentré de justice constitutionnelle, l'instance ayant la mission de protéger la Constitution est mise dans les conditions d'avoir effectivement le dernier mot sur n'importe quel litige relevant de l'application de la Constitution.

Le système italien ne partage pas une telle logique. Le contrôle concentré « à l'italienne » ne se caractérise pas, en effet, par la reconnaissance du dernier mot au profit de la Cour constitutionnelle. L'absence d'un recours direct des particuliers empêche la Cour de contrôler l'activité des juridictions ordinaires, dont l'indépendance n'est donc pas entourée de réserves : la Cour constitutionnelle est tout simplement externe - tant du point de vue de l'organisation que de celui des fonctions - à l'exercice du pouvoir juridictionnel ordinaire et elle ne peut donc pas superposer sa jurisprudence à celle de n'importe quelle autre instance judiciaire. Le résultat est que la Cour ne saurait être saisie quel que soit le grief, même si l'on contestait à la juridiction ordinaire un refus illégitime de soulever la question de constitutionnalité.

Le caractère concentré du système de justice constitutionnelle se résout, donc, principalement au monopole de l'annulation des dispositions et des actes législatifs qui est propre à la Cour ; par contre, rien n'assure que la Cour tranche un litige ayant une « portée constitutionnelle».

L'absence de remèdes contre le refus de soulever la question de constitutionnalité est sans doute - nous l'avons déjà remarqué - un acte de confiance qui a été fait aux juges ordinaires et qui est tempéré par l'obligation de soulever toute question qui ne soit pas perçue comme « futile » : cet aspect du contrôle incident se confirme donc décisif afin de comprendre les choix des Constituants.

Or, sans que cela affecte de manière générale la confiance susdite, la classe politique et la doctrine italiennes se sont parfois interrogées sur l'opportunité d'introduire un recours direct des particuliers, qui puisse renforcer la protection des droits fondamentaux (et, par cela, même des dispositions constitutionnelles qui garantissent ces droits), grâce notamment à la prévision d'un recours qui puisse intégrer le système en assurant le droit au juge (constitutionnel) pour tous les cas où la pratique avait montré l'absence de voies d'accès à la juridiction ou les inefficiences des voies existantes : pour reprendre une métaphore courante, l'idée était celle d'éclairer les « zones d'ombre » du

28 À ce propos, la réforme de la Loi organique sur le Tribunal constitutionnel espagnol opérée par la loi organique 6/2007 du 24 mai 2007 est un exemple très significatif de l'exigence de mettre en balance la protection des droits fondamentaux et le bon fonctionnement d'une juridiction constitutionnelle. Pour un bilan de la réforme, en français, voir F. BARQUE, « La réforme du recours d'amparo en Espagne : évolution ou révolution? Réflexions en guise de bilan », Revue des droits et libertés fondamentales, 2014, chron. ${ }^{\circ} 3$ (www.revuedlf.com). Plus en général, sur les modalités de sélection des recours, voir S. Nicot, La sélection des recours par la juridiction constitutionnelle. Allemagne, Espagne, États-Unis, Paris, Fondation Varenne - LGDJ, 2006. 
système de justice constitutionnelle ${ }^{29}$. La contestation du refus de soulever la question de constitutionnalité figurait, bien évidemment, dans la liste des zones trop à l'abri du soleil.

Si la classe politique s'est parfois penchée sur le sujet en proposant, par des réformes constitutionnelles (et notamment par des réformes organiques de la Constitution), un élargissement de l'éventail des compétences de la Cour constitutionnelle qui incluait même le recours direct des particuliers, une telle proposition n'a jamais été retenue, car seules les propositions de réforme dans lesquelles le sujet n'était pas abordé ont été adoptées.

Ce serait, bien évidemment, excessif de déduire de cette dernière circonstance un quelque lien de causalité sur la base de laquelle l'introduction éventuelle d'un recours direct aurait été un verrou pour n'importe quelle réforme. Cependant, on peut constater une résistance assez vive contre l'introduction de ce mode de saisine, qui a été manifestée par un nombre considérable de constitutionnalistes et surtout au sein de la Cour constitutionnelle même ${ }^{30}$. L'opposition la plus retentissante a eu lieu contre la réforme constitutionnelle proposée en 1998, qui a été sévèrement critiquée par le Président Granata lors de l'entretien avec la presse qui se tient tous les ans pour discuter de l'état de la juridiction constitutionnelle et de la jurisprudence de l'année précédente ${ }^{31}$. Par la même occasion, mais quelques années plus tard, en 2005, une approche complètement différente vis-à-vis de l'introduction d'un recours direct a été exposée par le Président Onida ${ }^{32}$.

Les avis à propos d'un recours direct ont donc été partagés. Cependant, les voix critiques ont été globalement beaucoup plus fortes, en nombre et en intensité ${ }^{33}$, que les voix favorables ${ }^{34}$. Les critiques, d'ailleurs, ne manquaient pas d'arguments à l'appui, parmi lesquels deux étaient les plus fréquemment invoqués. Le premier était d'ordre pratique et avait trait aux risques très sérieux d'assister à un encombrement du rôle de la Cour, résultant de l'augmentation significative, voire spectaculaire

29 L'expression « zones d'ombre » s'est imposée, dans la doctrine italienne, à la suite de deux colloques organisés par l'Association « Gruppo di Pisa » : cf. R. BALDUZzI - P. CostANzo (sous la direction de), Le zone d'ombra della giustizia costituzionale. I giudizi sulle leggi, Turin, Giappichelli, 2007 ; R. PINARDi (sous la direction de), Le zone d'ombra della giustizia costituzionale. I giudizi sui conflitti di attribuzione e sull'ammissibilità del referendum abrogativo, Atti del seminario di Modena svoltosi il 13 ottobre 2006, Turin, Giappichelli, 2007.

30 Les débats les plus anciens sont analysés par S. PAnizza, « Il ricorso diretto dei singoli », in A. Anzon - P. CAREtti - S. Grassi (sous la direction de), op. cit., p. 81 et s.

31 Cf. Conferenza stampa del Presidente della Corte costituzionale, Renato Granata, 11 febbraio 1998, disponible en ligne à la page www.cortecostituzionale.it/ActionPagina_485.do [10 juin 2016].

32 Cf. Conferenza stampa del Presidente della Corte costituzionale, Valerio Onida, 20 gennaio 2005, disponible en ligne à la page www.cortecostituzionale.it/ActionPagina_264.do [10 juin 2016] : « je crois que l'on puisse dire que, généralement, les carences et les lacunes susceptibles de se produire dans notre pays à l'égard de la protection des droits dérivent, plutôt que de l'existence éventuelle de normes législatives lacunaires ou en conflit avec la Convention européenne, des incertitudes interprétatives ou des mauvaises interprétations des lois ou des dysfonctionnements de l'appareil [administratif ou juridictionnel] »; ces défauts « nécessitent, afin d'être remédiés, plutôt que d'un contrôle de la constitutionnalité des lois, de moyens efficaces de protection dans les cas concrets, et donc du bon fonctionnement des remèdes juridictionnels : les remèdes de droit commun et, le cas échéant, le remède offert par un recours direct de constitutionnalité ».

33 Une position clairement contraire à l'introduction d'un recours direct des particuliers est celle de R. RomBOLI, « La riforma dell'amparo costituzionale in Spagna e l'introduzione di un ricorso individuale diretto in Italia », Scritti in onore di Lorenza Carlassare, Naples, Jovene, 2009, p. 1555 et suiv. ; voir aussi P. PASSAgLIA, «Sull'inopportunità di introdurre il ricorso diretto individuale: il dibattito italiano », in R. TARCHI (sous la direction de), Patrimonio costituzionale europeo e tutela dei diritti fondamentali. Il ricorso diretto di costituzionalità, Turin, Giappichelli, 2012, p. 323 et suiv. ; en français, voir M. Luciani - P. PAssaglia - A. Pizzorusso - R. Romboli, « Justice constitutionnelle, justice ordinaire, justice supranationale: à qui revient la protection des droits fondamentaux en Europe? - Rapport italien », Annuaire international de justice constitutionnelle, 2004, p. 264 et suiv.

34 En ce sens, voir M. PAtrono, « Corte costituzionale, giudizio a quo e promovimento del processo costituzionale (note in margine al ricorso diretto alla Corte) », in Giudizio «a quo» e promovimento del processo costituzionale, Atti del Seminario svoltosi in Roma, Palazzo della Consulta, nei giorni 13 e 14 novembre 1989, Milan, Giuffrè, 1990, p. 13 et suiv. ; V. OnIDA, « La Corte e i diritti. Tutela dei diritti fondamentali e accesso alla giustizia costituzionale », in L. CARLASSARE (sous la direction de), Il diritto costituzionale a duecento anni dall'istituzione della prima cattedra in Europa, Atti del Convegno di Ferrara, 2-3 maggio 1997, Padoue, Cedam, 1998, p. 177 et suiv. 
des affaires à traiter. L'autre argument se concentrait davantage sur la nature du système de justice constitutionnelle : on faisait remarquer que l'introduction d'un recours direct aurait changé à jamais les rapports entre la Cour constitutionnelle et les juridictions ordinaires, puisqu'en introduisant au profit de la première un moyen de contrôle de l'activité des secondes, le recours direct, probablement, aurait eu l'effet de faire pénétrer des éléments de tension dans un dialogue qui, tout en ayant connu des moments difficiles, avait abouti à des résultats remarquables du point de vue de la protection de la Constitution et de l'irradiation du principe de constitutionnalité dans l'ordre juridique.

\section{b. Les limitations par la jurisprudence constitutionnelle :}

\section{l'utilisabilité purement théorique des conflits d'attribution}

Si l'absence d'un recours direct des particuliers a des conséquences majeures sur la possibilité pour la Cour constitutionnelle de contrôler l'activité des juges, on ne saurait toutefois exclure de manière générale un pouvoir de contrôle du juge constitutionnel sur les arrêts rendus par les juridictions ordinaires. Parmi les voies d'accès à la Cour figurent, en effet, deux modes de saisine qui peuvent être utilisés à cette fin : les conflits d'attribution qui opposent l'État à une ou plusieurs Régions et ceux qui opposent des pouvoirs de l'État. Il s'agit de conflits par lesquels les parties demandent à la Cour de trancher des litiges concernant la répartition de leurs domaines de compétence respectifs, tels qu'indiqués par des normes constitutionnelles ${ }^{35}$. L'objet des conflits est donc précisément l'attribution constitutionnelle, cependant les empiétements dénoncés sont, en général, la résultante d'un ou plusieurs actes adoptés par une autorité, dont on censure le fait d'avoir méconnu les compétences de l'autorité requérante devant la Cour, soit parce qu'on a exercé un pouvoir dont on était dépourvu (conflit dérivant d'une « usurpation » du pouvoir d'autrui), soit parce que l'exercice au concret d'un pouvoir propre à l'autorité s'est traduit par une atteinte à la compétence de la requérante (conflit dérivant d'une « interférence » avec le pouvoir d'autrui) ${ }^{36}$.

Les deux catégories de conflits peuvent entraîner le contrôle d'un acte provenant d'une instance juridictionnelle, et notamment - à l'évidence - d'un arrêt ${ }^{37}$. En ce qui concerne les conflits entre l'État et les Régions, comme la juridiction ne relève que de l'État, les seuls conflits ayant comme objet un acte juridictionnel sont soulevés par une ou plusieurs Régions. Et dans ce genre de conflits, les Régions ne peuvent pas contester l'usurpation d'un pouvoir qui leur est propre : la seule démarche possible est donc la contestation à l'État de l'empiétement sur les attributions (législatives ou administratives)

\footnotetext{
35 En général, sur les conflits d'attribution tranchés par la Cour constitutionnelle, voir A. Pensovecchio Li BAssi, « Conflitti costituzionali », Enciclopedia del diritto, volume VIII, Milan, Giuffrè, 1961, p. 998 et suiv. ; A. Pizzorusso, «Conflitto », Novissimo digesto italiano, Appendice, volume II, Turin, Utet, 1981, p. 375 et suiv.; S. Grassi, « Conflitti costituzionali », Digesto delle discipline pubblicistiche, volume III, Turin, Utet, 1989, p. 362 et suiv. À propos des conflits entre l'État et les Régions, voir G. GrotTANELli DE' SANTI, I conflitti di attribuzione tra Stato e Regioni e tra Regioni, Milan, Giuffrè, 1961 ; S. GRASSI, Il giudizio costituzionale sui conflitti di attribuzione tra Stato e Regioni e tra Regioni, Milan, Giuffrè, 1984. En ce qui concerne les conflits entre les pouvoirs de l'État, voir A. PIsAneschi, I conflitti di attribuzioni tra poteri dello Stato. Presupposti e processo, Milan, Giuffrè, 1992 ; R. BIN, L’ultima fortezza. Teoria della Costituzione e conflitti di attribuzione, Milan, Giuffrè, 1996.

36 À propos de ces typologies de conflits, voir C. Mezzanotte, « Le nozioni di potere e di conflitto nella giurisprudenza della Corte costituzionale », Giurisprudenza costituzionale, 1979, I, p. 110 et suiv. ; V. CRISAfulli, "Cattivo uso del potere e confitto di attribuzioni », Giurisprudenza costituzionale, 1980, I, p. 220 et suiv. ; P. Veronesi, I poteri davanti alla Corte. "Cattivo uso" del potere e sindacato costituzionale, Milan, Giuffrè, 1999.

37 Voir, ex plurimis, pour le conflit entre l'État et les Régions, R. Rombolı, « Conflitto tra enti su atto giurisdzionale : le soluzioni della dottrina al vaglio della Corte costituzionale, nella perdurante latitanza del legislatore », Le Regioni, 2001, p. 397 et suiv., et, pour le conflit entre les pouvoirs de l'État, G. Gemma, « Conflitti di attribuzione fra poteri dello Stato e sindacato sugli atti giurisdizionali », Rivista di diritto processuale, 1997, p. 452 et suiv.
} 
régionales découlant d'un exercice abusif du pouvoir juridictionnel. Pour ce qui est des conflits entre les pouvoirs de l'État, les possibilités s'accroissent, car n'importe quel pouvoir peut contester un acte juridictionnel qui a empiété sur ses attributions ou même qui a engendré une « usurpation de pouvoir », découlant du fait que le juge a exercé un pouvoir qui ne lui appartenait pas.

Du point de vue théorique, pourvu que la contestation se fonde sur une prétendue méconnaissance des attributions du requérant, rien ne s'oppose à ce que, dans le cadre d'un conflit d'attribution, une Région ou un organe de l'État conteste l'exercice qui a été fait du pouvoir juridictionnel et qui a abouti à une décision qui aurait été différente si le juge avait soulevé une question préjudicielle de constitutionnalité. Autrement dit, la contestation du refus de soulever une question de constitutionnalité est bien envisageable, tout en étant limitée, cependant, aux cas où le refus se répercute sur une atteinte portée aux attributions de l'entité ou de l'organe qui a soulevé le conflit.

Si des possibilités de saisir la Cour existent, ce sont les chances d'avoir un jugement sur le fond qui font défaut ou, du moins, qui s'avèrent plutôt dérisoires. Dès $1964^{38}$, la « Cour a jugé que même des actes juridictionnels, ou encore [des actes] instrumentaux inhérent à l'exercice de la fonction juridictionnelle, sont susceptibles de faire l'objet de conflits d'attribution [...], dans la mesure où l'on en conteste l'empiétement sur le domaine de compétence constitutionnellement reconnu [au] requérant ou la méconnaissance d'un tel domaine $»^{39}$. Cependant, « une chose est que l'atteinte dénoncée de la compétence [du requérant] découle du simple fait d'exercer la juridiction à l'égard d'actes ou de sujets que l'on considère hors de sa portée en vertu de normes constitutionnelles, autre chose est » - comme c'était le cas dans l'affaire en instance - « de censurer la façon dans laquelle la juridiction a été concrètement exercée, en dénonçant des erreurs de droit [errores in judicando] que le juge $[\ldots]$ aurait encouru $»^{40}$.

Or, puisque la Cour constitutionnelle s'est déclarée dépourvue du pouvoir de censurer de simples erreurs de droit, qui ne se répercutent pas directement sur les attributions des requérants, on voit mal comment les conflits pourraient entraîner le contrôle du refus de soulever une question de constitutionnalité.

Une affaire emblématique à ce propos est l'ainsi nommée « affaire Englaro », qui a été à l'origine de l'arrêt (adopté dans la forme simplifiée de l'ordonnance) du 8 octobre 2008, $\mathrm{n}^{\circ} 334^{41}$. Les deux chambres du Parlement avaient saisi la Cour pour contester un arrêt de la Cour de cassation et une décision de la Cour d'appel de Milan qui étaient censés avoir empiété sur les attributions législatives du Parlement, dans la mesure où ils avaient établi les conditions nécessaires pour arrêter la perfusion de nutrition et d'hydratation parentérale d'un patient en état végétatif permanent. Selon les requérants, les juridictions auraient statué de manière à modifier le droit positif et à se substituer

Cf. l'arrêt du 20 juin 1964, nº6.

Le passage cité est tiré de l'arrêt du 27 décembre 1974, nº 289

Ibidem.

Sur cette décision, voir G. GemmA, «Parlamento contro giudici : un temerario conflitto di attribuzioni sul "caso Eluana" », Giurisprudenza costituzionale, 2008, p. 3723 et suiv. ; R. RomboLI, « Il conflitto tra poteri dello Stato sulla vicenda Englaro : un caso di evidente inammissibilità », Foro italiano, 2009, I, c. 49 et suiv. 
ainsi abusivement au législateur. Parmi les moyens évoqués, on observait que les juges auraient dû plutôt soulever une question de constitutionnalité ayant comme objet l'article du Code civil qui avait été par contre interprété de façon à permettre d' « écarter les normes législatives qui auraient empêché l'adoption de la solution » qui avait été adoptée en concret et qui se traduisait par l'élaboration d'une réglementation tout à fait nouvelle.

La Cour constitutionnelle n'a pas répondu spécifiquement sur le refus de soulever la question de constitutionnalité, mais la portée de son arrêt est quand même dépourvue de toute ambiguïté, car le rejet des deux recours a été motivé en raison de la dénonciation d'erreurs de droit qui auraient été commises dans les phases de la sélection et de l'interprétation des dispositions à appliquer. En se référant à sa jurisprudence constante, la Cour a mis en évidence le fait qu'un conflit d'attribution «ne peut pas se réduire à la proposition d'une démarche logique et juridique alternative à celle qui est dénoncée », car le conflit d'attribution « ne saurait être transformé en une voie de recours atypique envers les arrêts des juges $»$ ordinaires $^{42}$.

Ces principes dégagés, la Cour a exclu de pouvoir juger l'affaire sur le fond, car les arrêts contestés dans le cas d'espèce avaient tous les deux les caractères qui sont propres aux actes juridictionnels, et donc aucun empiétement sur les attributions du législateur ne pouvait être constaté, d'autant plus qu'au moment où la Cour rendait sa décision « le Parlement pouvait [encore et] à tout moment adopter une réglementation spécifique du sujet $»^{43}$.

L'arrêt qui a tranché l' « affaire Englaro » n'est qu'un exemple, parmi les plus récents, de l'attitude très retenue de la Cour lorsqu'il s'agit de contrôler des actes juridictionnels. Une attitude qui fonde, à l'évidence, l'impossibilité d'indiquer dans les conflits d'attribution une voie ordinaire viable pour s'opposer aux refus de soulever de questions préjudicielles de constitutionnalité.

\section{Les contestations devant d'autres instances juridictionnelles : des remèdes partiels}

Si le refus de soulever une question de constitutionnalité n'est pas contestable devant la Cour constitutionnelle, il est par contre possible de le contester devant d'autres juridictions. Cette possibilité, toutefois, est soumise à des conditions et à des limitations assez strictes (a), qui n'apparaissent pas tout à fait compensées par la très large ouverture à l'égard d'une critique indirecte, voire implicite, à l'occasion d'autres instances (b).

\section{a. Les contestations relatives au litige en cours : des remèdes conditionnés}

Le refus de soulever une question préjudicielle de constitutionnalité est, ni plus ni moins, la manifestation d'un pouvoir ordinaire revenant aux juridictions. Il s'agit d'un sujet parmi ceux sur lesquels n'importe quel juge à la faculté et, en même temps, l'obligation (sous peine d'encourir un

$42 \quad$ Arrêt rendu par ordonnance du 8 octobre $2008, \mathrm{n}^{\circ} 334$.

43 Par ce biais, la Cour a pris soin de censurer, quoiqu'implicitement, l'attitude des Chambres, qui avaient saisi la Cour pour que celle-ci règle un problème que le législateur lui-même aurait pu régler, en adoptant une loi. 
déni de justice) de se prononcer. De ce fait, il est évident qu'une exigence de cohérence de l'ordre juridique implique que la décision adoptée sur cet aspect soit encadrée par les mêmes principes et les mêmes règles qui régissent la contestation des autres actes juridictionnels. Or, si la décision de soulever la question n'est pas contestable, car c'est la Cour constitutionnelle qui, en rendant son arrêt, va se prononcer sur la recevabilité de la question et sur son bien-fondé, la décision de refus nécessite une voie de contestation. Une contestation dont la Cour constitutionnelle n'est pas saisie et dont d'autres instances doivent, par conséquent, assurer le contrôle.

Le sujet est réglementé par l'article 24 de la loi no 87 de 1953, qui définit, d'un côté, les critères que la décision de refus doit remplir et, de l'autre, ceux de sa contestation.

Le $1^{\text {er }}$ alinéa exige que « l'ordonnance de rejet de l'exception d'inconstitutionnalité », en raison du défaut d'influence sur le litige en cours (découlant du manque de «rilevanza») ou de sa « futilité », « doit être dûment motivée ». Par cette disposition, le législateur a opéré une distinction claire entre l'exception qui est soulevée par les parties et la question soulevée d'office par le juge : dans le premier cas, on demande au juge de statuer sur la question de manière spécifique et d'adopter une mesure particulière, ayant la forme d'une ordonnance ; dans le second cas, si le doute vient du juge et si le juge même le dissipe, alors aucune condition de forme n'est requise, ce qui est tout à fait normal, car la question de constitutionnalité pourrait très bien rester dans l'esprit du juge, sans même s'expliciter.

Dans la pratique, la distinction apparemment claire entre les deux cas est devenue nébuleuse, du fait que normalement aucune ordonnance particulière n'est adoptée pour refuser de soulever la question de constitutionnalité. Le refus figure donc, en règle générale, au sein de l'arrêt qui tranche le litige. Cette tendance à la concentration des décisions à adopter s'explique assez facilement par l'exigence de rapidité, mais de fortes réserves persistent à l'égard de son fondement du point de vue du respect des principes régissant la procédure. En renvoyant la formulation de la décision sur le renvoi au moment de la décision sur le fond de l'affaire, l'importance de la question de constitutionnalité, et surtout son influence potentielle sur l'issue du litige, risquent d'être sous-estimées, pour ne pas dire compromises : par exemple, en se concentrant sur l'inconstitutionnalité éventuelle d'une disposition législative, une partie pourrait adopter une attitude moins attentive aux faits contestés qu'aux aspects de droit du litige, et donc le fait d'attendre jusqu'à la fin la décision du juge pourrait lui créer un préjudice, notamment à l'égard de certains choix relatifs à sa conduite au cours du procès.

D'autres raisons aussi, encore plus fortes, militent contre la pratique consolidée. L'article 24 susmentionné, en effet, impose à la décision de ne pas soulever la question d'adopter une forme équivalente à la décision contraire : dans les deux cas, une ordonnance est (serait) requise. Cette équivalence n'est pas limitée à la forme, car l'ordonnance portant sur le refus doit être " dûment motivée », tout comme l'ordonnance de renvoi doit indiquer les normes qui font l'objet de la question préjudicielle, les normes de référence et les «motifs de la demande par laquelle la question a été soulevée » (article 23, alinéa 2, de la loi n 87 de 1953). 
Or, lorsque le refus est prononcé dans une ordonnance spécifique, il est fort probable que les motifs qui le fondent soient explicités de manière adéquate ; par contre, lorsque le refus n'occupe qu'un paragraphe - ou pire un considérant - de l'arrêt rien n'assure que les motifs soient aussi clairs et bien identifiables. En d'autres termes, la partie qui a soulevé l'exception d'inconstitutionnalité risque concrètement de subir une atteinte à son droit de contester la décision du juge, car une motivation expéditive pourrait entraver la recherche de contradictions dans le parcours argumentatif qui a conduit au refus de saisir la Cour constitutionnelle.

À cet égard, il convient de remarquer que l'article 24 suggère précisément un lien direct entre la motivation de l'ordonnance, imposée par l'alinéa $1^{\mathrm{er}}$, et sa contestation, réglementée à l'alinéa 2. Celui-ci précise que l'exception peut être proposée à nouveau « au commencement de tout stade supplémentaire du procès », devant une autre instance judiciaire ${ }^{44}$.

Sur la base de cette disposition, on est autorisé à accorder au recours devant d'autres instances la place de voie ordinaire pour contester le refus de soulever la question de constitutionnalité. Par conséquent, surtout si la pratique était (ou plutôt, aurait été) conforme aux exigences de forme et de fond imposées par l'alinéa $1^{\text {er }}$ de l'article 24 , la contestation du refus pourrait (aurait pu) être reléguée au rang des problèmes largement résolus par le législateur.

Largement, mais non complètement, car si la contestation est bien possible à propos des refus opposés par les juridictions de première et de deuxième instance, cela n'est pas le cas pour les refus qui sont prononcés par les cours de dernière instance, et notamment par la Cour de cassation, le Conseil d'État ou la Cour des comptes. Les décisions de ces juridictions ne sont pas susceptibles de recours ${ }^{45}$, et donc aucune voie de contestation n'est prévue.

Un tel défaut a donc des conséquences majeures sur la possibilité pour la Cour constitutionnelle d'être saisie, car tout dépend des juridictions qui occupent la place de « concierge » du Palais de la Consulta ${ }^{46}$. À cette remarque on pourrait ajouter que lorsque la décision sur la question de constitutionnalité se pose pour la première fois devant la juridiction suprême (ce qui est loin de se produire rarement, par exemple lorsqu'une disposition de procédure est dénoncée), de problèmes supplémentaires se posent, eu égard, en particulier, au respect du principe du double degré de juridiction ${ }^{47}$.

Certes, les décisions des juridictions suprêmes peuvent faire l'objet d'un contrôle de la part de la Cour européenne des droits de l'Homme, mais cette voie de protection ne rentre pas, à l'évidence,

44 En se fondant précisément sur cette possibilité, la Cour de cassation a pu préciser que même le défaut de toute décision à l'égard d'une exception d'inconstitutionnalité avancée par une partie n'entache pas de nullité l'arrêt rendu par un juge de première ou de deuxième instance (cf. Cour de cassation, $V^{\mathrm{e}}$ chambre criminelle, 9 décembre 1994). Cette jurisprudence a été critiquée, dans la note sous la décision de la Cassation, par S. Pignochino, «Conseguenze processuali dell'omesso esame di una questione di legittimità costituzionale », Giurisprudenza italiana, 1996, partie 2, p. 78 et suiv., qui a fait valoir, entre autres, les arguments que nous avons exposé plus haut à l'égard de la stratégie déployée au sein du procès par les parties.

45 Pour ce qui a trait aux arrêts du Conseil d'État et de la Cour des comptes, la Cour de cassation peut être saisie de contestations, mais uniquement à l'égard de questions de répartition de la juridiction entre juges judiciaires et juges spéciaux. Au sujet du refus de soulever de questions de constitutionnalité, il est donc exclu que celui-ci puisse faire l'objet d'un recours.

46 Pour cette définition, voir supra, I, A.1.b.

47 À propos de la portée de ce principe et de son ancrage constitutionnel, voir A. Pizzorusso, « Doppio grado di giurisdizione e principi costituzionali », Rivista di diritto processuale, 1978, p. 36 et suiv. ; G. SERGES, Il principio del « doppio grado di giurisdizione » nel sistema costituzionale italiano, Milan, Giuffrè, 1993. 
dans le champ d'application de la protection de la Constitution, ne fût-ce que pour le fait que les normes de références sont issues de la Convention européenne, et non de la Constitution. Autant dire que le refus d'une juridiction suprême de soulever une question de constitutionnalité ne peut trouver de réponse que lorsqu'il se reflète dans la méconnaissance d'une disposition conventionnelle. Mais alors il ne s'agit pas - il ne s'agit plus - de protéger la Constitution, mais de constater, tout au plus, la cohérence de la Constitution avec une source du droit supranational.

\section{b. Les contestations à l'occasion d'autres litiges : des remèdes aléatoires}

La notion de «contestation » que nous avons employée jusqu'ici à l'égard des remèdes contre le refus de soulever une question préjudicielle de constitutionnalité a trait aux voies ouvertes - ou aux «fentes », devrait-on dire - au profit des justiciables pour que leur litige ne soit pas tranché sans que la Cour constitutionnelle ait pu se prononcer sur la question préjudicielle.

Ces remèdes, toutefois, n'épuisent pas l'éventail des possibilités reconnues par l'ordre juridique. En effet, la contestation n'est pas uniquement celle qui se dirige spécifiquement contre la décision de refus, car elle peut se manifester de manière plus anodine, comme une contestation indirecte et implicite. C'est ce qui arrive lorsqu'une question de constitutionnalité dont le renvoi a été refusé à l'occasion d'un litige est proposée à nouveau au sein d'un autre litige, devant un autre juge ou encore devant le même juge (mais à l'occasion d'une autre affaire), dans l'espoir qu'il ait changé d'avis par rapport au refus déjà prononcé.

Il est quand même à préciser que les effets ne sont associés au refus opposé, car il n’y a aucune distinction possible entre les autres litiges où la question préjudicielle a été refusée et ceux où la question n'a même pas été évoquée. Par conséquent, ce qui compte n'est que l'identité des dispositions législatives susceptibles d'application au sein des litiges. D'ailleurs, la contestation que l'on pourrait qualifier de «transversale » n'est que purement éventuelle : si rien ne s'oppose à ce que le second juge tienne compte du refus opposé par son collègue et exprime un avis opposé, rien ne s'oppose non plus à ce que le second juge néglige tout simplement le refus ; il en va de même pour les parties qui soumettent la question préjudicielle au second juge, car elles sont libres de faire référence à la décision négative adoptée auparavant. Elles peuvent donc tout simplement omettre toute mention de la décision.

Les effets de cette « contestation transversale » diffèrent selon que le second juge entérine ou renverse le refus opposé par le premier. S'il l'entérine, sa décision n'a, bien évidemment, aucun effet sur le premier refus, ni même celui de conditionner, du moins du point de vue formel, d'éventuelles décisions relatives à la même question qui se présenteraient dans l'avenir. En effet, il est bien possible que la question de constitutionnalité soit soulevée par un juge après que d'autres juges - même très nombreux - aient opposé un refus. Si le refus est renversé et la question est donc soulevée, alors des effets peuvent se produire sur les litiges au sein desquels le refus a été opposé, et leur portée change considérablement selon que le litige précédent soit définitivement tranché ou bien soit encore en cours. 
Une « contestation transversale »n'a pas de conséquences sur les litiges tranchés par un arrêt ayant l'autorité de la chose jugée. Le seul impact possible ne concerne pas la question soulevée en tant que telle, mais plutôt la décision qui en résulte, puisque dans le cas où la Cour constitutionnelle déclarerait l'inconstitutionnalité de la disposition ou des dispositions législatives, des conséquences sur la chose jugée seraient envisageables, du moins dans certains cas. Si, en principe, les effets dans le temps des déclarations d'inconstitutionnalité sont caractérisés par une rétroactivité qui s'arrête devant la chose jugée ${ }^{48}$, le législateur a prévu une dérogation à cette règle pour ce qui a trait aux déclarations d'inconstitutionnalité frappant une disposition législative pénale, car si un jugement de condamnation se fondait sur une disposition dont l'inconstitutionnalité était par la suite reconnue, l'exécution et tous les (autres) effets de la condamnation cesseraient, indépendamment de l'autorité de la chose jugée au pénal (article 30, alinéa 4, de la loi nº 87 de 1953).

Cela dit, on constate sans surprise que la « contestation transversale » a des répercussions bien plus importantes sur les litiges qui n'ont pas encore été tranchés de manière définitive. Les effets les plus évidents se manifestent lorsque la question de constitutionnalité aboutit à une décision par laquelle la Cour déclare l'inconstitutionnalité de la disposition ou des dispositions dénoncées, car la portée générale de l'annulation implique l'impossibilité de donner application à la disposition inconstitutionnelle une fois que l'arrêt de la Cour est publié. Le refus opposé n'aura donc pas empêché que le résultat que l'on poursuivait avec la question de constitutionnalité se produise dans tous les litiges, y compris dans le litige au sein duquel le juge avait considéré la question comme non influente pour l'issue du litige ou bien « futile », et il avait par conséquent refusé d'en saisir le juge de la loi.

Indépendamment du sort de la question préjudicielle devant la Cour constitutionnelle, quelques effets sur les autres litiges sont à reconnaître même au simple renvoi de la question. D'abord, il peut se produire (et en fait il se produit assez souvent ${ }^{49}$ ) un effet " psychologique », pour ainsi dire, qui se traduit par une sorte de réaction en chaîne conduisant les juges ordinaires à saisir la Cour d'une question identique ou analogue à celle qui a été déjà soulevée. Les justiciables pourraient très bien profiter d'un tel effet si, après s'être vus opposer un refus, ils demandaient le renvoi à nouveau devant le juge de l'instance supérieure. Dans la pratique, il s'avère aussi qu'une question de constitutionnalité soulevée au cours d'un litige produise des effets plus nuancés sur les autres : compte tenu de la question en instance devant la Cour, le juge d'un autre litige qui ne suit pas son collègue, et donc ne soulève pas,

\footnotetext{
48 L'article 30, alinéa 3, de la loi n 87 de 1953 précise que « les normes déclarées inconstitutionnelles ne peuvent plus être appliquées dès le lendemain de la publication de la décision ». Cette disposition permet d'attribuer aux déclarations d'inconstitutionnalité des effets rétroactifs, que la lettre de l'article 136, alinéa $\mathrm{I}^{\mathrm{er}}$, de la Constitution paraîtrait exclure (cf. supra, A.1 ${ }^{\mathrm{er}}$.a). Sur les effets dans le temps des déclarations d'inconstitutionnalité, voir M. D’Amico, Giudizio sulle leggi ed efficacia temporale dele decisioni di incostituzionalità, Milan, Giuffrè, 1993 ; R. PinARdi, La Corte, i giudici ed il legislatore. Il problema degli effetti temporali delle sentenze di incostituzionalità, Milan, Giuffrè, 1993 ; F. Politi, Gli effetti nel tempo delle sentenze di accoglimento della Corte costituzionale, Padoue, Cedam, 1997 ; M. Ruotolo, La dimensione temporale dell'invalidità della legge, Padoue, Cedam, 2000 ; D. Butrurini - M. Nicolini (sous la direction de), Tipologie ed effetti temporali delle decisioni di incostituzionalità. Percorsi di diritto costituzionale interno e comparato, Naples, Edizioni Scientifiche Italiane, 2014.

49 Il n'est pas rare que, à propos de certaines dispositions législatives très discutées, le nombre de questions de constitutionnalité atteint plusieurs dizaines voire centaines. Un cas emblématique est celui de la contestation de certains articles de la loi de réforme du droit de l'immigration (loi du 30 juillet 2002, $n^{\circ}$ 189). La Cour constitutionnelle, une fois statué sur les premières questions qui étaient arrivées au greffe, a ensuite rendu des arrêts statuant conjointement sur des dizaines de questions identiques à celles qui avaient déjà été examinées sur le fond.
} 
à son tour, la même question de constitutionnalité, a tout de même une tendance « naturelle » à éviter de statuer avant que la Cour ait rendu son arrêt, et donc le litige reste suspendu.

Cette suspension de fait assure une protection minimale pour les justiciables pour ce qui est du fond de la question, mais entraîne une méconnaissance de leurs droits procéduraux ${ }^{50}$. Cela, du moins, jusqu'à ce que la jurisprudence de la Cour constitutionnelle n'évolue pas dans le sens d'un assouplissement de la rigueur de la procédure contradictoire dans le cadre du contrôle incident ${ }^{51}$. Le fait qu'une question soit soumise à la Cour et que la décision de celle-ci puisse engendrer des conséquences d'ordre général, notamment en cas de déclaration d'inconstitutionnalité, fonde sans doute un intérêt direct qui est propre, non seulement aux parties du litige a quo, mais aussi aux parties de tout autre litige dans lequel les dispositions faisant l'objet de la question de constitutionnalité sont susceptibles d'application. Par conséquent, les parties des autres litiges paraîtraient très bien placées pour pouvoir justifier leur intérêt à intervenir devant la Cour comme tierces personnes. Cependant, la jurisprudence constitutionnelle a constamment exclu un tel pouvoir au profit de cette catégorie d'intervenants, et cela a été confirmé, à plusieurs reprises, même récemment ${ }^{52}$, en se fondant sur une attitude tendant à limiter la procédure contradictoire aux «seules parties du litige a quo [ou aux] tierces personnes ayant un intérêt qualifié, c'est-à-dire immédiatement inhérent aux rapports substantiels objet du litige et qui n'est pas simplement objet de réglementation, à l'instar de tout autre, de la part de la norme ou des normes qui font l'objet de la question $»^{53}$.

\section{La diffusion inéluctable de la protection d'un acte normatif à part entière}

Le système de justice constitutionnelle, tel que conçu par les Constituants et mis en place par le législateur, a connu, au fil des ans, une évolution profonde, dont les premiers pas se sont manifestés dès le début de l'activité de la Cour.

$\mathrm{Au}$ fur et à mesure que les principes de la Charte républicaine étaient mis en œuvre et intégrés dans l'ordre juridique, la Constitution, tout en gardant son caractère suprême, se rapprochait des autres sources du droit du fait de son application dans la pratique. En d'autres termes, les caractères distinctifs de la Constitution par rapport aux autres sources, qui avaient justifié entre autres l'adoption d'un système de protection particulier, fondé sur une juridiction spéciale, ont progressivement perdu du terrain au profit d'une approche visant davantage à mettre en exergue le caractère normatif de la Charte, et donc son appartenance à la catégorie des sources. Une fois conçue comme

50 Justement pour cette raison, la doctrine a souvent critiqué cette attitude, en suggérant des « renvois généralisés » à la Cour, même si cela peut impliquer une augmentation spectaculaire des affaires à traiter par celle-ci : cf. M. D'AMIco, « Sospensione del processo e questione di costituzionalità pendente », Rivista di diritto civile, 1988, II, p. 75 et suiv.

51 Sur la procédure contradictoire devant la Cour constitutionnelle statuant dans le cadre d'un contrôle incident, voir R. RomвоLI, $I l$ giudizio costituzionale incidentale come processo senza parti, Milan, Giuffrè, 1985 ; M. D’Amico, Parti e processo nella giustizia costituzionale, Turin, Giappichelli, 1991 ; V. Angrolini (sous la direction de), Il contraddittorio nel giudizio sulle leggi, Atti del seminario di Milano svoltosi il 16 e 17 maggio 1997, Turin, Giappichelli, 1998 ; L. CALIFAno, Il contraddittorio nel processo costituzionale incidentale, Turin, Giappichelli, 2003. 52 Voir, par exemple (mais la liste des décisions serait très longue), l'ordonnance du 20 octobre 2015, rendue à l'occasion du procès défini par l'arrêt du 19 novembre 2015, n 236.

53 Ibidem. 
une source du droit à part entière, la Constitution a pu connaître des applications qui n'avaient pas fait l'objet d'attention de la part des rédacteurs des dispositions concernant le système de justice constitutionnelle et tout particulièrement le contrôle incident de la constitutionnalité des lois. Et ces applications «nouvelles » ont contribué, à leur tour, à renforcer l'idée que la Constitution n'est pas seulement la Charte portant les principes fondateurs du système, mais elle est aussi - et peut-être avant tout - un acte normatif.

Le changement d'approche se manifeste dans toute son ampleur dans le domaine des critères régissant l'interprétation des lois (A), mais il a des conséquences d'une importance capitale même dans la définition de la portée du refus de soulever la question préjudicielle de constitutionnalité (B).

\section{A. L'influence profonde de l'interprétation sur les caractères du système concentré}

En optant pour un système concentré de justice constitutionnelle, les Constituants ont mis en exergue le pouvoir d'annulation des actes normatifs, pierre angulaire du système de protection de la Constitution. La reprise de la notion kelsenienne de « législateur négatif » en est un indice sans doute remarquable.

Toutefois, lorsque la théorie a cédé la place à la pratique, le pouvoir d'annulation a dû être encadré dans le contexte général de l'exercice des fonctions juridictionnelles, au sein desquelles l'interprétation occupe une place centrale. Justement en raison de son importance, l'interprétation est très vite devenue un élément décisif pour définir les rapports entre la Cour constitutionnelle et les juridictions ordinaires (1) et pour délimiter le champ d'application du pouvoir d'annulation dans le cadre du contrôle incident de la constitutionnalité des lois (2).

\section{Un équilibre difficile entre la Cour constitutionnelle et les juridictions ordinaires}

Le choix d'un système concentré de justice constitutionnelle ne fait pas obstacle, en soi, à une répartition des pouvoirs d'interprétation des actes législatifs. Or, la répartition concrète de ces pouvoirs a engendré, au cours de l'histoire républicaine, un certain nombre de problèmes, concernant, d'une part, les limites des pouvoirs propres de la Cour constitutionnelle (a) et, de l'autre, la reconnaissance de pouvoirs revenant aux juridictions ordinaires (b).

\section{a. Les pouvoirs contestés de la Cour constitutionnelle}

Si la Cour constitutionnelle avait été conçue comme un « législateur négatif », dès ses débuts la jurisprudence constitutionnelle a montré qu'une telle définition était loin de pouvoir encadrer ses attributions, car l'alternative entre l'annulation de la disposition législative et le rejet de la question de constitutionnalité n'épuisait pas l'éventail des pouvoirs de la juridiction constitutionnelle. 
Dès les premiers arrêts rendus ${ }^{54}$, la Cour s'est d'ailleurs reconnue le pouvoir d'interpréter les dispositions qui faisaient l'objet d'une question préjudicielle, pour la simple et bonne raison qu'avant de contrôler une disposition il est nécessaire d'en déterminer les contenus. Une telle conclusion ne pouvait pas être tenue pour acquise dans la logique du système tel qu'il avait été mis en place. Cela parce qu'en conférant à la Cour constitutionnelle la mission d'exercer un contrôle de constitutionnalité concentré et en conférant aux juges ordinaires le pouvoir de saisine, l'attribution du pouvoir d'arrêter les contenus des dispositions était resté dans le flou : d'un côté, on aurait pu défendre la thèse selon laquelle rien ni personne aurait empêché la Cour constitutionnelle de faire emploi des pouvoirs interprétatifs qui dérivaient tout simplement de sa nature juridictionnelle; de l'autre, on aurait pu valoriser le rôle des juges ordinaires en leur réservant le pouvoir de déterminer les contenus des dispositions qu'eux-mêmes déféraient à la Cour. L'adoption de cette dernière thèse aurait impliqué une distinction nette entre le « domaine de la constitutionnalité » et le « domaine de la légalité », distinction par laquelle les pouvoirs d'interprétation auraient dû se distinguer selon l'acte à interpréter, de manière à réserver à la Cour constitutionnelle l'interprétation de la Constitution et aux juridictions ordinaires celle des lois $^{55}$. En renvoyant une question préjudicielle, le juge aurait donc arrêté la portée de la disposition soumise au contrôle et aurait appelé la Cour à faire emploi de son pouvoir d'annulation et, le cas échéant, de son pouvoir d'interpréter la Constitution, sans qu'aucune interprétation de la loi ne lui soit permise.

La solution retenue par la Cour constitutionnelle de revendiquer des pouvoirs herméneutiques à l'égard de la législation a donc eu une portée capitale. D'abord, parce qu'elle a remis en cause la définition du système qui paraît être propre au Constituant : la linéarité de la théorie du contrôle concentré, fondé sur le pouvoir d'annulation de la Cour, a été remplacée par un modèle plus dynamique, axé sur les relations concrètement existantes entre la juridiction constitutionnelle et les juridictions ordinaires. En outre, la remise en cause de la distinction rigide entre légalité et constitutionnalité a ouvert la voie à une conception de la Constitution fortement marquée par son caractère normatif, et à la conséquente assimilation de la Constitution aux (autres) lois, notamment pour ce qui a trait à son application judiciaire et à son ancrage dans le système. Ces bénéfices incontestables n'ont cependant pas été obtenu sans en payer le prix, comme en témoigne notamment la recherche nécessaire d'un équilibre entre la Cour et les juridictions ordinaires, qui, de leur côté, n'ont pas renoncé à revendiquer leurs pouvoirs interprétatifs.

Dans cette revendication, les juges ont pu se prévaloir du fait qu'une fois admise - par la Cour constitutionnelle même - la priorité logique de l'interprétation par rapport au contrôle de constitutionnalité, la Cour a dû faire face à la situation dans laquelle l'issue du contrôle était commandée, non par l'alternative entre inconstitutionnalité et rejet de la question de constitutionnalité, mais plutôt

$54 \quad$ Un cas emblématique remonte à quelques semaines à peine après l'entrée en fonction de la Cour : dans l'arrêt du 2 juillet $1956, \mathrm{n}^{\circ} 8$, la Cour a reconnu que la disposition dénoncée devait être « interprétée, pour qu'on en contrôle la constitutionnalité, non dans le cadre du système dans lequel elle avait trouvé son origine, mais dans le système actuel dans lequel elle vit ».

55 Sur cette distinction, voir C. Mezzanotre, « La Corte costituzionale: esperienze e prospettive », in Attualità e attuazione della Costituzione, Rome-Bari, Laterza, 1979, p. 149 et suiv. (en particulier, p. 160). 
par l'interprétation qu'on donnait de la disposition ${ }^{56}$. Pour qu'une telle situation se manifeste, il était suffisant que la Cour soit confrontée à une affaire où le sort d'une disposition législative pouvait changer selon l'interprétation donnée : si en attribuant une certaine portée à l'énoncé normatif l'antinomie avec la Constitution avait conduit à la déclaration d'inconstitutionnalité, l'attribution d'une portée différente aurait pu apaiser le conflit entre la loi et la Constitution, de manière à ce qu'aucune inconstitutionnalité ne soit à déclarer. L'alternative s'est très vite présentée ${ }^{57}$; et le principe de conservation des actes juridiques (utile per inutile non vitiatur) a conduit la Cour à franchir la barrière idéale établie par la notion de « législateur négatif » ${ }^{58}$. L'alternative à la déclaration d'inconstitutionnalité n'a plus été seulement le rejet tout court de la question préjudicielle, mais elle s'est concrétisée aussi dans les dits « arrêts interprétatifs de rejet $»^{59}$, par lesquels la constatation de l'absence de vices de constitutionnalité est subordonnée à l'adoption d'une certaine interprétation de la disposition législative contestée, ce qui est généralement explicité dans le dispositif de l'arrêt, où la Cour déclare la question de constitutionnalité dépourvue de fondement «nei sensi di cui in motivazione » ${ }^{60}$, c'est-àdire en faisant référence aux contenus de la disposition ayant fait l'objet de la question tels qu'ils ont été dégagés par la Cour et qui ont été indiqués dans les motifs de l'arrêt ${ }^{61}$.

Ce sont précisément les arrêts interprétatifs de rejet qui ont catalysé les revendications des juges ordinaires : la réception de ces arrêts atypiques était, en effet, une occasion pour contester les pouvoirs d'interprétation de la Cour constitutionnelle ${ }^{62}$.

Pour comprendre à quel point l'occasion était propice, il convient de remarquer que l'autorité de la chose jugée des arrêts de la Cour n'est pas des plus assurées : si les déclarations d'inconstitutionnalité d'une disposition ou d'un acte législatif ont, à l'évidence, les effets généraux qui s'attachent aux annulations, les arrêts de rejet n'ont pas d'effets semblables, puisqu'ils ne confèrent aucun « brevet de constitutionnalité », du fait qu'ils ne statuent que sur la question posé ${ }^{63}$. Les

56 Le sujet a été abordé par la doctrine dès les premières années : cf. V. CRISAfulli, «Questioni in tema di interpretazione della Corte costituzionale nei rapporti con l'interpretazione giudiziaria », Giurisprudenza costituzionale, 1956, p. 929 et suiv. ; T. AsCARELLI, « Giurisprudenza costituzionale e teoria dell'interpretazione », Rivista di diritto processuale, 1957, p. 351 et suiv. ; F. CARNELUTti, «Poteri della Corte costituzionale in tema di interpretazione della legge impugnata », Rivita di diritto processuale, 1962, p. 349 et suiv. ; E.T. LiEBMAN, « Legge e interpretazione nel giudizio di legittimità costituzionale », Rivista di diritto processuale, 196, p. 567 et suiv.

57 La première décision dans laquelle l'alternative s'est posée de manière explicite est l'arrêt du 26 janvier $1957, \mathrm{n}^{\circ} 1$.

58 La notion de « législateur négatif », qui est évoquée ici en rapport aux pouvoirs interprétatifs de la Cour, est plus souvent indiquée comme dépassée par le pouvoir de la Cour de rendre des arrêts d'inconstitutionnalité dits « manipulatifs », car ils manipulent le texte de la disposition, en y ajoutant les contenus que le législateur a omis (arrêts additifs), en éliminant les contenus inconstitutionnels (arrêts ablatifs) ou en substituant les contenus inconstitutionnels avec les contenus qui découlent des principes et normes constitutionnelles (arrêts substitutifs). Sur cette catégorie d'arrêts, voir voir G. SiLvestri, « Le sentenze normative della Corte costituzionale », Giurisprudenza costituzionale, 1981, I, p. 1684 et suiv. ; L. ElIA, « Le sentenze additive e la più recente giurisprudenza della Corte costituzionale », Scritti su La giustizia costituzionale in onore di Vezio Crisafulli, op. cit., 1985, vol. I ${ }^{\mathrm{er}}$, p. 299 et suiv. ; G. D’OrAzIO, « Le sentenze costituzionali additive tra esaltazione e contestazione », Rivista trimestrale di diritto pubblico, 1992, p. 61 et suiv. ; R. PinARd, L horror vacui nel giudizio sulle leggi, Milan, Giuffrè, 2007.

59 Sur l'origine et la nature des arrêts interprétatifs de rejet, voir G. SoRRENTI, L'interpretazione conforme a Costituzione, op. cit., p. 177 et suiv. ; R. Romboli, «Qualcosa di nuovo ... anzi d'antico: la contesa sull'interpretazione conforme della legge », in P. CARNEVALE - C. COLAPIETRO (sous la direction de), op. cit., p. 89 et suiv.

60 Cette formule a été inaugurée dans l'arrêt $n^{\circ} 1$ de 1957 , précité.

61 Les arrêts interprétatifs ont été rendus, bien que plus rarement, même dans le cadre de la constatation de l'inconstitutionnalité. Dans certains cas, en effet, la Cour rend même des arrêts interprétatifs d'inconstitutionnalité, par lesquels elle déclare l'inconstitutionnalité, non d'une disposition, mais d'une interprétation qu'on lui donne : la disposition reste donc en vigueur, mais la déclaration de la Cour interdit qu'on lui donne une certaine interprétation.

62 Sur la réception des premiers arrêts interprétatifs de rejet, voir C. MoRTATı, « Effetti pratici delle sentenze interpretative della Corte costituzionale », Giurisprudenza costituzionale, 1959, p. 550 et suiv.

63 Il en résulte qu'une autre question ayant comme objet la même norme, mais fondée sur d'autres moyens (invoquant, par exemple, d'autres normes de référence), peut à tout moment être soulevée, permettant ainsi de contester la norme législative à nouveau. En outre, puisque l'objet 
arrêts interprétatifs de rejet ne font pas exception à cette règle, d'autant plus que leurs effets sont relativisés de manière significative par l'étendue de l'autorité de la chose jugée. Celle-ci est limitée, en effet, aux dispositifs des arrêts de la Cour et ne touche donc pas les motifs ${ }^{64}$ : par conséquent, les arrêts interprétatifs de rejet ne disposent pas de la force juridique permettant d'imposer aux juges ordinaires l'interprétation prônée par la Cour ${ }^{65}$.

La « faiblesse » des arrêts interprétatifs rendus par la Cour a produit une situation d'ambiguïté, concernant l'impact des solutions interprétatives dégagées dans les arrêts : l'absence d'effets contraignants, pour les arrêts de rejet et pour les motifs, impliquaient que les juges ordinaires n'étaient pas tenus de suivre l'interprétation proposée par la Cour. Plusieurs théories ont été élaborées afin d'introduire dans le système quelques limites à la marge d'appréciation des juges ${ }^{66}$ mais aucune d'entre elles n'a pu fonder une obligation positive générale découlant de l'arrêt de la Cour.

Si, d'un côté, les arrêts interprétatifs montraient bien que la prohibition pour la Cour de substituer sa propre interprétation à celle du juge a quo n'était plus sérieusement défendable, de l'autre les résistances des juridictions ordinaires dans la réception de ce genre d'arrêts montraient très clairement que les juges n'étaient pas disposés à céder leurs prérogatives à la Cour. Il revenait donc à la Cour constitutionnelle d'éviter le déclenchement d'un conflit qui aurait pu conduire à une paralysie du système. À l'évidence, une reconnaissance expresse des pouvoirs interprétatifs des juges s'imposait.

\section{b. La reconnaissance inévitable des pouvoirs des juges ordinaires}

Le refus des juridictions ordinaires de se conformer aux interprétations proposées par la Cour constitutionnelle dans les arrêts interprétatifs de rejet a fait émerger de manière indiscutable le fait que la Cour manque de moyens pour s'imposer par rapport aux juges si ce n'est par l'exercice de ses pouvoirs d'annulation des dispositions et des actes législatifs. Cet aspect s'avère décisif pour comprendre l'évolution des relations entre la Cour et les (autres) juridictions. Le paradoxe du système concentré « à l'italienne » consiste, en effet, dans une sorte de renversement des moyens de contrainte existant par rapport à ce que l'on pourrait s'attendre à la lumière de l'objectif de confier la protection de la Constitution à une instance judiciaire spécifique : s'il est vrai que la Cour, grâce à son monopole du pouvoir d'annulation des lois, est l'organe central dans le système de justice constitutionnelle, il n'est pas moins vrai que l'étendue et l'importance de son rôle dépendent, pour l'essentiel, des saisines qui proviennent des juridictions ordinaires ; par contre, une fois la décision

de la déclaration est limité à la question soulevée, l'interdiction de la réitération de la même question ne vaut que pour le juge qui l'a soulevée (au cours du même procès), et non pas pour les autres juges (ni pour le juge même, au cours d'un autre procès).

64 À ce propos, voir A. Pizzorusso, « La motivazione delle decisioni della Corte costituzionale : comandi o consigli ? », Rivista trimestrale di diritto pubblico, 1963, p. 346 et suiv. En général, sur la motivation des arrêts de la Cour constitutionnelle, voir A. RUGGERI (dir.), La motivazione delle decisioni della Corte costituzionale, Atti del seminario di Messina, 7-8 maggio 1993, Turin, Giappichelli, 1994.

65 Les arrêts interprétatifs d'inconstitutionnalité, par contre, ne posent pas de problème, car, en s'agissant de déclarations d'inconstitutionnalité (bien que ne frappant qu'une interprétation, au lieu d'une disposition), ils partagent les mêmes effets obligatoires qui sont propres aux déclarations d'inconstitutionnalité tout court.

66 Le souci a été manifesté, notamment, par V. CRISAfulLI, « Ancora delle sentenze interpretative di rigetto della Corte costituzionale », Giurisprudenza costituzionale, 1965, p. 96 et suiv. Plus nuancée est la position de L. EliA, "Sentenze "interpretative" di norme costituzionali e vincolo dei giudici », Giurisprudenza costituzionale, 1966, p. 1715 et suiv., qui a relevé qu'au moment où la Cour constitutionnelle rend un arrêt interprétatif de rejet, le juge ordinaire qui n'entend pas s'y conformer devrait, en principe, reconnaître l'existence d'un doute concernant la constitutionnalité de la norme à appliquer, d'où l'obligation de soulever la question préjudicielle de constitutionnalité. 
rendue, la Cour constitutionnelle n'a pas de moyens de pression ni de contrôle vis-à-vis de l'activité des juridictions ordinaires ${ }^{67}$. En d'autres termes, on ne saurait fonder une hiérarchie entre la Cour et les autres juridictions, leurs rapports étant caractérisés plutôt par la distinction de leurs tâches respectives : une coordination, donc, plutôt qu'une subordination. D’où la nécessité d'une coopération, animée par un dialogue dans lequel le dernier mot ne revient pas invariablement à l'un des interlocuteurs : si le dialogue aboutit à une déclaration d'inconstitutionnalité, le dernier mot est en principe - celui de la Cour, mais s'il aboutit à une décision qui appelle à l'application (et donc à l’interprétation) de la disposition, ce sont les juges à en bénéficier ${ }^{68}$.

Ces remarques ont un impact décisif sur le sujet de la reconnaissance par la Cour des pouvoirs interprétatifs des juges ordinaires, car elles conduisent à définir une telle reconnaissance moins comme une « concession » que comme une imposition. Tout en s'attribuant le pouvoir d'interpréter les lois (et non seulement la Constitution), la Cour constitutionnelle n'était en mesure de revendiquer aucun monopole à ce propos. Par conséquent, confrontée à l'opposition des juridictions ordinaires, la Cour n'a pu que confirmer ses pouvoirs, sans pour autant que cela puisse impliquer une contestation du fait que ces mêmes pouvoirs revenaient aussi aux juges ordinaires.

Or, la duplication des titulaires de pouvoirs interprétatifs aurait pu engendrer, pour les justiciables, une situation de forte instabilité dans l'application des lois et, dans les relations entre les juridictions, une compétition, voire une véritable « guerre ». En effet, au cours des années soixante, le système italien a connu la dite « guerre des deux cours », un " dialogue entre deux sourds » qui a vu se confronter, d'un côté, la Cour constitutionnelle, qui visait à conserver les pouvoirs d'interprétation qu'elle s'était attribuée dès le début de son fonctionnement, et, de l'autre, la Cour de cassation, qui mettait en avant tant la nécessité pour tout juge d'interpréter le droit positif que la mission spécifiquement confiée à la Cassation d'assurer l'interprétation uniforme de la loi (la dite nomofilachia $\left.{ }^{70}\right)$.

67 Pour preuve de l'importance du sujet pour comprendre la nature du système de justice constitutionnelle, la Cour constitutionnelle a commandé - il y a quelques années - une étude sur la réception des arrêts interprétatifs et additifs de principe (c'est-à-dire les arrêts manipulatifs qui ajoutent - au lieu de dispositions précises - des contenus génériques dérivant d'un ou plusieurs principes, dont la mise en œuvre revient, en définitive, au législateur et, provisoirement, aux juges, appelés à appliquer les principes dans les cas concrets, dans l'attente d'une réponse du législateur ayant une portée générale) : cf. E. LAMARQUE, Il seguito delle decisioni interpretative e additive di principio della Corte costituzionale presso le autorità giurisdizionali (anni 2000 - 2005). Relazione illustrativa, Corte costituzionale. Servizio Studi e Massimario, décembre 2007, disponible en ligne à la page www.cortecostituzionale.it/documenti/convegni_seminari/STU\%20200_Relazione_illustrativa.pdf[10 juin 2016].

68 En général, sur les rapports entre la Cour constitutionnelle et le juridictions ordinaires, voir V. ONIDA, « Giurisdizione e giudici nella giurisprudenza della Corte costituzionale », in P. BARILE - E. CHELI - S. Grassi (sous la direction de), Corte costituzionale e sviluppo della forma di governo in Italia, Bologne, il Mulino, 1982, p. 159 et suiv.; P. Ciarlo - G. Pitruzzella - R. TARChi (sous la direction de), Giudici e giurisdizioni nella giurisprudenza della Corte costituzionale, Turin, Giappichelli, 1997 ; E. NAvarretta - A. Pertici (sous la direction de), Il dialogo tra le Corti. Principi e modelli di argomentazione, Pise, Plus, 2004 ; G. CAMPANELl, Incontri e scontri tra Corte suprema e Corte costituzionale in Italia e in Spagna, Turin, Giappichelli, 2005 ; G. SoRREnti, L’interpretazione conforme a Costituzione, op. cit., p. 177 et suiv. ; R. RomBOLI, « Giudici comuni e Corte costituzionale nel giudizio sulle leggi », in M. Revenga SÁnchez - E.J. Pajares Montolío - J.R. Rodríguez-Drincourt Alvarez (coord.), 50 años de Corte Constitucional italiana, 25 años de Tribunal Constitucional español, Ministerio de Justicia, Madrid, 2007, p. 359 et suiv. ; R. Romboli, «Qualcosa di nuovo ... anzi d'antico: la contesa sull'interpretazione conforme della legge », op. cit., p. 89 et suiv. ; E. LAMARQUE, Corte costituzionale e giudici nell'Italia repubblicana, Rome-Bari, Laterza, 2012 ; A. Pugiotto, « Dalla "porta stretta" alla "fuga” dalla giustizia costituzionale? Sessant'anni di rapporti tra Corte e giudici comuni », Quaderni costituzionali, 2016, p. 148 et suiv.

69 Cf. V. Crisafulli, « Ancora delle sentenze interpretative di rigetto della Corte costituzionale », op. cit., p. 98.

70 À propos de l'incidence de la «nomofilachia» sur les décisions de la Cour constitutionnelle, voir A. CARDONE, « Funzione di nomofilachia della Cassazione e pronunce della Corte costituzionale », Giurisprudenza costituzionale, 2001, p. 2884 et suiv. ; T. GuARNIER, Interpretazione costituzionale e diritto giurisprudenziale. Specificità e problemi dell'interpretazione costituzionale nell'ordinamento giuridico integrato, Naples, Editoriale Scientifica, 2014, p. 147 et suiv. 
La confrontation, qui avait pour enjeu principal, justement, la nature et l'étendue des effets des arrêts interprétatifs de rejet, n'a pris fin qu'au moment où la Cour constitutionnelle a accepté de prendre du recul en présence de certaines circonstances. Si le principe de la duplicité des titulaires des pouvoirs interprétatifs n'a pas été remis en question, concrètement la Cour constitutionnelle a accepté de céder le passage dans les cas où la jurisprudence des juridictions ordinaires, eu égard à son uniformité, pouvait être considérée comme dotée d'une autorité renforcée. Il s'agit de la doctrine $\mathrm{du}$ « droit vivant $»^{71}$, par laquelle le juge constitutionnel renonce à proposer sa propre interprétation d'une disposition législative et se soumet à celle qui a été dégagée par la jurisprudence de manière largement partagée, et notamment par la jurisprudence consolidée de la Cour de cassation (ou du Conseil d'État) : dans ce cas, la Cour constitutionnelle contrôle la constitutionnalité de la disposition en se considérant obligée à suivre l'interprétation consolidée, ce qui implique que l'issue du contrôle est soit le rejet tout court de la question soit la déclaration d'inconstitutionnalité, car aucune marge ne subsiste pour un arrêt interprétatif, qui impliquerait la proposition (ou l'imposition ${ }^{72}$ ) de la part de la Cour d'une interprétation différente.

L'auto-limitation du juge constitutionnel s'est donc associée, d'un côté, à la reconnaissance du rôle d'unification de la jurisprudence qui est propre aux juridictions ordinaires suprêmes - et notamment à la Cassation - et, de l'autre, au respect de l'exigence de stabilité de l'interprétation, dont les justiciables sont les premiers bénéficiaires. Bien évidemment, pour les cas où les conditions pour que la Cour constitutionnelle s'incline ne seraient pas remplies, la Cour s'est réservée la possibilité de proposer son interprétation, de manière à ce qu'elle mette en jeu moins son autorité que son influence pour contribuer à dégager une interprétation qui débouche, le cas échéant, sur la formation d'un nouveau « droit vivant ».

La règle que la Cour constitutionnelle s'est elle-même imposée a permis de sortir de l'impasse et a assuré le maintien de la « paix » entre les juridictions constitutionnelle et suprêmes pendant plusieurs décennies. Ce n'est que vers la fin des années quatre-vingt-dix que quelques turbulences se sont manifestées, notamment lorsque la Cour constitutionnelle a abandonné l'attitude strictement respectueuse du «droit vivant », et donc, même en présence d'une interprétation uniforme, a parfois évité une déclaration d'inconstitutionnalité en proposant une interprétation différente de la disposition capable d'éliminer la cause de l'invalidité qui l'affectait ${ }^{73}$. La Cour de cassation, dans un

\footnotetext{
71 Sur laquelle les contributions doctrinales sont très nombreuses. Parmi celles-ci, voir, notamment, A. PugiotTo, Sindacato di costituzionalità $e$ « diritto vivente », Milan, Giuffrè 1994 ; G. SorRenti, L'interpretazione conforme a Costituzione, op. cit., p. 183 et suiv. ; V. MARINELLI, Studi sul diritto vivente, Naples, Jovene, 2008 ; E. Resta, Diritto vivente, Rome-Bari, Laterza, 2008 ; M. CAvino (sous la direction de), Esperienze di diritto vivente. La giurisprudenza negli ordinamenti di diritto legislativo, volume I, Milan, Giuffrè, 2009; M. CAVINO, « Diritto vivente », Digesto delle discipline pubblicistiche - Aggiornamento, Turin, Utet, 2010, p. 134 et suiv. ; A.S. Bruno - M. CAVINo (sous la direction de), Esperienze di diritto vivente. La giurisprudenza negli ordinamenti di diritto legislativo, volume II, Milan, Giuffrè, 2011). Une étude récente concentrée sur la jurisprudence est celle de L. Salvato, Profili del «diritto vivente» nella giurisprudenza costituzionale, Corte costituzionale, Servizio Studi e Massimario, février 2015, disponible en ligne à la page www.cortecostituzionale.it/documenti/convegni_seminari/stu_276.pdf[10 juin 2016].

72 Nous avons pu constater que la proposition est celle qui découle d'un arrêt interprétatif de rejet, tandis que les arrêts interprétatifs d'inconstitutionnalité se traduisent par l'obligation faite aux juges ordinaires de ne pas suivrel'interprétation qui a été déclarée inconstitutionnelle. 73 T. Groppi a parlé d'une véritable « crise » de la doctrine du «droit vivant » : T. GroppI, « Verso una giustizia costituzionale "mite"? Recenti tendenze dei rapporti tra Corte costituzionale e giudici comuni », Politica del diritto, 2002, 217 et s. ; cf., aussi, R. RombolI, « Qualcosa di nuovo ... anzi d'antico: la contesa sull'interpretazione conforme della legge », op. cit., p. 89 et suiv.
} 
premier temps, notamment par un arrêt de $1998^{74}$, s'est montrée très « attentive » aux indications venant de la Cour constitutionnelle ; mais une telle attitude, que l'on aurait pu définir surprenante en comparaison avec celle adoptée dans le passé, a laissé la place, quelques années plus tard, par un arrêt de $2004^{75}$, à une nouvelle revendication des pouvoirs interprétatifs des juges ordinaires, qui ne peuvent aucunement se voir obligés à suivre l'interprétation des dispositions législatives suggérée par la Cour constitutionnelle.

Cette dernière position de la Cour de cassation n'a quand même pas donné lieu à une nouvelle « guerre entre les cours », vu que la Cour constitutionnelle, par un arrêt de $2005^{76}$, une fois constaté que son interprétation « constitutionnellement orientée » avait été rejetée par la Cour de cassation, n'a pas insisté dans l'approche conservatrice à l'égard de la disposition législative et a donc accepté d'en déclarer l'inconstitutionnalité 77 .

La perturbation des équilibres entre la Cour constitutionnelle et la Cour de cassation est, en soi, un événement important dans la vie du système (de n'importe quel système) de justice constitutionnelle, mais, peut-être, plus importantes encore sont les causes de cette perturbation. Or, la discontinuité qui s'est produite entre la fin du $\mathrm{xx}^{\mathrm{e}}$ siècle et le début du $\mathrm{XXI}^{\mathrm{e}}$ ne peut qu'être associée principalement à l'émergence de l'« interprétation conforme » comme élément central dans le système de justice constitutionnelle.

\section{L'interprétation conforme à la Constitution, alternative au contrôle incident}

L'alternative entre la censure des dispositions législatives pour méconnaissance de la Constitution et leur interprétation « conforme à la Constitution » fait en sorte que le contrôle incident ne se concrétise qu'au moment où l'interprétation conforme s'avère impossible (a), en raison des limites qui s'imposent à l'exercice herméneutique visant à l'élimination des antinomies entre la loi et la Constitution (b).

\section{a. Un exercice prioritaire}

L'alternative entre « interpréter » et « soulever » a été consacré par la Cour constitutionnelle elle-même, lorsque, en 1996, elle a posé le principe selon lequel « les lois ne sont pas déclarées inconstitutionnelles parce que l'on peut en donner des interprétations inconstitutionnelles [...], mais parce qu'il est impossible d'en donner des interprétations constitutionnelles ». Ce passage, tiré de l'arrêt du 22 octobre 1996, n 356, a eu de conséquences majeures tant pour l'ancrage de la Constitution dans l'ordre juridique que pour le système de justice constitutionnelle.

\footnotetext{
74 Cf. Cour de cassation, chambres pénales unies, arrêt du 16 décembre 1998, Anagni; l'arrêt est commenté par E. LAMARQuE, « Le sezioni unite penali della Cassazione « si adeguano » ... all'interpretazione adeguatrice della Corte costituzionale », Giurisprudenza costituzionale, 1999, p. 1412 et suiv.

75 Cf. Cour de cassation, chambres pénales unies, arrêt du 17 mai 2004, Pezzella ; l'arrêt est commenté par G.P. Dolso, « Le interpretative di rigetto tra Corte costituzionale e Corte di cassazione », Giurisprudenza costituzionale, 2004, p. 3021 et suiv.

76 Cf. Cour constitutionnelle, arrêt du 22 juillet 2005, n 299 ; l'arrêt est commenté par G.P. Dolso, « Prognosi sul futuro delle intepretative di rigetto », Giurisprudenza costituzionale, 2005, p. 2930 et suiv.

77 Pour l'évolution des rapports entre Cour constitutionnelle et Cour de cassation marquée par les arrêts qui viennent d'être mentionnés, voir R. Romboli, « Giudici comuni e Corte costituzionale nel giudizio sulle leggi », op. cit., p. 389 et suiv.
} 
Pour ce qui est du premier aspect, on ne saurait négliger la correspondance évidente entre le passage de l'arrêt de 1996 concernant les rapports entre les lois et la Constitution et le passage d'un arrêt de 1988 relatif aux rapports entre les règlements et les lois qui énonce que « le principe de conservation des valeurs juridiques [...] amène à supposer qu'une disposition [réglementaire] n'est pas déclarée illégitime tant qu'il est possible en dégager au moins une portée conforme aux lois $\gg^{78}$. Le parallélisme entre les deux passages cités est la preuve la plus explicite du fait que l'application concrète de la Constitution est devenue, du moins à partir de 1996, parfaitement correspondante à celle qui est propre aux autres sources du droit. En d'autres termes, le caractère distinctif de la Constitution ne saurait être déduit de prétendues particularités qui en affecteraient la nature normative, car il ne réside désormais qu'en sa position apicale dans le système des sources du droit.

Or, si la Constitution est une source du droit à l'instar des autres, les juges ordinaires sont tenus d'en faire application de la même façon que les autres sources du droit. Et c'est justement en raison de cette équivalence potentielle qu'on peut mesurer les effets de l'ancrage de la Constitution sur le système de justice constitutionnelle. Si la Constitution elle-même prévoit un régime spécifique pour sa protection (le contrôle concentré), le rapprochement entre la Constitution et les autres sources du droit implique que la spécificité du régime doive être conçue comme une exception, d'où la nécessité de l'encadrer de la manière la plus restrictive possible. La Cour constitutionnelle a fait sienne cette approche par l'arrêt de 1996 précité, dans la mesure où celui-ci a ouvert la voie à une réduction maximale du domaine du contrôle concentré de constitutionnalité, un contrôle qui n'intervient que lorsque les options herméneutiques n'arrivent pas à assurer la cohérence du système : cantonné aux situations où le principe de conservation des actes juridiques s'efface, le contrôle concentré de constitutionnalité ne doit intervenir qu'en dernier ressort.

Dans la pratique, cette nouvelle approche théorique a eu des conséquences fondamentales sur le fonctionnement du système de justice constitutionnelle, non seulement du point de vue du changement concernant le rôle et la position de la Cour, mais aussi pour ce qui a trait aux juges ordinaires et notamment les conditions qui s'imposent afin de soulever une question préjudicielle de constitutionnalité.

La mise en exergue de l'interprétation impliquait, à l'évidence, que la Cour constitutionnelle encourageait l'emploi, de la part des juges ordinaires, de tous leurs outils interprétatifs afin de limiter le recours à la question préjudicielle de constitutionnalité. En d'autres termes, les juges ordinaires ont été poussés, autant que possible, à ne pas demander à la Cour de déclarer l'inconstitutionnalité des dispositions législatives, mais plutôt à faire en sorte de dégager une interprétation conforme à la Constitution ${ }^{79}$.

\footnotetext{
$78 \quad$ Arrêt du 19 mai 1988, n 559, paragraphe 4.1.2. de la partie en droit.

79 Sur l'interprétation des dispositions législatives visant à les rendre conformes à la Constitution et sur l'impact qu'une telle interprétation peut avoir sur le procès constitutionnel, voir P. FEMIA (sous la direction de), Interpretazione a fini applicativi e legittimità costituzionale, Naples, Edizioni Scientifiche Italiane, 2006 ; G. Sorrenti, L’interpretazione conforme a Costituzione, op. cit. ; M. LucIANI, « Le funzioni sistemiche della Corte costituzionale, oggi, e l'interpretazione "conforme a" », Federalismi.it, 8 août 2007, n. 16 ; R. Romвol, Qualcosa di nuovo ... anzi d'antico: la contesa sull'interpretazione conforme alla legge, op. cit., p. 89 et suiv.; M. D’Amico - B. RANDAzzo, Interpretazione conforme e tecniche argomentative, Atti del Convegno di Milano svoltosi il 6-7 giugno 2008, Turin, Giappichelli, 2009 ; Corte costituzionale, Corte costituzionale, giudici comuni
} 
Cette tâche aurait pu rester cantonnée au niveau des recommandations, ce qui n'aurait changé guère la mission des juges, car dans leur recherche de l'interprétation à donner à une disposition législative ils ne sauraient négliger, en tous les cas, la source supérieure qui conditionne la validité de l'énoncé normatif. La Cour constitutionnelle, cependant, est allée considérablement plus loin et a créé une véritable obligation de rechercher une interprétation conforme. L'obligation a même été assortie de sanction, car la Cour a requis que le juge n'arrive à la saisir qu'une fois constatée l'impossibilité de donner à la disposition législative contestée une interprétation susceptible de la rendre compatible avec la Constitution. Par conséquent, si le juge soulève une question de constitutionnalité sans avoir au préalable expérimenté une interprétation conforme, la Cour ne jugera pas sur le fond de la question, mais rendra un arrêt d'irrecevabilité, voire une ordonnance d'irrecevabilité manifeste, par laquelle on sanctionne l'omission encourue par le juge dans l'accomplissement d'un devoir ${ }^{80}:$ l'alternative entre « interpréter » et « soulever » s'est donc transformé en une consécution dans laquelle « interpréter » est l'antécédent nécessaire et « soulever » est le conséquent éventuel.

Eu égard à cette jurisprudence, on a pu enregistrer l'introduction prétorienne d'une troisième condition requise afin de pouvoir soulever des questions de constitutionnalité, une condition qui serait, en apparence, incompatible avec la deuxième, car la recherche nécessaire d'une interprétation conforme ne saurait s'adapter au jugement sommaire lié au contrôle du caractère " non-futile ». Les remarques que l'on a pu faire à propos de l'inéluctabilité de l'interprétation et de son corollaire consistant dans l'impossibilité de s'arrêter à un jugement purement sommaire ${ }^{81}$ surmontent, cependant, la difficulté sur le plan théorique. L'imposition de la recherche au préalable d'une interprétation conforme peut donc s'encadrer dans l'évolution concrète de la jurisprudence constitutionnelle, qui est devenue de plus en plus exigeante peut-être moins dans le but de limiter le nombre de renvois de questions de constitutionnalité (qui est désormais loin d'atteindre des seuils préoccupants pour le fonctionnement de la Cour ${ }^{82}$ que dans celui de « prendre la Constitution au sérieux ${ }^{83}$.

e interpretazioni adeguatrici, Atti del Seminario (Roma, 6 novembre 2009), Milan, Giuffrè, 2010; A. CiERvo, Saggio sull'interpretazione adeguatrice, Rome, Aracne, 2011 ; F. Mannella, op.cit., p. 135 et suiv. ; G. LANEve, La giustizia costituzionale nel sistema dei poteri. Vol. 1. Interpretazione e giustizia costituzionale: profili ricostruttivi, Bari, Cacucci, 2014 ; M. Ruotolo, Interpretare: nel segno della Costituzione, Naples, Editoriale Scientifica, 2014 ; F. Modugno, « Al fondo della teoria dell'“interpretazione conforme alla Costituzione” », Diritto e società, 2015, p. 461 et suiv. ; M. Nisticò, L'interpretazione giudiziale nella tensione tra i poteri dello Stato. Contributo al dibattito sui confini della giurisdizione, Turin, Giappichelli, 2015, p. 106 et suiv. 80 À propos de cette obligation faite aux juges (et à la sanction de l'irrecevabilité), voir M.R. MorELLI, « Doverosità della previa verifica di una possibile « interpretazione adeguatrice » ai fini dell'ammissibilità dell'incidente di costituzionalità e diverso regime del giudizio in via principale », Giustizia civile, 1997, I, p. 2353 et suiv. ; A. CARDONE, " Ancora sulla dichiarazione di manifesta inammissibilità per difetto di interpretazione adeguatrice a quo », Giurisprudenza costituzionale, 2002, p. 35 et suiv. ; V. MARCENÒ, « Le ordinanze di manifesta inammissibilità per "insufficiente sforzo interpretativo" : una tecnica che può coesistere con le decisioni manipolative (di norme) e con la dottrina del diritto vivente? », Giurisprudenza costituzionale, 2005, p. 785 et suiv. ; F. ModUGNO, «Inammissibilità della quaestio legitimitatis per omessa interpretazione costituzionalmente conforme e bilanciamento in concreto di diverse esigenze costituzionali », Giurisprudenza costituzionale, 2009, p. 2405 et suiv. ; M. RAVERAIRA, Le critiche all'interpretazione conforme: dalla teoria alla prassi di un'incidentalità "accidentata”?, in Giur. it., 2010, 1968 et s. ; A. BoNOMI, « Il dovere del giudice di ricercare l'interpretazione conforme a Costituzione della disposizione impugnata vanifica i requisiti della rilevanza e della non manifesta infondatezza? », Osservatorio costituzionale. Associazione italiana dei costituzionalisti (www.osservatorioaic.it), octobre 2013, ainsi que les contributions citées à la note précédente.

81 Cf. supra, I, A.2.a.

82 Sur cette évolution, qui a fortement caractérisé le contrôle incident et son importance dans le cadre du système de justice constitutionnelle, voir P. PAssaglia, « Les âges du contrôle de la constitutionnalité des lois par voie d'exception en Italie », in L. GAY (sous la direction de), La question prioritaire de constitutionnalité. Approche de droit comparé, Bruxelles, Bruylant, 2014, p. 573 et suiv.

83 L'expression reprend, à l'évidence, le célèbre ouvrage de R. Dworkin, Taking Rights Seriously (1977), trad. fr. par M.J. Rossignol et F. Limare, Prendre les droits au sérieux, Paris, Presses universitaires de France, 1995. 
L'obligation faite aux juges, d'ailleurs, n'a pas eu de conséquences uniquement sur la recevabilité des questions, car lorsque le juge soulève la question de constitutionnalité, et donc conclut qu'aucune interprétation n'est en mesure de rendre la disposition législative conforme à la Constitution, la Cour constitutionnelle n'est pas astreinte à cette conclusion. Autrement dit, la Cour constitutionnelle est elle-même tenue de chercher une interprétation conforme, puisque dans l'alternative entre « interpréter » et « annuler », elle devra donner la priorité à l'interprétation : il se peut, donc, qu'en statuant sur une question de constitutionnalité, la Cour arrive à corriger le juge a quo en dégageant une interprétation conforme qu'il n'avait pas réussi à identifier. Bien évidemment, une telle correction aura lieu dans le cadre d'un arrêt de rejet, aucune déclaration d'inconstitutionnalité n'étant requise ou, à proprement parler, n'étant même possible, eu égard au principe décelé en 1996 : en effet, pour la Cour aussi l'alternative entre l'interprétation et l'annulation n'est pas une alternative réelle, car il s'agit à nouveau d'une consécution qui a, comme premier stade nécessaire, l'interprétation, et comme second éventuel, l'annulation qui est effectivement à concevoir comme un véritable dernier ressort.

\section{b. Un pouvoir limité}

Le débat concernant les pouvoirs interprétatifs des juridictions constitutionnelle et ordinaires a acquis une importance capitale pour la définition même du système de justice constitutionnelle. Si l'interprétation conforme a désormais une place de premier plan au sein du contentieux constitutionnel, le recours à cette technique n'est pour autant pas dépourvu de limites. Les principales limites ont trait, d'un côté, à la compatibilité entre le dégagement d'une interprétation conforme et le texte de la disposition à interpréter (i) et, de l'autre, à la possibilité de dégager une interprétation conforme qui diffère de l'interprétation couramment adoptée pour la disposition (ii).

(i) Dans l'ordre italien, le droit positif n'encadre pas les méthodes d'interprétation des lois. L'article 12 des Dispositions sur la loi en général, préliminaires au Code civil de 1942, énonce des règles, qui ne sont toutefois pas contraignantes pour les juges ${ }^{84}$. La première, et la plus importante, est celle de l'interprétation littérale : « en faisant application de la loi, on ne saurait lui attribuer un contenu différent de celui qui résulte de la portée des mots sur la base de leur connexion »; ensuite, l'article 12 fait référence à l' « intention du législateur », à l'analogie et, enfin, à la nécessité d'avoir recours, le cas échéant, aux principes généraux de l'ordre juridique. D’autres méthodes ont été identifiées par la doctrine, tels que, par exemple, l'interprétation systématique, qui se fonde sur le contexte juridique dans lequel la disposition de loi s'insère, l'interprétation téléologique, qui fait primer les objectifs du législateur, et l'interprétation évolutive, qui tend à adapter la portée de la disposition aux changements intervenus au sein de la société.

Or, l'interprétation conforme à la Constitution parait pouvoir se définir comme une interprétation systématique ${ }^{85}$, du fait que la portée de l'énoncé normatif est déterminée en faisant référence

84 Sur la portée de l'article 12 des Dispositions sur la loi en général, voir, récemment, F. Modugno, Interpretazione giuridica, op. cit., p. 368 et suiv. ; M. Nisticò, op. cit., p. 81 et suiv.

85 Cf., notamment, F. Modugno, « Al fondo della teoria dell'“interpretazione conforme alla Costituzione” », op. cit., p. 465 et suiv. 
à des dispositions autres, qui se trouvent dans le système et qui le caractérisent en raison de leur position apicale. L'enjeu principal, cependant, n'est pas d'ordre définitoire. Il réside, plutôt, dans la question concernant jusqu'où l'interprétation conforme peut se pousser. Si le sens commun, avant même n'importe quelle règle juridique, implique que le point de départ de toute interprétation ne puisse être que le texte de la disposition, aucune règle ne définit la manière et la mesure qui justifient une interprétation conforme par laquelle on s'écarte du texte. Autrement dit, il n'est pas possible de donner au préalable une définition des limites textuelles qui s'imposent dans la recherche de la compatibilité avec la Constitution ${ }^{86}$.

C'est justement en raison de l'absence de règles que la jurisprudence constitutionnelle est essentielle afin de donner des précisions et d'orienter la pratique. À ce propos, la Cour constitutionnelle n'a pas montré une approche constante ; bien au contraire, la jurisprudence a considérablement changé au cours des ans. Si, surtout dans une première phase, la Cour a encouragé l'emploi de la méthode de l'interprétation conforme même dans des cas où les énoncés normatifs paraissaient l'empêcher ou, du moins, présentaient des obstacles significatifs ${ }^{87}$, plus récemment la pratique est allée dans le sens d'une certaine attention, voire déférence, à l'égard du texte de la disposition à interpréter. Un exemple parlant de cette dernière attitude - parmi beaucoup d'autres - est sans doute offert par le récent arrêt de la Cour dans lequel elle a pris soin de préciser que « l'obligation de parvenir à une interprétation conforme à la Constitution cède le pas au contrôle incident de la constitutionnalité [de la loi] chaque fois que celle-ci est incompatible avec le texte de la disposition et s'avère tout à fait excentrique et bizarre, même à la lumière du contexte normatif dans lequel la disposition se situe » : «l'interprétation conformément à la Constitution est obligatoire et elle a une priorité indiscutable vis-à-vis des autres [...], mais elle relève tout de même de la catégorie des techniques interprétatives qui ont une portée déclarative et dont le juge dispose dans l'exercice de sa fonction juridictionnelle »; « par conséquent, si, en faisant emploi de ces techniques, il n'est pas possible de dégager de la disposition une norme conforme à la Constitution, le juge est tenu de saisir [la] Cour de la question de constitutionnalité relative $»^{88}$.

En définitive, le texte de la disposition doit rester le point de repère pour toute activité herméneutique, ce qui paraît nécessaire, d'une part, pour s'assurer contre toute dérive de l'activité interprétative qui empiète sur la prévisibilité des décisions juridictionnelles et, de l'autre, pour garantir la cohérence du système de justice constitutionnelle, qui demeure fondé, du point de vue de la protection de la Constitution, sur le pouvoir d'annuler les dispositions législatives inconstitutionnelles ${ }^{89}$.

\footnotetext{
86 À propos des limites à l'interprétation conforme, voir, récemment, F. ModUGNO, « Al fondo della teoria dell'“interpretazione conforme alla Costituzione" », op. cit., p. 467 et suiv. ; M. Nisticò, op. cit., p. 126 et suiv.

87 Pour une critique de cette attitude de la Cour constitutionnelle, voir M. Luciani, « Funzioni e responsabilità della giurisdizione. Una vicenda italiana (e non solo) », Giurisprudenza costituzionale, 2012, p. 3833 et suiv.

88 Les passages cités sont tirés de l'arrêt du 19 février 2016, n 36. Dans l'arrêt, la Cour opère une référence explicite à l'arrêt du 20 juin 2008 , $\mathrm{n}^{\circ} 219$, qui a également indiqué - quoique de façon peut-être moins efficace - dans la compatibilité avec le texte de la disposition une limite infranchissable pour l'interprétation conforme.

89 Dans le sens que la limite naturelle de l'interprétation conforme réside dans l'impossibilité de transformer, dans la pratique, le contrôle de constitutionnalité concentré en un contrôle diffus, voir M. LuCIANI, « Le funzioni sistemiche della Corte costituzionale, oggi, e l'interpretazione "conforme a" », op. cit., p. 15 et suiv.
} 
(ii) L'interprétation conforme peut se voir limitée, non seulement par le texte de la disposition législative, mais aussi par l'interprétation qui s'est consolidée sur celle-ci, car le fait qu'un énoncé soit généralement interprété d'une certaine manière crée un obstacle majeur au dégagement et à la diffusion de toute autre interprétation. Autrement dit, dans la pratique on ne saurait exclure que la possibilité d'adopter une interprétation conforme soit entravée par l'existence d'un « droit vivant » contraire $^{90}$. On a pu constater que la fin de la «guerre des deux cours » s'est produite lorsque la Cour constitutionnelle a accepté de ne pas toucher au droit vivant par voie d'interprétation et ne s'est réservée que le pouvoir de censurer, le cas échéant, l'inconstitutionnalité de la disposition telle qu'elle résultait du droit vivant.

La question qui s'est posée est donc de savoir si les juges ordinaires, en présence d'un droit vivant, étaient censés chercher une interprétation conforme à la Constitution ou bien si, une fois constatée l'incompatibilité entre la disposition législative (résultant du droit vivant) et la Constitution, il leur était demandé de soulever directement la question préjudicielle de constitutionnalité. La réponse donnée par la Cour constitutionnelle a certifié la « crise »du droit vivant ${ }^{91}$, dans la mesure où celui-ci n'est pas un obstacle à l'interprétation conforme. La solution à laquelle la jurisprudence constitutionnelle est arrivée est que, d'un côté, en défaut d'un droit vivant le juge a l'obligation de chercher une interprétation conforme, tandis que, de l'autre, en présence d'un droit vivant le juge a le choix entre « se conformer (au droit vivant) » et « tenter de conformer (la disposition législative à la Constitution) » : la question de constitutionnalité peut donc suivre la réception de l'interprétation consolidée ou bien la constatation de l'impossibilité de donner à la disposition une interprétation qui la rende compatible avec la Constitution.

Il en résulte que la montée en puissance de la méthode de l'interprétation conforme a eu des conséquences tellement importantes que même une des pierres angulaires des rapports entre Cour constitutionnelle et juridictions ordinaires, tel que le droit vivant, en a été affectée, au point que son existence peut être ignorée lors du renvoi de la question de constitutionnalité.

Cette constatation n'est qu'une preuve supplémentaire du fait que l'ancrage de la Constitution a rendu le respect et l'application de celle-ci la seule véritable clef de voûte du système de justice constitutionnelle.

\section{B. Une Constitution protégée indépendamment des remèdes contre le refus de soulever la question de constitutionnalité}

Le choix de créer un système de justice constitutionnelle concentré a été justifié par un certain nombre de raisons, qui étaient sans doute très fortes lorsque la Constitution a été adoptée. En tenant compte de l'évolution qui a caractérisé l'ordre juridique italien, les raisons n'apparaissent plus aussi fortes que dans le passé. Par conséquent, l'idée même d'un monopole du contrôle de constitutionnalité

90 À ce propos, voir A. Anzon, «Il giudice a quo tra dottrina dell'interpretazione conforme a Costituzione e dottrina del diritto vivente »,

91 Cf. supra, II, A.1.b. 
dont jouit la juridiction spécialisée devient un sujet de débat, à l'instar de l'existence et de l'efficacité des voies qui assurent un tel monopole.

Dans ce cadre, il ne semble pas impossible de défendre la thèse selon laquelle les remèdes existants contre le refus de soulever la question de constitutionnalité ne seraient marqués par les défaillances constatées auparavant, mais plutôt par leur inutilité (1) ou même par la possibilité d'être nuisibles pour la sécurité juridique (2).

\section{Des remèdes potentiellement inutiles}

L'importance attachée au monopole du contrôle de constitutionnalité confié à la Cour constitutionnelle a une influence majeure sur la nature et sur l'intensité de l'impact à reconnaitre aux remèdes contre le refus opposé par un juge ordinaire de saisir la Cour (a). Il en résulte que si la confiance dans les vertus du modèle concentré s'affaiblit, l'utilité même de ces remèdes peut être mise en question (b).

\section{a. L'efficacité postulée du système concentré}

Le choix du modèle européen de justice constitutionnelle trouve sa justification profonde dans l'idée que la création d'une juridiction spécialisée puisse représenter une forme de protection de la Constitution plus efficace et plus adéquate, eu égard à la tradition, à l'histoire des institutions et à celle des pensées politiques qui caractérisent le continent européen.

Ce sont justement celles-ci qui ont conduit au refus du modèle américain (qu'il serait, en réalité, plus correct d'identifier dans le modèle anglo-saxon ${ }^{92}$ ), un refus qui s'est manifesté d'abord dans la pratique $^{93}$ et qui a pu être par la suite formalisé du point de vue théorique, notamment par l'élaboration de Kelsen.

L'alternative entre modèle européen (concentré) et modèle anglo-saxon (diffus) s'est appuyée en particulier sur les différences concernant, d'un côté, la conception de la loi et, de l'autre, la position des juges au sein du système.

92 L'idée reçue selon laquelle le contrôle de la constitutionnalité des lois a été inauguré par le célèbre arrêt Marbury v. Madison, 5 U.S. 137, 177 (1803), nous paraît susceptible de révision critique, notamment eu égard à l'évolution connue par le droit britannique avant les révolutions du XVII ${ }^{\mathrm{e}}$ siècle et à l'influence que la jurisprudence anglaise de cette période a eu sur l'élaboration de la « doctrine Marshall ». À ce propos, la possibilité de contrôler la compatibilité des lois avec les principes du common law s'était affirmée du moins à partir du Dr. Bonham's Case, au début du siècle (« [i]l appert dans nos livres que, dans nombre de cas, le common law contrôlera les actes du Parlement et parfois les annulera complètement : car lorsqu'un acte du Parlement est contraire au commun bien et à la commune raison ou est répugnant ou impossible à exécuter, le common law le contrôle et considère qu'un tel acte est nul »: Dr. Bonham (1611) 8 Co. Rep. 107a, 114a CP), avant que la situation institutionnelle et politique suggère une attitude plus déférente vis-à-vis du législateur. À ce propos, voir, en français, C. GIRARD, «Le réalisme du juge constitutionnel britannique : un réalisme doucement réformé », Cahiers du Conseil constitutionnel, n 22, 2007, p. 256 et suiv.

93 Un tel refus s'est manifesté, par exemple, en France, au cours de la III ${ }^{e}$ République, lorsque les tentatives d'introduire un contrôle des lois « à l'américaine » ont toutes été repoussées. Pour l'analyse du débat (doctrinal, jurisprudentiel et politique), voir J.-P. MAchelON, La République contre les libertés ?, Paris, Presses de la Fondation nationale des Sciences politiques, 1976 ; M. VERPEAUx, « Le contrôle de la loi par la voie d'exception dans les propositions parlementaires sous la III République », Revue française de droit constitutionnel, 1990 , p. 688 et suiv. ; D. RousseAu, « La question du contrôle de la constitutionnalité des lois sous la III ${ }^{e}$ République », Revue belge de droit constitutionnel, 1994, p. 311 et suiv. ; J.-P. MACHElon, « Parlementarisme absolu, État de droit relatif. À propos du contrôle de la constitutionnalité des lois en France sous la III ${ }^{\mathrm{e}}$ République (positions et controverses) », Revue administrative, 1995, p. 628 et suiv. ; M. MILET, « La controverse de 1925 sur l'exception d'inconstitutionnalité. Genèse d'un débat : l'affaire Ratier », Revue française de science politique, 1999, p. 783 et suiv. ; A. LAQuiÈzE, «Le contrôle de constitutionnalité des lois aux États-Unis vu par les penseurs libéraux français du XIX ${ }^{\mathrm{e}}$ siècle », Annuaire international de justice constitutionnelle, 2002, p. 29 et suiv. 
Pour ce qui est de la conception de la loi, la sacralisation qui en avait été faite au Siècle des Lumières, notamment par Rousseau ${ }^{94}$, entérinée, ensuite, par l'œuvre des révolutionnaires, s'était répandue depuis la France vers un bon nombre de systèmes européens, parmi lesquels figurait sans doute l'Italie. Eu égard à ce point de départ, l'introduction d'une constitution rigide était forcément la manifestation d'un abaissement de la loi, qui s'était déjà produit du point de vue matériel, du fait de la perte des caractères qui étaient propres à la loi selon l'article 6 de la Déclaration des droits de l'homme et du citoyen de 1789, et qui se concrétisait désormais même sur le plan formel, par l'introduction d'un niveau supra-législatif dans la hiérarchie des normes.

L'abaissement n'impliquait pas, toutefois, une « banalisation » de la loi : tout en devenant un acte subordonné, la loi ne perdait pas tout son prestige, au point qu'il aurait été même difficile de proposer une assimilation, sur le plan du contrôle juridictionnel, avec les règlements et les autres actes normatifs. Ceci parce que la loi étant (encore) adoptée par les représentants du peuple, l'idée même de la soumettre à un contrôle juridictionnel était loin d'être incontestée : on a pu constater ${ }^{95}$ que, d'un côté, une partie considérable des forces politiques présentes dans l'Assemblée constituante s'opposait à tout contrôle et, de l'autre, même les partisans du contrôle avaient été profondément influencés par une culture juridique marquée par le légicentrisme, d'où leur recherche d'entourer la loi d'une forme de protection au moment même où le principe de constitutionnalité s'imposait.

Dans ce cadre, les particularités de l'objet du contrôle de constitutionnalité ont justifié la création d'un système où la garantie juridictionnelle s'associait à la prise en compte des spécificités de la loi, tirées, d'une part, de ses effets généraux et, de l'autre, de la nature intrinsèquement politique de la décision qui est à son origine. La juridiction constitutionnelle, tout en marquant une rupture avec la tradition de l'incontestabilité de la loi ou, tout au plus, de sa soumission à un contrôle uniquement politique ${ }^{96}$, était donc le moyen pour mettre en œuvre le principe de constitutionnalité sans pour autant négliger l'opportunité d'entourer la loi d'un statut qui soit quelque peu protecteur. Et la protection résultait d'une juridiction qui, par sa composition et par sa position dans le système institutionnel, était censée juger en tenant compte des implications politiques de ses jugements. En d'autres termes, la juridiction constitutionnelle était conçue comme le moyen pour atteindre un équilibre entre les raisons du droit (la protection de la Constitution vis-à-vis des sources subordonnées) et les raisons de la politique (par le biais de l'attention aux conditions d'adoption et aux effets des décisions des représentants du peuple). Compte tenu de cet équilibre, la création d'une juridiction constitutionnelle, dans les attentes des Constituants, devait assurer de meilleurs jugements, c'est-à-dire des

94 La référence est, bien sûr, à J.-J. RousseAu, Du contrat social, ou Principes du droit politique, Amsterdam, Rey, 1762), Livre II, Chapitre VI, et à sa définition de la loi comme l'acte de la volonté générale (« quand tout le peuple statue sur tout le peuple, il ne considère que lui-même ; et s'il se forme alors un rapport, c'est de l'objet entier sous un point de vue à l'objet entier sous un autre point de vue, sans aucune division du tout. Alors la matière sur laquelle on statue est générale comme la volonté qui statue. C'est cet acte que j'appelle une loi »).

95 Cf. supra, I, A.1.a.

96 La notion de contrôle politique de la loi a trouvé son élaboration première et sans doute fondamentale dans la proposition d'institution du Jury constitutionnaire (« dépositaire-conservateur de l'acte constitutionnel »), faite par l'abbé Sieyès lors de l'écriture de la Constitution de l'An III (cf. «Convention nationale. Opinion de Sieyès sur les attributions et l'organisation du Jury constitutionnaire proposé le 2 thermidor, prononcée à la Convention nationale le 18 du même mois, l'an III de la République ; imprimée par ordre de la Convention nationale », in E.-J. SieYÈs, Essai sur les privilèges et autres textes, Paris, Dalloz, 2007, p. 137 et suiv.). 
jugements plus complets au niveau des arguments pris en considération et plus équilibrés entre la pratique du système institutionnel et politique et la théorie du principe de constitutionnalité.

Au soutien de la création d'une juridiction constitutionnelle, cependant, il n'y avait pas que la protection de la loi ${ }^{97}$. Le principe de séparation des pouvoirs, tel qu'il a été conçu sur le continent européen, a joué un rôle essentiel, notamment dans la mesure où il a encadré sur le plan théorique la méfiance vis-à-vis des juges qui s'était nourrie de la polémique des Lumières ${ }^{98}$, d'abord, et de la critique du système américain ${ }^{99}$, ensuite.

La position subordonnée des juges par rapport à la loi (et au législateur), dans un système pourtant caractérisé par l'application du principe de séparation des pouvoirs, avait été très clairement dégagé déjà par Montesquieu, lorsqu'il s'était demandé comment les juges auraient dû se comporter dans le cas où « la loi, qui est en même temps clairvoyante et aveugle, serait [...] trop rigoureuse $»^{100}$. La réponse figure parmi les passages les plus cités de l'histoire de la pensée juridique : « les juges de la nation ne sont [...] que la bouche qui prononce les paroles de la loi ; des êtres inanimés qui n'en peuvent modérer ni la force ni la rigueur $»^{101}$.

L'empreinte de cette théorie s'est affichée dans les systèmes européens, où le rôle du juge a été longtemps cantonné dans un domaine autre que celui des acteurs politiques. La prohibition de tout empiétement s'est traduite, d'abord, par l'article 10 de la loi des 16 et 24 août 1790 sur l'organisation judiciaire, aux termes duquel « les tribunaux ne pourront prendre directement ou indirectement aucune part à l'exercice du pouvoir législatif, ni empêcher ou suspendre l'exécution des décrets du Corps législatif sanctionnés par le Roi, à peine de forfaiture », avant de trouver une consécration constitutionnelle par la Constitution de 1791, Titre IIIe, Chapitre V, Article 3 : « les tribunaux ne peuvent s'immiscer dans l'exercice du pouvoir législatif ou suspendre l'exécution des lois ». Une telle attitude vis-à-vis des juges, propre au système français, s'est manifestée dans un bon nombre de pays continentaux, y compris en Italie, en contribuant de manière considérable à dégrader « la puissance de juger, si terrible parmi les hommes » au rang d'une puissance, «pour ainsi dire, invisible et nulle $»^{102}$.

Le fait que les juges italiens n'aient pu s'opposer efficacement à l'instauration de la dictature fasciste, qu'ils n'aient pas eu la force de faire primer les principes libéraux envers la subversion, fût, pour le passé, une conséquence du cantonnement des juges hors des questions «politiques » et, en même temps, a été, pour l'avenir, la preuve des risques que le nouveau système républicain aurait pu encourir si sa protection avait été laissée dans les mains des juges ordinaires. À cet égard aussi, donc, la création d'une juridiction constitutionnelle représentait un bouleversement du système

\footnotetext{
97 L'ensemble des raisons qui ont été à l'origine du modèle européen de justice constitutionnelle est analysé avec l'habituelle profondeur et richesse de détails par L. Favoreu, Les Cours constitutionnelles, $2^{\mathrm{e}}$ éd., Paris, Presses universitaires de France, 1992 , p. 6 et suiv.

98 Parmi le grand nombre d'exemples que l'on pourrait mentionner, une place particulière est - semble-t-il - à réserver, pour sa virulence et son efficacité, au conte de Voltaire, Zadig ou la Destinée, Histoire orientale, Londres, 1748.

99 La référence obligée est à É. LAMBERT, Le gouvernement des juges et la lutte contre la législation sociale aux États-Unis, Paris, Giard, 1921.

100 C. De Secondat de Montesouieu, De l'esprit des lois, Livre XI, Chapitre VI.

101 Ibidem.

102 Ibidem.
} 
plus limité que celui qui aurait pu se réaliser par l'élargissement des pouvoirs confiés aux juridictions ordinaires existantes. Cela parce que la mise en place de la nouvelle institution pouvait être justifiée, en même temps, par deux raisons en quelque sorte opposées : d'un côté, une juridiction constitutionnelle évitait que se matérialise un « gouvernement des juges » fondé sur leurs pouvoirs de sanctionner les actes des représentants du peuple ; de l'autre, la juridiction constitutionnelle, en raison de son efficacité, aurait mieux et plus efficacement protégé la Constitution.

À l'évidence, pour que ces bénéfices se produisent, la Cour constitutionnelle devait et doit être en mesure de trancher les litiges. C'est cette constatation qui fonde l'importance des remèdes contre les décisions des juges refusant de soulever les questions de constitutionnalité. Or, une telle importance pourrait être remise en cause dans le cas où ses fondements théoriques deviendraient discutables : l'évolution connue par le système au fil des ans pourrait offrir une opportunité de discussion.

\section{b. Une efficacité discutable}

Soixante ans se sont écoulés depuis que la Cour constitutionnelle a été mise en place et presque soixante-dix depuis que le choix a été fait en faveur d'un contrôle concentré de la constitutionnalité des lois. Il se peut qu'il soit temps de réexaminer les raisons qui ont été avancées pour justifier ce choix, car l'ordre juridique a profondément évolué, notamment grâce à l'ancrage de la Constitution, ainsi qu'à d'autres raisons peut-être moins évidentes, mais tout de même non négligeables.

Si la Cour constitutionnelle a été créée pour la confiance qui reposait sur son efficacité, on ne saurait contester que cette confiance était tout à fait justifiée, eu égard à l'œuvre qui a caractérisé la Cour tout au long de son histoire. La question n'est donc pas de savoir si le système a bien fonctionné, puisque la réponse est évidente, mais plutôt si le système ne pouvait pas fonctionner autrement et - surtout - si, dans l'avenir, il ne pourrait pas fonctionner autrement. Les réponses à donner ont une influence majeure sur l'appréciation des remèdes contre les refus de saisir la Cour, du moment que leur utilité, voire leur nécessité se mesure justement par rapport à l'importance que l'on reconnaît au système concentré et au monopole du contrôle de constitutionnalité qui en résulte au profit de la Cour.

Or, puisque le monopole du contrôle s'est appuyé, pour l'essentiel, sur l'idée que la Cour était en mesure de rendre des jugements meilleurs que ceux qui auraient pu être rendus par les juges ordinaires, la mission est de vérifier si, à présent, les raisons qui jadis fondaient incontestablement l'usage du comparatif de supériorité sont encore valides aujourd'hui. Ces multiples raisons se résument, pour l'essentiel, au fait que la Cour constitutionnelle, à la différence des juges ordinaires, était censée être suffisamment équipée pour répondre de manière adéquate aux sollicitations venant du principe de constitutionnalité et, en même temps, des exigences «politiques » (lato sensu) du système.

Une approche comparatiste permet d'avancer des réserves envers l'idée que le système concentré se caractérise pour le fait d'assurer une mise en balance plus efficace entre les exigences du droit et celles de la « politique ». Les expériences des systèmes diffus offrent, en effet, de très bons exemples de contrôles de constitutionnalité qui ne manquent pas de prendre en considération des raisons 
autres que la pure appréciation de la validité des normes. Il suffit de faire référence à la Cour suprême des États-Unis pour en avoir la preuve : l'évocation de la doctrine des «political questions » s'impose. Pour cette dernière, certaines questions, eu égard à leur caractère principalement politique, sortent du domaine des affaires qui peuvent être soumis au contrôle juridictionnel et, par conséquent, la Cour en refuse tout simplement l'examen sur le fond ${ }^{103}$.

Mais encore plus révélatrice est la jurisprudence issue de la célèbre Footnote Four (la note en bas de page qui figure dans l'Opinion de la Cour de l'arrêt United States v. Carolene Products Company ${ }^{104}$ ), qui a très clairement énoncé l'existence de plusieurs niveaux du contrôle, associés à des intensités diverses selon le caractère du vice dénoncé, et notamment les principes et les droits dont la méconnaissance est en cause, de la sorte que le niveau du contrôle le plus strict de la constitutionnalité des lois a été limité aux trois conditions suivantes : la violation manifeste d'une disposition constitutionnelle ; l'atteinte visant à dénaturer ou à truquer le processus politique ; la discrimination contre de minorités, et notamment contre celles qui ne disposent pas d'une consistance ou de pouvoirs suffisants pour chercher à obtenir une réparation au sein du processus politique ${ }^{105}$. On aurait du mal à contester que cette approche est ouverte aux exigences politiques.

Si cette position de la Cour suprême des États-Unis est peut-être celle qui montre de la manière la plus explicite la modulation de l'intensité du contrôle par rapport aux implications politiques, bien d'autres exemples pourraient être tirés d'autres juridictions de common law, à partir de l'arrêt R. c. Oakes ${ }^{106}$ de la Cour suprême canadienne, qui a remarquablement énoncé les volets du contrôle de proportionnalité de la loi.

À ce stade de l'argumentation, on pourrait objecter que les Cours suprêmes des systèmes diffus, en raison de leur histoire, de leur composition et des missions qui leur ont été confiées, sont en mesure d'opérer un contrôle que les juges ordinaires des systèmes de droit continental ne sauraient pas opérer. On a pu préciser, à cet égard, que les juges de l'Europe continentale sont des magistrats de carrière dont la formation leur empêche de saisir parfaitement la portée de la Constitution, car « les normes des Constitutions modernes sont quelque chose de très différent des normes de lois usuelles, que les juges des Cours suprêmes européennes [...] ont été habitués pendant des décennies à interpréter, à respecter et à faire respecter, avec une technique herméneutique très lointaine des «policy-making decisions » qui sont nécessairement requises dans une activité de contrôle de la validité matérielle des lois et de mise en œuvre de la norme constitutionnelle ${ }^{107}$.

103 La formulation « moderne » de cette doctrine remonte à l'opinion concourante du juge William J. Brennan dans l'arrêt Baker v. Carr, 369 U.S. 186 (1962). Pour plus de détails, voir F.W. SchARPF, « Judicial Review and the Political Question : A Functional Analysis », Yale Law fournal, 1966 (75), p. 517 et suiv. ; R.F. BARkow, « More Supreme Than Court? The Fall of the Political Question Doctrine and the Rise of Judicial Supremacy », Columbia Law Review, 2000 (102), p. 237 et suiv.

104304 U.S. 144 (1938).

105 La note est considérée comme « la note la plus célébrée du droit constitutionnel » : cf. L. F. Powell, « Carole Products Revisited », Columbia Law Review, 1982 (82), p. 1087 ; voir aussi F. Gilman, « The Famous Footnote Four : A History of the Carolene Products Footnote », South Texas Law Review, 2004 (46), p. 163 et suiv.

106 [1986] 1 R.C.S. 103.

107 Cf. M. CAPpelletti, Il controllo giudiziario di costituzionalità delle leggi nel diritto comparato, Milan, Giuffrè, 1968, p. 75. 
Dans le contexte italien, de telles remarques étaient indiscutables lorsque la Constitution venait à peine d'entrer en vigueur, d'autant plus que la large majorité des juges qui étaient alors en charge avaient longtemps exercé leur profession pendant la période fasciste ou bien ils avaient reçu leur formation juridique pendant la période fasciste, ce qui ne pouvait évidemment pas assurer leur attachement aux principes constitutionnels tout neufs que l'Assemblée constituante venait de livrer.

Presque sept décennies après, le contexte a sans doute changé de manière considérable. On ne fait pas références aux révisions intervenues ni même aux contenus normatifs qui découlent des articles de la Constitution à la suite de leur interprétation : les changements majeurs ont eu trait à la perception de la Constitution dans l'ordre juridique.

L'ancrage de la Constitution n'est plus en question, ainsi que l'attachement des juges aux principes constitutionnels, car leur formation est une formation entièrement « républicaine ». Encore, et surtout, dans leur activité ils sont désormais habitués à faire emploi de la Constitution en tant que source du droit à part entière, susceptible, selon les cas, d'application directe ou d'orienter l'interprétation des actes subordonnés. On pourrait même arriver à dire, sans que cela puisse être sérieusement contestable, que, si la Constitution est ancrée dans le système, cela n'est pas seulement le résultat de l'œuvre de la Cour constitutionnelle, mais aussi de l'engagement des juges ordinaires, qui ont été d'excellents élèves du magistère de la juridiction du Palais de la Consulta.

Il n'est pas question de soutenir que les disciples ont dépassé le maître. Bien plus simplement, il est question de relativiser l'efficacité du contrôle concentré : si l'on ne saurait contester que le contrôle de la Cour est efficace, on ne saurait exclure non plus que le contrôle par les juges ordinaires est également efficace. Dans ce cadre, l'utilité même des remèdes contre le refus de saisir la Cour constitutionnelle doit être relativisée, car ceux-ci sont moins une protection indispensable pour la Constitution que des moyens pour assurer le fonctionnement d'un certain système de protection, un système qui n'est pas le seul à être envisageable ${ }^{108}$.

\footnotetext{
108 La doctrine italienne admet de plus en plus explicitement que le système de justice constitutionnelle, né comme concentré, a acquis des aspects qui le rapprochent de plus en plus d'un système diffus. Tout en enregistrant cette tournure, plutôt que prôner une transformation du système, on a tendance à mettre en évidence sa nature hybride dérivant de la coexistence du contrôle concentré originaire et des éléments de diffusion survenus : cf., par exemple, E. MALFATTI - R. Romboli - E. Rossi (sous la direction de), Il giudizio sulle leggi e la sua "diffusione", op. cit.; A.M. Nico, L'accentramento e la diffusione nel giudizio sulle leggi, Turin, Giappichelli, 2007 ; L. CAPpuccio - E. LAMARQue (sous la direction de), Dove va il sistema italiano accentrato di controllo di costituzionalità? Ragionando intorno al libro di Víctor Ferreres Comella Constitucional Courts and Democratic Values, Naples, Editoriale Scientifica, 2013 ; voir aussi, A. RugGERI, « La giustizia costituzionale italiana tra finzione e realtà, ovverosia tra esibizione della "diffusione" e vocazione all'“accentramento" », Rivista di diritto costituzionale, 2007, p. 69 et suiv., qui toutefois pointe plutôt l'attention sur la force des éléments qui fondent le contrôle concentré.

Une approche différente est celle qui propose de s'interroger sur l'opportunité d'un changement du système de justice constitutionnelle qui puisse mettre davantage en valeur le rôle des juges comme protecteurs des droits fondamentaux et - par cela, même - de la Constitution. Dans cette perspective, notamment, R. RomBolI, «I differenti livelli di protezione dei diritti : un invito a ripensare i modelli », Osservatoriosullefonti.it, $2015, n^{\circ} 1$, avance l'idée d'un système où le contrôle concentré et le contrôle diffus coexistent. Pour notre part, nous avons eu l'occasion de poser la question (en s'arrêtant toutefois à ce stade) concernant la possibilité d'envisager une transformation du système par l'adoption du modèle diffus : cf. P. PAssaglia, « The Italian system of constitutional review : a Kelsenian model moving towards a decentralized model ? », in J. BeLl - M.-L. PARIs (sous la direction de), Rights-Based Constitutional Review: Constitutional Courts in a Changing Landscape, Cheltenham - Northampton, Massachusetts, Elgar, 2016, p. 247 et suiv.
} 


\section{Des remèdes potentiellement nuisibles à la sécurité juridique}

La sécurité juridique est un autre principe qui est très souvent évoqué pour justifier le choix du modèle de justice constitutionnelle concentré. Toutefois, aucun système ne peut assurer une protection complète du principe (a). Eu égard aux différents éléments à considérer et à mettre en balance, il se peut même que la recherche d'une protection plus forte, par le biais d'un renforcement du « degré de concentration » du système, puisse conduire à des résultats contraires à l'objectif poursuivi (b).

\section{a. Une protection inachevable}

Un des atouts les plus remarquables des systèmes concentrés est souvent identifié dans les bénéfices qu'ils apportent à la sécurité juridique. Le monopole du contrôle de constitutionnalité, associé à celui du pouvoir d'annulation des dispositions législatives inconstitutionnelles, fait de la juridiction constitutionnelle un garant perçu comme particulièrement performant de la sécurité, en ce qu'elle efface de l'ordre juridique toutes les dispositions dont elle est saisie et dont elle constate la non conformité à la Constitution. Les dispositions qui sont annulées (ou, selon les cas, déclarées nulles $\left.{ }^{109}\right)$ ne sont plus susceptibles d'application, pour la simple et bonne raison qu'elles ne figurent pas (ne figurent plus) parmi les composantes du droit positif.

L'impossibilité de faire recours contre les jugements des cours ou des tribunaux constitutionnels ${ }^{110}$ parachève le système de protection de la sécurité juridique, car elle exclut toute oscillation sur le point de savoir si une disposition est à appliquer ou pas.

Ces arguments sont à la base de la critique la plus forte portée par une partie de la doctrine italienne envers la jurisprudence de la Cour qui a fortement encouragé l'interprétation conforme comme alternative à l'inconstitutionnalité ${ }^{111}$.

À l'appui de la critique, il est précisément fait valoir que le principe de conservation des actes juridiques n'est pas sans conséquences sur la sécurité juridique, notamment lorsqu'il est poussé jusqu'à rechercher une interprétation conforme qui est loin d'être évidente et qui est donc susceptible à tout moment d'être contestée dans la pratique judiciaire. Si le prix à payer pour l'observance du principe de conservation est celui de maintenir au sein du droit positif une disposition dont la constitutionnalité est discutable, un tel sacrifice doit être limité autant que possible, notamment par un recours très prudent à l'interprétation conforme, recours qui ne peut donc pas se traduire par l'adoption d'interprétations trop audacieuses.

\footnotetext{
109 Les notions d'annulation et de nullité peuvent engendrer quelques malentendus, car dans un bon nombre de systèmes la juridiction constitutionnelle (par exemple, en Allemagne et en Espagne) est chargée de déclarer la nullité des dispositions inconstitutionnelles, alors qu'en Italie la déclaration d'inconstitutionnalité se traduit par une annulation. La notion de "nullité » se rapproche plutôt de l'inexistence de la loi, c'est-à-dire d'une cause d'invalidité qui affecte l'acte législatif de la manière la plus radicale (généralement pour des vices graves affectant la procédure législative). Or, quand l'on constate une cause d'inexistence, ce n'est pas la Cour constitutionnelle qui doit la déclarer, mais ce sont les juges ordinaires qui ont l'obligation de ne pas appliquer la loi. La référence faite à la nullité dans le texte n'a rien à voir avec le vice radical d'inexistence ; elle est donc à entendre comme une tentative de généraliser l'argumentation au-delà du seul cas italien.

110 La règle est établie, dans l'ordre juridique italien, par l'article 137, alinéa 3, de la Constitution, aux termes duquel « [a]ucune voie de recours n'est admise contre les décisions de la Cour constitutionnelle ».

111 Cf., par exemple, M. Luciani, « Le funzioni sistemiche della Corte costituzionale, oggi, e l'interpretazione "conforme a" », op. cit., p. 8.
} 
Une telle prudence s'imposerait, non seulement afin d'assurer l'existence d'un rapport facilement vérifiable de compatibilité entre la Constitution et les dispositions législatives, mais aussi du fait que l'absence d'un système fondé sur le précédent obligatoire, à l'instar des pays anglo-saxons, empêche d'arrêter la position de la jurisprudence relativement à l'interprétation d'une disposition législative que l'on pourrait qualifier de « constitutionnelle sous réserve », en reprenant ainsi une terminologie courante dans la pratique française de la justice constitutionnelle.

Or, dans un système correspondant au modèle théorique de droit continental, les critiques envers l'encouragement excessif de l'usage des pouvoirs interprétatifs au lieu de l'inconstitutionnalité paraîtraient assez difficiles à surmonter. Un tel système, d'ailleurs, avait été très clairement préconisé par Kelsen lorsqu'il esquissait les grandes lignes du modèle de justice constitutionnelle alternatif au système américain, en conférant à la juridiction constitutionnelle la mission d'un " législateur négatif $»^{112}$. L'image est très évocatrice, car elle renvoie au mécanisme de l'action (la décision du législateur) et de la réaction (l'arrêt d'inconstitutionnalité) qui ont la même force (normative) et qui produisent des résultats identiques mais spéculaires (la publication officielle de la loi portant la disposition et, ensuite, de l'arrêt qui l'annule). Le problème est que le système juridique tel qu'il existe dans la pratique ne correspond pas forcément au modèle théorique. On dirait même qu'il s'en éloigne de manière considérable sous plusieurs points de vue et cet éloignement n'est pas sans conséquences sur l'appréciation de l'impact de l'interprétation conforme sur la sécurité juridique.

Une première question qui se pose est si la disposition législative (ainsi que son annulation) est un gage véritable de sécurité juridique. Les études sur les techniques de rédaction des actes normatifs et sur la pratique relative laissent peu de chances que la réponse puisse être affirmative sans réserves.

Il en va de même, à peu près, pour ce qui est des formes de publication. S'il est vrai que l'inconstitutionnalité est assistée par une forme de publication qui est en tout équivalente à celle de la disposition annulée, il n'est pas moins vrai cependant que la publication officielle est de moins en moins décisive pour assurer la connaissance du droit positif. Par conséquent, tout en n'étant pas assistés de formes de publicité spéciales, les arrêts portant interprétation conforme rendus par les juridictions ordinaires (ceux qui sont rendus par la Cour sont tous publiés sur le Journal officiel) ne se voient pas nécessairement diminués dans leur visibilité, notamment grâce à la diffusion du réseau Internet et aux banques de données juridiques mises à jour quasiment en temps réel.

La référence aux banques de données pourrait se prêter à la critique suivante : s'agissant d'un instrument dont disposent les juristes seuls, les banques de données ne seraient pas en réalité un élément pour assurer la sécurité juridique, mais seraient plutôt la preuve de l'atteinte portée au principe. En d'autres termes, si les juristes ont besoin des banques de données, cela implique que les particuliers non-juristes, en n'ayant pas d'accès à celles-ci, ne sont pas en mesure de connaître les dispositions et les normes qui régissent leurs rapports juridiques. L'argument est incontestable en soi, mais, d'un point de vue concret, il n'a que guère d'impact sur le sujet qui nous occupe, car il 
part d'une hypothèse dont le bien-fondé est pour le moins discutable. L'idée selon laquelle les particuliers orientent leurs conduites et leurs rapports juridiques sur la base de la lecture et de leur compréhension des textes normatifs correspondait très bien aux idéaux des Lumières et pouvait encore être retenue en 1838, c'est-à-dire lorsque Stendhal écrivait La Chartreuse de Parme, pour le style de laquelle la lecture du Code civil aurait eu semble-t-il un certain impact ${ }^{113}$. Aujourd'hui, toutefois, on a du mal ne serait-ce qu'à imaginer un non-juriste qui arrive à s'orienter dans le droit positif et à saisir la portée des dispositions qui le concernent : le droit - que cela plaise ou pas - est désormais, et sans ambiguïé, l'affaire de spécialistes, et même dans la mise en œuvre de la sécurité juridique on ne peut négliger ce caractère, sous peine de s'attacher à une utopie qui a vécu et de chercher à protéger ce qui ne peut plus l'être car il n'existe plus.

L'évolution du système vers des formes moins rigidement encadrées par la formulation des textes normatifs implique, par conséquent, une mutation des moyens visant à conforter les exigences liées à la sécurité juridique. C'est justement dans ce cadre que la critique dérivant de l'absence de précédents obligatoires devient centrale : le développement de l'interprétation (conforme) au détriment de l'annulation se traduit par l'augmentation des conflits entre la Constitution et les lois qui sont résolus par des jugements n'ayant pas d'effets obligatoires généraux. Le risque que les solutions élaborées ne soient pas uniformes ne saurait être méconnu, et alors les remèdes contre le refus de saisir la Cour pourraient très bien se qualifier de moyens pour protéger la sécurité juridique, à moins qu'on ne constate, à ce propos aussi, qu'il est peut-être temps de réexaminer les acquis de la tradition.

\section{b. L'effet paradoxal des remèdes affaiblissant la protection}

Le choix entre modèle diffus et modèle concentré de justice constitutionnelle est fréquemment motivé en faisant référence à la règle du précédent, car une thèse assez souvent avancée veut que le modèle diffus soit impossible s'il ne peut compter sur la règle du précédent obligatoire pour garantir une protection convenable du principe de la sécurité juridique.

Or, les correspondances entre pays de common law et modèle diffus, d'une part, et pays de droit romano-germanique et modèle concentré, de l'autre, connaissent bien des exceptions, non seulement pour ce qui est du premier binôme, mais aussi - bien que les cas soient plus limités - pour le second. Même sans compter les systèmes mixtes, tels que le système grec ou portugais, les systèmes argentin, danois, suédois et norvégien sont, à ce propos, des exemples révélateurs.

Ces exceptions pourraient, en soi, ne pas infirmer la règle générale. C'est, néanmoins, la règle même qui paraît susceptible d'une remise en cause, car l'opposition traditionnelle entre systèmes de common law et systèmes de droit romano-germanique, au fil des dernières décennies, n'est plus aussi forte qu'elle était aux temps de René David ${ }^{114}$. En effet, on a pu constater un rapprochement considérable des deux expériences, jusqu'à ce que la séparation rigide entre les deux familles cède parfois

113 C'est Stendhal même qui s'exprime de la sorte, dans une lettre à Honoré de Balzac du 30 octobre 1840 : « En composant la Chartreuse, pour prendre le ton, je lisais chaque matin deux ou trois pages du code civil, afin d'être toujours naturel ».

114 La référence est, évidemment, à sa classification des systèmes juridiques, fortement influencée par l'opposition entre droit romanogermanique et common law: cf. R. DAVID, Les grands systèmes de droit contemporains, Paris, Dalloz, 1964. 
le pas à la recherche des éléments communs, à l'aune de l'appartenance à une tradition juridique commune, la «tradition occidentale ${ }^{115}$. Parmi ces éléments figure sans doute le « droit jurisprudentiel ${ }^{116}$, qui, au Xxi ${ }^{e}$ siècle, n'est pas forcément à définir sur la base de l'alternative rigide entre précédents obligatoires et absence de contraintes dérivant de jugements antérieurs. En effet, dans maints pays de l'Europe continentale, et notamment en Italie, la jurisprudence a connu des changements majeurs, pour ne pas dire un véritable bouleversement par rapport au rôle traditionnel des juges conçus comme les « bouche[s] de la loi ${ }^{117}$.

Pour l'essentiel, les changements ont fait suite, du côté plus théorique, à une révision de la notion même de « loi » et, du côté plus pratique, à une reconsidération profonde de la portée des jugements en tant qu'actes susceptibles d'avoir une portée générale.

En ce qui concerne le premier plan, la faiblesse des juridictions et en particulier du droit jurisprudentiel dans la période suivant la Révolution française dérivait, en bonne mesure, de l'idée que la loi, expression de la volonté générale, était l'acte par lequel le souverain faisait pénétrer la Raison au sein de l'ordre juridique, créant ainsi les conditions pour que le droit positif coïncide le plus possible avec la Justice. Le principe de légalité était, donc, en même temps, garantie du respect du principe démocratique et de la sagesse/justice de la réglementation adoptée. La place résultant pour l'activité des juridictions était donc très limitée, car elles ne pouvaient pas déborder de l'œuvre de pure répétition et concrétisation des énoncés législatifs.

L'évolution de la société et des institutions a imposé une révision des idées reçues, du fait que, d'une part, les dérives dictatoriales avaient très clairement démenti le caractère nécessairement démocratique et rationnel de la législation (d'où le besoin perçu d'adopter des constitutions rigides qui soient protégées par une instance juridictionnelle contre les dérives pseudo-démocratiques) et, de l'autre, la complexité sociale et la pluralité des exigences à considérer et à contrebalancer ont pu être de moins en moins efficacement encadrées par des actes de portée générale comme les lois. Le besoin de se référer aux cas concrets pour chercher à dégager une solution qui soit la plus juste possible dans l'espèce a conduit à une nouvelle considération du rôle des juges, seuls acteurs institutionnels capables de prendre en compte l'ensemble des éléments caractérisant chaque cas ${ }^{118}$.

Sur le plan pratique, le principe selon lequel dans les pays de droit romano-germanique le précédent n'a pas d'effets obligatoires, tout en n'étant pas contesté du point de vue théorique, a subi une érosion considérable, au point que les effets des jugements rendus par des juridictions

115 Sur cette notion, voir H.J. Berman, Law and Revolution: The Formation of the Western Legal Tradition, Cambridge, Massachusetts, Harvard Law Review Association, 1983, et plus récemment H.J. Berman, « The Western Legal Tradition in a Millennial Perspective: Past and Future », Louisiana Law Review, 2000 (60), p. 739 et suiv.

116 L'importance accrue de la jurisprudence dans le système italien est mise en évidence surtout par A. Pizzorusso, « Fonti del diritto »Disposizioni sulla legge in generale art. 1-9, in Commentario del Codice civile Scialoja-Branca, $2^{\mathrm{e}}$ éd., Bologne-Rome, Zanichelli-Il Foro italiano, 2011, p. 705 et suiv., qui parle explicitement du « droit jurisprudentiel » comme d'une source du droit, tantôt officielle tantôt informelle.

117 Sur le changement des missions des juges par rapport à la vision traditionnelle de leur rôle, voir M. BESsONE (sous la direction de), Diritto giurisprudenziale, Turin, Giappichelli, 1996.

118 L'exigence de rendre une décision qui se fonde sur les particularités du cas spécifique a été à l'origine de la théorie du « droit en douceur », qui appelle le législateur à ne donner pas de règles précises, mais des principes, en laissant ainsi aux juges le soin de les concrétiser et, par cela, de tenter de répondre aux exigences concrètes de Justice : cf. G. ZAGREBELSKY, Il diritto mite (1992), traduit en français par M. Leroy, Le droit en douceur, Paris, Economica, 2000. 
supérieures sont normalement respectés par les juridictions inférieures ${ }^{119}$. Le fonctionnement concret du système s'est donc remarquablement rapproché de la façon avec laquelle la règle du précédent vertical est mise en œuvre dans les systèmes de common law. Ce n'est pas une règle obligatoire qui a conduit à ce résultat, mais une sorte de principe de conservation des actes juridiques, qui fait que le juge a tendance à se conformer aux décisions des juges qui pourraient être saisis du recours contre sa décision : pour limiter au maximum le risque d'annulations ou même pour limiter les cas de recours, le juge se conforme à l'avance, tout en restant libre, le cas échéant, de ne pas se conformer et de chercher par là même à imposer une nouvelle règle jurisprudentielle.

La force « informellement obligatoire » du précédent ${ }^{120}$, qui grandit au fur et à mesure que le nombre de jugements conformes s'accroît et que le rang des juridictions concernées s'élève, s'est d'ailleurs manifestée de manière indiscutable par la reconnaissance de la doctrine du « droit vivant », une doctrine qui, si on devait la traduire à l'usage d'un juriste anglo-saxon, pourrait sans trop de réserves être définie comme une jurisprudence caractérisée par une grande autorité pour les juridictions subordonnées à la Cour suprême de cassation (à l'instar de l'effet vertical du précédent), qui s'est généralement (même si non nécessairement) renforcée par l'uniformité des arrêts rendus par la Cour de cassation elle-même (d'une forme qui pourrait évoquer l'effet horizontal du précédent).

Le rapprochement du droit jurisprudentiel des deux côtés de la Manche et de l'Atlantique n'est pas sans conséquences sur la question de la sécurité juridique. Si dans les pays de common law la règle du précédent s'est imposée justement pour garantir la sécurité juridique, eu égard aussi à ce que l'on a pu constater auparavant à propos de l'évaporation de la garantie sécuritaire liée au droit législatif ${ }^{121}$, les arguments se renforcent en faveur de la thèse selon laquelle la montée en puissance de la jurisprudence, et notamment de celle issue des juridictions suprêmes, serait un facteur déterminant pour assurer la sécurité juridique même dans les pays de droit romano-germanique.

En adoptant une telle approche, la question initiale, relative à la nécessité ou à l'opportunité de remèdes contre le refus de soulever une question de constitutionnalité, se pose de manière tout à fait nouvelle. Dans cette perspective, les « remèdes » deviennent un moyen pour les juridictions, et en particulier pour les juridictions subordonnées, de se libérer de l'obligation informelle de se conformer à la juridiction supérieure, en faisant appel à la Cour constitutionnelle. La prévision du remède est donc une atteinte à la « sécurité jurisprudentielle » qui devrait être compensée par les bénéfices consistant, d'un côté, dans le renforcement de la sécurité juridique assurée par l'annulation éventuelle et, de l'autre, dans la plus grande efficacité du contrôle de constitutionnalité opéré par la juridiction spéciale. L'emploi du verbe au conditionnel est motivé par ce que nous avons cherché à prouver précédemment, c'est-à-dire que tant le premier que le second des bénéfices évoqués ne sont tels en réalité. Mais alors, l'atteinte

119 Au soutien de ces remarques, cf. D.N. MACCoRmick - R.S. Summers (sous la direction de), Interpreting Precedents: A Comparative Study, Farnham, U.K., Ashgate Dartmouth, 1997 ; l'ouvrage présente les résultats d'une recherche de droit comparé qui a touché un grand nombre de pays (y compris l'Italie : cf. M. TARUfFo - M. LA TORRE, « Precedent in Italy », ibidem, p. 141 et suiv.).

120 Pour l'analyse du débat concernant la possibilité de qualifier, en Italie, le précédent jurisprudentiel de source du droit, voir, récemment, M. Nisticò, op. cit., p. 223 et suiv., ainsi que les références bibliographiques qu'il indique.

121 Voir supra, II, B.2.a 
à la « sécurité jurisprudentielle » n'aurait pas de contreparties si ce n'est celle de se conformer au choix qui a été fait en faveur d'un contrôle concentré. Un choix qui ne paraît pas indiscutable à jamais.

\section{Conclusion}

L'analyse des remèdes contre le refus de soulever une question préjudicielle de constitutionnalité dévoile une perspective assez intéressante pour une recherche sur l'évolution du contrôle incident des lois dans le système italien.

Les résultats auxquels nous sommes arrivés, en effet, montrent assez clairement - semble-t-il que la voie d'accès à la juridiction constitutionnelle originellement conçue comme « ordinaire »a perdu une partie significative de son importance. Cela n'est pas la conséquence du seul renforcement des voies d'accès directe (tels que le recours abstrait), très fréquemment évoqué pour décrire la phase actuelle de la justice constitutionnelle. D'autres raisons sont peut-être encore plus importantes (du moins du point de vue propre à la recherche qui s'achève), car elles tiennent à la nature même du contrôle incident et aux rapports entre la Cour constitutionnelle et les juges ordinaires.

L'idée que le caractère essentiel du système italien a été la position occupée par le contrôle incident ne saurait être sérieusement contestable. Il n'en va pas de même si l'on tire de cet argument des conclusions pour l'avenir, du moment qu'il ne paraît pas impossible de définir le contrôle incident comme un moyen introduit pour répondre à des exigences qui étaient fortes hier et qui ne sont probablement pas négligeables aujourd'hui, mais qui pourraient ne plus l'être demain. Nous serions même séduits par l'idée que le contrôle incident soit une sorte d'action positive, visant à protéger et renforcer un sujet qui était faible à son origine, tellement faible qu'on craignait qu'il ne puisse être suffisamment protégé par les voies ordinaires. Au fur et à mesure que ce sujet s'est renforcé et se renforce, la nécessité d'un régime de protection particulière est de moins en moins forte.

Si le sujet dont nous parlions est la Constitution, et si son renforcement est dû à son ancrage dans le système, il n'est donc peut-être pas trop aventureux de conclure que l'importance du contrôle incident, qui était l'élément fondamental du système à l'origine, tend à se réduire parallèlement à la croissance de la culture et de la sensibilité constitutionnelle des juges ordinaires, qui peuvent désormais très souvent faire primer la Constitution sans avoir besoin de faire appel à la Cour.

Il y a peut-être de quoi avancer l'idée qu'il existe une sorte de proportionnalité inverse entre l'importance du contrôle incident dans le système de justice constitutionnelle et l'ancrage de la Constitution au sein de l'ordre juridique. Si un tel rapport existait effectivement, nous devrions tout simplement nous réjouir de la « crise » actuelle du contrôle incident.

Il s'agit là sans doute d'une lecture optimiste de l'évolution du système italien, mais cet optimisme ne paraît pas nécessairement panglossien. 


\title{
DÉBATS
}

\author{
sous la présidence de Madame Nicole BeLloubet
}

Laurence Gay souhaite revenir sur l'idée selon laquelle, au nom de la sécurité juridique, le juge de cassation éviterait le renvoi de QPC au Conseil constitutionnel lorsque cela est possible. Toutefois, la sécurité juridique doit-elle être maintenue au prix d'une violation potentielle de la Constitution ? Est-ce que la sécurité juridique doit bénéficier d'une protection supérieure par rapport aux autres normes constitutionnelles ? Pour sa part, elle ne le pense pas.

Monsieur Ludet répond à Laurence Gay en précisant qu'il n'a pas évoqué la sécurité juridique comme une problématique conduisant à retenir les renvois au Conseil constitutionnel. Pour le moment, les hypothèses dans lesquelles la Cour de cassation s'est chargée elle-même de résoudre les problèmes, en faisant évoluer sa propre jurisprudence, ne sont pas très nombreuses. On peut considérer qu'il s'agit d'hypothèses où il n'y a aucun doute, pour la Cour de cassation, sur le fait que la jurisprudence actuelle n'est pas en conformité avec la Constitution. Il y a plein d'autres hypothèses où un doute existera, ce qui justifiera le renvoi.

Paolo Passaglia propose ici de faire confiance aux juges ordinaires. Lorsqu'il y a un doute sur la constitutionnalité d'une interprétation, au lieu de procéder à un renvoi devant la Cour constitutionnelle, on peut chercher à faire changer l'interprétation de la Cour de cassation ou du Conseil d'État. L'idée est que ces juges sont tout à fait en mesure de vérifier la cohérence entre le droit législatif et la Constitution. Si les Cours suprêmes considèrent qu'il y a une incohérence, cela les conduira au renvoi devant la Cour constitutionnelle. En revanche, s'il n'y a pas d'incohérence, il ne sera pas nécessaire de réaliser un renvoi, mais plutôt, de la part du juge de première instance ou d'appel, de proposer une lecture différente de la disposition et de demander au Conseil d'État ou à la Cour de cassation qu'ils changent leur jurisprudence.

Mathieu Disant remarque que, finalement, les échanges révèlent une chose importante pour l'analyse du sujet du colloque : la QPC n'a pas été pensée, à l'origine, pour contrôler la jurisprudence. Les questions d'interprétation n'étaient pas méconnues évidemment, mais elle a d'abord été pensée pour et à travers la loi, sorte de survivance d'un légicentrisme méthodologique. Cela ne signifie pas qu'elle ne peut avoir la jurisprudence pour objet, mais que le fonctionnement de la procédure construite pour se saisir d'une source politique (la loi) peut naturellement se trouver malhabile à l'égard d'une source technique (la jurisprudence). 
En ce qui concerne la question de savoir si l'auteur de la jurisprudence peut en être le contrôleur habituel, pour lui, cette question ne se pose pas en termes d'impartialité. Le Conseil d'État et la Cour de cassation ont d'ailleurs tranché cette question (Jurisprudence Dion) et la CEDH l'a également confirmé, en août 2015. Ceci étant dit, puisqu'a été évoqué le retour au texte, le texte prévoit la transmission de la QPC en cas de question sérieuse. Précisément, le recours à l'interprétation conforme et plus encore, l'hypothèse du revirement de jurisprudence, c'est la reconnaissance manifeste d'une difficulté sérieuse sur l'état du droit, à tel point qu'il faut en passer par une interprétation conforme ou un revirement de jurisprudence pour le modifier. En termes de logique, c'est un aveu du caractère sérieux, la démonstration de l'existence d'une difficulté par la simple observation qu'il s'agit de prétendre la vider.

Il convient aussi de prendre garde aux différences techniques, notamment celle liée à l'autorité de l'interprétation conforme : lorsque le Conseil constitutionnel émet une réserve d'interprétation, celle-ci bénéficie de l'article 62 al. 3 de la Constitution qui confère une autorité de droit aux décisions du Conseil constitutionnel et qui permet de se préserver d'un contournement de ces interprétations par le législateur. L'interprétation conforme par les juridictions suprêmes ne bénéficie pas de cet article, et plus encore la décision de non-renvoi qui la contient n'a aucune autorité de chose jugée. On ne peut donc considérer comme équivalente l'usage de la technique, comme cela est trop souvent affirmé.

Au demeurant, concernant les revirements de la Cour de cassation, les pratiques ne sont pas totalement harmonisées. Apparemment, la $1^{\mathrm{re}}$ chambre civile ne pratique pas le revirement et préfère renvoyer au Conseil constitutionnel. Le bon sens n'est pas sans ressource : procéder à un revirement de jurisprudence par crainte d'une censure, alors que l'on n'est pas sûr à $100 \%$ de la solution qui sera rendue par le Conseil constitutionnel, n'est pas forcément le plus opportun.

Nicole Belloubet estime que lorsque le filtre a été mis en place, un point d'équilibre a été trouvé par le biais d'un système qui permet au Conseil constitutionnel d'affirmer, avec la force de l'article 62 de la Constitution, l'ascendant de ses décisions sans écarter pour autant les cours suprêmes du traitement des questions de constitutionnalité. La logique proposée par Mathieu Disant, à laquelle elle adhère, est implacable. D'un certain point de vue, Madame Belloubet n'est pas choquée par le fait que les cours suprêmes modifient leur jurisprudence pour éviter de transmettre une QPC au Conseil constitutionnel, car d'une part, la rapidité de traitement peut rendre service au justiciable et, d'autre part, cela permet à la juridiction de renvoi de modifier sa propre jurisprudence pour l'avenir. À condition, toutefois que, par ailleurs, les cours suprêmes jouent le jeu et transmettent réellement au Conseil constitutionnel les décisions sur lesquelles il y a un doute constitutionnel. Le système ne peut fonctionner que si chacun remplit pleinement et sincèrement son office. 
Chapitre 2

CoEXISTENCE ENTRE RECOURS DIRECT ET QUESTION PRÉJUDICIELLE 



\section{Présidence de Madame Nicole Belloubet, Membre du Conseil constitutionnel}

Madame Nicole Belloubet relève que la question ici posée est à la fois iconoclaste quelques années seulement après l'instauration de la QPC, plurielle tant les systèmes de recours que l'on peut qualifier de « directs » sont variables selon les États qui le pratiquent, et en même temps assez banale puisqu'elle est pratiquée par bien des systèmes juridiques.

Une telle évolution est-elle envisageable en France ? Et pour quoi faire?

L'articulation entre les contrôles est bien entendu essentielle, non pas en tant que guerre des pouvoirs entre les différentes juridictions mais comme clarification des différents systèmes procéduraux et vecteur d'efficacité des procédures. L'articulation des recours doit surtout être recherchée pour plus de clarté et de lisibilité au bénéfice du justiciable. Il ne s'agit pas ici seulement de rapports de force ou de pouvoirs entre juges mais à bien considérer la situation, il y aurait dans ces concours entre juges « qui protègent le mieux les droits fondamentaux » un effet cliquet positif pour la protection globale des droits.

Le recours direct au juge constitutionnel est nécessairement plus attractif pour les citoyens. Quel que soit le système mis en place, contrôle semi-concentré ou contrôle diffus, et quelles que soient les conditions d'encadrement de ce recours direct, il apparaît plus protecteur des droits fondamentaux et plus immédiatement disponible pour les justiciables. Toutefois l'introduction d'un tel recours imposerait un changement total de la nature du Conseil constitutionnel : changement des modalités de contrôle qui prendraient nécessairement une dimension plus concrète, modifications des délais qui seraient indiscutablement allongés, évolution de l'organisation du Conseil pour absorber l'afflux de tels recours.

Il importe dès lors de bien comprendre à quelle finalité répondrait l'introduction d'un tel système. S’il s'agit de prévoir un éventuel remède à une insuffisante saisine du Conseil constitutionnel par la technique du filtre, d'autres procédures pourraient être préalablement envisagées : élargissement des requérants aux autorités administratives indépendantes, au défenseur des droits, mise en place d'un système d'évocation etc...

L'ensemble de ces questions peut être éclairé par la lecture des systèmes étrangers dont la présentation va nous être proposée par Thomas Hochmann pour l'Allemagne et Itziar Gomez pour l'Espagne. 



\title{
LA JURIDICTION CONSTITUTIONNELLE EN ESPAGNE : UN SYSTÈME INTÉGRAL DE JUSTICE CONSTITUTIONNELLE?
}

\author{
Itziar Gómez FERNÁNDEZ ${ }^{1}$
}

\section{Quelques observations liminaires}

Le Tribunal constitutionnel, défini par sa loi régulatrice comme «l'interprète suprême de la constitution » [article 1 de la Loi organique 2/1979, portant sur le Tribunal constitutionnel $\left(\right.$ LOTC $\left.^{2}\right)$ ], constitue l'une des juridictions constitutionnelles ayant les compétences les plus larges dans le panorama du droit comparé européen ${ }^{3}$. Et cela autant du point de vue de l'objet du contrôle de constitutionnalité, que du point de vue des pouvoirs soumis au contrôle. La question à se poser, donc - dans le contexte de la réflexion commune aux travaux de cet ouvrage collectif -, est de savoir si cette juridiction étendue peut être, ou non, définie comme un système « intégral » de justice constitutionnelle. La réponse à cette question exige, toutefois, de déterminer ce que l'on conçoit par «système intégral ».

Dans une perspective exclusivement juridique, il est possible d'affirmer qu'une juridiction constitutionnelle « intégrale » est celle qui est susceptible de connaître de toute l'activité des pouvoirs publics, avec l'objectif principal d'assurer la constitutionnalité d'une telle activité et, corrélativement, la préservation des décisions politiques fondamentales adoptées par le pouvoir constituant, sans oublier la protection des droits de l'individu et des groupes (minoritaires ou pas) auxquels celui-ci s'intègre ${ }^{4}$. Cette définition s'avère très pertinente concernant l'objet de notre réflexion, car sa projection sur la description de l'ensemble du système espagnol de justice constitutionnelle permettra au lecteur comparatiste de décider si la conception normative du système en Espagne conduit à l'appréciation de « l'intégralité » du modèle.

\footnotetext{
Référendaire au Tribunal constitutionnel Espagnol, Maitre de Conférences en Droit Constitutionnel à l'Université Carlos III de Madrid.. Loi organique du 3 octobre 1979 modifiée conformément aux Lois organiques 8/1984, du 26 décembre 1984 ; 4/1985, du 7 juin 1985 ; 6/1988, du 9 juin $1988 ; 7 / 1999$, du 21 avril $1999 ; 1 / 2000$, du 7 janvier $2000 ; 6 / 2007$, du 24 mai 2007 ; 1/2010, du 19février 2010; 8/2010, du 4 novembre ; $12 / 2015$ du 22 septembre et $15 / 2015$ du 16 octobre.

3 Pierre Bon, «Présentation du Tribunal constitutionnel espagnol », Cahiers du Conseil constitutionnel, n² 2, 1997.

4 Francisco Rubio Llorente, “Tendencias actuales de la jurisdicción constitucional en Europa”, en F. Rubio Llorente y J. JimÉnez CAmpo, Estudios sobre jurisdicción constitucional, McGraw-Hill, Madrid, 1998, p. 155-173, p. 156.
} 
La question subséquente consiste à déterminer s'il existe des éléments de ce modèle qui pourraient être utiles dans un autre contexte, auquel la doctrine s'intéresse, celui de l'étendue du contrôle de constitutionnalité vers des sphères du pouvoir encore intouchables. Toutefois, à mon avis, la réponse à cette deuxième question, va au-delà de l'analyse normative ; il ne suffit pas de donner une réponse complète à une question complexe, si elle est n'est pas accompagnée de l'examen de l'efficacité réelle de l'archétype. De ce fait, la deuxième partie de ce travail, décrit la complexité du modèle de justice constitutionnelle espagnole prévue dans la Constitution et la LOTC. La troisième partie se concentre sur la mutation du système original prévu, et sur le rôle changeant du juge ordinaire dans cette transformation. Le paragraphe final, une fois accepté la qualification du système espagnol de justice constitutionnelle comme étant un « système intégral », pointe le principal problème d'une telle qualification quand l'extension des actes de pouvoir soumis à contrôle n'est pas suivie d'un renforcement de l'intérêt à agir pour avoir accès au Tribunal.

\section{Description sommaire du modèle de justice constitutionnelle espagnol}

Le Titre X de la Constitution Espagnole (CE) de 1978 (articles 159 à 165), ainsi que la LOTC, prévoient une juridiction constitutionnelle «concentrée » aux compétences particulièrement étendues. Les vastes attributions du Tribunal peuvent être structurées autour de trois axes, définis par le rôle que le juge constitutionnel joue dans le contexte du contrôle des pouvoirs qui lui est dévolu.

1. Le premier axe, par volume d'activité et de ressources - humaines et techniques - employés dans la tâche, est celui de la garantie des droits fondamentaux à travers le recours direct, dit encore recours en protection ou recours individuel d'amparo (RA).

L'objet de ce type de procès, prévue à l'art. $162 \mathrm{CE}$, est la protection du justiciable contre les violations des droits et libertés reconnus aux articles 14 à $29 \mathrm{CE}$, qui seraient provoquées par des dispositions, des actes juridiques, des omissions ou une simple voie de fait de la part des pouvoirs publics étatiques, des Communautés Autonomes et des autres entités publiques de caractère territorial, corporatif ou institutionnel, ainsi que de leurs fonctionnaires ou agents. L'article 53.2 CE détermine que « tout citoyen peut réclamer la protection des libertés et des droits reconnus à l'article 14 et à la section première du chapitre II devant les tribunaux ordinaires, selon une procédure prioritaire et abrégée et, le cas échéant, au moyen du recours en garantie des droits devant la Cour constitutionnelle. Ce dernier recours sera applicable à l'objection de conscience, reconnue à l'article 30 ».

En bref, l'amparo est le recours direct, ouvert aux particuliers devant le juge constitutionnel, contre des décisions administratives (art. 43 LOTC), juridictionnelles (art. 44 LOTC) ou parlementaires sans force de loi (art. 42 LOTC), afin de garantir leurs droits et libertés constitutionnels. Et, si on veut parler du contrôle des décisions de justice, le recours direct confère au juge constitutionnel un certain pouvoir de contrôle sur l'application ou la non-application d'une partie de la Constitution (art. 14 à $30 \S 2 \mathrm{CE}$ ) de la part des juges ordinaires. Ainsi, le rôle du TC, quand il affronte la résolution 
d'un RA, est celui d'être juge des juges (ordinaires), juge du pouvoir exécutif et juge de l'administration du pouvoir législatif. De ce fait, il est facile de déduire, si l'on connaît l'histoire constitutionnelle récente de l'Espagne, que cette procédure a été fondamentale, pendant deux décennies, pour créer une culture judiciaire des droits fondamentaux, à travers le contrôle de l'activité des juges et magistrats. La possibilité pour le Tribunal d'annuler des décisions judiciaires en cas de violation de certains droits fondamentaux ${ }^{5}$, aurait fait prendre conscience aux juges ordinaires de la nécessité d'intégrer la doctrine constitutionnelle sur les droits fondamentaux dans leurs propres décisions, face au risque que l'absence d'intégration ou de respect de la jurisprudence constitutionnelle puisse conduire à l'annulation de la décision judiciaire « rebelle».

Nonobstant, l'amparo ne peut être vu seulement comme un mécanisme de contrôle constitutionnel des décisions de justice, mais comme un mécanisme de coopération nécessaire. Il ne faut pas oublier que l'article 53 précité de la Constitution, confie aux juges et aux tribunaux la garantie principale des libertés et des droits fondamentaux. La saisine du Tribunal constitutionnel par le biais du RA répond à un principe absolu de subsidiarité. Il faut s'adresser d'abord à la juridiction ordinaire pour demander la protection des droits fondamentaux et, en cas d'échec, saisir le Tribunal constitutionnel. Donc, la connexion et la coordination entre « juridiction ordinaire » et juridiction constitutionnelle dans le domaine de la protection des droits individuels est prioritaire et fondamentale, même si le RA est perçu, parfois, comme un mécanisme de contrôle de l'activité judiciaire « ordinaire ». Effectivement, il s'agit bien d'un mécanisme de contrôle, mais c'est aussi un instrument de « pédagogie » constitutionnelle qui exige une certaine réceptivité de la part des juges ordinaires.

2. Le deuxième axe identifie le Tribunal constitutionnel comme l'arbitre des conflits entre pouvoirs. Ainsi, la Constitution demande, d'une façon directe, au Tribunal de régler les conflits de compétence entre l'État et les Communautés autonomes et les conflits de compétence entre ces diverses Communautés (art. $160 \S 1$ c) et art. $160 \$ 2 \mathrm{CE})^{6}$ et prévoit aussi que la loi organique puisse développer d'autres fonctions en faveur de la justice constitutionnelle [art. 160§1 d] CE]. Cette possibilité a conduit à élargir les facultés du Tribunal dans son rôle d'arbitre des conflits, et donc, à présent, la LOTC prévoit que l'assemblée plénière puisse connaître : des appels interjetés contre les normes fiscales (« normas forales fiscales ») des territoires de Álava, Guipúzcoa et Vizcaya (DA 5 ${ }^{\text {e }}$ LOTC $)^{7}$; des contestations prévues à l'alinéa 2 de l'article 161 de la Constitution [art. 10 §1 e] et

5 Les droits constitutionnels compris entre l'article 31 et l'article 52 ne profitent pas de la garantie judiciaire du « recours d'amparo ». L'exclusion concerne le droit au mariage (art. $32 \mathrm{CE}$ ), le droit à la propriété privée et à l'héritage (art. $33 \mathrm{CE}$ ), le droit de fondation (art. $34 \mathrm{CE}$ ), le droit au travail, au libre choix de profession ou de métier, à la promotion par le travail et à une rémunération suffisante (art. 35 §1 CE), le droit à la négociation collective et aux procédures de conflit collectif (art. $37 \mathrm{CE}$ ), le droit à la sécurité et à l'hygiène au travail, à la limitation de la journée de travail et aux congés payés périodiques (art. $40 \mathrm{CE}$ ), la liberté d'entreprise (art. $38 \mathrm{CE}$ ), le droit à la protection sociale, économique et juridique de la famille et des enfants (art. $39 \mathrm{CE}$ ), la garantie d'une Sécurité Sociale Publique (art. $41 \mathrm{CE}$ ), le droit à la protection de la santé (art. $43 \mathrm{CE}$ ), le droit d'accès à la culture (art. 44), le droit de jouir d'un environnement approprié (art. $45 \mathrm{CE}$ ), le droit à la conservation du patrimoine historique, culturel et artistique (art. $46 \mathrm{CE}$ ), le droit de disposer d'un logement digne et approprié (art. $47 \mathrm{CE}$ ), la protection de groupes vulnérables, notamment les jeunes, les handicapés et les personnes âgées (arts. 48, 49 et $50 \mathrm{CE}$ ), et les droits de consommateurs (art. 51 CE). Les conflits constitutionnels font l'objet des arts. 59 à 72 (Chapitres I et II, du Titre IV LOTC)

Disposition additionnelle cinquième, introduite par la Loi organique 1/2010, du 19 février 2010. 
76 LOTC ${ }^{8}$; des conflits en défense de l'autonomie locale [art. $10 \S 1 \mathrm{f}$ ] et 75 bis et suivantes LOTC]'; des conflits en défense de l'autonomie des territoires historiques de la Communauté Autonome du Pays Basque (DA $5^{\mathrm{e}}$ LOTC) ${ }^{10}$; des conflits entre organes constitutionnels de l'État qui opposent le Gouvernement au Congrès des Députés, au Sénat ou au Conseil Général du Pouvoir Judiciaire, ou ces organes constitutionnels entre eux (art. 10§1.g) et art. 73 à 75 LOTC).

3. Troisièmement, le Tribunal assume le contrôle du pouvoir législatif, par le contrôle de constitutionnalité des lois, des dispositions législatives ou des actes ayant force de loi (art. $161 \mathrm{CE}$, et art. 2 LOTC) et affirme, grâce aux procédures de déclaration d'inconstitutionnalité, la primauté de la Constitution sur la loi entendue au sens large (art. 27 LOTC) ${ }^{11}$. Ce contrôle est effectué à travers trois procédures différentes :

1) Le contrôle préalable de constitutionnalité (RPI). On parle d'un contrôle abstrait et antérieur à l'approbation de la norme, réservé à l'examen des traités internationaux (art. 95 CE et 78 LOTC), ainsi qu'au texte définitif du projet de Statut d'Autonomie ou la proposition de réforme d'un Statut, une fois approuvée par les « Cortes Generales » (art. 79 LOTC $\left.^{12}\right)$.

2) Le recours d'inconstitutionnalité (RI) $)^{13}$, qui est une procédure de contrôle abstrait sur des normes déjà promulguées - donc a posteriori -, au service de la minorité parlementaire (50 députés ou 50 sénateurs), des autorités législatives ou exécutives des Communautés Autonomes (Assemblées autonomiques ou organes collégiaux exécutifs autonomiques) ${ }^{14}$, du « Défenseur du Peuple », et du Président du Gouvernement de l'État (art. 162 CE).

\footnotetext{
8 L'alinéa 2 de l'art. $161 \mathrm{CE}$ prévoit que « 2. Le Gouvernement pourra attaquer devant le Tribunal constitutionnel les dispositions et les décisions adoptées par les organes des Communautés autonomes. Le recours entrainera la suspension de la disposition ou de la décision contre laquelle il est porté, mais le Tribunal devra, s'il y a lieu, le ratifier ou l'infirmer dans un délai maximum de cinq mois ». Ce conflit entre pouvoir étatique, et pouvoirs autonomiques ne tournera pas autour de la distribution de compétences entre eux, mais autour du respect des préceptes constitutionnels sans rapport direct avec le système de distribution de pouvoirs entre centre et périphérie. L'objet de ce type de conflit, aussi connus comme « conflits du Titre V », par rapport à sa régulation dans la LOTC, sont les dispositions normatives sans force de loi et les résolutions émanant de n'importe quel organe des Communautés Autonomes (art. 76 LOTC).

$9 \quad$ Cette faculté a été introduite dans le système, par la Loi organique 7/1999, du 21 avril 1999, dans le but de garantir l'autonomie des communes prévue par l'article 140 de la Constitution.

10 Disposition additionnelle cinquième, introduite par la Loi organique 1/2010, du 19 février 2010.

11 Les deux procédures de contrôle visent toute «norme ayant force de loi », expression concrétisée par l'art. 27 LOTC. Donc, on considère comme norme ayant force de loi : a) Les règlements des Chambres et des Cortes Générales (Chambre des Députés et Sénat réunies), ainsi que les règlements des assemblées législatives des Communautés Autonomes ; b) Les traités internationaux (arrêt 38/2007, du 15 février), ayant été ou non soumis au contrôle abstrait a priori (art. $95 \mathrm{CE}$ ) de constitutionnalité, si l'article objet concret du contrôle $a$ posteriori n'est pas coïncident ; c) Les statuts d'autonomie et les autres lois organiques, sachant que d'après l'art. $81 \mathrm{CE}$ les lois organiques sont celles qui, approuvées par le Parlement national, se réfèrent au développement des droits fondamentaux et des libertés publiques, celles qui approuvent le régime électoral général et toutes celles auxquelles la Constitution a reconnu un tel caractère; d) Les lois ordinaires, les décrets législatifs (acte normatif de l'exécutif ayant force de loi, par effet d'une délégation préalable du Parlement au Gouvernement faite en application de l'art. 82 CE) et les décrets lois [norme temporaire adoptée par le Gouvernement en cas d'extraordinaire et urgente nécessité qui doit être confirmée (ou pas) dans un délai de 30 jours après sa publication au J.O. (art. $86 \mathrm{CE})]$.

12 Le recours préalable contre les statuts d'autonomie a été réintroduit dans le système de justice constitutionnelle espagnol par la LO 12/2015, du 22 septembre, ayant été banni du modèle par la Loi 4/1985, du 7 juin, qui abroge le chapitre II du titreVI de la loi organique 2/1979, 3 octobre, réglementant le Tribunal constitutionnel.

13 L'article 161 CE prévoit que la Cour constitutionnelle, dans l'exercice de sa juridiction sur tout le territoire espagnol est compétente pour connaître « du recours en inconstitutionnalité contre les lois et les dispositions normatives ayant force de loi. La déclaration d'inconstitutionnalité d'une norme juridique ayant force de loi, interprétée par la jurisprudence, affectera celle-ci, mais la sentence ou les sentences rendues ne perdront pas l'autorité de la chose jugée ».

14 L'art. 32 § 2 LOTC précise que les organes collégiaux exécutifs et les assemblées des Communautés autonomes sont habilités, après un accord préalable établi à cet effet, à exercer le recours d'inconstitutionnalité contre les lois, dispositions ou actes ayant force de loi de l'État qui pourraient affecter leur propre sphère d'autonomie, donc il y a une circonstance particulière liée à la possibilité de saisir le Tribunal de la part des Communautés Autonomes.
} 
3) La question d'inconstitutionnalité (QI), contrôle a posteriori, liée à l'existence d'une procédure judiciaire dans laquelle il faut appliquer la loi objet du contrôle ${ }^{15}$. L'article 163 de la Constitution espagnole présente la question dans les termes suivants :

"Lorsqu'un organe judiciaire ${ }^{16}$ considérera, au cours d'un procès, qu'une norme ayant force de loi, s'appliquant en l'espèce et de la validité de laquelle dépend la solution du litige, pourrait être contraire à la Constitution, il saisira le Tribunal constitutionnel dans les conditions, sous la forme et avec les effets établis par la loi et qui ne seront en aucun cas suspensifs ».

Une partie de la doctrine parle de contrôle « concret », de par la connexion nécessaire entre l'application de la norme à la résolution d'un conflit juridique déterminé et la recevabilité de la QI qui procède de la norme ; et aussi par l'équivalence substantielle à l'institution établie par l'art. 100 de la Loi Fondamentale de Bonn ${ }^{17}$. L'arrêt du Tribunal constitutionnel 146/2012, du 5 juillet, récapitule la doctrine constitutionnelle à cet égard, pour expliquer pourquoi et comment la norme doit être applicable en l'espèce. L'individualisation de la norme applicable revient au juge a quo, tandis que le Tribunal constitutionnel - juge ad quem - accompli un contrôle simplement externe de l'activité du juge ordinaire (incohérence ou erreur dans le raisonnement ${ }^{18}$ ). En outre, la norme doit être nécessaire, du point de vue du juge a quo, pour la résolution de l'affaire (lien de causalité entre la validité du précepte juridique contesté et la décision à prendre dans le procès a quo). Ce jugement peut être révisé par le TC, dans l'analyse de recevabilité, ou dans l'arrêt définitif. Si le Tribunal estime que la norme n'est pas nécessaire, il décidera de rejeter la QI.

La qualification de ce contrôle en tant que contrôle concret fait, cependant, l'objet de certaines critiques, autant de la part de certains auteurs espagnols que français. Le Professeur Pierre Bon, par exemple, critique cette idée de l'assimilation de la QI au contrôle concret, en affirmant que

«Ce contrôle est, ici, dit concret seulement parce qu'il est exercé par la juridiction constitutionnelle à partir d'un litige concret posé au juge ordinaire et, de ce fait, il est opposé au contrôle dit abstrait qui est exercé sans que le point de départ en soit une affaire concrète. Mais le juge constitutionnel de la question d'inconstitutionnalité est en réalité confronté au seul problème objectif de la conformité de la norme attaquée à la Constitution, à l'instar de ce qui se passe au cas de recours d'inconstitutionnalité, et il ne prend à aucun moment en considération les circonstances concrètes du litige qui est à l'origine de la question sauf pour vérifier qu'elle est

15 Le Magistrat Pedro Cruz Villalón niait déjà en 1987 l'existence de deux contrôles spécifiques de constitutionnalité malgré la double voie procédurale car, à son avis, « le contrôle suppose un égal jugement dans les deux cas, avec les mêmes catégories, dans le même but et avec les mêmes conséquences » (Pedro CRUz Villalón, La formación del sistema europeo de control de constitucionalidad, CEPC, 1987, p. 46). Toutefois, dans la doctrine, il existe des opinions qui soutiennent que la double procédure conduit à l'existence de deux contrôles de constitutionnalité différents (Javier JIMÉnEZ CAMPO, "Consideraciones sobre el control de constitucionalidad de la ley en el derecho español”, AAVV, La jurisdicción constitucional en España. CEC, 1995, Madrid, p. 76).

16 Donc, la légitimité pour poser une question d'inconstitutionnalité est accordée par la Constitution à un juge ordinaire, un tribunal ou une cour, quelle que soit sa place dans la hiérarchie des instances juridictionnelles et la juridiction d'origine, civile, pénale, du travail, de contentieux administratif, commerciale, militaire ou même constitutionnelle, car on ne peut pas oublier que le Tribunal constitutionnel, lui-même, peut soulever la dénommée "question interne de constitutionnalité" (J. URÍAs MARTínEz, La cuestión interna de inconstitucionalidad. McGraw-Hill, Madrid, 1996), dans le cadre d'un recours d'amparo (art. 55 § 2 LOTC).

17 Voir Luis AguiAR DE LuQue, « Contrôle concret versus contrôle abstrait dans le modèle espagnol de justice constitutionnelle », Annuaire international de justice constitutionnelle, XXIX, 2013, p. 43-47, 2013.

18 Ordonnance 145/2012, du 16 juillet ; arrêt 151/2011, du 29 septembre, ou arrêt 200/2011, du 13 décembre. 
bien recevable. Dans ces conditions, l'appellation classique de contrôle concret est sans doute impropre et il a été soutenu, non sans pertinence, qu'il s'agissait d'un contrôle aussi abstrait que le contrôle du même nom ${ }^{19}{ }^{»}$.

Une dernière réflexion s'impose. La QI est aussi la procédure de contrôle la plus proche de la question prioritaire de constitutionnalité française (QPC), introduite par la révision du 23 juillet 2008 (article $61 \S 1$ de la Constitution française). La similitude, toutefois, n'est pas totale ${ }^{20}$.

- Ainsi, le modèle français confère un rôle de protagoniste aux citoyens dans la procédure a quo, devant le juge ordinaire, parce qu'il empêche celui-ci de soulever d'office la question. Par contre, le modèle espagnol place le juge au centre du système, étant donné que c'est à lui que revient la faculté de soulever la question, avec ou sans l'accord des parties qui doivent, toutefois, être écoutées dans le cadre de la procédure devant le juge a quo (art. 35 LOTC). Autrement dit, le fait de poser ou de ne pas poser la question est une prérogative exclusive du juge ${ }^{21}$, qui ne se trouve pas liée par la demande des parties au procès ordinaire. La QPC française peut être définie comme un droit-garantie du justiciable. La QI espagnole, ainsi que l'italienne, est un instrument objectif, une procédure de collaboration entre juge ordinaire et juge constitutionnel, mais n’a jamais été considérée comme un droit individuel.

- Le modèle français a pour finalité la protection des droits fondamentaux et des libertés de rang constitutionnel, et la surveillance de la loi que pourrait être contraire aux droits reconnus aux citoyens. De son côté, le modèle espagnol, vise à préserver la primauté de la Constitution sur les normes ayant force de loi (art. 163 CE). L'art. 39 LOTC dispose que « Le Tribunal constitutionnel pourra fonder la déclaration d'inconstitutionnalité sur la violation de n'importe quelle disposition constitutionnelle, qu'elle ait été invoquée ou non lors du procès ». Donc, la question d'inconstitutionnalité espagnole n'est pas limitée, comme la QPC française, à vérifier la compatibilité entre la loi, au sens large, et les droits et les libertés fondamentaux. Au contraire, le Tribunal constitutionnel se servira de la totalité de la Constitution, voire du bloc de constitutionnalité, comme paramètre du contrôle ${ }^{22}$.

\footnotetext{
19 Pierre Bon, « Présentation du Tribunal constitutionnel espagnol », Cahiers du Conseil constitutionnel n 2, 1997.

20 Laurence GAY, Pierre Bon et Thierry Di MANno, La QPC vue du droit comparé. Le contrôle de constitutionnalité sur renvoi du juge ordinaire en France, Espagne et Italie. Mission de recherche Droit et Justice, 2013.

21 Pierre Bon, «La question d'inconstitutionnalité en Espagne », Pouvoirs n 137 - La question prioritaire de constitutionnalité, avril, 2011, p. 123-141, en particulier p. 134.

22 Il faut préciser que le bloc de constitutionnalité en Espagne est intégré par les préceptes constitutionnels, et par les lois qui, dans le cadre constitutionnel, auraient été édictées pour délimiter les compétences de l'État et des différentes Communautés Autonomes ou pour réglementer ou harmoniser l'exercice des compétences de celles-ci (art. 28.1 LOTC). Cette définition du bloc de constitutionnalité, va réfuter le statut constitutionnel aux droits et libertés proclamés dans les textes internationaux, malgré la prévision de l'alinéa 2 de l'article 10 de la Constitution espagnole. Ainsi l'article 10 alinéa 2 CE établit le lien entre notre système de droits fondamentaux et les conventions et traités internationaux relatifs à ces mêmes droits ratifiés par l'Espagne, mais n'identifie pas les conventions internationales relatives aux droits de l'homme comme paramètre direct de contrôle de constitutionnalité.
} 
La fonction particulière de préservation des droits individuels, en Espagne, est tenue par le recours en protection (recours d'amparo). L'ancien président du Tribunal, M. Rodriguez Bereijo, pour autant, présente un regard différent sur l'ensemble du système, et sur la valeur de la QI en tant que recours d'amparo face à la loi (perspective que je ne partage pas) :

« De ce point de vue, l'expérience espagnole (autour de la question d'inconstitutionnalité) a été extraordinairement positive en contribuant, avec le recours d'amparo, à faire de la Constitution une norme vivante et proche de la réalité quotidienne des citoyens et un moyen de se protéger du pouvoir et de l'injustice. Elle a renforcé, sans aucun doute, le rôle du juge ordinaire en tant que juge de la Constitution, le liant à sa défense. Enfin, à travers la question d'inconstitutionnalité, les citoyens peuvent combattre l'inconstitutionnalité des lois qui affectent leurs droits constitutionnels au-delà du cadre strict des droits fondamentaux susceptibles d'être défendus par la voie du recours d'amparo, et cela malgré quelques obstacles d'ordre procédural : ils ne sont pas compétents pour comparaître devant le Tribunal constitutionnel [...], ils n'ont pas non plus, comme je l'ai noté auparavant, un droit à exiger du juge qu'il pose la question d'inconstitutionnalité, mais seulement la faculté de la suggérer. Je crois que l'amparo face à la loi est l'une des fonctions qu'accomplit, dans notre système, la question d'inconstitutionnalité ${ }^{23}$.

- Le modèle de QPC français établit un système de double filtre. Le Conseil d'État et la Cour de cassation ont l'exclusivité pour renvoyer la question au Conseil, et ils peuvent faire de leur capacité exclusive une vraie barrière d'accès du justiciable au Conseil. Cette possibilité donne la clé de la QPC aux hautes Cours, et détermine les rapports, de collaboration ou de "rivalité », entre celles-ci et le Conseil constitutionnel. En Espagne, la QI peut être soulevée par un juge ordinaire ou un tribunal quelconque, de la juridiction civile, commerciale, pénale, du travail, du contentieux administratif, ou militaire $^{24}$, ce qui renforce encore plus la caractéristique de collaboration entre juridictions attribuées au système. Dans le cadre du système espagnol, les chiffres contenus dans les Rapports annuels du Tribunal $^{25}$, montrent qu'un intérêt à agir plus large pour saisir le Tribunal, n'est pas une source additionnelle de surcharge de la juridiction constitutionnelle, parce que la surcharge vient du RA.

À mon avis, la QI est une voie de droit qui favorise les rapports entre juges ordinaires et juges constitutionnels, mieux qu'un type de recours individuel «pur », comme le recours en protection. Même des auteurs français ont reconnu qu'en Espagne, la QI favorise « des rapports relativement harmonieux entre le juge ordinaire et le juge constitutionnel en matière de garantie de la primauté constitutionnelle, des rapports en tout cas sensiblement plus harmonieux que ceux qui ont pu découler des recours d'amparo. Lorsque le Tribunal constitutionnel statue sur un recours d'amparo,

23 Alvaro Rodriguez Bereijo, «Entretien avec Alvaro Rodriguez Bereijo, Président du Tribunal constitutionnel espagnol », Cahiers du Conseil constitutionnel, ${ }^{\circ} 2$ (Dossier : Espagne), mai, 1997.

24 L'amplitude de ce pouvoir de saisine, est limitée par le fait que l'organe juridictionnel doit agir dans le cadre de ses attributions juridictionnelles, et jamais dans ses attributions administratives. Par exemple, le juge chargé du Registre de l'État Civil (ordonnances 505/2005, du 13 décembre, et 12/2008, du 16 janvier) en tant qu'institution administrative, ne peut pas saisir le Tribunal, comme ne le peuvent pas les arbitres (ordonnance 259/1993, du 20 juillet), ou le juge de paix.

25 Les rapports annuels du Tribunal sont disponibles en ligne à https://www.tribunalconstitucional.es/fr/memorias/Paginas/default.aspx (dernier accès le 9/1/2017) 
il est dans l'immense majorité des cas saisi d'un arrêt rendu par le juge ordinaire auquel il est reproché de ne pas avoir protégé les droits fondamentaux proclamés par la Constitution. Dès lors, s'il estime le recours fondé et accorde l'amparo, il annulera la décision du juge ordinaire qui n'a pas assuré cette protection. Le recours d'amparo place ainsi le juge ordinaire dans une nette position de subordination hiérarchique par rapport au Tribunal constitutionnel et il a pu s'en froisser ${ }^{26}$.»

- Dans le système français, la motivation pour soulever la QPC est faible, pour garantir que le juge constitutionnel ne se mue pas en Cour suprême dotée d'un pouvoir d'examen du litige au fond à l'origine du renvoi, et reste sur un contrôle fortement abstrait de constitutionnalité, malgré l'origine concrète du doute de constitutionnalité. Par contre, la motivation exigée de l'ordonnance de saisine de la QI est une motivation très exhaustive, condition qui vient renforcer le rôle du juge ordinaire dans la procédure. Ainsi, la question doit préciser la loi ou la norme ayant force de loi dont la constitutionnalité est en cause, le précepte constitutionnel qui est supposé être enfreint, et spécifier et justifier dans quelle mesure la décision sur le procès dépend de la validité de la norme en question (art. $35 \S 1 \mathrm{CE}$ ). L'ordonnance que soulève la question d'inconstitutionnalité, doit s'accompagner d'une attestation des jugements principaux rendus et des allégations des parties et du Ministère public (art. 36 LOTC).

On pourrait certainement y trouver certains éléments additionnels de distinction entre la QI et la QPC, mais ceux-là suffisent à expliquer qu'il n'est pas facile d'établir un parallélisme complet entre les deux questions et que, pour cette raison, il n'est pas facile de proposer des solutions d'évolution du modèle français de justice constitutionnelle depuis le modèle espagnol.

L'intégralité du système de justice constitutionnelle espagnol, au moins dans le domaine théorique, suppose la concurrence des logiques de toutes les procédures et tous les mécanismes de garantie de la suprématie constitutionnelle. Le transfert partiel des processus d'un système à l'autre, ou des éléments procéduraux spécifiques, ne garantit pas, à mon avis, la transmission de ce caractère d'intégralité du modèle que l'on souhaite obtenir, si la logique inspiratrice de chacun des processus dans le système de réception, n’est pas convergente.

En outre, il existe un autre facteur déterminant lors de l'évaluation de la complexité des modèles et leur intégralité, dérivée de l'évolution et de la pratique des procédures de contrôle de constitutionnalité ou de contrôle constitutionnel des pouvoirs publics, et qu'on pourrait appeler « le système intégral en contexte ».

26 Pierre Bon, « La question d'inconstitutionnalité en Espagne », Pouvoirs n 137 - La question prioritaire de constitutionnalité, avril, 2011, p. 123-141 (ici, p. 126) 


\section{Le rôle du juge ordinaire dans un système intégral de justice constitutionnelle « en contexte " : sujet ou objet du contrôle}

Comme on a pu l'apercevoir, ce modèle large de garantie de la suprématie constitutionnelle prévoit le contrôle de la totalité des actes des pouvoirs publics.

Par le biais du contrôle de constitutionnalité (RI, QI, RPI) sont contrôlés les actes du pouvoir législatif (des différents pouvoirs législatifs si on veut être précis) ayant force de loi. À travers les conflits d'attributions ou de compétences, il est possible d'examiner l'activité normative infralégale, ainsi que l'activité exécutive des administrations publiques (nationale, autonomique et municipale). Et le RA permet l'examen de la constitutionnalité des actes sans force de loi du pouvoir législatif (art. 42 LOTC), des actes judiciaires (art. 44 LOTC) et des actes du pouvoir exécutif (art. 43 LOTC). Nous pouvons même parler de contrôle constitutionnel de l'activité des individus par le biais du recours en protection contre des actes du pouvoir judiciaire, qui ne garantissent pas le respect des droits fondamentaux de la part des particuliers, si l'on accepte l'application par notre Tribunal de la théorie de la « drittwirkung $»^{27}$.

Le champ d'application de ce contrôle, c'est-à-dire le paramètre de contrôle, n'est pas toujours identique, étant plus large en ce qui concerne le contrôle de la loi et plus restrictif en matière de contrôle des actes administratifs et des décisions des juges. Ainsi, le contrôle de l'activité judiciaire à travers l'instrument privilégié du RA reste limité à la vérification du respect de la part des juges des droits et libertés reconnus aux articles 14 à 29 et de l'objection de conscience de l'article $30 \S 2 \mathrm{CE}$.

Donc, si on reprend l'idée initiale, et que l'on reconnaît qu'un « système de justice constitutionnelle intégral » est celui qui est susceptible de connaître de toute l'activité des pouvoirs publics dans le but d'assurer la constitutionnalité d'une telle activité, on peut conclure que le système espagnol de justice constitutionnelle représente un modèle intégral. Au moins en ce qui concerne la stricte prévision normative. Mais cette conclusion ne suffit pas. Il est nécessaire de s'arrêter sur certains détails déterminants du contexte dans lequel opère la justice constitutionnelle, et il est autant nécessaire de situer le rôle des juges ordinaires dans le système pour mieux comprendre sa complexité et sa portée.

\section{A. Contrôle de constitutionnalité, contrôle de légalité : le juge ordinaire comme juge constitutionnel}

Bien que nous ayons défini le système espagnol de justice constitutionnelle comme un « modèle concentré », en fait, la justice constitutionnelle en Espagne « est fonctionnellement intégrée par le Tribunal constitutionnel et d'autres tribunaux faisant partie de la juridiction ordinaire et la juridiction militaire $»^{28}$. Si l'on parle de « concentration » de la juridiction constitutionnelle, c'est parce que

27 Rafael Sarazá Jimena, La protección jurisdiccional de los derechos fundamentales en las relaciones entre particulares, Valencia, Tirant lo Blanch, 2011

28 Pablo Pérez Tremps, Sistema de justicia constitucional, Cizur Menor (Navarra), Civitas, 2016, p. 23. 
le Tribunal possède « le monopole de rejet des normes ayant force de loi ${ }^{29}$, car il s'agit de la seule autorité capable de déclarer l'inconstitutionnalité des lois, et de les exclure de l'ordonnancement juridique [voir arrêts du TC (ATC) 17/1981, du 1er juin, 73/2000, du 14 mars, 58/2004, du 19 avril, et 177/2013, du 21 octobre].

Par contre, il faut noter que l'on ne parle pas de l'interprète « unique » de la Constitution, étant donné que la Constitution est une norme obligatoire et applicable directement par les juges et les tribunaux (art. $9 \S 1 \mathrm{CE}$ ), lesquels, au moment de l'application de la loi, doivent aussi interpréter correctement le texte constitutionnel, conformément à l'article 5 de la Loi organique espagnole régulant le Pouvoir Judiciaire (LOPJ) ${ }^{30}$. Subséquemment, on doit partir de la présomption que les juges et magistrats ordinaires ont la capacité et l'obligation d'appliquer la Constitution ${ }^{31}$, mais ont l'incapacité « relative »- on verra pourquoi - de déplacer les lois contraires à la Constitution. On parlerait donc de contrôle de constitutionnalité en référence à l'activité dépurative et interprétative du Tribunal constitutionnel, et de contrôle de légalité pour décrire l'activité des juges ordinaires en tant qu'interprètes de la Constitution, compte tenu du rôle protagoniste du TC dans l'interprétation constitutionnelle et de la projection notable de ce rôle dans le système judiciaire, et dans l'activité herméneutique du juge « ordinaire ». Selon l'opinion de $\mathrm{M}^{\mathrm{me}}$ Casas Baamonde, ancienne Présidente du Tribunal constitutionnel :

"Cette séparation traditionnelle entre "constitutionnalité" et "simple légalité" a été nuancée par la jurisprudence constitutionnelle, concrètement dans la décision du Tribunal constitutionnel 50/1980 du 5 avril 1980, qui établit : "La distinction entre la juridiction constitutionnelle et la juridiction ordinaire ne saurait être établie, comme c'est parfois le cas, en associant la première sur le plan de la constitutionnalité" et la seconde sur celui de la "simple légalité", car l'unité de l'ordonnancement et la suprématie de la Constitution ne sauraient tolérer que ces deux plans soient considérés comme des univers distincts et sans possibilité d'interaction. En effet, la juridiction ordinaire ne peut pas, dans son interprétation et application de la loi, bouder l'existence de la Constitution. La juridiction constitutionnelle quant à elle ne peut pas faire abstraction de l'analyse critique de l'application que la juridiction ordinaire fait de la loi, alors qu'une telle analyse est nécessaire pour déterminer si l'un des droits fondamentaux ou libertés publiques dont la sauvegarde lui est confiée a été violé32 ».

Partir de cette opinion conduit à comprendre que la définition de l'intégralité du système de justice constitutionnelle passe aussi par trouver une place, dans cette définition, à l'activité de la

\footnotetext{
29 Pablo Pérez Tremps, Ibidem, p. 22.

30 Loi organique 6/1985, du 1 juillet. La LOPJ a statué en ces termes : « La Constitution est la norme suprême de l'ordonnancement juridique, laquelle est contraignante pour tous les juges et tribunaux, qui devront interpréter et appliquer les lois et règlements suivant les préceptes et principes constitutionnels, conformément à l'interprétation de ces derniers résultant des décisions rendues par le Tribunal constitutionnel dans tous types d'instances ».

31 Guillermo JimÉnez SÁnchez, "El recurso de amparo ante las funciones específicas del Tribunal Constitucional y las propias de los jueces y tribunales integrantes del Poder Judicial. El control de la constitucionalidad y el enjuiciamiento de las cuestiones de legalidad ordinaria" en La Constitución española de 1978 en su XXV aniversario, Barcelona, Bosch, 2003, p. 241-244.

32 Maria Emilia CASAs BAAmonde, « Le contrôle de constitutionnalité, l'expérience espagnole », Cahiers du Conseil constitutionnel, horssérie, Colloque du Cinquantenaire, 3 novembre, 2009.
} 
juridiction ordinaire en tant que juges de la Constitution, tenant compte, en même temps, des limites associées à cette fonction. Ainsi, les membres des juridictions ordinaires ne peuvent que déposer des jugements positifs sur la constitutionnalité des actes ayant force de loi, mais ils peuvent faire des jugements de constitutionnalité positifs ou négatifs sur les règlements, décrets, actes du pouvoir exécutif ou même sur les actions des individus ${ }^{33}$. Cette possibilité se « matérialise » à travers des mécanismes divers et variés d'amparo ordinaire prévues à l'article $53 \S 2 \mathrm{CE}^{34}$, comme à travers toute autre procédure ordinaire dans laquelle le justiciable invoque un précepte constitutionnel.

Ceci dit, on ne peut pas négliger la capacité des juges ordinaires à faire un contrôle de constitutionnalité, dans le sens strict de l'expression, même si cette capacité reste particulièrement restreinte à trois hypothèses :

1. Les juges ordinaires ont la faculté de ne pas appliquer les lois antérieures à l'entrée en vigueur de la Constitution, s'ils considèrent qu'elles ont été abrogées par celle-là, en application de la disposition dérogatoire de la Constitution (arrêt 4/1981, du 2 février, 17/1981, du $1^{\text {er }}$ juin, 73/2000, du 14 mars). Si le Tribunal était saisi pour contrôler la constitutionnalité d'une loi préconstitutionnelle, son analyse se ferait en termes de hiérarchie et donc de validité des normes. Pourtant, les juges ordinaires, dans les mêmes circonstances, vont raisonner en termes de succession des normes dans le temps, c'est-àdire, d'applicabilité des normes ${ }^{35}$.

2. Est réservé au juge ordinaire le contrôle de «l'ultra vires » des décrets législatifs, dans le cadre d'une délégation législative des articles 82 et suivants de la Constitution ${ }^{36}$. Par conséquent, il peut être accordé au juge ordinaire la capacité de contrôle du pouvoir exécutif à l'égard du respect des conditions légales d'attribution de la fonction législative, contenues dans une loi basique de délégation (ordonnance 69/1983, du 17 février). L'art. 27 § 2 b) LOTC prend soin de préciser, avec l'interprétation coïncidente du Tribunal (ATC 51/1982, du 19 juillet), que les tribunaux ordinaires ont la compétence pour sanctionner les décrets législatifs qui excéderaient les termes de l'habilitation votée par le Parlement ; malgré ceci, le Tribunal ne refuse pas ce contrôle, même s'il n'empêche pas les juges ordinaires de l'assumer.

3. L'article 149 § $3 \mathrm{CE}$ contient une « clause de prévalence (cláusula de prevalencia)» en faveur du droit étatique. De manière littérale, le précepte veut que «la compétence dans les matières qui ne figurent pas dans les statuts d'autonomie incombera à l'État, dont les normes prévaudront, en cas de conflit, sur celles des Communautés autonomes dans tous les domaines qui ne sont pas attribués à leur compétence exclusive ». La jurisprudence constitutionnelle récente (arrêts 102/2016, du

\footnotetext{
33 Rafael SarazÁ Jimena, "Recurso de amparo y recurso de casación civil. Tribunal Constitucional, jueces ordinarios y derecho privado", fueces para la Democracia, núm. 76, marzo, 2013, p. 22 ; et Miguel Angel Aparicio PÉrez, "La aplicación de la Constitución por los jueces y la determinación del objeto del amparo constitucional", Revista del Centro de Estudios Constitucionales, 1989, nº. 3, p. 47-86, 49.

34 Manuel Carrasco Durán, “Amparo judicial: presente y futuro”, Revista de Derecho Político, n. 68, 2007, p. 145-182

35 Miguel Angel Aparicio Pérez, "La aplicación de la Constitución por los jueces y la determinación del objeto del amparo constitucional",

Revista del Centro de Estudios Constitucionales, $\mathrm{n}^{\circ} .3$, 1989, p. 47-86. Ici, p. 56.

36 Miguel Angel Aparicio PÉrez, Ibídem, p. 67.
} 
25 mai, 127/2016, du 7 juillet, 116/2016, du 20 juin, et 204/2016, du $1^{\text {er }}$ décembre) a donné une portée procédurale à cette clause en attribuant aux juges ordinaires la faculté de décliner l'application d'une norme autonomique en faveur d'une norme étatique, dans le cadre de la clause de prévalence du droit de l'État. Cette doctrine s'éloigne, et cela est reconnu dans l'arrêt 102/2016, de l'idée classique que les tribunaux ne peuvent pas contrôler les règles post-constitutionnelles ayant force de loi, étant donné que la constituante voulait empêcher au juge ordinaire d'avoir la possibilité de nier l'applicabilité d'une loi devant un doute d'inconstitutionnalité. Donc, un juge ordinaire confronté à un conflit entre norme étatique et norme autonomique peut, lui-même, sans soulever une QI, choisir l'application de la loi de l'État s'il se trouve face à une hypothèse de législation partagée, dans laquelle la législation régionale se limite à reproduire une loi basique de l'État, ensuite modifiée dans un sens incompatible avec la législation autonomique préalable.

Le TC attribue au juge ordinaire, par ce biais, une faculté auparavant exclue, sachant que la loi autonomique ne devient pas invalide depuis la modification de la loi étatique basique, mais juste inapplicable, et donc que les modifications successives de la régulation étatique ne portent ni sur l'abrogation de la régulation autonomique, ni sur son invalidité pour inconstitutionnalité indirecte (« inconstitucionalidad mediata ») pour violation d'une norme interposée. En synthèse, le conflit entre une loi autonomique antérieure et la subséquente modification de la loi basique de l'État trouvera une solution en vertu du principe de la prévalence du droit de l'État, et conduira au délaissement de la loi régionale par le juge ordinaire, qui ne sera pas obligé de soulever la question d'inconstitutionnalité auprès du TC.

Par conséquent, aujourd'hui, les juges ordinaires en Espagne, font partie du système de justice constitutionnelle au sens large, et ils ont certaines facultés de contrôle diffus de constitutionnalité des normes, même si ces facultés restent bien enfermées dans les limites figées, non pas par la Loi organique du Tribunal, mais par la jurisprudence constitutionnelle.

\section{B. L'activité du juge ordinaire comme juge d'amparo ordinaire et comme objet du contrôle du Tribunal constitutionnel}

\section{Le recours individuel d'amparo}

La protection judiciaire des droits est accordée par l'article $24 \mathrm{CE}$, qui reconnaît à toutes les personnes « le droit d'obtenir la protection effective des juges et des tribunaux pour exercer ses droits et ses intérêts légitimes, sans qu'en aucun cas cette protection puisse lui être refusée ». En ce qui concerne, en particulier, les droits et des libertés reconnus au chapitre deux du Titre I de la Constitution, les juges et tribunaux pourront veiller sur ceux-ci à travers les procédures ordinaires et, de leur côté, les juges constitutionnels assureront cette protection conformément aux dispositions de l'article 161, paragraphe 1, a) (art. 53 § $1 \mathrm{CE}$ ). Pour autant, si l'on veut faire référence à la protection des libertés et des droits reconnus à l'article 14 et à la section première du Chapitre II, l'art. 53 $\S 2 \mathrm{CE}$ concède une action devant les tribunaux ordinaires - que l'on finirait par nommer recours 
judiciaire d'amparo ou recours d'amparo « ordinaire $»^{37}$ - fondée sur les principes de priorité et de procédure sommaire et, le cas échéant, prévoit également le recours individuel d'amparo « constitu tionnel » devant le $\mathrm{TC}^{38}$

Donc, le système de garantie des droits et libertés fondamentaux repose sur deux piliers. L'un est ancré dans la juridiction ordinaire. L'autre se situe rue Domenico Scarlatti. Et les équilibres entre les deux ont changé progressivement, bousculées par la surcharge de travail à laquelle a dû faire face le Tribunal constitutionnel.

Durant la première décennie de fonctionnement du Tribunal constitutionnel, le recours d'amparo devint le symbole d'une justice constitutionnelle puissante, évolutive, ouverte au système de protection de droits de l'homme du Conseil de l'Europe et, particulièrement, à la jurisprudence de la Cour européenne des Droits de l'Homme, mise à l'honneur par les juges ordinaires et par les citoyens, qui a trouvé dans le Tribunal constitutionnel un auditoire attentif à la préservation de ses droits fondamentaux. Le début de la deuxième décennie (1988) avait conçu et connu déjà une révision du recours en protection dans le but de restreindre l'accès au Tribunal constitutionnel, permettant à celui-ci de faire un test préliminaire sur le fond de la demande au moment de l'examen de recevabilité, et d'évacuer, donc, à ce moment-là, un nombre de recours plus important ${ }^{39}$. Cette modification cherchait à permettre le rejet des recours en protection dénués de véritable fondement. Mais le vrai changement d'équilibre entre juridiction ordinaire et juridiction constitutionnelle sera provoqué par la Loi organique 6/2007, du 24 mai.

Cette loi transforme substantiellement le recours d'amparo, à travers la modification de la procédure d'admission ${ }^{40}$. Ainsi, la recevabilité du recours d'amparo sera décidée par une section du Tribunal (trois Magistrats), si le contenu du recours justifie une décision sur le fond de la part du Tribunal constitutionnel en raison de son importance constitutionnelle spéciale (« especial trascendencia constitucional » ou ETC). Cela sera apprécié au regard de l'importance du recours pour l'interprétation de la Constitution, pour son application ou pour son efficacité générale, et pour la détermination du contenu et de la portée des droits fondamentaux [art. $50 \S 1 \mathrm{~b}$ ] LOTC et arrêt 155/2009, du 25 juin]. On parle, donc, de l'objectivation du recours d'amparo parce que la violation d'un droit ou d'une liberté n'est pas la cause unique de recevabilité de la demande d'amparo, si le Tribunal n'apprécie pas aussi l'importance constitutionnelle spéciale du recours que le justiciable est censé démontrer à travers une justification suffisante. La conclusion est facile à déduire : la

\footnotetext{
37 Les procédures d'amparo judiciaire ou amparo ordinaire sont celles que prévoient les lois suivantes : Loi organique 1/1982, du 5 mai, relative à la protection civile du droit à l'honneur, l'intimité personnelle et familiale, et l'image ; Loi organique 2/1984, relative au droit de rectification ; Loi organique 6/1984, sur la procédure de l' « Habeas Corpus »; Arts. 114 à 121 de la Loi de la Juridiction contentieuse-administrative, régulateurs de la procédure spéciale pour la protection des droits fondamentaux ; arts. 122 de la Loi de la Juridiction contentieuse-administrative, procédure spéciale pour la garantie du droit de réunion; art. 122 bis de la Loi de la Juridiction contentieuse-administrative, relative à l'accès aux données ou aux services de la société de l’information ; arts. 177 à 184 de la Loi de la juridiction sociale, portant sur la modalité procédurale spécifique de garantie des droits et libertés fondamentaux (Loi 36/2011).

38 Miguel Angel ApAricio Pérez, "La aplicación de la Constitución por los jueces y la determinación del objeto del amparo constitucional", Revista del Centro de Estudios Constitucionales, nº. 3, 1989, p. 47-86. Ici, p. 69.

39 Révision introduite pour la Loi organique 6/1988, du 9 juin 1988, portant sur la modification des arts. 50 et $86 \S 1$ de la Loi organique sur le Tribunal constitutionnel.

40 Pablo PÉrez Tremps, El recurso de amparo, Valencia, Tirant lo Blanch, 2015.
} 
voie d'accès directe du justiciable au Tribunal constitutionnel existe toujours, mais la procédure de recevabilité ferme les portes d'entrée dans $98,8 \%$ des $\operatorname{cas}^{41}$.

L'objectif de la LO 6/2007 était clair et double : réduire la charge de travail que le Tribunal constitutionnel consacre au recours en protection, et basculer le poids du système de garantie des droits et libertés vers les juges ordinaires ${ }^{42}$. La modification de l'article $241 \S 1^{43}$ de la Loi organique sur le Pouvoir judiciaire s'attache à ce deuxième objectif à travers la nouvelle régulation de la procédure de déclaration de nullité des actions (« incidente de nulidad de actuaciones »). Ainsi, à titre exceptionnel, ceux qui sont, ou auraient dû être parties légitimes d'une procédure, peuvent demander par écrit l'annulation de la procédure, sur la base de la violation d'un droit fondamental visé à l'article 53.2 CE. Ceci à condition que la violation n'ait pu être dénoncée avant la résolution qui met fin au procès, et que cette résolution ne soit pas susceptible d'un recours ordinaire ou extraordinaire. La compétence de résolution de cet incident, pour lequel l'appel à l'art. 24 constitue presque la voie de recours exclusive, appartient au même tribunal qui a rendu le jugement devenu définitif, dans le but de donner à ce juge une chance de réparer la violation de(s) droit(s) dénoncé(s) par le justiciable. La procédure de déclaration de nullité des actions devient ainsi la dernière étape obligatoire avant de pouvoir soulever un recours en protection. Il s'agit d'un chemin plus long et plus difficile pour avoir accès au Tribunal constitutionnel, qui finira par choisir parmi les recours d'amparo ceux qui présentent un intérêt suffisant pour obtenir un arrêt sur le fond.

Le paradoxe de ce système de garantie judiciaire des droits et libertés, progressivement tourné vers la juridiction ordinaire, se retrouve dans les statistiques du recours individuel d'amparo. On constate qu'environ $75 \%$ des prétentions de recours visent à rétablir le droit à la protection effective des juges et des tribunaux pour exercer les droits et les intérêts légitimes (art. $24 \mathrm{CE}$ ). C'est-à-dire qu'environ $75 \%$ des recours individuels sont des procédures de contrôle des juges. L'art. 44 LOTC prévoit que les actes ou omissions d'un organe judiciaire, pourront donner lieu au recours en protection, si la violation dénoncée leur est imputable de manière immédiate et directe. Ces violations sont liées, dans la majorité des cas, à l'art. $24 \mathrm{CE}^{45}$ ou à l'art. $14 \mathrm{CE}$ (égalité dans l'application de la loi). La conclusion est donc évidente : les décisions de justice restent un objet privilégié des demandes d'amparo individuel de l'article 44 LOTC, mais ne sont plus un objet prioritaire d'attention du Tribunal constitutionnel qui se concentre, de moins en moins, sur la protection des droits individuels, et s'occupe d'avantage des conflits de compétences ou du contrôle abstrait de constitutionnalité des normes ayant force de loi. En 2015, 35\% seulement des arrêts rendus par le Tribunal constitutionnel furent consacrés à la résolution des recours en protection, qui, en 2007 représentaient 87 \% des arrêts du TC.

\section{La question d'inconstitutionnalité comme contrôle de l'interprétation faite}

\footnotetext{
41 Cf. le rapport annuel 2015 du Tribunal, en particulier la table 17, et la page 56 du rapport, disponible in ligne à https://www. tribunalconstitucional.es/fr/memorias/Paginas/default.aspx (consulté le 10/01/2017)

42 SARAZÁ Jimena, précité, 2013, 24

43 Premier paragraphe de l'article 241 établi par la première disposition finale de la LO 6/2007 du 24 mai, en modifiant la LO 2/1979 du 3 octobre.

44 Cf. le rapport annuel $2015 \mathrm{du}$ Tribunal, disponible in ligne à https://www.tribunalconstitucional.es/fr/memorias/Paginas/default.aspx 45 Miguel Angel Aparicio PÉREz, "La aplicación de la Constitución por los jueces y la determinación del objeto del amparo constitucional", Revista del Centro de Estudios Constitucionales, nº. 3, 1989, p. 47-86. Ici p. 81.
} 


\section{par le "Tribunal Supremo"}

Une dernière question attire notre attention en termes de contrôle de constitutionnalité des décisions de justice et de l'évolution du modèle espagnol de justice constitutionnelle : la possibilité de soumettre à contrôle constitutionnel l'interprétation de la Constitution faite par le "Tribunal Supremo" (Cour de cassation et Conseil d'État), dans le cadre d'un recours de cassation en unification de doctrine.

Ainsi, l'arrêt 37/2012, du 19 mars, accepte de contrôler, par le biais de la QI, la correcte interprétation constitutionnelle de la loi faite par le Tribunal suprême, en réponse à un recours de cassation en unification de doctrine. Malgré une jurisprudence constitutionnelle consolidée, refusant qu'une interprétation jurisprudentielle soit susceptible d'être contestée par la procédure de la QI, le TC, dans le cas de l'espèce, soutient que l'interprétation faite par le « Tribunal Supremo », et la doctrine légale obligatoire fixée par celui-ci, concrétise le contenu normatif de la loi, et porte une vraie force contraignante pour les juges et les tribunaux inférieurs (art. $100 \S 7$ Loi de la Juridiction contentieuse-administrative -LJCA). C'est ainsi que le TC reconnaît qu'il est possible de contrôler la jurisprudence "obligatoire" de la Cour suprême car cette doctrine "fait partie" de la loi elle-même. L'arrêt signale également que la QI va servir à contrôler l'interprétation que le Tribunal supremo fait de la loi et de la Constitution, mais elle ne doit pas être considérée comme une arme entre les mains des tribunaux d'instance inférieure pour protéger leur indépendance face au Tribunal supremo.

La conclusion que l'on peut en déduire est que la QI permet d'élargir l'objet du contrôle de constitutionnalité au-delà de ce que prévoit l'art. 27 LOTC. Par conséquent, la question peut permettre de contrôler l'activité judiciaire du Tribunal supremo dans certains cas très concrets qui, jusqu'à présent, ne se sont présentés qu'une seule fois, à l'occasion de la QI que devait résoudre, précisément, l'arrêt 37/2012.

\section{Conseils de la part d'un système intégral qui rêverait de ne plus l'être}

Il est difficile de mettre en cause le système espagnol de justice constitutionnelle en tant que système intégral, car, comme on l'a défini au début, et comme on l'a démontré à travers cette modeste réflexion, celui-ci permet de contrôler toute l'activité des pouvoirs publics, avec l'objectif d'assurer la constitutionnalité d'une telle activité.

Mais il s'agit d'un système en surcharge qui, soit par la voie législative, soit par action jurisprudentielle du Tribunal constitutionnel, a rendu une partie de leurs propres compétences aux juges ordinaires, qui deviennent, de plus en plus, juges de la constitutionnalité des normes, juges de la constitutionnalité des actes du pouvoir exécutif et des actions des individus, et, paradoxalement, juges de la constitutionnalité de leurs propres actes à travers la procédure de l'article 241 LOPJ. En apparence, le temps de la méfiance entre la justice constitutionnelle et la justice ordinaire est passé, et on est dans la période de la délégation implicite (ou peut-être explicite ?) de pouvoirs. On peut penser que le système intégral rêve de ne plus l'être, soucieux de sa viabilité. 
Les effets collatéraux sont clairs : une participation toujours limitée des citoyens dans le contrôle de constitutionnalité des lois devant le Tribunal constitutionnel et un accès des individus au Tribunal de plus en plus difficile à travers la procédure de recours en protection (recours d'amparo).

La légitimité pour saisir le TC par le biais d'un recours en inconstitutionnalité ne reconnaît aucune intervention des personnes physiques ou juridiques. On pourrait dire que ni la Constitution ni la Loi organique ne reconnaissent l'intérêt légitimant la comparution des individus dans ce procès constitutionnel. Il existe, nonobstant, une certaine intervention des particuliers dans le procès $a$ quo et dans le procès ad quem de la QI, mais cette intervention est admise (et permise) dans un contexte d'exclusivité de la compétence accordée aux juges ou aux tribunaux. La décision de poser, ou de ne pas poser la QI, est une prérogative exclusive du juge qui ne se trouve pas liée à l'éventualité d'une demande des parties au procès ordinaire. La seule participation obligatoire des parties dans la procédure a quo revient à un droit d'audience (art. 35 LOTC) $)^{46}$ et les défauts associés à cette audience, comportent un risque d'irrecevabilité de la $\mathrm{QI}^{47}$. En ce qui concerne le procès ad quem, l'article 37 alinéa 2 LOTC reconnaît aux parties du procès a quo, la faculté de comparaître devant le Tribunal pour formuler leurs allégations, cette disposition marquant la différence principale entre la procédure de la question d'inconstitutionnalité et celle du recours d'inconstitutionnalité, car cette faculté pointe une participation (limitée et écrite) des particuliers devant le $\mathrm{TC}^{48}$.

Finalement, ni le recours en inconstitutionnalité, ni la question d'inconstitutionnalité, n'aspirent à seconder l'accès des individus au Tribunal. Cet accès est limité à la procédure du recours en protection. Toutefois, le RA a renoncé à être une voie d'accès prioritaire et privilégiée des citoyens au Tribunal en raison de la surcharge découlant de l'utilisation massive de cette voie.

Donc, le système de justice constitutionnelle espagnol, qui vise l'intégralité des actes des pouvoirs publics, échappe, de plus en plus, au contrôle direct par les citoyens. On pourrait dire qu'on avance vers un modèle de contrôle des actes de pouvoir par ceux qui détiennent le pouvoir. Le Tribunal joue un rôle d'arbitre dans la définition des limites que l'exercice du pouvoir public, par une autorité concrète, impose aux facultés d'exercice du pouvoir par une autre autorité.

\footnotetext{
46 L'article 35 dispose : «Avant d'adopter sa décision définitive, l'organe judiciaire entendra les parties et le Ministère public afin que, dans un délai commun de dix jours ne pouvant pas être prorogé, elles puissent alléguer ce qu'elles désirent quant à la pertinence de poser la question d'inconstitutionnalité ».

47 Si une ou plusieurs parties demandent le soulèvement d'une QI, le juge ou tribunal ordinaire doit motiver son refus, au risque d'attaquer le droit à la motivation des résolutions judiciaires (art. 24 CE interprété par l'arrêt 35/2002, du 11 février). Nonobstant, les titulaires de ces droits ne détiennent pas un « droit » individuel à l'interposition d'une question devant le Tribunal, mais un droit à une réponse motivée sur la décision négative du juge de saisir le TC.

48 Cette révision a été imposée par la Cour de Strasbourg. La rédaction originale de la LOTC ne prévoyait pas la participation des parties au cours de la procédure devant le juge constitutionnel, mais la Cour européenne des Droits de l'Homme, dans l'affaire Ruiz Mateos contre Espagne (Requête n.12952/87, arrêt du 26 juin 1993) a considéré cette (absence de) régulation comme une atteinte aux droits de la défense, précisément au principe de l'égalité des armes, inhérent au droit à un procès équitable que garantit l'art. $24 \mathrm{CE}$. Nonobstant, la Loi organique portant sur le TC n'a été modifiée que vingt ans plus tard par la LO 6/2007, du 24 mai. En attendant, le TC interprétât l'arrêt de Strasbourg d'une façon restrictive, car le Tribunal - forcément soumis à sa Loi organique - devait attendre que le pouvoir législatif accomplisse son rôle, et modifie la loi interne contraire à la Convention Européenne des Droits de l'homme. De ce fait, et jusqu'à l'approbation de la LO 6/2007, le Tribunal reconnaissait aux parties du procès $a$ quo la défense de leurs intérêts devant le juge constitutionnel uniquement si la question d'inconstitutionnalité visait une « ley singular », c'est-à-dire une loi dépourvue du caractère de généralité (Pierre Bon, «Présentation du Tribunal constitutionnel espagnol », Cahiers du Conseil constitutionnel ${ }^{\circ} 2,1997$ ).
} 
Toutefois, la personne ne trouve plus sa place dans ce modèle, et il faut se poser des questions quant à la récupération de cet espace qui concerne, non pas seulement l'accessibilité des individus au système de justice constitutionnelle, mais aussi la pertinence d'une institution contre-majoritaire, qui détient une partie importante de sa légitimité de la protection des individus les plus vulnérables de la société.

Si, dans le système espagnol de justice constitutionnelle, on partait de l'idée qu'il est nécessaire de rapprocher la Constitution de la réalité quotidienne des citoyens, on pourrait travailler sur le développement d'un "droit individuel" d'accès du citoyen au Tribunal constitutionnel par le biais de l'élargissement des sujets autorisés à saisir le Tribunal à travers le recours en inconstitutionnalité. On pourrait aussi envisager une réforme de la question d'inconstitutionnalité, et suivre le modèle de la QPC, où les citoyens ont un vrai rôle de promoteurs de la question. On pourrait également élargir l'objet du recours en protection aux atteintes provoquées par les particuliers.

Toutefois, existera toujours la question de l'encombrement voire du blocage du Tribunal. Cette affirmation vaut autant pour les réflexions relatives à l'évolution du modèle espagnol, que pour celles relatives au modèle français de justice constitutionnelle.

Élargir la saisine et l'objet du contrôle peut avoir des conséquences directes sur l'efficacité du travail d'une institution aux ressources (humaines, économiques et délais) limitées. Il faut, donc, bien réfléchir avant d'opérer une réforme, car l'enseignement que l'on peut tirer de l'expérience espagnole est que « l'intégralité » normative d'un modèle peut aller de pair avec l'inefficacité d'une partie de celui-ci et, par conséquence, conduire à l’absence de véritable « plénitude ». 



\title{
LA COEXISTENCE DE LA QUESTION PRÉJUdiCIELLE et du Recours direct en Allemagne
}

\author{
Thomas HochmanN ${ }^{1}$
}

Si la Cour constitutionnelle jouit en Allemagne d'une telle popularité ${ }^{2}$, si elle est perçue comme la gardienne des droits fondamentaux, c'est certainement en grande partie grâce au recours constitutionnel (Verfassungsbeschwerde). En vertu de l'article 93 de la Constitution, « quiconque estime avoir été lésé par la puissance publique dans l'un de ses droits fondamentaux » peut saisir la Cour³. Depuis 1951, ce sont plus de 200000 recours qui ont ainsi été formés ${ }^{4}$. Loin derrière, avec 3610 décisions, le deuxième mode de saisine le plus utilisé est celui de la question préjudicielle prévue à l'article 100 alinéa 1 de la Loi Fondamentale 5 .

La question par laquelle un juge saisit la Cour de Karlsruhe de l'inconstitutionnalité d'une loi n'est qu'un des multiples modes de questions préjudicielles prévus en droit allemand, même s'il est le plus utilisé. La Cour peut également être amenée à se prononcer sur la conformité d'une loi régionale à une loi fédérale (article 100 alinéa $1 \mathrm{LF}$ ), sur l'appartenance d'une règle de droit international au droit fédéral (article 100 alinéa 2 LF), sur le souhait du tribunal constitutionnel d'un Land de s'écarter de l'interprétation de la Loi Fondamentale retenue par un de ses homologues ou par la Cour constitutionnelle (article 100 alinéa 3 LF), ou encore sur l'appartenance au droit fédéral d'une norme adoptée avant l'entrée en vigueur de la Constitution (article 126 LF et 86 alinéa 2 BVerfGG).

Seule la question relative à la conformité d'une loi à la Constitution retiendra notre attention, dès lors que c'est à son égard que l'existence du recours constitutionnel soulève les principales

\footnotetext{
Professeur de droit public à l'Université de Reims Champagne-Ardenne.

Cf. Uwe Kranenpohl, Hinter dem Schleier des Beratungsgeheimnisses. Der Willensbildungs- und Entscheidungsprozess des Bundesverfassungsgerichts, Wiesbaden, VS Verlag für Sozialwissenschaften, 2010, p. 19.

3 Article 93, alinéa 1, 4a de la Loi Fondamentale (LF). Le recours constitutionnel a été créé par le législateur en 1951 dans la loi sur la Cour constitutionnelle (BVerfGG). Il n'est mentionné par la Constitution que depuis 1969. Cf. Rüdiger Zuck, Das Recht der Verfassungsbeschwerde, $4^{\mathrm{e}}$ éd., München, C.H. Beck, 2013, par. 4 et 149.

4212827 précisément au 31 décembre 2015. Il faut immédiatement préciser que le requérant n’obtient satisfaction que dans $2 \%$ des cas (1,92\% en 2014, 1,89\% en 2015). Cf. les statistiques disponibles sur le site de la Cour, http://www.bundesverfassungsgericht.de/DE/Verfahren/ Jahresstatistiken/2015/statistik_2015_node.html.

«Si un tribunal estime qu'une loi dont la validité conditionne sa décision est inconstitutionnelle, il doit surseoir à statuer et soumettre la question à la décision du tribunal compétent pour les litiges constitutionnels du Land s'il s'agit de la violation de la constitution d'un Land, à la décision de la Cour constitutionnelle fédérale s'il s'agit de la violation de la présente Loi fondamentale. Il en est de même s'il s'agit de la violation de la présente Loi fondamentale par le droit d'un Land ou de l'incompatibilité d'une loi de Land avec une loi fédérale ».
} 
questions. Un certain «parallélisme » est en effet d'emblée observable entre les deux modes de saisine : « quiconque », dans un cas, et n'importe quel juge, dans l'autre, peut directement saisir la Cour constitutionnelle d'une violation de la Loi Fondamentale ${ }^{6}$. L'objet du recours est en revanche différent. Le recours constitutionnel peut être formé contre tout acte d'une personne publique. Pour des raisons que l'on expliquera dans un instant, l'essentiel des recours concerne cependant des décisions de justice. La question préjudicielle ne porte quant à elle que sur la loi. La désignation habituelle de cette compétence de la Cour constitutionnelle ne doit pas tromper : on affirme traditionnellement que, saisie d'une question préjudicielle, la Cour exerce un contrôle « concret » (konkrete Normenkontrolle). Mais l'examen réalisé par la Cour n'est pas davantage concret que celui auquel se livre en France le Conseil constitutionnel saisi d'une question prioritaire de constitutionnalité. Ce contrôle est qualifié de concret parce qu'il naît à l'occasion d'un litige, et que la Cour n'examine la loi qu'en ce qu'elle est essentielle à la solution de celui-ci. Cette procédure est ainsi distinguée du contrôle « abstrait » (article 93 alinéa 1.2 LF), pour lequel la Cour est saisie par certaines autorités politiques en dehors de tout litige. Mais, suite à une question préjudicielle, la Cour se contente bien de confronter abstraitement la loi à la Constitution.

Une précision mérite tout de même d'être apportée, en raison de son lien évident avec l'objet du présent ouvrage. Une question préjudicielle donne forcément lieu, en un certain sens, à un contrôle des décisions de justice, puisque la saisine de la Cour constitutionnelle est elle-même une décision de justice. Celle-ci fait donc l'objet d'un contrôle à travers l'examen de la recevabilité de la question. Or, cette analyse très approfondie peut être qualifiée de contrôle de constitutionnalité. En effet, l'article 100 alinéa 1 LF ne permet au juge de saisir la Cour qu'à propos d'une loi dont la validité « conditionne » sa décision. L'article 80 BVerfGG précise que, dans la motivation de sa question, le tribunal doit indiquer à quel point sa décision au fond dépend de la validité de la loi. Le respect de cette exigence est vérifié de manière extrêmement serrée par la Cour. Elle exige du tribunal qu'il développe et compare les solutions auxquelles il parviendrait en présence ou en absence de la loi concernée ${ }^{7}$. La Cour n'entend pas se substituer au tribunal pour la résolution du litige concret, mais elle contestera le caractère indispensable de la loi déférée si les appréciations du tribunal lui paraissent «évidemment intenables » (offensichtlich unhaltbar) ${ }^{8}$. Dès lors que ce contrôle de la jurisprudence « virtuelle » du tribunal se justifie par l'exigence constitutionnelle selon laquelle la décision du juge doit « dépendre » de la validité de la loi, il semble permis d'évoquer un contrôle de constitutionnalité des décisions de justice par le biais de la question préjudicielle.

Bien entendu, on n'ignore pas que le véritable thème des contributions rassemblées ici porte sur la possibilité donnée à un organe de contrôler le respect des droits fondamentaux par les décisions de justice. De ce point de vue, l'instrument pertinent en Allemagne est bien le recours constitutionnel'. Lorsqu'il s'agit de savoir si un juge a suffisamment tenu compte des droits fondamentaux

Klaus Schlaich et Stefan KoRioth, Das Bundesverfassungsgericht. Stellung, Verfahren, Entscheidungen, 8e éd., München, C.H. Beck, 2010, p. 101. Cf. K. Schlaich et St. Korioth, op. cit., p. 108 ; Jan-Reinard Sieckmann, « Art. 100 », in Hermann v. Mangoldt, Friedrich Klein et Christian Starck (dir.), Kommentar zum Grundgesetz, 6e éd., Tome 3, 2010, Munich, Franz Vahlen, par. 41 et s.

Cf. J.-R. Sieckmann, art. cit., par. 50 (avec les références jurisprudentielles).

Cf. dans ce volume la contribution de Michel Fromont. 
en appliquant une loi conforme à la Constitution, la question préjudicielle n'a aucune espèce de pertinence. Mais il se peut également qu'une loi porte atteinte aux droits fondamentaux. Sa concrétisation juridictionnelle sera susceptible d'un recours constitutionnel, mais la question préjudicielle a également dans ce cas un rôle à jouer. Les deux recours semblent alors complémentaires (I), même si l'on peut s'interroger sur les risques d'une neutralisation réciproque (II).

\section{La complémentarité des recours}

Face à ce qui lui semble former une atteinte législative à ses droits fondamentaux, un justiciable peut envisager de saisir directement la Cour constitutionnelle. Un tel recours, possible en théorie, n'en demeure pas moins extrêmement hasardeux en pratique. La question préjudicielle peut venir au secours du requérant débouté (A). Si la Cour ne devait pas être saisie de la sorte, il demeure toujours possible d'attaquer devant elle la décision de justice qui fait application de la loi litigieuse (B).

\section{A. La question préjudicielle : un remède à la probable irrecevabilité du recours direct contre la loi}

Le recours constitutionnel, ouvert à « quiconque estime avoir été lésé par la puissance publique dans l'un de ses droits fondamentaux », peut bien entendu viser une loi. La loi sur la Cour constitutionnelle le précise explicitement ${ }^{10}$. Néanmoins, ce type de recours direct contre la loi ne sera jugé recevable que dans de très rares cas ${ }^{11}$, et ce pour deux raisons principales.

Afin de ne pas transformer le recours constitutionnel en actio popularis, la Cour constitutionnelle a très tôt exigé que celui qui la saisit d'une loi démontre un intérêt à agir qualifié pour que son recours soit recevable ${ }^{12}$. Il ne suffit pas d'assurer vaguement avoir été « lésé » dans l'un de ses droits fondamentaux. Le requérant devra établir être touché personnellement, actuellement et directement par la mesure attaquée ${ }^{13}$. Or, le caractère direct de l'atteinte forme une barrière souvent difficile à franchir pour le recours dirigé directement contre une loi. Bien souvent, seule l'intervention d'un acte d'exécution de la loi portera atteinte au droit fondamental. Le recours direct contre la loi ne sera donc recevable que dans les rares cas où la loi est « self-executing », où elle modifie la situation juridique du requérant sans qu'un acte de concrétisation soit nécessaire ${ }^{14}$.

Ce critère de recevabilité suffit à exclure la plupart des recours constitutionnels directs contre des lois. La Cour constitutionnelle a néanmoins ajouté une barrière supplémentaire. En vertu de l'article 90 alinéa 2 BVerfGG, le recours constitutionnel n'est recevable qu'après épuisement des autres voies de droit. Cette condition est inopérante lorsqu'une loi est attaquée, dès lors qu'il n'existe

10 Cf. par exemple l'article 93 alinéa 3 BVerfGG : «Si le recours constitutionnel est dirigé contre une loi [...]».

11 Pour une monographie sur la question, cf. Markus vAN DEN HöveL, Zulässigkeits- und Zulassungsprobleme der Verfassungsbeschwerde gegen Gesetze, Berlin, Duncker \& Humblot, 1990.

12 BVerfGE 1, 97, p. 101 et $\mathrm{s}$.

13 D'abord développée au sujet des recours contre une loi, cette triple exigence a par la suite été étendue à l'ensemble des recours constitutionnels, notamment afin de lutter contre l'engorgement de la Cour. Herbert BETHGE, «§ 90 [Erhebung der Verfassungsbeschwerde] » (2013), in Th. Maunz, B. Schmidt-Bleibtreu, F. Klein, H. Bethge, Bundesverfassungsgerichtsgesetz, Beck online, 2016, par. 342.

14 H. BETHGE, art. cit., par. 373 ; R. Zuck, op. cit., par. 702. 
aucun autre recours direct contre les lois ${ }^{15}$. La Cour a néanmoins considéré que la condition d'épuisement des voies de recours n'était que l'expression d'un principe plus général, la « subsidiarité » du recours constitutionnel ${ }^{16}$. En vertu de ce «principe » inventé par la Cour, le requérant doit utiliser tous les moyens procéduraux à sa disposition pour faire cesser l'atteinte. En particulier, il lui faudra attaquer l'acte d'exécution de la loi devant les tribunaux compétents, plutôt que de saisir directement la Cour de la loi ${ }^{17}$. La Cour justifie cette exigence par la nécessité de conserver le rôle des tribunaux $\mathrm{du}$ fond comme premiers gardiens des droits fondamentaux, et d'éviter que la Cour constitutionnelle se prononce sans qu'un juge du fond ait «préparé » le terrain en établissant le contexte juridique et factuel du litige ${ }^{18}$.

La Cour admet certaines exceptions à l'exigence d'attaquer l'acte d'exécution ${ }^{19}$. Il en va ainsi des actes dont le requérant ne peut avoir connaissance, par exemple en matière de surveillance ${ }^{20}$. La Cour a également considéré qu'on pouvait permettre à un requérant d'attaquer, sans attendre d'être plus directement touché par une mesure d'exécution, la loi qui permettait d'abattre les avions détournés par des terroristes ${ }^{21}$. On ne peut en outre imposer au requérant de commencer par enfreindre une loi pénale avant de pouvoir arguer de son inconstitutionnalité. Enfin, la Cour n'exige pas du requérant qu'il provoque de manière purement formelle un acte d' « exécution » qui n'était pas indispensable.

Il n'en demeure pas moins que l'essentiel des recours constitutionnels intentés directement contre des lois échouent à satisfaire les conditions de recevabilitée ${ }^{22}$. Le requérant devra attaquer un acte d'exécution, et le recours constitutionnel ne sera possible qu'à l'issue de la procédure contre cet acte, après épuisement des voies de recours. C'est alors que le requérant pourra demander à la Cour constitutionnelle de constater l'inconstitutionnalité de la loi exécutée par l'acte contesté. Néanmoins, il est possible que la Cour soit saisie plus tôt de la loi concernée, par le biais d'une question préjudicielle transmise par le juge qui examine un litige lié à l'application de cette loi.

\section{B. Le recours constitutionnel : un remède à l'absence de transmission d'une question préjudicielle}

Le requérant se gardera bien de nourrir d'excessifs espoirs. En effet, les conditions de recevabilité de la question préjudicielle sont elles aussi très élevées, et peuvent s'opposer à l'examen de la question ou dissuader le juge de saisir la Cour constitutionnelle. La condition en vertu de laquelle l'issue du litige doit dépendre de la loi concernée a déjà été mentionnée. En outre, la question préjudicielle n'est pas, du moins en théorie, une faculté du juge : sa transmission n'est jamais une simple

15 L'article 93 alinéa 3 BVerfGG le remarque : «Si le recours constitutionnel est dirigé contre une loi ou contre un autre acte à l'encontre duquel n'est ouverte aucune voie de droit [...]».

16 Cf. Eckart Klein, « Subsidiarität der Verfassungsgerichsbarkeit und Subsidiarität der Verfassungsbeschwerde », in Walther FüRst et al. (dir.), Festschrift für Wolfgang Zeidler, tome 2, Berlin, de Gruyter, 1987, p. 1305.

17 Dans la plupart des cas, le critère de l'atteinte directe suffisait à obtenir ce résultat, et il n'était guère besoin d'invoquer ce principe de subsidiarité. Cf. H. BETHGE, art. cit., par. 412.

18 H. Bethge, art. cit., par. 403 ; Michael Sachs, Verfassungsprozessrecht, 3e éd., Tübingen, Mohr Siebeck, 2010, par. 537.

19 Cf H. BethGe, art. cit., par. 376 s., et par. 408.

20 Cf. BVerfGE 109, 279, à propos d'une loi qui facilitait les écoutes à l'intérieur du domicile.

21 BVerfGE 115, 118, p. 139.

22 Pour un exemple récent de recours recevable, cf. BVerfG, 14 janvier 2015, 1 BvR 931/12, par. 24. 
permission, elle relève soit de l'obligation soit de l'interdiction. Le juge ne peut saisir la Cour constitutionnelle que s'il est convaincu de l'inconstitutionnalité de la loi. Il doit donc s'efforcer d'interpréter l'énoncé de la loi d'une telle manière qu'elle contienne une norme conforme à la Constitution. Ce n'est que s'il parvient à la conclusion que le texte ne permet aucune interprétation conforme que le juge pourra saisir la Cour. Il aura alors même l'obligation de le faire.

Cette obligation doit bien être comprise : elle traduit en réalité une interdiction, celle faite au juge d'écarter lui-même l'application de la loi. La question préjudicielle n'est pas conçue en Allemagne, comme elle peut l'être en France, comme une augmentation des compétences du juge afin d'assurer le respect des droits fondamentaux. La conception dominante en Allemagne semble être que les lois contraires à la Constitution sont des nullités ${ }^{23}$. En bonne logique, le juge qui identifie une inconstitutionnalité devrait donc être libre de ne pas appliquer l'apparente loi, qui est en réalité dénuée de validité. Pour éviter une telle situation, la Loi Fondamentale impose au juge de saisir la Cour constitutionnelle, ce qui permet de centraliser le contrôle de constitutionnalité, et qui a incidemment pour effet de maintenir en vigueur les lois inconstitutionnelles tant qu'elles n'ont pas été « déclarées nulles $»^{24}$ (plus exactement : annulées) par la Cour constitutionnelle ${ }^{25}$. L'article 100 alinéa $1 \mathrm{LF}$ introduit ainsi dans le droit positif ce qu'Adolf Merkl appelait une « prise en compte des défauts » (Fehlerkalkül) : les lois demeurent valides en dépit de leur contrariété à la Constitution ${ }^{26}$.

Cette obligation de déposer une question préjudicielle ne s'applique donc que lorsque le juge est convaincu de l'inconstitutionnalité de la loi. En effet, on ne saurait imaginer que le juge écarte une loi à l'égard de laquelle il ne fait que nourrir certains doutes. La Cour exige donc du juge qu'il motive sa question en démontrant sa conviction sans omettre de s'appuyer sur la doctrine et la jurisprudence. Il doit justifier l'impossibilité de retenir une interprétation conforme. Ajoutées à la lourde tâche qui tient à établir le caractère déterminant de la loi pour l'issue du litige, ces exigences forment des conditions de recevabilité qu'un juge ne peut satisfaire aisément. La Cour constitutionnelle a rendu très difficile d'accès le chemin de la question préjudicielle, en se donnant les moyens d'écarter facilement les saisines ${ }^{27}$. Il ne fait guère de doute que de nombreux juges sont ainsi dissuadés de faire usage de l'article 100 alinéa 1 . Il leur est aisé de renoncer, dès lors qu'ils sont les seuls à connaître leur « conviction » et donc à pouvoir déclencher l'obligation de saisir la Cour ${ }^{28}$. Le juge devra simplement donner une interprétation de l'énoncé législatif qui semble conforme à la Constitution.

Cf. K. Schlaich et St. Korioth, op. cit., p. 244 et s.

Article 78 BVerfGG.

Cf. Rainer LipPoLD, « Gilt im Deutschen Recht ein Fehlerkalkül für Gesetze? Eine Untersuchung des Problems des verfassungswidrigen Gesetzes auf der Grundlage der Reinen Rechtslehre », Der Staat, vol. 29, 1990, p. 185-208.

26 Sur le Fehlerkalkül, cf. notamment Adolf Julius MerkL, « Die gerichtliche Prüfung von Gesetzen und Verordnungen. Die Idee einer gerichtlichen Rechtskontrolle » (1921), in Adolf Julius MerkL, Gesammelte Schriften, éd. par Dorothea Mayer-Maly, Herbert Schambeck et Wolf-Dietrich Grussmann, vol. II/1, Berlin, Duncker \& Humblot, 1999, p. 393-438. Pour une présentation en français, cf. Otto PFERsMANN, « La production des normes : production normative et hiérarchie des normes », in Michel Troper et Dominique CHAGNOLLAUD, Traité international de droit constitutionnel, tome 2, Paris, Dalloz, 2012, p. 498 et s.

27 K. Schlaich et St. Korioth, op. cit., p. 107.

28 Cette construction normative dans laquelle le sujet de l'obligation est seul à même de pouvoir identifier son fait générateur peut paraître surprenante. Encore une fois, elle s'explique très bien si l'on garde en mémoire que l'obligation prévue à l'article 100 alinéa 1 est surtout une interdiction du contrôle diffus. 
La question préjudicielle, qui offre un raccourci procédural permettant de saisir la Cour avant la fin de la procédure, demeure donc un remède bien relatif aux perspectives réduites qu'offre le recours constitutionnel direct contre les lois. Le requérant n'est pas démuni pour autant. À l'issue de la procédure, il pourra former un recours constitutionnel contre la décision de dernière instance. La grande majorité des recours constitutionnels sont soulevés contre des jugements (Urteilsverfassungsbeschwerde). Le requérant pourra ainsi s'efforcer d'obtenir, cette fois de manière indirecte, l'annulation de la loi, en arguant que l'inconstitutionnalité du jugement est due à l'inconstitutionnalité de la loi qu'il applique.

Notons en outre que l'absence de question préjudicielle peut elle-même faire l'objet du recours constitutionnel. En effet, les juges sont directement liés par les droits fondamentaux (article 1 alinéa 3 LF) et doivent donc en tenir compte dans leur interprétation et leur application du droit ${ }^{29}$. S'ils s'abstiennent d'un tel examen, et donc notamment s'ils renoncent à saisir la Cour constitutionnelle alors même que l'énoncé législatif ne semble pas permettre une interprétation conforme à la Loi Fondamentale, ils violent le droit fondamental concerné ${ }^{30}$. L'absence de question préjudicielle peut en outre constituer la violation d'un droit fondamental spécifique, le droit de voir son affaire examinée par le juge prévu par la loi ${ }^{31}$.

Le recours constitutionnel permet ainsi de compenser l'absence de question préjudicielle, il garantit la possibilité de saisir la Cour constitutionnelle, même en l'absence de saisine juridictionnelle. Cette virtualité contentieuse enlève un poids des épaules du juge du fond : renoncer à poser une question préjudicielle ne revient pas à barrer définitivement la route de Karlsruhe. Néanmoins, en déresponsabilisant de la sorte le juge, le recours constitutionnel ne conduit-il pas à l'effacement de la question préjudicielle?

\section{Une neutralisation des recours?}

En dépit des évidences, la multiplication des voies d'accès à la Cour constitutionnelle a-t-elle pour effet d'en compliquer la saisine ? L'expérience allemande, à l'égard de laquelle cette crainte peut être écartée (A), invite à la vigilance en cas d'introduction d'un recours direct en France (B).

\section{A. L'absence de neutralisation en Allemagne}

Une première thèse consisterait à affirmer que la possibilité du recours constitutionnel neutralise la question préjudicielle. Dès lors qu'il sera toujours possible au requérant d'attaquer devant la Cour le jugement de dernière instance, le juge du fond pourrait être tenté de renoncer à se livrer lui-même à la lourde tâche que représente une question préjudicielle dûment motivée. Mais l'on pourrait tout aussi bien faire la pari inverse, et voir dans l'éventuel recours constitutionnel contre le

\footnotetext{
29 Cf. BVerfGE 7, 198 Lüth.

30 BVerfGE 66, 313, par. 18.

31 Article 101 alinéa 1 LF : « [...] Nul ne doit être soustrait à son juge légal ». Cf. K. Schlaich et St. Korioth, op. cit., p. 115 ; BVerfGE 138 , 64 (16 décembre 2014).
} 
jugement une incitation pour le juge à saisir la Cour. Ainsi évitera-t-il de voir son « interprétation » de l'énoncé législatif dénoncée comme une déformation qui n'était pas permise par le texte.

Surtout, la perspective d'un recours constitutionnel, voire d'une multitude de ceux-ci, peut inciter le juge à poser une question préjudicielle, et la Cour constitutionnelle à accepter de l'examiner alors même que les conditions de recevabilité ne sont pas parfaitement remplies. Un arrêt rendu à propos d'une loi qui encadrait la création de centrales nucléaires illustre ce point ${ }^{32}$. En règle générale, lorsqu'une loi organise un régime d'autorisation d'activités par ailleurs interdites, la question préjudicielle n'est recevable que si le juge établit que le requérant satisfait les conditions posées. En effet, dans le cas contraire, il n'a de toutes façons pas droit à l'autorisation, et la solution du litige est la même avec ou sans la loi litigieuse. En l'espèce, le juge avait saisi la Cour sans examiner si le projet de centrale satisfaisait les nombreuses conditions, notamment de sécurité, prévues par la loi. La Cour accepta néanmoins d'examiner la question, en raison de sa « signification générale et fondamentale pour le bien commun $»^{33}$. La Cour applique ainsi à la procédure de la question préjudicielle une disposition prévue par le législateur à l'égard du recours constitutionnel : l'article 90 alinéa 2 BVerfGG impose l'épuisement des voies de recours mais réserve les cas où le recours revêt une « signification générale ». La Cour transpose cette exception à la question préjudicielle, et accepte la saisine sans imposer au juge du fond de réaliser auparavant un examen des preuves «long, difficile et coûteux $»^{34}$. Or, pour la Cour, une question de droit revêt une « signification générale » notamment lorsque sa réponse sera décisive pour un grand nombre de recours pendants ou futurs ${ }^{35}$. Appliquée au mécanisme de l'article 100 alinéa 1 LF, ce raisonnement signifie que la question préjudicielle sera plus aisément acceptée par la Cour lorsqu'il lui apparaît que de multiples recours constitutionnels sont susceptibles d'invoquer l'inconstitutionnalité de la loi concernée. Loin de neutraliser la question préjudicielle, la virtualité du recours constitutionnel peut donc la faciliter.

Un plus grand danger de neutralisation apparaît dans l'autre sens. Il est en effet envisageable que la possibilité donnée au juge de poser une question préjudicielle augmente les chances d'irrecevabilité d'un recours constitutionnel ultérieur. L'absence de question préjudicielle ne saurait pourtant contrevenir à l'exigence d'épuisement des voies de recours, dès lors que c'est au juge qu'il revient de saisir d'office la Cour constitutionnelle ${ }^{36}$. Les parties au procès ne peuvent pas formellement demander le dépôt d'une question préjudicielle, et le tribunal n'est nullement tenu de répondre à une requête en ce sens ${ }^{37}$. Néanmoins, afin d'écarter davantage de recours au stade de la recevabilité, la Cour constitutionnelle a inventé le « principe » déjà mentionné de « subsidiarité du recours

BVerfGE 47, 146 (31 janvier 1978).

Ibid., p. 157.

BVerfGE 47,146 , p. 161

Cf. BVerfGE 108, 370, p. 386 ; Nikolaus MARsch, « Die objektive Funktion der Verfassungsbeschwerde in der Rechtsprechung des Bundesverfassungsgerichts », Archiv des öffentlichen Rechts, 2012, vol. 137, p. 611; Th. HochmANN, «Les limites de l'objectivation du contentieux des droits fondamentaux en Allemagne », in Jordane ARLETTAZ et Julien BonnET (dir.), L'objectivation du contentieux des droits fondamentaux, Pedone, 2015, p. 111-125.

36 Cf. l'article 80 alinéa 3 BVerfGG : «La requête du tribunal est indépendante de l'invocation de la nullité de la disposition juridique par une partie au procès ».

37 Article 80 alinéa 3 BVerfGG. Cf. Müller-Terpitz, « $§ 80$ [Vorlage] » (2015), in Th. Maunz, B. Schmidt-Bleibtreu, F. Klein, H. Bethge, Bundesverfassungsgerichtsgesetz, Beck online, 2016, par. 254. 
constitutionnel », dont l'exigence d'épuisement des voies de recours ne serait qu'une illustration. Pour la Cour, le requérant ne doit pas se contenter d'épuiser formellement les voies de droit disponibles. Il lui faut utiliser toutes les possibilités procédurales pour s'efforcer d'empêcher l'atteinte à son droit fondamental ${ }^{38}$. Il en va ainsi, comme il a déjà été expliqué, à l'égard des recours constitutionnels intentés contre des lois. Plutôt que de saisir directement la Cour, le requérant doit attaquer un acte d'exécution de la loi et espérer le dépôt d'une question préjudicielle ${ }^{39}:$ « le contrôle incident avec possibilité d'une question préjudicielle en vertu de l'article 100 alinéa $1 \mathrm{LG}$ prime sur le recours constitutionnel principal contre la loi $»^{40}$.

En va-t-il de même à l'égard du recours constitutionnel contre une décision de justice ? La Cour a pu considérer que le requérant devait soulever des moyens d'inconstitutionnalité dès le procès au fond, afin de s'efforcer de provoquer une question préjudicielle. Faute d'avoir procédé de la sorte, son recours constitutionnel contre la décision de dernière instance serait irrecevable ${ }^{41}$. Suivant une telle conception, la question préjudicielle joue au détriment du recours constitutionnel : l'existence de ce mode juridictionnel de saisine augmente les risques d'irrecevabilité du recours individuel.

La Cour a néanmoins clairement abandonné cette ligne de jurisprudence ${ }^{42}$. Le requérant n'est tenu d'apporter au juge que des arguments de fait et les moyens de preuve qui s'y rapportent. Hormis les cas où le droit procédural en décide autrement, il ne lui revient pas d'indiquer au juge le droit à appliquer ${ }^{43}$ : « iura novit curia $»^{44}$. Aussi le requérant n'a-t-il pas à montrer qu'il a dès le début de la procédure soulevé des arguments de droit constitutionnel, et qu'il a fait valoir qu'il était blessé dans ses droits fondamentaux. L'absence de moyen d'inconstitutionnalité lors du procès au fond ne pourra être opposée au requérant que dans les cas où son silence lui ôtait toute chance de succès. Il en va ainsi lorsque sa prétention repose sur l'inconstitutionnalité d'une norme, ou sur une interprétation qui ne s'explique que par des considérations constitutionnelles. Dans de tels cas, il lui faut faire le nécessaire pour que les juridictions se saisissent de ces aspects de droit constitutionnel.

Mais, de manière générale, l'exigence d'épuisement des voies de recours et le principe de subsidiarité ne doivent pas conduire à une « constitutionnalisation » du procès au fond, le requérant n'est pas tenu de mener un «procès constitutionnel » dès ce stade ${ }^{45}$. La neutralisation du recours constitutionnel est ainsi évitée en Allemagne. En revanche, si un recours similaire était créé en droit français, la coexistence avec la question préjudicielle paraîtrait plus problématique.

Cf. BVerfGE 123, 148, p. 172 ; E. KLeIN, art. cit., p. 1306 s. ; et H. BETHGE, art. cit., par. 401, avec d'autres références jurisprudentielles.

Cf. BVerfGE 123, 148, p. 172 s. ; et récemment BVerfG (3e section de la première chambre), 25 juin 2015, par. 4.

H. BETHGE, art. cit., par. 402.

BVerfGE 68, 334. Cf. K. Schlaich et St. Korioth, op. cit., p. 156.

BVerfGE 112, 50 (9 novembre 2004)

BVerfGE 112, 50, p. 60 s.

Cf. K. Schlaich et St. Korioth, op. cit., p. 157.

BVerfGE 112, 50, p. 61 ; BVerfGE 129, 78 (19 juillet 2011), p. 93. 


\section{B. Le risque d'une neutralisation en France}

L'examen des rapports entre la question préjudicielle et un éventuel recours constitutionnel direct en droit français relève évidemment de la gageure. Il n'en demeure pas moins possible d'étudier quelques pistes à la lumière de l'expérience allemande.

Si une voie de recours permettait de saisir directement le Conseil constitutionnel pour contester la conformité à la Constitution d'une décision de justice, on pourrait d'abord s'attendre à un tarissement des questions prioritaires de constitutionnalité. Peut-être que les tribunaux du fond et les juridictions suprêmes refuseraient (encore) plus volontiers de transmettre ou renvoyer les questions qui leur parviennent, conscientes que le justiciable conserve ultérieurement une voie d'accès directe au Conseil constitutionnel.

Néanmoins, l'hypothèse inverse est tout aussi vraisemblable, sinon plus. Les juges pourraient être davantage tentés de saisir le Conseil, afin de « renforcer » leurs décisions et de rendre plus improbable une annulation ultérieure suite à un recours constitutionnel. Le problème, cependant, est que la création d'un tel recours risque de conduire les justiciables à soulever systématiquement des questions prioritaires de constitutionnalité. Du moins est-ce ce que l'on voudrait démontrer.

On peut imaginer qu'un recours constitutionnel, s'il était créé en droit français, serait accompagné par des exigences de recevabilité semblables à celles que connaît le droit allemand. En particulier, il ne fait guère de doute qu'il serait soumis à un épuisement préalable des voies de recours. Sous cet angle, la différence fondamentale entre la question prioritaire de constitutionnalité et la question préjudicielle de l'article 100 alinéa 1 LF joue un rôle déterminant. Comme chacun sait, la question prioritaire de constitutionnalité doit être initiée par le requérant, le juge ne peut la soulever d'office. Dans le concert de célébration qui a accompagné la création de cet instrument, une mélodie récurrente touchait justement à cette « constitutionnalisation » du procès rejetée par la Cour allemande. Enfin, les français allaient «s'approprier » leur Constitution ${ }^{46}$. Enfin, le « réflexe constitutionnel » appelé de ses vœux par Louis Favoreu allait s'épanouir, « c'est-à-dire la réaction consistant à se demander, dans tout procès, si les aspects constitutionnels ne doivent pas être évoqués ${ }^{47}$. Bref, dans les termes de la Cour de Karlsruhe, un « procès constitutionnel » allait pouvoir être mené d'emblée.

La situation est donc opposée à celle qui prévaut en Allemagne. À partir du moment où la question prioritaire de constitutionnalité est dans les mains du requérant, l'épuisement des voies de recours exige qu'une telle question soit soulevée lors du procès au fond. À défaut, un recours constitutionnel qui attaque une décision de justice sera irrecevable, au moins dans les cas où ce recours reproche au jugement d'avoir appliqué une loi inconstitutionnelle. On risque ainsi d'assister, dans un premier temps, à des décisions répétées d'irrecevabilité et, dans un deuxième temps, au

\footnotetext{
46 Guy Carcassonne et Olivier Duhamel, QPC, La question prioritaire de constitutionnalité, Paris, Dalloz, 2011 , p. 44 ; Wanda MAstor, « La QPC au cœur du dialogue - conflit? - des juges », in Xavier MAGNON et al. (dir.), Le réflexe constitutionnel. Question sur la question prioritaire de constitutionnalité, Bruxelles, Bruylant, 2013, p. 144

47 Louis Favoreu, « La constitutionnalisation du droit » (1996), in L. Favoreu, La Constitution et son juge, Paris, Economica, 2014 , p. 1092.
} 
développement d'une stratégie contentieuse assimilable à une "Intercopie constitutionnelle ${ }^{48}$ : afin de ne pas fermer la porte à un recours constitutionnel, la question prioritaire de constitutionnalité deviendra systématique.

La Cour constitutionnelle allemande prévoit une exception : une voie de droit n'a pas besoin d'être empruntée lorsqu'elle est évidemment vouée à l'échec ${ }^{49}$. Dans le même esprit, on pourrait considérer qu'une question prioritaire de constitutionnalité n'a pas besoin d'être soulevée contre une loi déjà déclarée conforme à la Constitution par le Conseil constitutionnel. Mais on peut supputer qu'il y a là un péril que les justiciables renonceront à courir. La question sera également soulevée contre des lois déjà déclarées conformes, afin de ne prendre aucun risque et de ne pas se voir opposer l'éventualité d'un changement de circonstances.

Cette multiplication des questions prioritaires de constitutionnalité ne devrait guère encombrer l'agenda du Conseil constitutionnel. La plupart de ces questions ne franchiront vraisemblablement pas les étapes qui filtrent l'accès au Conseil. Cette complication procédurale pèsera surtout sur les justiciables et leurs avocats, ou en tous cas sur les premiers, qui seront facturés par les seconds.

48 CE, 20 février 1953, Société Intercopie.

49 Cf. par exemple récemment BVerfG, 14 janvier 2015, 1 BvR 931/12, par. 23, avec d'autres références jurisprudentielles. 


\section{Chapitre 3}

\section{CONTRÔLE DE CONSTITUTIONNALITÉ ET CONTRÔLE DE CONVENTIONNALITÉ DES DÉCISIONS DE JUSTICE}





\section{Présidence de Madame Nicole Belloubet, Membre du Conseil constitutionnel}

$\mathbf{M}^{\text {me }}$ Nicole Belloubet observe que la mise en relation des contrôles de conventionnalité et de constitutionnalité est un marronnier de la réflexion constitutionnelle française. Sans revenir ici sur la jurisprudence du Conseil constitutionnel, et notamment la décision IVG de 1975 positionnant les rapports entre droit interne et droit international, ou la décision de 2004 relative aux directives de l'UE, on comprend bien aujourd'hui que le contrôle de conventionalité peut constituer une zone d'affrontement juridique entre les cours suprêmes et le Conseil constitutionnel.

$\mathrm{M}^{\text {me }}$ Belloubet rappelle que des positionnements différents de ceux adoptés par le Conseil constitutionnel français existent. En Belgique, les textes organisent la coexistence entre le contrôle diffus de conventionnalité qui fonctionne sous la surveillance de la Cour de cassation et le contrôle de constitutionnalité qui est concentré entre les mains de la Cour constitutionnelle. Mais cette Cour assure la primauté effective du droit de l'Union. La règle de priorité en faveur de la question préjudicielle de constitutionnalité permet donc de répartir les compétences entre la Cour constitutionnelle et les deux autres cours suprêmes.

En France, malgré ou à cause de la jurisprudence $M e l k i^{1}$, les relations sont plus complexes et évolutives. Dans l'affaire n ${ }^{\circ} 2015-520$ QPC $^{2}$, le Conseil constitutionnel a franchi un pas supplémentaire, bien qu'indirect, dans la reconnaissance de la suprématie du droit de l'UE. Il avait été saisi d'une disposition fiscale par laquelle le législateur avait entendu uniformiser un aspect du régime des remontées de dividendes de la société-fille vers la société-mère, quelles que soient les «nationalités » de ces entreprises. Il en résultait la coexistence de deux régimes : la loi nationale continuait de s'appliquer aux situations « nationales » alors que la directive communautaire s'appliquait directement aux situations communautaires. Or la règle communautaire était plus favorable que la règle issue de la loi nationale. Le Conseil constitutionnel a accepté de censurer cette discrimination dite « à rebours » ou «par ricochet ». Il a considéré qu'une loi peut entraîner une méconnaissance du principe d'égalité lorsqu'en vertu d'une jurisprudence constante, elle est écartée par le juge dans les cas qui entrent dans le champ d'application du droit de l'UE, tandis qu'elle continue de s'appliquer dans les autres cas.

1 CJUE, 22 juin 2010, Aziz Melki et Sélim Abdeli, aff. jointes C-188/10 et C-189/10.

2 Décision n²015-520 QPC du 3 février 2016, Société Metro Holding France SA venant aux droits de la société CRFP Cash [Application du régime fiscal des sociétés mères aux produits de titres auxquels ne sont pas attachés des droits de vote]. 
Est-ce en réaction circonstancielle à cette jurisprudence Metro Holding ou par analyse juridique pure, toujours est-il que le 31 Mai 2016, dans une décision $\mathcal{F} a c^{3} b^{3}$ rendue en Assemblée, le Conseil d'État a fait le choix de transmettre une question préjudicielle à la Cour de justice de l'UE (CJUE) au lieu d'interroger le Conseil constitutionnel par une QPC. La question porte alors sur l'imposition des plus-values réalisées lors d'une opération de fusion. Le requérant soutient que les dispositions du code général des impôts ${ }^{4}$ lui sont applicables car sa situation est purement nationale, alors qu'elles ne le seraient pas dans une situation communautaire dès lors qu'elles sont contraires à la directive « fusions ». Le régime différencié qui en découle serait, de l'avis du requérant, contraire au principe d'égalité en ce qu'il engendrerait une discrimination défavorable pour la situation nationale. Pour examiner la QPC soulevée par le requérant, le Conseil d'État s'est fondé sur la décision Metro Holding. Il a considéré qu'il fallait d'abord interpréter la directive « fusions » pour savoir si le texte français, lorsqu'il s'applique aux situations communautaires, était ou non contraire à cette directive. À défaut de cette interprétation par la CJUE, puis par le juge administratif, le Conseil d'État considère que le requérant ne pouvait pas se fonder sur une jurisprudence établie. Selon l'interprétation qui serait en effet donnée du droit de l'UE, le juge fiscal pourrait soit écarter l'article de loi en cause s'il n'était pas compatible avec le droit de l'Union ; soit, à l'inverse, faire application de cet article s'il était compatible avec le droit de l'UE ; soit enfin adopter une interprétation de cet article qui assurerait sa compatibilité avec le droit de l'Union. En l'absence de jurisprudence affirmant que la loi devrait être écartée pour certaines opérations, aucune différence de traitement n'était créée, et la loi restait donc la même pour tous. Elle ne pouvait en conséquence pas être contraire, sur ce fondement, au principe d'égalité et on ne pouvait pas conclure à l'existence d'une discrimination à rebours. Le Conseil d'État a déduit de cette situation que la QPC posée ne présentait pas, en l'état, de caractère sérieux. Refusant de transmettre la QPC au Conseil constitutionnel, le Conseil d'État, pour statuer sur le reste du litige, a posé une question préjudicielle à la CJUE sur le fondement de l'article $267 \mathrm{du}$ TFUE. En fonction de la réponse de la CJUE, le juge pourra déterminer la portée exacte de la loi et le requérant pourra alors, s'il l'estime utile, présenter une nouvelle QPC.

La voie choisie par le Conseil d'État est fondée sur deux éléments explicatifs : l'absence de jurisprudence constante et le fait que, étant juge de la conventionnalité, il lui revient de transmettre une question préjudicielle à la Cour de Luxembourg. La voie retenue peut s'expliquer mais elle eut sans doute pu être autre! Le Conseil d'État aurait pu soit simultanément poser une question préjudicielle et transmettre la QPC ; soit transmettre prioritairement la QPC au Conseil constitutionnel. En effet la QPC soulevée n'était pas nouvelle ou sérieuse, au sens de l'ordonnance de 1958, elle était ET nouvelle ET sérieuse !

Est, en effet, nouvelle la question de savoir si une QPC peut être formée contre une loi dont aucune jurisprudence ne permet d'affirmer qu'elle institue une différence de traitement entre les situations purement nationales et les situations communautaires.

\footnotetext{
CE, Ass, 31 mai 2016, Jacob n 393881.

Aux termes du II de l'article $92 \mathrm{~B}$ et du I ter de l'article 160 du code général des impôts.
} 
Est sérieuse la question qui mobilise une réflexion sur le partage des rôles entre le juge du filtre et le Conseil constitutionnel dans le cas où une question préjudicielle est jugée nécessaire pour apprécier la constitutionnalité d'une disposition législative. Est-ce qu'il ne revient pas alors au seul Conseil constitutionnel de se déterminer sur la question de savoir si le jugement d'une QPC rend nécessaire la transmission d'une question préjudicielle à la CJUE ? Dans la circonstance spécifique où la question préjudicielle transmise à la CJUE n'a pour seul objet que de savoir si la QPC est sérieuse, c'est sans doute un rôle qu'aurait pu pleinement assumer le Conseil constitutionnel!

Cette affaire soulevait donc une véritable question d'articulation entre QPC et question préjudicielle. Le Conseil d'État l'a résolue d'une manière qui exclut dans un premier temps le Conseil constitutionnel alors même que l'esprit et la lettre du constituant de 2008 avaient consacré le caractère prioritaire de la QPC. Au fond, il ne faudrait pas qu'au nom de logiques purement formelles, le Conseil d'État n'hésite pas à transmettre au Conseil constitutionnel des QPC « de réplique » dont la solution de fond est déjà tranchée alors que les vrais sujets, incluant les rapports de pouvoirs entre ordres de juridictions, demeureraient hors d'atteinte pour le Conseil constitutionnel.

Il y a des rapports institutionnels qui méritent d'être envisagés et réfléchis, d'autant plus que les cours suprêmes témoignent par ailleurs, dans certains arrêts, d'une évolution des modalités de leur contrôle. Ces évolutions, c'est une question déjà soulevée par Guy Canivet, ne sont pas sans intérêt quant à leurs incidences sur le type de contrôle exercé par le Conseil constitutionnel. Faudrait-il, pour ce dernier, esquisser le passage d'un contrôle in abstracto vers un contrôle in concreto?

Dans le cadre de son contrôle abstrait, le Conseil constitutionnel s'exprime sur les propriétés intrinsèques de la règle de droit. Il n'a pas à prendre en compte l'existence d'une situation juridique particulière. Il considère les effets unifiés du texte.

Deux jurisprudences récentes du juge de l'application de la loi peuvent-elles l'inciter à modifier cette approche?

Dans un arrêt du 4 décembre $2013^{5}$ relatif à l'interdiction du mariage entre alliés posée par l'article 161 du code civil, la Cour de cassation a estimé que le prononcé de la nullité du mariage entre un beau-père et sa belle-fille au moment du décès de l'époux constituait en l'espèce une ingérence injustifiée dans les droits de la femme au respect de sa vie privée, dès lors que cette union, célébrée sans opposition, avait duré plus de 20 ans.

Une jurisprudence plus récente du Conseil d'État ${ }^{6}$ a autorisé l'exportation en Espagne des gamètes du mari décédé de la requérante, conservées par la France, afin qu'il puisse être procédé dans ce pays à une insémination post-mortem. Cette décision d' « exportation » a été prise alors même que la loi française semble poser dans ce domaine un interdit absolu.

$5 \quad$ Cass, $1^{\text {re }}$ civ, 4 décembre $2013, \mathrm{n}^{\circ} 12-26.066$.

$6 \quad$ CE, Assemblée, 31 mai 2016, $M^{m e}$ G..., n 396848, A. 
Les décisions rendues par les deux cours suprêmes traduisent l'exercice d'un contrôle in concreto les rapprochant du contrôle effectué par la Cour européenne des droits de l'homme. En jugeant ainsi, les deux cours suprêmes mettent en œuvre une arme dont le Conseil constitutionnel ne dispose pas. Il ne lui est en effet pas possible d'écarter, dans un cas d'espèce, une loi qui serait par ailleurs conforme à la Constitution. Bien évidemment ce contrôle d'application de la loi, exercé in concreto, est supérieur en termes de garanties des droits au contrôle abstrait. Mais il ne faut pas oublier que lorsque la QPC a été créée, l'objectif central de la réforme de 2008 était de placer le contrôle de constitutionnalité au même niveau que le contrôle de conventionalité.

Face à ces subtiles avancées dans l'exercice du contrôle de proportionnalité et si les recours ne s'organisent pas correctement au bénéfice du justiciable, le Conseil constitutionnel, au-delà même de toute forme nouvelle de maîtrise de la conventionalité, ne serait toutefois pas sans stratégie d'évolution possible :

- il dispose en effet des réserves d'interprétation qui lui permettent d'atténuer les effets d'une loi dans le sens qu'il juge indispensable à la protection des droits constitutionnels ;

- rien d'interdit non plus de penser à une utilisation amplifiée de l'art 62 al 2 de la Constitution? Cet article pourrait permettre de régler, non pas seulement dans la forme, dans le temps, mais peutêtre aussi au fond (« les conditions et limites ») le suivi singulier des effets des décisions du Conseil, leur conférant ainsi un effet utile amplifié ;

- on pourrait aussi imaginer, mais il s'agirait alors d'un changement profond du système existant, de déployer une QPC sans filtre : le Conseil constitutionnel disposerait alors d'un droit d'évocation qui lui permettrait d'aller piocher dans le stock des cours suprêmes pour trancher les questions principielles.

Il est possible que, lorsque les principales interrogations constitutionnelles seront stabilisées, le stock de QPC soit logiquement conduit à diminuer sauf questions nouvelles spécifiques, de nature fiscale par exemple. La marge de manœuvre du Conseil constitutionnel serait alors plus réduite. À supposer que cette situation se stabilise effectivement, les solutions évoquées pourraient être envisagées. Mais sans doute faut-il atteindre une plus grande maturité dans la pratique actuelle des QPC pour s'engager dans ces voies nouvelles.

Les exemples étrangers qui vont nous être présentés seront surement très éclairants à cet égard.

7 «Une disposition déclarée inconstitutionnelle sur le fondement de l'article 61-1 est abrogée à compter de la publication de la décision du Conseil constitutionnel ou d'une date ultérieure fixée par cette décision. Le Conseil constitutionnel détermine les conditions et limites dans lesquelles les effets que la disposition a produits sont susceptibles d'être remis en cause. » 


\title{
CONTRÔLE DE CONSTITUTIONNALITÉ ET CONTRÔLE DE CONVENTIONNALITÉ DES DÉCISIONS DE JUSTICE QUELLES DISTINCTIONS DANS LES CONTRÔLES EXERCÉS?
}

\author{
Patrick GAÏA ${ }^{1}$
}

La question que les organisatrices de ce colloque nous ont invité à traiter ne nous conduit pas, a priori, à pénétrer en terre inconnue.

Ce serait bien tout le contraire même.

Mais c'est bien là, la raison de redouter le risque que je n'irai pas toutefois jusqu'à faire procès aux intéressées de m'avoir fait sciemment courir.

Car comment éviter de commettre un propos figé dans la banalité sur un sujet aussi ressassé que celui des rapports entre contrôle de constitutionnalité et contrôle de conventionnalité.

On connaît en effet tout ou presque de la vie mouvementée et parfois tourmentée de ce vieux couple. On a pu suivre pas à pas ses disputes, retracer par le menu détail ses ruptures fracassantes, puis ses rapprochements, jusqu'à peut-être devoir faire son miel aujourd'hui de cette forme " d'entente cordiale » (à moins qu'il ne faille parler de «paix armée ») et qui s'observe désormais sous nos latitudes françaises - moins ailleurs - s'agissant de leurs relations. Mais chacun a pu observer aussi - en jetant à l'occasion un peu d'huile sur le feu - les « chamailleries » de ceux qui en observent le cours depuis fort longtemps et se disputent le bon pronostic : qui du juge de droit commun ou du juge constitutionnel doit s'en emparer, se les accaparer ? Est-il recommandable qu'ils s'en répartissent ou bien en monopolisent, pour le tout, l'exercice ? Lequel du contrôle de constitutionnalité ou du contrôle de conventionnalité parviendra à imposer sa préséance et ainsi, d'une certaine manière, à disposer de l'autre ? Et cela ne date pas (en France) de 1975 - moment fondateur certes, où, par une série de considérants dont chacun ici garde la mémoire intacte, le Conseil constitutionnel a paru définitivement acter le divorce entre les deux «partenaires ». Un tel débat a resurgi de l'ombre en 2008 au moment où la QPC sortait des limbes. Il reprend de la vigueur aujourd'hui encore à l'heure où la Cour de cassation par exemple a semble-t-il fait du « contrôle de conventionnalité européen » (axé essentiellement sur la mobilisation très audacieuse de la Convention européenne des droits

1 Professeur, Aix Marseille Univ, Université de Toulon, Univ Pau \& Pays Adour, CNRS, DICE, ILF-GERJC, Aix-en-Provence, France. 
de l'homme) le vecteur d'une (ré)affirmation d'un pouvoir juridictionnel que l'on s'est complu à présenter comme quelque peu entamé ces derniers temps ${ }^{2}$.

Car c'est bien de cela qu'il faut se convaincre en première intention, si l'on veut délaisser un instant le champ du « micro normatif » (les jugements et arrêts des cours et tribunaux) pour restituer à l'échelle " macro normative » (celui des normes générales et abstraites) ce que recèle d'intérêt le contrôle - juridictionnel si l'on comprend bien - des décisions de justice.

Cet examen n'est en effet bien compris, c'est-à-dire en tant qu'il est rapporté aux deux paramètres que l'on sait, qu'une déclinaison d'espèce, un avatar du contrôle de la licéité des normes en général. Ce que nous nommons « décision de justice » ne peut se défaire de l'exigence commune qui désormais contraint tout énoncé normatif de rang subordonné (ou posé comme tel) d'avoir à composer avec le respect d'une « légalité » dite supérieure. La constitutionnalité comme la conventionnalité sont en ce sens devenues, pour faire nôtre la formule de Charles Eisenmann, des « mètres de calcul » de la licéité juridique de toute décision prise en la forme juridictionnelle comme elles le sont ordinairement - banalement -s'agissant de la loi ou du décret ; et aussi, comme l'une et l'autre peuvent l'être lorsqu'elles entreprennent de passer au tamis de la licéité les normes venues d'un « ailleurs juridique », c'est-à-dire d'un autre système normatif. La constitutionnalité peut ainsi, comme à l'ordinaire, se maintenir à bonne distance de la conventionnalité et réciproquement, toutes les fois que des règles relevant d'une autre allégeance normative prétendent être portées à effet dans un ordre qui n'en a pas directement décidé la production. C'est dire que, comme cela se vérifie pour tout autre énoncé normatif, constitutionnalité et conventionnalité peuvent au choix, entretenir un commerce pacifique ou, à l'inverse, plus « heurté » au moment où elles décident du sort qu'il convient de réserver à la res judicata selon que celle-ci s'accorde ou se désaccorde avec l'une ou l'autre. L'on peut par suite être mis en présence, comme cela a été savamment énoncé, de concordances ou de discordances de sentences juridictionnelles en fonction du point d'observation choisi ${ }^{3}$.

Le propos pourrait alors s'interrompre dans l'instant; et prendre la forme d'un aveu à peu de frais : « rien à dire »- de neuf s'entend - sur le sujet. Il suffirait pour s'en justifier, de subsumer l'espèce sous le genre et de renvoyer chacun au cadre général dans lequel les deux types de contrôles ont posé leurs marques depuis quatre décennies.

Point besoin de gloser dans la répétition d'une histoire cent fois écrite.

De là à être accusé de céder à la facilité ... il y a un pas qu'il faut néanmoins se garder de franchir ; car en creusant un peu plus profond le sillon, on s'aperçoit que le bornage des frontières entre les deux contrôles ne se laisse pas aussi facilement découvrir lorsque, précisément, il s'agit de passer à examen des décisions de justice.

2 Voir en ce sens l'étude de Marc Guerrini, « L'utilisation du contrôle de conventionnalité par la Cour de cassation ou le paradoxe de l'acceptation », RDLF, 2017, chron. 21.

3 Denys DE BEChillon, « Conflits de sentences entre les juges de la loi », Pouvoirs, n 96, 2001, Les Cours européennes. Luxembourg et Strasbourg, p. 107-122 ; « Cinq cours suprêmes? Apologie (mesurée) du désordre », Pouvoirs, n 137, 2011, La question prioritaire de constitutionnalité, p. $33-45$. 
Cela tient d'abord à ce que celles-ci recouvrent une grande variété de situations selon les locuteurs concernés. On ne traite pas en bloc, sous l'angle considéré, les décisions de justice dites « ordinaires » et les décisions de justice constitutionnelle ; on ne peut davantage faire masse de ce qui émane de juridictions jugeant du fait et du fond par comparaison avec ce que décident les cours suprêmes, en pur droit. L'on est sans doute enclin aussi, à prêter attention à la manière dont une décision de justice produite par un locuteur supranational pourrait ou devrait être contrainte par le respect d'une « autre conventionnalité » que la sienne (l'on songe ici par exemple au contrôle de conventionnalité internationale ou européenne du droit de l'Union européenne), voire être obligée de se plier au respect d'une constitutionnalité plurielle (celle des ordres juridiques qu'elle prétend surplomber). La Cour constitutionnelle italienne - et l'exemple n'est pas resté isolé, loin s'en faut -a montré en quelle estime elle tenait les arrêts de la Cour européenne des droits de l'homme au moment même où le législateur constitutionnel a fait le choix, en 2001, de hisser la Convention au rang de «norma Interposta $»^{4}$. Décidément, le dualisme italien a la vie dure et il n'est probablement pas le seul.

À la vérité donc, la catégorie des décisions de justice fournit des déclinaisons autrement plus riches que celles qui s'appliquent aux lois par exemple.

Ce qui interdit ensuite de tout ramener aux acquis d'une analyse « légicentrée », c'est l'idée que le contrôle juridictionnel des décisions de justice, qu'il soit rapporté à leur constitutionnalité ou à leur conventionnalité, fait incontestablement bouger les lignes ; celles des compétences, celles des procédures ou même celles qui touchent à la portée du contrôle exercé. Alors même qu'en France par exemple, le clivage entre constitutionnalité et conventionnalité produit des effets assez radicaux lorsque le sujet est le contrôle de la loi ou du décret, la force en est quelque peu atténuée, le rendant plus mouvant, plus ondulé, aussitôt qu'il s'agit d'accuser constitutionnellement ou conventionnellement ce qu'a décidé un juge. L'hybridation entre les deux normativités semble alors prendre des formes renouvelées et bousculer les schémas de pensée habituels.

Enfin, les décisions de justice ont ceci de particulier qu'elles sont des énoncés de concrétisation de normes générales et abstraites - de normes conventionnelles internationales, de normes constitutionnelles, législatives, règlementaires, ou encore de normes conventionnelles internes ... Si bien que ces énoncés une fois repris (dans les visas) et devenant partie intégrante du raisonnement syllogistique d'un jugement ou arrêt, vont en définitive faire corps avec la décision censée clore le débat contentieux. C'est dire que toute décision de justice n'est jamais dissociable du ou des textes qu'elle applique et qu'au moment d'en juger la régularité ou le bien fondé, il peut être entrepris aussi quoique de manière non systématique - de juger la licéité de la norme issue du texte positionné en amont. C'est ce qui explique (en partie) comment, par exemple, le juge supra étatique de la conventionnalité peut, au détour du sort fait au requérant par le juge interne, entreprendre de sceller celui de la loi, de la Constitution ou de tout autre énoncé de portée plus générale sous l'angle de leur conventionnalité ou inconventionnalité.

4 Voir Fanny Jacouelot, « La Cour constitutionnelle italienne La Cour constitutionnelle italienne et la Convention européenne des droits de l'homme : la révolution à rebours des arrêts n 348 et $n^{\circ} 349$ de 2007 », RFDC, 2008, p. 883-892 ; Nicoletta PERLO, « La Cour constitutionnelle italienne et ses résistances à la globalisation de la protection des droits fondamentaux : un « barrage contre le Pacifique »?», RFDC, 2013, p. 717-734. 
Il faut par suite se convaincre de ce que l'exercice des contrôles de constitutionnalité et de conventionnalité des décisions de justice peut, tantôt être le lieu d'une distinction atténuée entre les deux normativités (I), tantôt être le motif d'une confirmation de leur spécificité respective (II).

\section{Contrôle de constitutionnalité et contrôle de conventionnalité des décisions de justice : des distinctions globalement atténuées}

On prendra la mesure de cette atténuation en évoquant la question des compétences et celle des procédures. Quant au contenu du contrôle, il suit pour sa part, non sans nuance, les lignes dessinées de longue date en faveur de l'hybridation des contrôles.

\section{A. Les compétences et les procédures}

C'est sans conteste sous cet angle que les ajustements sont les plus visibles.

1. Allons à l'essentiel : les compétences ont, en premier lieu, tendance à déborder de leur lit, se déclinant dans une sorte de chassé croisé qui consiste pour certains juges à occuper la place laissée vacante par d'autres ; bref, à s'immiscer en des lieux où ils n'ont pas pour habitude de s'aventurer ; ce qui leur laisse à loisir le soin d'étendre à peu de frais, c'est-à-dire sans y avoir été expressément conviés, leur office. La constitutionnalité peut surgir ainsi, là où on l'attend moins que d'ordinaire, donnant même à observer la possibilité d'un véritable cumul des compétences consistant à rapporter dans les mains d'un même juge l'exercice des contrôles de constitutionnalité et de conventionnalité. En France, par exemple, le juge de droit commun peut sans aucun doute (mais sans toujours le dire ouvertement), pratiquer ce cumul des contrôles, ajoutant le contrôle de constitutionnalité à l'endroit d'une décision de justice subordonnée, au contrôle de conventionnalité ou inversement ; ou même, comme cela a été montré, pratiquer une forme «d'auto révision » ou d'auto-censure de sa propre jurisprudence pour se plier à l'autorité (au besoin même à l'autorité de chose interprétée) supérieure de la Loi fondamentale.

Il peut tout autant, et dans le même temps, en qualité de juge suprême de l'ordre juridictionnel qu'il coiffe, et pour peu qu'il y ait en principe, été invité, se poser en juge de la conventionnalité des autres décisions - celles prononcées par d'autres juridictions placées sous sa dépendance ; et même s'investir de la compétence de juger ses propres décisions en les couvrant d'une autorité déduite de leur « orthodoxie conventionnelle » ou en les infirmant - parfois après quelque velléités de résistance - dans le cas contraire. Au passage, le Conseil constitutionnel a beaucoup œuvré à l'entreprise lorsqu'il rappelait en 1986 « qu'il appartient aux divers organes de l'État » (ce qui, assurément, visait en première intention les juridictions) de veiller à l'application des traités et accords liant la France « dans le cadre de leurs compétences respectives » (nous soulignons). Au risque d'appuyer encore des dires maintes fois entendus, le séisme jurisprudentiel de 1975 (facques Vabre) et sa réplique de 1989 (Nicolo), ont fait sentir leurs effets bien au-delà de ce pourquoi ils avaient été pensés au départ : non seulement tous les juges, administratifs comme judiciaires, ont été, «à tout moment, en mesure 
de faire échec à une loi $»^{5}$, mais ils sont aussi devenus, à chaque niveau supérieur, des censeurs potentiels de l'inconventionnalité des jugements frappés de contestation.

Les procédures organisant les voies de recours viennent ici au renfort de l'exercice des compétences contentieuses pour en élargir au besoin le cercle selon une heureuse conjonction. À l'étage des cours suprêmes de l'ordre de juridiction concerné, les moyens d'inconstitutionnalité et d'inconventionnalité peuvent l'un et l'autre être mobilisés (sans, il est vrai, l'être ni dans les mêmes conditions, ni avec la même fréquence) comme moyens de droit dirigés contre un arrêt ou jugement frappé d'appel ou de pourvoi. Les deux contrôles peuvent alors, selon le cas, se cumuler et se confondre en fonction des normes de références mobilisées et selon que celles-ci s'accordent ou se distinguent tout en se complétant. Le clivage ressurgira néanmoins lorsque la constitutionnalité et la conventionnalité en viendront à s'opposer dans un conflit irréductible en dépit de l'usage bien compris des voies ordinaires de l'interprétation. Le juge devra alors faire le choix(difficile) de la précellence en faveur ou en défaveur de l'un des paramètres avant de statuer la rectitude du jugement querellé. Le même clivage est susceptible de se réaliser au niveau de cours suprêmes car si elles n'échappent pas au contrôle de conventionnalité de leurs décisions, elles sont pour l'heure, en France, à l'abri d'un contrôle de constitutionnalité de celles-ci.

On ne peut davantage s'imaginer, sans céder à la spéculation, que le juge relevant d'un ordre de juridiction puisse sans sourciller s'autoriser à contrôler la constitutionnalité d'un jugement ou arrêt émanant de l'ordre de juridiction voisin. Le doute ne paraît pas davantage permis s'il s'agissait pour un juge judiciaire de juger la chose jugée par un juge administratif à l'aune de la conventionnalité. Le principe de séparation des autorités administratives et judiciaires, s'il a bien cédé devant le Tribunal de conflits face au droit de l'Union européenne pour juger de la licéité conventionnelle d'un acte administratif ${ }^{6}$, ne semble pas devoir conduire au même résultat s'agissant d'une décision de l'autre ordre de juridiction nantie de l'autorité ou de la force de chose jugée car alors c'est au sens précis, l'article 16 de la déclaration de 1789 qui y ferait obstacle.

La question demeure néanmoins posée de savoir si une décision du Conseil constitutionnel, sans bien évidemment pouvoir faire l'objet d'un contrôle de constitutionnalité, pourrait néanmoins être sujette à une autre forme de contrôle de la part du juge administratif, par exemple un contrôle de conventionnalité. Pour étrange qu'elle paraisse, la question a néanmoins surgi dans le débat à la suite de l'arrêt lu en assemblée du contentieux par le Conseil d'État en 2002 dans l'affaire Brouant ${ }^{7}$

$5 \quad$ René Chapus, Droit administratif général, Paris, Montchrestien,Tome.1, 15éd, 2001,n 193, p. 161.

6 Tribunal des conflits, 17 octobre 2011, Préfet de la Région Bretagne, Préfet d'Ille-et-Vilaine, Société civile d'exploitation agricole du Chéneau c. Interprofession nationale porcine, M. C et autres c. Centre national interprofessionnel de l'économie laitière, RFDA, 2012, p. 1122, concl. Jean-Dominique SARCELET ; Rec. Dalloz. 2011, p. 3046, note F. DonnAT.

7 CE, Ass., 25 octobre 2002, Brouant. Il s'agissait en l'espèce, de la décision du Conseil constitutionnel, dite « règlement intérieur » du 27 juin 2001 posant le principe et définissant les conditions d'accès à ses archives. Le Conseil d'État y a vu un acte administratif non détachable des «missions constitutionnelles » incombant au Conseil constitutionnel et, par suite, insusceptible de recours contentieux. Sur cette question et de manière plus générale, voir notamment, Louis FAVOREU, « Le Conseil constitutionnel peut-il être soumis à un contrôle du juge administratif? », RFDA 2003. p. 8 et s. ; Pascale GonOD et Olivier JouANJAN, « Le Conseil constitutionnel peut-il être soumis à un contrôle du juge administratif? », RFDA, 2003, p. 14et s. 
2. Inversement, et en second lieu, le Conseil constitutionnel est, pour l'heure et de prime abord, délesté de cet office contrairement à certains de ses homologues. Il n'a pas reçu compétence, du moins directement, pour connaître de la constitutionnalité d'un jugement ou arrêt quelconque émanant d'une juridiction nationale (non plus que supra étatique d'ailleurs). Ainsi, si l'examen de la constitutionnalité des jugements et arrêts des juridictions inférieures est en mesure d'être assurée par les cours suprêmes, ces dernières, sauf à pratiquer un auto contrôle conduisant à une forme d'autocensure de leurs propres décisions sous cet angle, sont par hypothèse beaucoup plus libres vis-à-vis de l'argument constitutionnel Quoi qu'il en soit, constitutionnalité et conventionnalité lui échappent l'une et l'autre pour le tout et finalement, se conjuguent à identité de conséquences parmi lesquelles, celle de l'éviction pure et simple de la compétence du Conseil constitutionnel à entreprendre quelque exercice contentieux que ce soit dans ces deux périmètres. L'on gage toutefois que l'asymétrie dans la manipulation des moyens ressurgirait si d'aventure la QPC venait à s'élargir pour saisir autre chose que des «dispositions législatives » : appelé sur renvoi - n'imaginons pas autre chose dans l'instant - à connaître par exemple de la constitutionnalité d'un arrêt ou jugement prononcé par une juridiction française, le Conseil constitutionnel, s'il reste fidèle comme tout semble le laisser supposer, aux préceptes de sa jurisprudence IVG, procèderait à l'identique de ce qu'il pratique à l'endroit des lois : il prononcerait l'éviction sans appel de tout moyen d'inconventionnalité. Le motif en serait identiquement dirimant : celui de son incompétence à manier autre chose que des moyens de constitutionnalité.

La prudence est pourtant de mise car il n'est pas dit que le Conseil constitutionnel soit totalement mis hors jeu et incapable, à son tour, de venir prendre sa part dans cet espace distrait formellement de son office habituel. Les frontières de sa compétence sont par exemple d'ores et déjà amenées à se déplacer lorsqu'il accepte, en QPC, de se prononcer sur la conformité aux droits et libertés que la Constitution garantit de dispositions législatives telles qu'interprétées par les cours suprêmes des deux ordres de juridiction. Il est vrai que cette éventualité demeure résiduelle et pour le dire sans détour, exceptionnelle. De manière plus conjecturale, l'occurrence d'un examen de constitutionnalité atteignant indirectement la décision d'un juge pourrait se vérifier s'il était saisi directement ou sur renvoi, d'une loi qui aurait fait sienne, en la codifiant, une jurisprudence consolidée voire une simple décision de justice isolée. Dans le cas d'une jurisprudence consolidée au niveau suprême des deux ordres de juridictions respectif, le Conseil d'État ou la Cour de cassation pourrait toutefois se retrouver indirectement affectés par l'éventuelle déclaration d'inconstitutionnalité de la loi ayant cet objet.

Le propos comme on le verra invite à l'inverse à une égale prudence s'agissant de ce que pourrait entreprendre le Conseil constitutionnel sous l'angle de l'examen éventuel de la constitutionnalité d'une sentence émanant de l'une ou l'autre cour européenne.

3. Les données de l'analyse apparaissent symétriquement inverses vu du côté des Cours européennes précisément. Celles-ci ne connaissent - jamais qu'indirectement certes - que de la conventionnalité sans avoir en principe le moindre égard ou regard pour la constitutionnalité ou inconstitutionnalité 
d'une décision de justice interne. Tout au plus, pourrait-on s'interroger sur le lien - dont il serait bienséant que la Cour de Strasbourg reprenne l'étude - entre la règle conventionnelle de l'épuisement des voies de recours internes et la mobilisation des procédures réglant constitutionnellement, c'est-à-dire en interne, les procès incidents de constitutionnalité. Elle a déjà fait un premier pas en ce sens - en mettant toutefois sur le même pied le renvoi préjudiciel conventionnel et constitutionnel - en ouvrant la porte à une possible déclaration d'incompatibilité avec la Convention d'une décision de refus de renvoi qu'elle jugerait entachée d'arbitraire comme procédant notamment d'une motivation insuffisante. Où l'on voit que la Cour de Strasbourg peut, une fois n'est pas coutume, se poser en défense du bon usage des procédures constitutionnelles ou communautaires réglant les procès incidents...

Pour le reste, c'est d'une conventionnalité pour ainsi dire totale ou indifférenciée dont il faut faire état lorsque le juge supra étatique devient juge de ce qui s'est déjà jugé par devant les prétoires nationaux. Le contrôle de conventionnalité peut alors «sauter sur tout ce qui bouge » : sentence constitutionnelle et sentences ordinaires confondues. Non pourtant sans nuance et particularités dans ce cas aussi. Si par exemple, la Cour européenne des droits de l'homme est en mesure de connaître en second examen d'une décision du Conseil constitutionnel ${ }^{8}$, elle ne le fait jamais officiellement ou formellement comme « juge d'appel » (ou de « quatrième degré ») strictement entendu et donc, en tant qu'elle serait par la seule vertu du traité qui l'institue une juridiction « hiérarchiquement au-dessus » de toutes les autres, c'est-à-dire « suprême ». Les présentations en raccourci sont ici trompeuses lorsqu'il est par exemple écrit que la Cour de Strasbourg a été «saisie d'un recours contre une décision du Conseil constitutionnel » dans telle ou telle affaire.

La mesure nécessaire donnée au propos tient également à ce que la conventionnalité ne se présente pas dans tous les cas sous un profil uniforme, notamment quant aux possibilités pour le justiciable disons « de base », d'actionner les voies de droit permettant de faire (re)juger en surplomb, le travail des juges internes. Il faut ici rappeler, même si cela froisse certaines susceptibilités, que les deux cours européennes ne jouent pas si l'on peut dire « à égalité des armes » dans ce domaine. En premier lieu, vu de Luxembourg, le déficit structurel d'accessibilité des individus à la Cour de justice fait du seul recours un tant soit peu efficace en la matière - le recours en manquement - une voie de droit dont les juridictions nationales ont, tout compte fait, peu à redouter. Ce recours étant fermé au commun des justiciables, il n'y a guère (en pratique) que la Commission qui, s'estimant froissée par une sentence nationale contraire au droit de l'Union, pourrait décider de traduire l'État fautif devant la Cour de justice et le faire condamner du chef d'avoir laissé ses juridictions se mettre en infraction avec la légalité communautaire. En bref, la probabilité pour le Conseil d’État ou la Cour de cassation et, a fortiori, le Conseil constitutionnel de se faire déjuger à Luxembourg est faiblè. À l'inverse, les possibilités de recours étant autrement plus ouvertes du côté de Strasbourg, les juridictions nationales (ensemble leurs décisions) sont toutes, sans exception désormais, des cibles faciles pour la

8 P. JAN, « Les recours ouverts contre les décisions du Conseil constitutionnel », Les Petites affiches, 1998, n 40, p.10 et s

9 Denys de Bechillon et Philippe Terneyre, «Le Conseil d'État et la Cour de justice des Communautés européennes. Nouvelle donne », Pouvoirs, n 123, 2007, p. 114. 
Cour EDH. Surtout, l'emprise des règles conventionnelles décidant les conditions dans lesquelles la « bonne justice » est censée se rendre partout et selon les mêmes standards, est telle que « la Cour de Strasbourg est en situation incomparablement plus venimeuse » vis-à-vis des juridictions nationales ${ }^{10}$. Usant du balisage rigoureux que lui fournissent les dispositions phares de la Convention (notamment ses articles 5, 6 et 13), la Cour est en mesure de s'ériger en superviseur général de l'essentiel de l'activité contentieuse des juridictions nationales.

Au demeurant, ces dernières ne sont pas les seules touchées par le phénomène : la soumission fonctionnelle et matérielle du droit de l'Union européenne à la Convention européenne des droits de l'homme - en clair, au regard attentif de la Cour de Strasbourg - quoiqu'encore non actée par une adhésion en bonne et due forme à la Convention de Rome - conduit volens nolens, la Cour de justice de l'Union européenne à faire montre d'une vigilance très singulière sous cet angle ; il s'agit d'éviter tout dérapage qui pourrait convaincre le juge de Strasbourg de prononcer aussi à l'endroit du « droit communautaire jurisprudentiel » un arrêt de condamnation pour infraction à la Convention de Rome et contraire à la parole de son interprète authentique. Ceci conduit à des situations inédites dans lesquelles on voit la Cour de Luxembourg, pour soulager sa conscience, se laisser aller à entreprendre ni plus ni moins qu'un auto contrôle de conventionnalité pour se délivrer au final un brevet de conventionnalité strasbourgeois. Elle en donne la mesure en ces termes, par exemple dans l'ordonnance rendue en 2006 dans l'affaire Echouikh : «[...], il suffit de relever à cet égard que l'interprétation que la présente ordonnance consacre en ce qui concerne l'article 65, paragraphe 1, premier alinéa, de l'accord d'association est conforme aux exigences des articles 14 de la CEDH et $1^{\text {er }}$ du protocole additionnel, tels qu'interprétés notamment par la Cour européenne des droits de l'homme dans son arrêt Gaygusuz c/Autriche du 16 septembre 1996 [...], de sorte que la Cour fournit à la juridiction de renvoi tous les éléments d'interprétation nécessaires à l'appréciation, par celle-ci, de la conformité de la réglementation nationale en cause avec les droits fondamentaux dont la Cour assure le respect, tels que ceux garantis par la $\mathrm{CEDH} \gg^{11}$.

C'est aussi au stade du contenu du contrôle qu'il faut se placer pour percevoir en quoi, deux types de contrôle se situent dans une proximité globalement recherchée.

\section{B. Le contenu du contrôle ou les ombres et lumières de l'hybridation entre constitutionnalité et conventionnalité}

1. Le passage à examen des décisions de justice n'échappe pas au constat plus général que l'on est amené à faire lorsque la constitutionnalité et la conventionnalité s'appliquent à déterminer la licéité juridique d'autres normes. Tantôt elles se distinguent, conduisant même à l'occasion à l'opposition et au conflit (infra, II). Tantôt constitutionnalité et conventionnalité se combinent par l'effet de leur superposition ; ou encore cette combinaison prend la forme d'une complémentarité dans l'application, conduisant à apprécier la situation juridique qui se présente au juge, alternativement

$10 \quad$ Ibid.

11 CJCE, Ord, 13 juin 2006, aff. C-336/05, Echouikh c/ Secrétaire d'État aux Anciens combattants. 
à l'aune de normes constitutionnelles puis conventionnelles différentes mais non opposées. C'est cette démarche que le Conseil d'État a suivie par exemple dans l'affaire M'Rida jugée en 2011 concernant le contentieux de la cristallisation des pensions : l'intégralité des conclusions de la requérante n'ayant pu être accueillies sous l'angle de la constitutionnalité, le repositionnement du litige « sous le timbre » (M. Guyomar) de la conventionnalité a conduit la Haute juridiction à purger plus avant le litige, évitant de la sorte le déport d'un nouvel épisode contentieux à Strasbourg ${ }^{12}$.

2. C'est cette occurrence qui met en présence d'une atténuation des distinctions communément admises et peut conduire à ce que l'on a pris pour habitude de décrire comme une forme d'hybridation ou de mixité des contrôles de constitutionnalité et de conventionnalité. Les décisions de justice comme les autres modes de production normative sont ainsi amenés à composer avec le respect d'une « double normativité fondamentale » qui, loin de se contredire conjugue le plus clair du temps ses forces au soutien de l'examen de licéité des normes. La production juridictionnelle en ressort selon le cas affermie ou affaiblie. Le cumul des effets qui s'attachent à la conjonction du constat de compatibilité (ou son contraire) montre ainsi comment, en saisissant aussi les décisions de justice, la conventionnalisation/constitutionnalisation du droit produit des implications de grande ampleur sur la reconfiguration de l'ordre juridique. Ce processus d'ajustement peut prendre la forme de renversements de jurisprudence et se limiter même à cela. Les modifications de jurisprudence peuvent avoir en effet des conséquences aussi décisives qu'un changement de la législation et/ou de la réglementation écrite, surtout lorsque les positions des cours suprêmes convergent, aidées en cela par la possibilité d'évincer les règles du droit national contraires. Il en ira a fortiori ainsi lorsque les mêmes règles sont appliquées par le Conseil constitutionnel, le Conseil d'État et la Cour de cassation.

Parallèlement, les lignes de force dessinées par cette double «fondamentalité » désormais à l'œuvre, offre aux justiciables une souplesse accrue pour actionner en justice ainsi qu'un large éventail de stratégies contentieuses pour agir dans le sens aussi bien du renforcement de leurs droits procéduraux que de leurs droits substantiels.

Le vecteur principal de ce mouvement est, on ne s'en étonnera pas, les droits et libertés fondamentaux qui sont devenus un point d'accroche tout à fait essentiel à l'aune duquel la régularité autant que le bien-fondé des jugements et arrêts, ont désormais vocation à s'apprécier.

Mais au-delà de la substance des droits, c'est aussi d'une « communauté de méthodes » dont il convient de faire état pour appuyer la relativité de la distinction sous examen. Les juges de la constitutionnalité comme les juges de la conventionnalité n'en viennent pas seulement à porter un regard le plus souvent convergent sur les décisions de justice en mobilisant en substance les mêmes droits ou libertés ; il le font aussi en usant de moyens et techniques de raisonnement très proches donnant

12 CE, Ass., 13 décembre 2011, M'Rida. Le Conseil d'État précise en ce sens que lorsque le juge n'a pas fait droit à l'ensemble des conclusions du requérant en tirant les conséquences de la déclaration d'inconstitutionnalité d'une disposition législative prononcée par le Conseil constitutionnel, il lui appartient d'examiner, sous réserve qu'un tel moyen soit soulevé devant lui, s'il doit, pour statuer sur les conclusions qu'il n'a pas déjà accueillies, écarter la disposition législative en cause du fait de son incompatibilité avec une règle conventionnelle dont la méconnaissance n'aurait pas été préalablement sanctionnée. 
corps à l'émergence de "méthodes commutatives » ou interchangeables articulant les motifs de leurs jugements respectifs. C'est le cas lorsqu'il faut arbitrer les «collisions » de droits fondamentaux, ou décider de moduler l'étendue du contrôle juridictionnel en fonction d'une marge d'appréciation ou d'un pouvoir discrétionnaire laissés aux autorités compétentes. Les décisions de justice ne restent pas à l'écart de cette sorte de manifestation de « self restraint judiciaire ». Par exemple lorsque la Cour européenne de Strasbourg concède que les écarts pris avec les règles du procès équitable peuvent être corrigés à un stade ultérieur de la procédure ou lorsqu'elle décide de ne pas attraire dans le champ matériel de la Convention certains contentieux.

3. Il faut néanmoins ajouter que le défaut, là où il se constate, d'une procédure adaptée et spécifique de contestation des arrêts et jugements sous l'angle particulier de leur légitimité constitutionnelle, laisse, en quelque sorte mécaniquement, un avantage comparatif sérieux aux moyens de conventionnalité par rapport aux moyens de constitutionnalité. C'est le cas en France où l'avance prise de longue date par le contrôle diffus de conventionnalité continue de s'affirmer (et peut être même de se creuser) au détriment du contrôle de constitutionnalité compte tenu de la double réfraction du périmètre dans lequel le législateur constitutionnel a maintenu jusqu'à présent la QPC : le mécanisme ne s'applique pas de plein droit aux décisions de justice et il ne protège pas toutes les normes de constitutionnalité. Ce qui fait que les jugements et arrêts sont, selon une proportion très clairement en faveur du droit conventionnel, censurés pour motif d'inconventionnalité plutôt que pour motif d'inconstitutionnalité. L'ampleur du contentieux de masse que représente les recours fondés sur les violations supposées ou avérées des règles du procès équitable découlant de l'article 6 de la Convention européenne des droits de l'homme, continue ainsi pour une large part à asseoir le reflexe du « tout conventionnel » dans l'esprit des justiciables et des praticiens du droit, y compris dans les cas où ce sont des décisions juridictionnelles qui sont attaquées.

Ce n'est ainsi qu'assez rarement que la Constitution est seule convoquée pour fonder le rejet ou l'admission dans son bienfondé d'un pourvoi en cassation devant la Cour de cassation par exemple ${ }^{13}$. Le plus souvent, la Constitution, lorsqu'elle est invoquée ou appliquée d'office par le juge, doit plutôt composer avec le renfort de la Convention européenne des droits de l'homme, celle-ci étant de surcroit, placée en pôle position dans les visas ${ }^{14}$.

Le Conseil d'État semble pour sa part sensible à l'argument constitutionnel lorsque celui-ci est convoqué à l'appui d'un pourvoi en cassation introduit contre un arrêt ou jugement. Le moyen d'inconstitutionnalité est, le cas échéant, traité seul et examiné sous l'angle de l'erreur de droit ${ }^{15}$.

13 En ce sens par ex., Cass. civ., $2^{\mathrm{e}}, 28$ juin 1995, Bechta, $\mathrm{n}^{\circ} 94-50002$.

14 Voir par ex., Cass, AP, 24 novembre 1989, $\mathrm{n}^{\circ} 89-84439$.

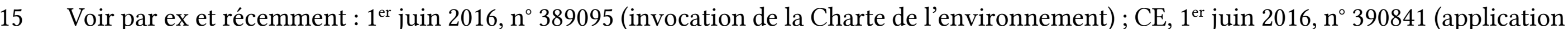
de l'article 8 DDHC, rétroactivité in mitius ; confirmation de l'arrêt de la Cour administrative de Nancy, n $13 \mathrm{NC}^{\circ} 1560$ du 21 mars 2015 , arrêt faisant application d'office des dispositions de l'article 8 précité ; et plus ancien : CE, Ass., 16 décembre 2005, Syndicat national des huissiers de justice, $\mathrm{n}^{\circ}$ 259584). Sur cette question, voir not., Karine BUTERI, L'application de la Constitution par le juge administratif, Thèse Université d'AixMarseille III, 2000, 460 p. ; Guillaume Drago, (dir.), L'application de la Constitution par les cours suprêmes : Conseil constitutionnel, Conseil d'État, Cour de cassation, Paris, Dalloz, 2007, 234 p. 


\section{Contrôle de constitutionnalité et contrôle de conventionnalité des décisions de justice : une spécificité partiellement confirmée}

L'idée que contrôle de constitutionnalité et contrôle de conventionnalité s'affirmeraient comme irréductibles l'un à l'autre aurait vécu. Le constat semblerait même relever d'un autre temps, appartenir à d'autres « mœurs judiciaires ». Pour preuve, l'usage du contrôle de conventionnalité de la loi n'est pas seulement devenu d'une banalité confondante, une partition sur-jouée par tous les « acteurs judiciaires ». Même les « juges constitutionnels » (en France et ailleurs) ont, pour reprendre les mots du Président Debré, commencé à « gouter au fruit défendu ». Inversement au pays des arrêts Paulin et Arrighi, les juridictions judiciaires et administratives ont, en convoquant par devers elles la QPC, comblé en partie le vide qui les tenait à distance du soin de se soucier de la constitutionnalité de la loi.

Un petit grain de sable semble pourtant s'être glissé dans cette mécanique bien huilée : c'est que, là où l'on imaginait que les convergences qui se sont fait jour ne pussent faire autrement que de se perpétuer dans une suite de progrès ininterrompus et dont la fusion des deux contrôles signerait peut-être un jour - la fin de l'histoire (l'on n'ose dire en vérité, l'absorption du premier par le second et donc sa disparition programmée) le temps plus rapproché de ce qui s'observe actuellement incline à un jugement plus nuancé.

Que l'on comprenne bien le sens du propos. Il n'est pas dans notre intention de nier que les contrôles de constitutionnalité et de conventionnalité connaissent désormais des trajectoires convergentes après avoir coexisté et prospéré - pour l'essentiel - dans une indifférence réciproque dont seules, n'en déplaise aux faiseurs de systèmes, quelques rares passe d'armes isolées sont venus troubler le cours.

Les droits fondamentaux et leur inexorable montée en puissance devenus l'archétype du Rule of law sont passés par là ; la crainte aussi d'une déflagration de grande ampleur à tous les étages - et le temps - ont probablement fait le reste pour œuvrer à des relations apaisées entre les systèmes et les juges censés les protéger.

Mais, si beaucoup ont fait leur cette vérité supposée définitive que l'étude des rapports de systèmes pouvait se ramener en entier à la dogmatique des droits et libertés fondamentaux, et même, à supposer que celle-ci fournisse l'essentiel des preuves et raisons de plaider pour l'avènement d'un monde normatif pacifié vu sous le prisme des rapports de systèmes, il y a encore loin avant que cette façon de cadrer la problématique n'épuise le sujet.

D’abord parce que ces rapports débordent encore largement le périmètre des seuls droits et libertés et alors surtout que les normes qui les substantifient en droit, ne sont pas pourvues de cette toute puissance qui leur permettrait de l'emporter dans chaque cas qui se présente sur tout autre énoncé normatif contraire. L'arrêt Melloni (pour n'évoquer que lui) a eu ce grand mérite de déciller tous ceux qui rêvaient tout éveillés que la primauté du droit de l'Union avait enfin trouvé en son sein même, plus fort qu'elle... 
Ensuite, parce que dans le cercle restreint des lieux dans lesquels justice se prononce, les faveurs que s'attire l'aphorisme « le dialogue plutôt que la guerre » (des juges) ${ }^{16}$ ont beau avoir été promues au rang de credo indépassable par tous ceux qui font commerce de leur « savoir dire le droit » en Europe, on pencherait plutôt, comme le laissent entre apercevoir quelques décisions soigneusement pensées rendues récemment par certaines juridictions constitutionnelles, pour le possible avènement d'un nouveau cycle ; peut-être un « post modernisme normatif » où l'opposition, la divergence, la résistance au « pseudo pouvoir de dernier mot », la dysharmonie entre choses jugées, et le désordre relatif que cela induit, ne seraient pas ou plus systématiquement tenus pour des dysfonctionnements insupportables dont il faudrait faire rendre gorge dans l'instant à tous les empêcheurs de tourner en rond.

Précisément, là où il y a matière à contrôle opéré sur des décisions de justice, les distinctions entre contrôle de constitutionnalité et contrôle de conventionnalité trouvent donc encore de fortes raisons de s'exprimer.

Et elles s'y emploient de diverses manières dans la bouche des juges. On fera état en ce sens de deux séries d'observations. Les unes ont trait aux conditions dans lesquelles les deux contrôles sont déclenchés et peuvent s'accomplir (A), les autres, aux effets qui s'y attachent (B).

\section{A. La distinction quant aux conditions de déclenchement et d'exercice du contrôle}

\section{La question de la nature des moyens : moyen d'ordre public ou non?}

Sans être uniquement déterminé par cela, le déclenchement des contrôles que l'on sait, est-il pour une part importante, sous la dépendance - c'est-à-dire découlant de leur qualification - des moyens propres à établir la « légalité » ou au contraire « l'illégalité » des actes que le juge a pour mission de contrôler? En suite de quoi, le contrôle qui sera, le cas échéant, effectué postérieurement par un autre juge sur la décision qu'il aura rendue sur ce point, sera-t-il donc aussi, pour partie, conditionné par l'attitude qui aura été la sienne relativement au traitement qu'il pourra ou devra réserver aux moyens dont s'agit et cela, en considération de leur nature juridique?

Sous cet angle, la question essentielle met en présence d'une opposition - pas forcément radicale et toujours fixée avec la constance et l'étendue que l'on serait en droit d'attendre - entre les moyens d'ordre public et les autres. Au demeurant, la manière dont se positionnent les juges sur cette question est assez variable. Et cela peut se répercuter en aval sur l'étendue du contrôle qu'un juge « supérieur » sera à même d'exercer sur la décision de son subordonné. En France par exemple, l'attitude des juges judiciaires et des juges administratifs sur la question des conditions de reconnaissance des moyens d'ordre public (ou d'office) est loin d'être identique tandis qu'à l'intérieur d'un même ordre de juridiction, on peut assister à des variations également tenant compte de la nature

16 Patrick Wachsmann, « Le dialogue plutôt que la guerre » in Le dialogue des juges, Mélanges en l'honneur du Président Bruno Genevois, Paris, Dalloz, 2009, p. 1121-1138. 
des normes de référence éligibles à cette qualité. Il en résultera que le contrôle exercé par les juges d'appel et de cassation notamment, sur les décisions des juridictions subordonnées, sera lui-même plus ou moins étendu.

Le même constat peut être fait au niveau des juridictions supra-étatiques : vis-à-vis des moyens d'ordre public -ceux qui sont tirés de la violation des normes découlant des traités - les deux cours européennes ont une approche différente qui s'explique en grande partie par la considération tirée des particularités de leur office respectif et des missions qui leur incombent. La Cour de justice de Luxembourg est plus attentive au regard que portent les juridictions internes sur le sort des moyens tirés de la violation du droit communautaire. Ce qu'elle a en vue avant tout, c'est que les justiciables soient certains de trouver dans le droit procédural national des garanties propres à leur assurer la sauvegarde des droits qu'ils tirent de l'effet direct du «droit communautaire » et qu'il n'y ait pas à cet égard un traitement moins favorable appliqué à ce dernier comparé à celui réservé au droit national. La Cour européenne des droits de l'homme est plus « indifférente » à cette question des moyens d'ordre public en considération du caractère essentiellement subsidiaire du mécanisme mis en place par la Convention ; mais elle ne s'y oppose pas non plus, bien au contraire dans la mesure où précisément le relevé d'office de moyens tirés de la violation de la Convention peut renforcer « l'effet utile » et la finalité tirée de la subsidiarité du contrôle conventionnel.

Dans le cadre limité de la présente étude on ne peut d'ailleurs retracer qu'à grands traits l'état du droit sur cette question éminemment complexe et qui le doit beaucoup à la grande variabilité des positionnements adoptés par les acteurs juridictionnels eux-mêmes.

La ligne directrice que l'on peut, avec prudence, dégager de l'étude du droit positif est la suivante : les moyens d'inconventionnalité sont en règle générale et par principe écartés au titre de moyens d'ordre public ; à l'inverse, mais avec des nuances également, la violation de la Constitution peut être, dans certains cas, reconnue comme moyen d'ordre public.

\section{a. Rejet, en règle générale, des moyens d'inconventionnalité comme moyens d'ordre public}

La position adoptée en ce sens est très marquée, voire constante du côté des juridictions administratives ${ }^{17}$. Le Conseil d'État en particulier, en fait sa ligne de conduite depuis l'arrêt de Section Société anonyme Morgane de 1991 et cela, indifféremment, selon que se trouve mise en cause une règle du droit communautaire ou une stipulation de la Convention européenne des droits de l'homme. Réexaminée à nouveau dans l'arrêt Maciolak, la question y reçoit une réponse identique parée cette fois de l'autorité de l'Assemblée du contentieux ${ }^{18}$.

À la suite de quoi, la Haute juridiction administrative en tire par exemple la conséquence que n'est pas recevable à l'appui d'un pourvoi, un moyen d'inconventionnalité (incompatibilité avec une

17 Voir not., Karine Michelet « La loi inconventionnelle », RFDA 2003, p. 23 et s.

18 Voir ég., dans le même sens : CE, 16 janvier 1995, SARL Constructions industrielles pour l'agriculture, Leb., p. 35 ; CE, Ass., 28 juin 2002 , Ministre de l'Économie, des Finances et de l'Industrie, ${ }^{\circ} 232276$. 
directive communautaire) non soulevé devant les juges du fond «et qui n'est pas d'ordre public». Implicitement, le juge de cassation donne en l'espèce raison au juge d'appel de s'être gardé de soulever d'office un tel moyen, l'abstention à ce faire de la juridiction d'appel n'étant pas entachée d'erreur de droit ${ }^{19}$. Inversement, l'examen (avant l'arrêt Nicolo) de la compatibilité d'une loi antérieure à la prise d'effet en France de la Convention européenne des droits de l'homme, auquel le juge du fond a procédé (sans commettre d'erreur de droit), est subordonné à la condition qu'un tel moyen ait été préalablement soulevé devant lui par le requérant ${ }^{20}$. Si bien que serait entaché d'erreur de droit un arrêt ou jugement qui procèderait à tel relevé d'office. Dans le prolongement, participe tout autant de cette attitude réservée la position adoptée par le Conseil d'État dans sa décision Cheriet Benséguir de $2010^{21}$ alors même qu'il y procède au renversement de sa jurisprudence Rekhou de $1981^{22}$ : s'il appartient au juge administratif de s'assurer que la condition de réciprocité visée par l'article $55 \mathrm{C}$ est ou non remplie, c'est à la condition qu'ait été soulevé devant lui le moyen tiré de ce qu'une décision administrative a à tort, sur le fondement de cette réserve, soit écarté l'application d'un traité, soit fait application de ses stipulations. La même solution devrait sans difficulté pouvoir être transposée au cas d'un jugement. Enfin, il n'est pas indifférent, à titre de dernier exemple, de relever que le Conseil d'État s'abstient de relever d'office tout moyen tendant à mette en cause la compatibilité internationale d'une réserve émise par la France à un traité international, alors même que celle-ci peut être sérieusement contestée à la lumière d'un arrêt de la Cour européenne des droits de l'homme ${ }^{23}$. On devrait logiquement en inférer que le moyen tiré de la méconnaissance de la chose jugée par la Cour européenne des droits de l'homme ou par la Cour de justice de l'Union européenne ne doit pas davantage être relevé d'office ${ }^{24}$.

19 CE, 28 juillet 1993, M. Raymond Bach et autres, n¹18717 ; Ass., 6 décembre 2002, fean Maciolak n 239540, Concl. contr. P. Fombeur. Ce dernier arrêt retient particulièrement l'attention en ce, qu'après avoir rappelé dans un premier temps, que le moyen tiré de la régularité de la composition d'une juridiction est un moyen d'ordre public et donc, que cette composition doit être conforme aux dispositions législatives et règlementaires en vigueur ainsi qu'aux principes généraux qui en gouvernent la mise en œuvre, il précise, dans un second temps, que la conformité de ces dispositions législatives aux traités et accords internationaux ne constitue pas une question d'ordre public. Comp. et du même jour : CE, Ass., 6 décembre 2002, facques Trognon, n 240028, Concl. P. Fombeur ; Abdelaziz Aïn-Lhout, n 221319, concl. F. Séners. Les deux arrêts examinent le moyen soulevé par les requérants de la compatibilité des mêmes dispositions législatives fixant la composition de juridictions administratives spécialisées avec les stipulations de l'article 6, §1 de la CEDH. Comp. aussi avec CE, 29 mai 2002, M. Vaillant, $\mathrm{n}^{\circ} 222279$ jugeant, au visa de ces stipulations, le requérant « recevable et fondé à soutenir qu'en ne soulevant pas d'office l'irrégularité de la composition de la juridiction de première instance la section des assurances sociales du Conseil national de l'Ordre des chirurgiens-dentistes a entaché sa décision d'erreur de droit ».

20 CE, 30 janvier $1981, \mathrm{n}^{\circ} 18327$.

21 CE, Ass., 9 juillet 2010, $M^{\text {me }}$ Cheriet Benseghir, $\mathrm{n}^{\circ} 317747$.

22 CE, Ass., 29 mai 1981, Sieur Rekhou, n 15092.

23 Voir en ce sens, conclusions A. Lallet sur CE, 22 octobre 2014, Syndicat des médecins d'Aix et région et autres, $\mathrm{n}^{\circ} 364384,365276,365818$, 36582 ; Voir ég., CE, 16 mars 2016, SAS Rapa, n 377874 : «Considérant [...] que la société requérante ne peut utilement contester le bien-fondé de l'arrêt qu'elle attaque en invoquant, pour la première fois devant le juge de cassation, le moyen, qui n'est pas d'ordre public et n'est pas né de cet arrêt, tiré de la méconnaissance d'une espérance légitime devant être regardée comme un bien au sens des stipulations de l'article $1^{\text {er }}$ du premier protocole additionnel à la convention européenne des droits de sauvegarde des droits de l'homme et des libertés fondamentales ».

24 Quelque restrictive que soit la doctrine du juge administratif quant à l'identification de « l'acte pris en dehors du champ d'application de la loi », on peut raisonnablement se demander s'il ne serait pas amené à n'avoir d'autre choix que de censurer un jugement à lui déféré après avoir relevé, au besoin d'office, le moyen tiré de ce qu'il aurait été fait application à la cause d'un acte dont l'inconventionnalité aurait par ailleurs été prononcée par une décision devenue définitive. Le Conseil d'État ayant, comme on le sait, admis la légalité du refus de pendre un décret d'application d'une loi viciée d'inconventionnalité, un tel acte néanmoins édicté, semble correspondre à la qualification que l'on sait ; ce qui devrait conduire le juge d'appel ou de cassation à censurer pour erreur de droit, le jugement rendu au fond pour n'avoir pas relevé, au besoin d'office, un tel moyen. 
De manière positive, l'articulation entre contrôle de constitutionnalité et contrôle de conventionnalité conduit toutefois le Conseil d'État à faire en sorte que le premier soit, le cas échéant, relayé par le second ${ }^{25}$.

La position tout en réserve du Conseil d'État, se sépare en partie de celle de la Cour de justice de Luxembourg qui n'écarte pas l'éventualité pour le juge national d'avoir à relever d'office les moyens tirés de l'incompatibilité du droit national avec le droit communautaire (CJCE, 14 décembre 1995, Peterbroeck, aff. C-312/93 : « le droit communautaire s'oppose à l'application d'une règle de procédure nationale qui, dans des conditions telles que celles de la procédure en cause en l'espèce au principal, interdit au juge national, saisi dans le cadre de sa compétence, d'apprécier d'office la compatibilité d'un acte de droit interne avec une disposition communautaire, lorsque cette dernière n’a pas été invoquée dans un certain délai par le justiciable » (pt 21) ${ }^{26}$.

La Cour administrative d'appel de Paris a pour sa part déjà accepté de procéder au relevé d'office du moyen (non invoqué en première instance) tiré de la contrariété d'une disposition du CGI à une directive communautaire : «il incombe le cas échéant au juge national de soulever d'office le moyen tiré de la non conformité du droit interne à (une) directive (communautaire) $»^{27}$.

Comme le souligne le Professeur Chapus ${ }^{28}$, la position traditionnelle de la juridiction administrative sur cette question est fondée sur une approche raisonnable et l'on ajoutera, réaliste : elle procède de l'impossibilité pratique dans laquelle se trouverait le juge du fond à s'obliger systématiquement et dans chaque litige, à rechercher dans la masse considérable des normes européennes et internationales en vigueur en France les normes invocables et applicables à la cause.

- Jurisprudence de la Cour de cassation. La Haute juridiction judiciaire manifeste de son côté une attitude en règle générale réservée sur la question du sort réservé aux moyens d'inconventionnallité soulevés pour la première fois devant elle y compris lorsqu'il s'agit de faire application de la Convention européenne des droits de l'homme. Mais elle fonde sa position sur une argumentation différente de celle du juge administratif. Néanmoins, comme le relève le rapport 2013 de la Cour de cassation : «Compte tenu de la nature du texte et de sa valeur supranationale, le moyen est

\footnotetext{
25 Décision M'Rida précitée et appliquant cette solution : « Il appartient au juge du litige, s'il n'a pas fait droit aux conclusions d'une requête en tirant les conséquences de la déclaration d'inconstitutionnalité d'une disposition législative prononcée par le Conseil constitutionnel, d'examiner, dans l'hypothèse où un moyen en ce sens est soulevé devant lui (nous soulignons) s'il doit écarter la disposition législative en cause du fait de son incompatibilité avec une stipulation conventionnelle ou, le cas échéant, une règle du droit de l'Union européenne » (CE, 10 avr. 2015, n 377207, Sté Red Bull on Premise).

26 CJCE, 14 décembre 1995, Peterbroeck, aff. C-312/93 : « le droit communautaire s'oppose à l'application d'une règle de procédure nationale qui, dans des conditions telles que celles de la procédure en cause en l'espèce au principal, interdit au juge national, saisi dans le cadre de sa compétence, d'apprécier d'office la compatibilité d'un acte de droit interne avec une disposition communautaire, lorsque cette dernière n'a pas été invoquée dans un certain délai par le justiciable » (pt 21). Voir ég., CJCE, 14 décembre 1995, Van Sc.hijndel/Stichting Pensioenfonds voor Fysiotherapeuten, aff. jtes C-430/93 et C-431/93 ; CJUE, 25 novembre 2008, Heemskerk et Schaap, aff. C-455/06 ; CJUE, 12 février 2008, Kempter, aff. C-2/06, (pt 45) ; CJUE, 6 octobre 2009 Asturcom Telecomunicaciones, aff. C-40/08, point 54). La Cour précise encore que lorsque le droit national confère au juge la faculté d'appliquer d'office la règle de droit contraignante, cette faculté se transforme en obligation pour lui, d'appliquer d'office la règle de droit de l'Union contraignante.

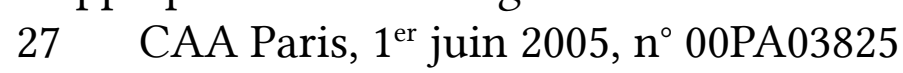

28 Droit du contentieux administratif, Paris, Montchrestien, $12^{\mathrm{e}}$ éd. 2008, n 938, p. 805.
} 
assurément d'ordre public ; mais ce critère ne suffit pas au juge du droit pour s'en saisir $»^{29}$. La raison tient aux spécificités des conditions de recevabilité des moyens appuyant un pourvoi qui ne doivent pas être mélangés de fait et de droit. Ainsi, comme le souligne le rapport précité : «La Cour de cassation ne peut connaître pour la première fois que des moyens de pur droit ou nés de la décision attaquée. Or, le moyen tiré de la violation de la Convention [...] est rarement de pur droit, même si on entend cette notion comme incluant les éléments de fait disponibles dans le débat dont la Cour de cassation peut se saisir ». S'appuyant sur le bilan de l'année 2013, l'étude précise que « toutes les chambres de la Cour de cassation ont eu l'occasion de déclarer irrecevable un moyen tiré de la violation de la Convention de sauvegarde des droits de l'homme et des libertés fondamentales au motif qu'il était nouveau et mélangé de fait et de droit $»^{30}$.

La doctrine de ses différentes chambres sur la question n'est cependant pas arrêtée une fois pour toute, certaines chambres faisant même à l'occasion, preuve d'audace. L'Assemblée plénière quant à elle n'a pas hésité à faire usage de cette possibilité, en de rares occasions il est vrai ${ }^{31}$. En des occasions plus nombreuses en revanche, d'autres formations se sont convaincues d'appliquer d'office, soit la Convention, soit la jurisprudence de la Cour de Strasbourg. C'est le cas de la chambre sociale qui est sans doute - ou du moins l'a été car les choses ont changé depuis quelques années - la plus en pointe sur cette question ${ }^{32}$.

- Relevé d'office d'un moyen tiré du droit de l'UE. La Cour de cassation répond là encore de manière nuancée à cette question. Le relevé d'office d'un moyen tiré du droit de l'Union s'impose aux juges $d u$ fond eu égard aux effets combinés « des règles procédurales françaises » (articles 12 et 18 du code de procédure civile) «et de la jurisprudence de la Cour de justice $»^{33}$. Il en résulte que l'obligation joue (sous la seule réserve du respect du principe dispositif) ${ }^{34}$ indépendamment de la qualification du moyen comme moyen d'ordre public. S'agissant de la Cour de cassation elle-même, l'on retrouve la règle traditionnelle qui découle $a$ contrario de l'article $620 \mathrm{du}$ code de procédure civile qui veut qu'un moyen de cassation ne puisse, sauf à se heurter à une irrecevabilité, être mélangé de fait et droit. Seuls sont donc éligibles au relevé d'office les moyens de pur droit. Il résulte ainsi de la jurisprudence de la Cour qu' " un moyen de cassation est de pur droit dès lors qu'il ne se réfère à aucune considération de fait qui ne résulterait pas des énonciations du juge du fond $»^{3536}$. S'y ajoute la considération que la Haute juridiction a la faculté mais non l'obligation de soulever d'office un

29 Texte du rapport disponible sur le site de la cour de cassation, https://www.courdecassation.fr/publications_26/rapport_annuel_36/ rapport_2013_6615/etude_ordre_6618/notion_ordre_6659/ordre_public_6660/utilisation_ordre_29155.html.

$30 \quad$ Ibid. et la jurisprudence citée.

31 Voir par ex. C. cass., A.P., 24 novembre 1989, n 89-84439.

32 Voir par ex., 15 novembre 1990, M. Pedrono, Association pour la formation professionnelle et le développement de l'éducation permanente, $\mathrm{n}^{\circ}$ 87-45.862 : relevant d'office la violation du principe du « libre exercice des droits de la défense ainsi que la règle, selon laquelle toute personne a droit à ce que sa cause soit entendue équitablement »; Cass. soc., 8 janv. 1997, n 94-42.241 : relevé d'office de la violation par un jugement prudhommal du principe d'impartialité posé par l'article 6, §1 CEDH ; Cass. soc., 14 janv. 1999, Bozkurt c/ CPAM de Saint-Étienne : relevé d'office des articles 14 de la Convention EDH et $1^{\text {er }}$ du Protocole $n^{\circ} 1$, combinés et « tels qu'interprétés par la Cour EDH ».

33 Rapport précité.

34 Le principe dispositif impose d'une part que le juge ne puisse sortir des limites du litige tel que circonscrit par les demandes des parties, d'autre part, qu'il ne puisse se fonder que sur des faits qui sont dans le débat et tels qu'ils ressortent par conséquent des pièces du dossier, Ibid.

35 Ibid. et illustrant ce cas, voir, par exemple, $1^{\text {re }}$ Civ., 16 février 1994, pourvoi no $91-17.270$, Bull.1994, I, nº 68.

36 Rapport précité. 
moyen de pur droit ; toutefois, faisant application de la jurisprudence précitée de la Cour de justice de Luxembourg, la Cour de cassation s'est rangée à l'idée que comme les juges du fond, elle est dans l'obligation de soulever d'office un moyen tiré du droit de l'Union à la condition qu'il s'agisse d'un moyen de pur droit. La question demeure néanmoins posée de savoir si la Cour irait jusqu'à se réserver le pouvoir de censurer un arrêt qui méconnaitrait l'obligation pesant sur les juges du fond, de soulever d'office un moyen mélangé de fait et de droit et ce, pour les besoins de l'application du droit de l'Union ${ }^{37}$.

\section{b. Le moyen d'inconstitutionnalité est-il moyen d'ordre public?}

Le débat sur la nature de la Constitution en tant qu'elle peut être vecteur d'un " contrôle de légalité » des décisions de justice, et à ce titre, donnant lieu à l'identification de moyens d'ordre public ou pouvant (ou devant) être soulevés d'office, reste empreint d'une grande incertitude. Et disons-le d'emblée, les cas correspondants, sans être inexistants, sont rares.

Du reste et sur un plan général, la mobilisation de principes ou règles de valeur constitutionnelle comme moyens d'ordre public appliqués au contrôle de légalité des actes juridiques en général n'est pas des mieux établis. Le mécanisme de la QPC, loin d'avoir clarifié le débat, en a accentué le flou ; l'exigence de principe demeure que le juge a quo doit s'interdire d'entreprendre de la soulever d'office. Tandis que placée, quant à son déclenchement, dans les mains du justiciable, celui-ci peut en faire un usage modulé, la tenant tantôt en réserve au seuil de l'instance, décidant tantôt de la faire surgir dans le débat en appel et même, pour la première fois, en cassation.

Le jeu de la QPC laisse toutefois subsister la question du sort à réserver, devant le juge de droit commun, aux moyens d'inconstitutionnalité qui ne prendraient pas pour cible une disposition législative, mais seraient dirigés, directement et exclusivement, contre un acte distinct et reconnu comme indépendant parce que détaché de toute prédétermination législative. L'hypothèse est, avouons-le, des plus improbables compte tenu de l'extension continue du domaine de la loi et du jeu très contraignant de la réserve de $\mathrm{loi}^{38}$ ainsi que, par voie de conséquence, de la prégnance, fut-elle toute relative désormais, de la théorie de la loi écran. Il y a donc de fortes chances que la plupart des situations mettent en présence de l'existence d'une loi écran intercalée entre l'acte administratif attaqué et la Constitution, ce qui conduira le juge administratif à rejeter sans l'examiner le moyen tiré de la méconnaissance d'une norme constitutionnelle par une loi et présenté à l'appui d'un recours pour excès de pouvoir dirigé contre un acte administratif pris segundum legem ; le moyen sera pareillement, et par principe écarté, devant le juge judiciaire appelé à se prononcer par exemple sur un argument en défense fondé sur l'inconstitutionnalité d'une infraction ou d'une peine établie par la loi.

$37 \quad$ Sur ce point, le rapport précité demeure prudent.

38 Il n'est d'ailleurs pas sans intérêt de relever, à la suite de Karine Michelet (article précité, note 2 supra) que dans l'hypothèse, comme cela a été le cas pour la fixation des dates d'ouverture et de fermeture de la chasse, de régulation réalisée en totalité par la loi, le contrôle de conventionnalité lui-même peut être neutralisé faute d'intervention de tout acte subséquent d'application ou de mise en œuvre. 
Si bien que décidant aussi du sort à réserver cette fois, aux décisions de justice, l'invocation d'office de la Constitution ne peut pas donner lieu à des prises de positions catégoriques et encore moins définitives. La recherche de la « perle rare » permettant d'étayer l'hypothèse d'un relevé d'office d'un moyen d'inconstitutionnalité s'apparente davantage à la quête de Graal. En règle générale, la question n'est pas ou peu abordée par la doctrine ${ }^{39}$. Ce qui évidemment ne signifie pas qu'elle ne se pose pas devant le juge. M. Régis de Gouttes, évoquant à l'occasion d'un colloque tenu en 2007 la question de « l'application de la Constitution par la Cour de cassation » avançait en ce sens que si cette application intervient " généralement, en réponse à des moyens de cassation présentés par les parties, [...] rien n'empêche que la Cour de cassation soulève d'office un moyen de pur droit tiré de la violation de la Constitution $»^{40}$

Sur le plan des principes, il ne manque cependant pas d'arguments pour plaider en faveur de cette éventualité.

Un premier argument tient à ce que le Conseil constitutionnel lui-même n'hésite pas à avoir recours à la technique du relevé d'office, y compris en QPC. Certains auteurs n'hésitent pas à qualifier d'ailleurs « le contentieux constitutionnel des lois » de " contentieux d'ordre public par nature » (G. Drago). L'on s'appuie pour cela, notamment sur la considération des plus significative que le Conseil peut déployer son contrôle dans les cas mêmes de saisines non motivée (ou de désistement) ${ }^{41}$ et se détacher si besoin, des arguments des requérants pour en faire émerger des conclusions ou moyens d'office. Ceci est en mesure de conforter le caractère objectif du contrôle de constitutionnalité des normes (de toutes les normes ?), un contrôle fondé sur l'idée que la Constitution structure un ordre constitutionnel objectif imposant ses contraintes, en particulier à l'ensemble des organes ou acteurs dotés d'un pouvoir normatif.

Un deuxième élément se réfère à l'idée que le contrôle de constitutionnalité poursuit des objectifs qui excèdent l'intérêt immédiat que les requérants - animés au demeurant par des préoccupations différentes - peuvent rechercher. L'examen de constitutionnalité des normes est en ce sens, présenté comme un instrument de « défense de la Constitution » (G. Drago), et même, allons jusqu'à le dire, de «l'ordre constitutionnel », plus qu'une simple voie de droit bornée par la défense de droits subjectifs ou la défense d'intérêts communs (la défense de leurs prérogatives pour les parlementaires ou la protection de leurs droits fondamentaux pour les individus).

\footnotetext{
39 Voir par exemple, B. Genevois, « Le Conseil d'État et l'application de la Constitution », in L'application de la Constitution par les Cours suprêmes, ouvrage précité, pp.31-54;

40 R. DE GoutTES, «L'application de la Constitution par la Cour de cassation », in G. Drago (dir.), L'application de la Constitution par les Cours suprêmes, ouvrage précité, p. 66. L'auteur cite à titre d'exemple un arrêt de la chambre criminelle du 5 juillet 1983 relevant d'office un moyen tiré de la violation l'article 26, alinéa 2 de la Constitution. L'arrêt est en effet explicite : "Sur les moyens relevés d'office, pris de la violation des articles 26 de la Constitution du 4 octobre 1958, 467 et 593 du code de procédure pénale » (Crim., 5 juillet 1983, n 82-92737). On relèvera cependant que le relevé d'office de la violation de la norme supérieure n'est pas dissocié de celui qui bénéficie aux règles de valeur législative du code de procédure pénale.

41 C'est évidemment le cas lorsque le Conseil est saisi, comme il en est d'ordinaire, par le président de la République de l'examen de la compatibilité d'un engagement international avec la Constitution en application de son article 54 . De manière plus singulière, on relèvera aussi le cas qui s'est présenté au Conseil en 2015 à propos de la loi sur le renseignement : sans mettre directement en cause la constitutionnalité de la loi, le président de la République invitait le Conseil à en confronter certaines dispositions expressément visées à un certain nombre d'exigences constitutionnelles également précisées.
} 
Un troisième et dernier élément tient à la place singulière et pour tout dire exclusive qu'occupe la Constitution dans l'ordre juridique étatique. La Constitution n'est pas une norme « ordinaire »; sa supériorité n'est à nulle autre comparable ; au point qu'il est davantage seyant de rehausser encore la terminologie pour évoquer plutôt que sa supériorité, sa suprématie. La Constitution étant, comme le constatent unanimement les juges français, située « au sommet de l'ordre juridique interne »- aucune autre norme (si ce n'est celle produite en la forme constitutionnelle) n'étant, ni en mesure de l'égaler, ni en possession du pouvoir de la contraindre à plier devant elle-elle est par la même dotée d'une « supériorité » d'une nature particulière : à la fois permanente, unique, absolue et générale (dans l'ordre juridique interne s'entend). L'extension des exigences de conformité au-delà de la seule validité (les conditions de production) est d'ailleurs renforcée par le fait que le contenu des normes subordonnées devient pour partie à son tour déterminé par le respect d'exigences constitutionnelles de fond. Si bien qu'il peut paraître recommandable, s'agissant de la Constitution plus que de tout autre norme, que validité et conformité soient mises en situation de coïncider le mieux possible. Le relevé d'office ou l'admission comme moyen d'ordre public des distorsions ou défauts constatables, s'impose dès lors de plus fort en vue de la correction qu'exige le respect de la règle de droit suprême.

Ces arguments se heurtent toutefois :

1\% À la considération que le caractère d'ordre public d'un moyen est laissé à la libre appréciation du juge ;

$2^{\circ}$ / À celle que ce n'est pas la gravité de l'atteinte à la « légalité » qui détermine à elle seule l'attitude qu'adoptera le juge ;

3\% À ceci que l'irrecevabilité d'un moyen l'emporte sur son caractère d'ordre public (tel est le cas en situation de loi écran $)^{42}$

L'hypothèse d'une invocation d'office de la Constitution contre une décision de justice est dans ces conditions d'autant plus rare qu'elle ne pourrait concerner en amont que le cas où un acte administratif par exemple, puisse être directement confronté à la Constitution (absence de loi écran).

Il faut ensuite que l'absence d'invocation du moyen d'inconstitutionnalité frappant l'acte administratif soit suppléée par son relevé d'office. Il n'y a cependant pas toujours de relation de condition à conséquence entre moyen d'ordre public et relevé d'office. Si c'est le cas devant le juge administratif (les moyens d'ordre public étant les seuls éligibles au relevé d'office) il n'en va pas de même devant le juge judiciaire (celui-ci pouvant relever d'office des moyens qui ne sont pas d'ordre public).

Dans le prolongement, on pourrait en inférer en toute logique que devant le juge administratif, un jugement ayant omis de procéder à un relevé d'office d'un moyen d'inconstitutionnalité encourrait la réformation ou l'annulation ex post; ou encore, situation qui aboutirait au même résultat, que ledit

42 Sur ces différents points, voir René Chapus, Droit du contentieux administratif, $12^{\mathrm{e}}$ éd. $2005, \mathrm{n}^{\circ} 932, \mathrm{p} .800$. 
moyen soit soulevé après l'expiration du délai de recours (et ce, sans considération pour le fait qu'il s'agisse d'une demande nouvelle) ou encore pour la première fois en appel ou en cassation et que le juge accepte, au titre de sa qualité de moyen d'ordre public d'en examiner le bienfondé. Une difficulté supplémentaire résulte de la situation qui veut que, hormis le cas où ils sont expressément dits comme tels (ou reconnaissables par utilisation d'une formule fréquente mais pas systématique) ${ }^{43}$, il se peut que le juge en ait bien identifié l'existence tout en le rejetant par prétérition s'il n'est pas fondé ${ }^{44}$.

Enfin, l'hypothèse d'un relevé d'office d'un moyen d'inconstitutionnalité dirigé contre la décision d'un juge ne pourrait s'appliquer par hypothèse qu'aux jugements de première instance ou d'appel.

On est conduit par suite à dresser un bilan globalement stérile relativement à la question évoquée.

Une première hypothèse fournit un indice intéressant. C'est celle du constat de caducité de la loi inconstitutionnelle ; si l'on met à part les avis prononcés en ce sens par le Conseil d'État ${ }^{45}$, les arrêts (ou ordonnances) connus s'appuient non pas sur un relevé d'office mais bien sur un moyen soulevé par les requérants ${ }^{46}$. Cette éventualité est au contraire radicalement exclue par la chambre criminelle de la Cour de cassation : « il n'appartient pas aux tribunaux judiciaires de relever l'inconstitutionnalité des lois, quelle que soit la date de leur promulgation $»^{47}$.

La précision énoncée ci-avant quant au rapport de condition (gravité de l'illégalité de l'acte ou du comportement) à conséquence (qualité d'ordre public du moyen tiré de cette illégalité), met en présence de situations au demeurant tout à fait opposées ; comme celle qui conduit d'un côté le juge administratif à censurer d'office la composition irrégulière d'une juridiction et de l'autre, à ne pas identifier comme d'ordre public, un moyen tiré de l'atteinte aux droits de la défense. Et alors que dans le même temps peut être sujet à relevé d'office un moyen de procédure comme l'absence de saisine du Conseil constitutionnel aux fins de déclassement d'un texte de forme législative avant sa modification par décret ${ }^{48}$

Un certain nombre de cas de figure ne devraient pas du reste prêter à discussion.

Il en va ainsi tout d'abord du moyen tiré de la violation de la chose définitivement jugée et que, s'agissant des actes administratifs, le Conseil d'État considère de longue date et sans difficulté, comme étant d'ordre public ; on pourrait donc assimiler à cet prise de position le cas où un jugement aurait fait application d'un texte (loi, règlement, décision individuelle...) entaché d'inconstitutionnalité alors que celle-ci aurait été déjà constatée par une décision définitive.

Devraient être censurée sur les mêmes fondements, une décision juridictionnelle faisant application d'une loi sans tenir compte des réserves d'interprétation énoncées par le Conseil

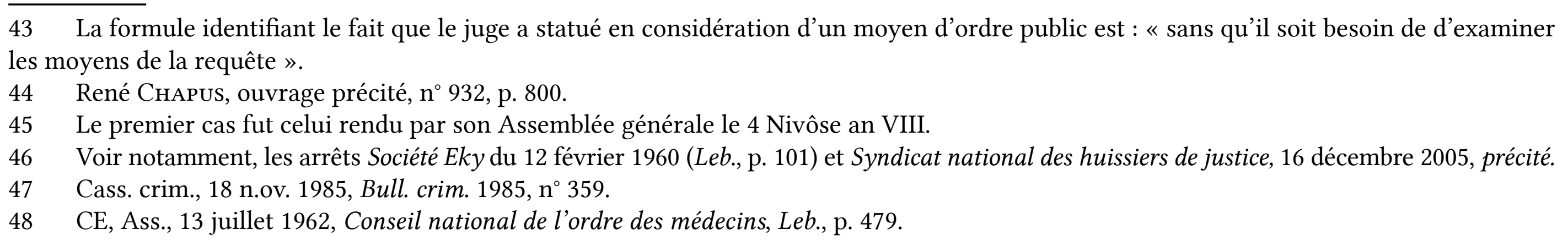


constitutionnel. Comme le soulignaient de manière générale, en 1992, le doyen Favoreu et le professeur $\operatorname{Renoux}^{49}:$ «L'autorité de chose jugée attachée aux décisions de justice est souvent présentée comme découlant d'un principe général du droit applicable sans texte [...]. Il s'agit en réalité d'un principe à valeur constitutionnelle, conséquence directe de la séparation des pouvoirs consacrée par l'article 16 de la Déclaration des droits de l'homme et du citoyen... » et l'on ajoutera, pour ce qui concerne les décisions du Conseil constitutionnel, de l'article 62 de la Constitution. Et les auteurs d'insister : «La violation par un acte administratif de la chose jugée d'une décision du Conseil constitutionnel constituera dès lors, comme pour toute décision de justice, un cas d'inconstitutionnalité (les auteurs soulignent) entrainant l'annulation pour excès de pouvoir, prononcée par le juge administratif dans les conditions du droit commun $»(\text { nous soulignons })^{50}$.

C'est également par application de l'article 13 de la Constitution que sera censuré d'office pour non délibération préalable en conseil des ministres un décret qui devait satisfaire à cette condition.

La solution est identique pour le relevé d'office qui pourrait être fait du principe fondamental reconnu par les lois de la République touchant aux compétences constitutionnellement réservées à l'un ou l'autre ordre de juridiction.

S'agissant enfin de l'hypothèse d'une validation législative d'un acte administratif, l'état du droit révèle une situation plus complexe. Confronté à une loi portant directement atteinte à la chose jugée (par exemple celle redonnant vie à un acte administratif annulé), le Conseil d'État n'avait auparavant d'autre choix que de s'incliner ${ }^{51}$. Il peut aujourd'hui procéder différemment en s'appuyant sur la Convention européenne des droits de l'homme mais à condition que le moyen tiré de la violation de l'article 6 §1 ait été soulevé par les requérants. Mais surtout, sous l'angle de l'examen de constitutionnalité, le Conseil constitutionnel a bien précisé dans sa décision du 22 juillet 1980 qu'il n'appartenait pas au législateur «de censurer les décisions des juridictions ». Le Conseil d'État aurait-il pu tirer toutes les implications de cette interprétation à l'égard d'une loi en vigueur ayant cet objet et ayant échappé à l'examen du Conseil constitutionnel, notamment en relevant d'office l'atteinte au principe de séparation des pouvoirs? Il ne le semble pas dans la mesure où cette situation ne relèverait pas au sens strict du champ d'application de l'article 62 de la Constitution et alors, au surplus, qu'elle serait couverte par la théorie de l'écran législatif. L'entrée en lice de la QPC offre désormais une « porte de sortie » ... au requérant dans une telle hypothèse, notamment pour des lois de validation anciennes. Ce qui montre que l'écran législatif, s'il est partiellement maintenu, se trouve potentiellemnt en sursis.

49 L. Favoreu et Th. S. Renoux, Le contentieux constitutionnel des actes administratifs, Paris, Sirey, 1992, n 244 , p. 125.

50 Ibid. $\mathrm{n}^{\circ}$ 245, p. 125 et la jurisprudence citée ; Adde, René. Chapus, ouvrage précité, $\mathrm{n}^{\circ}$ 939, p. 806 et la jurisprudence citée. Il est important de rappeler que la méconnaissance de la chose jugée par un jugement ou arrêt est, de manière très ancienne, un motif de cassation devant le Conseil d'État (CE, 8 juillet 1904, Botta, Leb., p. 557, concl. Romieu ; GAJA, $19^{\mathrm{e}}$ éd. 2015, n 13, p.79).

51 Par ex., CE, 7 mars 1980, Association de défense des intérêts des étudiants de l'Université de Paris XIII, Leb, p. 128. 


\section{Le reflux constant mais non définitif de «l'écran législatif»}

$\mathrm{Au}$-delà du cas particulier que peut représenter la technique de la validation législative, la théorie de la loi écran peut concerner toutes les autres hypothèses où une disposition législative vient s'intercaler entre la Constitution et la norme infra législative contestée. De telles hypothèses conduisaient, par le passé, le juge de droit commun à opposer au requérant son incompétence pour se prononcer sur un moyen tiré de l'inconstitutionnalité d'un acte administratif, par exemple, dès lors que ce dernier apparaissait au juge comme procédant dans sa substance même de l'inconstitutionnalité médiate - par omission ou par commission - de la loi. Alors même que le requérant se gardait bien dans un tel cas d'invoquer expressément l'inconstitutionnalité de la loi, le juge le ramenait derechef à la réalité en faisant remonter à sa source - la loi - l'inconstitutionnalité opposée au décret par exemple. Le juge avait alors toute aisance pour vouer au rejet le moyen soulevé, réitérant une position de principe qui, sous la plume du Conseil d'État, avait pris, dès 1936, la formulation que l'on sait : « Sur le moyen tiré de ce que l'art. 36 de la loi du 28 févr. 1934, en vertu duquel ont été pris les décrets des 4 avr. et 10 mai 1934, serait contraire aux lois constitutionnelles : Considérant qu'en l'état actuel du droit public français, ce moyen n'est pas de nature à être discuté devant le Conseil d'État statuant au contentieux $»^{52}$.

L'hypothèse ainsi ciblée a pu, paradoxalement, et dans un premier temps, apparaître comme vouée à une extension constante à la mesure même de l'extension corrélative du domaine de la loi sous l'impulsion conjuguée des jurisprudences du Conseil d'État et du Conseil constitutionnel, alors même que celle-ci procédait d'intrusions indues de la part du législateur dans le domaine constitutionnellement déterminé du règlement.

La théorie de la loi écran s'est néanmoins réduite progressivement sous l'effet conjugué de la banalisation du contrôle de conventionnalité et de l'implication étroite des juridictions du filtre dans le pré examen de constitutionnalité de la loi qu'appelle le mécanisme de la QPC. Il n'en reste pas moins que l'interdit qu'oppose - sans doute potentiellement et non définitivement - la loi écran n'a pas été réduit à néant alors même que, comme cela a été souligné, son jeu relèverait d'une forme d'inconséquence fortuite de la part du justiciable (et de son conseil). Il « suffit » pour qu'elle resurgisse, que l'intéressé ait « oublié » de se réclamer, et selon les cas, du moyen (d'inconventionnalité) ou de la nouvelle voie de droit $(\mathrm{QPC})^{53}$. On ne peut, toutefois, exclure une démarche parfaitement consciente en ce sens, mais avec les conséquences que l'on sait ${ }^{54}$.

\footnotetext{
52 Conseil d'État, Section, 6 novembre 1936, Arrighi et Dame veuve Coudert, Leb. p. 966, concl. Latournerie ; l'impossibilité ainsi énoncée prenait dans la bouche du président Latournerie une tournure catégorique : «Si large qu'ait été [...] l'extension des pouvoirs du juge dans l'interprétation de la loi, elle ne saurait aller jamais jusqu'à priver de force un acte législatif [...] Les règles de droit dégagées par une forte jurisprudence ont tôt ou tard [...] même en dehors de leur domaine, une influence salutaire et comme une sorte d'irradiation. C'est le seul rôle, selon nous, qu'en l'état du droit puisse avoir votre jurisprudence, en dehors du domaine qui vous est propre, des actes administratifs. ». Et réitérant cette doctrine plus récemment, CE, 5 janvier 2005, $M^{\text {lle }}$ Deprez et Baillard, $\mathrm{n}^{\circ} 257341$.

53 Voir l'étude de Marguerite CANEdo-PARIs, «La QPC et l'avenir (heureux ?) de la théorie de l'écran législatif », Les petites affiches, 6-7 septembre 2011, p. 7. L'oubli pouvant également prendre la forme de l'absence d'un écrit distinct et motivé.

54 Le Conseil d'État ne manque pas de le rappeler à l'occasion : « qu'en l'absence (...), de toute contestation de la constitutionnalité de la loi par la voie d'une question prioritaire de constitutionnalité, les moyens tirés de ce que cette limitation serait contraire au principe d'égalité ainsi qu'à l'article 2 de la Constitution (...) ne sont pas de nature à être utilement soulevés devant le juge administratif » (CE, 16 juillet 2010, Djamila D., n 319993$)$.
} 


\section{B. Distinction quant aux effets du contrôle}

C'est dans ce registre que les distinctions entre contrôle de constitutionnalité et contrôle de conventionnalité sont (encore) susceptibles de se manifester avec le plus de relief. On peut aller jusqu'à considérer que lorsque sont en cause des décisions de justice, la radicalité qui s'attache au constat de leur inconstitutionnalité, comparée à la relativité avec laquelle s'affirme (en règle générale) un constat d'inconventionnalité, renforce les termes de la distinction que l'on est conduit à faire d'ordinaire, s'agissant des lois, entre les exigences respectives de constitutionnalité et de conventionnalité (absence de ou perte de validité/inapplicabilité). Dit autrement, l'effet du constat d'inconstitutionnalité d'une décision juridictionnelle est beaucoup plus fort et plus étendu que ce que peut entraîner, sur sa « validité », la mise en évidence de son inconventionnalité.

On en tirera pour conséquence l'idée que si, sanctionnant au fond la méconnaissance du principe de séparation des pouvoirs, l'inconstitutionnalité d'une loi ou d'une décision de justice est appelée à produire des effets grosso modo identiques dans tous les cas (sanction de l'annulation/abrogation, impossibilité pour la règle ainsi frappée, d'accéder à la validité), le vice d'inconventionnalité d'une décision de justice produit des effets plus modulés, tantôt radicaux, tantôt relatifs, parce que précisément, dans certaines hypothèses, le principe de séparation des pouvoirs protège, sauf exception, la chose définitivement jugée de sa remise en cause frontale.

Il faut donc là encore, distinguer.

$1 \%$ Corrélation entre sanction de l'inconstitutionnalité et sanction de l'inconventionnalité d'une décision de justice : annulation/infirmation. C'est une donnée importante : ici s'opère en effet une jonction entre les deux formes de contrôles, ce qui conduit à une superposition de leurs effets. Encore faut-il préciser que nous raisonnons ici, s'agissant de la fonction de justice constitutionnelle, dans le cadre du modèle concentré de type européen (et sans tenir compte de son aménagement éventuel en modèle mixte, mi diffus, mi concentré).

Lorsque donc, un juge est appelé à statuer sur la régularité ou le bienfondé d'un jugement à lui déféré et que l'examen auquel il procède fait ressortir, en tout premier lieu, son inconstitutionnalité, l'annulation du jugement ainsi vicié est encourue, soit pour erreur de droit, soit pour violation directe de la règle de droit supérieure (par ex. l'article 62 de la Constitution). Elle sera prononcée soit par la juridiction constitutionnelle compétemment saisie d'un tel examen selon les voies de droit appropriées (recours direct, renvoi préjudiciel, question de constitutionnalité...), soit par le juge de droit commun saisi selon les voies de recours ordinaires ou extraordinaires (appel, cassation pour l'essentiel). En France, si la première voie est pour l'instant fermée aux requérants, la seconde leur laisse des possibilités d'action non négligeables pouvant conduire, en cas de " jugement entaché d'inconstitutionnalité » et selon le cas, à sa mise à néant exclusivement (cassation) ou à son infirmation (soit par réformation ou par annulation partielle). Ainsi, en se fondant sur des dispositions législatives déclarées contraires à la Constitution par le Conseil constitutionnel pour rejeter une requête tendant à obtenir la décharge d'une imposition, et alors même que le Conseil avait précisé 
que la déclaration d'inconstitutionnalité pouvait être invoquée dans toutes les instances en cours, une cour d'appel a commis une erreur de droit ${ }^{55}$.

Par comparaison, et en second lieu, la méconnaissance d'une norme conventionnelle internationale est susceptible de produire les mêmes effets : le juge administratif ou judiciaire pourra prononcer l'annulation d'un jugement de premier instance ou d'appel au motif que ce dernier fait apparaître qu'en statuant comme il l'a fait, le juge a « violé », « méconnu », le ou les textes pertinents ou encore, « a commis une erreur de droit ».

Ainsi, par exemple, après avoir affirmé que la personne qui a assisté une partie à un procès prudhommal ne peut être membre de la juridiction appelée à se prononcer sur le différend opposant les mêmes parties, la Cour de cassation juge qu'un conseil de prudhommes, statuant au fond, étant composé du même délégué syndical qui avait assisté le salarié, la cause n'a pas été entendue par un tribunal impartial et que le jugement prononcé doit être cassé pour violation de l'article $6 \S 1$ de la Convention européenne des droits de l'homme ${ }^{56}$. De même (après relevé d'office du moyen de cassation) la même chambre sociale, après avoir énoncé que l'immunité accordée par la loi du 29 juillet 1881 aux discours prononcés et aux écrits produits devant les tribunaux et qui est destinée à garantir le libre exercice des droits de la défense ainsi que la règle, selon laquelle toute personne a droit à ce que sa cause soit entendue équitablement, interdit, sauf le cas d'abus, de retenir à faute contre leur auteur le contenu de ces discours ou écrits, casse et annule un arrêt de la Cour d'appel de Poitiers qui, pour décider que le licenciement du salarié était fondé sur une cause réelle et sérieuse, a relevé le caractère injurieux des conclusions, l'arrêt attaqué ayant de ce chef, violé l'article $6 \S 1$ de la Convention européenne des droits de l'homme, ensemble, « le principe de la liberté des droits de la défense ${ }^{57}$. La position du Conseil d'État n'est au demeurant pas différente ${ }^{58}$.

$2^{\circ} /$ Distinction entre sanction de l'inconstitutionnalité et sanction de l'inconventionnalité d'une décision de justice : l'obstacle décisif de l'autorité de chose définitivement jugée.

L'on touche là sans doute à l'un des talons d'Achille du droit international en général et même nonobstant une jurisprudence tout en progression et en fermeté des cours européennes - du « droit de la Convention européenne des droits de l'homme » et du droit de l'Union européenne : celui des effets des décisions de justice des juridictions supranationales sur la validité des décisions de justice

$55 \quad$ CE, 6 avril 2016, Société Metro Holding France, n 367256. On ajoutera que l'inconstitutionnalité affectant le jugement ou arrêt pourra résulter selon le cas, de leur irrégularité (par exemple, l'absence du contradictoire dans le déroulé de la procédure juridictionnelle) ou de leur absence de bien fondé (méconnaissance au fond d'un autre principe de valeur constitutionnelle révélant une erreur de droit). La circonstance que s'agissant des principes de valeur constitutionnelle protégeant des «droits garanties », ceux-ci trouvent aussi leur affirmation dans des dispositions de valeur législative repris dans les textes (par exemple, dans le code de procédure pénale) est indifférente dans la mesure où de telles dispositions ne sont au fond que la concrétisation législative de règles ou de principes de valeur constitutionnelle. C'est donc bien au final ces derniers que le juge saisi sanctionnera le cas échéant en prononçant l'annulation du jugement querellé.

56 Cour cass., soc., 8 janvier $1997, \mathrm{n}^{\circ} 94-42.241$.

57 Cour cass., 15 novembre 1990, n 87-45.862 ; et mettant en évidence, après leur relevé d'office, les conséquences, ensemble, des moyens d'inconstitutionnalité et d'inconventionnalité dirigés contre un procès-verbal d'écoute et d'enregistrement d'une conversation téléphonique sur le sort d'un arrêt de la Cour d'appel de Paris, voir : Cour de cass., Ass. plén., 24 novembre 1989, n 89-84-439.

58 Voir notamment, CE 17 décembre 2014, n 369037 : erreur de droit entachant une décision du Haut conseil du commissariat aux comptes et prise en méconnaissance du « droit au recours » (sans autre précision mais alors que la Convention européenne des droits de l'homme est néanmoins mentionnée dans les visas. 
des juridictions internes, notamment suprêmes. Plus particulièrement, cela concerne la détermination de la capacité d'invalidation produite par les premières sur les secondes et les éventuelles conséquences à déduire en cas de réponse positive ou négative à cette question.

Les réponses « internes », notamment françaises à cette interrogation ne sont certes pas inexistantes. Les juridictions « suprêmes » en particulier, ne sont pas restées passives, encore moins figées, face une difficulté qui est devenue centrale dans la problématique de l'interaction des systèmes. Cela se comprend aisément. Les rapports de systèmes doivent dorénavant s'observer non plus seulement de manière en quelque sorte statique - ceux qui mettent aux prises les instruments normatifs - mais de manière dynamique, celles qui concernent les «positions doctrinales » respectives des différents « locuteurs juridictionnels », nationaux et supranationaux (rapports de systèmes juridictionnels et jurisprudentiels). Tous ces acteurs sont de la sorte appelés dans l'exercice ordinaire de leur office, à (re)structurer en les configurant par touches successives, les rapports de systèmes. En ce sens, il n'y a pas un mais une pluralité de " régulateurs des rapports de système » (Anne Levade), intervenant chacun dans un périmètre et à un niveau prédéterminé mais placés eux-mêmes dans des positions d’interdépendance de plus en plus resserrées.

En outre, on assiste, face à un certain nombre de positionnements jurisprudentiels qui apparaissent frontalement contradictoires, à un relèvement progressif du niveau d'intervention (constituant, législatif) où s'opère le processus de mise en adéquation du droit interne par rapport au droit supranational. Ainsi, en France, c'est par la loi que (de manière très ciblée pour le moment), la possibilité de réouverture d'une procédure juridictionnelle a été rendue possible pour pallier l'inconventionnalité constatée d'une décision juridictionnelle interne définitive. C'est du reste, la situation de loin la plus délicate à gérer : celle où la Cour européenne des droits de l'homme conclut à la condamnation d'un État parce que la cause directe de la violation de la Convention réside dans la décision de justice « nationale » elle-même (et, plus précisément, eu égard aux conditions irrégulières de son prononcé) et alors que celle-ci peut se prétendre revêtue de la qualité de force de chose jugée.

Les réponses apportées sur ce point par le droit européen et par les juridictions françaises (et de plus en plus par le législateur) restent empreintes en règle générale d'une grande prudence. Une prudence qui contraste là encore avec l'effet plus radical qu'emportent dans leur sillage les déclarations d'inconstitutionnalité.

L'état du droit demeure marqué par un principe essentiel et invariable jusqu'à présent : celui de l'interdiction que s'impose toute juridiction supranationale (à l'exception notoire de la Cour interaméricaine des droits de l'homme) de pouvoir prononcer l'annulation ou de déclarer nulle une sentence interne porteuse d'une incompatibilité frontale avec une norme supra étatique.

L'onde de choc provoquée par une telle déclaration se fait par suite ressentir de manière plus pondérée selon la nature de l'acte frappé d'inconventionnalité et l'autorité qui l'a édicté. Sous cet angle, le sort des décisions de justice est distinct de celui des actes sur lesquels le juge national a été amené à statuer. 
Le Conseil d'État a ainsi été conduit à franchir une série d'étapes importantes dans le sens d'une prise en considération plus soutenue des arrêts par lesquels la Cour européenne des droits de l'homme constate la violation de la Convention résultant de l'irrégularité du prononcé d'une sanction administrative devenue définitive. Mais, s'il admet dans son arrêt Vernes ${ }^{59}$, et dans le prolongement des arrêts Chevrol ${ }^{60}$ et Baumet $^{61}$, que l'existence d'un arrêt de condamnation de la France par la Cour européenne des droits de l'homme constitue un élément nouveau qui doit être pris en considération par l'autorité administrative investie du pouvoir de sanction, il oppose à cette avancée une double limite : $1^{\%}$ L'exécution de l'arrêt de la Cour n'implique pas, en l'absence de procédure organisée à cette fin, que l'autorité administrative compétente réexamine la question ; $2 \%$ L'exécution de l'arrêt ne peut davantage avoir pour effet de priver les décisions juridictionnelles, y compris celle où il a été statué sur l'acte querellé de leur caractère exécutoire, ce qui présuppose l'affirmation de leur pleine validité ${ }^{62}$.

Doit par ailleurs être rapprochée de cette solution, celle non moins classique selon laquelle, le constat de la durée excessive d'une procédure n'est d'aucun effet sur la validité de la décision juridictionnelle qui clôt la procédure ${ }^{63}$.

La Haute juridiction administrative rejoint par là même la Cour de cassation qui considère de longue date qu'un arrêt de condamnation de la Cour européenne des droits de l'homme est dépourvu d'incidence sur la validité des procédures relevant du droit interne ${ }^{64}$. Par comparaison, on soulignera que la position de la Cour constitutionnelle allemande sur la question est plus nuancée $e^{65}$.

Les deux Hautes juridictions françaises se séparent ainsi assez nettement des « recommandations » ou des « exigences » posées respectivement, par la Cour européenne des droits de l'homme et par la Cour de justice de l'Union européenne en la matière, et alors même qu'il demeure établi, une fois n'est pas coutume, que la première apparaît plus en pointe que la seconde sur la question ${ }^{66}$.

En définitive, et ainsi que le préconise à mots couverts le Conseil d'État, c'est au législateur que revient le soin d'introduire dans le droit interne des dispositifs spécifiques permettant la réformation des décisions passées en force de chose jugée statuées comme contraires à la Convention européenne des droits de l'Homme à la suite d'un arrêt de la Cour de Strasbourg. Si la France, à l'instar d'autres

59 CE Ass., 30 juillet 2014, Vernes, n 358564. L'arrêt met en évidence le fait qu'un traitement plus favorable est désormais réservé aux requérants bénéficiant d'un relèvement d'une sanction administrative déclarée contraire à la Convention par la Cour européenne des droits de l'homme, comparé à celui réservé aux personnes sanctionnées en application d'une décision juridictionnelle définitive (respect de l'autorité de chose jugée).

60 CE, 11 février 2004, Chevrol, $\mathrm{n}^{\circ} 257682$

61 CE, Sect., 4 octobre 2012, Gilbert Baumet, $\mathrm{n}^{\circ} 328502$.

62 V. déjà la rédaction très ferme de l'arrêt Chevrol ; «il ne résulte d'aucune stipulation de la Convention européenne de sauvegarde des droits de l'homme et des libertés fondamentales et notamment de son article 46, non plus que d'aucune disposition de droit interne, que la décision du 13 février 2003 par laquelle la Cour européenne des droits de l'homme a condamné la France puisse avoir pour effet de rouvrir la procédure juridictionnelle qui a été close par la décision du Conseil d’État du 9 avril 1999 à l’issue de laquelle $M^{\text {me }} \mathrm{X}$ a saisi la Cour européenne des droits de l'homme ».

63 Par ex., CE, 6 avril 2016, Société Stud'Arts, n 374489

64 Cass. crim., 3 févr. 1993, Kemmache ; Cass. crim., 4 mai 1994, Saïdi.

65 Voir en ce sens notamment, son arrêt du 14 oct. 2004, BVerfG, 2BvR 1481/04, Neuejuristische Wochenschrift.

66 La Cour de justice impose quant à elle et dans certains cas, le réexamen des décisions administratives violant le droit de l'Union mais pas des décisions juridictionnelles tout en considérant qu'une telle violation peut donner lieu à une obligation de réparation ; une telle obligation relève, en définitive, d'un mécanisme somme toute classique existant en droit international. 
États parties à la Convention (Autriche, Belgique, Danemark, Norvège, Suisse ...), s'est convaincue d'emprunter ce chemin, elle n'a pour l'heure choisi de le faire que dans le domaine pénal et à des conditions au demeurant assez strictes ${ }^{67}$.

On ne peut cependant exclure une évolution plus marquée de l'état du droit en la matière et ce, dans un avenir plus ou moins proche, y compris par la voie prétorienne. Pourrait être de nature à donner force à cette hypothèse, le constat de la capacité renouvelée dont fait montre depuis quelques années la Cour de cassation dans la mobilisation de la Convention européenne des droits de l'homme et surtout, de la jurisprudence de la Cour de Strasbourg ; une telle « empathie conventionnelle » traduit non seulement un nouvel état d'esprit de la Haute juridiction judiciaire en direction du droit conventionnel européen mais également la volonté de poursuivre la stratégie de démarcage (voire de neutralisation par contournement) entamée dès 2010 vis-à-vis de la QPC et à travers elle, vis-à-vis du Conseil constitutionnel ${ }^{68}$. Ce n'est pas tant ici la mise en cause au regard du droit de l'Union, du caractère prioritaire de la question de constitutionnalité «à la française » qui doit retenir l'attention que celle de la «neutralisation conventionnelle » à laquelle il a été procédé des effets différés d'une déclaration d'inconstitutionnalité prononcée en QPC par le Conseil constitutionnel. L'épisode bien connu de la garde à vue à l'occasion duquel l'Assemblée plénière de la Cour de cassation a imposé l'effet immédiat d'une déclaration d'inconventionnalité de la loi (par ailleurs déclarée inconstitutionnelle) par adhésion sans la moindre réserve à l'autorité interprétative de la jurisprudence de la Cour de Strasbourg ${ }^{69}$, n'est au demeurant pas resté isolée ${ }^{70}$. En parfaite orthodoxie juridique, cette doctrine ne fait d'ailleurs que prolonger les implications de la scission actée en 1975 entre constitutionnalité et conventionnalité et cela, sans prise de distance critiquable avec l'article 62 de la Constitution. Il n'en reste pas moins que cette jurisprudence ouvre des perspectives renouvelées au contrôle de conventionnalité, y compris des décisions de justice.

\footnotetext{
67 Article 626-1 du code de procédure pénale (inséré par loi nº 2000-516 du 15 juin 2000, art. 89, fORF16 juin 2000) : « Le réexamen d'une décision pénale définitive peut être demandé au bénéfice de toute personne reconnue coupable d'une infraction lorsqu'il résulte d'un arrêt rendu par la Cour européenne des droits de l'homme que la condamnation a été prononcée en violation des dispositions de la convention de sauvegarde des droits de l'homme et des libertés fondamentales ou de ses protocoles additionnels, dès lors que, par sa nature et sa gravité, la violation constatée entraîne pour le condamné des conséquences dommageables auxquelles la "satisfaction équitable" allouée sur le fondement de l'article 41 de la convention ne pourrait mettre un terme ».

68 Voir l'étude de Marc Guerrini précitée.

69 C. cass., Ass. plén., 15 avril 2011.

70 C. cass., civ., $1^{\text {re }}, 9$ mars $2013, n^{\circ} 11-27.071$.
} 



\title{
CONTRÔLE DE CONSTITUTIONNALITÉ ET CONTRÔLE DE CONVENTIONNALITÉ DES DÉCISIONS DE JUSTICE QUELLES FONCTIONS DIFFÉRENTES?
}

\author{
Emmanuel PIWNICA ${ }^{1}$
}

Un recours dirigé contre une décision juridictionnelle, qui, par hypothèse, a pour objet l'annulation - ou la réformation - de cette décision se fonde toujours sur un moyen pris de la méconnaissance d'un droit consacré par une norme, quelle que soit la valeur de cette norme, son origine, son contenu.

Que fait-on lorsque le jugement est conforme à la norme ? Sa validité ne serait pas contestable. Quoique...

Ne peut-on pas contester la norme ? Il y a là, il est vrai, une mise en abyme : la juridiction qui doit appliquer la norme en vue de sanctionner un acte ou un fait qui la méconnaît est invitée à la désapprouver, purement et simplement.

C'est le comportement à l'origine du procès qui recevra - éventuellement - l'approbation du juge et c'est la norme que cette attitude a transgressée qui sera sanctionnée : le gardien de la loi écarte la loi.

Cela étant, la situation n'est pas nouvelle : le juge administratif annule les actes réglementaires, c'est même sa raison d'être, le juge civil peut renvoyer la question de leur validité au juge administratif tandis que le juge répressif l'apprécie lui-même. Faut-il rappeler que, depuis plus de 40 ans, le juge judiciaire écarte les lois contraires aux conventions internationales ${ }^{2}$, la même solution étant adoptée par le juge administratif depuis près de $30 \mathrm{ans}^{3}$ ? Et la question prioritaire de constitutionnalité permet, désormais, de mettre à l'écart les lois contraires à la Constitution.

Contrôle de conventionnalité, contrôle de constitutionnalité, le pouvoir reconnu aux juridictions est considérable : elles peuvent - doivent -, toutes, exercer un contrôle de conventionnalité. Et, à l'exception, d'une part, du Tribunal des conflits ${ }^{4}$ qui n'est, par hypothèse, subordonné ni au Conseil

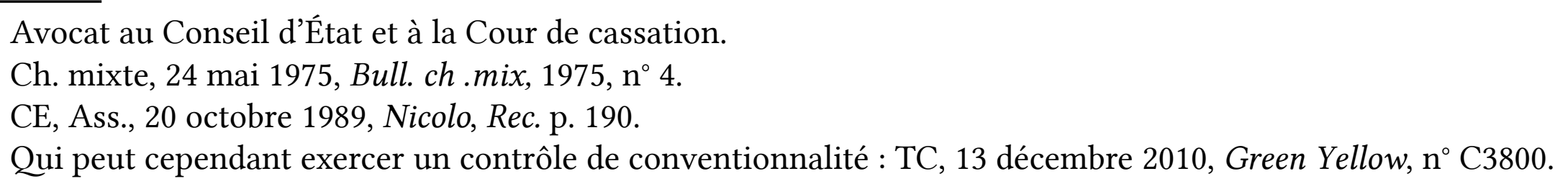


d'État ni à la Cour de cassation, et, d'autre part, de la cour d'assises ${ }^{5}$, pour des raisons évidentes de fonctionnement d'un jury, elles peuvent toutes exercer un contrôle de constitutionnalité.

Mieux, ce contrôle de conventionnalité ne se limite plus ni à une vérification abstraite de la validité de la loi, ni à une appréciation concrète d'une situation pour vérifier que le comportement en cause est conforme à une loi elle-même conforme à un traité, selon la hiérarchie classique des normes. Le juge peut, dans un premier temps, valider la loi, dans un deuxième temps, qualifier le comportement en cause au regard de la loi pour, dans un troisième temps, en écarter l'application car les conséquences de sa mise en œuvre au cas d'espèce seraient excessives. Un nouveau contrôle de proportionnalité est né ${ }^{6}$. Une latitude considérable est ainsi accordée au justiciable qui, non content de contester la loi au regard d'une norme supérieure, peut encore demander à ce que cette loi soit mise en suspens, à son seul profit, parce que son application, concrète, ne serait pas juste.

De nouveaux droits sont ainsi accordés au justiciable à qui il appartient de déterminer les modalités de leur mise en œuvre, le cas échéant en opérant des choix. Si la situation à l'origine du procès paraît conforme à la norme applicable, il lui est loisible de contester cette norme. S'il s'agit d'une loi, il a la faculté, le cas échéant, de poser une question prioritaire de constitutionnalité ou encore de contester sa conventionnalité. Il peut aussi suggérer une interprétation, voire une question préjudicielle dans l'hypothèse où un traité le prévoit. Ou encore demander à ce que cette loi ne soit pas appliquée dans ces circonstances particulières.

Comment vont s'articuler ces deux contrôles, respectivement de constitutionnalité et de conventionnalité ? Faut-il choisir ? De quelle manière ? Et quelle est l'incidence de ce nouveau contrôle de proportionnalité?

À la nécessité des exigences de droit processuel (I) fait écho le hasard des circonstances particulières relevant du droit substantiel (II).

\section{Le droit processuel ou la nécessité}

Il n'est pas question ici de présenter de manière exhaustive et complète les techniques procédurales permettant, à l'occasion de la contestation d'une décision de justice, de remettre en cause la norme applicable, le cas échéant par le biais d'une question prioritaire de constitutionnalité ou en soulevant un moyen d'inconventionnalité. Il s'agit plus simplement de confronter, sur le plan du droit processuel, question de constitutionnalité et question de conventionnalité en relevant certains aspects qui leurs sont inhérents (A) pour apprécier ensuite si le cumul est souhaitable (B).

\footnotetext{
$5 \quad$ Article $23-1$ de l'ordonnance $\mathrm{n}^{\circ}$ 58-1067 du 7 novembre 1958 portant loi organique sur le Conseil constitutionnel dans sa rédaction résultant de l'article $1^{\text {er }}$ de la loi organique $\mathrm{n}^{\circ} 2009-1523$ du 10 décembre 2009.

Les deux arrêts considérés comme fondateurs de ce nouveau contrôle de proportionnalité sont, en matière civile : $1^{\text {re }}$ Civ., 4 décembre 2013, Bull. 2013, I, n 234 ; Dalloz actualité, 13 déc. 2013, obs. R. MÉsA ; Dalloz 2014. 179, obs. C. de la Cour, note F. CHÉNEDÉ; ibid. 153, point de vue H. Fulchiron ; ibid. 1342, obs. J.-J. Lemouland et D. Vigneau ; Af famille 2014. 124, obs. S. Thouret ; ibid. 2013.663, point de vue F. ChÉnedÉ ; RTD civ. 2014. 88, obs. J. HAusER ; ibid. 307, obs. J.-P. MARguÉnAUd ; en matière administrative : CE, Ass., 31 mai $2016, \mathrm{n}^{\circ} 396.848, M^{\text {me }}$ Gonzalez Gomez, A7DA 2016, p. 1398, L. Dutheillet De Lamothe et G. Odinet ; Dr. famille 2016, comm. 178, R. Vessaud ; Dr. famille 2016, étude 15, J.-R. Binet ; FCP G 2016, 864, J.-P. Vauthier et F. Vialla ; Procédures 2016, comm. 244, S. Deygas ; RFDA 2016, p. 740, concl. A. Bretonneau, note P. Delvolvé ; et on ne compte plus les articles, contributions, interviews et colloques consacrés à cette notion.
} 


\section{A. Les mérites respectifs de la question prioritaire de constitutionnalité et du moyen d'inconventionnalité}

\section{La question prioritaire de constitutionnalité}

À la liberté du justiciable (a) répond la contrainte qui pèse sur le juge (b).

a) Le rôle des parties

Seul le justiciable peut soulever une question prioritaire de constitutionnalité, ce qui lui donne une maitrise totale de la procédure dont la souplesse est indiscutable. Cette facilité de mise en œuvre de la question prioritaire de constitutionnalité est sans doute l'un des éléments à l'origine de son succès.

La question peut être posée à tout moment de la procédure, que ce soit en première instance, en appel ou devant le juge de cassation, tant en demande qu'en défense. Peu importe qu'il s'agisse d'une exception, d'une fin de non-recevoir, d'un moyen nouveau. Il faut et il suffit que la disposition en cause soit applicable, qu'elle n'ait pas déjà été soumise au Conseil constitutionnel sauf changement de circonstances et, enfin, qu'elle ne soit pas dépourvue de caractère sérieux en première instance ou en appel, ou qu'elle présente un caractère sérieux devant le Conseil d'État ou la Cour de cassation. Quant aux exigences de forme - un écrit distinct et motivé portant la mention question prioritaire de constitutionnalité -, elles sont, somme toute, raisonnables ${ }^{7}$.

Il y a certes des distinctions sur les modalités de traitement des décisions rejetant les questions selon qu'elles relèvent du Conseil d'État ou de la Cour de cassation. Dans un cas, il faut impérativement former le recours contre l'arrêt qui refuse la transmission si l'on veut soumettre la question au Conseil d'État ${ }^{8}$. La situation est inverse devant la Cour de cassation : il est inutile de former un recours contre le refus de transmission ; il est en revanche indispensable de présenter à nouveau la question prioritaire de constitutionnalité devant la Cour de cassation si l'on veut obtenir son examen. Ces distinctions sont claires et elles sont, désormais, connues.

Le justiciable dispose, sur le plan procédural, d'une marge d'appréciation sans limite ; il décide seul, de la question qu'il va poser ; s'il va, ou ne va pas la poser, puisqu'elle ne peut être relevée d'office par le juge ; du moment opportun pour la poser, en première instance, en appel, devant le juge de cassation. C'est donc une liberté pleine et sans entrave qui lui est accordée.

Le juge est, en revanche, soumis à des exigences beaucoup plus sévères.

\footnotetext{
$7 \quad$ Article $23-1$ de l'ordonnance $\mathrm{n}^{\circ}$ 58-1067 du 7 novembre 1958 portant loi organique sur le Conseil constitutionnel modifiée ; les règles fixées tant par le code de justice administrative que par les codes de procédure pénale et de procédure civile sont limitées.

$8 \quad$ Article R. 771-9 du code de justice administrative.

9 Ass. Plén., 23 juillet 2010, Bull. 2010, Ass. Plén., nº 2.
} 


\section{b) L'office du juge}

À la liberté des parties aux procès fait écho la contrainte pesant sur le juge. Il ne peut soulever d'office une question prioritaire de constitutionnalité. En revanche, s'il est saisi - et quel que soit le moment auquel il est saisi -, il doit se prononcer par priorité sur la question posée avant de trancher tout autre point. Les cours et tribunaux statuent « sans délai $»^{10}$. Quant au Conseil d'État et à la Cour de cassation, ils disposent d'un délai de 3 mois à compter de l'enregistrement de la question, qu'elle soit posée directement devant eux ou transmise par le juge a quo pour se prononcer sur un éventuel renvoi ${ }^{11}$.

Il existe ainsi un double filtre : celui du juge a quo, puis celui du Conseil d'État ou de la Cour de cassation. Et, à cela, s'ajoute qu' in fine, le Conseil constitutionnel, peut, en déterminant les effets de sa décision en application de l'article 62 de la Constitution, priver le justiciable du bénéfice d'une décision d'annulation. Pour autant, ces contraintes limitées n'ont pas altéré l'enthousiasme des justiciables pour la question prioritaire de constitutionnalité ainsi qu'en atteste leur nombre depuis l'entrée en vigueur de la réforme.

Mais ces contrôles ne sont que d'ordre processuel : le juge a quo peut décider de ne pas transmettre la question, le Conseil d'État et la Cour de cassation de ne pas la renvoyer au Conseil constitutionnel et ce dernier d'abroger la disposition en fixant les effets de sa décision ainsi qu'il résulte de l'article 62 de la Constitution.

Ces considérations ne suffisent pas à détourner le justiciable au bénéfice d'un contrôle de conventionnalité.

\section{Le moyen d'inconventionnalité}

Si le moyen d'inconventionnalité obéit à des règles processuelles strictes (a), son dénouement n'est pas enfermé dans un délai (b).

\section{a) La rigueur des règles processuelles}

Les parties ne peuvent poser une question de conventionnalité qu'à la seule condition que les règles générales de droit processuel le permettent.

C'est donc par facilité de langage que l'on parle de question de conventionnalité. En réalité, il faut soulever un moyen, en demande ou en défense, pris de la méconnaissance d'une norme internationale. Et il ne suffit pas que la loi dont la contestation est entreprise soit applicable à l'instar de ce que prévoit l'article 23-2 de l'ordonnance du 7 novembre 1958 modifiée pour la question prioritaire de constitutionnalité. Il faut un véritable moyen qui doit répondre aux exigences classiques pour qu'il puisse être examiné : il doit être recevable; et opérant. Il faut que cette question de conventionnalité soit posée à l'appui d'un moyen recevable. S'il s'agit d'une exception, elle répondra à ce régime. Si

10 Article 23-2 de l'ordonnance n 58-1067 du 7 novembre 1958 portant loi organique sur le Conseil constitutionnel modifiée. 11 Article 23-4 de l'ordonnance ${ }^{\circ}$ 58-1067 du 7 novembre 1958 portant loi organique sur le Conseil constitutionnel modifiée. 
le moyen est mélangé de fait, il ne peut être présenté pour la première fois devant le juge du droit, etc. Et il faut que le moyen soit opérant. La réponse qui lui est donnée doit donc être nécessaire à la solution du litige. Pas question, ici, de se borner à affirmer que la loi est applicable.

Il est vrai qu'il existe un débat sur cette notion de loi applicable : si le moyen pris de la méconnaissance par la loi en cause d'une norme supérieure est opérant, la loi est nécessairement applicable. En revanche, la loi peut être applicable au litige sans que, pour autant, un moyen opérant soit soutenu, ou même soit susceptible de l'être.

Et le juge judiciaire peut relever d'office un moyen pris de la méconnaissance d'un traité international.

On voit ici que les rôles se partagent et que le justiciable perd la maîtrise des termes du débat.

b) L’absence de délai spécifique

La méconnaissance par la loi d'un traité n'étant que l'un des moyens venant au soutien d'une argumentation, le juge a, certes, le devoir de l'examiner lui-même, sauf à envisager un renvoi préjudiciel dans les cas où il est éventuellement possible. Mais un tel moyen ne présente aucun caractère prioritaire. Il sera examiné avec les autres moyens du recours, et peut être pas, s'il n'est pas nécessaire à la solution du litige.

S'agissant du droit de l'Union européenne, le renvoi préjudiciel appartient au seul juge ; et il ne portera que sur l'interprétation du droit de l'Union - ou sur sa validité - mais pas directement sur la validité de la loi interne. Et les renvois à Luxembourg prennent un temps considérable hors les cas rares qui bénéficient de la « procédure accélérée » ou de la « procédure préjudicielle d'urgence ». Étant observé que, selon les dispositions de l'article 267 du Traité sur le fonctionnement de l'Union européenne, seuls le Conseil d'État et la Cour de cassation ont le devoir de renvoyer une question préjudicielle à la Cour de justice de l'Union européenne, sachant qu'il leur appartient d'apprécier si les conditions d'un tel renvoi sont réunies conformément à la jurisprudence Cilfit ${ }^{12}$.

Enfin, si «bloc de constitutionnalité » et «bloc de conventionnalité », ne sont pas si différents, les droits fondamentaux, tout au moins pour ce qui est des plus classiques, étant, somme toute, comparables, quel que soit le texte qui leur sert de support ${ }^{13}$, il n'en reste pas moins qu'il faut s'armer de patience pour avoir une réponse de la Cour européenne des droits de l'homme, à l'issue d'un procès où aura été épuisé l'ensemble des voies de recours utiles - hors les cas exceptionnels ${ }^{14}$.

Et le mécanisme de l'avis consultatif prévu par le protocole n 16 à la Convention de sauvegarde des droits de l'homme et des libertés fondamentales, n'est toujours pas en vigueur faute de ratification suffisante.

12 CJCE, 6 octobre 1982, Cilfit, 283/81.

13 Sur les différences de solution selon la juridiction suprême qui en connaitra voir D. de Béchillon, « Cinq cours suprêmes ? Apologie (mesurée) du désordre », Pouvoirs, n¹37, avril 2011, p. 33

14 Dans l'affaire Lambert, un délai inférieur à un an s'est écoulé entre l'arrêt du Conseil d'État (24 juin 2014) et celui de la Cour européenne des droits de l'homme (5 juin 2015). 
La question prioritaire de constitutionnalité est donc la seule manière d'obtenir l'annulation d'une norme de valeur législative dans un délai raisonnable. Le contrôle de conventionnalité qui échoue devant le juge national suppose une saisine a posteriori du juge européen, qui n'est pas enfermé dans un délai raisonnable. Quant au droit de l'Union européenne, il est entre les mains du seul juge, qui décide de renvoyer ou non une question préjudicielle.

Pour autant, loin de s'exclure, les deux contrôles se cumulent.

\section{B. Le cumul de la question prioritaire de constitutionnalité et du contrôle de conventionnalité}

Par hypothèse, le débat sur le cumul ne peut exister qu'à l'égard d'une norme de valeur législative.

Si la norme est supérieure à la loi, le juge ne saurait en apprécier la validité. Il ne peut apprécier la validité d'un traité ${ }^{15}$ et, s'agissant du droit de l'Union européenne, a le devoir de renvoyer une question de validité des actes de l'Union à la Cour de Luxembourg ${ }^{16}$.

Pour les normes subordonnées à la loi, le juge de droit commun a tous les pouvoirs ; le Conseil d'État pour tous les actes administratifs qui relèvent de son office et le juge judiciaire non seulement pour les actes de droit privé, mais également pour les actes administratifs dans deux cas : méconnaissance tant du droit communautaire que d'une jurisprudence constante du Conseil d'État ${ }^{17}$.

Concernant une loi, la question peut se poser, sur un plan procédural, de savoir s'il est préférable de poser une question prioritaire de constitutionnalité ou un simple moyen de conventionnalité.

On observera, d'abord, que cette difficulté ne surgit que dans l'hypothèse où le débat porte effectivement sur la validité de la norme législative en cause, indépendamment de son application concrète au cas d'espèce.

Et on relèvera ensuite que, dans les cas où la norme est effectivement en cause, il n'y a aucune raison de choisir de manière exclusive l'un ou l'autre contrôle. Au contraire, il paraît souhaitable de cumuler. D’autant que le cumul n'est pas prohibé.

La réponse à une question de constitutionnalité est quasi immédiate. Si elle négative, elle ne présage pas nécessairement une réponse positive d'un autre juge. Certes. Mais rien n'est moins sûr ${ }^{18}$.

Et cela même s'il est vrai que la question de constitutionnalité ne paraît pas un préalable indispensable à la saisine de la Cour européenne des droits de l'homme (1) et n'exclut pas la spécificité du droit de l'Union européenne (2).

CE, Ass., 23 décembre 2011, M. Kandyrine de Brito Païva, n 303.678, Rec. p. 624, concl. J. Boucher ; RFDA 2012, p. 1 ; p. 26 note D. AlLand. CJCE, 22 octobre 1987, Foto-Frost, C-314/85.

TC, 17 octobre 2011, SCEA du Chéneau n C3828 et Chérel n C3829, Rec. p. 698 ; FCP A 2011, 2354, note H. PAULiat ; Dr. adm. 2012, comm. 9, note F. MELLERAY.

18 Cf. en ce sens, D. DE BÉCHILLON, préc. note 12. 


\section{L'épuisement des voies de recours ou le voyage de Strasbourg implique-t-il un arrêt rue de Montpensier?}

Les deux contrôles ayant des objets différents et le juge de la question prioritaire de constitutionnalité ne pouvant être saisi directement par le justiciable, on pourrait conclure, en application de la jurisprudence Spadea de la Cour européenne des droits de l'homme, que l'on peut soulever un moyen pris de la méconnaissance de la Convention de sauvegarde des droits de l'homme et des libertés fondamentales sans soulever son pendant sous le visa de la Constitution et, le cas échéant, saisir la Cour de Strasbourg sans se voir opposer une absence d'épuisement utile des voies de recours faute d'avoir présenté une question prioritaire de constitutionnalité ${ }^{19}$. Et il est vrai que cette question ne se pose que dans le cas où est discutée la validité même de la loi, de manière abstraite, indépendamment de tout contrôle concret sur son application dans les circonstances d'une espèce.

Même si la question de constitutionnalité n'est pas un préalable nécessaire, il n'en reste pas moins qu'il n'y a aucun obstacle à la poser pour avoir une réponse immédiate, bien au contraire. Il n'existe aucune raison valable, face à une norme législative méconnaissant un droit fondamental inscrit tant dans la Constitution que dans une norme internationale, de s'abstenir de poser une question de constitutionnalité. Une telle démarche ne serait pas cohérente. Elle ne se comprend que dans l'hypothèse où ce qui est en cause n'est plus la norme elle-même mais son application concrète à la situation d'espèce.

\section{La spécificité du droit de l'Union européenne}

De la même manière les exigences liées au droit de l'Union européenne n'ont ni pour objet ni pour effet d'exclure la question prioritaire de constitutionnalité.

S'il s'agit d'appliquer l'article 88-1 de la Constitution, la transposition d'une directive résultant d'une exigence constitutionnelle, comme l'énonce la décision Économie numérique ${ }^{20}$, la loi contraire au droit de l'Union européenne doit être écartée. Cela résulte de la décision feux en ligne ${ }^{21}$. Et la question prioritaire de constitutionnalité ne prive pas le juge de droit commun du pouvoir, voire du devoir, de renvoyer une question préjudicielle à Luxembourg.

\footnotetext{
19 La Cour de Strasbourg a jugé que la voie de recours constitutionnel italienne ne saurait être incluse dans l'épuisement des voies de recours interne (19 décembre 1989, Brozicek c/ Italie, n 10964/84; 26 février 1993, Padovani c/ Italie, n 13396/87, A7DA 1993. 483, chron. J.F. Flauss ; Rev. science crim. 1994. 362, obs. R. Koering-Joulin ; 28 septembre 1995, Spadea et Scalabrino c/ Italie, $\mathrm{n}^{\circ} 12868 / 87$, AfDA 1995. 124, chron. J.-F. Flauss ; ibid. 212, chron. J.-F. Flauss). Elle énonce : « La Cour rappelle que, dans le système juridique italien, un individu ne jouit pas d'un accès direct à la Cour constitutionnelle pour l'inviter à vérifier la constitutionnalité d'une loi ; seule a la faculté de la saisir, à la requête d'un plaideur ou d'office, une juridiction qui connaît du fond d'une affaire. Dès lors pareille demande ne saurait s'analyser en un recours dont l'article 26 exige l'épuisement ». P. Dourneau-Josette, « De l'esprit de la règle de l'épuisement des voies de recours internes dans la Convention européenne des droits de l'homme », Fustice et Cassation, Revue annuelle des avocats au Conseil d'État et à la Cour de cassation, 2008, p. 78. Voir également pour un avis différent : M. Guillaume, «Question prioritaire de constitutionnalité et Convention européenne des droits de l'homme », Nouveaux Cahiers du Conseil constitutionnel, $\mathrm{n}^{\circ} 32$, juillet 2011.

20 Cons. const., déc. $\mathrm{n}^{\circ}$ 2004-496 DC du 10 juin 2004, Loi pour la confiance dans l'économie numérique.

21 Cons. const., déc. $\mathrm{n}^{\circ}$ 2010-605 DC du 12 mai 2010, Loi relative à l'ouverture de la concurrence et à la régulation du secteur des jeux d'argent et de hasard en ligne.
} 
Quant à l'exigence constitutionnelle de transposition des directives, elle n'est pas au nombre des droits et libertés que la Constitution garantit au sens de l'article 61-1 de la Constitution.

Ce n'est donc que dans le cadre du contrôle a priori qu'on peut invoquer un tel manquement.

Est-on pour autant démuni ? Certainement pas.

D'abord parce qu'après l'article 88-1 figure dans la Constitution un article 88-2 : le mandat d'arrêt européen a donné au Conseil constitutionnel l'occasion de renvoyer une question préjudicielle à Luxembourg. Le Conseil constitutionnel juge dans les limites de sa marge d'appréciation, mais interroge la Cour de Luxembourg pour l'interprétation du droit de l'Union, en application de l'article 267 du Traité sur le fonctionnement de l'Union européenne ${ }^{22}$.

Ensuite parce que rien n'empêche de suggérer une question préjudicielle qui pourra être accueillie, alors même que l'on pourrait présenter une question prioritaire de constitutionnalité, la question préjudicielle ne privant pas le justiciable de présenter, voire de présenter à nouveau, une question prioritaire de constitutionnalitéé 23 .

Bref, il ne semble pas qu'il y ait une attitude spécifique à adopter lorsque le contrôle de conventionnalité relève in fine de la Cour de Luxembourg.

Le débat a été initié, on le sait, par la décision Melki de la Cour de cassation ${ }^{24}$.

À cette décision Melki, le Conseil d'État a fait écho par sa décision Rujovic ${ }^{25}$, laquelle a elle-même été rendue deux jours après la décision du Conseil constitutionnel feux en ligne ${ }^{26}$.

On pensait que la question était réglée.

Le contrôle de conventionnalité, quand bien même concernerait-il le droit de l'Union européenne, pouvait se cumuler, sans difficulté, avec le contrôle de constitutionnalité.

La question de constitutionnalité étant prioritaire, elle devait être réglée liminairement, quand bien même le demandeur ne l'aurait posée que de manière subsidiaire.

C'est d'ailleurs la solution qui a été retenue dans l'affaire Métro Holding ${ }^{27}$. Il s'agissait d'une discrimination à rebours. Pour apprécier le respect, en matière fiscale, du principe d'égalité, le Conseil constitutionnel a dû faire le détour suivant : constater que l'application de la loi en cause dans

22 Cons. const., déc. $\mathrm{n}^{\circ}$ 2013-314 QPC du 4 avril 2013, férémy $F$.

23 CE, Ass, 31 mai 2016, facob, n 393.881, AfDA 2016, p. 1392, L. Dutheillet de Lamothe et G. Odinet ; Dr. adm. 2016, comm. 51, G. Eveillard ; Dr. fisc. 2016, act. 354, N. Jacquot et P. Mispelon ; Dr. fisc. 2016, 476, D. Gutman et S. Austry ; FCP A 2016, act. 486, L. Erstein ; FCP G 2016, 759, B. Bonnet.

24 Ass. Plén., QPC, 16 avril 2010, n 10-40.001; RFDA 2010, p. 445, avis M. Domingo ; RTD civ. 2010, p. 499, obs. P. Deumier et p. 743, note P. RÉmY-Corlay ; AfDA 2010, p. 1023, note P. MANin ; D. 2010, p. 1234, chron. P. Cassia et E. Saulnier-Cassia ; RTD eur. 2010, p. 577, étude J. DutheIl de LA Rochère ; Constitutions 2010, p. 218, obs. B. MATHIEU.

25 CE, 14 mai 2010, Rujovic, Rec. p. 165 ; RFDA 2010, p. 458, note P. GAÏ̈ et p. 709, concl. J. Burguburu ; Constitutions 2010, p. 389 , obs. A. Levade; D. 2010, p. 1234, chron. P. Cassia et E. Saulnier-Cassia.

26 Préc. note 21.

27 Cons. const., déc. $\mathrm{n}^{\circ}$ 2015-520 QPC du 3 février 2016, Application du régime fiscal des sociétés-mères aux produits de titres auxquels ne sont pas attachés des droits de vote. 
d'autres États membres constitue l'application nécessaire et inconditionnelle d'une directive sans atteinte à l'identité constitutionnelle de la France.

Dans cette hypothèse, il n'y a pas de contrôle.

En revanche, si l'application en France ne procède pas de l'application de la directive, une distinction selon la localisation géographique est discriminatoire. Il s'agit donc d'une discrimination à rebours. C'est la transposition, par le Conseil constitutionnel à l'égard d'une loi, de la jurisprudence du Conseil d'État en matière réglementaire ${ }^{28}$.

Le dernier acte est la décision d'assemblée du Conseil d'État du 31 mai 2016 ${ }^{29}$. L'hypothèse est originale : la discrimination à rebours ne peut résulter que d'une interprétation du droit communautaire. C'est donc la réponse qui sera donnée par la Cour de Luxembourg en interprétation du droit de l'Union européenne qui permettra de savoir s'il y a ou non une différence de traitement et discrimination. En l'état, rien ne permet de l'imaginer. La question prioritaire de constitutionnalité n'est donc pas, à ce stade, tant que la Cour de Luxembourg n'a pas répondu, sérieuse. Ce n'est que dans l'hypothèse où il y aurait discrimination qu'il pourrait y avoir nouvelle question. Le mécanisme est, il faut l'admettre, subtil, puisque le sérieux de la question dépend de la réponse donnée par la Cour de Luxembourg. Prioritaire pour le juge, la question devient ainsi subsidiaire pour les parties, qui ne sont pas privées pour autant, ainsi que le rappelle le Conseil d'État, du droit de la poser à nouveau.

Sur le plan processuel, il n'y a pas concurrence entre question prioritaire de constitutionnalité et question de conventionnalité mais au contraire complémentarité, assurée par des mécanismes processuels mis en place, qui se veulent harmonieux.

Il n'y a pas davantage de dissonances à l'égard du droit substantiel.

\section{Au hasard du droit substantiel}

Les parties disposent d'une liberté considérable qui leur permet, là encore, de tirer profit de la complémentarité de la question prioritaire de constitutionnalité et du moyen d'inconventionnalité.

En présence d'une double contrariété, respectivement aux droits et libertés garantis par la Constitution et à une norme internationale, quel choix le justiciable devra-t-il opérer ?

Le cumul ; sans la moindre hésitation, parce que le contrôle abstrait sur la norme pourra s'opérer de la même manière (A) et que le contrôle concret sur une situation ne pâtit pas du contrôle sur la norme (B).

28 CE, 6 octobre 2008, Compagnie des architectes en chef des monuments historiques et autres, Rec. p. 341.

29 CE, Ass. 31 mai 2016, Jacob, préc. note 23. 


\section{A. Le contrôle abstrait de la norme}

La loi doit respecter tant la Constitution que les traités internationaux. On connaît le débat sur la hiérarchie entre la Constitution d'un côté, un traité international de l'autre ${ }^{30}$. On se bornera à observer que, la méconnaissance par la loi tant de la Constitution que d'un traité international aboutit à une solution différente, selon l'autorité qui prononcera cette invalidation : le Conseil constitutionnel fera application de l'article 62 de la Constitution et abrogera la loi ; le juge de droit commun, ne pourra qu'écarter son application dans les circonstances de l'espèce. La norme inconstitutionnelle ou inconventionnelle doit demeurer inappliquée. Et la décision de justice qui applique une norme contraire à la Constitution ou à une convention internationale méconnaît, elle-même, cette norme et doit, par suite, être annulée.

Mais dans un cas comme dans l'autre, l'examen de la validité de la norme est un contrôle abstrait (1) et de proportionnalité (2).

\section{Un contrôle abstrait}

Il s'agit ici d'un contrôle abstrait : la vérification qu'une norme - la loi - est conforme à une norme supérieure (la Constitution ou un traité).

Ceci relève de l'office du juge, qu'il s'agisse du juge du principal en cas de contrôle de conventionnalité voire du juge de l'Union européenne, lorsqu'il s'agit, par exemple, d'apprécier la validité d'une norme de l'Union européenne ou du juge constitutionnel, lorsqu'il s'agit de contrôle de constitutionnalité. Dans un cas comme dans l'autre, le contrôle portera, à ce stade, sur l'examen de la norme et l'appréciation de sa validité intrinsèque, abstraite, au regard d'une norme supérieure.

\section{Un contrôle de proportionnalité}

Cette vérification, pour abstraite qu'elle soit, constitue un contrôle de proportionnalité.

L'application du principe de proportionnalité à la validité d'une norme n'est pas une nouveauté. On songe à l'article 4 de la Déclaration de 1789 (« la loi ne doit établir que les peines strictement et évidemment nécessaires... »), à la jurisprudence administrative ${ }^{31}$ ou encore à la jurisprudence civile dans toutes les hypothèses où la loi, elle-même, a organisé un tel contrôle : la clause pénale manifestement dérisoire ou excessive peut faire l'objet d'une révision judiciaire ${ }^{32}$, les irrégularités les moins

\footnotetext{
30 Voir encore, D. DE BÉchillon, préc. note 12 et aussi : pour le juge administratif : CE, Ass., 30 octobre 1998, Sarran, Levacher et a., n² 200286, Rec. p. 368 ; pour le juge judiciaire, Ass. Plén,, 2 juin 2000, Bull. ass. plén. n 4 ; voir également les conclusions J. Boucher sur CE, Ass. 23 décembre 2011, M. Kandyrine de Brito Païva, $\mathrm{n}^{\circ}$ 303678, préc. note 15.

31 On ne compte plus les décisions en ce sens : pour les plus classiques, voir les conclusions Corneille sur CE, Sect., 10 août 1917, Baldy, Rec. p. 638 ; CE, 19 mai 1933, Benjamin, Rec. p. 541 ou encore CE, Ass., 28 mai 1971, Ville Nouvelle Est, Rec. p. 409, concl. Braibant.

32 Ancien article 1152 du code civil ; nouvel article 1231-5.
} 
graves ne peuvent entraîner la nullité sans grief $^{33}$, la résiliation d'un contrat est subordonnée à la démonstration d'un manquement d'une gravité suffisante ${ }^{34} \ldots$

Cette solution classique concernant la norme a été érigée en standard par le Conseil constitutionnel qui vérifie qu'une disposition législative est adéquate, nécessaire et proportionnée ${ }^{35}$.

Le principe d'adéquation implique qu'il existe un lien raisonnable entre la mesure et l'objectif poursuivi ; la mesure ne doit pas être excessive, mais doit être proportionnée au but.

De la même manière, en matière civile, la Cour de cassation vérifie, par exemple, que le code des assurances établit un juste équilibre entre la confidentialité des données médicales et les exigences du procès équitable ${ }^{36}$.

On songe également à la diffamation et à l'exception de bonne foi ou à la prescription et à l'adage contra non valentem.

La solution devient plus délicate lorsque la décision de justice qui applique la norme ne constate pas l'invalidité de celle-ci.

\section{B. Le contrôle concret de la situation}

L'hypothèse est celle où la loi est conforme à une norme supérieure, qu'il s'agisse de la Constitution ou d'un traité, tandis que c'est la situation concrète, telle que soumise au juge, qui révèle un conflit de droits fondamentaux.

Jusqu'à un passé très récent, cette question n'intéressait pas. On pouvait, parfois regretter, la dureté de la loi tout en étant satisfait de son application. On se bornait à inviter le législateur à revoir sa copie. Bref, invoquant la protection tutélaire de Goethe, on préférait l’injustice au désordre.

Cette manière de penser évolue et on assiste, depuis quelques années, à un véritable renouveau.

Evolution, révolution, contre-révolution tranquille, changement de paradigme. Toutes les appréciations et qualifications ont été employées pour saluer ce printemps de la proportionnalité.

Le contrôle de proportionnalité relève désormais du droit commun (1), comme en atteste la jurisprudence (2).

\footnotetext{
Article 114 du code de procédure civile ; 2 Civ., 16 octobre 2014, Bull. 2014, II, nº 213.

Ancien article 1184 du code civil ; nouveaux articles 1124 à $1230 ; 1^{\text {re }}$ Civ., 28 octobre 2003, Bull 2003, I, nº 211.

Cons. const., déc. $n^{\circ}$ 2013-685 DC du 29 décembre 2013, Loi de finances pour 2014.

$2^{\mathrm{e}}$ Civ., 31 mars 2016, pourvoi n 14-27.987.
} 


\section{Un contrôle de droit commun}

Le monde juridique est en ébullition à l'égard de ce nouveau contrôle de proportionnalité.

Il y a pourtant plus de quarante ans, le président Braibant publiait un article classique intitulé «Le principe de proportionnalité ${ }^{37}$, révélant ses qualités de visionnaire.

Et ce principe, aujourd'hui, constitue le véritable droit commun.

On a déjà beaucoup écrit sur le dernier état de la jurisprudence en la matière : différents arrêts depuis quelques années en ce qui concerne la Cour de cassation, quelques semaines pour le Conseil d'État qui, pourtant, avait été le premier à exprimer ce principe.

Les uns saluent cette percée indispensable des droits de l'homme.

D’autres s'inquiètent du retour du bon président Magnaud et n'hésitent pas à engager un véritable procès en sorcellerie.

Ce ne serait plus de la proportionnalité, ce serait de l'équité.

Voire $^{38}$.

Il est permis, dans un certain nombre d'hypothèses, d'envisager un contrôle mesuré du caractère excessif de l'application de la loi.

Tel est notamment le cas en situation de conflit de droits fondamentaux.

C'est la solution de la Cour européenne des droits de l'homme.

En présence d'un conflit de normes, lorsqu'elles sont de même valeur, plus exactement lorsque leur support est de même valeur, que les intérêts en présence sont légitimes, il appartient, nécessairement, au juge de régler le conflit. Il est même permis de se demander si ce n'est pas sa raison d'être.

Il ne s'agit certainement pas d'un abandon de la motivation « à la française »; et encore moins d'une question d'interprétation ou de refus du syllogisme.

Et il n'est à l'évidence pas question, à chaque fois que la loi est valide, de prétendre que son application serait « excessive».

Il suffit d'être capable de faire une balance, sans qu'elle soit sentimentale. Et c'est précisément ce qu'ont déjà fait tant la Cour européenne des droits de l'homme que le Conseil d'État et la Cour de cassation.

37 G. Braibant, «Le principe de proportionnalité » in Mélanges offerts à M. Waline, Le juge et le droit public, LGDJ 1974, Tome II, p. 297 ; cf. également les conclusions du président Braibant sur Ville Nouvelle Est, préc. note 31.

38 Dans son illustre introduction au code civil, Portalis lui-même énonçait « quand la loi est claire, il faut la suivre ; quand elle est obscure, il faut en approfondir les dispositions. Si l'on manque de lois, il faut consulter l'usage ou l'équité »... 


\section{Le contrôle est mis en ouvre par toutes les juridictions}

Sera laissée de côté la jurisprudence du Conseil constitutionnel, pour la simple raison que celui-ci opère un contrôle de la validité de la norme, qui est, par hypothèse même, abstrait, même s'il s'exerce à l'occasion d'un procès sur renvoi d'une question prioritaire de constitutionnalité.

La jurisprudence de la Cour de Luxembourg sera également mise à l'écart puisque, sur renvoi préjudiciel portant sur l'interprétation du droit de l'Union européenne, les réponses ne peuvent être qu'abstraites, le juge de l'Union européenne n'hésitant pas à rappeler au demeurant que c'est au juge national qu'il appartient de procéder aux vérifications concrètes.

Les exemples seront tirés, chronologiquement, de la jurisprudence de la Cour européenne des droits de l'homme (a), de la Cour de cassation (b) puis du Conseil d'État (c).

\section{a) La Cour européenne des droits de l'homme}

Pour la Cour européenne des droits de l'homme, deux espèces seront retenues parmi les nombreux cas qui illustrent ce mécanisme.

La Cour de Strasbourg juge que le droit interne doit être appliqué sans formalisme excessif.

À chaque fois qu'une règle de forme aboutit à méconnaitre un droit de manière excessive, il faut s'interroger sur sa pertinence.

Tout en admettant que l'obligation de produire certaines pièces à l'appui du pourvoi en cassation, à peine d'irrecevabilité, était, dans son principe, conforme aux exigences du procès équitable ${ }^{39}$, elle a jugé, dans une hypothèse particulière de correctionnalisation, qu'elle avait porté une atteinte disproportionnée au droit d'accès au juge ${ }^{40}$.

De même a-t-elle jugé que l'obligation de mentionner explicitement dans l'acte d'appel l'objet du recours formé par la partie civile à l'encontre d'une ordonnance de renvoi devant le tribunal correctionnel pouvait, dans certaines hypothèses, méconnaître le droit à un procès équitable ${ }^{41}$.

Plus intéressante encore est la décision du 14 janvier 2016 dans une affaire Mandet : « en jugeant que l'intérêt supérieur de l'enfant se trouvait moins dans le maintien de la filiation établie par la reconnaissance de paternité effectuée par le deuxième requérant que dans l'établissement de sa filiation réelle, ce en quoi son intérêt rejoignait en partie celui de M. G. les juridictions internes n'ont pas excédé la marge d'appréciation dont elles disposaient... »; il s'agissait, en l'occurrence, de l'annulation d'une reconnaissance de paternitét ${ }^{42}$.

\footnotetext{
CEDH, 23 octobre 1996, Levages Prestations Services c. France, req. n²1920/93.

CEDH, 5 novembre 2015, Henrioud c. France, req. n ${ }^{\circ}$ 21444/11.

CEDH 15 décembre 2011, Poirot c. France, req. n $^{\circ}$ 29938/07.

CEDH, 14 janvier 2016, Mandet c. France, req. n 30955/12.
} 


\section{b) La Cour de cassation}

Devant la Cour de cassation, l'arrêt fondateur est celui de la première chambre civile du 4 décembre 2013. La nullité du mariage d'un beau-père avec sa belle-fille, divorcée d'avec son fils, revêtait à l'égard de celle-ci le caractère d'une ingérence injustifiée dans l'exercice de son droit au respect de sa vie privée et familiale dès lors que cette union, célébrée sans opposition, avait duré plus de vingt ans ${ }^{43}$.

Il est permis de se demander si les prémisses de cette jurisprudence ne se trouvaient pas dans le revirement pour le futur.

On sait, en effet, qu'en matière de droit au juge, la Cour de cassation a admis qu'un revirement pouvait ne pas avoir un effet rétroactif lorsque ce caractère rétroactif risquait de priver le demandeur du droit au juge ${ }^{44}$. C'est bien le caractère excessif de l'application immédiate du revirement qui était ici en cause. Et ce, alors même qu'il est de principe qu'un revirement est d'application immédiate. Ainsi que le rappelle la Cour européenne des droits de l'homme, "les exigences de la sécurité juridique et de protection de la confiance légitime des justiciables ne consacrent pas de droit acquis à une jurisprudence constante $»^{45}$.

Dans le sillage de la décision du 4 décembre 2013, on peut encore citer les censures d'arrêts appliquant, par exemple, un délai légal de l'action en contestation de paternité en oubliant la mise en balance avec le droit à voir la filiation biologique établie ${ }^{46}$, celle d'un arrêt qui a prononcé l'annulation d'un contrat de construction de maisons individuelles et a ordonné la démolition de l'ouvrage sans rechercher si la sanction était proportionnée à la gravité des désordres et des non-conformités ${ }^{47}$ ou encore celle d'un arrêt ordonnant l'enlèvement de caravanes installées dans une réserve naturelle classée, sans rechercher si les mesures ordonnées étaient proportionnées au regard du droit au respect de la vie privée et familiale et du domicile ${ }^{48}$.

Comment cette balance doit-elle s'opérer pour la Cour de cassation?

Il faut, énonce-t-elle sous le visa de l'article $10 \S 2$ de la Convention de sauvegarde des droits de l'homme et des libertés fondamentales, « expliquer de façon concrète en quoi la recherche d'un juste équilibre entre les droits en présence commandait la condamnation qu'elle prononçait ${ }^{49}$, censurant un arrêt qui s'était abstenu de faire cet examen entre liberté d'expression d'un côté et droit d'auteur de l'autre.

\footnotetext{
$43 \quad 1^{\text {re }}$ Civ., 4 décembre 2013, préc. note 6

$2^{\text {e Civ., }} 8$ juillet 2004, Bull. 2004, II, n 387 ; Ass. Plén., 21 décembre 2006, Bull. 2006, Ass. Plén., n 15. ; voir également le rapport du groupe de travail présidé par N. Molfessis : Les revirements de jurisprudence, rapport remis à M. le premier président, Guy Canivet, Litec, 2005.

45 CEDH, Unédic c. France, 18 décembre 2008, req. n 20153/04 (§ 36); cf. également : CEDH, Marckx c. Belgique, (Plénière), 13 juin 1979 , req. $n^{\circ}$ 6833/74 (§ 58) et Legrand c. France, 26 mai 2011, req. n ${ }^{\circ} 23228 / 08$.

$46 \quad 1^{\text {re }}$ Civ., 10 juin 2015, pourvoi $\mathrm{n}^{\circ} 14-20.790$.

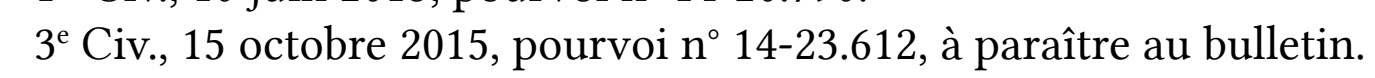

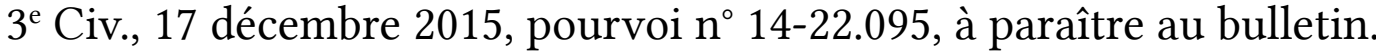

$1^{\text {re }}$ Civ., 15 mai 2015, pourvoi n 13-27.391, à paraître au bulletin, affaire Klasen, D. 2015, p. 1672, RTD com. 2015, p. 515, note F. PollAUDDulian, CCE 2015, comm. 7, n 55, obs. C. CARon, Légipresse 2015, III, 474, note VAREt, CCE 2015, Étude 17, M. VivanT.
} 
L'affaire dite du $\operatorname{Dr}$ Muller a permis à la première chambre civile d'énoncer un véritable motif de principe :

«Le droit au respect de la vie privée prévu par les articles 8 de la Convention et 9 du code civil et le droit à la liberté d'expression régi par l'article 10 de la Convention ont la même valeur normative » énonce la première chambre civile.

Et de conclure : « Il appartient au juge saisi de rechercher un équilibre entre ses droits et, le cas échéant, de privilégier la solution la plus protectrice de l'intérêt le plus légitime ${ }^{50}$.

La Chambre criminelle applique également cette jurisprudence (juste équilibre entre le droit au respect de la vie privée, familiale, les impératifs de la défense de l'ordre public ou encore secret des sources de journalistes) $)^{51}$, de même que la deuxième chambre civile en matière de procédure civile ${ }^{52}$.

Et le Conseil d'État n'est pas en reste.

c) Le Conseil d'État

L'affaire dite des gamètes lui en a donné l'occasion. La décision Gonzalez Gomez est importante, - non seulement parce qu'elle abandonne la jurisprudence Carminati $i^{53}$-, mais surtout parce qu'elle rappelle dans son neuvième motif que la compatibilité d'une loi avec les stipulations de la Convention « ne fait pas obstacle à ce que, dans certaines circonstances particulières, l'application de dispositions législatives puisse constituer une ingérence disproportionnée dans les droits garantis par cette Convention $»^{54}$.

D’où la nécessité, premièrement, d'une appréciation concrète pour déterminer, deuxièmement, si la mise en œuvre de la disposition applicable n'est pas excessive.

Où est le risque ici?

Il est bien évidemment dans la notion d'équité.

Il ne faudrait, en aucune manière, confondre proportionnalité et équité et admettre que, dans certains cas, parce qu'il s'agirait de « circonstances particulières », on pourrait ne pas appliquer une loi alors même que la validité de cette norme n'est pas discutable.

La réponse se trouve dans la motivation retenue, au onzième motif de ce même arrêt qui constate l'existence d'une atteinte grave et manifestement illégale à une liberté fondamentale.

Bref, il ne suffit pas d'être très triste, déçu ou en colère, encore faut-il qu'un droit fondamental ait été atteint dans sa substance.

$\overline{50 \quad 1^{\text {re }} \text { Civ., }} 30$ septembre 2015, pourvoi n 14-16.273, à paraître au bulletin, CCE 2015, comm. 92, obs. A. LEPAGE.

51 Crim., 3 juin 2015, pourvoi n 14-86.507, à paraître au bulletin ; Crim., 14 mai 2013, Bull. crim. 2013, nº 106, D. 2014, p. 503, note E. DREYER, Af Pénal 2013, p.467, obs. J. LASSERre CAPdeville, FCP 2013, act. 676, obs. E. Derieux.

$52 \quad 2^{\mathrm{e}}$ Civ., 24 septembre 2015, pourvoi n 13-28.017, à paraître au bulletin ; 15 octobre 2015, pourvoi n ${ }^{\circ} 14-17.792 ; 16$ décembre 2016 , pourvoi $\mathrm{n}^{\circ} 15-27.917$, à paraître au bulletin.

53 CE, 30 décembre 2002, Carminati, Rec. p. 510

54 CE, Ass., 31 mai 2016, précité note 65. 
Si cet arrêt consacre un droit, il en fixe les limites ou plus exactement, il livre le mode d'emploi permettant d'arbitrer entre deux droits de valeur équivalente. Et ce de manière concrète, sans pour autant porter atteinte à la norme qui les soutient.

Nouvelle preuve qu'il existe une place pour un cumul des contrôles. Les justiciables ne peuvent que s'en réjouir tandis que l'État de droit en sort renforcé. 


\title{
DÉBATS
}

\author{
sous la présidence de Madame Nicole Belloubet
}

Une question du public soulève deux interrogations. Une première interrogation porte sur la question des délais devant les juridictions constitutionnelles. La seconde traite de la question de savoir si, dans les systèmes constitutionnels espagnol et allemand, les questions préjudicielles sont nombreuses et si ce sont souvent les mêmes questions qui sont posées devant la juridiction.

Thomas Hochmann sur le premier point, relatif aux délais raisonnables, renvoie aux travaux réalisés par le Professeur Michel Fromont. Les délais sont assez longs. Sur la deuxième question, qui est celle de savoir si des questions préjudicielles ou des recours constitutionnels peuvent concerner une même loi, Monsieur Hochmann précise que la Cour constitutionnelle le fait régulièrement - ce cas est d'ailleurs arrivé très récemment - et que dans cette hypothèse, la Cour peut joindre dans une même décision à la fois une question préjudicielle et un recours constitutionnel, dès lors qu'il s'agit d'une même loi qui est traitée devant la juridiction constitutionnelle.

Sur la question des délais, Itziar Gomez-Fernandez a un double point de vue. En tant que Maître de conférences, elle considère comme honteux les délais de traitement devant la juridiction constitutionnelle. En tant que référendaire au Tribunal constitutionnel, elle considère que la juridiction fait de son mieux, car il y a autour de sept mille affaires par an actuellement. Les délais prescrits par la loi ne sont pas respectés. Certaines affaires sont traitées pendant six, sept ou dix ans avant de pouvoir rendre un arrêt. Par contre, l'examen d'irrecevabilité, est traitée dans les six mois. En d'autres termes, les questions qui ne seront pas étudiées sur le fond, sont traitées dans un délai très court et celles que la juridiction accepte de traiter mettent beaucoup plus de temps.

$\mathbf{M}^{\mathrm{me}}$ Nicole Belloubet rappelle qu'en France, les juridictions respectent les délais prescrits par la Constitution ou par la loi pour la transmission ou non des QPC et leur traitement par le Conseil constitutionnel. C'est un élément puissant de crédibilité des décisions de justice, notamment de celles rendues par le Conseil constitutionnel.

Une question du public porte sur le principe de subsidiarité. Selon le discutant, il faudrait davantage réguler les procédures, pour éviter un engorgement des cours constitutionnelles. Cela serait possible si l'on appliquait attentivement le principe de subsidiarité. 
Itziar Gomez-Fernandez explique qu'avec la réforme de 2007 en Espagne, l'amparo constitutionnel est détourné et la protection des droits fondamentaux est affaiblie. Toutefois, il reste l'amparo ordinaire qui demeure une garantie. Il y a un principe de subsidiarité prévu par la loi, mais il y a aussi une pratique contraire à l'application du principe. Ceci explique, d'une certaine manière, l'engorgement du Tribunal constitutionnel. Selon le point de vue de l'intervenant posant la question, il apparaîtrait que seul le Tribunal constitutionnel serait en mesure de protéger les droits fondamentaux, en faisant abstraction des autres recours ordinaires. Pour elle, la première cause de l'engorgement est le fait de faire croire aux justiciables qu'ils doivent passer forcément par le juge constitutionnel pour voir l'application de leurs droits fondamentaux assurée.

Une seconde interrogation du public porte sur l'Allemagne. Il semble qu'en vertu du principe de subsidiarité, il est possible d'agir contre une décision juridictionnelle dans les faits. Mais par dérogation à ce principe, il arrive aussi que la Cour constitutionnelle allemande accepte un recours direct contre la loi dans le cadre d'un recours individuel, parce que le requérant pourrait subir une atteinte disproportionnée à ses droits s'il devait suivre le principe de subsidiarité. En somme, la question est de savoir s'il ne serait pas possible de réduire le coût de la justice qui est impactée inévitablement. Ne pourrait-on pas permettre un recours constitutionnel plus flexible contre une loi, directement, si le requérant fait état d'un préjudice grave, et ce faisant de reprendre ce qui a été avancé sur la question préjudicielle, c'est-à-dire que la Cour constitutionnelle accepte d'examiner le recours constitutionnel même si les conditions ne sont pas totalement remplies avec l'idée que ce recours permettrait d'éclairer l'ordre constitutionnel et de désengorger les juridictions ordinaires?

Itziar Gomez Fernandez estime que le problème est que le citoyen, le justiciable, croit que la juridiction constitutionnelle a toujours le dernier mot et ceci n'est pas la faute de la juridiction constitutionnelle mais la faute de l'avocat qui le fait croire. Ceci explique que l'accès au tribunal soit de plus en plus réduit, puis que le Tribunal renforce de plus en plus la subsidiarité du modèle de garantie des droits fondamentaux, au risque de perdre sa position de juge des droits fondamentaux. Il faudrait donc former les avocats pour qu'ils fassent comprendre à leurs clients les véritables enjeux de la justice constitutionnelle.

Le professeur Thomas Hochmann est plutôt d'accord sur la question du principe de subsidiarité rapportée à la Cour constitutionnelle. Pour conclure, Monsieur Hochmann, volontairement provocateur à l'égard de Madame la Présidente Nicole Belloubet, rappelle, en revenant sur la question plus générale de la procédure, que la question des délais et celle de la motivation en France n'est pas tout à fait la même qu'en Allemagne ou en Espagne.

Nicole Belloubet accepte la critique, justifie les délais suivis devant le Conseil constitutionnel et reconnaît que des efforts méritent d'être poursuivis en matière de motivation des décisions du Conseil constitutionnel. Après cette précision, Madame Belloubet clôt les débats. 


\section{PARTIE IV}

\section{LES CONDITIONS D'UNE RÉFORME EN FRANCE, AU REGARD DES EXPÉRIENCES ÉTRANGÈRES}





\section{TABLE RONDE}

\section{Sous la présidence d'André Roux, Professeur à l'Université d'Aix-Marseille}

\section{Introduction : Marthe Fatin-Rouge Stefanini et Caterina Severino}

Le colloque organisé pose la question de l'intérêt de franchir une étape supplémentaire dans le contrôle de constitutionnalité en France en permettant d'attribuer à la juridiction constitutionnelle un contrôle de constitutionnalité de l'ensemble des décisions de justice. Cela permettrait de compléter le système existant, qui lui-même constitue une version enrichie du système imaginé en 1958, notamment grâce à l'introduction de la QPC. Cependant, le contrôle de constitutionnalité confié aujourd'hui à la juridiction constitutionnelle ne concerne que les lois, les traités internationaux et les règlements d'assemblées. Le contrôle de constitutionnalité des actes administratifs ou des contrats, par exemple, existe également devant les juridictions chargées de connaître du contentieux de ces actes mais ne peut être mis en œuvre que dans la mesure où aucune loi ne fait écran. De même, la constitutionnalité du raisonnement juridique suivi par les juridictions inférieures est susceptible d'être examinée par les juridictions supérieures. Ce faisant, la correcte interprétation et application de la Constitution au litige, dans les cas rares où une telle situation se présente, est elle-même susceptible d'être rappelée par la juridiction supérieure.

La réflexion sur laquelle porte ce colloque ne vise donc pas le contrôle de la loi, sauf dans le cas où le procès constitutionnel porterait sur une interprétation jurisprudentielle consolidée de cette dernière ; il s'agit d'aller plus loin et d'envisager la question du contrôle de la constitutionnalité d'une décision de justice, contrôle qui serait déclenché par un justiciable. Les expériences étrangères montrent qu'un tel contrôle peut être soit inhérent aux systèmes diffus, soit organisé sous forme de recours direct dans les systèmes concentrés de justice constitutionnelle, avec des modalités particulières pour des systèmes mixtes tel que celui que connaît le Portugal. Dans ces derniers cas, la mise en place de ces voies de recours a été justifiée par une volonté de parfaire l'État de droit. Avec ce complément, le contrôle de constitutionnalité est susceptible de toucher tous les actes. Il vise donc l'intégralité des actes juridiques. Cette conception d'un système intégral de la justice constitutionnelle est particulièrement présente dans les États qui ont connu le fascisme ou la dictature. Cependant, même dans des États comme la France où la souveraineté de la loi a longtemps dominé et où la cohérence de l'ordre juridique n'a pas été organisée, la question d'une évolution d'un contrôle 
de constitutionnalité au-delà de la loi peut se poser ne serait-ce que pour répondre à un besoin croissant de justice, besoin fondé lui-même sur un souci d'égalité.

Dès lors, le débat dans le cadre de la table ronde débutera sur une réflexion relative à l'intérêt d'un tel contrôle. Ce contrôle vous semblerait-il utile dans notre État de droit ? Existe-t-il des failles dans le système existant faisant courir le risque que les droits fondamentaux d'un justiciable ne soient pas pleinement protégés ? Si ces cas n'apparaissent pas très nombreux, ont-ils besoin de l'être pour justifier une réforme ? Cette interrogation suppose alors de dresser un bilan de la QPC : est-elle à la hauteur des espérances de ceux qui souhaitaient un contrôle a posteriori ? Répond-elle vraiment aux besoins des justiciables?

Par ailleurs, quels sont les effets collatéraux qu'engendrerait une telle réforme ? Dans un État dans lequel le recours direct existe, par exemple, est-ce que les recours devant la Cour EDH sont moins nombreux?

Si tant est que la nécessité de ce recours puisse être démontrée, quelle forme pourrait-il prendre ? Un recours direct? Risque-t-il d'être en concurrence avec les recours existants de type référé-liberté ?

Toutes les décisions de justice pourront-elles faire l'objet de ce type de recours (y compris celles dans lesquelles les juridictions administratives et judiciaires sont juges de droit commun du droit de la Convention européenne des droits de l'Homme ou du droit de l'Union)?

Est-ce que le risque d'alourdissement de la charge de travail de la juridiction est réel ? (question qu'il est légitime de se poser au regard de la place prise par les recours directs dans des États comme l'Espagne et l'Allemagne). Dès lors, quelles modalités prévoir pour éviter un engorgement de la juridiction constitutionnelle?

Quel serait l'objet réel d'un contrôle de constitutionnalité de la décision de justice : l'interprétation de la Constitution, son application au litige ou l'objet même du litige, par exemple ? Quelle serait l'étendue de ce contrôle? Quels sont les risques?

Quels seraient les effets des décisions rendues pour l'ordre juridique et pour le justiciable?

Ce type de recours serait-il plus «populaire » que la QPC qui finalement semble être de plus en plus utilisée avant tout par ceux qui en ont les moyens financiers (entreprises, associations, personnalité...)?

Enfin, cette réforme est-elle imaginable au regard du paysage juridictionnel français et de la légitimité forte dont se revendiquent la Cour de cassation et le Conseil d'État et avec lesquelles le Conseil constitutionnel français a du mal à rivaliser? 
Toutes ces questions et d'autres encore qui pourraient surgir au cours des débats pourront enrichir la réflexion. Elles ont été articulées autour de quatre grands axes :

\section{1 - Peut-on se satisfaire de la situation actuelle en France ? Quel serait l'intérêt d'une telle réforme?}

- Quels sont les aspects qui posent problème actuellement (lacunes/limites du système actuel) ?

- Quel intérêt pour les justiciables?

- Quel intérêt pour la cohérence de l'ordonnancement juridique?

\section{2 - Quelles pourraient être les modalités concrètes de la réforme?}

- Qui pourrait accéder à un tel recours (présence d'un intérêt, ou pas forcément)?

- Pour quel type de protection?

- Contre quels actes (toute sorte de décision de justice) ?

- Quelles conditions de filtrage mettre en place?

- Qui filtre?

- Quels délai pour intenter le recours ? Pour filtrer les requêtes ? Pour rendre la décision ?

- Quels effets seraient attachés aux décisions du juge constitutionnel ? (effets relatifs, effets absolus, possibilité de moduler dans le temps, effets éventuels sur les autres procédures déjà en cours, rétroactivité...)

3 - Une réforme, mais au prix de quels bouleversements pour les équilibres institutionnels ?

- Comment intégrer une telle réforme au sein du paysage juridico-institutionnel français?

- Quel rôle respectif veut-on confier aux juges constitutionnel et suprêmes?

- Comment articuler une telle réforme par rapport aux procédures déjà existantes ?

\section{4 - Quelle place pour le Conseil constitutionnel ?}

- Quelle est (et quelle serait) la place réelle du Conseil constitutionnel ? Quelle place par rapport aux autres juges français et par rapport aux juges européens?

- Le Conseil constitutionnel dispose-t-il d'une légitimité suffisante pour opérer un tel contrôle ?

- De quelle manière réformer le Conseil constitutionnel ?

- Une telle réforme conduirait-elle à un changement de « logique » en ce qui concerne le contrôle de constitutionnalité en France?

Intervenants : Julien Bonnet, Professeur à l'Université de Montpellier, CERCOP ; Michel Fromont, Professeur émérite à l'Université Paris 1 Panthéon-Sorbonne ; Laurence Gay, Chargée de recherches CNRS, ILF-GERJC, UMR 7318, DICE ; Olivier Le Bot, Professeur à l'Université d'Aix-Marseille ; Paolo Passaglia, Professeur à l'Université de Pise ; Xavier Magnon, Professeur à l'Université de Toulouse; Yasmine Sylvestre, Docteur en droit public à l'Université des Antilles et de la Guyane, Membre associé de LC2S ; Marc Verdussen, Professeur à l'Université de Louvain ; Alexandre Viala, Professeur à l'Université de Montpellier, Directeur du CERCOP ; Ariane Vidal-Naquet, Professeur à l'Université d'Aix-Marseille. 


\section{Discussions}

Olivier Le Bot, Professeur, Aix Marseille Univ, Université de Toulon, Univ Pau \& Pays Adour, CNRS, DICE, ILF-GERJC, Aix-en-Provence, France

\section{L’absence de nécessité d'un recours direct}

En France, la question d'introduire un recours direct ne se pose pas avec la même acuité que dans les pays où il a été instauré. En Allemagne, en Espagne et dans les pays d'Europe de l'Est, le recours direct a été institué au motif que les juges en place avaient été formés ou avaient exercé sous un régime autoritaire. En permettant un contrôle de leurs décisions, le recours direct visait à imposer à ces magistrats de se plier au nouvel ordre constitutionnel.

Ce motif n'est à l'évidence pas caractérisé dans le cas français. Il n'y a donc pas, de ce point de vue, de nécessité de mettre en place un recours direct. Sa création est peut-être utile (on peut en discuter); elle n'est en tout cas pas nécessaire.

En outre, il ne paraît pas justifié de concevoir la création d'un recours direct comme un moyen de surmonter les décisions de non-renvoi rendues par les juridictions suprêmes dans le cadre de la QPC. Un tel moyen serait tout à fait disproportionné au regard de l'objectif poursuivi. Si la finalité est simplement de surmonter un filtrage injustifié (par exemple, une juridiction suprême estime qu'une disposition est inapplicable au litige alors qu'elle lui est en réalité bien applicable), des réformes moins radicales peuvent être envisagées, notamment ouvrir la saisine du Conseil constitutionnel à toute juridiction, ou encore permettre à l'auteur d'une QPC de former, devant le Conseil constitutionnel, un recours contre le refus de lui renvoyer celle-ci. Si le problème vient de l'existence d'un filtre, il faut le supprimer ou l'aménager. Le moyen de remédier à la situation n'est pas de créer un recours direct.

\section{L'intérêt d'un recours direct pour le justiciable}

La mise en place d'un recours direct ouvrirait au justiciable une nouvelle voie de droit, sorte de super recours en cassation lui permettant de faire contrôler si le juge ordinaire a correctement jugé, c'est-à-dire si l'acte juridictionnel qui a statué en dernier lieu sur le litige a correctement appliqué au cas d'espèce les règles constitutionnelles pertinentes, et en particulier si la décision a été rendue dans les formes attendues au regard du droit à un procès équitable (impartialité, délai raisonnable, etc.).

L'intérêt de cette nouvelle voie de droit consisterait ainsi à instaurer un contrôle du contrôleur, c'est-à-dire de la juridiction suprême, à s'assurer que celle-ci respecte la Constitution. 


\section{Quelle serait la physionomie d'un recours direct?}

En s'inspirant des dispositions et de la pratique prévalant à l'étranger, le recours direct consisterait en un recours en protection des droits fondamentaux.

Du fait de l'exigence d'épuisement préalable des voies de recours, il serait dirigé contre les actes juridictionnels rendus par les juridictions suprêmes. L'absence de contrôle des décisions rendues par les juridictions inférieures est justifiée par deux considérations. D’une part, l'ouverture de ce contrôle extraordinaire à l'encontre de tout jugement ne serait pas compatible avec le caractère subsidiaire du mécanisme. D'autre part, le nombre de décisions pouvant potentiellement faire l'objet d'un contrôle serait trop important puisque 4 millions de décisions sont rendues chaque année par l'ensemble des juridictions françaises (contre 30000 pour le Conseil d'État et la Cour de cassation)1.

En outre, le recours direct ne serait recevable qu'à l'encontre des décisions qui éteignent un litige, c'est-à-dire qui tranchent une contestation avec autorité de la chose jugée au principal. Ce critère conduirait à exclure de son champ d'application deux séries de décisions : d'une part les décisions avant-dire droit (qui ordonnent, par exemple une mesure d'instruction) ; d'autre part les décisions provisoires prises en référé (référé-suspension, référé-constat, référé-expertise, etc.).

Le délai pour introduire le recours direct devrait être bref afin de garantir la stabilité des situations juridiques et des décisions juridictionnelles. Par analogie avec le délai d'exercice d'un recours en cassation, un délai de deux mois paraît raisonnable.

Il ne serait pas nécessaire de procéder à un examen de ces conditions de recevabilité en formation plénière. Une formation de trois juges, voire un juge unique du Conseil constitutionnel pourraient parfaitement rejeter les requêtes présentant un caractère irrecevable faute de satisfaire à une condition de recevabilité (délai, épuisement préalable des voies de recours).

\section{Un recours plus populaire que la QPC?}

Le recours direct représenterait un recours plus attractif que la QPC car les requérants recherchent le plus souvent un bénéfice immédiat et personnel, une amélioration de leur situation concrète. Le recours direct, axé sur la protection des situations individuelles, répond à cette attente alors que la QPC, dirigée contre une norme abstraite et générale, n'offre qu'une satisfaction par ricochet, voire pas de satisfaction du tout en cas d'annulation différée (laquelle intervient pour la moitié des décisions).

\section{Les changements qu'induirait la création d'un recours direct}

Le premier effet du recours direct serait de provoquer un changement paradigmatique de notre contentieux constitutionnel. Celui-ci passerait d'un contrôle abstrait (objectif), d'une norme générale

$1 \quad$ http://www.justice.gouv.fr/publication/chiffres_cles_20151005.pdf 
et impersonnelle à une autre norme générale et impersonnelle, indépendamment du contexte, des faits et des conditions d'application, à un contrôle concret, axé sur la situation particulière de l'espèce (sur le modèle du contrôle « in face » mis en œuvre dans le contentieux constitutionnel américain).

Un deuxième effet serait d'accroître de façon considérable la charge de travail du juge constitutionnel. En Allemagne et en Espagne, entre 4000 et 5000 recours directs sont introduits chaque année. Nul doute qu'un engouement comparable interviendrait en France. Le Conseil constitutionnel serait submergé d'un flot contentieux qui conduirait à allonger de façon très importante les délais de jugement et/ou à transférer le pouvoir de juger à du personnel administratif.

Aujourd'hui, l'une des forces du système français réside dans les délais de jugements très brefs (les plus courts d'Europe, et de très loin) pour le contrôle abstrait des normes. Il n'est pas certain que les bénéfices résultant de la création d'un recours direct puissent compenser les inconvénients qui en découleraient sur ce point.

Au demeurant, si l'objectif d'est d'améliorer l'accès au juge et la qualité de la justice, d'autres réformes sont susceptibles d'avoir un impact plus décisif et immédiat : stopper la généralisation du juge unique, la restriction de l'intérêt à agir là où elle est intervenue, rétablir l'appel dans de nombreux contentieux où il a été supprimé, revaloriser l'aide juridictionnelle. Si l'on veut améliorer le droit au juge et la garantie des droits, créer un recours direct n'est pas une priorité. Il serait pour le moins étonnant qu'un tel recours voit le jour alors que la tendance de fond est à la limitation des garanties offertes au justiciable.

\section{Recours direct et référé-liberté}

Le référé-liberté et le recours direct présentent un point commun : ces deux procédures ont pour objet exclusif la protection des libertés. Pour le reste, tout les oppose :

- les libertés protégées : uniquement les libertés constitutionnelles pour le recours direct ; des libertés d'origine constitutionnelle, conventionnelle et législative pour le référé-liberté (et encore ne servent-elles que de source d'inspiration : elles ne sont pas appliquées telles quelle et, lorsqu'il les consacre, le juge administratif modifie parfois l'intitulé de la liberté afin de pouvoir en définir librement le contenu);

- le juge compétent : juge ordinaire dans le cas du référé-liberté, juge constitutionnel dans le cas du recours direct (la notion de juge constitutionnel étant entendue comme une juridiction comptant, dans ses compétences, le pouvoir d'annuler une loi inconstitutionnelle);

- leur champ d'application : le référé-liberté peut être dirigé contre des actes administratifs ou des situations administratives (carences, actions) ; le recours direct, lui, ne peut être formé qu'à l'encontre d'actes, en pratique, le plus souvent, d'actes juridictionnels ; 
- ainsi, dans leur essence, ces procédures sont différentes : le référé-liberté est un recours autonome qui vise à contrôler l'administration ; le recours direct est un recours subsidiaire qui vise à contrôler les juridictions suprêmes (à apprécier si elles ont bien jugé, dans le respect du droit au procès équitable) ;

- dernière différence, de taille, le délai de jugement : de 1 à 5 jours en référé-liberté, de 1 à 5 ans pour le recours direct.

Dernière observation sur les deux procédures : un requérant a songé, en 2001, à faire du référé-liberté un recours direct indirect. L'idée était de donner un accès au juge constitutionnel par l'intermédiaire d'une autorité de saisine qualifiée. Saisi sur le fondement de l'article L. 521-2 du code de justice administrative, le juge administratif ordonnerait à l'autorité compétente de déférer au Conseil constitutionnel la loi contenant des dispositions portant atteinte à certaines libertés fondamentales constitutionnelles. En cas d'absence de saisine constitutive d'une atteinte grave et manifestement illégale à une liberté fondamentale, une injonction de saisir le Conseil constitutionnel pourrait être prononcée. Il fallait, pour cela, trouver une autorité dont l'absence de mise en œuvre du droit de saisine pouvait être critiquée. Le requérant a songé au Président de la République : le chef de l'État est le gardien de la Constitution (art. 5), il pèse sur lui une mission de vigilance constitutionnelle qui compte, parmi les différents moyens permettant de l'exercer, le pouvoir de saisir le Conseil constitutionnel. Le raisonnement était ingénieux mais, sans surprise, le juge des référés a rejeté le recours, estimant que le refus ou l'abstention de saisir le Conseil constitutionnel relève des actes de gouvernement et, par conséquent, qu'il n'appartient pas à la juridiction administrative d'en connaître ${ }^{2}$. En outre, la saisine du Conseil constitutionnel représente pour les autorités disposant de ce pouvoir une faculté et non une obligation.

Michel Fromont, Professeur émérite à l'Université Paris 1 Panthéon-Sorbonne

\section{À propos de la question de l'introduction en France du recours individuel contre une décision de justice pour violation d'un droit garanti par la Constitution}

Compte tenu de la place éminente occupée par la justice constitutionnelle allemande, rappelons tout d'abord les grandes lignes du système allemand, puis ses avantages et ses inconvénients. Le recours individuel pour violation d'un droit fondamental (Verfassungsbeschwerde) peut être dirigé contre tout acte de la puissance publique, c'est-à-dire, soit contre une loi (par exemple, une loi soumettant à certaines conditions l'avortement), soit un acte administratif (par exemple, l'interdiction d'une manifestation), soit une décision de justice pourvu qu'elle ne soit plus susceptible de recours. Mais, dans la pratique, la quasi-totalité des recours est dirigée contre des décisions de justice, ce qui fait de la Cour

2 CE, ord. 7 novembre 2001, Tabaka, Lebon T. p. 789, p. 1125, RDP2001, p. 1645-1657, note P. JAN ; LPA 22 mars 2002, n 59, p. 15-19, note O. CuRTIL. 
constitutionnelle fédérale une véritable cour suprême sur le mode suisse ou américain. Cette institution a connu un grand succès, ce qui a permis à la Cour constitutionnelle fédérale d'exiger une mise en conformité à la constitution de toutes les jurisprudences et donc, indirectement, des pratiques administratives ou judiciaires qui ont précédé ces décisions et qui avaient été approuvées par ces jurisprudences. Cela permet aux citoyens et autres habitants de l'Allemagne de considérer la Loi fondamentale comme un texte qui les protège directement et de susciter ainsi un véritable « patriotisme de la constitution » (Verfassungspatriotismus). De cette façon, l'ensemble du système juridique allemand et toute la société allemande se trouvent pleinement régis par les grandes règles inscrites dans la constitution fédérale. Ce succès a toutefois son prix : un trop grand nombre de recours individuels est porté devant la Cour de Karlsruhe et, pour empêcher la submersion de celle-ci, il a fallu recourir à des méthodes qui ne sont pas toujours parfaitement conformes à l'idéal d'une justice qui se veut pourtant exemplaire : les procédures sont assez lentes, et, une fois sur deux, elles ne sont pas contradictoires.

C'est donc avec une certaine prudence qu'il convient d'aborder la question d'une éventuelle introduction d'un recours individuel contre les décisions de justice en France. Ce n'est d'ailleurs pas la seule lacune du système français, mais nous passerons sous silence les deux autres lacunes. La première est incontestablement le recrutement et les moyens de travail des membres du Conseil constitutionnel. La deuxième est l'absence d'une compétence du Conseil constitutionnel pour juger les litiges entre organes constitutionnels ; il est en effet anormal qu'un parlementaire ne puisse pas s'adresser à un juge pour faire respecter ses droits vis-à-vis des organes dirigeants de l'assemblée ou encore qu'une divergence d'interprétation de la constitution opposant le Président de la République au Parlement ne puisse pas être arbitrée par un juge, mais cela n'était pas l'objet de ce colloque. Incontestablement, la troisième lacune est l'absence de contrôle de la constitutionnalité des décisions de justice. En effet, à l'heure actuelle, rien ne s'oppose à ce qu'une loi parfaitement conforme à la constitution soit interprétée par les juges ordinaires d'une façon contraire à la constitution (le Conseil constitutionnel ne contrôle que les interprétations constantes) ou qu'elle soit appliquée par une autorité judiciaire de façon inconstitutionnelle (dans le cas de l'exercice d'un pouvoir discrétionnaire).

Le premier remède auquel on peut penser, mais il est de portée limitée, consisterait à permettreaux justiciables ayant soulevé une question prioritaire de constitutionnalité qui n’a pas été acceptéepar l'une des deux juridictions suprêmes (Cour de cassation, Conseil d'État) de contester ce refus devant le Conseil constitutionnel. Le second remède consisterait à prévoir un recours individuel contre toutes les décisions de justice qui ont un caractère définitif (solution inspirée du modèle allemand) ; mais tout le problème réside dans la difficulté de limiter ces recours à un nombre raisonnable, c'està-dire à moins de 2000 par an. La solution allemande consiste à organiser un filtrage des recours par des formations de jugement formées de 3 juges constitutionnels et selon une procédure sommaire, ce qui n'est pas un système très satisfaisant. Peut-être faudrait-il retenir l'une des formules suivantes :soit confier le filtrage à des formations spécialisées placées au sein des deux juridictions suprêmes, soit réserver l'accès du Conseil constitutionnel à des recours formés par des groupes de justiciables. 
J'en conviens, ces solutions ne sont pas pleinement satisfaisantes. C'est pourquoi il me semble nécessaire d'y réfléchir encore. En effet, l'enjeu est de taille : seule l'introduction d'un recours contre les décisions de justice permettrait enfin d'imposer à toutes les autorités publiques le plein respect de la constitution et d'assurer ainsi la suprématie de la constitution sur l'ensemble du droit français.

\section{Marc Verdussen, Professeur à l’Université de Louvain}

En tant qu'observateur étranger, je peux tenter de répondre à la première question : la situation créée par la QPC est-elle satisfaisante ? Tel qu'il est aujourd'hui mis en œuvre, le mécanisme français de la QPC exclut l'exercice d'un contrôle concret par le Conseil constitutionnel. Je souhaiterais faire à ce sujet trois observations. Celles-ci se rejoignent dans la conviction, que j’ai déjà exprimée en France, à Aix-en-Provence ou dans d'autres universités, qu'une juridiction constitutionnelle ne peut pas rester insensible aux questions concrètes de constitutionnalité qui lui sont adressées par les juges de renvoi.

Tout d'abord, n'attend-t-on pas de toute juridiction qu'elle apporte une réponse, non pas à un problème de droit, mais au problème juridique dont elle a été précisément saisie. Ce problème est la source d'une irrégularité alléguée par une ou plusieurs personnes. Ne pas y répondre précisément, c'est manquer à l'exigence la plus élémentaire de la fonction de juger, qui est de contribuer à l'éradication des injustices. Pourquoi en serait-il autrement pour les juridictions constitutionnelles ? Une juridiction constitutionnelle qui se contente de fournir une réponse abstraite à une question concrète se laisse aller à une forme de déni de justice. Par ailleurs, ce faisant, elle porte atteinte au droit à une protection juridictionnelle effective, qui implique la possibilité concrète de faire valoir ses droits devant un juge. La garantie d'une protection juridictionnelle effective s'inscrit d'autant plus au cœur de la mission des juges constitutionnels que la vocation de toute juridiction constitutionnelle est d'être un prétoire pour celles et ceux dont la voix - le plus souvent minoritaire, voire marginalisée - n’a pas été entendue dans l'enceinte parlementaire.

Ensuite, on peut se poser la question de savoir si, en tant que tel, le mécanisme de la question préjudicielle de constitutionnalité n'induit pas nécessairement le caractère concret du contrôle et donc une jurisprudence constitutionnelle forcément casuistique. Ce mécanisme se justifie avant tout par ce constat qu'une inconstitutionnalité n'apparaît pas nécessairement au moment où la loi est votée ou promulguée, mais parfois bien longtemps après. Or, les inconstitutionnalités qui se révèlent tardivement ne germent dans les prétoires des juridictions qu'à la faveur de l'enracinement de la norme dans le terreau concret d'une situation particulière. Ce n'est pas alors la norme comme telle qui est appliquée par les juges, mais la norme dans des situations déterminées, donc concrètes. C'est précisément cette concrétisation qui révèle l'inconstitutionnalité. Pour que le mécanisme préjudiciel soit efficace, il est, de notre point de vue, indispensable que la juridiction constitutionnelle apporte à la question posée par le juge une réponse concrète. Une réponse contextualisée en quelque sorte. 
Enfin, l'exercice d'un contrôle concret n'est-il pas une manière - parmi bien d'autres bien sûr de rencontrer une objection élevée à l'encontre de la légitimité de la justice constitutionnelle : la juridiction constitutionnelle ne ferait que substituer l'opinion de quelques juges à celle de plusieurs dizaines d'élus, représentatifs de l'ensemble de la population. En réalité, le contrôle concret permet aux juges constitutionnels de compléter l'œuvre du législateur plutôt que de la défaire. Le degré de généralité qui s'attache à toute loi ne permet pas au législateur de prévoir toutes les conséquences qui découleront de l'application de cette loi. Lorsque ces conséquences heurtent la Constitution, les juges constitutionnels s'attachent à corriger l'oeuvre législative.

\section{Julien BonnET, Professeur à l'Université de Montpellier, CERCOP}

«Une voie étroite mais possible. »

Envisager l'insertion en France d'un contrôle de constitutionnalité des décisions de justice est une proposition stimulante qui suppose au préalable de s'interroger sur l'état actuel du droit. Or, le bilan lacunaire de la situation présente rend parfaitement légitime une réflexion sur le contrôle de constitutionnalité des décisions de justice (I). Pour autant, une lacune dans l'État de droit ne saurait suffire, en elle-même, à convaincre de l'instauration d'une réforme qui doit être envisagée dans toutes ces dimensions et au regard de l'ensemble des registres de discours qui peuvent s'exprimer sur cet objet : selon le point de vue adopté, la réforme peut être plus ou moins souhaitable et envisageable. En prenant le parti que le contrôle de constitutionnalité des décisions de justice constituerait une option opportune, plusieurs solutions de mise en œuvre sont envisageables. En définitive, les conditions de possibilité d'un contrôle de constitutionnalité des décisions de justice semblent réunies (II).

\section{Le bilan lacunaire de l'état du droit}

À l'origine, l'instauration de la QPC n'a pas été pensée et organisée pour permettre le contrôle des décisions de justice. Ce n'est que grâce à des contorsions juridiques que ce champ a été partiellement investi (A). Dès lors, rien d'étonnant à ce que des angles-morts du contrôle de constitutionnalité continuent de prospérer (B).

\section{A. Des contorsions}

Inutile, au terme de ce colloque, de revenir en détail sur le contrôle par le Conseil constitutionnel des interprétations constantes conférées à la loi par le Conseil d'État ou la Cour de cassation. La plupart du temps, le Conseil constitutionnel lève l'inconstitutionnalité au moyen de décisions de conformité sous réserve. La technique des réserves d'interprétation est d'ailleurs indispensable lorsque l'interprétation constante concerne un régime jurisprudentiel particulier qui découle d'une 
disposition législative à portée générale. Par exemple, si une QPC renvoyée au Conseil constitutionnel visait l'une des nombreuses interprétations constantes conférées à l'ancien article $1382 \mathrm{du}$ code civil, l'abrogation de cette disposition ne serait pas envisagée et seule une réserve permettrait de remédier à une éventuelle violation des droits et libertés constitutionnels.

De manière plus originale, le Conseil constitutionnel s'érige ponctuellement en avatar d'un «Tribunal des conflits constitutionnels » lorsqu'il doit se prononcer, sur renvoi d'une première cour suprême, sur la conformité d'une interprétation constante émise par l'autre cour suprême. Le justiciable patient et inventif peut donc, sous réserve que les données juridiques de l'espèce le permettent, contester une jurisprudence de la Cour de cassation ou du Conseil d'État sans passer par le filtrage de l'auteur de cette jurisprudence. Un tel scenario est donc rarement envisageable et, en pratique, il n'a été que rarement mis en œuvre. Par exemple, dans la décision du $1^{\text {er }}$ août $2013^{3}$, le Conseil constitutionnel est saisi par le Conseil d'État d'une QPC visant la notion d'entreprise publique dans le cadre du droit de participation des salariés aux résultats de l'entreprise, notion que la Cour de cassation n'entendait pas de la même manière. Après avoir cité expressément l'arrêt de la Cour de cassation dans les visas et les motifs de sa décision, le Conseil constitutionnel exerce directement son contrôle sur « l'interprétation que la Cour de cassation a retenue de la notion «d'entreprise publique» » pour considérer qu'elle n'a pas porté atteinte à une situation légalement acquise. La disposition contestée est néanmoins abrogée pour incompétence négative. Autre illustration, dans la décision du 31 juillet $2015^{4}$ le Conseil constitutionnel se prononce, sur renvoi du Conseil d'État, sur une jurisprudence de la Cour de cassation à propos de la présence d'une sanction punitive au sein d'un dispositif législatif. Si la position du juge judiciaire est confortée sur ce point, une partie intervenante obtient une réserve d'interprétation qui remet en cause une jurisprudence de la Cour de cassation relative à un autre aspect, d'ordre procédural, de la disposition législative contestée.

En dehors de ces hypothèses particulières, la conformité à la Constitution des décisions des cours suprêmes est assurée par un exercice d'autoévaluation qui n'est pas sans poser des difficultés.

\section{B. Des angles-morts}

L'État de droit ne peut et ne doit pas être total. La présence d'angles-morts au sein du mécanisme de la QPC n'est donc pas, par principe et en soi, contestable. En revanche, lorsque ces anglesmorts se multiplient et entraînent des violations potentielles de droits et libertés, ils deviennent problématiques.

L'origine de la question remonte aux choix du pouvoir politique de centraliser l'appréciation du caractère sérieux au profit du Conseil d'État et de la Cour de cassation. L'interprétation de la loi par les juges suprêmes du filtrage devient ainsi un outil de régulation du flux des QPC et, dans le même temps, un instrument de préservation de la jurisprudence judiciaire et administrative. Assumant cette

CC 2013-336 QPC, 1er août 2013.

$4 \quad$ CC 2015-479 QPC, 31 juillet 2015. 
nouvelle fonction, la Cour de cassation dans son rapport annuel pour 2014 considérait les arrêts de non-renvoi comme une « source de droit autonome et originale » permettant d'édicter « une nouvelle règle jurisprudentielle qui va de surcroît s'appliquer immédiatement au pourvoi sur lequel la question s'était greffée $»^{5}$. Le mécanisme de l'interprétation conforme était donc inévitable, notamment lorsque la QPC concerne une disposition qui n'avait pas été auparavant soumise au Conseil d'État ou à la Cour de cassation ${ }^{6}$. De même, les juges du filtrage peuvent dissiper un léger doute sur le sens de la loi, ou se référer à une décision précédente établissant la compatibilité de la loi avec une norme internationale ou européenne afin de conclure à l'absence de caractère sérieux de la $\mathrm{QPC}^{7}$.

En revanche, l'interprétation conforme franchit un cap lorsque le sens attribué à la loi découle d'un revirement de jurisprudence ${ }^{8}$ ou, plus encore, d'une interprétation nettement éloignée du sens littéral du texte législatif. Ainsi, à propos de la suspension de peine pour raisons médicales, l'arrêt du 26 juin $2013^{9}$ de la Cour de cassation réécrit intégralement la norme applicable en neutralisant les conditions prévues par la loi afin d'en déduire que la question ne présente pas, «à l'évidence », de caractère sérieux. De même, le risque de transformer le filtre en bouchon semble permanent lorsque la Chambre criminelle est saisie d'un grief relatif à la violation du principe de clarté et de précision de la loi pénale : inlassablement, la Cour rappelle que l'« application » ou « l'interprétation » de la disposition contestée « relève de l'office du juge » ou « entre dans l'office du juge pénal », ce qui permet selon elle d'écarter le risque d'arbitraire et ainsi ôter à la question son caractère sérieux. Ainsi, en suivant cette logique préservatrice des marges de manœuvre des juges du filtrage, la jurisprudence passée ou à venir bénéficie d'une présomption irréfragable de respect des droits et libertés constitutionnels.

Les effets de l'absence de contrôle de constitutionnalité des décisions des cours suprêmes sont également problématiques au regard de deux pratiques de la Cour de cassation.

D'une part, la Cour de cassation déclare irrecevable toute QPC dont l'objet porte sur les jurisprudences sans texte. En dépit de l'invocation par le justiciable d'un rattachement textuel, le lien avec la norme jurisprudentielle n'est pas jugé suffisamment établi et la question n'est pas renvoyée au Conseil constitutionnel pour ce seul motif. De manière théorique, les hypothèses de règles prétoriennes solitaires, errant sans aucune accroche textuelle législative, semblent globalement illusoires. Les conséquences de la règle prétorienne, les éléments qu'elle met en œuvre ou son cadre procédural sont la plupart du temps déterminées de proche en proche par un texte législatif. De plus, les hypothèses concrètes dans lesquelles ce motif de non-renvoi a été opposé ne sont pas convaincantes, spécialement lorsque la jurisprudence antérieure vise ou cite la disposition législative objet de la $\mathrm{QPC}^{10}$.

\footnotetext{
Cour de cassation, Rapport annuel 2014, La documentation française, 2015, p. 348, disponible sur www.courdecassation.fr

V. par ex. CE 29 septembre 2010, Sté SNERR Théâtre de Paris, n 341065 ; CE 9 juillet 2014, n 380377 ; CE 14 septembre 2015 , M. E., n³88766.

CE 16 juillet 2010, SCI La Saulaie, n³34665 ; Cass. crim. 15 mars 2011, n 10-90126 ;Cass. crim. 19 novembre 2013, n¹3-84909.

CE 14 septembre 2011, M. Michel A., n 348394 ;Cass. crim 5 octobre 2011 n¹1-90087 ; Cass. crim 12 avril 2012, n $12-90004$; Cass. com. 5 septembre 2013, n $13-40034$;Cass. $2^{\mathrm{e}}$ civ. 10 juillet 2014, n $13-25985$.

Cass. crim. 26 juin $2013, n^{\circ} 12-88284$.

10 Cass Soc. 28 nov. 2012, n 11-17941 ; Cass. 1re civ., 23 oct. 2013, n 13-15578; Cass. crim., 22 octobre 2014, n 14-82082.
} 
D’autre part, la Cour de cassation a développé un critère supplémentaire de filtrage fondé sur l'intérêt du justiciable à obtenir l'abrogation de la loi ${ }^{11}$. Dans le même esprit, au-delà de ce que prévoit la loi organique et à rebours de la politique de filtrage du Conseil d'État, la Cour de cassation peut également relever « que la réponse à la question prioritaire de constitutionnalité n'est pas de nature à exercer une influence sur l'issue du litige $»^{12}$ ou que les principes de valeur constitutionnelle invoqués ne peuvent exercer d'influence sur la solution du litige $»^{13}$. D'un usage plastique et commode, cette nouvelle condition sert parfois de prétexte pour ne pas renvoyer au Conseil constitutionnel une interprétation constante dont la conformité à la Constitution est douteuse. Parmi plusieurs illustrations, l'aveu récent des conclusions d'un avocat général sont particulièrement révélatrices. L'affaire concernait une QPC relative à l'article 545 du code civil, tel qu'interprété par une jurisprudence constante de la Cour de cassation, prévoyant que l'action en démolition de la partie d'une construction reposant sur le fonds d'un voisin ne peut jamais dégénérer en abus de droit. L'avocat général émet des doutes sérieux sur la conformité de cette norme au regard de la jurisprudence du Conseil constitutionnel en matière de droit de propriété : «Il y a tout lieu de craindre que l'affirmation d'un droit absolu à la démolition, telle qu'elle résulte de la jurisprudence actuelle de votre chambre, conduise à considérer que, dans certaines hypothèses, il puisse y avoir un doute sur sa compatibilité avec la protection du droit de propriété mise en œuvre par le Conseil constitutionnel.» ${ }^{14}$. Or, l'arrêt du 11 février 2016 de la Cour de cassation n'aborde même pas le caractère sérieux dès lors « que la disposition contestée n'est pas applicable au litige, lequel concerne la seule liquidation d'une astreinte que le juge de l'exécution peut seulement liquider ou modérer, sans remettre en cause le principe de l'obligation $»^{15}$. Les doutes de l'avocat général n'auront décidément pas convaincu la Cour de cassation de renvoyer au Conseil constitutionnel cette disposition puisque, dans un arrêt du 15 décembre $2016^{16}$, c'est cette fois le défaut de caractère sérieux qui justifie le non-renvoi.

Il est bien évident que la proposition d'instaurer un contrôle de constitutionnalité des décisions de justice permettrait de remédier à ces incohérences normatives et démocratiques qui conduisent à ce qu'une règle jurisprudentielle bénéficie d'une protection contentieuse davantage favorable qu'une loi. En effet, avec l'avocat général à la Cour de cassation B. Sturlèse, il est possible d'affirmer que « toute règle jurisprudentielle doit être éligible à la QPC, car le pouvoir prétorien ne saurait échapper au contrôle a posteriori de constitutionnalité $»^{17}$.

\footnotetext{
11 Cass., civ., $2^{\mathrm{e}}, 2$ avril 2015, $\mathrm{n}^{\circ} 14-24941$

Cass. 2e civ., 10 avril $2014, \mathrm{n}^{\circ} 13-24746$

Cass., Soc., 13 juin $2014, n^{\circ} 13-26353$ et autres.

B. StURLÈSE, «Une suspicion sérieuse d'inconstitutionnalité à l'égard de la jurisprudence relative au droit absolu à supprimer tout empiétement », $7 C P G, \mathrm{n}^{\circ} 13,28$ mars 2016, 363

15 Cass. 3 e civ., 11 févr. 2016, $\mathrm{n}^{\circ} 15-21.949$

16 Cass., $3^{\mathrm{e}}$ civ., 15 décembre 2016, $\mathrm{n}^{\circ} 16-40240$. V. également, sur le maintien d'une conception absolue du droit de propriété Cass., $3^{\mathrm{e}}$ civ., 10 nov. 2016, $\mathrm{n}^{\circ}$ 15-19561, malgré la nuance légère apportée par Cass., $3^{\mathrm{e}}$ civ., 10 nov. 2016, nº 15-25113 (cf. J. Dubarry, « Empiètement et proportionnalité : point d'équilibre ou de rupture ?», JCP $G, \mathrm{n}^{\circ} 48,28$ novembre 2016,1271 ).

17 B. Sturlèse, op. cit.
} 


\section{Les conditions de possibilité d'une réforme}

\section{A. Les discours de justification}

La décision d'un acteur juridique n'est jamais contestable ou incontestable en soi, elle l'est toujours en fonction de présupposés implicites et de référentiels axiologiques qui guident l'observateur. Sans prétendre à l'exhaustivité, il convient de distinguer trois registres de discours qui peuvent être tenus sur la question de savoir si l'instauration d'un contrôle de constitutionnalité des décisions de justice serait utile et opportune.

Un premier discours peut se placer du point de vue de l'intérêt global du système juridique. Ainsi, au nom de la logique de l'État de droit, de l'impératif de l'unité du droit, la conformité à la Constitution des décisions de justice devrait s'imposer. Cependant, ce même registre de discours peut nuancer l'intérêt d'une telle réforme au regard du risque d'excès de sophistication des recours juridictionnels, l'enchevêtrement des recours pouvant conduite à un engorgement des tribunaux et à une illisibilité du système juridique. De même, l'argument de l'unité du droit ne doit pas masquer le risque d'impérialisme constitutionnel. Le constitutionnaliste se doit de ne pas céder à la tentation de considérer le Conseil constitutionnel comme le juge naturel et exclusif de toute question constitutionnelle, que ce soit l'interprétation de la Constitution ou la garantie de son respect. La proposition soumise au débat dans le cadre de ce colloque ne tombe pas dans cet écueil, mais il convient de garder à l'esprit ce risque.

Un deuxième discours peut se placer du point de vue de l'intérêt du justiciable. Souvent omis, l'intérêt des destinataires des mécanismes juridictionnels est pourtant une composante indispensable de toute réflexion. Dans cette perspective, l'instauration d'un contrôle des décisions de justice sera utile et opportune si le recours est accessible, effectif et apporte une plus-value par rapport aux recours existants. Or, les angles-morts du mécanisme de la QPC démontrent qu'un certain nombre de créations prétoriennes judiciaires ou administratives bénéficient, en pratique, d'une immunité contentieuse : les portes de la QPC se referment, celles du contrôle de conventionnalité également sauf à attendre qu'une affaire remonte jusqu'à la Cour de Strasbourg. Cependant, comme tout registre de discours, l'intérêt du justiciable est réversible : le défaut d'unité du droit peut créer une émulation entre les juges qui, en définitive, peut profiter au justiciable, bien que cela ne soit pas toujours le cas au regard des angles-morts observés. La saine concurrence peut tout de même générer une course au mieux-disant en termes de niveau de protection des droits et libertés et, du point de vue du justiciable, peu importe que ce niveau de garantie découle de la Constitution ou du droit européen ou international. Par exemple, lorsque la Cour de cassation ne renvoie pas une QPC relative à la loi sur la géolocalisation en raison d'un revirement de jurisprudence établi quelques semaines plus tôt sur le fondement de la $\mathrm{CEDH}^{18}$, l'intérêt du justiciable est préservé en dehors de la constitutionnalité. 
Néanmoins, le niveau constitutionnel de protection des droits et libertés présente des spécificités qui permettent au Conseil constitutionnel de proposer une réelle plus-value pour le justiciable ${ }^{19}$.

Un troisième discours concerne les intérêts institutionnels des acteurs juridiques concernés. Dans une perspective de sociologie institutionnelle de l'espace constitutionnel, les intérêts stratégiques des trois juges suprêmes et les tensions entre eux doivent absolument être intégrés à la réflexion. Un tel regard permet d'envisager plus précisément ce que peut faire un acteur juridique, jusqu'où il peut s'avancer sans subir trop de représailles, ou quel prix il devra payer s'il souhaite surmonter les contraintes qu'il rencontre afin de parvenir à un objectif.

Ainsi, du point de vue des intérêts institutionnels du Conseil constitutionnel, l'exercice d'un nouveau contrôle portant sur les décisions de justice lui permettrait d'intensifier son influence sur le droit interne, de renforcer sa position par rapport au Conseil d'État et la Cour de cassation. Face à la nouvelle concurrence du contrôle concret de la conventionnalité des lois exercé par le Conseil d'État et la Cour de cassation ${ }^{20}$, il est bien évident qu'une nouvelle compétence accordée au Conseil constitutionnel lui donnerait un second souffle. Ceci étant, le déficit chronique d'image et de légitimité du Conseil constitutionnel, essentiellement lié à l'ambiguïté historique sur sa nature et à la remise en cause de ses modalités de composition, ne joue pas en sa faveur. Le pouvoir politique pourrait hésiter à lui confier une telle compétence, bien aidé par le Conseil d'État et la Cour de cassation qui ne manqueraient pas de freiner voire de s'opposer à cette réforme. Les prises de position de la Cour de cassation en amont de l'adoption de la QPC, lors des travaux préalables à l'adoption de la révision constitutionnelle et de la loi organique, comme en aval au moment de la controverse sur le renvoi préjudiciel à la CJUE, alimentent cette hypothèse. Il est vrai que, du point de vue du Conseil d'État et de la Cour de cassation, la réforme n'a que peu d'intérêt sur le plan institutionnel dès lors qu'elle consisterait à faire contrôler leurs propres décisions. Sauf à imaginer que ce contrôle leur revienne par le biais d'une procédure exceptionnelle formée devant une formation spéciale de chacune de ces juridictions. Ces mêmes juges peuvent aussi menacer ou mettre à exécution la menace d'exercer eux-mêmes un contrôle de constitutionnalité des lois par voie d'exception, afin de court-circuiter tout le mécanisme de la QPC : c'est juridiquement possible, très peu vraisemblable, mais la menace peut toujours être agitée.

\section{B. Les voies juridiquement envisageables}

Dans le cadre d'une démarche prospective, visant à penser les conditions de possibilité d'une réforme instaurant un contrôle de constitutionnalité des décisions de justice, plusieurs facteurs favorables sont récemment apparus. En effet, la jurisprudence est désormais une source de droit officiellement assumée, susceptible d'être contestée et pouvant constituer le fondement d'un recours en responsabilité. Parmi de nombreuses illustrations, les interprétations constantes conférées à la

19 Comp. par ex. CE, sect., avis, 18 juill. 2006, n²86122, M. KA et CC, n² 2010-1 QPC du 28 mai 2010 ; CEDH, 3 décembre 2002, Berger c/ France, ${ }^{\circ} 48221 / 99$ et CC, ${ }^{\circ} 2010-15 / 23$ QPC du 23 juillet 2010 .

20 Cass. $1^{\text {re }}$ civ., 4 déc. 2013, nº 12-26066, CE, 31 mai 2016, nº 396848. 
loi par le Conseil d'État et la Cour de cassation peuvent faire l'objet d'une QPC, le Conseil d'État peut contrôler le respect de sa propre jurisprudence par les juges du fond en citant expressément la norme prétorienne de référence ${ }^{21}$, la Cour de cassation cite désormais ses propres précédents jurisprudentiels dans la motivation de ses arrêts ${ }^{22}$, les effets d'une jurisprudence peuvent être modulés dans le temps, la CJCE reconnaît en droit de l'Union européenne une responsabilité des États du fait des décisions des cours suprêmes nationales ${ }^{23}$.

En dépit de ces facteurs favorables, la principale difficulté renvoie à la détermination de l'objet du contrôle. S'il s'agit simplement des jurisprudences sans texte, le contrôle serait résiduel. De manière générale, isoler la norme jurisprudentielle du texte législatif et soumettre seulement la première à un contrôle serait hasardeux, la plupart du temps impossible et, dans tous les cas, déconnecté des enjeux liés à la protection des intérêts du justiciable. Le contrôle pourrait également porter sur l'application particulière et concrète de la loi dans un litige donné, ce qui supposerait de transformer la nature de l'office du Conseil constitutionnel et d'adapter l'effet de ses décisions afin de répondre à une demande particulière. En dehors de l'éventualité d'une révision de l'article 62 de la Constitution, le Conseil constitutionnel pourrait inaugurer une nouvelle forme de réserve d'interprétation, la réserve concrète, qui ne s'appliquerait que dans certaines situations ou à l'égard de certaines catégories de justiciables.

En dehors du scenario d'une réforme constitutionnelle, qui n'est pas à exclure ${ }^{24}$, le Conseil constitutionnel pourrait fondre le contrôle des décisions de justice dans le contrôle des interprétations constantes de la loi dont le champ serait élargi. Ainsi, toute interprétation de la loi pourrait faire l'objet d'une QPC, même celles qui n'ont pas été soumises au Conseil d'État ou à la Cour de cassation : dès lors que la question est jugée sérieuse par ces deux cours suprêmes, l'interprétation de la loi par les juges du fond pourrait faire l'objet d'une QPC. De même, le lien avec une disposition législative pourrait être assouplie afin de mettre fin à la jurisprudence de la Cour de cassation déclarant irrecevable les QPC jurisprudentielles dont le lien avec un texte législatif est seulement indirect.

Le potentiel de l'autorité par analogie d'objet pourrait également être utilisé. En l'état de la jurisprudence constitutionnelle, l'autorité des décisions du Conseil constitutionnel s'étend aux « dispositions » d'une « loi » qui ont un objet analogue à celui des dispositions législatives sur lesquelles le Conseil constitutionnel s'est déjà prononcé ${ }^{25}$. Le caractère sérieux d'une QPC peut dès lors être retenu en raison d'une violation invoquée par le justiciable de l'article 62 de la Constitution ${ }^{26}$. Ainsi,

21 CE, sect., 19 avr. 2013, n 340093, CCI d'Angoulême : « la cour a fait à bon droit application, par l'arrêt attaqué du $1^{\mathrm{er}}$ avril 2010, de la règle énoncée par la décision du Conseil d’État, statuant au contentieux n $304802 \mathrm{du} 28$ décembre 2009, commune de Béziers [...] »

22 Cass., com. 22 mars 2016, $\mathrm{n}^{\circ} 14-14218$.

CJCE, 30 septembre 2003, Kobler c/ Autriche, affaire numéro C-244/01

Une révision constitutionnelle en ce sens pourrait, par exemple, prendre la forme suivante en ce qui concerne l'accès au contrôle : « Dans le mois suivant la notification de toute décision juridictionnelle insusceptible de recours en droit interne, une partie au litige peut former un recours en garantie des droits et libertés constitutionnels devant le Conseil constitutionnel. La recevabilité du recours est appréciée par le Conseil constitutionnel dans les modalités prévues par la loi organique. »

25 CC, $\mathrm{n}^{\circ}$ 2016-612 QPC, 24 février 2017.

26 CE 25 septembre 2015, n 391331 et n 392164 ; CC, nº 2014-417 QPC, 19 septembre 2014 ; CC, n 2015-504/505 QPC, 4 décembre 2015. 
le Conseil constitutionnel pourrait amender son considérant de principe afin d'affirmer que l'autorité de ses décisions s'étend aux «normes », et plus seulement aux dispositions législatives, qui ont, en substance, un objet analogue à celui des dispositions législatives déclarées contraires à la Constitution. Un mot de plus pour créer une brèche juridique permettant d'envisager un contrôle des décisions de justice en collaboration avec le Conseil d'État et la Cour de cassation : sans heurts, une telle voie médiane pourrait voir le jour afin de mettre en lumière la nécessité d'une réforme future de plus grande ampleur.

Laurence GAY, Chargée de recherches CNRS, Aix Marseille Univ, Université de Toulon, Univ Pau \& Pays Adour, CNRS, DICE, ILF-GERJC, Aix-en-Provence, France

\section{« Le contrôle de constitutionnalité des décisions de justice : quel(s) contrôle(s) pour quelle justice constitutionnelle?»}

Après la QPC, faut-il envisager un contrôle de constitutionnalité des décisions de justice ? Si l'interrogation est incontestablement novatrice, le premier terme du sujet mérite sans doute d'être employé au pluriel. En effet, les rapports nationaux éclairant la situation sur ce point chez certains de nos voisins européens et aux États-Unis font ressortir que, dans aucun de ces pays, il n'existe de recours visant exclusivement la décision de justice en tant que telle. C'est à l'occasion d'un contrôle ayant un objet plus large que la Cour constitutionnelle ou la Cour suprême est amenée à examiner, et éventuellement sanctionner d'un point de vue constitutionnel, tel ou tel aspect d'une décision de justice. Avant d'envisager la réforme suggérée par le colloque, il convient donc d'identifier quels sont les aspects d'une décision de justice susceptibles d'être concernés. Autrement dit, si contrôle il doit y avoir, quel en serait précisément l'objet ? À cet égard, on peut faire une première distinction entre le contrôle de constitutionnalité «externe» de la décision de justice - portant en quelque sorte sur le bon exercice de la fonction juridictionnelle - et le contrôle de constitutionnalité «interne»portant alors sur le contenu de la décision de justice. Ce second cas est lui-même très vaste; dans le cadre de l'expérience française, qui voit la compétence du Conseil constitutionnel largement centrée sur le contrôle de constitutionnalité de la loi, on pense en particulier au contrôle de l'interprétation de la loi, ou à celui de l'interprétation de la Constitution. Sans prétendre à un tour d'horizon complet du sujet, nous examinerons successivement ces trois hypothèses, en tentant un bilan du droit positif puis en nous interrogeant sur l'opportunité comme sur les perspectives d'évolution.

\section{Le contrôle de constitutionnalité « externe » de la décision de justice}

Le contrôle de constitutionnalité d'une décision de justice peut tout d'abord porter sur le respect des «canons» du procès équitable - impartialité, contradictoire, égalité des armes, etc. On sait que 
le Conseil constitutionnel a progressivement consacré ces différents éléments sur le fondement de l'article 16 de la Déclaration des droits de l'homme et du citoyen de 1789 ; il veille donc à leur respect par les dispositions législatives déférées, a priori ou a posteriori. En revanche, et de toute évidence, le Conseil n'en contrôle jamais le respect in concreto, par une décision de justice donnée. De ce point de vue, la QPC n'est pas venue concurrencer l'usage qui peut être fait de la Convention européenne des droits de l'homme, notamment de son article $6 \S 1^{\text {er }}$, devant les juridictions internes puis devant la Cour de Strasbourg. Cette dernière a pu, à travers la situation particulière d'un requérant, examiner des éléments de procédure généraux - l'exemple topique pour le publiciste français restant sans doute l'arrêt $\operatorname{Kress}^{27}$, mettant en cause la présence au délibéré de l'ancien commissaire du Gouvernement devant les juridictions administratives... Plus souvent, toutefois, la Cour doit examiner le respect de l'article $6 \S^{\text {er }}$ au regard du cas d'espèce exclusivement, type de contrôle inaccessible en l'état au Conseil constitutionnel. L'instauration d'un recours direct devant ce dernier, après épuisement des voies de recours préalables, créerait une brèche... risquant de devenir béance. Les enseignements ressortant des droits étrangers en la matière, notamment de la pratique du recours d'amparo en Espagne et du recours constitutionnel en Allemagne, confirment la tendance spontanée du justiciable à se situer sur ce terrain du contrôle de constitutionnalité «externe» des décisions de justice. Les demandes en ce sens constituent la principale source alimentant le flux abondant des recours individuels. Quid d'une réforme sur ce point en France ? Il nous semble difficile, si un recours direct était ouvert dont les décisions de justice pourraient faire l'objet, d'exclure ce contrôle «externe» pour éviter l'encombrement du rôle du Conseil constitutionnel. Une évolution vers le recours direct contre les décisions de justice imposerait donc une importante réforme de ce dernier, incluant la création de procédures de filtrage préalable des recours. Malgré un filtrage, le flot probable des recours ne nous paraît pas contrebalancé par une plus-value considérable pour le justiciable. Autrement dit, le contrôle de constitutionnalité externe des décisions de justice ne nous paraît pas être ce qui manque le plus à la France en l'état. Dès lors, nous sommes amenées à envisager le contrôle du contenu des décisions de justice, en commençant par le contrôle de l'interprétation de la loi.

\section{Le contrôle de constitutionnalité de l'interprétation de la loi}

En France, le contrôle de la jurisprudence des Cours suprêmes portant sur la loi est possible par le biais de la question prioritaire de constitutionnalité. La brève opposition de la Cour de cassation à cette hypothèse est désormais chose lointaine et il est établi « qu'en posant une question prioritaire de constitutionnalité, tout justiciable a le droit de contester la constitutionnalité de la portée effective qu'une interprétation jurisprudentielle constante confère à la disposition $»^{28}$ de loi. Emanant de la Cour suprême administrative ou judiciaire, une telle interprétation consolidée de la loi constitue le droit vivant, selon l'expression reprise de l'expérience italienne. Le contrôle du droit vivant dans le cadre de la QPC constitue en définitive un contrôle de la loi dans la signification spécifiée par le juge et appliquée par conséquent au justiciable. Nous ferons sur le sujet trois remarques.

27 CEDH, 7 juin 2001, Kress c. France, $n^{\circ} 39594 / 98$

28 CC, 6 octobre $2010, \mathrm{n}^{\circ} 2010-39$ QPC, cons. $\mathrm{n}^{\circ} 2$. 
La première remarque porte sur les techniques décisoires susceptibles d'être employées par le Conseil constitutionnel à l'occasion d'un tel contrôle du droit vivant. En Italie, la Cour constitutionnelle s'interdit d'émettre des réserves interprétatives qui iraient à l'encontre de ce droit vivant. La pratique du Conseil constitutionnel est différente, ce que justifient selon nous deux principales raisons. D'une part, la préférence donnée à une censure pure et simple de la loi par rapport à une réserve, quand elle est possible, revient paradoxalement à manifester plus d'égards pour la jurisprudence que pour l'acte législatif lui-même. D'autre part, le contexte qui a conduit la Cour italienne à arrêter sa solution ne se retrouve pas dans notre pays. En effet, en Italie, une décision évitant la censure au prix d'une réserve d'interprétation n'a qu'une autorité relative de chose jugée ; se présentant comme une sentence dite de rejet de la question de constitutionnalité, elle n'est dotée que d'un effet inter-partes. En France, cette difficulté n'existe pas, ou pas avec la même acuité, dès lors que toutes les décisions QPC ont une autorité absolue de chose jugée. Cette dernière est bien respectée par les deux ordres de juridiction dès lors que les conditions en sont réunies. Le Conseil d'État a même reconnu l'autorité absolue des réserves d'interprétation ${ }^{29}$, ainsi que l'autorité s'attachant à une précédente déclaration d'inconstitutionnalité, dès lors que sont mises en cause devant lui des « dispositions identiques, dans leur substance et dans leur rédaction $»^{30}$.

Si le contrôle du Conseil constitutionnel sur la jurisprudence des Cours suprêmes interprétant la loi est désormais établi, il demeure cependant une faille dans l'édifice de la QPC qui a trait aux jurisprudences détachées de support textuel exprès, que la Cour de cassation refuse au contraire de renvoyer $^{31}$. Le prétexte en est que, selon l'article 61-1 de la Constitution et la loi organique de 2009 prise pour son application, la question posée doit viser une « disposition législative ». De toute évidence, le législateur constituant et organique a entendu par là conférer au justiciable la possibilité de contester la norme législative devant lui être appliquée. Or, la jurisprudence de la Cour de cassation, en l'absence d'une éventuelle remise en cause par le législateur, tient bien lieu de loi à ceux à qui elle est appliquée. Il est donc paradoxal qu'elle puisse échapper à un contrôle auquel est au contraire soumis l'acte législatif ; c'est d'autant plus paradoxal que cette jurisprudence, en ce qu'elle est - de l'aveu même de son auteur - largement distante de tout support textuel, se présente comme la manifestation la plus poussée de l'activité normative du juge. Ce non contrôle des jurisprudences détachées de support textuel exprès paraît donc bien constitutif d'une faille, pour reprendre le terme de la grille d'analyse proposée pour cette table ronde, faille susceptible de justifier une réforme. Cette réforme pourrait soit être d'ordre général, comme l'envisage le sujet du colloque, soit porter spécifiquement sur la problématique des refus de renvoi de questions prioritaires de constitutionnalité. Nous ferons ici quelques remarques sur ce point particulier du filtrage des QPC.

Un contrôle par le Conseil constitutionnel des décisions de refus de renvoi de QPC - ce qui peut au demeurant mettre en cause tout aussi bien l'interprétation de la loi que l'interprétation de la Constitution - avait été envisagé dans les premiers mois de fonctionnement de la QPC. Auteur d'un rapport délivrant

29 CE, 15 mai 2013, Commune de Gurmençon, ${ }^{\circ} 340554$

30 CE, 16 janvier 2015, Société Métropole Télévision, $n^{\circ} 386031$.

31 Cass Soc. 28 nov. 2012, n 11-17941 ; Cass. $1^{\text {re }}$ civ., 23 oct. 2013, n 13-15578; Cass. crim., 22 octobre 2014, $\mathrm{n}^{\circ} 14-82082$ 
un premier bilan de la procédure, le député Warsmann évoquait la possibilité soit de faire appel d'un refus de renvoi devant le Conseil constitutionnel dans les 10 jours, soit d'un mécanisme d'évocation par le Conseil constitutionnel lui-même de certaines questions non transmises. Une troisième hypothèse, emportant en définitive la préférence du rapporteur, était celle d'une nouvelle délibération par les juridictions suprêmes à la demande du Conseil constitutionnel, lequel n'était plus alors en posture de contrôleur des décisions en cause ${ }^{32}$. Une évolution sur ce point a finalement été écartée assez rapidement. Pourtant, il reste que la situation française nous apparaît bien comme une anomalie. Dans les pays européens proches, il n'existe certes en général pas de recours contre les refus des juges a quibus de renvoyer une question de constitutionnalité à la Cour constitutionnelle. Toutefois, comme il a été rappelé pour l'Espagne par le Président du Tribunal constitutionnel, la raison en est que " poser la question d'inconstitutionnalité est de la compétence exclusive et souveraine de l'organe judiciaire qui ne se trouve pas lié par la demande qu'ont pu en faire à ce sujet ceux qui ont été parties dans le procès ordinaire $\gg^{33}$. À cette raison de principe, s'ajoute le fait que le renvoi n'est pas le monopole des Cours suprêmes, ce qui laisse bien plus de possibilités que, une question ayant été écartée par une juridiction, soit renvoyée néanmoins par une autre si elle présente vraiment une apparence de sérieux... Cette situation prévaut en Espagne, mais aussi en Italie, en Allemagne ou encore en Belgique ${ }^{34}$. En France, au contraire, Cour de cassation et Conseil d'État ont le monopole du renvoi alors que la QPC n'est pas le monopole du juge mais au contraire un droit exclusif des parties. La solution nous semble donc doublement incohérente, le refus de renvoi par la Cour de cassation des jurisprudences sans base textuelle n'en étant qu'un symptôme. Un recours spécifique y remédierait, même s'il serait sans doute bien plus simple et logique de supprimer le monopole de renvoi des Cours suprêmes. Par ailleurs, une réforme d'ordre plus général comme celle du recours direct déjà évoquée pourrait aussi offrir une solution. C'est ce que démontre l'articulation en Allemagne entre la question préjudicielle de constitutionnalité et le recours individuel direct. En effet, en cas de refus de renvoi d'une question préjudicielle, « lorsque ce jugement a admis à tort la constitutionnalité ou l'inconstitutionnalité de (la) règle de droit (applicable) et que celle-ci affecte le droit fondamental de l'une des parties au procès, celle-ci peut former contre le jugement un recours individuel pour violation de ce droit fondamental $»^{35}$. Par conséquent, selon les modalités procédurales retenues, créer en France un recours direct qui concernerait les décisions de justice pourrait aussi fournir un moyen de contester un refus de renvoi d'une QPC par la Cour de cassation ou le Conseil d'État, en tant que ce refus porterait atteinte à un droit fondamental, en particulier le droit à un recours juridictionnel effectif ${ }^{3637}$.

32 J.-L. WARSMANn, Rapport d'information n 2838 sur l'évaluation de la loi organique nº 2009-1523 du 10 décembre 2009 relative à l'application de l'article 61-1 de la Constitution, 5 octobre 2010, p. 19-21

33 Entretien du professeur Pierre Bon avec Alvaro Rodriguez Bereijo, Cah. Cons. Const., n 2/1997, p. 57

34 En Belgique, la situation est même inverse à celle de la France en ce sens que, pour éviter un verrou de la part de la Cour de cassation ou du Conseil d'État, ces deux juridictions sont dans l'obligation de renvoyer à la Cour constitutionnelle une question préjudicielle de constitutionnalité soulevée devant elles. Plus précisément, l'obligation de renvoi s'applique même si elles estiment que la réponse n'est pas indispensable pour rendre leur décision ou qu'il n'y a manifestement pas d'inconstitutionnalité, alors que les autres juridictions peuvent, dans ces deux hypothèses, refuser le renvoi.

35 M. Fromont, « Présentation de la Cour constitutionnelle fédérale allemande », Cah. Cons. const., n 15/2003, p. 97

36 On se souvient qu'au contraire, un refus motivé de renvoi par la Cour de cassation a été considéré comme ne portant pas atteinte à l'article $6 \S 1^{\text {er }} \mathrm{CEDH}$ par la Cour de Strasbourg : CEDH, 25 août 2015, Renard et a. c. France, n $^{\circ} 3569$

37 À noter qu'en Espagne, au contraire, l'amparo contre la décision de non renvoi d'une question d'inconstitutionnalité n'est pas possible, ce refus ne pouvant être considéré comme une violation des droits fondamentaux des parties, en particulier du droit fondamental à la protection juridictionnelle effective. Toutefois, cette solution est fondée par le TC sur le fait que la question d'inconstitutionnalité reste l'apanage du juge $a$ 
En définitive, si l'amplification des possibilités de contrôle portant sur la jurisprudence des Cours suprêmes par la QPC a pu susciter des crispations, elle a aussi donné lieu au développement de stratégies de filtrage de la part de ces dernières leur permettant de s'approprier des techniques nouvelles de contrôle de constitutionnalité. Ce n'est plus alors l'interprétation de la norme objet du contrôle qui est en jeu, mais celle de la norme paramètre : la Constitution.

\section{Le contrôle de l'interprétation de la Constitution}

Saisie d'une décision de justice, la Cour constitutionnelle peut vérifier qu'elle fait - pour reprendre les termes de la grille d'analyse proposée - une « correcte interprétation et application de la Constitution au litige » ... à l'instar de la Cour suprême américaine. Cet aspect est certainement décisif si une réforme dans le sens suggéré par l'intitulé du colloque devait être envisagée. Permettre au justiciable de contester devant la Cour constitutionnelle une décision de justice conduit en effet à établir une « justice constitutionnelle intégrale », laquelle assure le respect de la norme fondamentale quel que soit le type de norme dont l'application subordonne l'issue du litige initial - loi ou autre ; elle fournit aussi à cette Cour un moyen privilégié d'unifier et maîtriser l'interprétation de ladite loi fondamentale. Il s'agirait d'une évolution d'autant plus déterminante que, historiquement, le Conseil constitutionnel français apparaît comme ayant eu une maîtrise plutôt faible de cette interprétation.

L'antériorité des Cours suprêmes leur avait permis, en particulier au Conseil d'État, de pratiquer l'exercice de l'interprétation constitutionnelle, fût-ce occasionnellement, avant le juge constitutionnel lui-même. Cette donnée se retrouve certes dans d'autres pays européens. À ceci près qu'en France, il s'agissait, déjà, d'interpréter la Déclaration de $1789^{38}$ ou le préambule de $1946^{39}$, soit les textes mêmes qui constituent encore aujourd'hui la base du contrôle exercé par le Conseil constitutionnel. Difficile ainsi d'oublier que la décision de ce dernier dite Liberté d'association, qui inaugure le contrôle des lois au regard des droits constitutionnels, constitue un emprunt à une interprétation créative du préambule de 1946 par le Conseil d'État... Cette autonomie dans l'interprétation de la Constitution est toujours fermement revendiquée par les deux Cours suprêmes françaises, y compris en ce qu'elle inclut la possibilité de reconnaitre la valeur constitutionnelle d'un principe non expressément inscrit dans le texte de la Constitution - ou l'inverse ${ }^{40}$. En outre, le contrôle exclusivement a priori longtemps pratiqué par le Conseil constitutionnel a certainement contribué à limiter la diffusion de sa jurisprudence. Le seul canal de diffusion de son interprétation constitutionnelle, l'autorité de chose jugée, est assujetti à des conditions strictes qui ont pu être rappelées à l'occasion par les Cours suprêmes ${ }^{41}$. L'émancipation de ce cadre, probablement mal ajusté à la justice constitutionnelle, repose sur la seule bonne volonté des juridictions ordinaires. En définitive, la mise en place de la QPC a eu elle-même des conséquences quelque peu paradoxales. D’un côté, les saisines

\footnotetext{
quo, et non un droit des parties, comme l'expliquait le Président du Tribunal dans l'interview précitée (référence supra, note 33) ; cette prémisse ne se retrouve précisément pas en France.

38 CE, 7 juin 1957, Condamine.

39 CE, Ass., 7 juillet 1950, Dehaene; CE, Ass., 11 juillet 1956, Amicale des Annamites de Paris

40 Cass. plén., 20 mai 2011, n 11-90025; n 11-90032; n 11-90033; n 11-90042

41 Cass. plén., 10 octobre 2001, Breisacher.
} 
du Conseil constitutionnel ont considérablement augmenté, lui offrant l'occasion d'étoffer sa jurisprudence et aux autres juridictions, celle de s'appuyer sur cette jurisprudence pour jouer leur rôle de filtre. D’un autre côté, néanmoins, le mécanisme implique un certain degré de déconcentration du contrôle de constitutionnalité à travers l'appréciation du sérieux de la question ; le passage obligatoire de cette dernière par les deux Cours suprêmes leur a permis d'investir ce champ de contrôle bien plus qu'auparavant, les plaçant désormais en position de concurrentes du Conseil constitutionnel. Une des manifestations les plus caractéristiques de cette concurrence réside dans les refus de renvoi d'une QPC assortis d'un revirement de jurisprudence : la Cour suprême se fait alors interprète des exigences constitutionnelles, en détermine la portée au regard de la loi en cause, délivre à cette dernière un brevet implicite de constitutionnalité doté d'un simple effet inter-partes tout en refusant l'accès du justiciable au juge constitutionnel...

C'est pourquoi la création d'une voie de droit permettant au contraire au justiciable de déférer les décisions de justice au Conseil constitutionnel ne marquerait pas un simple approfondissement de la justice constitutionnelle en France, mais bien une rupture. Elle fournirait les moyens au Conseil constitutionnel d'unifier l'interprétation de la Constitution et de l'imposer aux deux ordres de juridiction. Quelles que soient les modalités procédurales concrètes qui seraient retenues, il est incontestable qu'une telle évolution rapprocherait le Conseil d'une Cour suprême, en particulier en ce qu'il serait alors bel et bien saisi d'un litige concret. Ce serait une autre rupture majeure, quand on connaitt le soin qui a été mis, dans le cadre de la QPC, à mettre le litige initial à distance de la question de constitutionnalité et de son jugement - a posteriori mais essentiellement abstrait - par le Conseil. On peut alors s'interroger sur les évolutions que ce dernier serait prêt à imprimer à sa jurisprudence et ses techniques décisoires, compte tenu de ce contexte procédural nouveau. Des perspectives pourraient s'ouvrir à lui, comme celle de combiner un contrôle abstrait et concret au sein d'une même décision, à l'instar de ce qu'a inauguré le Conseil d'État sur le terrain conventionnel en $2016^{42}$. Déclarer la conformité de la loi à la Constitution quant à son principe tout en jugeant son application au cas d'espèce contraire à certains droits fondamentaux : la voie est déjà empruntée par plusieurs Cours constitutionnelles. Sa transposition en France supposerait vraisemblablement une mutation profonde du Conseil constitutionnel, dans sa composition comme dans sa propre perception de sa fonction.

En définitive, une réforme du Conseil constitutionnel paraît en tout état de cause inhérente à l'hypothèse envisagée par le colloque, quelles que soient l'étendue et les modalités concrètes d'exercice de la compétence qui lui serait nouvellement dévolue. En réalité, l’important ne concerne pas tant les aspects techniques et organisationnels que de principe : quelle justice constitutionnelle parait-elle souhaitable pour notre pays ? Alors que la création du Conseil en 1958 doit finalement peu à la volonté de respecter les droits fondamentaux et l'État de droit, envisager un contrôle de constitutionnalité des décisions de justice fournirait une bonne occasion de réfléchir à cette question.

42 CE, Ass., 31 mai 2016, Me Gonzalez Gomez, n 396848, Rev. fr. dr. adm., 2016, conclusions A. BretonneAU, p. 740. 
Yasmine Sylvestre, Docteur en droit public à l'Université des Antilles et de la Guyane, Membre associé de LC2S

À titre liminaire, je tiens à vous préciser que la vision transversale, que je vous présenterai, de la question qui nous est posée dans le cadre de ce colloque, Le contrôle de constitutionnalité des décisions de justice : Une nouvelle étape après la QPC ?, est la résultante de ma double formation publiciste-privatiste.

La question du contrôle de constitutionnalité des décisions de justice ne doit pas selon moi, à cet égard, occulter les contingences s'imposant aux juridictions judiciaires, administratives, aux justiciables et à leurs représentants dans le cadre de ce contrôle de constitutionnalité.

Pour les justiciables et leurs représentants, la question prioritaire de constitutionnalité constitue un moyen de défense qu'ils choisiront ou non d'utiliser dans leur stratégie de défense. L'objectif pour eux est d'obtenir gain de cause par l'usage du contrôle de constitutionnalité a posteriori.

À ce titre, s'agissant du « faible » nombre de recours à la question prioritaire de constitutionnalité évoqué par certains des intervenants à ce colloque, celui-ci s'explique dans certains cas par le choix d'autres moyens de défense. Il ressort de discussions avec des avocats, deux éléments principaux justifiant ce constat. Il s'agit, en premier lieu, de la méconnaissance de cette procédure aboutissant corolairement au choix d'un autre moyen de défense mieux maîtrisé par les représentants des justiciables. En second lieu, il s'agit du surcoût de ce moyen de défense. Sur le terrain, cette problématique ne semble pas être résorbée par l'éligibilité de la procédure relative à la question prioritaire de constitutionnalité par le décret du 16 février 2010 relatif à la continuité de l'aide juridictionnelle en cas d'examen de la question prioritaire de constitutionnalité par le Conseil d'État, la Cour de cassation et le Conseil constitutionnel $^{43}$, à l'aide juridictionnelle. Face à la modeste compensation financière offerte dans le cadre de ce dispositif, l'aide juridictionnelle n'est en effet pas acceptée par tous les avocats. Eu égard à ces contingences pratiques, ce moyen de défense est dans la grande majorité utilisé par des justiciables disposant des moyens de financer le surcoût engendré par cette procédure.

S'agissant spécifiquement de la question du contrôle de constitutionnalité des décisions de justice, doit-on l'ouvrir à la jurisprudence ? Ou doit-on exclure cette dernière de ce contentieux ? Selon moi, la jurisprudence ne peut être écartée du contrôle de constitutionnalité des décisions de justice. Car dans certains cas, il y a coïncidence entre une décision et la jurisprudence. Ainsi pour illustration, chaque décision de l'Assemblée plénière de la Cour de cassation fait jurisprudence ${ }^{44}$. Dans ce cas le contrôle de constitutionnalité d'un tel arrêt remettrait en cause la jurisprudence ellemême. De même, la remise en cause du caractère constitutionnel d'une décision s'inscrivant dans une jurisprudence assise pourrait entraîner incidemment la remise en cause de cette dernière.

43 Décret $\mathrm{n}^{\circ}$ 2010-149 du 16 février 2010 relatif à la continuité de l'aide juridictionnelle en cas d'examen de la question prioritaire de constitutionnalité par le Conseil d'État, la Cour de cassation et le Conseil constitutionnel, JORF 18 février 2010 p. 2973

44 En ce sens, propos d'Olivier TALABARDON. 


\section{Paolo Passaglia, Professeur à l'Université de Pise}

Mes connaissances du système français ne me permettent pas de donner un avis suffisamment averti sur l'introduction d'un recours direct visant au contrôle de la constitutionnalité des décisions de justice.

Je me limiterai donc à quelques brèves remarques, suggérées par une comparaison avec le système italien.

Dans mon rapport sur l'expérience italienne, j'ai été assez clair (du moins, je l'espère) à l'égard de mon opposition à l'introduction d'un recours direct des particuliers en Italie. Les raisons qui fondent cette opposition sont liées, d'un côté, au risque, très concret, d'un alourdissement important de la charge de travail de la Cour et, de l'autre, à l'effet négatif que le recours engendrerait, vraisemblablement, à l'égard de la collaboration entre la Cour constitutionnelle et les juridictions de droit commun.

Ces mêmes raisons me paraissent valables pour le système français. Le nombre de justiciables étant, à peu près, équivalent, pour la France on peut partager les soucis exprimés pour l'Italie, et qui viennent du fait que dans les pays ayant plusieurs dizaines de million de justiciables il est très probable qu'une voie ouverte vers la juridiction constitutionnelle soit parcourue par plusieurs milliers de personnes chaque année.

Pour ce qui a trait à la collaboration entre la juridiction constitutionnelle et les juridictions de droit commun, il est évident qu'un recours direct dirigé contre les décisions de justice ferait en sorte que la Cour constitutionnelle et le Conseil constitutionnel seraient perçus par les autres juridictions comme des censeurs, plutôt que comme des organes ayant des tâches différentes, mais visant au même résultat : plutôt qu'une voie pour protéger la Constitution, le recours direct serait perçu par les contrôlés comme un moyen de pression. Par conséquent, il serait tout à fait normal que quelque méfiance vis-à-vis de la juridiction constitutionnelle s'affirme (ou s'accentue, selon les points de vue) parmi les juridictions, et notamment au sein de celles qui sont aujourd'hui au sommet des ordres judiciaires.

À mon avis, ces raisons justifieraient, à elles-seules, l'opposition à une réforme introduisant le recours direct en France. D'autres raisons - au moins, deux - me paraissent, toutefois, à mettre en exergue pour renforcer cette opposition.

La première concerne l'organisation et la structure du Conseil constitutionnel, qui ne me semble pas en mesure de pouvoir faire face de manière efficace à un afflux massif de recours : une réforme impliquerait donc des changements majeurs dans l'organisation du Conseil, ce qui peut très bien se faire. Il faut simplement en tenir compte, car le risque pourrait être celui de perturber de manière irréparable le fonctionnement de l'institution.

La seconde raison est liée à la réglementation de la question prioritaire de constitutionnalité, qui est conçue comme un moyen pour le justiciable de s'adresser au Conseil, plutôt que comme une voie 
d'accès « neutre » au Conseil visant au respect de la Constitution. Je m'explique : les questions prioritaires de constitutionnalité ne peuvent être soulevées que par les parties d'un litige, le juge n'ayant pas le pouvoir de soulever une question d'office. Cela me parait important dans le cadre d'un éventuel recours direct contre les décisions de justice : d'une part, les justiciables auraient une double possibilité d'invoquer le respect de la Constitution, notamment à l'occasion d'un litige (avec les filtrages des juridictions) et à la fin du litige, par la contestation de la décision devant le Conseil ; de l'autre part, les juridictions se trouveraient dans la position, très peu confortable, de devoir appliquer la loi, à défaut de contestation de sa constitutionnalité par une partie, et, après avoir rendu leur décision, de se voir censurées par le Conseil constitutionnel saisi d'un recours direct pour ne pas avoir fait primer la Constitution sur la loi. Autrement dit, les juges seraient censurés pour avoir accompli leur mission, telle qu'elle est limitée par la loi organique portant sur les questions prioritaires de constitutionnalité. De ce fait, avant d'introduire un recours direct contre les décisions de justice, il serait nécessaire de doter les juridictions de droit commun du pouvoir de soulever d'office des questions de constitutionnalité, de manière à leur permettre d'éviter d'éventuelles censures dérivant du fait d'avoir méconnu la Constitution au profit de la loi. Il s'agit, là aussi, d'une réforme tout à fait possible, mais d'une réforme qui serait aussi nécessaire pour assurer la cohérence du système.

À tout dire, peut-être, il s'agirait d'une réforme qui pourrait très bien être expérimentée avant l'introduction d'un recours direct des particuliers, car elle mesurerait en concret l'attitude des juges à l'égard de la Constitution. Et les résultats pourraient offrir des éléments de réflexion supplémentaires au sujet de l'introduction d'une voie d'accès qui serait destinée à changer en profondeur le système français de justice constitutionnelle. J'ai toujours été de l'avis qu'avant d'opérer des réformes de grande envergure, notamment lorsqu'il s'agit de réformer un système qui n'est pas sans failles, mais dont le bon fonctionnement ne saurait être sérieusement contesté, il faudrait bien considérer leurs avantages et leurs coûts, et dans cette considération une place centrale devrait être réservée aux alternatives moins retentissantes qui pourraient permettre d'améliorer le système sans pour autant le bouleverser.

Alexandre VIALA, Professeur à l'Université de Montpellier, Directeur du CERCOP

\section{Peut-on se satisfaire de la situation actuelle en France ? Quel serait l'intérêt d'une telle réforme?}

Quels sont les aspects qui posent problème actuellement (lacunes/limites du système actuel) ?

L'aspect qui me semble le plus problématique, aujourd'hui, est probablement lié à l'une des conséquences perverses de la QPC. Voilà une réforme qui est censée accroître, grâce au contrôle a posteriori, le processus de constitutionnalisation et d'unification de l'ordre juridique. Or, le système centralisé qui a été conçu, caractéristique de l'exception française, freine ce processus en raison du 
filtre des questions opéré par le Conseil d'État et la Cour de cassation. Il en résulte que le contrôle de constitutionnalité de la jurisprudence constante, qui est un acquis considérable pour le Conseil constitutionnel, est paradoxalement tributaire des juridictions suprêmes. Lors du filtrage, celles-ci peuvent en effet être tentées de rejeter le caractère sérieux d'une QPC visant leur propre jurisprudence afin de la soustraire au contrôle de constitutionnalité, comme l'a montré l'exemple de la décision de la Cour de cassation du 20 mai 2011 sur les emplois fictifs de la ville de Paris ${ }^{45}$.

Paradoxalement, le contrôle du droit vivant a renforcé le juge ordinaire, alors qu'il était permis de penser qu'à l'instar de ce qui s'est produit en Italie, l'examen de la constitutionnalité de la jurisprudence constante du juge administratif et du juge judiciaire rendrait inutile tout type de recours au contrôle de constitutionnalité des décisions de justice. La particularité de la situation française contribue au contraire à la nécessité d'un tel recours. C'est qu'en Italie, l'équivalent de l'amparo est inutile car ni le Conseil d'État ni la Cour de cassation n'ont un pouvoir de filtrage, de telle sorte que les juridictions de première instance et d'appel peuvent directement s'adresser, à tout moment, à la Cour constitutionnelle pour chercher à renverser des jurisprudences de leurs cours suprêmes respectives. La France est le seul pays européen où existe un double filtrage. En l'organisant, l'article 61-1 de la Constitution et la loi organique qui l'accompagne ont érigé les cours suprêmes administrative et judiciaire au rang de cours pré-constitutionnelles. Celles-ci ont dès lors pris une importance qui rendrait légitime l'existence d'un recours contre leurs décisions.

Quel intérêt pour la cohérence de l'ordonnancement juridique?

Les trois ordres de juridictions internes sont ordonnés autour d'une même finalité : la protection des droits de l'homme. On peut estimer en effet qu'à la faveur de la QPC, ils participent tous à cette commune entreprise. D'où le risque de confusion et de complexité que cela engendre et que le Conseil constitutionnel, en contrôlant la constitutionnalité des décisions de justice, pourrait conjurer. La réforme aurait un rôle d'unification de la jurisprudence car les deux juges suprêmes seraient également soumis au même contrôle. Elle permettrait tout particulièrement d'éviter des interprétations conformes différentes d'une Cour suprême à l'autre et de colmater ainsi les brèches inhérentes à la dualité de juridictions. Mais l'avantage majeur serait surtout de permettre au Conseil constitutionnel de contrôler définitivement et de façon certaine, l'autorité de ses propres décisions. La réforme donnerait au Conseil constitutionnel le moyen définitif de sanctionner l'application de ses réserves d'interprétation. Sur un plan strictement théorique, par cela seul qu'elle est définie, circonscrite et garantie par la jurisprudence du juge ordinaire, l'autorité des réserves d'interprétation n'est qu'une autorité de fait car le Conseil constitutionnel ne dispose d'aucun moyen juridique, analogue au recours d'amparo espagnol ou au recours constitutionnel allemand, qui lui offrirait le loisir d'examiner toute requête faite devant lui par un justiciable à l'encontre d'une décision de la Cour de cassation ou du Conseil d'État portant atteinte à ses droits garantis par la Constitution.

$45 \quad$ Cass., 20 mai 2011, $\mathrm{n}^{\circ}$ 11-90.025. 
Pour illustrer cette impuissance juridique du Conseil constitutionnel, j'évoquerai un cas fictif imaginé à partir d'une jurisprudence relativement ancienne qui garde néanmoins toute sa pertinence pour montrer que le juge ordinaire est libre de s'affranchir des réserves d'interprétation. Dans son arrêt d'assemblée plénière du 19 mai $1978^{46}$, la Cour de cassation avait jugé licite le licenciement d'une institutrice remariée à la suite d'un divorce, au mépris de la réserve du Conseil constitutionnel du 23 novembre $1977^{47}$ selon laquelle la notion de « caractère propre » d'un établissement scolaire de confession catholique ne saurait être regardée comme permettant de porter atteinte à la liberté de conscience. Imaginons qu'une autre institutrice remariée après divorce subisse aujourd'hui, à l'heure du contrôle de constitutionnalité a posteriori, le même sort. Elle pourrait, à l'occasion d'un contentieux, soulever une QPC contre la loi qui préserve le « caractère propre » des établissements privés telle qu'interprétée par la Cour de cassation en $1978^{48}$ à défaut d'être en mesure de contester, en raison de la règle du non bis in idem ${ }^{49}$, la loi sèche qui est préservée par la déclaration de conformité du 23 novembre 1977. Mais dans ce cas, rien n'interdirait à la Cour de cassation, dans son rôle de filtrage, de juger non sérieuse la QPC en ignorant la réserve du Conseil constitutionnel. Si la Cour de cassation acceptait néanmoins de soumettre au contrôle de constitutionnalité sa propre interprétation en transmettant la QPC au Conseil, celui-ci pourrait alors, sans abroger la loi, confirmer sa réserve du 23 novembre 1977 et désavouer, de la sorte, la Cour de cassation sous la forme d'une nouvelle réserve d'interprétation qui en reproduirait les termes. Mais là non plus, rien n'impose au juge du fond, à l'instar d'une Cour d'appel devant laquelle l'institutrice aurait soulevé la QPC, d'annuler le licenciement puisque la loi n'a pas été censurée. La requérante pourrait alors, en se fondant sur la réserve du Conseil, faire un pourvoi devant la Cour de cassation laquelle, à son tour, n'est pas juridiquement tenue de casser l'arrêt de la Cour d'appel dans la mesure où la loi sur le caractère propre des établissements privés est toujours en vigueur. C'est alors le recours constitutionnel direct qui permettrait à la requérante d'obtenir gain de cause et au Conseil constitutionnel, surtout, de sanctionner directement le respect de sa réserve d'interprétation en assurant, chemin faisant, la cohérence de l'ordre juridique.

Le fait même d'envisager, à titre d'hypothèse, la question du contrôle de constitutionalité des décisions de justice comme l'ont fait les organisatrices de cette rencontre, est le témoignage implicite de la frustration dans laquelle nous plonge l'article 62 al. 3 de la Constitution qui ne garantit pas l'autorité de la chose interprétée par le Conseil constitutionnel. Certes, s'il n'existe aucun moyen juridictionnel de sanctionner le défaut d'application des réserves d'interprétation par les juridictions ordinaires, la Cour de cassation ne saurait néanmoins s'entêter de manière inopportune, dans l'exemple fictif que je viens d'évoquer, devant un désaveu aussi ferme de sa propre jurisprudence par

\footnotetext{
46 Cass. Ass. Plén., 19 mai 1978, Dame R. c/ Association pour l'éducation populaire Sainte-Marthe D. 1978, p. 541.

47 CC n 77-87 DC, 23 novembre 1977, Rec., p. 42.

48 Depuis le 6 octobre 2010, le Conseil constitutionnel considère en effet qu'en « posant une QPC, tout justiciable a le droit de contester la constitutionnalité de la portée effective qu'une interprétation jurisprudentielle constante confère à la disposition contestée » $\left(\mathrm{CC} \mathrm{n}^{\circ} 2010\right.$-39 QPC, 6 octobre 2010, rec., p. 264). Après une éphémère résistance, la Cour de cassation a admis, dans un arrêt du 30 novembre 2010 (Cass. QPC, 30 novembre 2010, n 10-16828), la recevabilité d'une QPC qui vise ce qu'il est parmi d'appeler l'interprétation authentique qu'elle livre d'une disposition législative.

49 Aux termes de l'art. 23-2 de l'ordonnance du 7 novembre 1958 portant loi organique sur le Conseil constitutionnel modifiée par la loi organique du 10 décembre 2009 relative à l'application de l'art. 61-1 de la Constitution, la loi ne peut faire l'objet d'une question prioritaire de constitutionnalité que si « elle n'a pas déjà été déclarée conforme à la Constitution dans les motifs et le dispositif d'une décision du Conseil constitutionnel sauf changement des circonstances ».
} 
le Conseil constitutionnel. Mais le choix raisonnable de s'aligner sur le Conseil constitutionnel n'est que l'effet d'une contrainte et non l'application d'une norme. Un énoncé dépourvu de sanction, à l'instar de l'article 62 al. 3 de la Constitution, n'est pas l'énoncé d'une norme et le respect bienveillant par les juridictions ordinaires de la chose jugée par le Conseil constitutionnel n'est qu'un fait de sociologie jurisprudentielle auquel on ne saurait accorder la moindre valeur juridique en raison de la non-dérivabilité logique d'un devoir-être (l'autorité de la chose jugée) à partir d'un être (la bienveillance du juge ordinaire). Malgré la fermeté du verbe qui caractérise l'article 62 al. 3, le Constituant de 1958 accorde finalement au juge ordinaire le privilège d'assurer l'autorité des décisions du juge constitutionnel. Cette disposition constitutionnelle est ainsi rédigée qu'elle offre aux théories empiristes du droit l'occasion de montrer toute leur pertinence : la norme est ce que l'organe auquel elle s'adresse dit qu'elle est. L'autorité des décisions du juge constitutionnel est cette norme que la Cour de cassation et le Conseil d'État disent qu'elle est. C'est à eux seuls, en dernière analyse, auxquels cette autorité s'adresse et à qui il incombe de garantir son effectivité. L'autorité des décisions du Conseil constitutionnel se mesure à travers le prisme de leur réception par le juge ordinaire.

Seul un recours constitutionnel contre les décisions de justice, sanctionné par la possibilité pour le Conseil constitutionnel d'annuler de telles décisions, donnerait à cette autorité la valeur d'une norme juridique assortie de sanction. Une telle autorité quitterait le domaine de l'effectivité pour entrer dans celui de la validité. Mais cette perspective n'empêche pas de considérer que de facto les réserves du Conseil constitutionnel jouissent d'une forte réception auprès de la Cour de cassation et du Conseil d'État lequel, au demeurant, leur reconnaît une autorité absolue de chose jugée ${ }^{50}$. D'où la question de la plus-value effective qu'une telle réforme en faveur d'un recours constitutionnel contre les décisions de justice est susceptible d'apporter. Il n'est pas certain qu'elle soit significative et les pouvoirs publics, dont Montesquieu disait qu'ils doivent légiférer d'une main tremblante, doivent se demander, avant de l'adopter, si le bénéfice qu'elle est susceptible d'entraîner ne risque pas d'être dérisoire au regard de la lourdeur procédurale qu'elle implique.

\section{Quelles pourraient être les modalités concrètes de la réforme?}

Quels effets seraient attachés aux décisions du juge constitutionnel ? (effets relatifs, effets absolus, possibilité de moduler dans le temps, effets éventuels sur les autres procédures déjà en cours, rétroactivité ...)

L'objet du recours envisagé par cette hypothétique réforme est une décision de justice, c'està-dire un acte individuel qui intéresse un cas concret et porte sur un intérêt subjectif. Il n'intéresse personne d'autre que le requérant dans la mesure où ce qui est directement en jeu n'est pas le contrôle de constitutionnalité d'une jurisprudence mais le contrôle de constitutionnalité d'un verdict. Certes, celui-ci serait remis en cause sur le fondement d'une interprétation de la loi que le Conseil

50 CE, 15 mai 2013, Commune de Gurmençon, FCP A 2013, act. 461. 
constitutionnel opposerait à la juridiction suprême, c'est-à-dire une interprétation alternative à celle émise par cette juridiction et qui aurait vocation, par voie de conséquence, à s'imposer de manière générale et impersonnelle. Mais n'oublions pas, soit dit entre parenthèses, que dans le cadre de la QPC qui peut conduire le Conseil constitutionnel à opposer aux cours suprêmes une interprétation alternative à vocation générale et impersonnelle, l'origine du contentieux est, elle aussi, purement subjective.

Il faut alors trouver, en termes d'effets attachés aux décisions du juge constitutionnel prises sur un recours constitutionnel contre une décision de justice, une solution raisonnable car sans elle, la réforme risquerait d'alimenter l'insécurité juridique. Avec l'annulation d'une décision de justice pour atteinte à la Constitution, la chose jugée serait entamée. Or, le Conseil constitutionnel n'a ni pouvoir d'évocation, ni pouvoir de renvoi. Il n'est pas, au sens processuel, une juridiction de cassation. Il révoquerait sans évoquer, anéantirait sans renvoyer. Il laisserait entier le conflit et viderait la justice de sa raison d'être qui est de clore une affaire. C'est qu'en effet, l'utilité du procès est de faire la paix sociale. Elle réside dans l'idée que le litige prend fin. Tout cela serait compromis.

Par conséquent, on pourrait imaginer un système qui érige le Conseil constitutionnel au rang de « juge constitutionnel de cassation ». Dans la mesure où l'acte mis en cause par le Conseil constitutionnel est juridictionnel, c'est-à-dire individuel, l'effet de sa décision ne peut qu'être relatif. Sa décision n'aurait pas d'effets sur les autres procédures en cours. La décision anéantirait l'acte en cause, de sorte que le Conseil n'aurait pas d'autre solution, en cas d'annulation, que de renvoyer l'affaire devant la Cour suprême administrative ou judiciaire. Le Conseil serait une méta-Cour suprême. Néanmoins, si la décision du Conseil constitutionnel n'a qu'une portée inter partes, la loi n'étant pas abrogée, l'interprétation alternative sur le fondement de laquelle le Conseil constitutionnel « casse » cette décision aurait une portée dissuasive objective à l'égard de toutes les juridictions qui savent qu'à l'avenir, elles n'auraient pas intérêt à s'en départir. On pourrait même escompter le fait que tout justiciable aura le réflexe d'invoquer l'autorité de la chose interprétée par le Conseil constitutionnel à l'appui d'une future QPC contre une loi ou à l'appui d'un futur recours constitutionnel contre une décision de justice.

\section{Une réforme, mais au prix de quels bouleversements pour les équilibres institutionnels?}

Comment intégrer une telle réforme au sein du paysage juridico-institutionnel français?

Par la voie constitutionnelle et organique. Il s'agirait de compléter l'article 61-1 de la Constitution et l'ordonnance organique sur le Conseil constitutionnel.

Quel rôle respectif veut-on confier aux juges constitutionnel et suprêmes? 
Sur le plan théorique, la réforme conduirait le juge constitutionnel à casser une décision de justice sauf qu'au lieu de juger de la légalité de la décision (ce que fait le juge de cassation qui vérifie si le juge d'appel a appliqué correctement la loi), il jugerait de sa constitutionnalité... fût-ce au risque d'écarter une loi que la cour suprême aurait appliquée en méconnaissance de la Constitution. Le Conseil constitutionnel annulerait une décision de la Cour de cassation ou du Conseil d'État parce qu'il estimerait que l'une ou l'autre aurait appliqué à tort une loi qu'il juge inconstitutionnel. De sorte qu'en dernière analyse, le juge constitutionnel pratiquerait lui-même le contrôle par voie d'exception, à l'américaine. En cassant une décision de justice, le Conseil constitutionnel écarterait (pas systématiquement) l'application d'une loi.

Comment articuler une telle réforme par rapport aux procédures déjà existantes ?

En posant la règle de l'épuisement des voies de recours interne : le recours direct devant le Conseil constitutionnel ne serait recevable qu'après avoir tenté en vain d'obtenir l'abrogation d'une loi par la voie de la QPC. Il serait, d'une certaine manière, le procédé qui permet de contester le nonrenvoi des QPC par les deux cours suprêmes administrative et judiciaire.

\section{Quelle place pour le Conseil constitutionnel?}

Quelle est (et quelle serait) la place réelle du Conseil constitutionnel ? Quelle place par rapport aux autres juges français et par rapport aux juges européens?

Le Conseil constitutionnel serait dans la situation du gardien de la constitutionnalité de l'interprétation de la loi. On sait que le Conseil s'est déjà lui-même attribué cette fonction dans les décisions du 6 et du 14 octobre $2010^{51}$ tout en demeurant, néanmoins, dépendant de l'intervention des juridictions suprêmes qui disposent de l'arme du filtrage. Avec cette nouvelle compétence, le Conseil constitutionnel deviendrait le véritable recours ultime du justiciable et conforterait son autorité non seulement à l'égard des juridictions ordinaires mais également vis-à-vis du juge européen.

À l'égard du juge européen parce que c'est vers lui et non vers la Cour de Strasbourg que le justiciable se tournerait s'il n'est pas satisfait d'un traitement contentieux dont il a été l'objet. À l'égard des juridictions ordinaires car la procédure de la QPC, dans son état actuel, ne place pas le Conseil constitutionnel au-dessus d'elles. Le contrôle de constitutionnalité a posteriori organise une cohabitation entre la Cour constitutionnelle et les juridictions suprêmes surtout lorsque ces dernières, comme en France, disposent du monopole en matière de filtrage. Il y a donc des tensions que le système italien a su apaiser, dans les années 60 et 70, grâce à la doctrine du droit vivant. En Allemagne et en Espagne, en revanche, le recours constitutionnel et le recours d'amparo permettent aux Cours constitutionnelles d'annuler les jugements des juridictions ordinaires et d'assurer, par voie de conséquence, une application uniforme de la Constitution sur l'ensemble du territoire. Pour autant, le Conseil constitutionnel ne deviendrait pas une Cour suprême au sens classique du terme

51 C.C., $n^{\circ}$ 2010-39 QPC, 6 octobre 2010, Rec., p. 264 ; C.C., n 2010-52 QPC du 14 octobre 2010, Rec., p. 283. 
car le dernier mot n'est pas un critère pour définir ce type de cour. Il n'y a de cour suprême qu'à l'intérieur d'un même ordre. Or, le recours constitutionnel maintiendrait la séparation des ordres tout en les organisant en termes de hiérarchie. Le Conseil constitutionnel serait alors, en sa qualité de gardien constitutionnel du gardien de la loi, une « méta-Cour suprême ».

Le Conseil constitutionnel dispose-t-il d'une légitimité suffisante pour opérer un tel contrôle?

Oui à condition de s'en tenir à un strict contrôle de la constitutionnalité de la décision de justice. En cédant, au contraire, à la tentation de rejuger l'affaire, le Conseil constitutionnel troquerait son statut de juridiction constitutionnelle pour celui d'une juridiction de droit commun intégrée au sein de la hiérarchie judiciaire, tout en jouissant de la suprématie. Dans ce cas, il n'aurait pas la légitimité professionnelle pour juger des décisions prises par des juges de carrière. Cela dit, en jugeant (et en jugeant seulement) la constitutionnalité d'une décision de justice, il sera difficile pour le Conseil de ne pas tenir compte des éléments concrets de l'affaire à l'origine de laquelle cette décision a été prise. Son déficit de légitimité professionnelle devra alors conduire les pouvoirs publics à réformer l'institution de la rue de Montpensier.

De quelle manière réformer le Conseil constitutionnel?

Des réformes importantes seraient nécessaires : instaurer un filtrage des recours par le Conseil constitutionnel lui-même ; élargir sa composition ; changer les règles de nomination.

Une telle réforme conduirait-elle à un changement de « logique » en ce qui concerne le contrôle de constitutionnalité en France?

Habituellement, ce qui est tranché devant le Conseil constitutionnel est une question de constitutionnalité abstraite. Dans l'hypothèse d'un recours constitutionnel, la saisine du Conseil constitutionnel serait le fait d'un justiciable insatisfait du traitement concret que lui a réservé une juridiction ordinaire. Il est donc permis de penser qu'avec une telle réforme, le Conseil enrichirait son statut de gardien de l'ordre constitutionnel objectif en se rapprochant des justiciables. Mais le coût serait très élevé en termes d'engorgement ! Les expériences étrangères, à l'instar de l'Allemagne et de l'Espagne, montrent que d'un point de vue statistique, le changement de nature pourrait ne pas être négligeable. En Allemagne, des milliers de recours sont effectués chaque année devant le Tribunal de Karlsruhe sur le fondement de l'article 93 al. 1, $4^{\circ}$ (recours direct en protection des droits fondamentaux contre les actes administratif et juridictionnel dans le délai d'un mois). En Espagne, le recours d'amparo contre les actes parlementaires (art. 42 LOTC), administratifs (art. 43 LOTC), juridictionnels du juge ordinaire (art. 44 LOTC) occupent 99,5\% de l'activité du Tribunal constitutionnel. Cette dérive ne peut être évitée que si la réforme pose l'exigence de l'épuisement des voies de recours internes parmi lesquelles il faut inclure la procédure de la QPC. En somme, le recours constitutionnel ne serait, pour le justiciable, que le recours de la dernière chance et la QPC devrait rester la procédure prioritaire. 
Ariane VIDAl-Naduet, Professeur, Aix Marseille Univ, Université de Toulon, Univ Pau \& Pays Adour, CNRS, DICE, ILF-GERJC, Aix-en-Provence, France

\section{Pourquoi un contrôle de constitutionnalité des décisions de justice ?}

Idée neuve en France, que les organisatrices du présent colloque ont eu le mérite de faire émerger, l'introduction d'un contrôle de constitutionnalité des décisions de justice est envisagée comme une nouvelle étape, qui permettrait d'enrichir le système mis en place en 1958 et de parfaire l'État de droit. Trois raisons militent en ce sens.

Une telle réforme permettrait, en premier lieu, de perfectionner le contrôle de constitutionnalité tel qu'il s'exerce en France. L'introduction de ce contrôle permettrait, en effet, de pallier un angle mort du contrôle de constitutionnalité, auquel échappent, jusqu'à présent, les décisions de justice. Le contrôle de constitutionnalité est traditionnellement centré, en France, sur la norme et, plus particulièrement, sur la loi. La notion même de contentieux constitutionnel reste arc-boutée sur le contrôle de la conformité de la loi à la Constitution, qui semble l'absorber quasi intégralement, alors même que les juridictions de droit commun exercent également un contrôle de constitutionnalité des normes infra-constitutionnelles, notamment des actes administratifs. L'introduction de la QPC ne fait que confirmer ce mouvement : certes, elle valorise la participation des juridictions de droit commun à l'exercice du contrôle de constitutionnalité, à travers l'exercice du filtrage, mais la question reste limitée, focalisée sur le contrôle de la loi et continue d'ignorer ou de minorer l'exercice, par les juridictions ordinaires, d'un contrôle de constitutionnalité des actes infra-législatifs. Centré sur la loi, le contrôle de constitutionnalité porte, au mieux, sur la norme, y compris sur la norme législative telle qu'interprétée par le juge. C'est ce que souligne l'évolution de la QPC : peut être contestée, sur le fondement de l'article 61-1 C, la portée effective qu'une interprétation jurisprudentielle constante confère à une disposition législative. Mais les conditions d'application de cette jurisprudence restent focalisées sur la norme : la QPC est recevable lorsque la jurisprudence s'est substituée à la norme, lorsqu'elle est devenue norme. Cette focalisation du contrôle de constitutionnalité sur la loi peut être perçue comme un avatar du légicentrisme. Dans ces conditions, l'introduction d'un contrôle de constitutionnalité des décisions de justice constituerait une réelle rupture, voire une réelle révolution. Elle permettrait de rapprocher la France des pays étrangers, comme le montrent les échanges qui ont eu lieu lors de ce colloque, et de résorber, en conséquence, ce qui pourrait apparaître comme une anomalie française.

En deuxième lieu, l'introduction d'un contrôle de constitutionnalité des décisions de justice permettrait de prolonger la logique portée par la QPC et de poursuivre ainsi un mouvement entamé, en pratique, en 2010. D’une part, elle contribuerait à la démocratisation du contrôle de constitutionnalité, mouvement théoriquement amorcé par la QPC, mais qui mérite encore d'être largement amplifié. En effet, la QPC semble aujourd'hui assez largement monopolisée par les associations, les lobbies, les groupes et, alors même qu'elle a été présentée comme un droit du 
citoyen ordinaire, elle semble assez largement confisquée. Permettre la contestation des décisions de justice serait un moyen de remettre la justice constitutionnelle à portée du citoyen ordinaire et de remettre les justiciables au cœur du contrôle de constitutionnalité. D'autre part, l'introduction d'un contrôle de constitutionnalité des décisions de justice assurerait un renforcement de la QPC par rapport au contrôle de conventionnalité. Cette logique de concurrence entre constitutionnalité et conventionnalité a été parfaitement assumée dès les travaux préparatoires de la révision constitutionnelle de 2008 et accentuée au moment de l'adoption de la loi organique établissant la priorité de la QPC. Or, le contrôle de conventionnalité présente un avantage structurel, celui de porter sur la situation du justiciable telle qu'elle résulte de l'application de la norme et donc sur la situation telle qu'elle résulte d'une décision de justice. L'introduction d'un contrôle de constitutionnalité des décisions de justice permettrait ainsi d'affuter l'avantage concurrentiel de la QPC au regard du contrôle de conventionnalité.

Enfin, un tel contrôle de constitutionnalité des décisions de justice serait l'occasion d'améliorer la qualité des décisions de justice, préoccupation aujourd'hui largement partagée par le Conseil de l'Europe. La bonne décision de justice n'est pas seulement une décision juste mais une décision bien rendue, adoptée selon des procédures adaptées, respectant les exigences de motivation, d'impartialité, de délais etc. Il y a là le passage d'une conception substantielle de la décision de justice à une vision plus procédurale de cette dernière. Si les qualités formelles de la décision de justice viennent le plus spontanément à l'esprit, par exemple la simplicité ou encore la lisibilité, pourquoi ne pas y ajouter une autre qualité, qui serait celle de sa constitutionnalité ? N'y aurait-il pas là, d'ailleurs, un singulier retournement des choses ? Car pendant longtemps, la bonne décision a été, précisément, la légalité de la décision de justice, c'est-à-dire sa conformité à la loi et à la volonté du législateur (en ce sens, voir B. FRYDMAN, L'évolution des critères et des modes de contrôle de la qualité des décisions de justice, WorkingPapers du Centre Perelman de philosophie du droit, ${ }^{\circ}$ 2007/4, mis en ligne le 11 octobre 2007,http://www.philodroit.be ). Ainsi, la bonne décision de justice (re)-deviendrait la décision conforme non plus à la loi mais à la Constitution et à la volonté du constituant. À l'instar du référé-législatif, qui devait permettre au juge de s'assurer de la volonté du législateur, la QPC pourrait permettre de franchir une nouvelle étape et d'assurer la constitutionnalité des décisions de justice.

\section{Comment penser la constitutionnalité des décisions de justice?}

Prospective, une telle démarche invite à s'interroger d'abord sur l'inconstitutionnalité d'une décision de justice : quelles sont les hypothèses d'inconstitutionnalité d'une décision de justice ? Il semble que plusieurs sources/causes/manifestations d'inconstitutionnalité semblent envisageables, emportant d'ailleurs une modulation de l'objet du contrôle de constitutionnalité.

Dans la première hypothèse, c'est la décision de justice qui est, en soi, l'objet du contrôle de constitutionnalité. L'inconstitutionnalité de la décision de justice peut tenir soit à une inconstitutionnalité externe, soit à une inconstitutionnalité interne. Dans le premier cas de figure, la décision de justice est 
inconstitutionnelle car rendue selon une procédure irrégulière. Elle a, par exemple, été rendue au terme d'une procédure qui ne respecterait pas les principes d'impartialité, du contradictoire, du délai raisonnable ou de la motivation. À titre d'hypothèse-fiction, on peut penser que si l'obligation de motivation avait été consacrée en tant qu'exigence constitutionnelle (ce qui a été exclu par la décision 2011-113/115 QPC sur la motivation des arrêts de cours d'assise), une décision de justice mal motivée pourrait être entachée d'inconstitutionnalité. Ces domaines sont, pour l'instant, les domaines de prédilection du droit de la Convention européenne ; le contrôle de constitutionnalité pourrait ainsi venir concurrencer, dans ce domaine nouveau, le contrôle de conventionnalité. Reste que si le Conseil constitutionnel a décliné, progressivement, les droits découlant de l'article 16 de la Constitution pour les aligner sur les standards du procès équitable, les exigences constitutionnelles demeurent, pour l'instant, très en retrait, rendant sur ce point le contrôle de constitutionnalité peu concurrentiel.

Dans le second cas de figure, le contrôle de constitutionnalité des décisions de justice viendrait sanctionner une inconstitutionnalité interne : la décision de justice méconnait, sur le fond, des exigences constitutionnelles. Ce n'est pas la situation du requérant qui est inconstitutionnelle ou, plus exactement, contraire aux droits et libertés que la Constitution garantit, mais bien la décision de justice en soi. On pourrait, par exemple, envisager qu'une décision de justice soit attaquée sur le fondement de la méconnaissance du principe d'égalité, par exemple parce qu'elle s'est écartée de la solution retenue dans d'autres cas identiques ou parce qu'elle concrétise une divergence de jurisprudence entre ordres administratif et judiciaire ou encore parce qu'elle constitue un revirement de jurisprudence, portant également atteinte à la confiance que le requérant peut avoir dans le système juridique ou encore aux espérances qu'il a pu nourrir... Autant d'hypothèses qui peuvent apparaître comme des angles morts du contrôle de constitutionnalité et dans lesquelles c'est la décision de justice, en soi, qui est contraire à la Constitution.

Deuxième hypothèse, c'est la situation qui résulte de la décision de justice qui est contraire à la Constitution, contraire aux droits et libertés que la Constitution garantit. C'est une hypothèse qui se rapproche finalement beaucoup du contrôle exercé par la Convention européenne des Droits de l'homme et qui permettrait de repositionner avantageusement le contrôle de constitutionnalité par rapport au contrôle de conventionalité. Mais on perçoit immédiatement que cette hypothèse emporterait un changement profond de logique, en impliquant un contrôle concret, un contrôle portant sur la situation du requérant, alors même que le Conseil constitutionnel s'évertue à préserver, au prix de quelques contorsions et de quelques entorses, un contrôle abstrait. De ce point de vue, on peut penser que le maintien du contrôle abstrait est commandé par deux logiques : d'une part, le souci du Conseil constitutionnel de ne pas s'ériger en Cour suprême, qui explique le souci d'éloigner au maximum ce dernier des faits de l'espèce et de la solution du litige ; d'autre part, le souci de conserver une cohérence voire une continuité entre contrôle a priori et contrôle a posteriori de constitutionnalité. Or il semble probable que l'introduction d'un contrôle de constitutionnalité des décisions de justice modifie à ce point la physionomie de la QPC que celle-ci puisse acquérir une réelle autonomie par rapport au contrôle a priori, n'étant plus considérée comme un prolongement de ce dernier, mais comme une nouvelle voie de droit totalement autonome. 
Troisième hypothèse, ce n'est pas la décision de justice en soi qui semble entachée d'inconstitutionnalité mais bien plutôt les normes utilisées à l'appui de la décision de justice. Dans cette hypothèse, la décision de justice n'est donc que le cadre du contrôle de constitutionnalité. On pourrait ainsi songer que la décision rendue s'est appuyée sur une loi inconstitutionnelle, sur un acte administratif ou un acte de droit privé inconstitutionnel voire même sur une jurisprudence inconstitutionnelle. Dans cette hypothèse se pose la question de savoir sil'inconstitutionnalité de l'acte en cause aurait dû être invoquée à un autre moment de la procédure, posant ainsi la question de l'articulation des recours.

Ces hypothèses d'inconstitutionnalité des décisions de justice, qui mériteraient évidemment d'être complétées et affinées, permettent de prendre la mesure des changements, voire des bouleversements, que l'introduction d'un tel contrôle susciterait.

\section{Comment pourrait s'articuler ce contrôle de constitutionnalité des décisions de justice avec les mécanismes existants?}

Ce contrôle de constitutionnalité des décisions de justice doit se combiner avec les possibilités de contrôle existantes, en particulier avec le contrôle de constitutionnalité, qu'il s'agisse du contrôle de la loi ou de celui des actes administratifs, et avec le contrôle de conventionnalité.

Comment concilier la QPC portant sur une décision de justice avec le contrôle de constitutionnalité des actes infra-constitutionnels ? Est-il envisageable qu'un justiciable puisse invoquer l'inconstitutionnalité d'une décision de justice sans avoir, au préalable, soulevé la non-conformité aux exigences constitutionnelles tantôt d'une disposition législative, tantôt d'un acte administratif, voire, hypothèse pour l'instant exclue, de la jurisprudence ? Il semble qu'un contrôle de constitutionnalité des décisions de justice implique la mise en œuvre d'une règle d'épuisement des voies de recours interne, qui permettrait d'éviter 3 écueils : déjouer « l'effet-d'aubaine », qui offrirait au requérant insatisfait de la décision rendue en dernier ressort la possibilité d'agiter l'argument de constitutionnalité sans l'avoir jamais fait auparavant ; limiter le nombre de contestations portant sur la constitutionnalité des décisions de justice et atténuer ainsi les risques d'engorgement du Conseil constitutionnel ; préserver le rôle des Cours suprêmes en leur donnant la possibilité de participer, en amont de la saisine du Conseil constitutionnel, à l'exercice du contrôle de constitutionnalité. Le contrôle de constitutionnalité des décisions de justice doit demeurer un contrôle subsidiaire, les juridictions suprêmes demeurant les juges de droit commun d'un tel contrôle. Cette règle de l'épuisement des voies de recours interne est loin de tarir toutes les questions : l'inconstitutionnalité de la loi-support de décision de justice doit-elle seulement avoir été soulevée devant le juge du fond (juge a quo? juge suprême ?) ou doit-elle avoir été examinée par le Conseil constitutionnel ? Quid pour les actes administratifs voire les actes de droit privé ? Leur inconstitutionnalité ne devrait-elle pas avoir été soulevée au préalable, soit par voie d'action, soit par voie d'exception? On mesure évidemment les difficultés qui pourraient résulter de cette règle d'épuisement des voies de recours internes, source d'un enchevêtrement des procédures, d'un rallongement des délais et d'une complexification pour le justiciable. Reste qu'une telle règle aurait le mérite d'inciter à la généralisation, voire à la systématisation, du recours à l'argument 
d'inconstitutionnalité, qu'il emprunte la voie de la question de constitutionnalité, du recours direct ou de l'exception d'illégalité devant les juridictions ordinaires, administratives notamment.

Dès lors que l'exercice préalable d'une action en inconstitutionnalité ouvre la voie au contrôle de constitutionnalité des décisions de justice, les conditions de recevabilité de la QPC semblent devoir être assouplies. Il en va notamment ainsi de la seconde condition de recevabilité, qui mériterait d'être supprimée, car le fait que le Conseil constitutionnel se soit prononcé, in abstracto, dans les motifs et le dispositif d'une précédente décision, sur la disposition législative en cause ne permet pas de garantir la constitutionnalité de la décision de justice. La QPC pourrait ainsi être soulevée dès lors que la question est applicable au litige et qu'elle revêt un caractère sérieux. L'introduction d'une règle d'épuisement des voies de recours interne invite également à une pratique plus souple de la troisième condition de recevabilité. En effet, si l'on admet que la QPC doive seulement être soulevée par le justiciable, le refus du juge du filtre de renvoyer la QPC ne pourra pas empêcher le contrôle de la constitutionnalité de la décision rendue. Plus encore, on pourrait envisager que le refus de transmission soit constitutif d'une inconstitutionnalité, portant atteinte au droit à un recours juridictionnel effectif, englobant le droit à ce que la constitutionnalité de la loi puisse être discutée devant le juge.

L'éventualité d'un contrôle de constitutionnalité des décisions de justice peut également inciter à un élargissement de l'objet des QPC. On sait, en effet, que si la QPC porte, aux termes de l'article 61-1, sur une « disposition législative », champ élargi à la portée effective qu'une interprétation jurisprudentielle constante confère à une disposition législative, elle ne peut, en revanche, porter sur une jurisprudence dénuée de tout fondement textuel. De cette sorte, la jurisprudence " pure » échappe à tout contrôle de constitutionnalité, alors même que la loi y est désormais bel et bien soumise, asymétrie qui constitue une réelle anomalie et un véritable angle mort du contrôle de constitutionnalité. De ce point de vue, il est probable que la menace d'un contrôle de constitutionnalité des décisions de justice joue pleinement son effet dissuasif / incitatif, invitant les juridictions du fond à renvoyer leur propre jurisprudence au Conseil constitutionnel pour prévenir la possibilité d'une censure pure et simple de leurs décisions.

Enfin, on peut également penser que l'introduction d'une telle règle incite le Conseil constitutionnel à adapter l'exercice de son propre contrôle de constitutionnalité. Imaginons qu'une QPC ait été soulevée et renvoyée au Conseil constitutionnel, cela n'empêche pas, bien évidemment, que soit contestée la constitutionnalité de la décision de justice rendue. Dans cette hypothèse, le Conseil constitutionnel deviendrait ainsi juge, indirect certes, du contrôle QPC, assurant de la sorte une espèce d'auto-contrôle de la constitutionnalité des décisions de justice. Or, pour l'instant, la pratique de la QPC peut sembler décevante pour le requérant, dans la mesure où le Conseil constitutionnel est loin d'assurer l'effet utile de la décision, comme le montrent les décisions d'abrogation à effet différé. Dans cette hypothèse, la contestation de la constitutionnalité de la loi-support de la décision ne garantit en rien la satisfaction du justiciable, qui pourrait ainsi être amené à se positionner sur le terrain de l'inconstitutionnalité de la décision de justice. De ce point de vue, l'introduction d'un contrôle de constitutionnalité des décisions de justice inviterait le Conseil constitutionnel à 
maximiser l'effet utile des décisions QPC, lui permettant de concurrencer, par la même occasion, d'autant plus efficacement le contrôle de conventionnalité.

\section{Quels mécanismes pour le contrôle de constitutionnalité des décisions de justice?}

La logique véhiculée par le présent colloque fait de la QPC le moyen privilégié - voire le seul moyen - d'assurer le contrôle de constitutionnalité des décisions de justice. Reste que l'introduction d'un tel contrôle incite à reconsidérer l'ensemble du mécanisme QPC, non seulement par souci de cohérence globale mais aussi parce qu'il parait difficile d'instaurer un contrôle de constitutionnalité « spécial décisions de justice » sans risquer d'en faire une arme dirigée contre les juridictions de droit commun.

Le champ d'application de cette dernière semble devoir être maintenu, à savoir les droits et libertés que la Constitution garantit, permettant ainsi de garantir la cohérence d'ensemble du dispositif. En revanche, le mécanisme du filtrage est incompatible avec l'existence même d'un contrôle, car on voit mal le juge, et tout particulièrement les juridictions suprêmes, se prononcer sur le renvoi de leurs propres décisions. La réticence avec laquelle les juridictions suprêmes renvoient au Conseil constitutionnel les QPC portant sur la portée effective qu'une interprétation jurisprudentielle constante confère à leurs décisions en témoigne. L'instauration d'un contrôle de constitutionnalité des décisions de justice plaide ainsi en faveur d'une disparition du filtrage et d'une saisine directe du Conseil constitutionnel, à charge pour ce dernier de juger de la recevabilité des questions de constitutionnalité posées par les décisions de justice, par exemple au travers d'une chambre des requêtes. Une telle éventualité plaide, évidemment, en faveur d'une disparition pure et simple du filtrage pour l'ensemble du dispositif QPC.

Comme il a été souligné plus haut, l'instauration d'un tel contrôle implique également un changement de logique profond de la QPC, évoluant d'un contrôle abstrait à un contrôle concret de constitutionnalité. Là encore, la cohérence du dispositif suppose qu'à terme, l'ensemble du dispositif QPC devienne un contrôle concret, logique à peine timidement esquissée jusqu’à présent.

L'objet de ce contrôle de constitutionnalité mériterait d'être discuté. Le contrôle des décisions de justice devra-t-il être limité aux seules décisions rendues par les Cours suprêmes ? Cette solution aurait le mérite de permettre à ces dernières d'exercer leur rôle régulateur, comme cela est imposé s'agissant du contrôle de l'interprétation des dispositions législatives, puisque seule peuvent être portées devant le Conseil constitutionnel les jurisprudences confirmées par les juridictions suprêmes de chaque ordre de juridiction, ce qui exclut du contrôle de constitutionnalité le droit vivant issu de la jurisprudence des juges du fond (Décision 2011-120 QPC). Cette solution aurait également le mérite de limiter le nombre de décisions pouvant potentiellement faire l'objet d'un contrôle de constitutionnalité. En revanche, elle rendrait inévitablement plus visible l'affrontement sous-jacent entre juridictions suprêmes et Conseil constitutionnel, invitant à s'interroger sur les bouleversements qu'un tel contrôle induirait sur l'architecture juridictionnelle et son équilibre. 


\section{Quel rôle pour le Conseil constitutionnel ?}

L'hypothèse d'un contrôle de constitutionnalité des décisions de justice nécessite d'être replacée dans une perspective plus institutionnelle. Les débuts de la QPC ont alimenté des débats intenses sur la place du Conseil constitutionnel dans l'architecture juridictionnelle et institutionnelle. Le spectre d'un Conseil constitutionnel Cour suprême a largement été agité, de même que la rhétorique de la concurrence voire de la guerre des juges, avant que la logique bien-pensante du dialogue des juges ne reprenne le dessus. Mais le Conseil constitutionnel a-t-il réellement les moyens d'assumer ce contrôle de constitutionnalité des décisions de justice ? La question n'est évidemment pas d'ordre technique, car rien n'empêche de créer une chambre de recevabilité pour trier les requêtes, d'assister les juges constitutionnels pour les aider à faire face à l'élargissement de leurs missions voire d'en étendre le nombre, mais bien d'ordre politique. Pour l'instant, le Conseil constitutionnel n'a aucunement, essentiellement en raison de sa composition, la légitimité à assurer ce contrôle de constitutionnalité des décisions de justice. Peut-on sérieusement envisager qu'un membre du Conseil constitutionnel, sans aucune garantie de compétence juridique, puisse annuler une décision rendue par la Cour de cassation ou le Conseil d'État ? L'introduction d'un contrôle de constitutionnalité des décisions de justice devrait ainsi être l'occasion de repenser radicalement la question de la composition du Conseil constitutionnel, en allant bien au-delà de la seule suppression des membres de droit.

Finalement, la possibilité d'un contrôle de constitutionnalité des décisions de justice est intéressante par les perspectives qu'elle ouvre. Elle part du constat d'un angle mort du contrôle de constitutionnalité mais, en invitant à penser les conditions d'un contrôle des décisions de justice, elle permet de prendre la mesure des failles et des défauts qui l'entachent. Car, après tout, l'avènement d'un contrôle concret de constitutionnalité associé à une modification des conditions de recevabilité de la QPC, à une possibilité de contrôle des décisions de non renvoi, à un élargissement du contrôle à la jurisprudence pure, ne laisserait qu'un intérêt résiduel au contrôle de constitutionnalité des décisions de justice... La question n'est-elle pas finalement, et avant tout, un prétexte à penser la nécessité d'une évolution du mécanisme de la QPC?

\section{Xavier MAgnon, Professeur à l'Université de Toulouse}

À soumettre le Conseil constitutionnel à un regard critique et constater toutes les carences du système qui l'entoure (composition politique de l'institution, aucune exigence de compétence juridique de ses membres, motivation lapidaire, mainmise du secrétaire général conseiller d'état sur son fonctionnement, contrôle abstrait dans le cadre de la question prioritaire de constitutionnalité, défense de la loi plus que du justiciable...), l'on risque d'éprouver quelques difficultés à entreprendre une réflexion visant à compléter les voies d'accès au « juge » constitutionnel. Tant que les problèmes 
structurels et organisationnels du Conseil constitutionnel ne seront pas résolus, il peut apparaître vain de vouloir multiplier les procédures de contrôle de constitutionnalité visant à sanctionner le respect de la Constitution dans l'ordre juridique. Il n'en reste pas moins qu'il s'agit du thème de réflexion qui nous occupe aujourd'hui et que nous supposerons en conséquence, pour la pertinence de l'exercice, qu'une justice constitutionnelle existe en France et qu'elle est tout à fait satisfaisante.

La mise en place d'un contrôle de constitutionnalité des décisions de justice s'inscrit dans le cadre général du contrôle de la régularité au sein de l'ordre juridique et entend instituer une procédure de sanction des décisions de justice qui seraient contraires à la Constitution. S'il est une question que soulève cette procédure c'est peut-être, du moins c'est sous cet angle que nous nous placerons, sous l'angle de son opportunité. Nous soutiendrons que cette procédure est inopportune en tant que procédure de contrôle de la régularité constitutionnelle des décisions de justice, même si elle peut être utile si l'on entend poursuivre d'autres objectifs, plus ou moins avouables.

L'objet de ce contrôle ne saurait être constitué que par les décisions de justice elles-mêmes et donc par la motivation que celles-ci proposent pour parvenir à la solution retenue dans le litige qu'elles sont censées résoudre.

Plus précisément, c'est la manière dont les juges appliquent le droit, et en particulier la loi, qui fera l'objet du contrôle. Pour ne s'en tenir, dans un premier temps, qu'à la loi, il ne s'agirait pas, avec une telle procédure, de contrôler la loi en vigueur elle-même, il existe déjà la question prioritaire de constitutionnalité qui couvre cette situation, mais la manière dont elle est appliquée. Or, l'interprétation de la loi, la portée effective qu'une interprétation jurisprudentielle constante par une cour suprême confère à une disposition législative, fait déjà l'objet d'un contrôle dans le cadre de la question prioritaire de constitutionnalité. La nouvelle procédure serait donc inutile dans ce cas. Seules les «normes » jurisprudentielles générales et abstraites prétoriennes, dépourvues de support formel législatif, qui échappent aujourd'hui à tout contrôle, pourraient faire l'objet d'un contrôle grâce à cette nouvelle procédure. Existe-t-il cependant suffisamment de cas de normes jurisprudentielles prétoriennes qui justifient la mise en place de ce contrôle ? En tout état de cause, il est vrai que l'existence d'une telle procédure permettrait d'éviter que des normes jurisprudentielles prétoriennes irrégulières ne puissent être adoptées par les juges de droit commun.

En dehors de l'application de la loi, c'est l'application du droit en général qui sera appréciée et l'on peut penser, avec Olivier Le Bot, qu'en pratique, une telle procédure conduise à un contrôle des décisions de justice sous le seul angle procédural. L'on ne peut pas totalement écarter non plus que cette procédure permette de sanctionner des interprétations inconstitutionnelles d'actes administratifs ou de contrats par le juge, sans que l'on soit, pour autant, plus convaincu de l'opportunité consécutive de cette procédure.

Quoiqu'il en soit, il reste que le contrôle de régularité constitutionnelle des décisions de justice existe déjà et qu'il est exercé en appel et en cassation par les cours d'appel, le Conseil d'État et la Cour de cassation. La mise en place d'un autre contrôle aux mains du Conseil constitutionnel ne 
ferait qu'ajouter un niveau supplémentaire de contrôle qui aboutit, en réalité, à exercer un contrôle sur la manière dont les cours suprêmes françaises interprètent la Constitution.

Telle peut être d'ailleurs la seule raison d'être sous-jacente d'une telle procédure : garantir une interprétation centralisée de la Constitution par le Conseil constitutionnel. Autrement dit, c'est moins la régularité constitutionnelle des décisions de justice qui importe que la création d'une voie de droit permettant au Conseil constitutionnel de garantir à son profit une maîtrise, un dernier mot, dans l'interprétation de la Constitution. Faut-il le rappeler, le Conseil constitutionnel est interprète authentique de la Constitution, au sens kelsénien du terme, à l'instar de toutes les autres juridictions, quelle qu'elles soient, dans l'exercice de leurs compétences. Le premier n'a aucun monopole d'interprétation et ne dispose d'aucun moyen de sanctionner le non-respect par les secondes des interprétations qu'il propose de la Constitution. D’une logique de contrôle de régularité, l'on glisse alors vers une logique de centralisation des interprétations de la Constitution. Le Conseil constitutionnel s'inscrirait alors dans une logique de cour suprême, si l'on considère que le modèle « cour suprême » de sanction de la régularité dans un ordre juridique vise à garantir l'unité d'application du droit par les juges dans un système juridictionnel décentralisé.

Il faut encore mentionner la possibilité, par la mise en place de cette procédure, de contrôler la manière dont les juridictions de droit commun exercent un contrôle de conventionnalité. En effet, en contrôlant les décisions de justice, il sera possible d'apprécier la manière dont elles exercent un contrôle de conventionnalité. Dans un tel cadre, ce qu'elles ont jugé au titre de la conventionnalité pourra être remise en cause au nom du respect de la Constitution. La procédure apparaitrait ainsi comme une procédure de sanction de la primauté interne de la Constitution sur les engagements internationaux grâce à un contrôle de constitutionnalité du juge constitutionnel portant sur le contrôle de conventionnalité exercé par les juridictions de droit commun.

De manière synthétique, l'on retiendra que le contrôle de constitutionnalité des décisions de justice n'est pas opportun en lui-même, dans une fonction de sanction de la régularité dans l'ordre juridique, mais peut constituer un instrument efficace de centralisation des interprétations de la Constitution et de sanction de la primauté interne de la constitutionnalité sur la conventionnalité. Tout dépendra de ce que le pouvoir politique voudra(it) faire, à condition de ne pas avancer masqué. 


\title{
Propos conclusifs
}

\author{
Marthe Fatin-Rouge Stefanini et Caterina Severino
}

Était-il bien raisonnable de s'interroger, six ans seulement après l'introduction de la QPC, sur la possibilité de franchir une étape supplémentaire, par la mise en place d'un contrôle de la constitutionnalité des décisions de justice ? La QPC ayant atteint « sa vitesse de croisière » et de nombreuses décisions ayant été rendues dans le cadre de ce nouveau mécanisme, à quoi bon s'interroger sur de possibles évolutions ? Le système de protection déjà en place ne suffit-il pas à garantir convenablement les droits et les libertés du citoyen, dans un État de droit comme la France?

$\mathrm{Au}$ regard de l'introduction récente et du succès de la QPC, ces questionnements pouvaient paraître surprenants ; l'adoption d'une procédure de contrôle a posteriori de la constitutionnalité des lois, sous la forme d'une question de constitutionnalité, a été considérée comme un réel progrès pour l'État de droit français. La QPC permet de remettre en cause la constitutionnalité d'une loi entrée en vigueur dont la non-conformité à la Constitution peut se révéler bien des années après son adoption, notamment lors de ses applications concrètes. Elle participe ainsi progressivement à une « démarginalisation » de la Constitution comme norme juridique de contrôle, elle rapproche celle-ci des justiciables et démocratise, de ce fait, l'accès au Conseil constitutionnel.

Toutefois, en dépit du progrès que représente la QPC et de la réussite qu'atteste le nombre de saisine réalisé depuis 2010, on pouvait se demander si l'objectif affiché par la réforme telle que pensée en 2008 avait bel et bien été atteint. Si l'un des intérêts de la QPC était en effet de lutter contre la concurrence des normes internationales en matière de protection des droits fondamentaux, en particulier celle de la $\mathrm{CEDH}$, l'objectif premier de la réforme était d'ouvrir une nouvelle voie de recours aux justiciables, pour assurer la protection de leurs droits constitutionnels. Or, bien qu'il s'explique notamment par le souci de ne pas engorger le Conseil constitutionnel, le filtrage opéré par les juridictions administratives et judiciaires paraît sévère. En outre, l'appréciation du caractère sérieux de la question posée par les juridictions suprêmes n'est pas toujours très compréhensible et peut poser des difficultés, notamment lorsqu'il s'agit de questions qui ont pour objet l'interprétation jurisprudentielle de la loi donnée par les cours suprêmes elles-mêmes. Le système de contrôle de constitutionnalité organisé en France recèle donc encore des lacunes, il est nécessairement perfectible et ces défauts, ajoutés aux difficultés pratiques pour atteindre le Conseil constitutionnel, semblent contribuer à un certain délaissement de la QPC par les justiciables ordinaires. 
Par l'organisation de ce colloque, qui a réuni des spécialistes français et étrangers de justice constitutionnelle, l'objectif poursuivi était double : d'une part, tirer les leçons du fonctionnement des systèmes étrangers qui pratiquent, entre autres, un contrôle de la constitutionnalité des décisions de justice, en vérifiant notamment si ce contrôle est une véritable plus-value pour la protection des droits et libertés ; et d'autre part, vérifier l'état du système de justice constitutionnelle français après cette réforme capitale, tout en s'interrogeant sur ses éventuelles lacunes et ses possibles perfectionnements.

L'approche comparative privilégiée durant ces deux journées a, certes, confirmé qu'aucun système n'est parfait et que toute procédure, tout en présentant des avantages, peut être accompagnée d'inconvénients. Par ailleurs, l'histoire d'un État, sa culture institutionnelle et constitutionnelle, les mécanismes déjà en place font qu'aucun système n'est ni strictement comparable aux autres, ni immédiatement transposable ailleurs. Les particularités de la QPC, par exemple, tenant à son caractère prioritaire, à la limitation de son champ d'application aux droits et libertés constitutionnels et à son déclenchement, réservé aux justiciables, avec un double filtre réalisé par les cours suprêmes, en font une procédure à part, à la fois très proche des questions d'inconstitutionnalité présentes en Allemagne, en Autriche, en Espagne ou en Italie, mais également originale et comparable, à certains égards, aux recours directs en protection des droits fondamentaux.

Cependant, tout en tenant compte de ces nuances ainsi que des précautions nécessaires (et préalables) à toute démarche comparative, ce colloque poursuivait l'idée ambitieuse de réfléchir déjà à une nouvelle évolution du système de justice constitutionnelle français, consistant à introduire un contrôle de constitutionnalité des décisions de justice qui serait confié au Conseil constitutionnel.

Plus qu'une simple évolution, une telle réforme serait une révolution car c'est la logique même de la justice constitutionnelle telle qu'elle s'est développée en France depuis 1958 qui serait modifiée. En se rapprochant de systèmes étrangers ayant opté pour un contrôle intégral de constitutionnalité des actes juridiques, une telle réforme engendrerait un véritable bouleversement des équilibres juridictionnels.

Ainsi, l'introduction d'un contrôle de constitutionnalité des décisions de justice pourrait s'avérer un moyen d'élargir l'accès des justiciables au Conseil constitutionnel, tout en remédiant à l'un des angles morts du système de justice constitutionnelle français.

La riche réflexion et les analyses menées au cours de la rencontre nous portent, cependant, à penser que le recours direct des citoyens contre les décisions de justice, à l'image du recours constitutionnel allemand ou du recours d'Amparo espagnol, ne constitue pas la seule possibilité qui peut être envisagée pour réaliser un tel contrôle, d'autant qu'elle est la plus radicale. Les différents rapports sur l'Allemagne et l'Espagne ont souligné les difficultés engendrées par ce type de recours (engorgement de la juridiction, nécessité d'introduire des critères de recevabilité drastiques). Introduire un recours direct en inconstitutionnalité conduirait, en outre, à une concurrence des voies de recours, 
susceptible de réduire fortement l'intérêt de la QPC. Il est vrai que des conditions pourraient être posées pour éviter toute redondance et permettre au contraire une complémentarité des voies de recours, comme cela se fait en Espagne ou en Allemagne, et pour éviter également une surcharge inutile du Conseil constitutionnel. Les exemples allemand et espagnol ont d'ailleurs montré l'intérêt de la coexistence de voie de recours en permettant la diffusion des droits fondamentaux à toutes les branches du droit, l'appropriation de la Constitution par les individus et l'absence de « zone de non-droit constitutionnel » (Michel Fromont) dans les systèmes juridiques étudiés.

On pourrait également imaginer qu'un mécanisme comparable au système de justice constitutionnelle instauré par la Constitution portugaise puisse un jour être transposé à la France. Cela supposerait alors que le passage au contrôle diffus soit acté, tout en conservant un rôle particulier au Conseil constitutionnel afin d'assurer une certaine unité des interprétations constitutionnelles.

Une alternative bien moins radicale pourrait être la consécration d'un droit d'évocation du Conseil constitutionnel qui pourrait se saisir de telle ou telle interprétation, au détour des décisions de non-renvoi qui lui sont transmises. Une autre solution consisterait à permettre au Conseil constitutionnel de se saisir d'une décision d'une juridiction suprême en cas de divergence d'interprétation avec l'autre juridiction suprême, ou avec la jurisprudence du Conseil constitutionnel lui-même, dans les hypothèses où aucune QPC n'a été soulevée ou n'a abouti.

Plusieurs scénarios sont donc envisageables, comme cela a pu être développé dans les différentes interventions présentées dans cet ouvrage, mais la solution la plus « acceptable » dans le paysage juridique et institutionnel actuel, serait peut-être le droit d'évocation.

En tout état de cause, confier une telle mission au Conseil constitutionnel serait lui accorder une confiance qu'il n'a pas obtenu jusqu'à présent. Cela aboutirait dans les faits à lui conférer un rôle de superviseur susceptible de mettre mal à l'aise les juridictions suprêmes et, plus généralement, les juridictions dites de droit commun qui éprouvent encore des difficultés à accepter que le Conseil constitutionnel puisse être considéré comme une véritable juridiction. Pourtant, ce système pourrait permettre de satisfaire à la fois ceux qui estiment que le filtrage des QPC est parfois aléatoire, ceux qui pensent que le contrôle par les juridictions suprêmes de la constitutionnalité de leur propre jurisprudence, lors du filtrage des QPC, pose problème tant pour la crédibilité de ces juges que pour l'État de droit, et ceux, enfin, qui craignent que le Conseil constitutionnel puisse être surchargé de recours, puisque, finalement, il serait totalement maître du flux des décisions qui feraient l'objet de son contrôle.

Au-delà d'une confrontation de cette idée aux expériences étrangères, l'objectif de ce colloque était de soumettre cette proposition d'introduire un contrôle de constitutionnalité des décisions de justice confié au Conseil constitutionnel à la critique et au débat, grâce à l'intervention de magistrats de l'ordre judiciaire, de juges administratifs, de juges et anciens juges constitutionnels, d'avocats mais aussi de nombreux universitaires français et étrangers. 
Sans grande surprise, les magistrats de l'ordre judiciaire et les conseillers d'État se sont montrés sceptiques vis-à-vis d'une telle proposition, estimant qu'elle serait inutile et complexe et qu'elle serait susceptible, finalement, de conduire le Conseil constitutionnel à devenir une sorte de cour suprême chargée essentiellement de vérifier la constitutionnalité des décisions du Conseil d'État et de la Cour de cassation. Les chercheurs étrangers ou spécialistes de droit étranger, en s'appuyant sur une analyse approfondie des expériences dans lesquelles il existe ou dans lesquelles il a été envisagé d'insérer un contrôle de constitutionnalité des décisions de justice, se sont principalement interrogés sur l'éventuel contenu d'une telle réforme. Ils ont souligné le bouleversement que cela impliquerait pour le système français, qui pourrait notamment passer d'un contrôle abstrait à un contrôle concret de la constitutionnalité des normes, par le biais du contrôle beaucoup plus systématique des interprétations et des applications de la loi réalisées par les juridictions. Les universitaires et chercheurs français ont, quant à eux, souligné la nécessité, et même l'urgence, de procéder à une réforme du Conseil constitutionnel, indispensable et préalable à tout renforcement de ses compétences juridictionnelles. Assurer un meilleur rayonnement des droits fondamentaux consacrés par la Constitution dans l'ordre juridique français suppose, en effet, une réforme affectant l'institution elle-même, afin de la rendre plus crédible et de contribuer ainsi à asseoir sa légitimité. De nouveaux modes de désignation, de véritables critères de nomination, de nouveaux moyens, de nouvelles compétences, un changement de dénomination pourraient faire de la juridiction constitutionnelle française une juridiction plus proche des citoyens, au cœur du système de garantie des droits fondamentaux. Ce dernier pourrait gagner en cohérence face à l'éparpillement actuel de la protection des droits et libertés et par rapport aux valeurs à vocation universelle véhiculées depuis 1789 .

Seul l'avenir nous dira si des éléments d'analyse issus de cette réflexion collective autour de l'amélioration de notre système de justice constitutionnelle trouveront une concrétisation effective. C'est en tout cas, à nos yeux, le propre de la science juridique que de semer des doutes sur l'existant, d'analyser avec un œil critique ce qui se fait ailleurs et d'avoir toujours une tension, parfois même faisant œuvre d'imagination, vers une amélioration continue des systèmes de protection des droits fondamentaux. 
TABLE DES MATIÈ RES

Avant-Propos

Sandrine MaLjEAN-Dubois

Propos introductifs - L'IDÉE D'Un Contrôle de CONSTITUTIONNALITÉ DES DÉCISIONS DE JUSTICE : INTÉRÊTS ET QUESTIONNEMENTS

Marthe Fatin-Rouge Stefanini

\section{Partie I}

LE CONTRôle DE CONSTITUTIONNALITÉ DES DÉCISIONS DE JUSTICE PAR LES COURS SUPRÊMES

Présidence de Monsieur Guy CANIVET

CHAPITRE 1

UN CONTRôle TRADITIONNEL POUR LES COURS SUPRÊMES EN FrANCE

Le contrôle par la Cour de cassation et le Conseil d'État : PERSPECTIVES HISTORIQUES

Jean-Louis Mestre

Le contrôle Par le Conseil d'État aujourd'hui

Laurent Domingo et Didier Ribes

I. Le contrôle de constitutionnalité et la régularité des décisions des juridictions administratives

II. Le contrôle de constitutionnalité et le bien-fondé des décisions des juridictions administratives

En guise de conclusion

La place de la Constitution dans le contrôle de la Cour DE CASSATION (EN DEHORS DE LA QPC)

Valentine Buck et Olivier Desaulnay

Introduction 
I. Les potentialités du contrôle de constitutionnalité des actes juridictionnels devant la Cour de cassation

A. Les conditions existentielles du contrôle de constitutionnalité devant la Cour de cassation

1. Les contraintes procédurales commandant la recevabilité des moyens de constitutionnalité en cassation

2. Un déficit de compétitivité de l'instrument constitutionnel

B. La réalisation d'un office judiciaire de la constitutionnalité des actes juridictionnels

1. Une typologie du contrôle de constitutionnalité conforme au contentieux de cassation

2. L'office d'un juge de la constitutionnalité.

II. Des potentialités renouvelées dans le contexte d'un renforcement de la protection des droits fondamentaux

A. Une application encore marginale de la Constitution malgré la procédure QPC

1. Un cadre strict d'application de la Constitution renforcé par la procédure autonome de la QPC.

2. Le moyen d'inconstitutionnalité fortement concurrencé par le moyen d'inconventionnalité

3. Le renforcement d'une culture constitutionnelle à la faveur de la QPC

B. Les perspectives ouvertes par les réflexions actuelles sur la réforme de la Cour de cassation

1. Une place prépondérante de la CEDH

2. La transposition à la Constitution des réflexions actuelles de la Cour de cassation

3. L'apport de la QPC dans les réflexions actuelles de la Cour. 
Chapitre 2

UN CONTRÔLE NATUREL DANS LES SYSTÈMES DIffUS

L'UNITÉ JURIDICTIONNELLE ET SES CONSÉQUENCES SUR LES MODALITÉS du contrôle de constitutionnalité au Québec et au Canada . . .89 Patrick Taillon et Amélie Binette

I. L'unité juridictionnelle, ses sources et ses effets ..................91

A. Les origines de l'unité juridictionnelle .......................91

B. Les forces du système intégré d'unité juridictionnelle .............994

C. Les inconvénients du système intégré d'unité juridictionnelle ......96

II. Un contrôle sans limites des décisions de justice

A. L'impossibilité pour le législateur de limiter la compétence des cours supérieures

B. Le contrôle des avis consultatifs

C. Le « réexamen» des décisions judiciaires

Conclusion

LE CONTRÔLE DE CONSTITUTIONNALITÉ DES DÉCISIONS DE JUSTICE EN SUISSE OU L'EXERCICE D'UN CONTRÔLE CONCRET DES NORMES

Michel HotTelier

Introduction

I. L'origine historique du contrôle concret

A. La situation lors de la création de l'État fédéral.

B. La révision totale de la Constitution fédérale de $\mathbf{1 8 7 4}$

C. L'immunisation des lois fédérales.

D. L'évolution de la clause d'immunisation

II. Le Tribunal fédéral

A. Statut et organisation

B. Composition

III. La juridiction constitutionnelle

A. Le cadre contentieux

B. Le double rôle du Tribunal fédéral

IV. L'aménagement du contrôle concret 


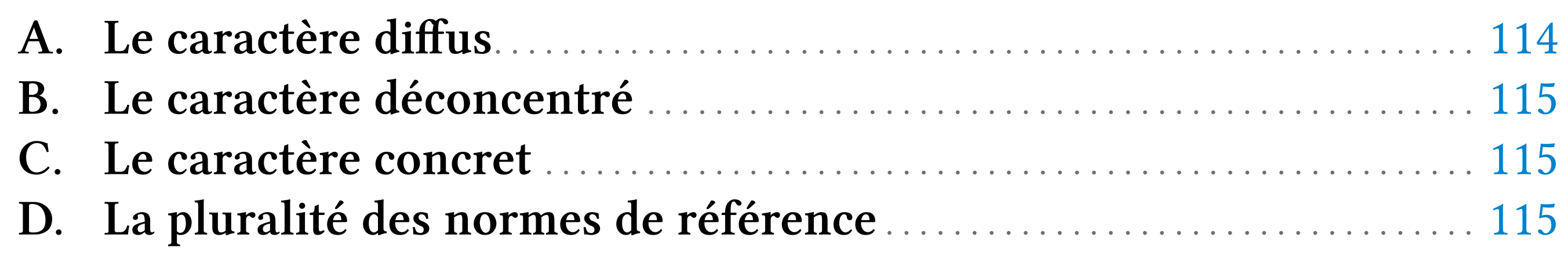

V. Le fondement juridique du contrôle concret .................. 116

VI. Le fonctionnement du contrôle concret ......................... 116

A. Le mode de saisine du Tribunal fédéral ....................... 116

B. Les types de recours ...................................... 117

C. La motivation des griefs .................................... 117

D. L'instruction et le jugement .............................. 118

E. Le pouvoir de décision du Tribunal fédéral ..................... 119

VII. Le contrôle abstrait et le contrôle concret .................... 120

A. L'étendue du contrôle abstrait ............................ 120

B. Les cas de contrôle concret ............................... 121

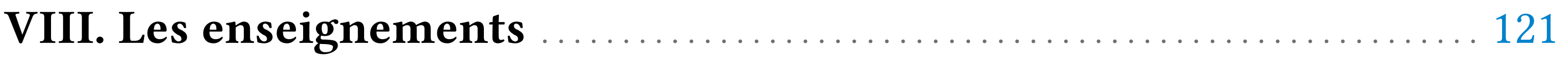

A. Généralités ............................................. 121

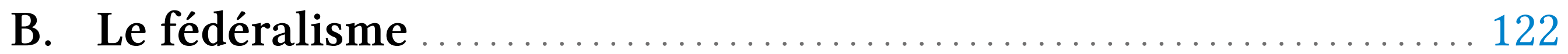

C. La démocratie ............................................ 124

D. Les droits fondamentaux .................................. 125

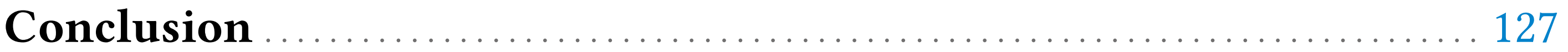

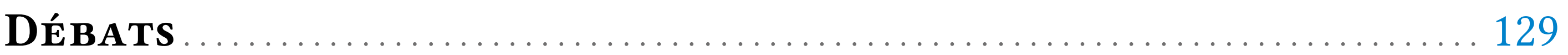

sous la présidence de Monsieur Guy CANivet

\section{Partie II}

LE CONTRÔLE DES DÉCISIONS DE JUSTICE PAR LES COURS CONSTITUTIONNELLES

Présidence de Madame le Professeur Anne LeVAde

Chapitre 1

LE CONTRÔLE DES DÉCISIONS DE JUSTICE EXERCÉ DANS LE CADRE DES RECOURS DIRECTS 
LE RECOURS INDIVIDUEL DIRIGÉ CONTRE UNE DÉCISION DE JUSTICE POUR VIOLATION D'UN DROIT FONDAMENTAL DANS LA RÉPUBLIQUE FÉdÉRALE D'AlLEMAGNE

Michel Fromont

I. La place des recours individuels dirigés contre les décisions de justice dans le contentieux constitutionnel allemand. 142

A. Les recours portés devant les autres juridictions 143

1. Devant les Cours constitutionnelles des Länder 143

2. Le contentieux porté devant une juridiction non constitutionnelle 143

B. Les recours individuels dirigés contre une décision de justice et portés devant la Cour constitutionnelle fédérale.

1. Les titres de compétence autres que les recours individuels ........ 144

2. Les recours individuels dirigés contre les décisions de justice 145

II. Les problèmes d'organisation posés par les recours individuels dirigés contre les décisions de justice

A. L'organisation de l'examen des recours individuels dirigés contre des décisions de justice.

1. La multiplication des collaborateurs scientifiques

2. La création d'une procédure dite d' "admission à la décision »et de six Sections chargées de l'essentiel du contentieux.

B. Les règles de recevabilité et de fond applicables aux recours dirigés contre une décision de justice

1. Les règles s'appliquant indistinctement aux Sections et aux Chambres

2. Les règles s'imposant aux Sections.

3. Les règles s'imposant aux Chambres

III. Les conséquences de l'existence d'un contrôle de la constitutionnalité des décisions de justice.

A. La place de la Cour constitutionnelle fédérale parmi les institutions

1. La Cour constitutionnelle fédérale, organe constitutionnel........ 152

2. La Cour constitutionnelle fédérale, juridiction suprême ........... 153

3. La Cour constitutionnelle fédérale, protectrice de tous les justiciables. 
B. L'emprise des droits fondamentaux sur l'ensemble du droit allemand

1. L'extension de la portée de certains droits fondamentaux......... 155

2. L'application des droits fondamentaux aux litiges de droit privé ....156

3. La multiplication des interprétations de la loi faites en conformité avec les droits fondamentaux ............................... 156

Conclusion - Quelques observations comparatives

LE RECOURS D'AMPARO CONTRE LES DÉCISIONS JURIDICTIONNELLES -

LE CAS DE L'ESPAGNE.

Hubert AlcARAZ

I. Le régime de l'amparo constitutionnel contre les décisions juridictionnelles

A. Les conditions de formation du recours d'amparo ............... 164

B. Les modalités d'examen du recours d'amparo

II. L'état du recours d'amparo contre les décisions juridictionnelles ...170

A. L'articulation entre juridiction ordinaire et juridiction constitutionnelle

B. L'influence du recours d'amparo sur l'office du juge constitutionnel

Le Contrôle de constitutionnalité des décisions de JUSTICE EN AUTRICHe

Marie-Caroline ARreto

I. Le recours direct contre les décisions de justice administrative : une innovation modérée

A. Une mise en cohérence des compétences en matière de justice administrative

B. Une évolution de la justice administrative spéciale au seul niveau de l'acte contestable

1. La violation caractérisée des droits constitutionnellement garantis par la décision de justice administrative

2. Une violation des droits résultant de l'application d'une norme fautive par la décision de justice administrative. 
II. L'introduction d'un recours indirect contre les décisions de justice ordinaire : une procédure nouvelle et originale

A. Une protection constitutionnelle complétée

B. Une architecture juridictionnelle préservée

DÉBATS

sous la présidence de Madame Anne Levade

Chapitre 2

LE CONTRÔLE DES DÉCISIONS DE JUSTICE EXERCÉ DANS LE CADRE DES QUESTIONS PRÉJUDICIELLES

Le contrôle des décisions de Justice par la Cour CONSTITUTIONNELLE BELGE

Marc VERdussen

I. La situation actuelle

II. Les perspectives envisageables

CONTRÔLE DE CONSTITUTIONNALITÉ, INTE RPRÉTATION CONFORME ET DÉCISIONS DE JUSTICE EN ITALIE : VERS UNE NOUVELLE CONFIGURATION DES RAPPORTS ENTRE LA COUR CONSTITUTIONNELle

ET LES JUGES ORDINAIRES

Jean-Jacques PARDinI

I. Le juge de renvoi, interprète obligé de la loi : l'interprétation conforme à la Constitution

A. La consistance de l'obligation, pour le juge a quo, de rechercher l'interprétation conforme de la loi

B. L'articulation entre l'obligation d'interprétation conforme de la loi à la Constitution et la doctrine du droit vivant

II. L'altération possible du contrôle incident de constitutionnalité . . 223

A. Le sens de l'obligation de l'interprétation conforme de la loi à la Constitution : le principe de suprématie constitutionnelle ... 223

B. La régulation des interprétations conformes par la Cour constitutionnelle 
Le contrôle des décisions de Justice par le Conseil CONSTITUTIONNEL FRANÇAIS EXERCÉ DANS LE CADRE DES QUESTIONS PRIORITAIRES DE CONSTITUTIONNALITÉ

Bertrand MATHIEU

I. La limitation du champ du contrôle exercé sur les décisions des juridictions de renvoi.

A. Une absence de contrôle subie : le contrôle de constitutionnalité «négatif » exercé par le juge de renvoi

B. Une absence de contrôle acceptée : l'interprétation de la loi par les juridictions de renvoi.

II. L'existence de contrôles indirects sur les décisions des juridictions de renvoi.

A. Le contrôle de la qualification opérée par le juge de renvoi

B. Le contrôle de l'appréciation du changement de circonstances justifiant un réexamen de la constitutionnalité d'une disposition législative

C. Le contrôle préventif au moyen de réserves d'interprétation

III. Un contrôle potentiel et nécessaire : la portée rétroactive de la loi résultant de l'interprétation jurisprudentielle.

Chapitre 3

L'exemple d'un système miXte : le cas du Portugal

LE CONTRôle de CONSTITUTIONNALITÉ DES DÉCISIONS DE JUSTICE au Portugal

Vasco Pereira da Silva et Rui Tavares Lanceiro

I. Considérations générales

II. Les décisions judiciaires et le contrôle du Tribunal constitutionnel portugais

A. Le contrôle concret de constitutionnalité et les recours devant le Tribunal constitutionnel

B. Les conditions et exigences procédurales du recours en inconstitutionnalité et son contrôle par le Tribunal constitutionnel .. 251

C. Le contrôle concret de constitutionnalité et le réexamen des décisions judiciaires par le Tribunal constitutionnel

D. Effets des décisions du Tribunal constitutionnel sur le contrôle concret 
III. Le lien entre le Tribunal constitutionnel et les autres juridictions ... 256 DÉBATS

sous la présidence de Madame Anne Levade

\section{Partie III}

COEXISTENCE DES VOIES DE RECOURS ET ARTICULATION DES CONTRÔLES

Présidence de Madame Nicole Belloubet

Chapitre 1

LE CONTRÔLE PAR LES JURIDICTIONS SUPRÊMES

DE LEUR PROPRE JURISPRUDENCE

Le cas de la France - Table ronde

LE CONTRÔLE PAR LES JURIDICTIONS SUPRÊMES DE LEUR PROPRE JURISPRUDENCE - L'EXCEPTION JURISPRUDENTIELLE EN QPC

Mathieu DisAnT

I. Sur la notion de « jurisprudence », objet du contrôle ............ 276

II. Le non-lieu à renvoi de la jurisprudence ........................ 279

III. Les évolutions du contrôle ................................... 282

IV. La fusion du juge de renvoi avec le juge interprète ? .............. 285

Le CONTRÔLe PAR Les COURS SUPRÊMES DE LEUR PROPRE JURISPRUdENCE - APPROCHE CRITIQUE

Caterina SEVERINo

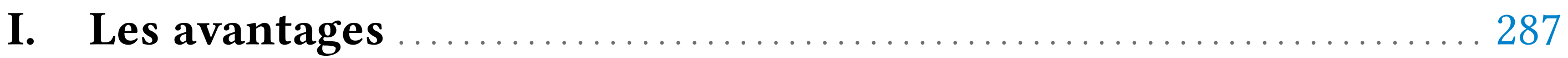

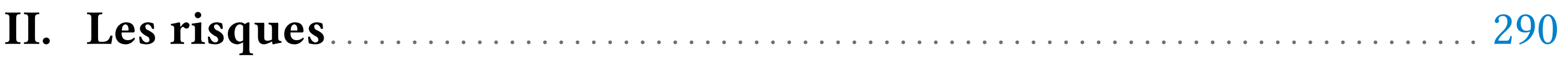

QUESTIONS ADRESSÉES AUX JUGES ................................. 295

Jacques Arrighi de CASANova (p. 296), Daniel Ludet (p. 299),

Olivier TALABARDON (p. 301)

MODÈLE CONCENTRÉ ET ANCRAGE DE LA CONSTITUTION DANS L'ÉVOLUTION DU CONTRÔLE INCIDENT EN ITALIE : CONTRIBUTION À L'ÉTUDE DES REMÈDES CONTRE LE REFUS DE SOULEVER LA QUESTION PRÉJUDICIELLE DE CONSTITUTIONNALITÉ

Paolo Passaglia

Introduction

I. L'établissement du contrôle incident, protection imparfaite d'un acte sui generis. 
A. Le contrôle concentré et le renvoi des questions préjudicielles à la Cour constitutionnelle

1. Un contrôle concentré à l'initiative diffuse

a. L'option en faveur d'un contrôle concentré de la constitutionnalité des lois.

b. La question préjudicielle de constitutionnalité, voie d'accès privilégiée à la Cour.

2. Les conditions de fond requises pour soulever une question préjudicielle de constitutionnalité.

a. Le caractère «non-futile » de la question.

b. Les rapports entre le renvoi et l'interprétation: un sujet initialement négligé.

B. Le système défaillant des remèdes contre le refus de soulever une question de constitutionnalité.

1. Les contestations devant la Cour constitutionnelle: les remèdes introuvables

a. Les limitations par le droit positif : l'absence d'un recours direct des particuliers

b. Les limitations par la jurisprudence constitutionnelle : l'utilisabilité purement théorique des conflits d'attribution.

2. Les contestations devant d'autres instances juridictionnelles : des remèdes partiels

a. Les contestations relatives au litige en cours : des remèdes conditionnés.

b. Les contestations à l'occasion d'autres litiges : des remèdes aléatoires.

II. La diffusion inéluctable de la protection d'un acte normatif à part entière

A. L'influence profonde de l'interprétation sur les caractères du système concentré

1. Un équilibre difficile entre la Cour constitutionnelle et les juridictions ordinaires

a. Les pouvoirs contestés de la Cour constitutionnelle.

b. La reconnaissance inévitable des pouvoirs des juges ordinaires 
2. L'interprétation conforme à la Constitution, alternative au contrôle incident

a. Un exercice prioritaire

b. Un pouvoir limité

B. Une Constitution protégée indépendamment des remèdes contre le refus de soulever la question de constitutionnalité

1. Des remèdes potentiellement inutiles.......................... 345

a. L'efficacité postulée du système concentré ..................... 345

b. Une efficacité discutable................................... 348

2. Des remèdes potentiellement nuisibles à la sécurité juridique .... 350

a. Une protection inachevable ................................. 351

b. L'effet paradoxal des remèdes affaiblissant la protection.......... 353

Conclusion

DÉBATS

sous la présidence de Madame Nicole Belloubet

Chapitre 2

COEXISTENCE ENTRE RECOURS DIRECT ET QUESTION PRÉJUDICIELLE

LA JURIDICTION CONSTITUTIONNELLE EN ESPAGNE : UN SYSTÈME INTÉGRAL DE JUSTICE CONSTITUTIONNELLE?

Itziar Gómez FERNÁNDEZ

I. Quelques observations liminaires

II. Description sommaire du modèle de justice constitutionnelle espagnol.

III. Le rôle du juge ordinaire dans un système intégral de justice constitutionnelle " en contexte » : sujet ou objet du contrôle

A. Contrôle de constitutionnalité, contrôle de légalité : le juge ordinaire comme juge constitutionnel

B. L'activité du juge ordinaire comme juge d'amparo ordinaire et comme objet du contrôle du Tribunal constitutionnel

1. Le recours individuel d'amparo

2. La question d'inconstitutionnalité comme contrôle de l'interprétation faite par le "Tribunal Supremo" 
IV. Conseils de la part d'un système intégral qui rêverait de ne plus l'être

LA COEXISTENCE DE LA QUeSTION PRÉJUdicielle ET DU RECOURS Direct en Allemagne

Thomas HochmanN

I. La complémentarité des recours

A. La question préjudicielle : un remède à la probable irrecevabilité du recours direct contre la loi

B. Le recours constitutionnel : un remède à l'absence de transmission d'une question préjudicielle

II. Une neutralisation des recours?

A. L'absence de neutralisation en Allemagne

B. Le risque d'une neutralisation en France

Chapitre 3

CONTRÔLE DE CONSTITUTIONNALITÉ ET CONTRÔLE

DE CONVENTIONNALITÉ DES DÉCISIONS DE JUSTICE

CONTRÔLE dE CONSTITUTIONNALITÉ ET CONTRÔLE DE CONVENTIONNALITÉ DES DÉCISIONS DE JUSTICE - QUELLES DISTINCTIONS DANS LES CONTRÔLES EXERCÉS?

Patrick GAÏA

I. Contrôle de constitutionnalité et contrôle de conventionnalité des décisions de justice : des distinctions globalement atténuées ...400

A. Les compétences et les procédures

B. Le contenu du contrôle ou les ombres et lumières de l'hybridation entre constitutionnalité et conventionnalité

II. Contrôle de constitutionnalité et contrôle de conventionnalité des décisions de justice : une spécificité partiellement confirmée ...407

A. La distinction quant aux conditions de déclenchement et d'exercice du contrôle

1. La question de la nature des moyens : moyen d'ordre public ou non ?.. 408

a. Rejet, en règle générale, des moyens d'inconventionnalité ........ comme moyens d'ordre public .

b. Le moyen d'inconstitutionnalité est-il moyen d'ordre public ?..... 413 
2. Le reflux constant mais non définitif de «l'écran législatif»..... 418

B. Distinction quant aux effets du contrôle

CONTRÔLE DE CONSTITUTIONNALITÉ ET CONTRÔLE DE CONVENTIONNALITÉ DES DÉCISIONS DE JUSTICE - QUELLES FONCTIONS DIFFÉRENTES ? . . . 425

Emmanuel PiwnicA

I. Le droit processuel ou la nécessité 426

A. Les mérites respectifs de la question prioritaire de constitutionnalité et du moyen d'inconventionnalité

1. La question prioritaire de constitutionnalité

a) Le rôle des parties

b) L'office du juge

2. Le moyen d'inconventionnalité

a) La rigueur des règles processuelles

b) L’absence de délai spécifique.

B. Le cumul de la question prioritaire de constitutionnalité et du contrôle de conventionnalité

1. L'épuisement des voies de recours ou le voyage de Strasbourg implique-t-il un arrêt rue de Montpensier?

2. La spécificité du droit de l'Union européenne.

II. Au hasard du droit substantiel

A. Le contrôle abstrait de la norme.

1. Un contrôle abstrait

2. Un contrôle de proportionnalité

B. Le contrôle concret de la situation

1. Un contrôle de droit commun .................................4 436

2. Le contrôle est mis en œuvre par toutes les juridictions ........... 437

a) La Cour européenne des droits de l'homme................... 437

b) La Cour de cassation ........................................ 438

c) Le Conseil d'État ........................................439

DÉBATS 


\section{Partie IV \\ LES CONDITIONS D'UNE RÉforme EN FranCe, AU REGARD DES EXPÉRIENCES ÉTRANGÈRES}

\section{TABLE RONDE} 445

sous la Présidence de Monsieur le Professeur André Roux

Introduction 445

Marthe Fatin-Rouge Stefanini et Caterina Severino

\section{Discussions}

Olivier Le BoT 448

Michel Fromont. 451

Marc VERDUSSEN. 453

Julien BONNET 454

Laurence GAY 461

Yasmine SYlvestre. 467

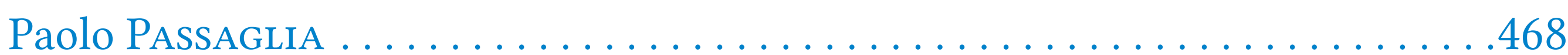

Alexandre VIALA . . . . . . . . . . . . . . . . . . . . . . . . . . . . . . . 469

Ariane VIDAL-NAQUET. ............................................... 476

Xavier MAgnon ...................................................... 482

Propos conclusifs. .............................................. 487

Marthe Fatin-Rouge Stefanini et Caterina Severino 
UMR Droits International, Comparé et Européen (DICE)

Espace René Cassin

3, avenue Robert Schuman

13628 Aix-en-Provence

dice-editions@univ-amu.fr

Composition et mise en page :

Donia Landoulsi, UMR DICE, Aix-Marseille Université

Conception de la couverture :

Donia Landoulsi, UMR DICE, Aix-Marseille Université 